\title{
EXPERIMENTAL STUDY ON THE SLIP RESISTANCE, BOLT RELAXATION AND FATIGUE BEHAVIOUR OF ASTM A1010 STAINLESS STEEL FOR BRIDGE APPLICATIONS
}

By

\author{
Ilion Ndreko \\ Bachelor of Engineering \\ Ryerson University \\ Toronto, Canada, 2015
}

\author{
A thesis \\ presented to Ryerson University \\ in partial fulfillment of the \\ requirements for the degree of \\ Master of Applied Science \\ in the program of \\ Civil Engineering
}

Toronto, Ontario, Canada, 2020

(C) Ilion Ndreko, 2020 


\section{AUTHOR'S DECLARATION}

I hereby declare that I am the sole author of this thesis. This is a true copy of the thesis, including any required final revisions, as accepted by my examiners.

I authorize Ryerson University to lend this thesis to other institutions or individuals for the purpose of scholarly research.

I further authorize Ryerson University to reproduce this thesis by photocopying or by other means, in total or in part, at the request of other institutions or individuals for the purpose of scholarly research.

I understand that my thesis may be made electronically available to the public. 


\title{
ABSTRACT
}

\section{EXPERIMENTAL STUDY ON THE SLIP COEFFICIENT, BOLT RELAXATION AND FATIGUE BEHAVIOUR OF ASTM A1010 STAINLESS STEEL FOR BRIDGE APPLICATIONS}

\author{
Ilion Ndreko \\ Master of Applied Science, 2020 \\ Civil Engineering, Ryerson University \\ Toronto, Canada
}

Unpainted weathering steel has been used extensively in Canada for bridge construction primarily to reduce the maintenance requirements and increase durability in comparison to regular structural steel. However, weathering steel has not performed well in bridges where chlorides from de-icing salts get onto the steel and prevent the development of a proper protective patina on its surface. An alternative solution to this problem is the use of ASTM A1010 stainless steel with a chemical composition that enhances corrosion resistance compared to the standard weathering steel. Most bridge splice connections are made up of gusset plates and high strength bolts (namely; A325 and A490) and are designed using the slip-critical method. The Canadian Highway Bridge Design Code (CSA S6-14) specifies an equation for the calculations of slip resistance of bolted joints using either the A325 or A490 high strength bolts with regular structural steel, at varying surface conditions. However, this equation is not applicable to stainless steel ASTM A1010 due to lack of research data. In addition, the fatigue category of A1010 steel is as of yet unavailable. Therefore, this research seeks to determine: (i) the slip resistance coefficient of slip-critical joints made of A1010 steel plates; (ii) bolt relaxation of three bolt types, namely: A325 plain, A325 galvanized, A193 B8 stainless steel; and (iii) fatigue behaviour of A1010 stainless steel plates. Identical specimens made of Canadian structural steel plates (CSA G40.21 350W grade) were fabricated and tested to represent the baseline performance for A1010 stainless steel. The experimental findings led to recommendations for design of slip-critical connections and further research on different fatigue detail categories. 


\section{ACKNOWLEDGMENT}

First and foremost, the author would like to thank his supervisor, Dr. Khaled Sennah, for the patience, dedication, and advice provided throughout the duration of this research.

The author would also like to recognize the technical and administrative staff from the Civil Engineering Department at Ryerson University, namely Nidal Jaalouk, Domenic Valle, Khaleel Stoney and Dan Peneff for their technical advice in facilitating all experiments for this project and for always being there when something went wrong.

The author would like to acknowledge Central Welding \& Iron Works from North Bay, Ontario for the donation \& help in welding of the stainless steel samples.

The author would also like to sincerely thank Mr. Martin Francis from ArcelorMittal for donating their A1010 stainless steel plates to Ryerson University to conduct this research.

The author acknowledges the contribution of Ontario Ministry of Transportation's Highway Infrastructure Innovation Funding Program (MTO-HIIFP) to support this research. The author would like to acknowledge and thank Mr. David Lai from the Ministry of Transportation of Ontario for his advice on the project. 


\section{DEDICATION}

To my mother \& father

Nevila \& Jovan Ndreko 


\section{TABLE OF CONTENTS}

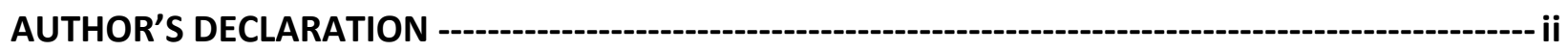

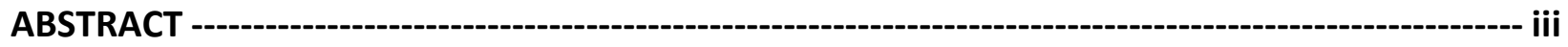

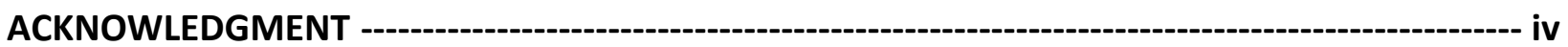

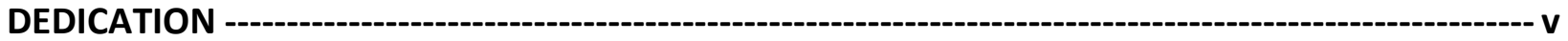

LIST OF FIGURES --

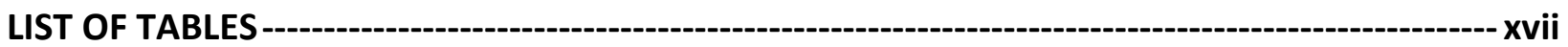

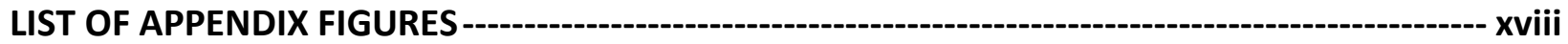

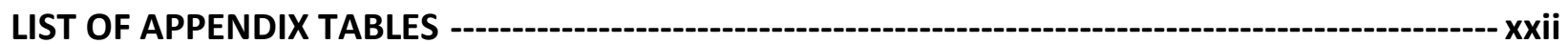

Chapter 1 - Introduction --------------------------------------------------------------------------------------- 1

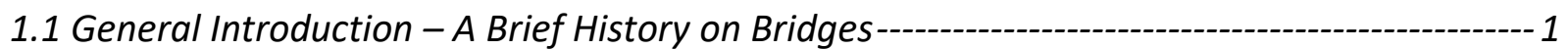

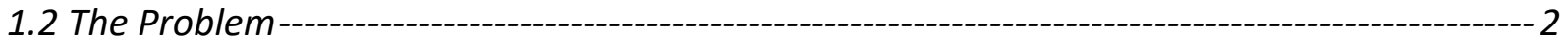

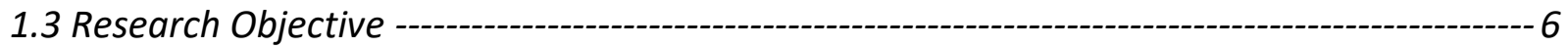

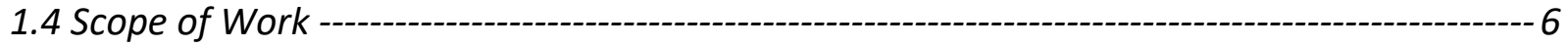

1.5 Thesis Layout---- 8

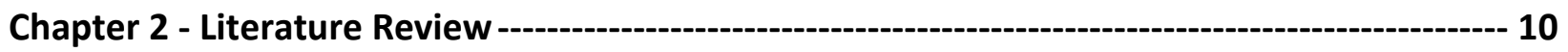

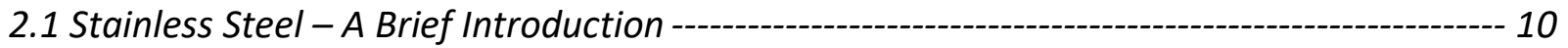

2.2 ASTM A1010 Stainless Steel ---------------------------------------------------------------------- 15

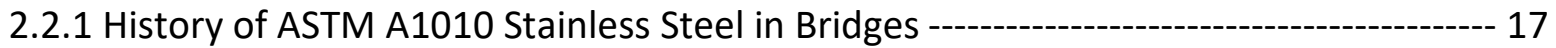

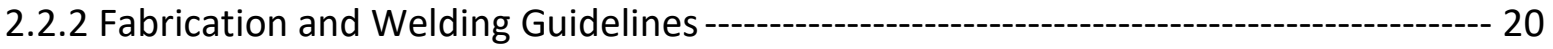

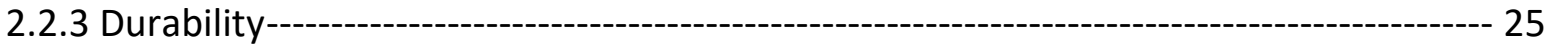




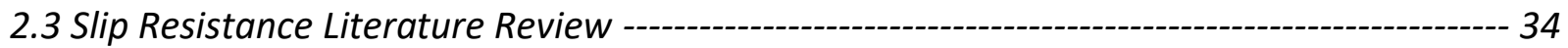

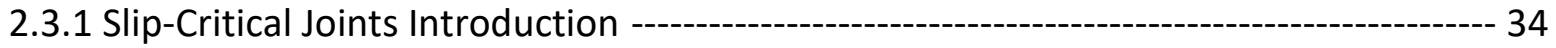

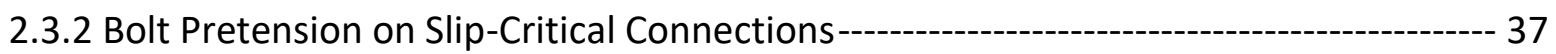

2.3.3 Research Council on Structural Connections' Slip Coefficient Testing Method-------- 40

2.3.4 European Standard EN 1090-2 Annex G: Test to Determine Slip Resistance Factor-- 42

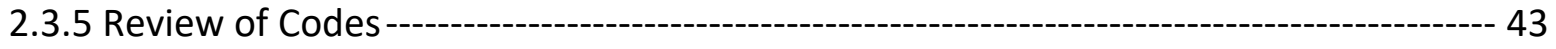

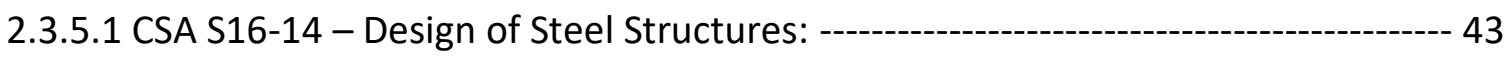

2.3.5.2 AASHTO LRFD Bridge Design Specifications ------------------------------------------ 45

2.3.5.3 Eurocode 3 - Design of Steel Structures ------------------------------------------------ 46

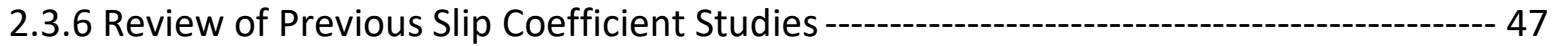

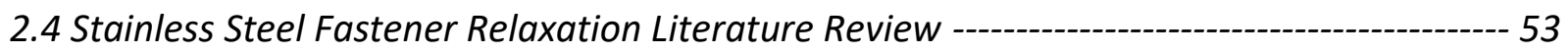

2.5 ASTM A1010 Tensile Testing Literature Review------------------------------------------------ 57

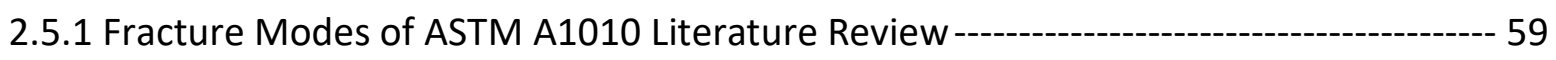

2.6 Fatigue Literature Review------------------------------------------------------------------- 61

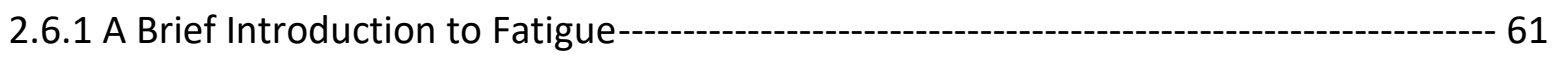

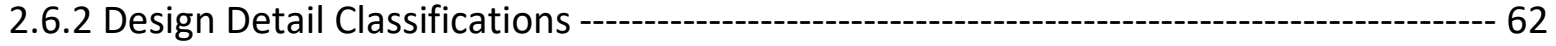

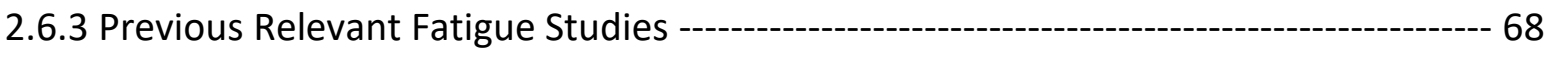

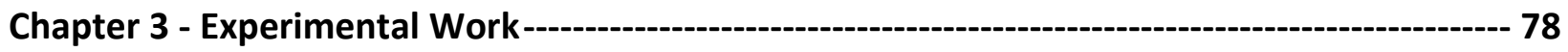

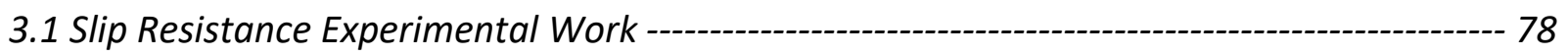

3.1.1 Preparation of Samples for Slip Resistance Testing --------------------------------------- 79

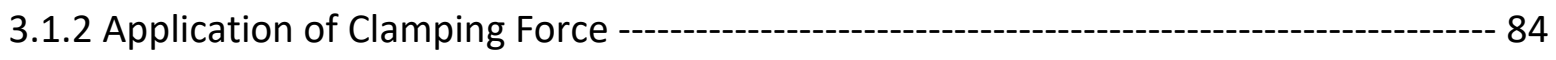

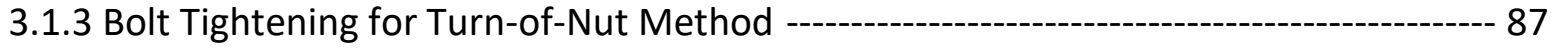

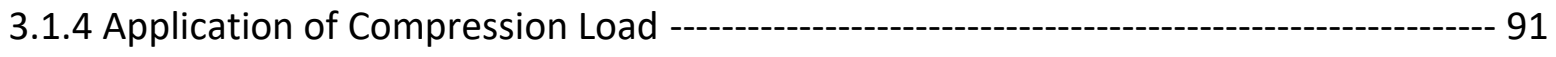

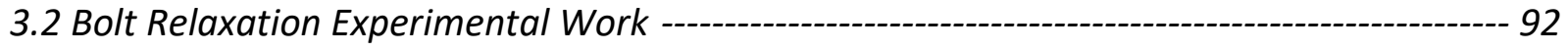

3.3 Dissimilar Metal Galvanic Corrosion Testing -------------------------------------------------------- 93

3.4 Fatigue and Tensile Testing Experimental Set-Up --- 
3.4.1 Steel Coupon Dimensions and Fabrication ------------------------------------------------------ 97

3.4.2 Fabrication of Welded Specimens----------------------------------------------------------------102

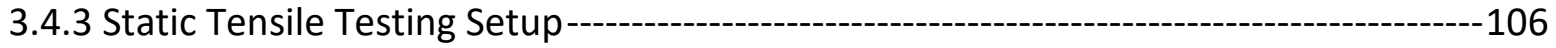

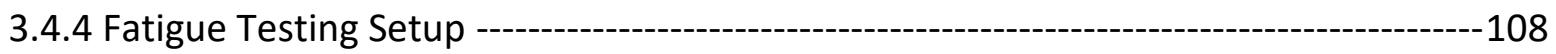

Chapter 4 - Slip Resistance and Bolt Relaxation Results----------------------------------------------111

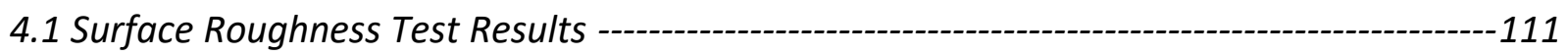

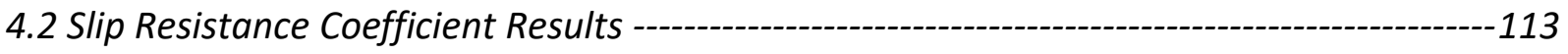

4.2.1 A1010 Stainless Steel Slip Resistant Coefficient--------------------------------------------121

4.2.2 CSA G40.21 350W Slip Resistant Coefficient-----------------------------------------------126

4.3 Slip Resistance Coefficient vs Roughness Analysis------------------------------------------------135

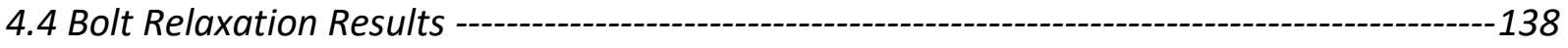

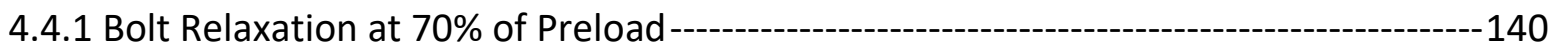

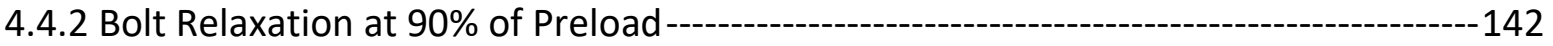

4.4.3 ASTM A193 B8 Class 2 Stainless Steel Bolt Relaxation------------------------------------144

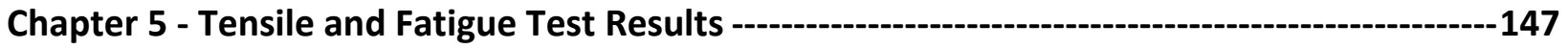

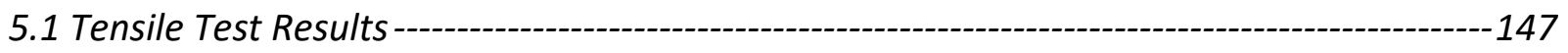

5.1.1 Stress-Strain Relationships Obtained from Tensile Tests ----------------------------------148

5.1.2 Fracture Modes of Tensile Coupon Specimens----------------------------------------------151

5.2 Fatigue Test Results for the Bare Steel Coupon Specimens--------------------------------------158

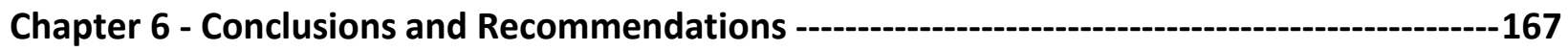

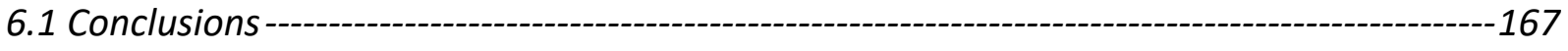

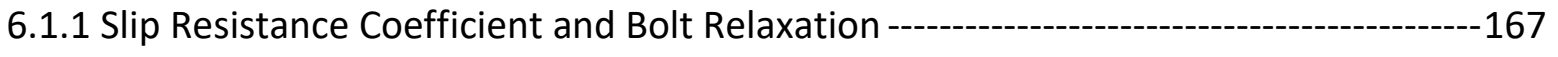

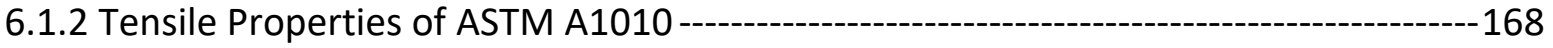

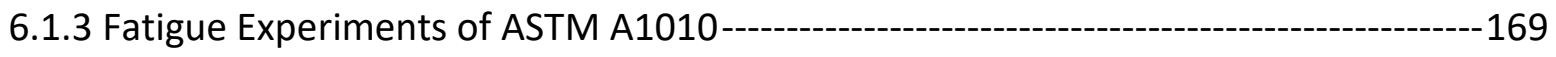

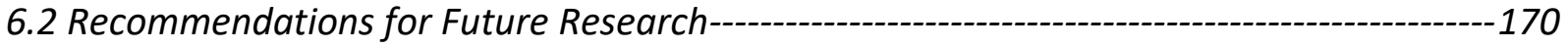

6.2.1 Slip Resistance Coefficient and Bolt Relaxation ----------------------------------------------170 
Appendix A - Slip Graphs of ASTM A1010 Stainless Steel with Class B Surface Treatment ---173

Appendix B - Slip Graphs of CSA G40.21 350W with Class B Surface Treatment $-186$

Appendix C - Slip Graphs of CSA G40.21 350W Steel with Class A Surface Treatment ---------199

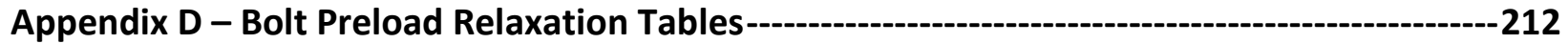

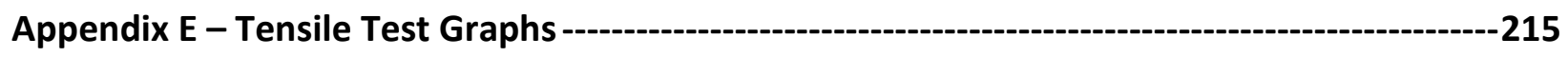

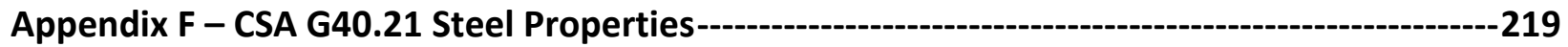

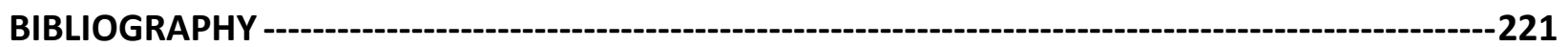




\section{LIST OF FIGURES}

Figure 1-1: General Life Cycle of Steel (Davis, 2000) ---------------------------------------------- 3

Figure 1-2: Weathering steel girder coated 3 meters apart from the expansion joint----------------- 5

Figure 1-3: Text Matrix for Slip Resistance Evaluation Study ----------------------------------------- 7

Figure 1-4: Test Matrix for Bolt Preload Relaxation Evaluation Study ------------------------------- 8

Figure 1-5: Test Matrix for Fatigue Evaluation Study ------------------------------------------------ 8

Figure 2-1: Family Tree of Austenitic Stainless Steels Based on AISI and UNS Classification

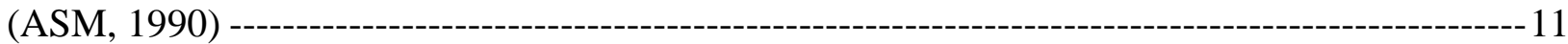

Figure 2-2: Family Tree of Common Ferritic Stainless Steels (ASM, 1990)-----------------------12

Figure 2-3: Family Tree of Martensitic Stainless Steels (ASM, 1990) -----------------------------13

Figure 2-4: Mechanical Properties of Various Stainless Steel Types Relative to Other Alloys

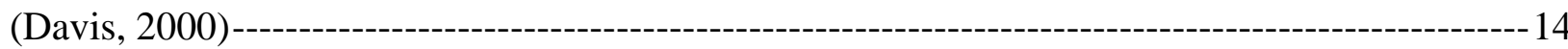

Figure 2-5: Colusa County Multi-Cell Box Girder Bridge (Fletcher, 2011; Fletcher et al. 2005) 18

Figure 2-6: Left: ArcelorMittal A1010 Bridge; Right: Oregon DOT Dodge Creek A1010 Bridge

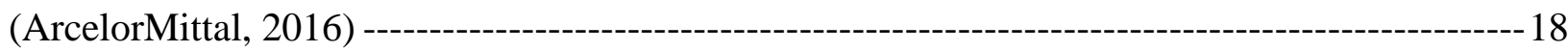

Figure 2-7: Iowa bridge showing the 2 A1010 girders on the far right (Iowa DOT, 2016) ------- 19

Figure 2-8: Speed River Bridges Site Plan over West Bound Lanes of Highway 401 in

Cambridge, Ontario (McLeod et al., 2018)

Figure 2-9: Virginia DOT Route 340 Bridge: (a) Worker installing splice connection with

stainless steel bolts; (b) A1010 girders showing various shades of rust patina depending on exposure duration; (c) Finished Route 340 Bridge (Sharp et al. 2018)------------------------------20

Figure 2-10: Welding Microstructure of A1010 Plate (ArcelorMittal, 2010) -----------------------22

Figure 2-11: Fusion Zone Hardness of Welded 0.25” A1010 Steel (ArcelorMittal, 2010)--------22

Figure 2-12: Carbon steel (CS) vs A1010 Stainless Steel (SS) difference in welding distortion

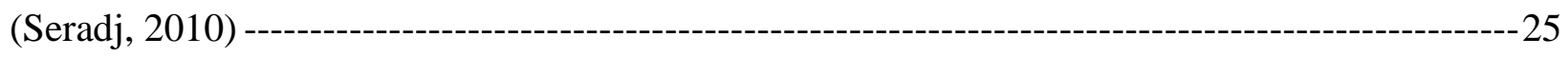

Figure 2-13: Thickness Loss Comparison Between Various Metals (Fletcher, 2011) -------------27

Figure 2-14: Thickness Loss at Kure Beach 25 m Site of Various Steels (Fletcher et al., 2005)-27

Figure 2-15: A1010 Corrosion Loss Compared to Other Steels (Fletcher et al., 2005) ------------28

Figure 2-16: Uniform Rust Patina on Control Specimens After 20 Cycles (Groshek and Hebdon, 
Figure 2-17: Galvanic Corrosion on Various Types of Fastener Systems Paired with A1010 plate

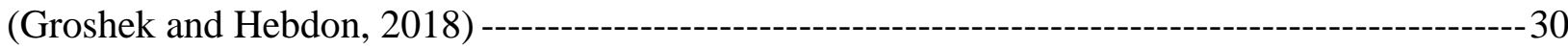

Figure 2-18: Galvanic Corrosion of: i) Weathered Steel \& Galvanized A325 Bolt, ii) A1010

Steel \& A325 Galvanized Bolt, and iii) A1010 Steel \& A193 B8 Stainless Bolt (Zhang et al.,

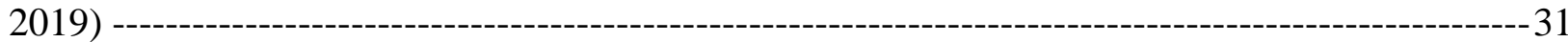

Figure 2-19: Relative Pricing of Various Steel Alloys in 2013 (Kogler, 2015) ---------------------32

Figure 2-20: Probabilistic Life Cycle Cost Analysis of A1010 vs Conventional Steel: (a) Total

Cost vs Time; (b) Probability That Cost of A1010 is Cheaper over Time (Fletcher, 2011)-------33

Figure 2-21: Worker installing bolted slip-critical joint on bridge girder (Sterner, 2005)---------35

Figure 2-22: Pretension on the bolt ensures that the faying surfaces through the force of friction

carry the applied load on the element (Haodi, 2017)------------------------------------------------36

Figure 2-23: Minimum bolt pretension requirements depending on their diameter (CSA, 2014b)

Figure 2-24: Nut rotation to meet or exceed minimum pretension force (CSA, 2014b) -----------39

Figure 2-25: Real bolt tension exceeding minimum requirement when the turn-of-nut tightening method is used (Kulak et al., 2001)----------------------------------------------------------------------39

Figure 2-26: Plate specimen dimensions and testing set up for slip resistance (RCSC, 2014)----41

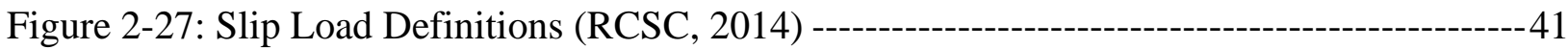

Figure 2-28: Standard Test Specimens for Slip Factor Test EN1090-2 (Stranghöner et al. 2017)

Figure 2-29: Specified slip resistance coefficients in the Canadian Highway Bridge Design Code, CSA S6-14 (CSA, 2014a)

Figure 2-30: AASHTO LRFD tables for minimum required bolt tension and coefficients for the calculation of slip resistance (AASHTO, 2017) $-46$

Figure 2-31: Summary of slip coefficients by steel type and surface treatment (Kulak et al., 2001)

Figure 2-32: Slip resistance for different stainless steel grades and surface treatments using Class 8.8 stainless steel bolts (Stranghöner et al., 2017) $-51$

Figure 2-33: EN1090-2 Proposal for Stainless Steel Slip Coefficient based on Grade, Surface Roughness, and Surface Finish (Stranghöner et al., 2019) --------------------------------------------53

Figure 2-34: Test Matrix and Results of Fastener Assembly Preload Loss (Afzali et al., 2017) -55 
Figure 2-35: Tension development due to the angle of rotation for common stainless and carbon alloyed fasteners (Williams et al., 2017) ------------------------------------------------------------------56

Figure 2-36: Stress-Strain Curve of 25 mm Thick ASTM A1010 (Daghash et al., 2019)---------58

Figure 2-37: Delaminated Fracture of A1010 Tensile Specimen (Daghash et al. 2019)-----------59

Figure 2-38: Delamination Showing Perpendicular Fracture. (Provines et al., 2019)--------------60

Figure 2-39: Welded A1010 Transverse Tensile Samples (Seradj, 2010) --------------------------60

Figure 2-40: Tensile Fracture of 12\% Cr Stainless Steel (Taban et al., 2009).----------------------61

Figure 2-41: S-N Curves from the Canadian Highway Bridge Design Code (CSA, 2014a) ------65

Figure 2-42: S-N Curves from AASHTO LRFD Bridge Design Specifications (AASHTO, 2017)

Figure 2-43: Tables 10.5 and 10.6 Required for Fatigue Design from the Canadian Highway

Bridge Design Code (CSA, 2014a)

Figure 2-44: Fatigue Test Set-Up and Dimensions of Bolted Splice Connection (Provines et al. 2019) $-68$

Figure 2-45: S-N Curve of A709 50CR Slip-Critical Bolted Connections (Provines et al. 2019)69

Figure 2-46: Fatigue Welded Specimen Dimensions (Provines et al. 2019) 70

Figure 2-47: S-N Curves for Welded A709 50CR Stainless Steel Coupons (Provines et al. 2019)

Figure 2-48: Fatigue Coupon Specimen Dimensions (Phares et al. 2020)---------------------------71

Figure 2-49: Table Showing Results of Fatigue Testing (Phares et al. 2020) ----------------------- 72

Figure 2-50: Fatigue Comparisons between A1010 and Other Steels (Phares et al. 2020)--------72

Figure 2-51: Comparison between Constant Amplitude Fatigue Loading and Actual Variable

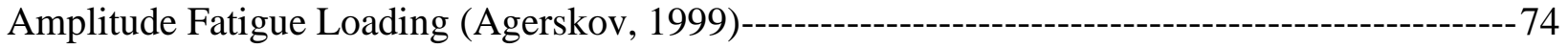

Figure 2-52: S-N Curve Showing Fatigue Run-Out of Butt Welded HPS-485W Specimens

(Bennett et al. 2009) $-75$

Figure 2-53: S-N Curve of Regular Mild Steel, Welded Steel, and Welded with Overfill

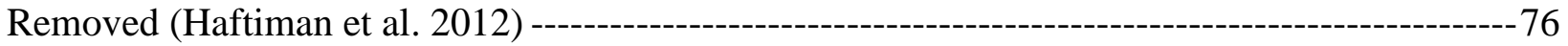

Figure 2-54: Table Showing Fatigue Life of Different Thickness Butt Welded Specimens (Zong

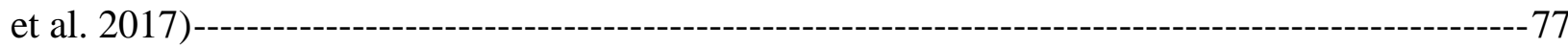

Figure 3-1: Specimen Dimensions for Slip Resistance Test ------------------------------------------80

Figure 3-2: Waterjet table systems (Source: OMAX Corporation) ----------------------------------- 80 
Figure 3-3: Specimen Before and After Blast Cleaning with Stainless Steel Grit $-81$

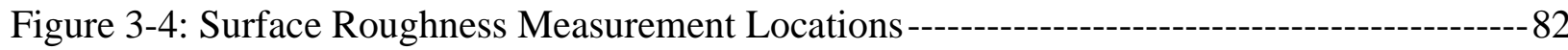

Figure 3-5: (a) Shimana SHGLST022; (b) Shimana SHGLST129; -------------------------------83

Figure 3-6: Clamping Load Test Set-Up with Hydraulic Jack----------------------------------------84

Figure 3-7: Close-Up View of Hydraulic Clamp Test Set-Up----------------------------------------- 85

Figure 3-8: (a) Bolt Tensioning Hydraulic Piston; (b) Handheld Hydraulic Pump------------------ 85

Figure 3-9: HBM KBR 400 kN Load Cell and Hardened Washer Dimensioning ------------------86

Figure 3-10: Photo of Washer Type Load Cell for Measuring Clamping Force --------------------86

Figure 3-11: Slip Resistance Test Setup by Using Hydraulic Piston to Maintain the Clamping

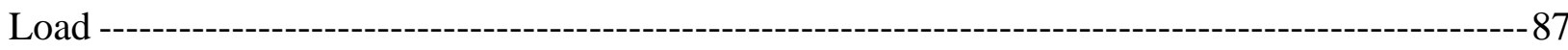

Figure 3-12: (a) Skidmore Whilhelm Load Cell with Bolt; (b) Spud Wrench Used for Snug-

Tightening; (c) Electric Torque Wrench Used to Rotate the Nut $120^{\circ}$------------------------------- 88

Figure 3-13: Specially manufactured jig and plate assembly for the turn-of-nut clamping method

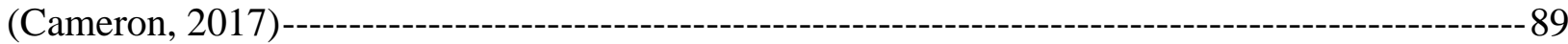

Figure 3-14: Specimen with Fastener Tightened by the Turn-of-Nut Method ---------------------- 89

Figure 3-15: 3D Isometric and Side View Cut of Specimen Showing Plate Positioning ----------90

Figure 3-16: Test Specimen Set-Up for Turn-of-Nut Preload Application --------------------------90

Figure 3-17: View of the MTS Machine with Slip Resistance Test Set-Up ------------------------91

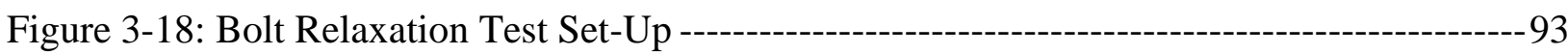

Figure 3-19: Accelerated Testing Set-Up Pre-Corrosion -----------------------------------------------94

Figure 3-20: Accelerated Testing Setup Post-Corrosion -----------------------------------------95

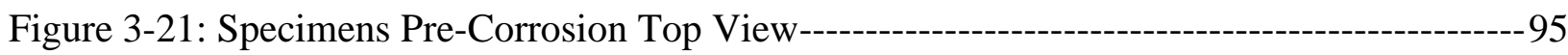

Figure 3-22: Specimens Post-Corrosion Top View ----------------------------------------------96

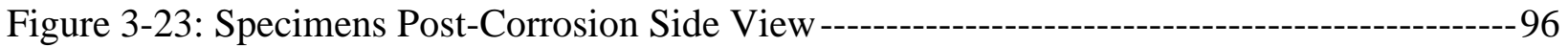

Figure 3-24: Typical A1010 Girder Elevation for the Speed River Bridge (Source: Parsons

Corporation Drawing) ---------------------------------------------------------------------------------------97

Figure 3-25: Top and Bottom Flange Connections at Thickness Change for Speed River Bridge

(Source: Parsons Corporation Drawing) -------------------------------------------------------------------98

Figure 3-26: Rectangular Specimen Dimension Recommendations for Fatigue Testing (ASTM,

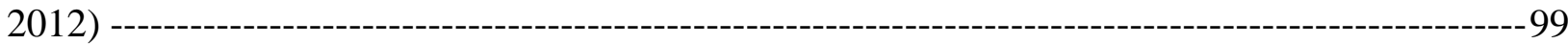

Figure 3-27: Difference in Waterjet Cutting Edge Quality (Source: WARDJet, wardjet.com)- 100 
Figure 3-28: Lag of Jet Stream Creating Poor Quality Edge Finish (Source: Dr. J. Olsen, drolsenslab.com) 100

Figure 3-29: Long Coupon Specimen Dimensioning for Bare Steel and Groove Welded Steel 101 Figure 3-30: Short Coupon Specimen Dimensioning for Bare Steel and Groove Welded Steel 102 Figure 3-31: (a) A1010 Plate with Beveled Edge; (b) A1010 Plates Tack Welded to Bottom Strip 103

Figure 3-32: (a) Preheating of Groove; (b) SAW Welding of Groove 103

Figure 3-33: (a) SAW Welding of Other Side of Groove; (b) Close Up of Finished Welded Groove 104

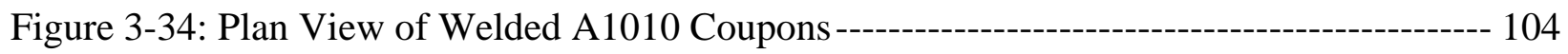

Figure 3-35: Side View of Welded A1010 Coupons ------------------------------------------------- 105

Figure 3-36: Close-Up View of Welded A1010 Specimen After Chemical Etching------------- 105

Figure 3-37: Tensile Test Set-Up ----------------------------------------------------------------------- 108

Figure 3-38: One Sinusoidal Stress Cycle for all Tested Fatigue Stress Ranges------------------- 110

Figure 4-1: Surface Roughness Parameters: (a) $\mathrm{R}_{\mathrm{a}}$; (b) $\mathrm{R}_{\mathrm{t}}$; (c) $\mathrm{R}_{\mathrm{z}}$ (Source: Shimana) ------------ 112

Figure 4-2: Average Load vs Slip Relationships from the Slip Resistance Test ------------------ 115

Figure 4-3: Slip Coefficients for Different Types of Stainless Steels and Surfaces -------------- 117

Figure 4-4: Filtered photo of A1010 plate showing slip area ---------------------------------- 119

Figure 4-5: Filtered photo of A1010 plates after slip testing showing points of contact--------- 119

Figure 4-6: (a-b) Close-up photo of A1010 showing yielded rough surface contact points and slip marks in the direction of the applied shear load; (c) A1010 post-slip surface near the center hole;

(d) A1010 post-slip surface near the edge of the plate 120

Figure 4-7: (a) A1010 close-up view of the rusted side near hole; (b) A1010 close-up view of the rusted side near edge, all before grit blasting in the current study ------------------------------- 121

Figure 4-8: Recorded Load-Slip Relationships for A1010 Hydraulic Clamped Specimens----- 123

Figure 4-9: A1010 specimen clamping load throughout the test duration ------------------------ 124

Figure 4-10: Load-Slip Relationship for A1010 Specimens Clamped by Using the Turn-of-Nut

Method 125

Figure 4-11: Load-Slip Relationship for 350W Hydraulic Clamped Specimens ----------------- 128

Figure 4-12: 350W Clamping Load Recorded Throughout the Test Duration --------------------- 129

Figure 4-13: Load-Slip Relationship for 350W Specimens Clamped by Turn-of-Nut Method- 130 
Figure 4-14: (a) 350W Steel with Class B Surface Condition Post-Slip Near Hole (b) 350W Steel with Class B Surface Condition Post-Slip Near the Edge of the Plate ----------------------------- 131 Figure 4-15: Load vs Slip Relationship for all CSA G40.21 350W Steel Specimens with Class A Surface Condition and Clamped by Hydraulic Jack--------------------------------------------------- 133

Figure 4-16: Average Clamping Load Recorded Throughout the Test Duration for CSA G40.21

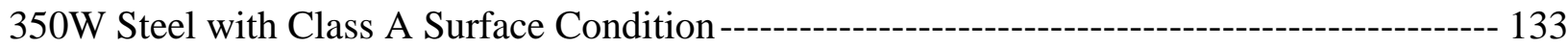

Figure 4-17: Load-Slip Relationship for all CSA G40.21 350W Steel Specimens --------------- 134 Figure 4-18: (a-b) 350W Steel with Class A Surface Condition Post-Slip Near Hole; (c) 350W Steel with Class A Surface Condition Post-Slip Near the Edge ------------------------------------- 135

Figure 4-19: Slip Resistance Coefficient vs Surface Roughness for A1010 Stainless Steel ---- 137 Figure 4-20: Slip Resistance Coefficient vs Surface Roughness for 350W Structural Steel ---- 138 Figure 4-21: A325 Plain and Galvanized Bolt Relaxation from 70\% Preload --------------------- 141

Figure 4-22: Extrapolation of 70\% Preload Loss for A325 Plain and Galvanized Bolts -------- 142 Figure 4-23: A325 Plain and Galvanized Bolt Relaxation from 90\% Preload -------------------- 143 Figure 4-24: Extrapolation of 90\% Preload Loss for A325 Plain and Galvanized Bolts -------- 144 Figure 4-25: B8 Class 2 Stainless Steel Bolt with Plain and Galvanized Nut Relaxation from $70 \%$ Preload-

Figure 4-26: Extrapolation of \% Preload Loss for B8 Class 2 Bolts with Plain and Galvanized Nut146

Figure 5-1: Stress-Strain Curves for All tested Coupon 149

Figure 5-2: Stress-Strain Relationships for A1010 Regular and Welded Stainless Steel Coupons 150

Figure 5-3: Close-up View of the First Porting of the Recorded Stress-Strain Relationship for A1010 Coupon Specimens 150

Figure 5-4: Stress-Strain Comparison between CSA G40.21 350W Regular \& Welded Steel - 151

Figure 5-5: A1010 necking followed by delaminated splitting and ultimate rupture------------- 152

Figure 5-6: Close-Up View of A1010 Delaminated Fracture------------------------------------- 152

Figure 5-7: Top View of A1010 vs 350W Tensile Coupon Specimen Fracture ------------------ 153

Figure 5-8: Side View of A1010 vs 350W Tensile Coupon Specimen Fracture------------------ 153

Figure 5-9: Top View of A1010 vs 350W Welded Coupon Specimens Fracture----------------- 155

Figure 5-10: A1010 vs 350W Welded Coupon Specimens Fracture Side View ------------------ 155 
Figure 5-11: Fracture Close-Up of CSA G40.21 350W Structural Steel Coupon ---------------- 156

Figure 5-12: Fracture Close-Up of ASTM A1010 Stainless Steel Coupon ------------------------ 156

Figure 5-13: Close-Up Side View of Delaminated Fracture in A1010 Tensile Coupon --------- 157

Figure 5-14: (a-b) Close-Up View of Fracture from the Top of A1010 Coupon ---------------- 157

Figure 5-15: A1010 Delaminated Fracture Crack Tip and Discontinuities from Abrasive Cutting

Figure 5-16: Fatigue test results plotted in the CSA S6-14 S-N Curve----------------------------- 160

Figure 5-17: Regression Analysis of Fatigue Results of 350W and A1010 Regular Long

Specimens

Figure 5-18: Top View of the Bare Coupons Made of 350W Post Fatigue------------------------ 163

Figure 5-19: Side View of the Bare Coupons Made of 350W Post Fatigue ----------------------- 163

Figure 5-20: 350W Fatigue Fracture of: a) Specimen 2 tested at $\Delta \sigma=270 \mathrm{MPa}$; b) Specimen 3 tested at $\Delta \sigma=250 \mathrm{MPa}$; c) Specimen 4 tested at $\Delta \sigma=225 \mathrm{MPa}$; d) Specimen 5 tested at $\Delta \sigma=$ $200 \mathrm{MPa}$

Figure 5-21: Top View of the Bare Coupons Made of A1010 Steel Post Fatigue ---------------- 165

Figure 5-22: Side View of the Bare Coupons Made of A1010 Steel Post Fatigue 165

Figure 5-23: A1010 Fatigue Fracture of: (a) Coupon Specimen 2 tested at $\Delta \sigma=270 \mathrm{MPa}$; (b)

Coupon Specimen 3 tested at $\Delta \sigma=250 \mathrm{MPa}$; (c) Coupon Specimen 4 tested at $\Delta \sigma=225 \mathrm{MPa} 166$ 


\section{LIST OF TABLES}

Table 2-1: Chemical Composition Requirements for ASTM A1010, \% A (ASTM, 2013b) ------ 15

Table 2-2: Mechanical Properties for ASTM A1010 (ASTM, 2013b) -------------------------------15

Table 2-3: Chemical Composition of Duracorr from ArcelorMittal, \% (ArcelorMittal, 2015) --- 17

Table 2-4: Recommended Welding Process Consumables (ArcelorMittal, 2016)------------------23

Table 2-5: Summary of Applications and Requirements for Bolted Joints (RCSC, 2014) --------37

Table 2-6: Summary of Slip Coefficients on Clean Mill Surfaces (Grondin et al., 2007) ---------48

Table 2-7: Summary of Slip Coefficients on Blasted Clean Surfaces (Grondin et al., 2007) -----49

Table 2-8: Constant Amplitude Threshold Stress Range \& Fatigue Life Constant Specified in the Canadian Highway Bridge Design Code (CSA, 2014a) ---------------------------------------------64

Table 2-9: Constant Amplitude Threshold and Detail Category Constant Specified in the AASHTO LRFD Bridge Design Specifications (AASHTO, 2017)--------------------------------65

Table 3-1: Research Matrix for Slip Resistance Test --------------------------------------------------79

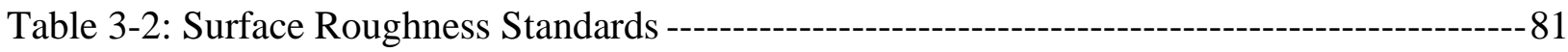

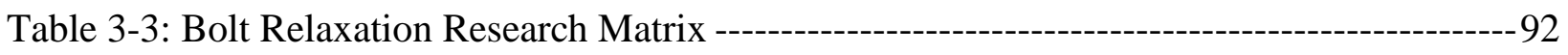

Table 3-4: Summary of Coupon Specimens Tested for Fatigue and Tensile Testing ------------ 106

Table 3-5: Summary of Applied Fatigue Stresses ----------------------------------------------------- 110

Table 4-1: Recorded Average Surface Roughness -------------------------------------------------- 113

Table 4-2: Average Slip Coefficient for Class B Surface ---------------------------------------- 116

Table 4-3: ASTM A1010 Stainless Steel Results Detailed Summary ------------------------------ 122

Table 4-4: Summary of Results of CSA G40.21 350W Steel with Class B Surface Condition 126

Table 4-5: Slip Summary of Results of CSA G40.21 350W with Class A Surface ------------- 132

Table 4-6: Summary of Bolt Relaxation Results ---------------------------------------------------- 140

Table 5-1: Summary of Tensile Test Results for A1010 and 350W Steels ------------------------ 148

Table 5-2: Summary of Stress Range vs Fatigue Life of Regular 350W and A1010 Steel Coupon Specimens 159 


\section{LIST OF APPENDIX FIGURES}

Figure A-1: Slip Load vs Displacement of Specimen A1010_1------------------------------- 173

Figure A-2: Clamping Load of Specimen A1010_1 -------- 173

Figure A-3: Slip Load vs Displacement Graph of Specimen A1010_2 --------------------- 174

Figure A-4: Clamping Load of Specimen A1010_2 --------------------------------- 174

Figure A-5: Slip Load vs Displacement of Specimen A1010_3----------------------------- 175

Figure A-6: Clamping Load of Specimen A1010_3 -------- 175

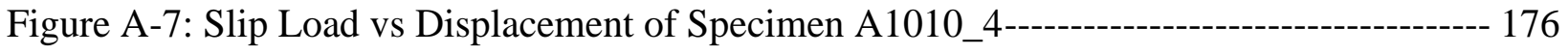

Figure A-8: Clamping Load of Specimen A1010_4 ---_o 176

Figure A-9: Slip Load vs Displacement of Specimen A1010_5---------------------------- 177

Figure A-10: Clamping Load of Specimen A1010_5 ------------------------------- 177

Figure A-11: Slip Load vs Displacement of Specimen A1010_6 ----------------------------- 178

Figure A-12: Clamping Load of Specimen A1010_6-------------------------------- 178

Figure A-13: Slip Load vs Displacement of Specimen A1010_7 -------------- 179

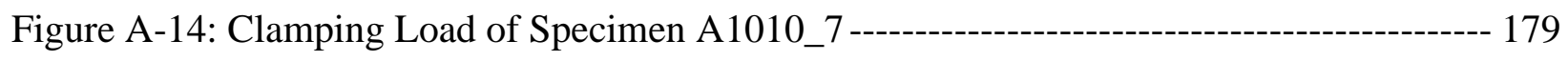

Figure A-15: Slip Load vs Displacement of Specimen A1010_8 -------------------------- 180

Figure A-16: Clamping Load of Specimen A1010_8 ------- 180

Figure A-17: Slip Load vs Displacement of Specimen A1010_9

Figure A-18: Clamping Load of Specimen A1010_9

Figure A-19: Slip Load vs Displacement of Specimen A1010_10--------------------------- 182

Figure A-20: Clamping Load of Specimen A1010_10 --------------- 182

Figure A-21: Slip Load vs Displacement of Specimen A1010_11 Clamped with the Turn-of-Nut

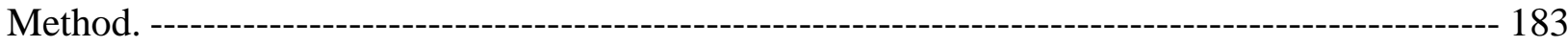

Figure A-22: Slip Load vs Displacement of Specimen A1010_12 Clamped with the Turn-of-Nut

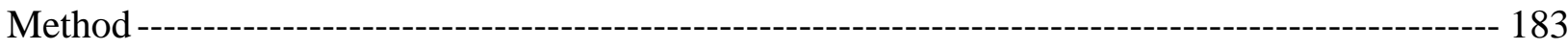

Figure A-23: Slip Load vs Displacement of Specimen A1010_13 Clamped with the Turn-of-Nut

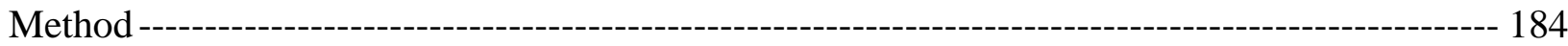

Figure A-24: Slip Load vs Displacement of Specimen A1010_14 Clmaped with the Turn-of-Nut

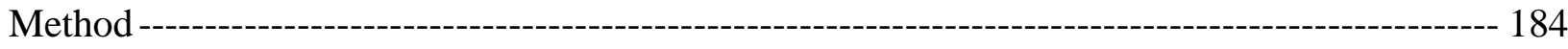


Figure A-25: Slip Load vs Displacement of Specimen A1010_15 Clamped with the Turn-of-Nut

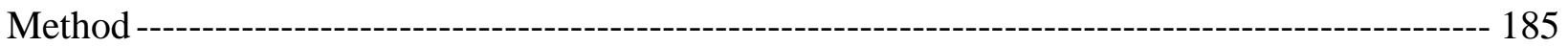

Figure B-1: Slip Load vs Displacement of Specimen 350W01-------------------------------------- 186

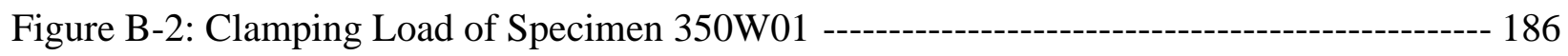

Figure B-3: Slip Load vs Displacement of Specimen 350W2 --------------------------------------- 187

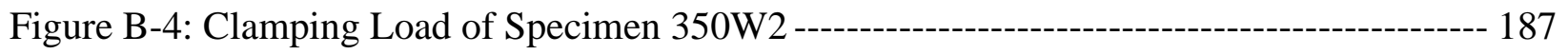

Figure B-5: Slip Load vs Displacement of Specimen 350W3 --------------------------------------- 188

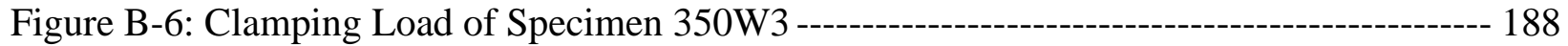

Figure B-7: Slip Load vs Displacement of Specimen 350W4 ------------------------------------- 189

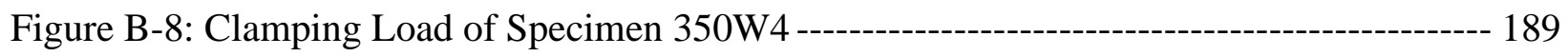

Figure B-9: Slip Load vs Displacement of Specimen 350W5 -------------------------------------- 190

Figure B-10: Clamping Load of Specimen 350W5 ----------------------------------------------- 190

Figure B-11: Slip Load vs Displacement of Specimen 350W6-------------------------------------- 191

Figure B-12: Clamping Load of Specimen 350W6 -------------------------------------------- 191

Figure B-13: Slip Load vs Displacement of Specimen 350W7------------------------------------ 192

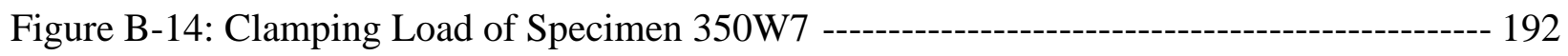

Figure B-15: Slip Load vs Displacement of Specimen 350W8-------------------------- 193

Figure B-16: Clamping Load of Specimen 350W8 --------------------------------------------------- 193

Figure B-17: Slip Load vs Displacement of Specimen 350W9-------------------------------- 194

Figure B-18: Clamping Load of Specimen 350W9 --------------------------------------------------- 194

Figure B-19: Slip Load vs Displacement of Specimen 350W10 -------------------------------- 195

Figure B-20: Clamping Load of Specimen 350W10 --------------------------------------------- 195

Figure B-21: Slip Load vs Displacement of Specimen 350W11 Clamped with the Turn-of-Nut

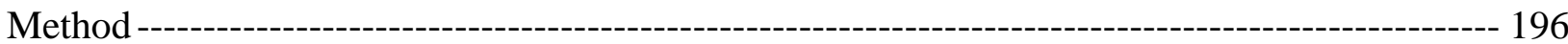

Figure B-22: Slip Load vs Displacement of Specimen 350W12 Clamped with the Turn-of-Nut

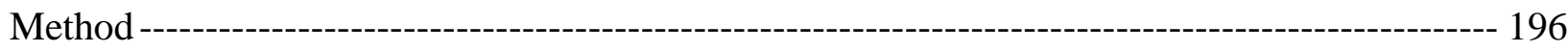

Figure B-23: Slip Load vs Displacement of Specimen 350W13 Clamped with the Turn-of-Nut

Method

Figure B-24: Slip Load vs Displacement of Specimen 350W14 Clamped with the Turn-of-Nut

Method 197 
Figure B-25: Slip Load vs Displacement of Specimen 350W15 Clamped with the Turn-of-Nut

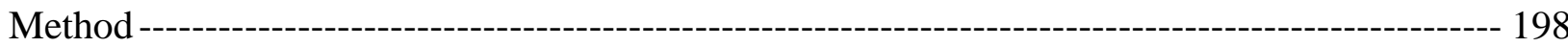

Figure C-1: Slip Load vs Displacement of Specimen 350WA01 with Class A Surface --------- 199

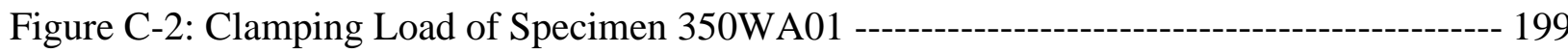

Figure C-3: Slip Load vs Displacement for Specimen 350WA02 with Class A Surface -------- 200

Figure C-4: Clamping Load for Specimen 350WA02 -------------------------------------------- 200

Figure C-5: Slip Load vs Displacement of Specimen 350WA03 with Class A Surface--------- 201

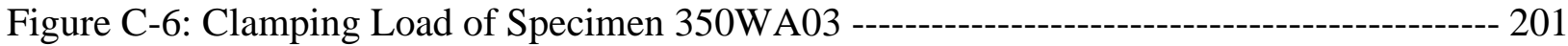

Figure C-7: Slip Load vs Displacement of Specimen 350WA04 with Class A Surface--------- 202

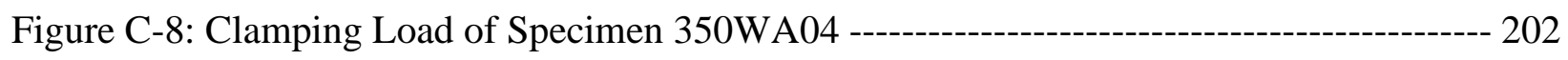

Figure C-9: Slip Load vs Displacement of Specimen 350WA05 with Class A Surface --------- 203

Figure C-10: Clamping Load of Specimen 350WA05------------------------------------------------ 203

Figure C-11: Slip Load vs Displacement of Specimen 350WA06 with Class A Surface ------- 204

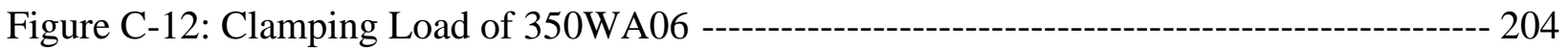

Figure C-13: Slip Load vs Displacement of Specimen 350WA07 with Class A Surface ------- 205

Figure C-14: Clamping Load of Specimen 350WA07------------------------------------------ 205

Figure C-15: Slip Load vs Displacement of Specimen 350WA08 with Class A Surface ------- 206

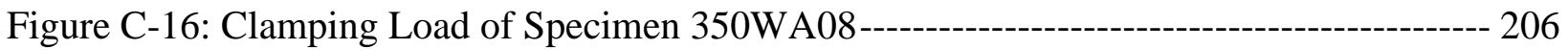

Figure C-17: Slip Load vs Displacement of Specimen 350WA09 with Class A Surface ------- 207

Figure C-18: Clamping Load of Specimen 350WA09----------------------------------------------- 207

Figure C-19: Slip Load vs Displacement of Specimen 350WA10 with Class A Surface ------- 208

Figure C-20: Clamping Load of Specimen 350WA10----------------------------------------- 208

Figure C-21: Slip Load vs Displacement of Specimen 350WA11 with Class A Surface and

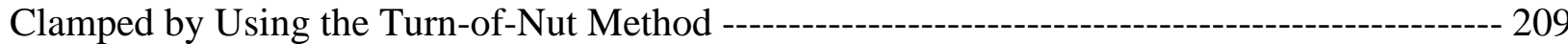

Figure C-22: Slip Load vs Displacement of Specimen 350WA12 with Class A Surface and

Clamped by Using the Turn-of-Nut Method 209

Figure C-23: Slip Load vs Displacement of Specimen 350WA13 with Class A Surface and Clamped by Using the Turn-of-Nut Method 210

Figure C-24: Slip Load vs Displacement of Specimen 350WA14 with Class A Surface Clamped by Using the Turn-of-Nut Method 210 
Figure C-25: Slip Load vs Displacement of Specimen 350WA15 with Class A Surface and

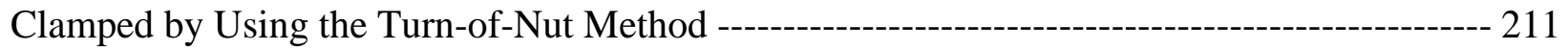

Figure E-1: Stress vs Strain Curve of A1010 Short Specimen-------------------------------------- 215

Figure E-2: Stress vs Strain Curve of A1010 Long Specimen------------------------------------ 215

Figure E-3: Stress vs Strain Curve of A1010 Welded Short Specimen ---------------------------- 216

Figure E-4: Stress vs Strain Curve of A1010 Welded Long Specimen----------------------------- 216

Figure E-5: Stress vs Strain Curve of 350W Short Specimen ------------------------------------ 217

Figure E-6: Stress vs Strain Curve of 350W Long Specimen---------------------------------------- 217

Figure E-7: Stress vs Strain Curve for 350W Welded Short Specimen ---------------------------- 218

Figure E-8: Stress vs Strain Curve of 350W Welded Long Specimen ---------------------------- 218 


\section{LIST OF APPENDIX TABLES}

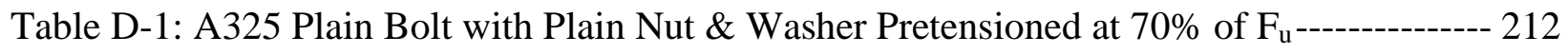

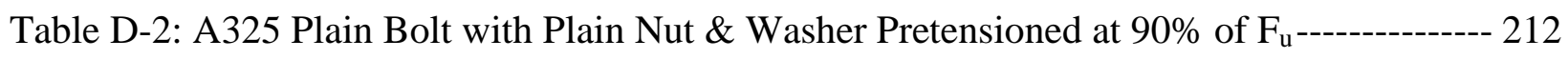

Table D-3: A325 Galvanized Bolt with Galvanized Nut \& Washer Pretensioned at $70 \%$ of $F_{\mathrm{u}} 212$

Table D-4: A325 Galvanized Bolt with Galvanized Nut and Washer Pretensioned to $90 \%$ of $\mathrm{F}_{\mathrm{u}}$

Table D-5: A193 B8 Class 2 Stainless Steel Bolt with Galvanized Nut and Stainless Steel

Washer Pretensioned at $70 \%$ of $\mathrm{F}_{\mathrm{u}}$

Table D-6: A193 B8 Class 2 Stainless Steel Bolt with Plain Nut and Stainless Steel Washer

Pretensioned at $70 \%$ of $\mathrm{F}_{\mathrm{u}}$

Table F-1: Chemical composition by heat analysis of Canadian grade 350 steel plates, bars, shapes, and sheets

Table F-2: Mechanical properties of Canadian steel grade 350 plates, bars, sheets, and welded shapes 


\section{Chapter 1 - Introduction}

\subsection{General Introduction - A Brief History on Bridges}

Bridges worldwide serve as a link between humanity. They are the main structures used to connect different regions and provide for safe passage over geographical obstacles that hinder the movement of humanity. For this reason alone, they bring wealth and prosperity which in turn allows for the enrichment and advancement of human development. Bridges are some of the most essential transportation structures that mankind has come to study and know. It is without a doubt that decision makers worldwide do their best to preserve and extend the functional service life of these structures. However, to properly accomplish this task one must acknowledge past deficiencies and improve on them.

Humans first started building bridges simply by laying flat longitudinal objects such as trees or rocks across an obstacle. This method became obsolete when the early humans needed to carry more weight or pass larger obstacles. Eventually, stone arch bridges were developed and used by the ancient Greeks \& Romans to further advance civilization. Stone bridges also became obsolete due to their large weight, limited spans, and longer construction time. As civilizations became more advance with their tools, wood bridges became prevalent during the middle ages. They were lightweight and simple to construct but were limited in carrying capacity and hindered from the fast degradation of wood due to rot and insects. Finally, during the early age of the industrial revolution in the $17^{\text {th }}$ and $18^{\text {th }}$ centuries, cast iron was developed. This gave rise to some of the first iron bridges in Europe and Worldwide. Eventually, cast iron was developed into various types of steel alloys by mixing it with other elements, such as carbon, nickel, silicon, phosphorus, sulphur to get different structural properties as a result of different chemical compositions.

Modern structural steel has become a versatile material due to its low weight, high strength, high stiffness per weight, ease of mass production, ease of installation and cheap transportation costs. Having said that, with the very fast development of concrete and reinforced concrete materials in recent times, structural steel is seen as a second option by a lot of decision makers, due to its high susceptibility to corrosion and swings in costs. Decision makers have been fighting against time 
for ages to prevent corrosion of steel bridges. It is a fact that corrosion of unprotected iron-based steel starts the minute that it leaves the factory. Hence, the development of special corrosion protective coatings has come into existence. Although these coatings help prevent corrosion, they are very expensive and oftentimes need to be re-applied every decade. Due to budget constraints, bridge owners often neglect to apply protective coatings, which could potentially lead to catastrophic degradation and collapse over time. Having said this, it is not to say that steel, which does not easily corrode, does not exist, however, the issue lies in keeping a balance between functionality and budget in check when deciding to build with corrosion resistant steel. One potential solution to combat corrosion is to use a newly-developed stainless steel composition that provides the proper functionality within a reasonable budget and can be used in mass structures such as bridges.

\subsection{The Problem}

In the $21^{\text {st }}$ century, it is important to build sustainable structures for future generations. Sustainability is defined as "meeting current needs without compromising future needs". For structures, sustainability usually comes about by creating long-lasting structures that will require minimal maintenance throughout its life-cycle at a reasonable cost. The longer a bridge can last with minimal maintenance, the more sustainable it is. For steel bridges, corrosion is the number one cause of deterioration which can lead to frequent heavy maintenance work or total replacement of the structure. The word corrosion itself comes from the Latin word "corrodere" which simply means to "chomp to pieces". Corrosion is a natural process whereby iron and steel tend to want to combine with oxygen and water to chemically reach their lowest natural energy state. When this chemical combination happens in the environment, hydrated iron oxides are formed, commonly known as rust. Rust is very similar chemically to naturally mined iron ore which is the first step in the cycle of steel production (Davis, 2000). Hence, corrosion is considered a naturally occurring process, where steel products tend to find the appropriate chemical balance and naturally go back to their original chemical composition, as seen in Figure 1-1 on the next page. 


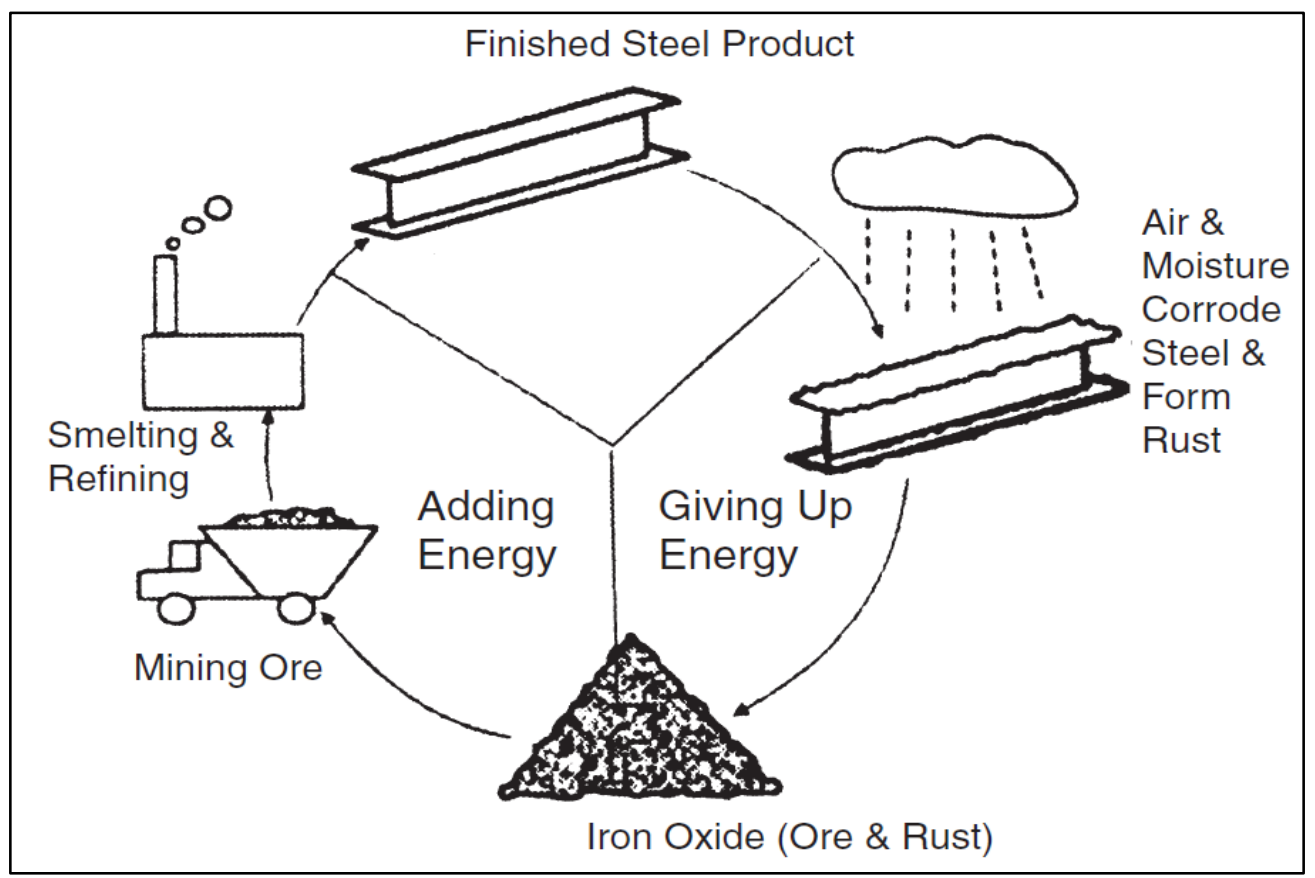

Figure 1-1: General Life Cycle of Steel (Davis, 2000)

For the purpose of this thesis, we can start to think of rust as a form of deterioration in steel structures. Since rust is an unstable by-product of corrosion, it severely reduces section dimensions and thus overall strength capacity of the structure. This can lead to underestimation of carrying capacity for many bridges and premature corrosion fatigue failures over the initially estimated service life. Although ultimate failures and total fatigue failures due to steel deterioration are rare occurrences, they usually happen when decision makers neglect deteriorated structures. Hence, inspection and maintenance are the most important step towards preventing catastrophic failures. Unfortunately, neglect is usually a cause of budget constraints from ownership. A huge burden is placed on the decision-maker(s) to properly plan through the design phase by accurately predicting deterioration states before the structure is built. This ensures the most cost-effective structure is built for a specific scope.

One can confidently state that most corrosion consequences are economic. Replacement, overdesign, protective and preventive maintenance all add up to the overall economic impact in ensuring structural safety. If a bridge is constantly closed off or lanes are reduced for proper construction maintenance, its usefulness decreases. Thus, we have to account for traffic during construction, slowing down the day-to-day business conducted. At the same time, the risk for environmental pollution also increases during necessary construction maintenance, since a lot of 
bridge structures are built over bodies of water which are usually home to precious marine life, playing their necessary part in the natural ecosystem. From a societal perspective, the aesthetics of a corroded steel structure are not very pleasing and do not ensure confidence in the general public.

In general, the primary corrosion control methods in steel bridges include material selection, design, coatings, and cathodic protection. It is generally recommended that these methods are used in combination with one another, to achieve a longer service life with minimal maintenance. For example, design considerations such as deciding to build a jointless bridge or an integral abutment instead of a regular abutment can be used in combination with the application of protective coatings to further increase the service life of a bridge. Similarly, a lot of the newer protective coatings are made from sacrificial materials which act as a form of cathodic protection. According to the U.S Department of Transportation's Federal Highway Administration (FHWA), the most common methods developed to battle corrosion on highway steel bridges include (i) selecting proper corrosion resistive steels, (ii) using zinc-rich primer paint systems, (iii) fully hot-dip galvanizing bridge elements, and (iv) thermal spray metalizing. All of these methods have their drawbacks and benefits. Over the last 20 years, decision makers have lost interest in building steel bridges because the preventive maintenance from corrosion has taken a lot out of their budgets. Also, it is a fact that the cost of applying corrosive resistant paints in-field has increased by almost $250 \%$ over the last 20 years (FHWA, 2015). So far, none of these methods have stood out over one another. A lot of discussions have been ongoing and questions regarding the long-term onfield performance are hard to answer because of how slow the onset of corrosion is and the many environmental variables that it is attributed to.

In the 1960s, a type of corrosion-resistant steel called weathering steel or atmospheric corrosion resistant (ACR) steel was introduced for bridge use in North America. Weathering steel is made from alloying regular carbon-based steel with small amounts of copper, nickel, chromium, and silicon. Regular steel usually produces rust when it oxidizes from exposure to moisture. These oxides usually flake off and expose the new uncorroded surface of the steel. The process continues until the steel member is left with nothing. Weathering steel acts similarly, the difference being, that the oxides do not flake off but instead remain intact, forming a patina of rust, thereby protecting the inner substrate of the steel from corroding indefinitely. The development of this layer is caused by the formation of nanophase goethite $(\alpha-\mathrm{FeOOH})$ in the absence of moisture 
(Fletcher, 2011). The first bridges made out of weathering steel were built in the 1960s in both Michigan and Ontario. Thousands of weathered steel bridges were constructed all throughout the world since then. However, the main issue with this was that even though weathering steel performed very well in terms of durability compared to regular steel, it showed signs of insignificant durability improvements in very aggressive environments making it not costeffective. These aggressive environments include marine environments or environments where regular salt spray is applied during the winter months on the road to ensure motorist safety. Therefore, the conclusion on weathering steel has been that the protective patina does not form well in environments exposed to chlorides. More specifically, a certain level of chlorides in the oxy-hydroxide surface layer prevents the formation of nanophase goethite, instead favour the formation of akageneite $(\beta-\mathrm{FeOOH})$ and/or maghemite $\left(\mathrm{FeO} \bullet \mathrm{Fe}_{2} \mathrm{O}_{3}\right)$ (Fletcher, 2011).

In the 1980s, Michigan put an outright moratorium on weathering steel after an 8-year study concluded that the corrosion rate never slowed down. As a result, in 1989 the FHWA issued a technical advisory to give guidance towards the proper use of weathering steel. Similarly, the Ministry of Transportation of Ontario (MTO), started to paint weathering steel bridge girders up to 3 meters $(\sim 10 \mathrm{ft})$ out near problematic areas prone to severe exposure of wetting and salt leeching, such as expansion joints or girder ends (McLeod et al, 2018).

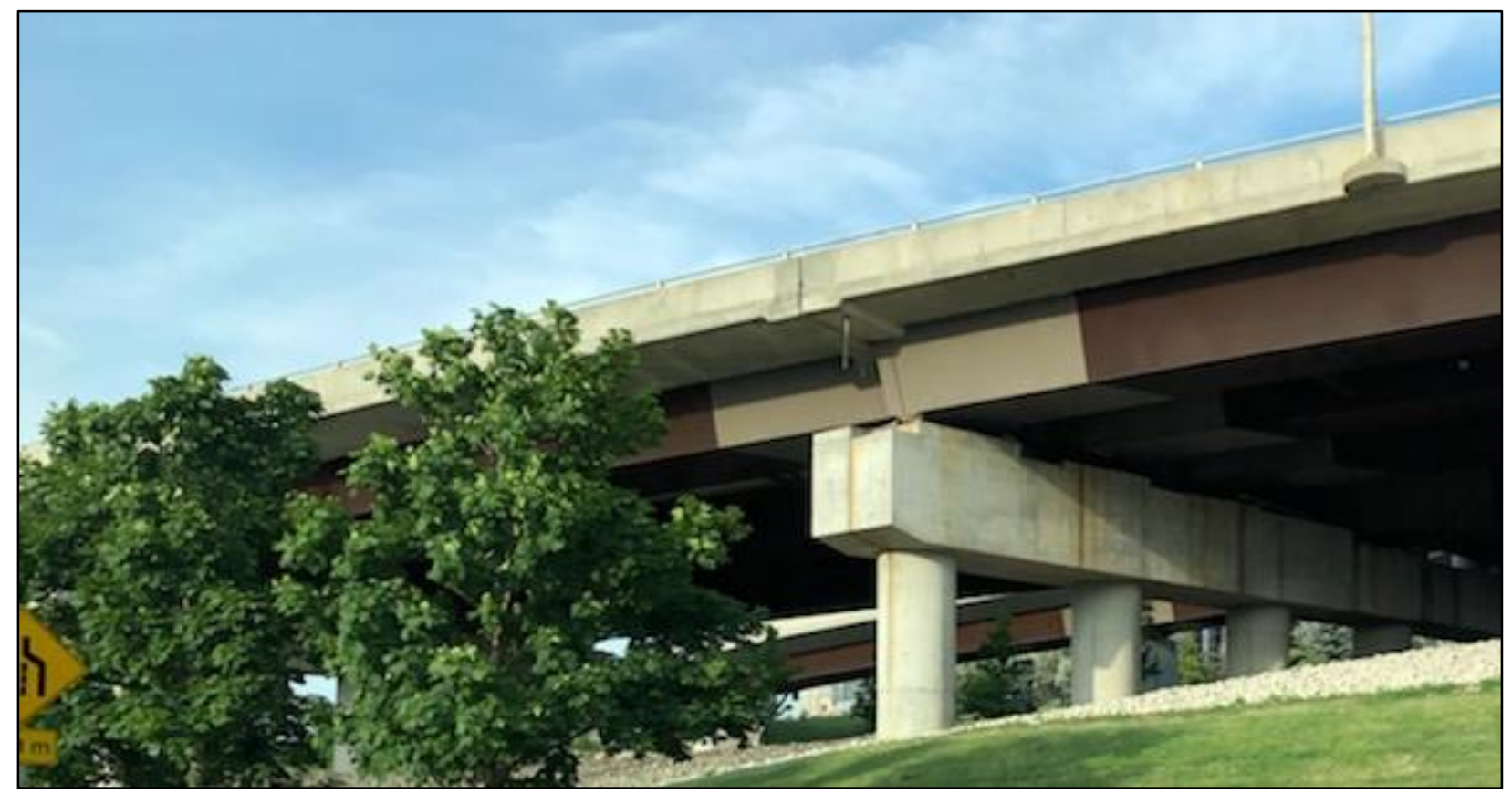

Figure 1-2: Weathering steel girder coated 3 meters apart from the expansion joint 


\subsection{Research Objective}

This research aims at developing standard practices from a structural perspective, for the specific use of ASTM A1010 stainless steel plate girders on bridges. The research objectives are to accomplish the following;

- Determining experimentally the slip resistance of stainless steel plates and correlating it with traditional structural steel through known experimental testing for blasted clean surface condition. With this knowledge, engineers will be able to ascertain whether they can use the same slip coefficient on bolted spliced connections as that provided on the current Canadian Highway Bridge Design Code, CHBDC S6-14, (CSA, 2014a) or whether a new slip coefficient needs to be established.

- Examining experimentally the difference in clamping load relaxation for specific bolt types, namely: regular A325 bots, galvanized A325 bolts and A193 B8 Class 2 stainless steel bolts.

- Static tensile testing on ASTM A1010 stainless steel and CSA G40.21 350W steel coupon specimens to determine whether A1010 has similar mechanical properties to that of traditional Canadian structural steel for ultimate limit state design.

- Fatigue testing on A1010 stainless steel and CSA G40.21 350W steel coupon specimens to determine whether A1010 has similar mechanical properties to that of traditional Canadian structural steel for fatigue limit state design.

\subsection{Scope of Work}

In order to establish a slip resistance coefficient, 15 ASTM A1010 steel specimens and 15 regular structural steel specimens made of CSA G40.21 350W steel grade were fabricated and tested under compression loading that creates shear force at the interface of connecting plates. Five of these specimens were bolted with the standard turn-of-nut method commonly used in the field and 10 of the remaining specimens were tightened together by a hydraulic load cell to accurately measure the clamping load applied by the bolt to the plates and as a result, come up with a precise slip resistance coefficient. Figure 1-3 shows the test matrix for slip resistance evaluation study. A Skidmore-Wilhelm bolt clamping force measuring device was used to ascertain the forces yielded 
by the turn-of-nut method from 7/8" regular A325 high-strength bolts, galvanized A325 bolts and B8 stainless steel bolts. Bolt clamp relaxation was measured and compared for all bolts with a washer-like load cell on the Skidmore-Wilhelm device itself.

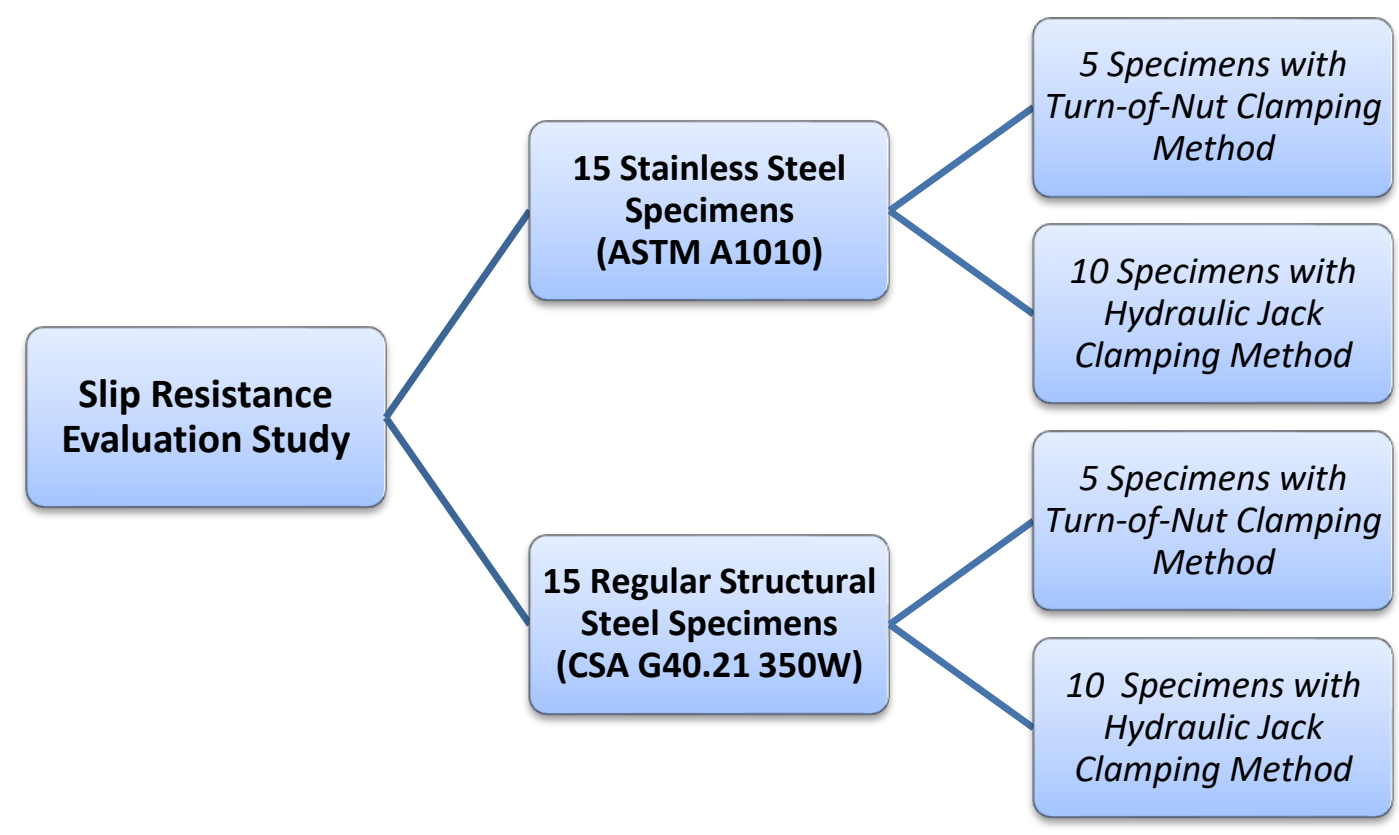

Figure 1-3: Text Matrix for Slip Resistance Evaluation Study

Standard monotonic tensile testing was performed on 8 short and long coupon specimens to obtain yield, ultimate, and fracture strength of A1010 bare coupons as well as identical coupons but with full penetration groove welding. Similar monotonic testing was performed on coupon specimens made of conventional structural steel (CSA G40.21 350W grade) for the sake of comparison. Finally, tensile fatigue tests were performed on 5 regular A1010 coupon specimens and 5 regular CSA G40.21 350W coupon specimens at different fatigue stress ranges in order to find experimentally the number of cycles to failure and determine the appropriate fatigue category for A1010 steel. 


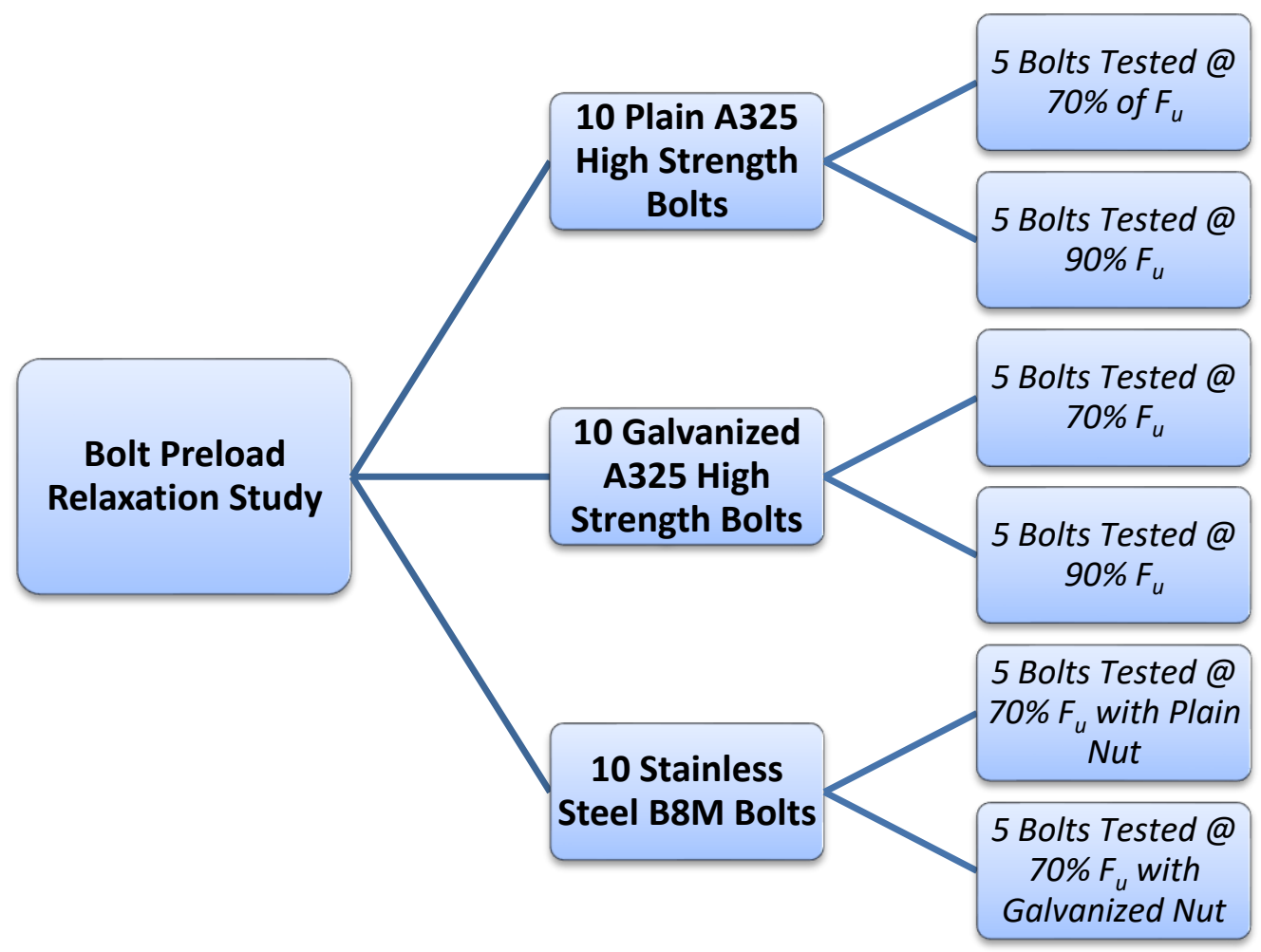

Figure 1-4: Test Matrix for Bolt Preload Relaxation Evaluation Study

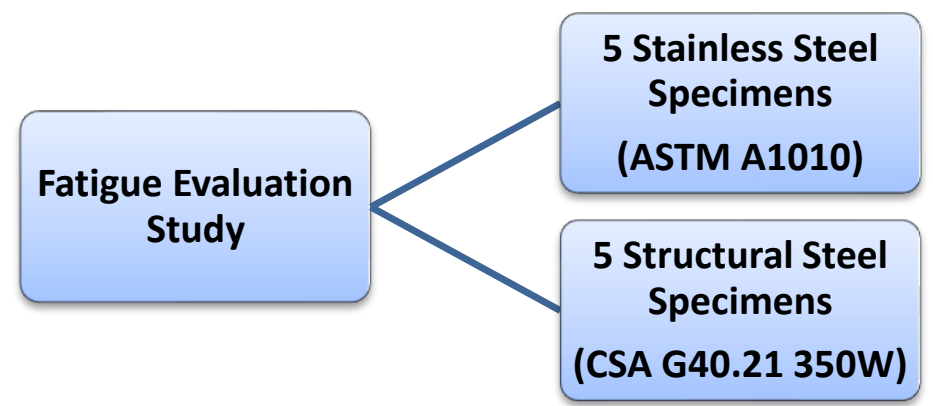

Figure 1-5: Test Matrix for Fatigue Evaluation Study

\subsection{Thesis Layout}

Chapter 1 of this thesis gives a brief introduction of steel bridges to the general reader while outlining how this study came about, the research objectives and what work was performed to meet these objectives.

Chapter 2 is sub-divided into several literature review sections. The first section is on ASTM A1010 stainless steel material. It outlines the general manufacturing and fabrication guidelines of 
stainless steel, its mechanical properties, durability, its cost compared to other steels, and recommended welding procedures. The second section gives a detailed review of previous studies done on the slip resistance coefficient and bolt relaxation for conventional and various stainless steels. This literature review is the basis for establishing a similar experimental ground for testing the slip resistance coefficient of A1010 stainless steel. The third section provides a detailed literature review on general bridge fatigue and fatigue testing as it relates to the design code and other relevant studies.

Chapter 3 outlines detailed procedure for all of the experimental work conducted in this thesis. Namely, slip resistance testing, bolt preload relaxation, galvanic corrosion of dissimilar fastenersteel assemblies, static tensile testing and cyclic fatigue testing.

Chapter 4 outlines the main results and trends found from the slip resistance experiments in this study. This chapter also presents the bolt relaxation and surface roughness results.

Chapter 5 includes monotonic tensile testing and fatigue test results for both stainless and regular structural steels.

Chapter 6 concludes this thesis along with future recommendations for conducting further relevant studies on A1010 stainless steel for bridge applications. 


\section{Chapter 2 - Literature Review}

\subsection{Stainless Steel - A Brief Introduction}

Stainless steel is the name given to corrosion or heat resistant carbon alloyed steel with a composition that contains at least $10.5 \%$ chromium content by weight (Baddoo, 2013; ASM, 1990). A wide range of stainless steels exist with a variety of alloy combinations that accordingly have an effect on corrosion resistance and strength. The corrosion resistance of stainless steel comes from a thin adherent film that forms on the surface of the steel due to oxidation. This film is primarily made out of chromium-rich oxides. When the film gets damaged from scratches it has the ability to reform itself in the presence of oxygen. This passive layer is very stable and its durability depends on the composition of stainless steel, surface treatment and corrosiveness of the environment. In general, the stability of the film increases with an increase of chromium content, which could be enhanced by the additions of molybdenum and nitrogen. It is important to state that for the purpose of structural applications where large structural steel elements are used, the economics of stainless steel becomes very important when compared to other corrosive resistance chemical elements that are used to ensure longer service life. It is without a doubt that the more rare and expensive alloying elements added to the steel the more its price will increase. Although chromium is not a rare element, its price is substantially more than that for iron ore. Thus, the higher the chromium content, the higher the cost of the stainless steel. In order for stainless steel to be a competitive material from a structural standpoint, it needs to have a minimal amount of alloying and chromium content for most regular bridge environments.

Usually, stainless steels are classified into 5 groups. These groups are categorized by different chemical, mechanical, and microstructure properties. The following are the most common classifications:

\section{- Austenitic Stainless Steels:}

Austenitic stainless steels are most commonly comprised of $17-18 \%$ chromium and $8-11 \%$ nickel contents. They have a face-centered cubic (FCC) crystal atomic structure and as a result, have high ductility, are readily weldable and can easily be strengthened by cold working, but 
not heat treatment. Corrosion performance can be enhanced by higher levels of chromium, molybdenum, and nitrogen (Baddoo, 2013).

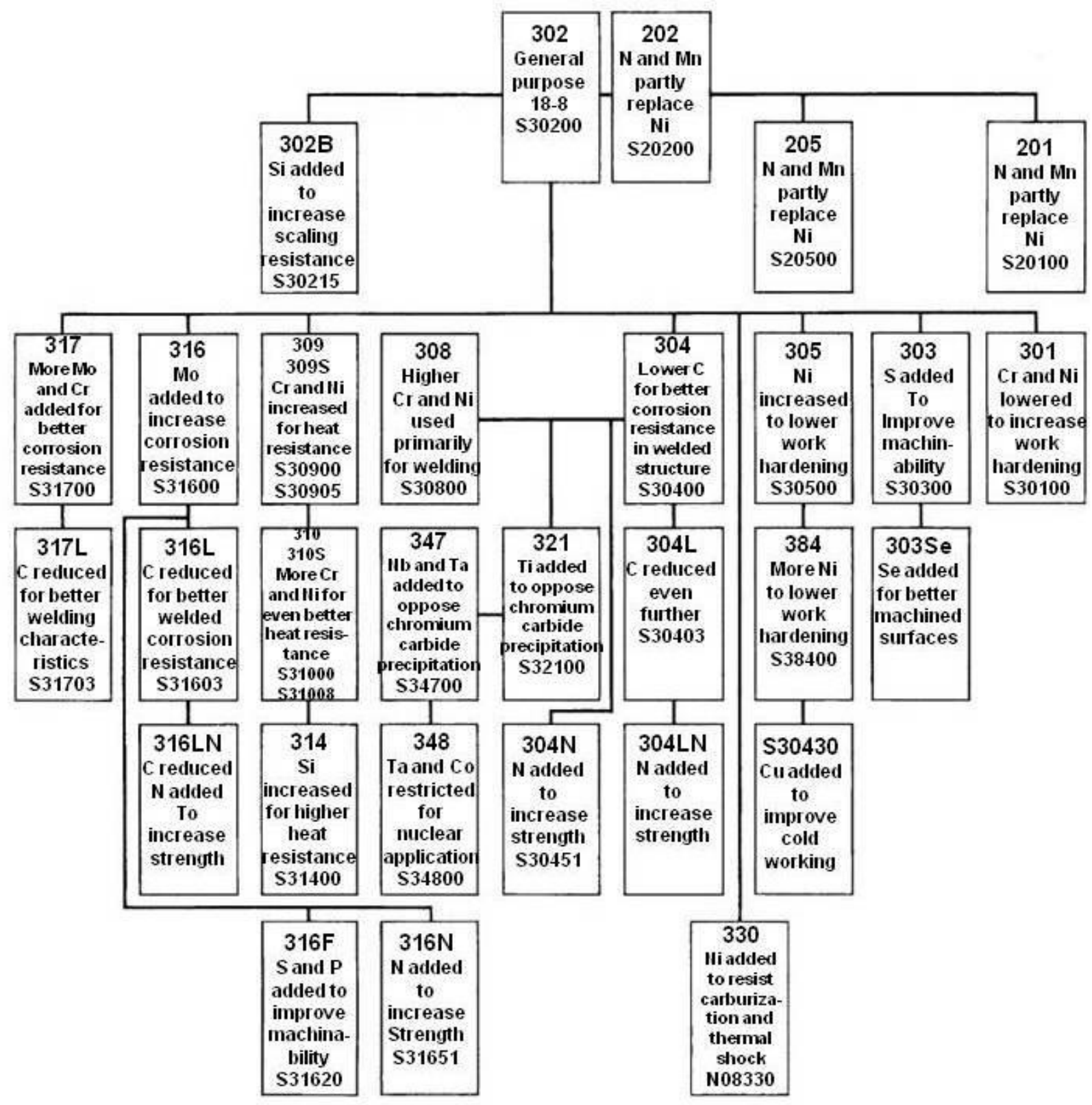

Figure 2-1: Family Tree of Austenitic Stainless Steels Based on AISI and UNS Classification (ASM, 1990)

\section{- Ferritic Stainless Steels:}

Ferritic stainless steels have a chromium content of 10.5-18\% and may contain small amounts of nickel. They are similar to structural steel in terms of having a body-centered cubic (BCC) atomic structure which makes them less ductile, less formable, and less weldable than 
austenitic stainless steel. However, they can be strengthened by cold working but in general, are more limited. They have very good resistance to stress corrosion cracking (Baddoo, 2013).

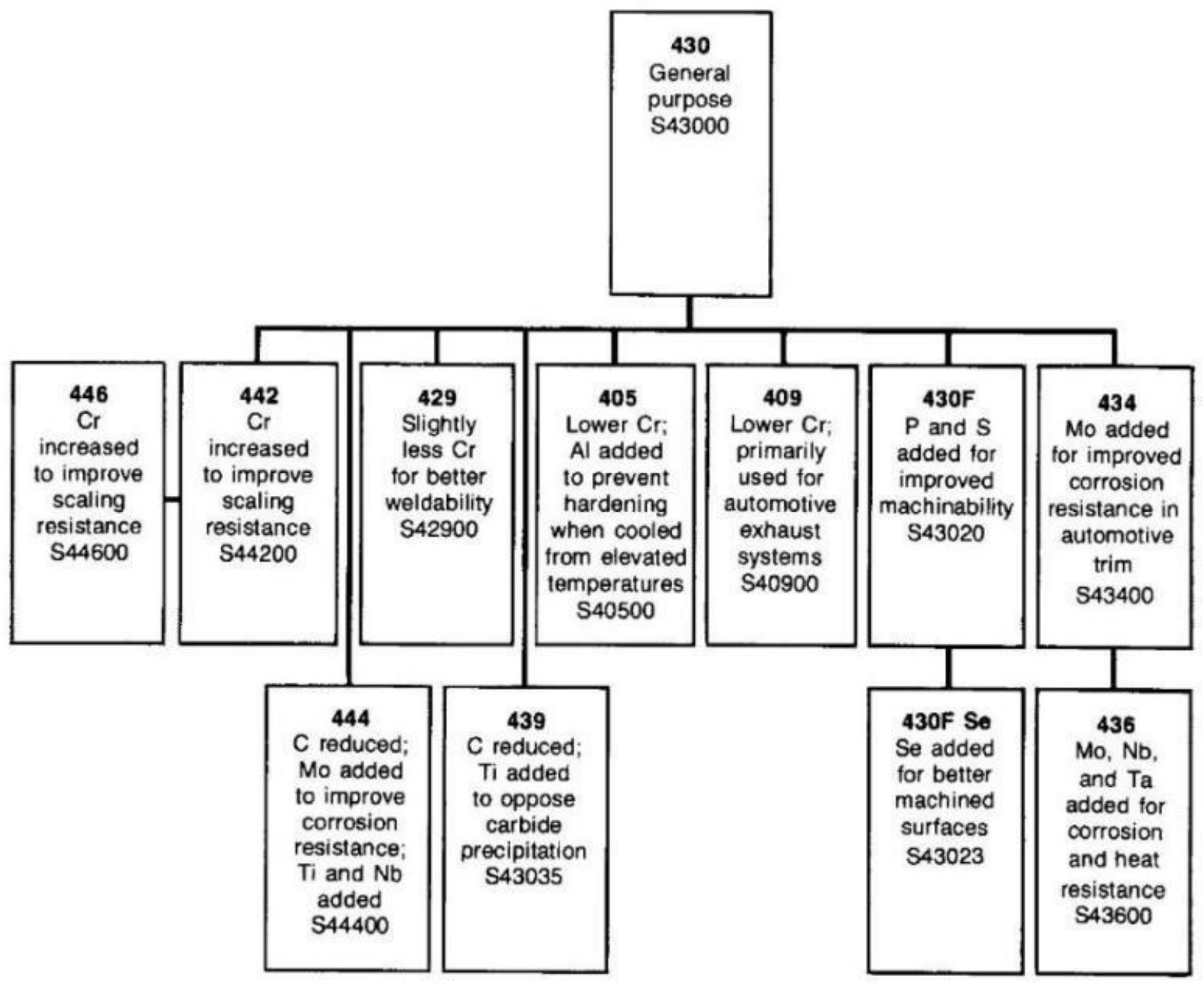

Figure 2-2: Family Tree of Common Ferritic Stainless Steels (ASM, 1990)

\section{- Duplex Stainless Steels:}

Duplex stainless steels have a mixed combination of austenite and ferrite in their microstructure. Usually they contain 20-26\% chromium, 1-8\% nickel, $0.05-5 \%$ molybdenum, and $0.05-0.3 \%$ nitrogen content. They are much stronger than austenitic stainless steel. However, the high strength restricts their formability. In general, they have great weldability, can be strengthened by cold working, and have good resistance to stress corrosion cracking (Baddoo, 2013). 


\section{- Martensitic Stainless Steels:}

Martensitic stainless steels are very similar to ferritic in terms of having the same atomic structure, body-centered cubic (BCC). These types of stainless steels have a higher carbon content ranging from $0.03 \%$ to over $1 \%$ enabling them to be strengthened by heat treatment (ASM, 1990). They show very good abrasion and wear resistance and can be used in hardened or tempered conditions. They are less ductile and more notch sensitive than the other types of stainless steel. When it comes to welding, martensitic stainless steels can be welded but usually require more work because they need preheat and post-weld heat treatment (Baddoo, 2013).

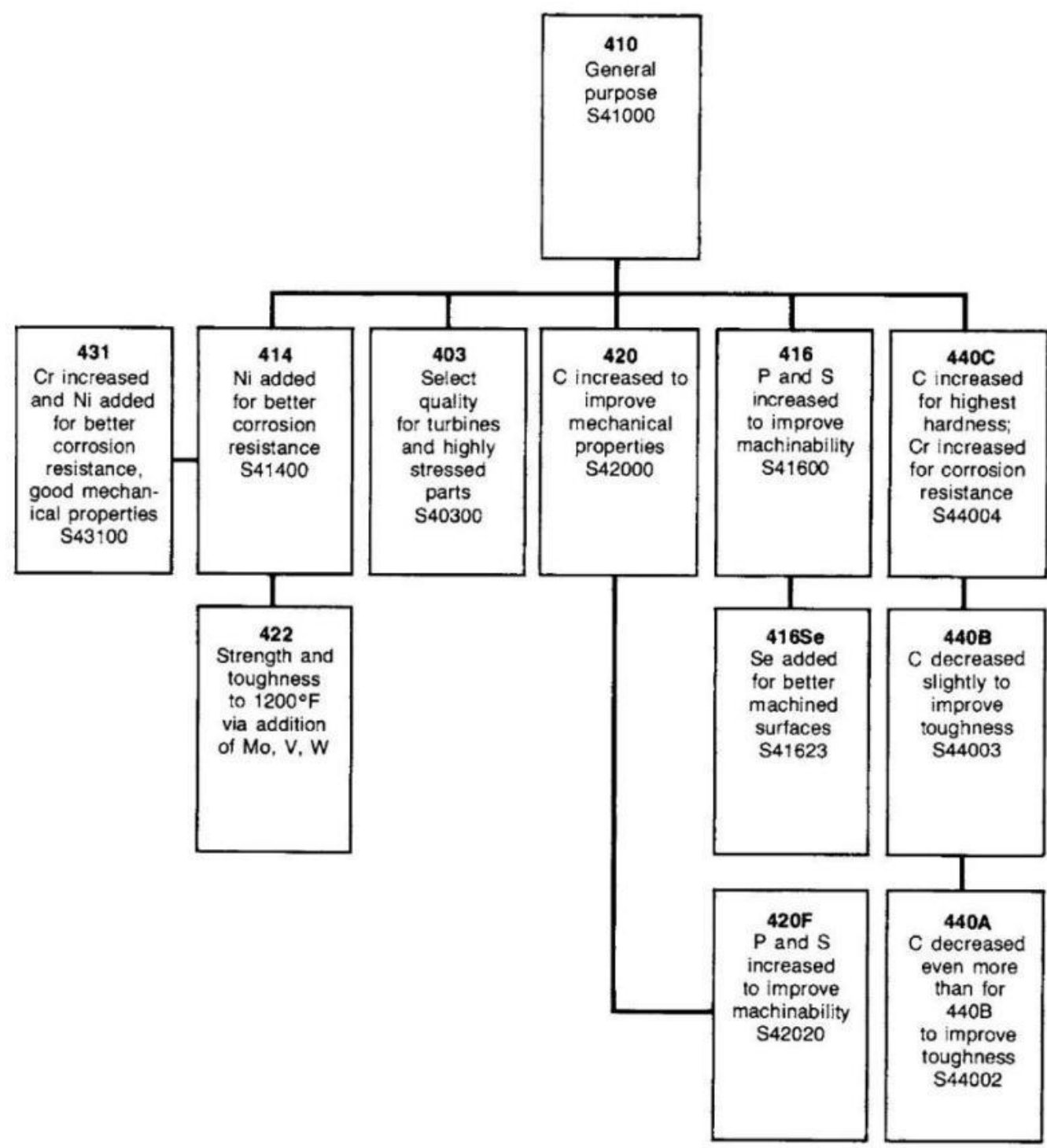

Figure 2-3: Family Tree of Martensitic Stainless Steels (ASM, 1990) 


\section{- Precipitation Hardening Stainless Steels:}

These types of stainless steels are strengthened by heat treatment to very large tensile strengths. In terms of corrosion resistance, they are similar to austenitic types of stainless steel containing $18 \%$ chromium and $8 \%$ nickel content. These types of steels are usually used for tension bars, shafts, bolts, and niche applications requiring a combination of strength and high corrosion resistance (Baddoo, 2013).

\begin{tabular}{|c|c|c|c|c|c|c|c|c|c|c|}
\hline \multirow[b]{3}{*}{ UNS or AISI type } & \multirow[b]{3}{*}{ Condition } & \multirow{3}{*}{$\begin{array}{l}\text { Rockwell } \\
\text { hardness }\end{array}$} & \multicolumn{6}{|c|}{ Average tensile properties } & \multirow{2}{*}{\multicolumn{2}{|c|}{$\begin{array}{l}\text { Charpy V-notch } \\
\text { impact strength }\end{array}$}} \\
\hline & & & \multicolumn{2}{|c|}{$\begin{array}{c}\text { Yield strength, } \\
0.2 \% \text { offset }\end{array}$} & \multicolumn{2}{|c|}{$\begin{array}{c}\text { Ultimate tensile } \\
\text { strength }\end{array}$} & \multirow{2}{*}{$\begin{array}{l}\text { Elongation } \\
\text { in } 50.8 \mathrm{~mm} \\
(2.0 \mathrm{in} .), \% \\
\end{array}$} & \multirow{2}{*}{$\begin{array}{l}\text { Reduction } \\
\text { of area, } \%\end{array}$} & & \\
\hline & & & $\mathrm{MPa}$ & ksi & $\mathrm{MPa}$ & ksi & & & $\mathrm{J}$ & $\mathrm{ft} \cdot \mathrm{lb}$ \\
\hline \multicolumn{11}{|l|}{ Austenitic stainless } \\
\hline Type 304 & Annealed & $81 \mathrm{HRB}$ & 241 & 35 & 586 & 85 & 60.0 & 70.0 & $\geq 325$ & $\geq 240$ \\
\hline N08020 & Annealed & $84 \mathrm{HRB}$ & 276 & 40 & 621 & 90 & 50.0 & 65.0 & 271 & 200 \\
\hline S20161 & Annealed & $93 \mathrm{HRB}$ & 365 & 53 & 970 & 140 & 59.0 & 64.0 & $\geq 325$ & $\geq 240$ \\
\hline S21800 & Annealed & 95 HRB & 414 & 60 & 710 & 103 & 64.0 & 74.0 & $\geq 325$ & $\geq 240$ \\
\hline \multicolumn{11}{|l|}{ Ferritic } \\
\hline Type 405 & Annealed & $81 \mathrm{HRB}$ & 276 & 40 & 483 & 70 & 30.0 & 60.0 & $\ldots$ & $\ldots$ \\
\hline Type 430 & Annealed & $82 \mathrm{HRB}$ & 310 & 45 & 517 & 75 & 30.0 & 65.0 & 217 & 161 \\
\hline \multicolumn{11}{|l|}{ Duplex } \\
\hline S32950 & Annealed & $100 \mathrm{HRB}$ & 570 & 82 & 760 & 110 & 38.0 & 78.0 & 157 & 116 \\
\hline \multicolumn{11}{|l|}{ Martensitic } \\
\hline \multirow[t]{4}{*}{ Type 410} & Annealed & $82 \mathrm{HRB}$ & 276 & 40 & 517 & 75 & 35.0 & 70.0 & $\ldots$ & $\ldots$ \\
\hline & $\begin{array}{l}\text { Oil quenched from } 1010^{\circ} \mathrm{C}\left(1850^{\circ} \mathrm{F}\right) \\
\text { and tempered: }\end{array}$ & & & & & & & & & \\
\hline & at $250^{\circ} \mathrm{C}\left(500^{\circ} \mathrm{F}\right)$ & $43 \mathrm{HRC}$ & 1089 & 158 & 1337 & 193 & 17.0 & 62.0 & 76 & 56 \\
\hline & at $593^{\circ} \mathrm{C}\left(1100^{\circ} \mathrm{F}\right)$ & $26 \mathrm{HRC}$ & 724 & 105 & 827 & 120 & 20.0 & 63.0 & 52 & 38 \\
\hline \multirow[t]{3}{*}{ Type 420} & Annealed & $92 \mathrm{HRB}$ & 345 & 50 & 655 & 95 & 25.0 & 55.0 & $\ldots$ & $\ldots$ \\
\hline & Oil quenched from $1038^{\circ} \mathrm{C}\left(1900^{\circ} \mathrm{F}\right)$ & & & & & & & & & \\
\hline & and tempered at $316^{\circ} \mathrm{C}\left(600^{\circ} \mathrm{F}\right)$ & $52 \mathrm{HRC}$ & 1482 & 215 & 1724 & 250 & 8.0 & 25.0 & 20 & 15 \\
\hline \multirow[t]{2}{*}{ Type 440C } & Annealed & $97 \mathrm{HRB}$ & 448 & 65 & 758 & 110 & 14.0 & 30.0 & $\ldots$ & $\cdots$ \\
\hline & $\begin{array}{r}\text { Oil quenched from } 1038^{\circ} \mathrm{C}\left(1900^{\circ} \mathrm{F}\right) \\
\text { and tempered at } 316^{\circ} \mathrm{C}\left(600^{\circ} \mathrm{F}\right)\end{array}$ & $57 \mathrm{HRC}$ & 1896 & 275 & 1975 & 285 & 2.0 & 10.0 & 2 & 3 \\
\hline \multicolumn{11}{|l|}{ Precipitation hardened } \\
\hline \multirow[t]{4}{*}{ S45500 } & Annealed & $31 \mathrm{HRC}$ & 793 & 115 & 1000 & 145 & 14.0 & 70.0 & $\ldots$ & $\ldots$ \\
\hline & $\begin{array}{l}\text { Water quenched from } 1038^{\circ} \mathrm{C}\left(1900^{\circ} \mathrm{F}\right) \\
\text { and aged: }\end{array}$ & & & & & & & & & \\
\hline & at $482^{\circ} \mathrm{C}\left(900^{\circ} \mathrm{F}\right)$ & $49 \mathrm{HRC}$ & 1620 & 235 & 1689 & 245 & 10.0 & 45.0 & 12 & 9 \\
\hline & at $566^{\circ} \mathrm{C}\left(1050^{\circ} \mathrm{F}\right)$ & $40 \mathrm{HRC}$ & 1207 & 175 & 1310 & 190 & 15.0 & 55.0 & 47 & 35 \\
\hline \multirow[t]{4}{*}{ S17400 } & Annealed & $31 \mathrm{HRC}$ & 793 & 115 & 965 & 140 & 12.0 & 50.0 & $\ldots$ & $\cdots$ \\
\hline & $\begin{array}{l}\text { Water quenched from } 1038^{\circ} \mathrm{C}\left(1900^{\circ} \mathrm{F}\right) \\
\text { and aged: }\end{array}$ & & & & & & & & & \\
\hline & at $482^{\circ} \mathrm{C}\left(900^{\circ} \mathrm{F}\right)$ & $44 \mathrm{HRC}$ & 1262 & 183 & 1365 & 198 & 15.0 & 52.0 & 21 & 16 \\
\hline & at $621^{\circ} \mathrm{C}\left(1150^{\circ} \mathrm{F}\right)$ & $33 \mathrm{HRC}$ & 869 & 126 & 1131 & 164 & 17.0 & 59.0 & 75 & 55 \\
\hline \multicolumn{11}{|l|}{ Carbon steel } \\
\hline \multirow[t]{2}{*}{ AISI 1080} & $\begin{array}{l}\text { Annealed } \\
\text { Oil quenched from } 816^{\circ} \mathrm{C}\left(1500^{\circ} \mathrm{F}\right)\end{array}$ & $97 \mathrm{HRB}$ & 455 & 66 & 821 & 119 & 15.0 & 22.0 & $\cdots$ & $\cdots$ \\
\hline & and tempered at $204^{\circ} \mathrm{C}\left(400^{\circ} \mathrm{F}\right)$ & $42 \mathrm{HRC}$ & 980 & 142 & 1304 & 189 & 12.0 & 35.0 & $\cdots$ & $\cdots$ \\
\hline \multicolumn{11}{|l|}{ Aluminum alloy } \\
\hline \multirow[t]{2}{*}{ Type 6061} & Annealed & $\ldots$ & 55 & 8 & 124 & 18 & 25.0 & $\ldots$ & $\ldots$ & $\ldots$ \\
\hline & Aged & $56 \mathrm{HRB}$ & 276 & 40 & 311 & 45 & 12.0 & $\ldots$ & $\ldots$ & $\ldots$ \\
\hline \multicolumn{11}{|l|}{ Copper alloy } \\
\hline Al bronze $(95 \mathrm{Cu}-5 \mathrm{Al})$ & Annealed & $45 \mathrm{HRB}$ & 173 & 25 & 380 & 55 & 65.0 & $\ldots$ & $\ldots$ & $\ldots$ \\
\hline
\end{tabular}

Figure 2-4: Mechanical Properties of Various Stainless Steel Types Relative to Other Alloys (Davis, 2000) 


\subsection{ASTM A1010 Stainless Steel}

The American Society for Testing \& Materials (ASTM) published in 2013 the standard specification for higher-strength martensitic stainless steel plate, sheet, and strip under the A1010 designation (ASTM, 2013b). The standard outlines the mechanical test requirements, chemical composition requirements, heat-treatment, and maximum thickness. As seen in Table 2-1, A1010 stainless steel shall have a chromium content ranging between 10.5 to $12.5 \%$, maximum carbon content of $0.03 \%$, manganese content of $1.5 \%$, silicon content of $1 \%$, nickel content of $1.5 \%$. As seen in Table 2-2, the A1010 standard comes in two standard grades, with yield strengths of 275 $\mathrm{MPa}(40 \mathrm{ksi})$ and $345 \mathrm{MPa}(50 \mathrm{ksi})$, respectively. According to the standard, the material should be heat-treated by tempering to a temperature that should not exceed $760{ }^{\circ} \mathrm{C}\left[1400{ }^{\circ} \mathrm{F}\right]$ to meet the required specification. Prior to tempering, A1010 should be in the as-rolled, normalized or quenched condition (ASTM, 2013b). Standard supplementary requirements should include Charpy V-notch impact tests conducted according to ASTM A673/A673M specification and the material should be ultrasonically examined accordingly. ASTM A1010 steel is also listed on the ASTM A240 standard as UNS designation S41003. It is also listed under ASTM A709 standard specification for structural steel in bridges as a corrosive resistant grade 50 steel, ASTM A709 50CR (ASTM, 2019b).

Table 2-1: Chemical Composition Requirements for ASTM A1010, \% ${ }^{\mathrm{A}}$ (ASTM, 2013b)

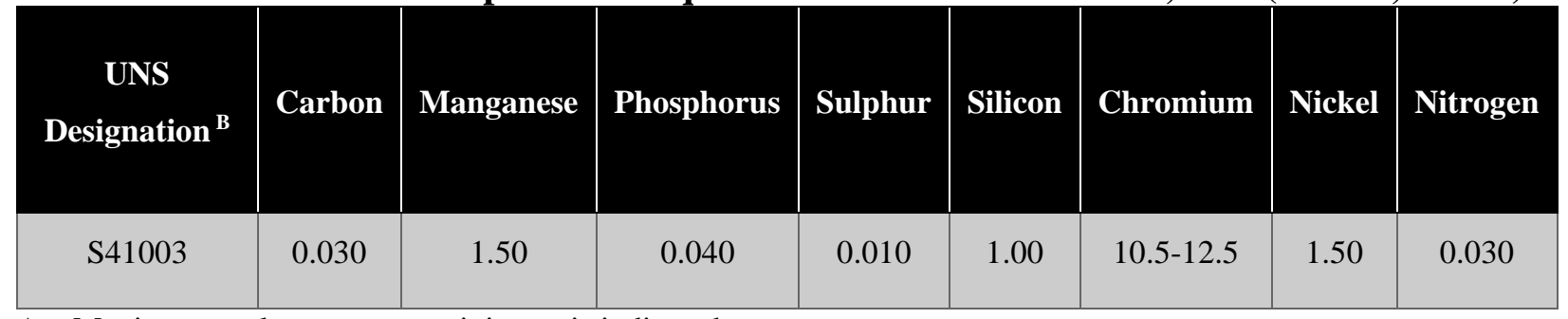

A - Maximum, unless range or minimum is indicated.

B - Designation established in accordance with ASTM Practice E527 and SAE J1086.

Table 2-2: Mechanical Properties for ASTM A1010 (ASTM, 2013b)

\begin{tabular}{|c|c|c|c|c|}
\hline \multirow{2}{*}{ Grade } & $\begin{array}{c}\text { Yield Strength, } \\
\text { min, MPa [ksi] }\end{array}$ & $\begin{array}{c}\text { Tensile Strength, } \\
\text { min, MPa [ksi] }\end{array}$ & $\begin{array}{c}\text { Elongation in 50 } \\
\mathbf{m m} \text { [2 in.], min, \% }\end{array}$ & Cold Blend \\
\hline 40 & $275[40]$ & $455[66]$ & 18 & Not Required \\
\hline 50 & $345[50]$ & $485[70]$ & 18 & Not Required \\
\hline
\end{tabular}


A1010 stainless steel is very similar chemically to the 1984 U.S. Patent Number 4608099 titled "General purpose maintenance-free constructional steel of superior processability". R.M. Davison and P.J. Grobner of Amax Inc. filed this patent in 1984. This patent has run its 20-year coarse and is now officially available for use by anyone. Hence, ASTM A1010 stainless steel is not a proprietary product. The patent describes the composition as a dual-phase ferrite and martensite steel hot-rolled between $750^{\circ} \mathrm{C}$ to $800^{\circ} \mathrm{C}$ and then tempered for 1 hour at temperatures between $670-730{ }^{\circ} \mathrm{C}$. The chemical composition of the steel described in the patent contains the following proportions: $0.015-0.031 \%$ Carbon, 11-12\% Chromium, 0.2-0.5\% Molybdenum, 1.5\%max Nickel, 1.5\% max Manganese, 0.8\% max Silicon, 0.05\% max Titanium, 0.03\% max Nitrogen, $0.03 \%$ max Phosphorous, and $0.03 \%$ max Sulphur. The steel described in the patent reached a yield strength between 303-450 MPa (44-65 ksi); tensile strength of 455-600 MPa (66-87 ksi); elongation of $23 \%-32 \%$; and a reduction of area of $70-76 \%$. The range in the results is due to the variations in compositions and variations in heat treatment. To narrow these ranges, the tempering temperature range should be narrowed as much as possible. At $660-670^{\circ} \mathrm{C}$, a yield strength of $480-$ $510 \mathrm{MPa}(70-74 \mathrm{ksi})$ was achieved. At $700-720^{\circ} \mathrm{C}$, a yield strength of $290-320 \mathrm{MPa}$ (42-46 ksi) was achieved.

ASTM A1010 stainless steel also goes by the brand name Duracorr ${ }^{\circledR}$ produced by ArcelorMittal USA (ArcelorMittal, 2016). It is similarly described as a dual-phase ferrite and tempered martensite stainless steel. It is produced in 2 grades, namely: 40 and $50 \mathrm{ksi}$ grades. It is described as being formable, weldable and exhibiting good toughness. Another product called Duracorr 300 features a nominal hardness of $300 \mathrm{HB}$ due to it being heat treated. Duracorr 300 is recommended for applications where both abrasion and corrosion resistance are required such as floor plates and rail cars. Duracorr's chemical composition is listed in Table 2-3. The chemical composition is similar to that of A1010. However, the main differences between Duracorr and the ASTM A1010 standard include a slightly lower content of carbon, a slightly higher lower range limit for chromium, and slightly lower silicon and nickel content. Duracorr's mechanical properties are exactly the same as those listed in Table 2-2 from the ASTM A1010 standard. 
Table 2-3: Chemical Composition of Duracorr from ArcelorMittal, \% (ArcelorMittal, 2015)

\begin{tabular}{|l|c|c|c|c|c|c|c|c|c|} 
& Carbon & Manganese & Phosphorus & Sulphur & Silicone & Chromium & Nickel & Nitrogen & Molybdenum \\
\hline Duracorr ${ }^{\circledR}$ & 0.025 & 1.50 & 0.040 & 0.010 & 0.70 & $11.0-12.5$ & 1.00 & 0.030 & $0.20-0.35$ \\
\hline
\end{tabular}

Duracorr is available up to a maximum thickness of $51 \mathrm{~mm}$ ( $2 \mathrm{in}$.), maximum widths of up to 3.2 meters (126 in.) and maximum lengths of up to 13.7 meters (540 in.) from ArcelorMittal. So far, the manufacturer produces only hot-rolled annealed plate products and does not have any plans of producing cold-bent structural steel shapes which may put it at a disadvantage as a material when decision makers decide to build a whole bridge out of A1010 steel. So far, decision makers have decided to build these secondary structural members, such as cross-frame bracing, from either A709 50W weathered steel, galvanized steels, or duplex stainless steels which are available in cold-rolled structural shapes (VDOT, 2019).

\subsubsection{History of ASTM A1010 Stainless Steel in Bridges}

A total of 9 bridges have been constructed in both the USA and Canada by using ASTM A1010 stainless steel as a primary construction material. In 2004, the FHWA build the first-ever bridge using A1010 multi-cell box girders in Colusa County near Williams, California. The bridge consisted of two 10.7-meter-long spans and had a width of 9.6 meters (Fletcher et al., 2005; Seradj, 2010). The first plate girder A1010 bridge was built in Coatesville, Pennsylvania at ArcelorMittal's steel mill. Following this, in 2012 and 2013 the Oregon Department of Transportation (ODOT) constructed two ASTM A1010 steel plate girder bridges and made great advancement in welding and A1010 testing research (Seradj, 2014, Seradj, 2015). Further in 2016, the Iowa Department of Transportation built an overpass plate girder bridge in which 2 of the 6 girders were made out of A1010. The rest of the girders were fabricated from A709 Grade 50W weathered steel (Sharp et al., 2018). Also, in 2016, Ministry of Transportation of Ontario (MTO) constructed two A1010 plate girder bridges, each with a total of 3 spans $(18 \mathrm{~m}, 28 \mathrm{~m}$, and $18 \mathrm{~m})$. The bridge was part of Highway 401 over the Speed River in Cambridge, Ontario. MTO followed this large project by constructing an A1010 box girder bridge made out of 2 spans (38 m each) on Highway 19 over Highway 401 in Ingersoll, Ontario (McLeod et al., 2018). Also, in 2017, the Virginia Department of Transportation (VDOT) constructed an A1010 haunched steel plate girder bridge on Route 340 
over the South River in Waynesboro, Virginia - a first of its kind. It was also the first time that A1010 steel was used for the secondary structural members on a bridge (Sharp et al., 2018).
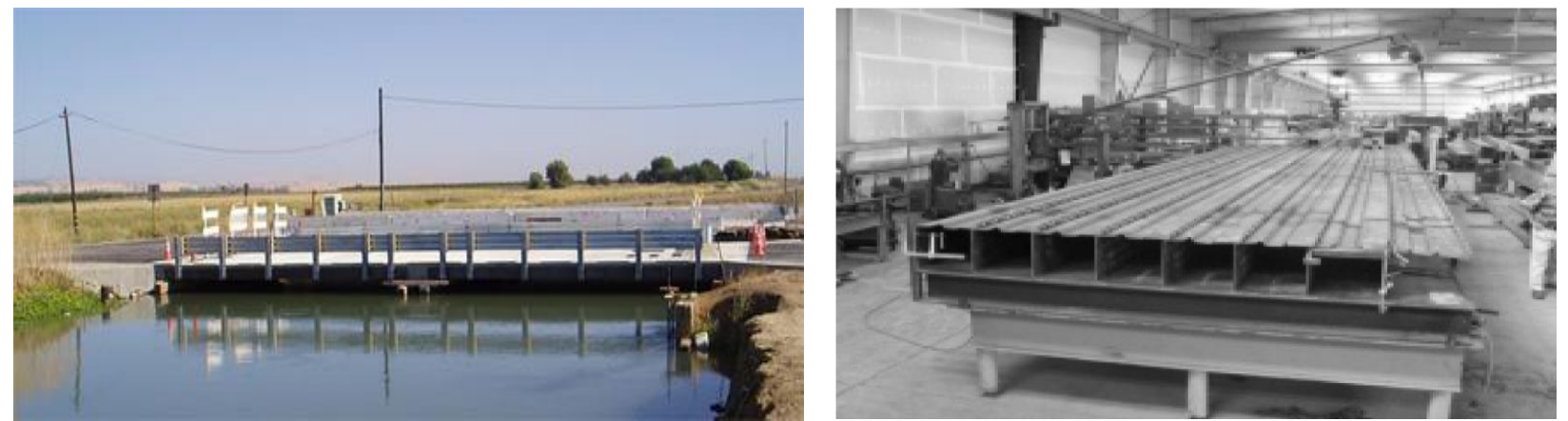

Figure 2-5: Colusa County Multi-Cell Box Girder Bridge (Fletcher, 2011; Fletcher et al. 2005)
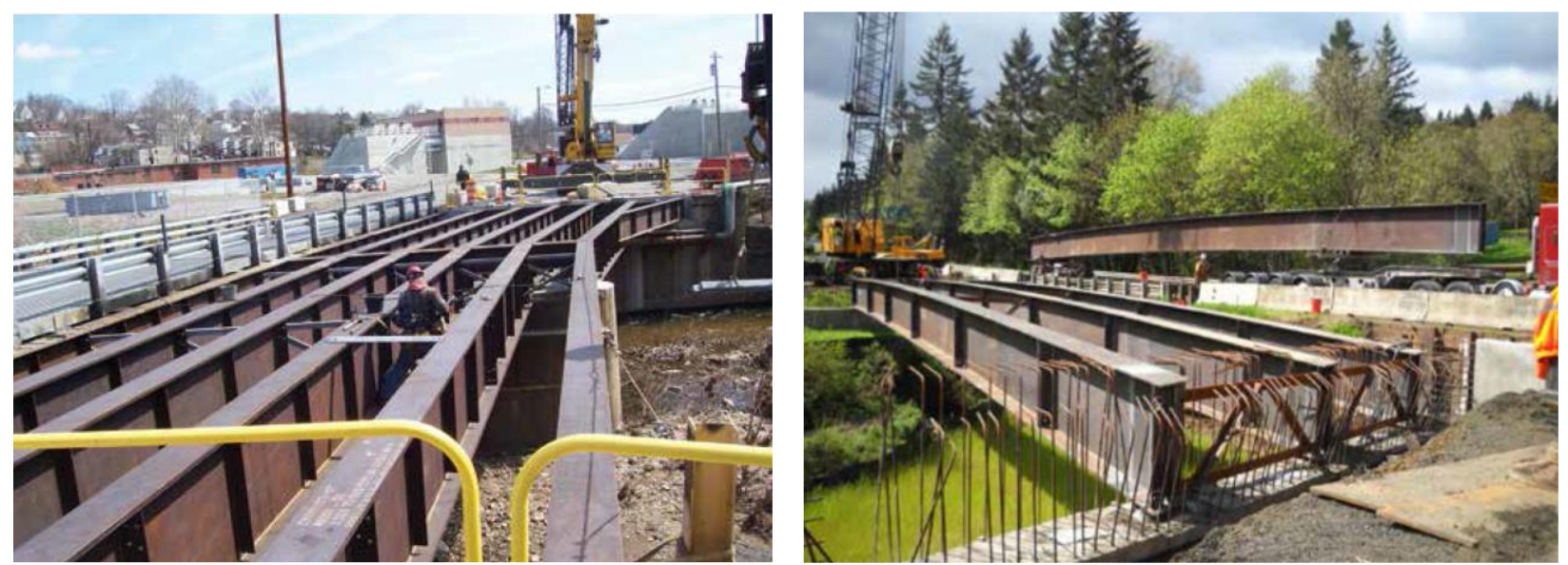

Figure 2-6: Left: ArcelorMittal A1010 Bridge; Right: Oregon DOT Dodge Creek A1010 Bridge (ArcelorMittal, 2016) 


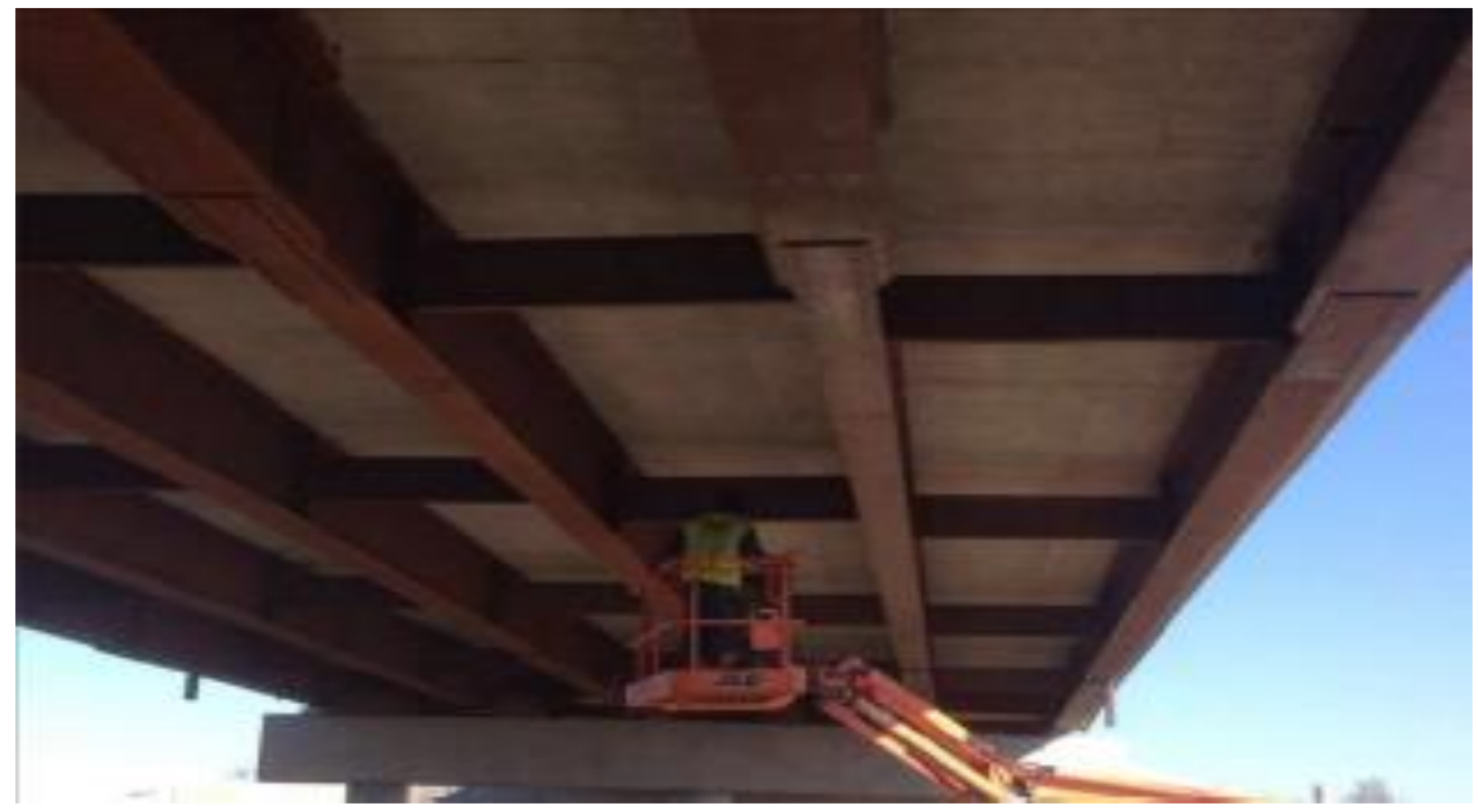

Figure 2-7: Iowa bridge showing the 2 A1010 girders on the far right (Iowa DOT, 2016)

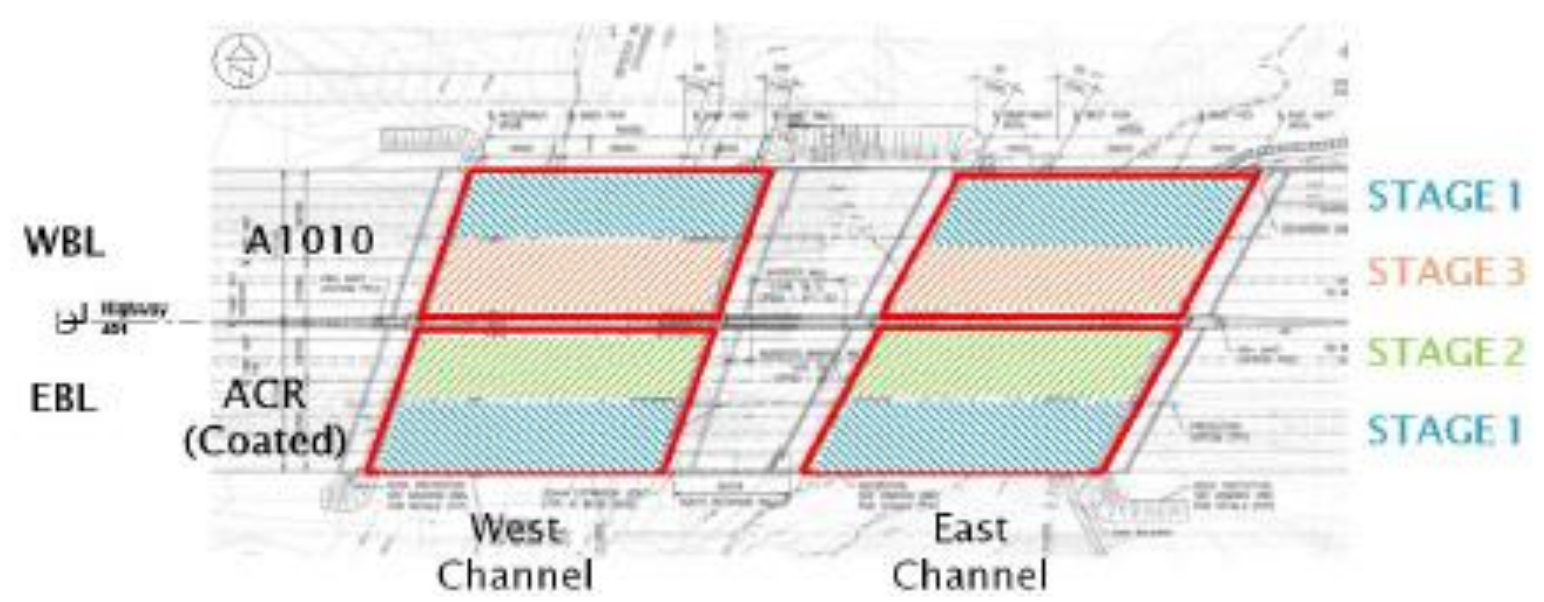

Figure 2-8: Speed River Bridges Site Plan over West Bound Lanes of Highway 401 in Cambridge, Ontario (McLeod et al., 2018) 


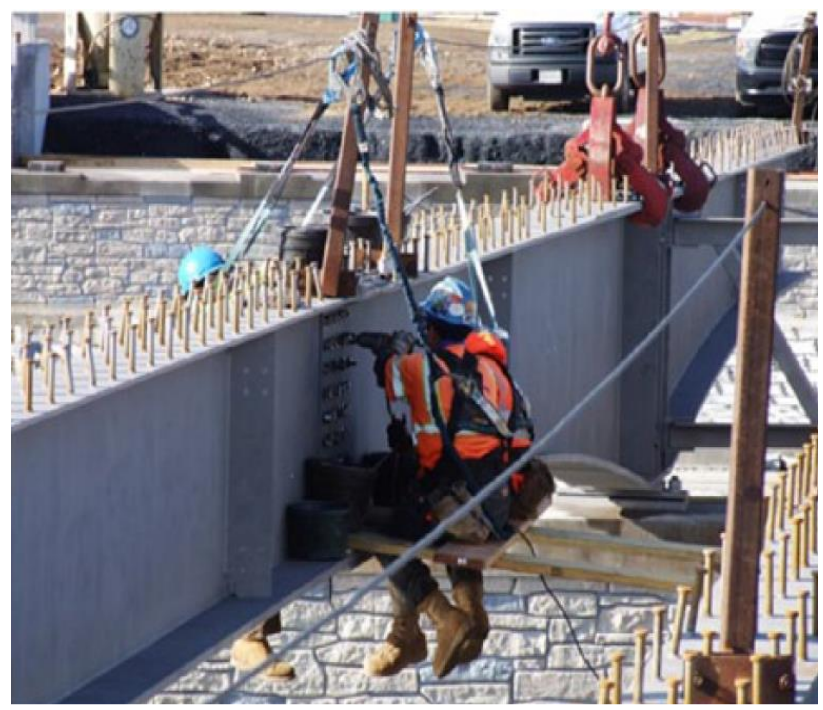

(a)

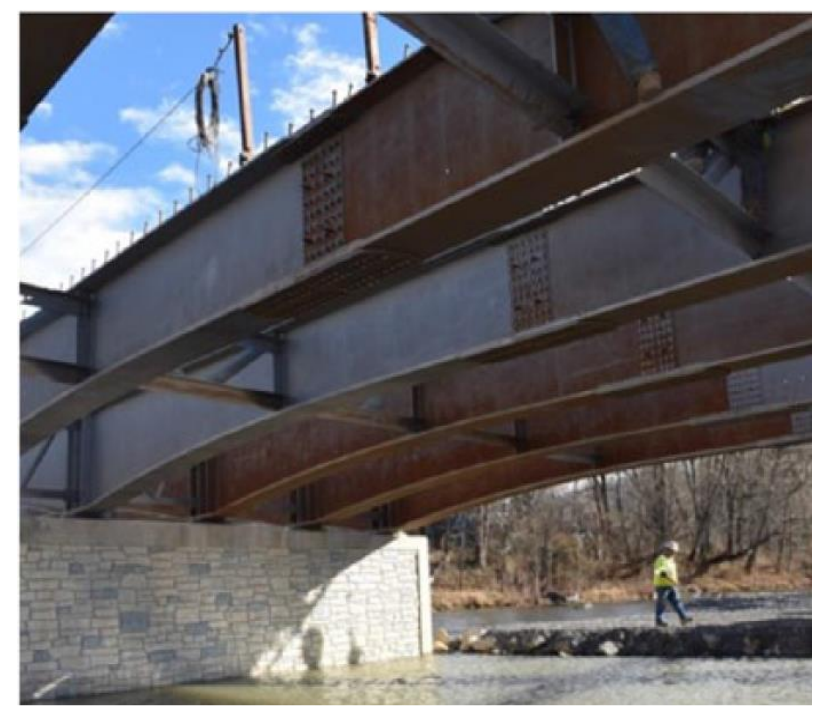

(b)

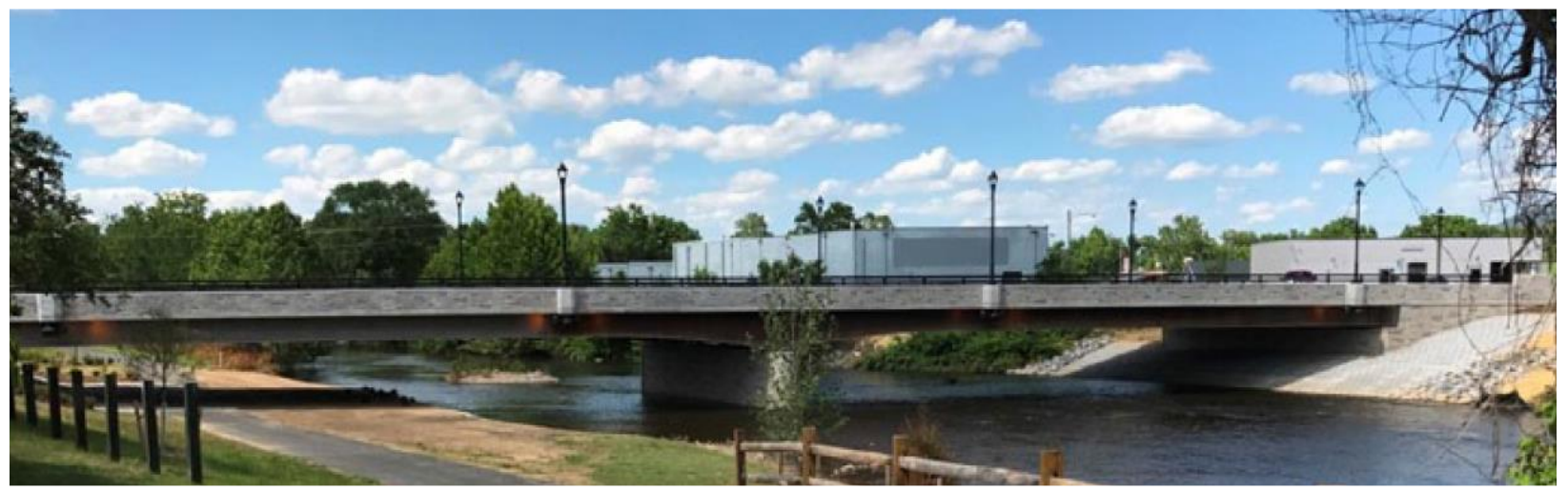

(c)

Figure 2-9: Virginia DOT Route 340 Bridge: (a) Worker installing splice connection with stainless steel bolts; (b) A1010 girders showing various shades of rust patina depending on exposure duration; (c) Finished Route 340 Bridge (Sharp et al. 2018)

\subsubsection{Fabrication and Welding Guidelines}

A1010 stainless steel yields similar results to that of A709 50W and CSA G40.21 350W steels in terms of formability and machining. A1010 can be modified by heat curving when a maximum temperature of $650^{\circ} \mathrm{C}\left(1200^{\circ} \mathrm{F}\right)$ is reached. As mentioned earlier, the manufacturer does not produce cold bend shapes. However, the Virginia Department of Transportation successfully found local steel fabricators that made secondary structural steel shapes such as, water supports, diaphragms, and cross-bracing from A1010 steel for Route 340 bridge (Sharp et al, 2018). Like most other stainless steels, due to a large chromium content A1010 should not be cut by traditional 
oxy-fuel or gas cutting techniques. Instead, the manufacturer recommends using plasma cutting with a water table, powder cutting or laser cutting. Excessive cutting speeds should not be used because the low carbon content could mean that A1010 edges are not very hard. It is also important that workers are wearing proper protective equipment and/or a downdraft table is used when cutting A1010 because of the toxic hexavalent chromium fumes that are emitted (ArcelorMittal, 2010; Sharp et al., 2018; McLeod et al., 2018; Salib et al., 2018). The A1010 manufacturer also recommends blasting clean the steel in order to get a more even rust patina forming on it. Decisionmakers must be careful not to use traditional steel (iron-based) blast media because of the potential for contamination left behind by the debris which will rust quicker giving a speckled look. Instead, stainless steel or non-iron media is recommended such as ceramic or sand. A dull white starting appearance is recommended in accordance with Society for Protective Coating Standard SP 6, SSPC SP6 (ArcelorMittal, 2016).

According to the manufacturer, ASTM A1010 can be welded by standard welding processes. Qualification of the welding procedure should be done by using the appropriate code AWS D1.5 - Bridge Welding Code in America (AWS, 2015) and CSA W59 - Bridge Welding Code in Canada (CSA, 2018). However, neither of these standards contains provisions in regards to A1010 stainless steel welding. As stated by the manufacturer, during arc welding, filler wire and base metal are melted together to produce a fused zone consisting of ferrite, martensite, and austenite. If welding is performed in accordance with recommended practices, the fused zone of welded A1010 steel is expected to achieve a hardness in the range of 175 to 225 VHN on the Vickers hardness scale. Excessive heat inputs are known to melt more of the base material forming more martensite in the fusion zone and thus can increase hardness up to $325 \mathrm{VHN}$. 


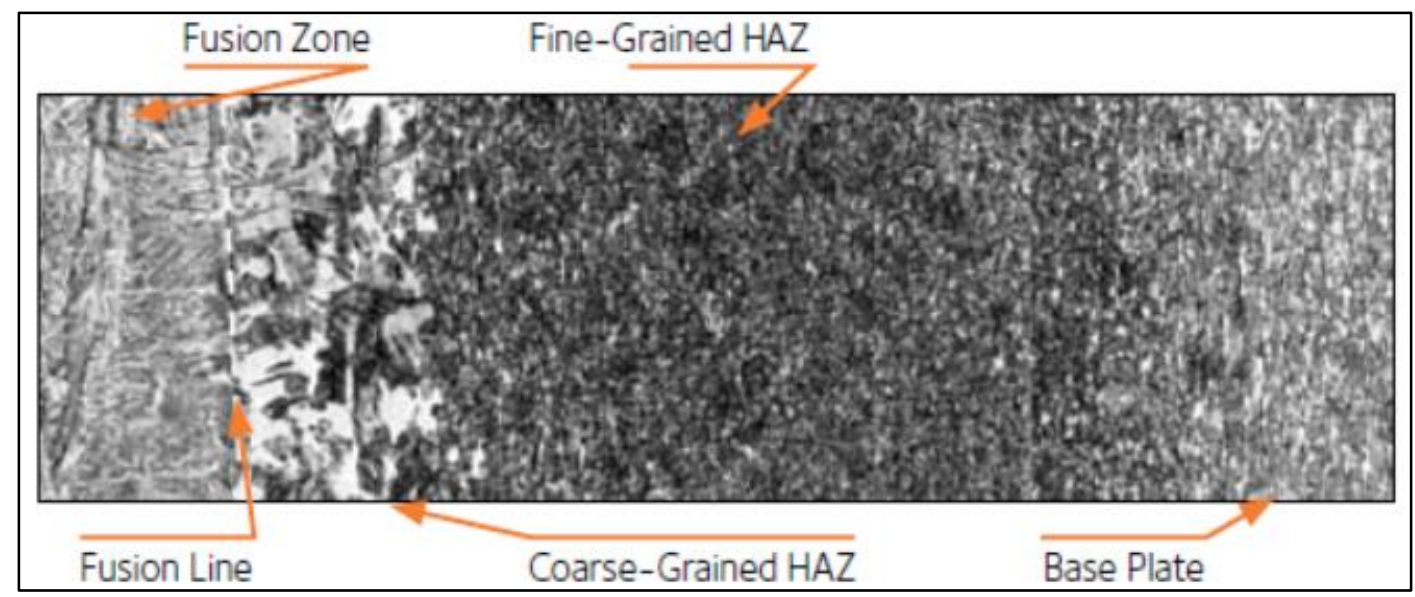

Figure 2-10: Welding Microstructure of A1010 Plate (ArcelorMittal, 2010)

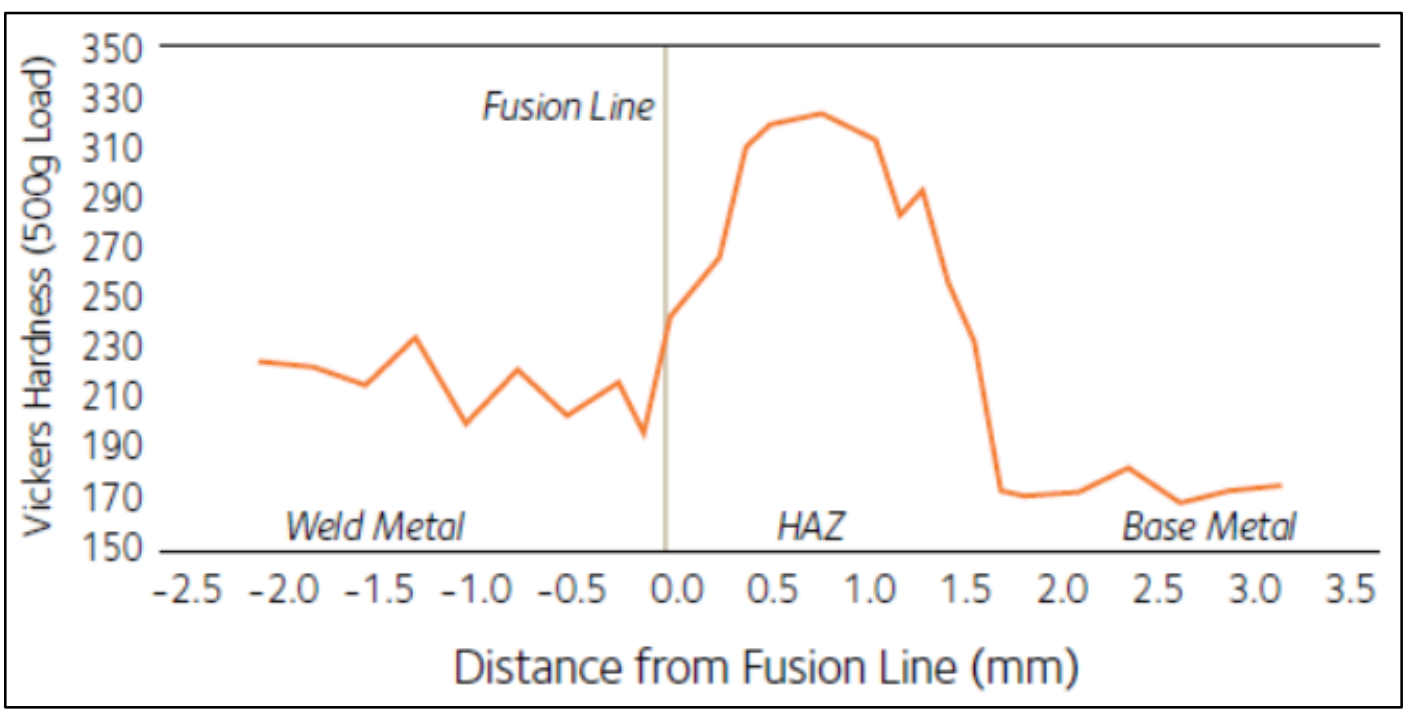

Figure 2-11: Fusion Zone Hardness of Welded 0.25” A1010 Steel (ArcelorMittal, 2010)

Some guidelines supplied by the manufacturer for welding include the following:

- If the thickness is less than 0.5 ", a maximum of $25 \mathrm{~kJ} / \mathrm{in}$. weld heat input shall be used to avoid a decrease in strength at the heat-affected zone (HAZ). On thicker plates, higher heat inputs up to $70 \mathrm{~kJ} / \mathrm{in}$. are allowed. Equation 2.1 is recommended for calculating the heat input (kJ/inch); Where E is arc voltage (Volts), I is the weld current (Amps), and WS is the welding speed (inch/minute).

Heat Input $=\frac{60(E \times I)}{1000 W S}$

- Flux-cored arc (FCAW), gas metal arc (GMAW), shield metal arc (SMAW), and gas tungsten arc (GTAW) are suitable for welding A1010 pieces together. It is recommended that processes 
like submerged arc welding (SAW, which input higher heat, should only be used after proper verification of weld properties.

- In order to eliminate surface moisture, A1010 can be preheated to a maximum interpass temperature of $200^{\circ} \mathrm{C}\left(400^{\circ} \mathrm{F}\right)$.

- A maximum temperature of $650^{\circ} \mathrm{C}\left(1200^{\circ} \mathrm{F}\right)$ is allowable for post-weld stress relief heat treatment.

- Welding A1010 to carbon steel should always be accomplished by using 309L austenitic stainless steel filler metal.

- Austenitic filler metals such as 309L, 308L, and 316 stainless are advised to be used in arc welding A1010. Also, versions containing a higher silicone of stainless steel welding material (309LSi, 308LSi, 316LSi) can be used to improve wetting and weld appearance, however, there is a risk of increasing weld metal crack sensitivity.

Table 2-4: Recommended Welding Process Consumables (ArcelorMittal, 2016)

\begin{tabular}{|c|c|c|c|}
\hline \multirow{2}{*}{ Welding Process } & \multicolumn{2}{|c|}{ Filler Wire } & \multirow{2}{*}{$\begin{array}{c}\text { Flux or Shielding } \\
\text { Gas }\end{array}$} \\
\hline & Designation & Specification & \\
\hline FCAW & $\begin{array}{c}\text { E309LTx-x, E308LTx-x, } \\
\text { E316LTx-x }\end{array}$ & ANSI/AWS A5.22 & $\begin{array}{c}\mathrm{CO}_{2}, \mathrm{Ar}-\mathrm{O}_{2}(1-5 \%) \\
\mathrm{Ar}-\mathrm{CO}_{2}(5-25 \%)\end{array}$ \\
\hline GMAW & $\begin{array}{c}\text { E309L, ER308L, ER316L, } \\
\text { E309LSi*, ER308LSi*, } \\
\text { ER316LSi* }\end{array}$ & ANSI/AWS A5.9 & $\begin{array}{c}\mathrm{Ar}-\mathrm{O}_{2}(1-5 \%) \\
\mathrm{Ar}-\mathrm{CO}_{2}(5-25 \%)\end{array}$ \\
\hline SMA W & $\begin{array}{c}\text { E309L-xx, E308L-xx, } \\
\text { E316L-xx }\end{array}$ & ANSI/AWS A5.4 & Not Used \\
\hline GTAW & $\begin{array}{c}\text { ER309L, ER308L, ER316L, } \\
\text { ER309LSi*, ER308LSi*, } \\
\text { ER316LSi* }\end{array}$ & ANSI/AWS A5.9 & Argon \\
\hline SAW & $\begin{array}{c}\text { ER309L, ER308L, ER316L, } \\
\text { ER309LSi*, ER308LSi*, } \\
\text { ER316LSi* }\end{array}$ & ANSI/AWS A5.9 & Neutral Flux \\
\hline
\end{tabular}

* Higher silicon wires yield improved wetting and bead appearance at the expense of some increased risk of weld metal cracking.

** Match to electrode per manufacturer's recommendation. 
According to McLeod et al. (2018), in order to properly understand welding procedures of ASTM A1010 stainless steel, the Ministry of Transportation of Ontario (MTO) contracted a welding consultant to introduce new procedure, testing, and trial assemblies. This was also done in collaboration with the Materials \& Joining Innovation Centre (MAJIC), a federally funded research organization for metal connection technology. The following points were found during their developmental work:

- $8 \mathrm{~mm}$ web-to-flange fillet weld is not achievable in a single pass in the horizontal position for both SAW and FCAW welding.

- Stainless steel electrode ER309L is a great filler metal for welding A1010. ER309L electrode can meet as-welded notch toughness for bridges in Southern Ontario. However, bridges located in Northern Ontario require higher notch toughness, thus custom metal fillers are needed to meet this requirement.

- SAW welding A1010 exhibits 2 times greater distortion than traditional carbon steel.

- FCAW welding of A1010 exhibits 1.5 times greater distortion than traditional carbon steel.

- A1010 steel and concave welds are susceptible to hot cracking in the restrained position; A possible solution is to lower arc voltages.

- It is important to find the optimal parameters in terms of size of root opening, current rate, and heat input in groove welding using SAW in order to gain proper fusion, penetration, and avoid burn through.

Seradj (2010) conducted an experimental program into A1010 welding in preparation for Oregon's DOT's 2012 and 2013 bridge projects. Welding was performed by using an ER309L consumable and it shows that A1010 was distorted significantly due to high residual stresses during the process, in comparison to that of traditional carbon steel (ASTM A709 Grade 50). Fabricators must be careful to properly restrain and/or adjust the alignments of two welded pieces so that distortion is not an issue during welding. The fabricator of the Speed River bridge in Cambridge, Ontario, successfully managed to correct distortion by properly aligning the A1010 plates (McLeod et al., 2018). 


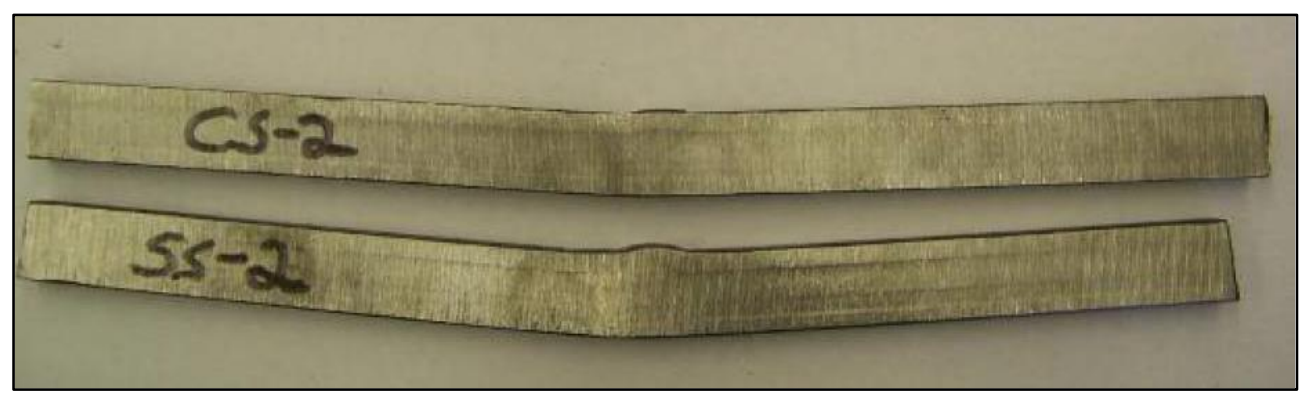

Figure 2-12: Carbon steel (CS) vs A1010 Stainless Steel (SS) difference in welding distortion (Seradj, 2010)

Sharp et al. (2018) conducted welding on the Route 340 bridge by using the submerged arc weld (SAW) process with a Lincoln Weld 309/309L filler metal and Lincoln Weld 880M flux. FCAW process was used for tack welding the web and flange and it also used the same filler metal as SAW welding. It was found that the web-to-flange fillet welds were best done in the $1 \mathrm{~F}$ position where the web and flange plates are rotated at $45^{\circ}$ so that the top of the weld metal is flat when placed.

McLeod et al. (2018) stated that both MTO bridge projects incorporated Type B headed shear studs as outlined in CSA W59. A more noble metal is required for the weld filler material to avoid galvanic corrosion of the weld metal. Fabricators used unequal double bevel groove welds for the flange splices and the webs were connected with a single bevel groove weld. The welding electrodes specified to be used in both projects were E309L and E316L type electrodes.

The production of the multi-cell box girders incorporated by the Colusa County bridge in California was done by creating a module made by adjoining 8 sections together through stitch welding. FCAW welding with E309L metal wire was used at low heat in order to improve the heat-affected zone (HAZ) toughness (Fletcher et al., 2005).

\subsubsection{Durability}

Decision makers are forever looking for enhanced structural materials to make bridge structures last much longer without performing substantial maintenance to extend their functional service life. In simple terms, a longer-lasting "maintenance free" bridge structure means much lower life cycle costs and an increase in sustainability. Hence, improved durability over conventional steel is the main reason that A1010 stainless steel is being incorporated in structural steel bridges. Although it is difficult to assess in-field corrosion as it will take many years before decision- 
makers know of its impact, preliminary laboratory studies, primarily based on accelerated corrosion tests, have been done by several researchers and showed substantial results favouring A1010 steel over traditional steel used in bridges. In general, the three major types of corrosion that were studied included; (i) general (uniform) corrosion which occurs in all types of metals when they start to oxidize through atmospheric conditions, (ii) galvanic corrosion which occurs between two dissimilar metals in contact with each other, and (iii) crevice corrosion which occurs when moisture accumulates on a localized gap between two surfaces, metal to metal or metal to non-metal.

Fletcher (2011) conducted extensive research for the FHWA to see if they can come up with a metal chemical composition that has similar performance to A1010 steel while having reduced chromium content making it more economical. A modified version of the Society of Automotive Engineers (SAE) J2334 accelerated corrosion test was used to simulate atmospheric conditions that occur on bridge metals over many years. The specimens were placed in an environmental chamber where they were subjected to salt, moisture, humid, and dry conditions for a period of 100 cycles. This particular experiment found that A1010 performed 10 times better in terms of corrosion loss in comparison to other ASTM A588 weathering steel and significantly better than other metals with lower chromium content as seen in Figure 2-13.

Another popular way to conduct corrosion experiments on steels or other materials is at the historical Kure Beach test site located in North Carolina close to the Atlantic Ocean. Specimens were left there for many years and periodic measurements on thickness losses were taken. Kure

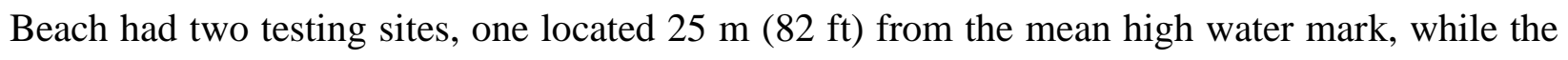
other was $200 \mathrm{~m}$ (656 ft) from the water edge. As can be seen in Figure 2-14 and Figure 2-15, A1010 steel was the best performing steel in comparison to other kinds of steels including A36 carbon steel and low alloy weathering steels (Fletcher, 2005). 


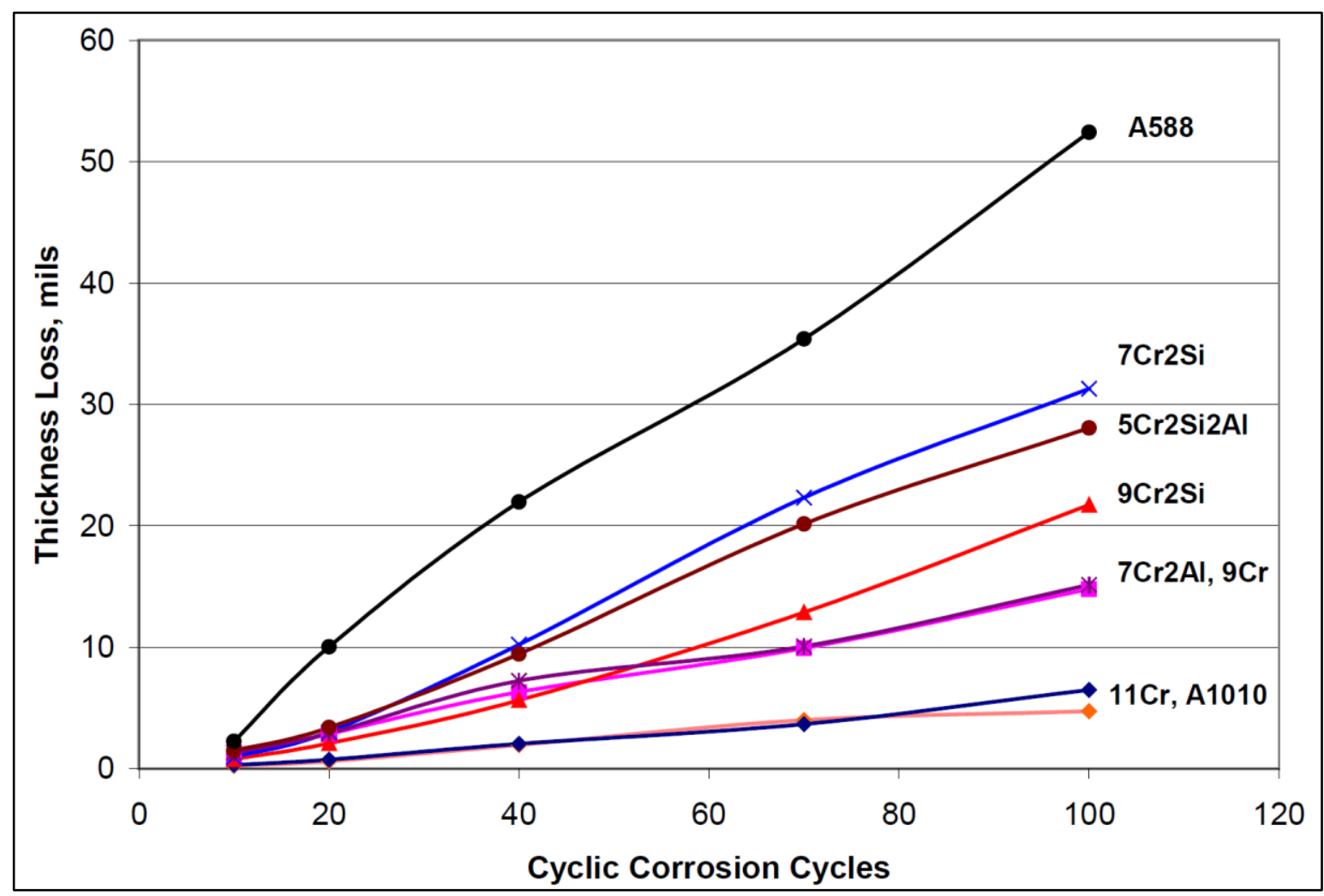

Figure 2-13: Thickness Loss Comparison Between Various Metals (Fletcher, 2011)

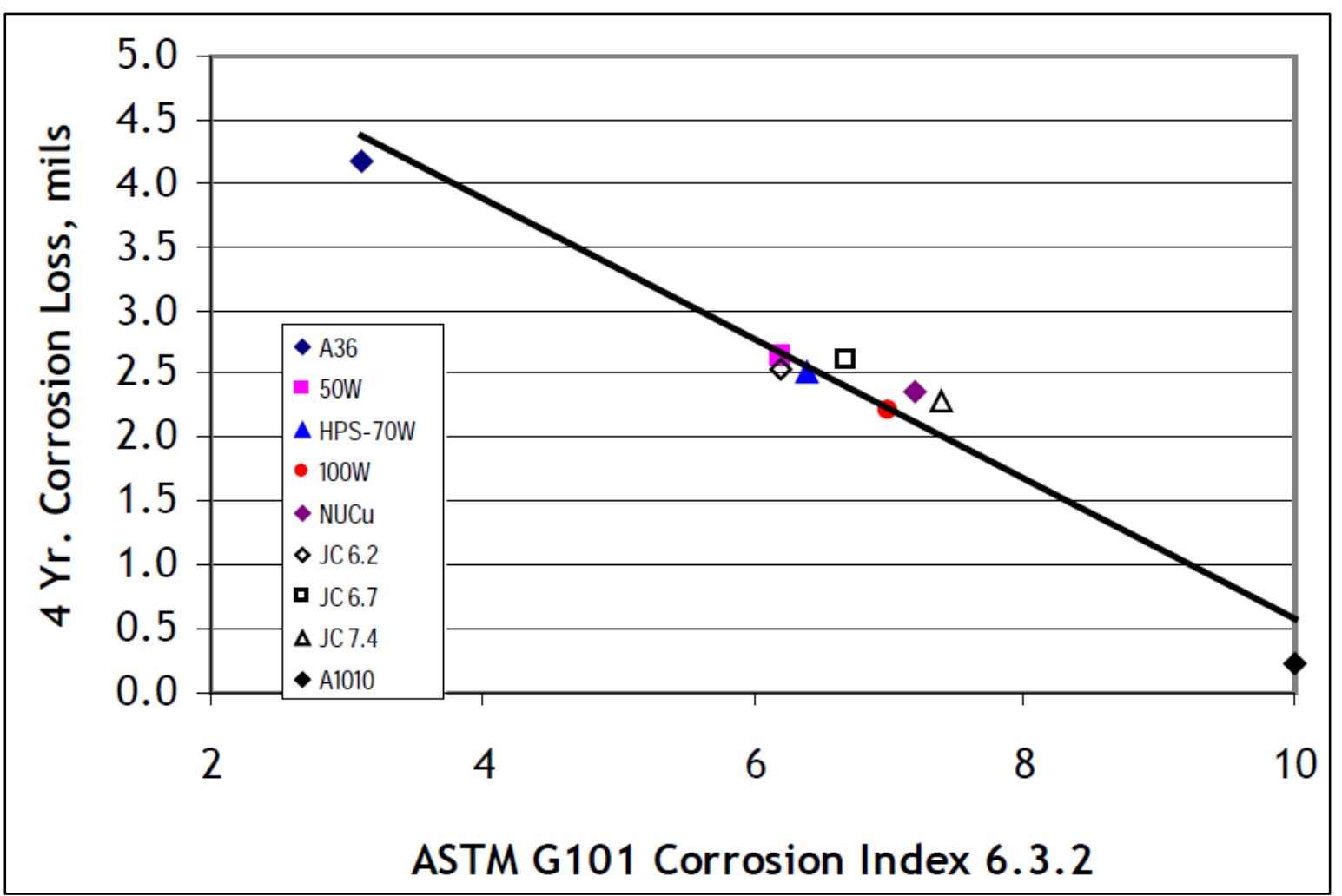

Figure 2-14: Thickness Loss at Kure Beach 25 m Site of Various Steels (Fletcher et al., 2005) 


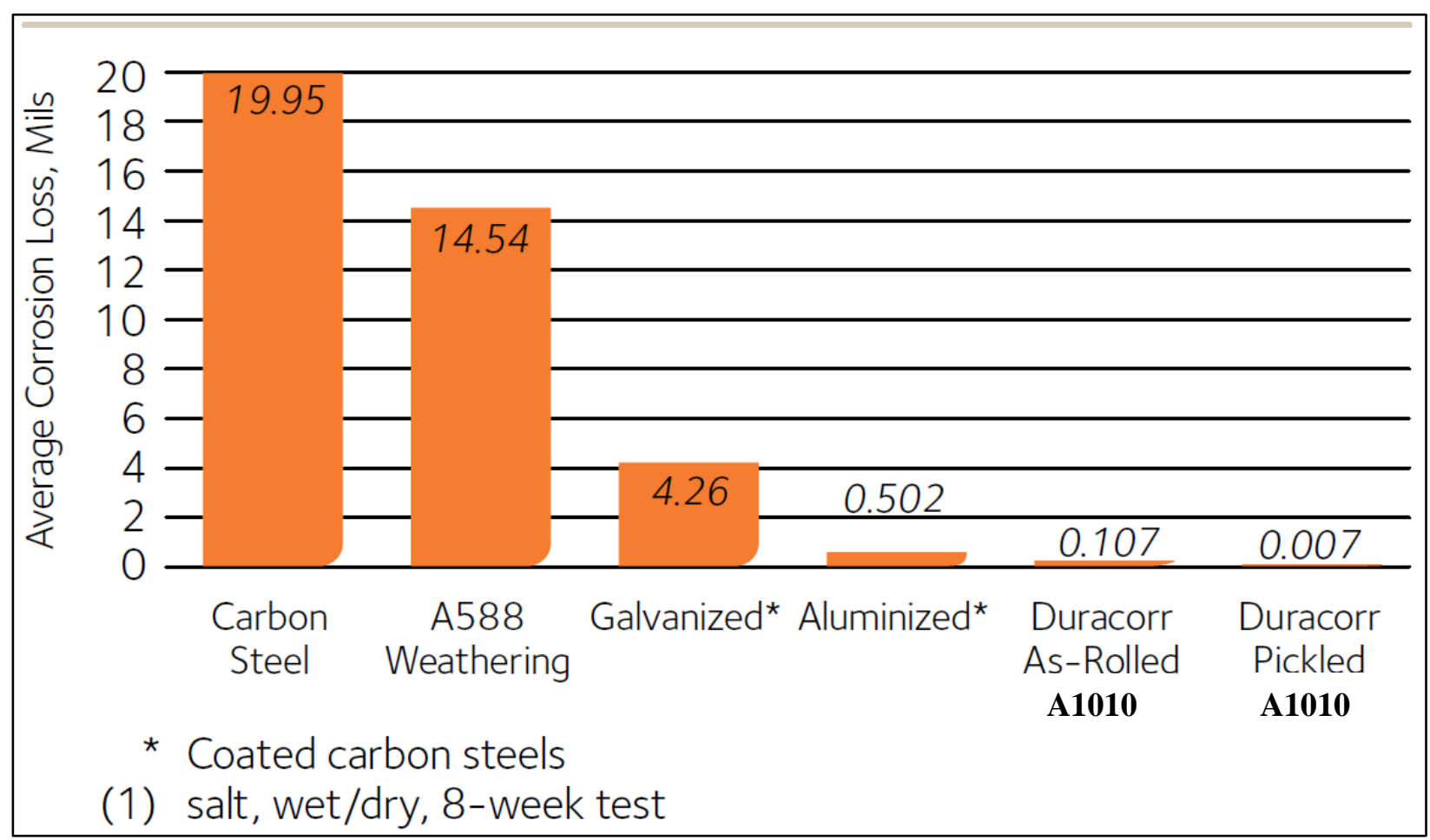

Figure 2-15: A1010 Corrosion Loss Compared to Other Steels (Fletcher et al., 2005)

Cook (2010) and Fletcher (2011) also conducted field exposure testing on the Moore Drive Bridge over the I-39S highway in Rochester, New York. This location was known to have high exposure to deicing salts used on the interstate highway. Various steel type specimens such as ASTM A588 weathering steel were placed on racks and mounted on the lower flange of the bridge girder. The results from this study showed that following 4 years of exposure, ASTM A588 specimen experienced a thickness loss of $60 \mu \mathrm{m} /$ year (2.5 mils/year) which was 10 times the accepted maximum rate for weathering steel. However, ASTM A1010 showed to experience a thickness loss of only $14.7 \mu \mathrm{m} /$ year $(0.58 \mathrm{mils} / \mathrm{year})$ which is 4 times less compared to the weathered steel.

More recently, Groshek and Hebdon (2018) conducted a large detailed accelerated corrosion study, for different corrosion types, on the behavior of A1010 stainless steel at Virginia Tech University. Knowing that A1010 could be used with other types of metals in the field, the study aimed at finding out the effects of galvanic corrosion. The study also took into account the usage of different bolt types, namely: A193 B8 Class 2 stainless steel, A193 B6, A325 regular Type 1 and 3, A325 Type 1 galvanized, and their effects on crevice/galvanic corrosion when used in combination with A1010 stainless steel plates. The study also aimed at determining the effects of surface preparation 
by blasting the steel with various different mediums such as steel shot, aluminum oxide grid, and garnet grit.

Groshek (2017) concluded that A1010 specimens experienced 12 times less thickness loss compared to ASTM A709 Grade 50 regular carbon steel and 10 times less thickness loss than ASTM A709 Grade 50 weathering steel. Also, the orientation of A1010 plates greatly impacts the ability to form a passive protective layer. Horizontal orientations have greater exposure to a corrosive environment because they experience more cycles of wetting and drying making it more difficult for the protective layer to form. Groshek also concluded that A1010 plates have 4 times greater resistance to corrosion in the horizontal orientation (facing up) and 10 times greater resistance to corrosion in the vertical direction, in comparison to A709 G50 weathered steel. Also, A1010 experienced substantial pitting corrosion in details that are prone to trapping moisture. In terms of surface preparation, shot blasting media does not have a major effect on the long-term appearance of the passive layer. However, in the early stages of the patina formation, steel shot blasting resulted in a small reduction in thickness loss rates in comparison with aluminum grit media. This may result in the uneven formation of rust in the early stages. The galvanic corrosion thickness loss for carbon and weathering steel plates, when connected to A1010 plates, was much smaller than the thickness loss due to general uniform corrosion. Galvanic corrosion of hot-dip galvanized plates attached to A1010 could be up to 50\% more than uncoupled plates (Groshek and Hebdon, 2018). As far as stainless steel fasteners connected to A1010 plates, ASTM A193 B6 stainless steel bolts experienced an increase in thickness loss and pitting corrosion. While ASTM A193 B8 Class 2 stainless steel bolts experienced negligible galvanic corrosion loss. Overall the 2 lowest thickness losses were from using A325 Type 1 galvanized bolts and A193 B8 Class 2 stainless steel bolts. 


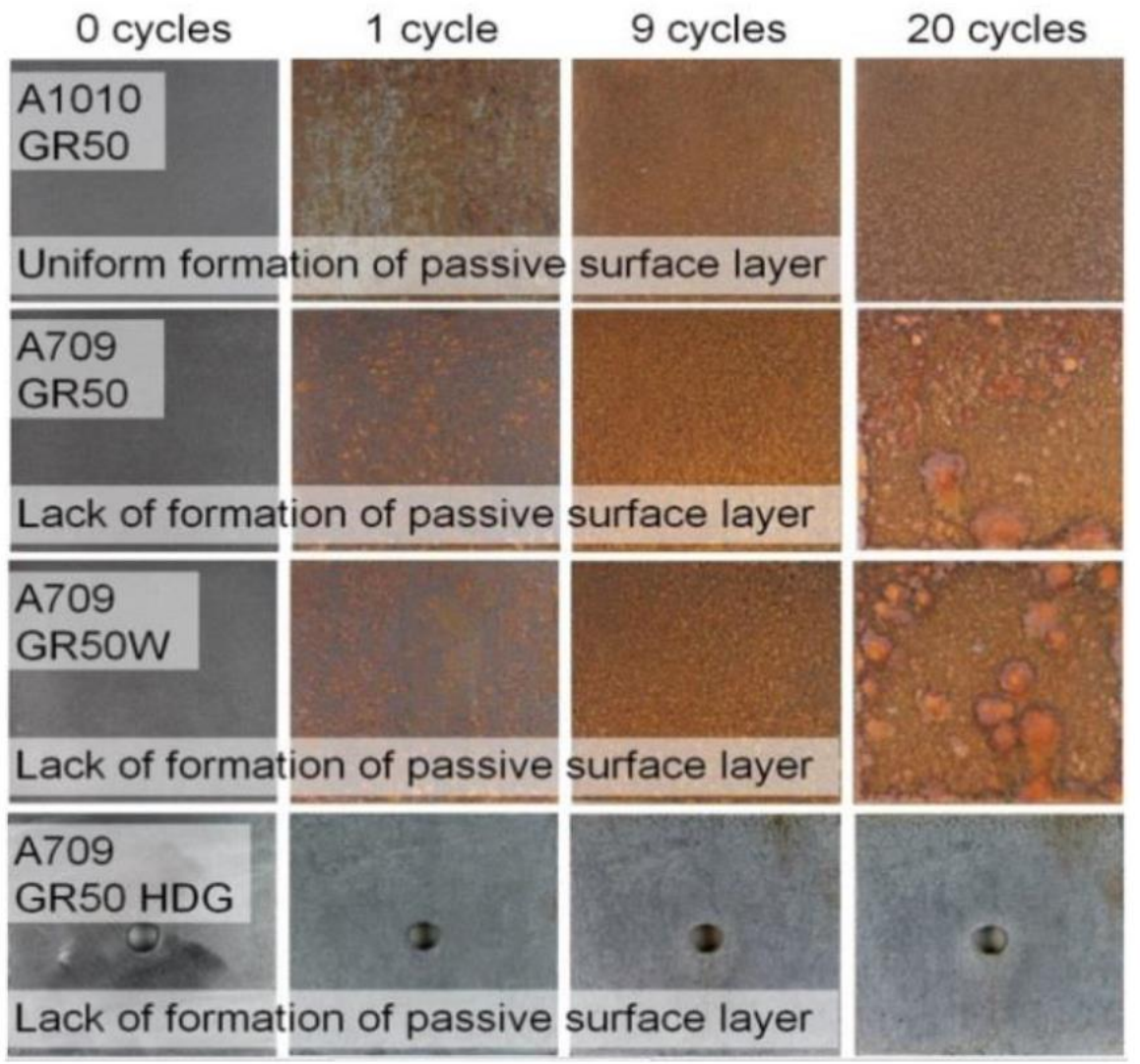

Figure 2-16: Uniform Rust Patina on Control Specimens After 20 Cycles (Groshek and Hebdon, 2018)
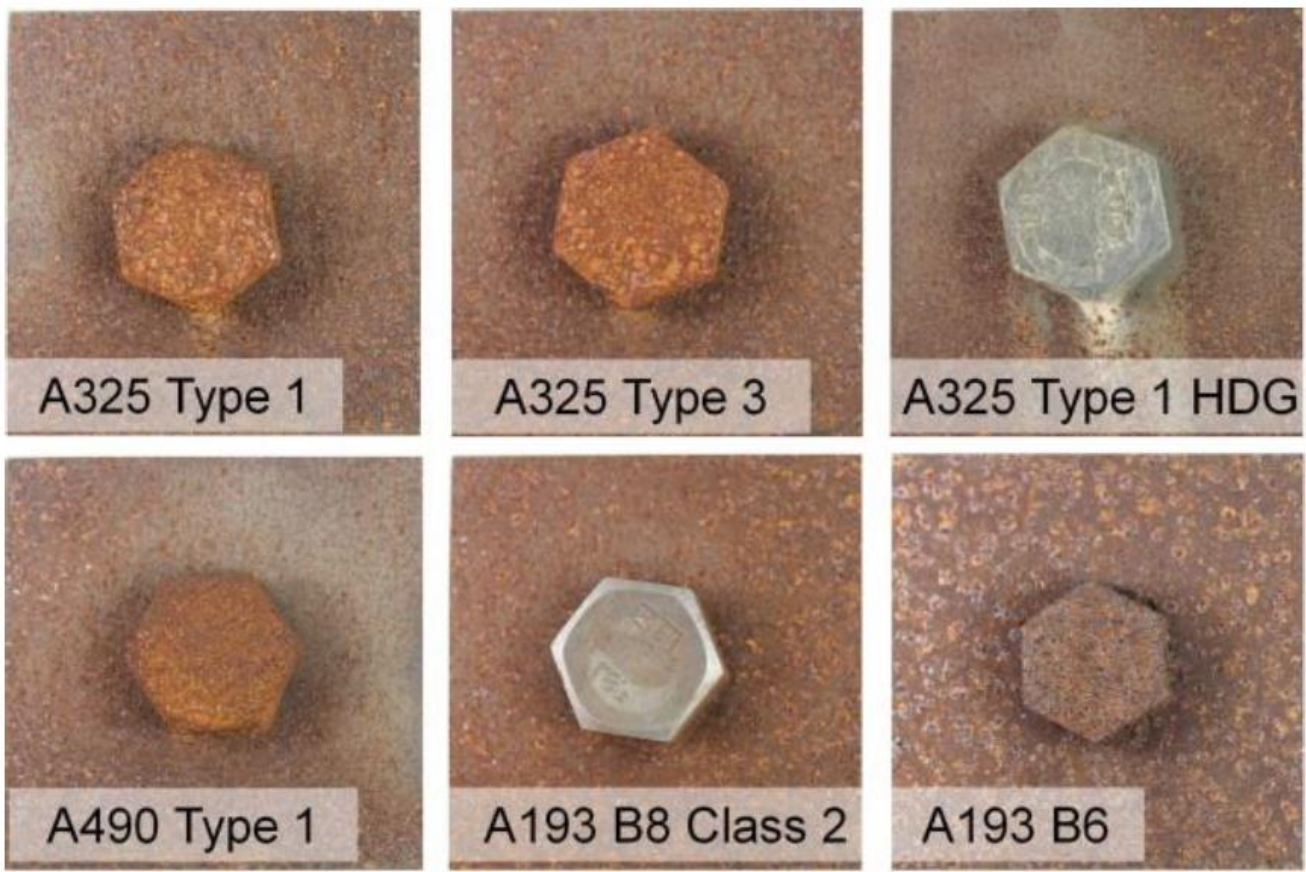

Figure 2-17: Galvanic Corrosion on Various Types of Fastener Systems Paired with A1010 plate (Groshek and Hebdon, 2018) 
Zhang et al. (2019) did experiments on galvanic corrosion of A1010 \& A325 Type 1 galvanized bolt, A1010 and B8 stainless steel bolt, and A588 weathered steel paired with A325 Type 1 galvanized bolt. It was found that after 4 weeks of salt spray, there is a thickness loss of A325 galvanized bolts when used with weathering steel and A1010 steel. On the other hand, using an A193 B8 stainless steel bolt has negligible galvanic corrosion risk.
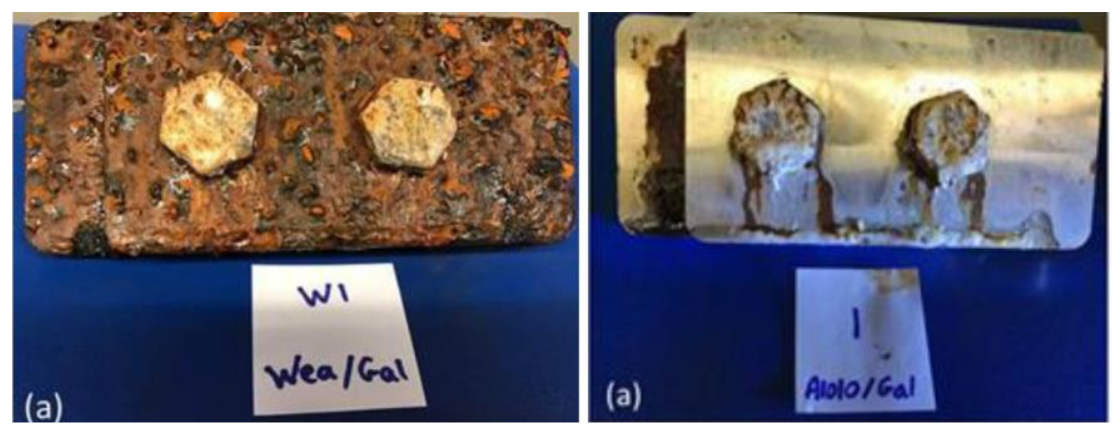

Figure 2-18: Galvanic Corrosion of: i) Weathered Steel \& Galvanized A325 Bolt, ii) A1010 Steel \& A325 Galvanized Bolt, and iii) A1010 Steel \& A193 B8 Stainless Bolt (Zhang et al., 2019)

\subsubsection{Cost}

Cost is a major factor for decision-makers to implement and try new material on their structures. As mentioned earlier, it is expected that A1010 stainless steel will have a much higher initial material cost due to its alloying nature requiring a more expensive chemical composition to make. Research on A1010 showed that it is the most durable material when it comes to resisting corrosion over time. It has the potential to extend the functional life of bridges by meeting and exceeding a 75 -year functional life requirement with minimal maintenance. This would mean that although initial costs are high, it would eventually end up costing less over the life cycle of the bridge when we factor in the large reduction in maintenance costs.

According to the FHWA Corrosion Protection of Steel Bridges Handbook published in 2015 (Kogler, 2015), Estimating the initial material cost is the first step towards completing life-cycle cost analysis. The numbers provided by a steel manufacturer in 2013 for plates of 1 " thickness by 96" width and 480" length show that corrosive-resistant steels were in the magnitude of 3 to 6 times higher than conventional steel shown in Figure 2-19. Efforts to develop cheaper steels with similar performance to A1010 failed because all the experimental low chromium stainless steels did not meet the strength and impact toughness required for the fabrication of steel bridges (Fletcher, 2011). 


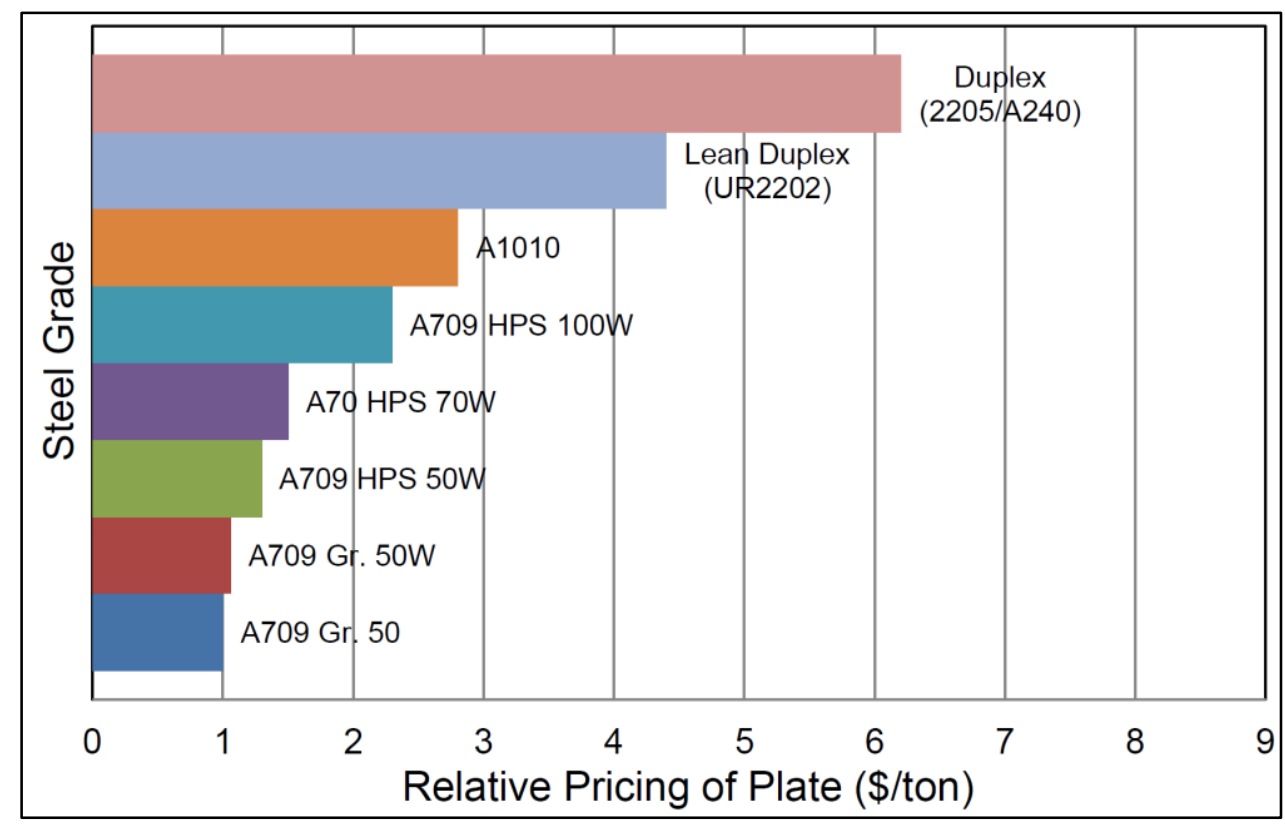

Figure 2-19: Relative Pricing of Various Steel Alloys in 2013 (Kogler, 2015)

According to Fletcher (2011), a life cycle cost analysis was conducted for a 125-year life span bridge girder made from ASTM A1010 stainless steel and compared to traditional painted carbon steel. A1010 steel showed that it was much more economical over the life-cycle. The study concluded that the probability that an A1010 girder costs less than a painted carbon steel girder increases substantially at the 12-year mark. At the 20-year mark, the probability that A1010 steel girder will cost less than the carbon steel girder is substantial at over 90 percent. While after 40 years it becomes certain that A1010 steel girder is less expensive than painted carbon steel as seen in Figure 2-20. Fletcher mentions that the LCC analysis is based on estimates of costs and paint longevity for severe local environments as of 2010. The methodology used assumed that the A1010 girder is maintenance-free, requiring no painting. The life-cycle costs are fairly conservative because they did not include costs associated with bridge closures during maintenance. 


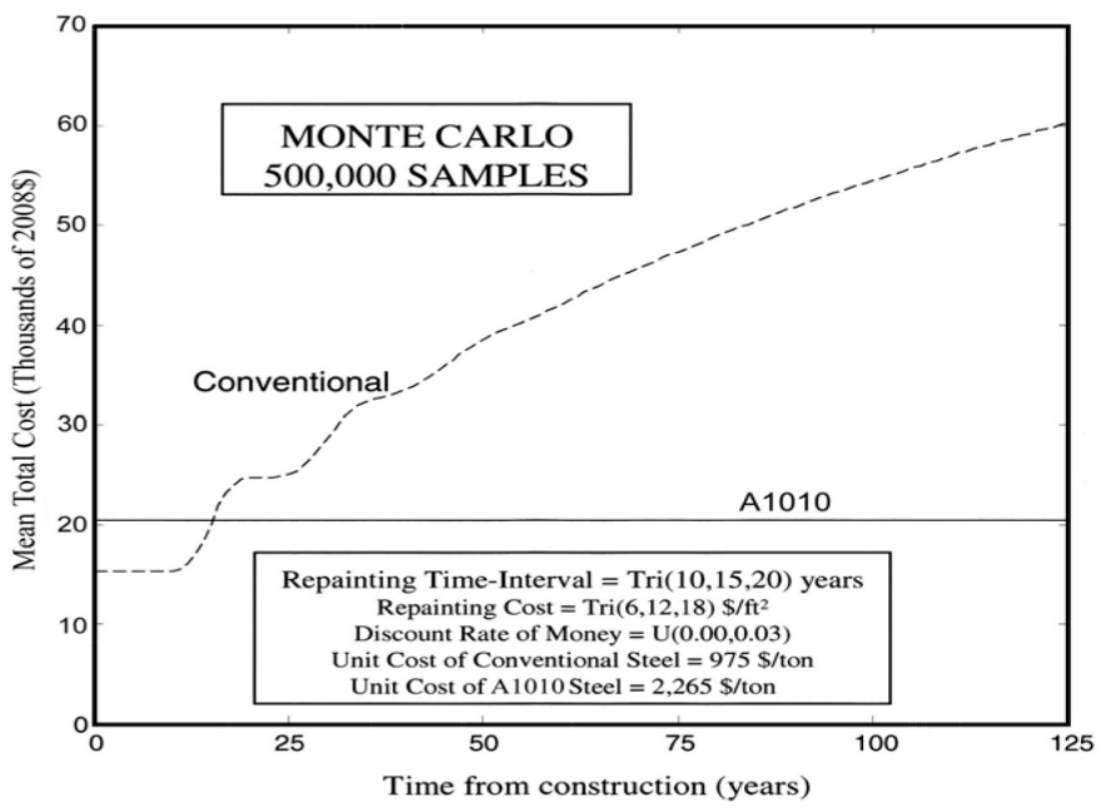

(a)

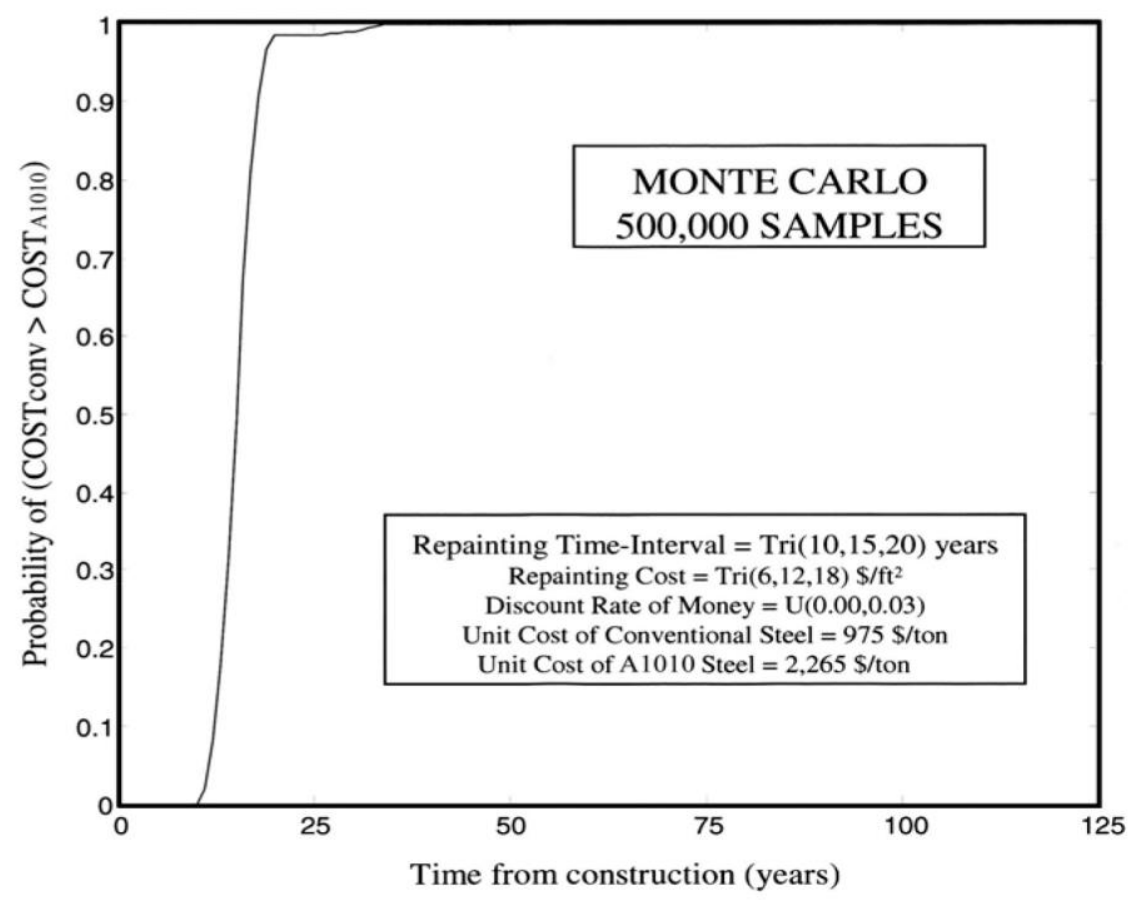

(b)

Figure 2-20: Probabilistic Life Cycle Cost Analysis of A1010 vs Conventional Steel: (a) Total Cost vs Time; (b) Probability That Cost of A1010 is Cheaper over Time (Fletcher, 2011) 
Daghash et al. (2019) performed an in-depth life cycle cost analysis based on actual cost numbers given by the Virginia DOT of A1010 steels reported to be $\$ 13,095 /$ ton $(\$ 5.94 / 1 b)$ and carbon-based steel reported to be $\$ 5,335 /$ ton $(\$ 2.42 / \mathrm{lb})$. These unit costs include material, fabrication, and erection costs. The corrosion-related maintenance cost for A1010 was assumed to be zero. Whereas, painting costs for carbon steel were calculated based on bridge tonnage and a conditionbased maintenance schedule. Direct maintenance costs included repainting material, surface preparation, and application costs. The study also incorporated indirect maintenance costs related to traffic delays based on income loss for users and carbon dioxide emissions to the environment. In the life-cycle cost analysis studies, 2 bridges were considered located on 2 different corrosion exposure environments described as C3 (medium corrosion level) and C5 (coastal area with significant chlorides effect). The study concluded that A1010 is not economically beneficial without considering indirect maintenance costs. Also, for the bridge exposed under $\mathrm{C} 3$ condition, the pay off time of A1010 is over 75 years, making it not cost-effective, whereas, the bridge located under C5 exposure conditions had a 20-year payoff time making A1010 very cost-effective when used for this bridge. The study also showed that life cycle costs are significantly influenced by its total weight and Average Daily Traffic (ADT) number, maintenance duration, and length of the traffic control region. Payoff time of A1010 compared to conventional carbon steel is reduced when the ADT affected during maintenance is larger and when the exposure environment is harsher. On the other hand, payoff time increases when we have a heavier bridge, larger discount rate.

\subsection{Slip Resistance Literature Review}

\subsubsection{Slip-Critical Joints Introduction}

Since ASTM A1010 stainless steel is a new material in relation to its use as a structural steel for bridge elements, there is not a lot of research publications available in determining its slip resistance coefficient. Therefore, this literature review section will rely on exposing the previous methodologies used in determining slip resistance from past studies done on other structural steel materials.

Joints in bridges are required to connect several elements together. Usually, when the bridge length exceeds that of a manufactured girder, it means that two or more girder parts are needed to be 
connected by a splice joint to transfer loading (see Figure 2-21). The three main loads that need to be transferred on bridge elements are shear, tension, and combined shear-tension based on the applied loading on the structural member. When it comes to structural steel bolted joints, each different load transfer type requires a different type of joint. One of these joints is the snugtightened joint that is bearing joint in which bolts are tightened with the full physical effort of an ironworker using a regular spud wrench to bring the plies into contact. The second type of joints is pretensioned joint in which the bolts are installed to reach a minimum required tension in the bolt by either turning the nut a predefined amount giving the probability that it will reach the minimum required tension. This is usually accomplished by a torque wrench or a calibrated wrench. The third type of joint is the slip-critical joint that transmits shear loads or shear loads in combination with tensile loads, in which bolts are installed to provide a predetermined minimum pretension load so that all the faying surfaces are clamped to provide resistance against slip, shown in Figure 2-22 (RCSC, 2014). Applications in which slip-critical joints are required include: joints subject to fatigue load with reversal of the load direction; joints that utilize oversized holes; joints that utilize slotted holes; and in general, any other applications in which slip at the faying surface would be detrimental towards the performance of the structure. Hence, slip-critical joints are usually a requirement for connecting bridge structural elements.

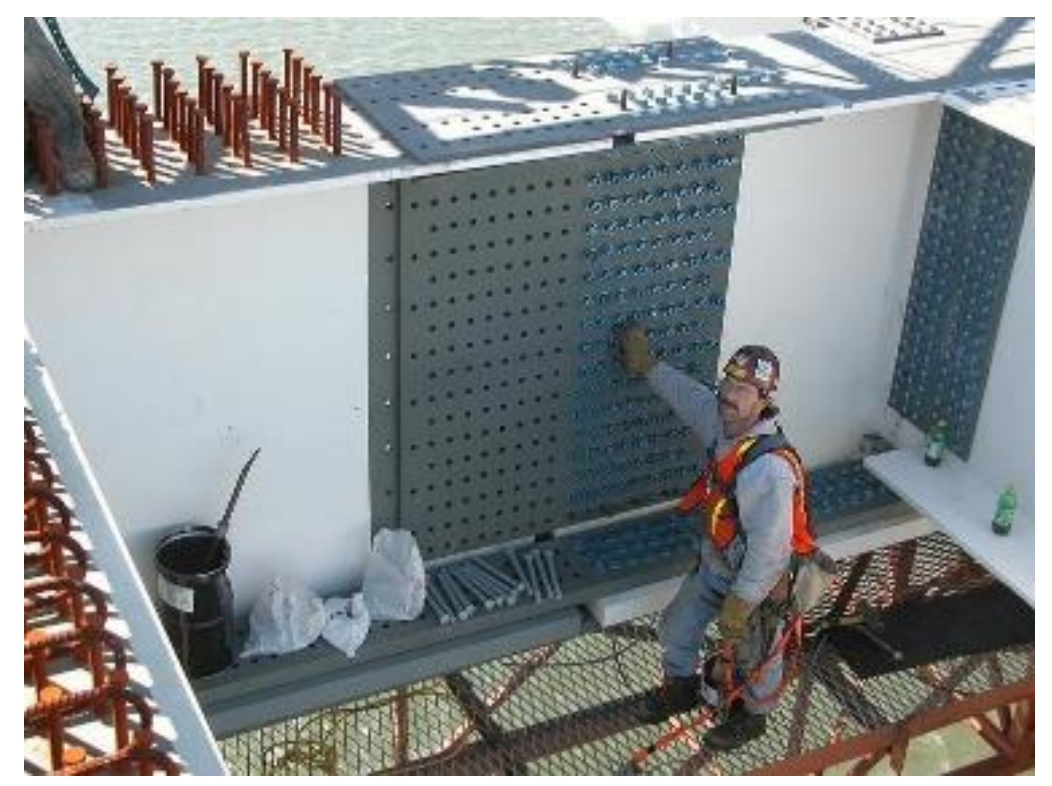

Figure 2-21: Worker installing bolted slip-critical joint on bridge girder (Sterner, 2005) 


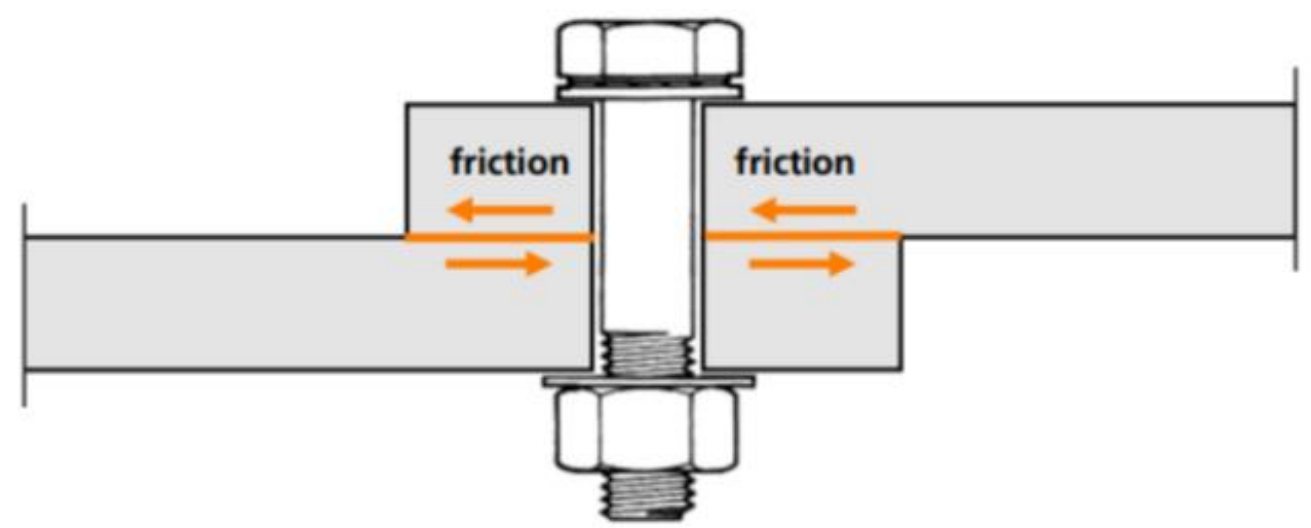

Figure 2-22: Pretension on the bolt ensures that the faying surfaces through the force of friction carry the applied load on the element (Haodi, 2017)

Faying surface conditions play an important role in slip-critical joints. It is expected that after supplying a minimum pretension (usually $70 \%$ of bolt's tensile strength) the design load is solely carried by the friction of the faying surfaces. Most codes specify three types of faying surfaces.

The first type of faying surfaces is the uncoated faying surface which should be free of scale and free of coatings, except for tight mill scale in the faying area which is one bolt diameter, except not less than $25.4 \mathrm{~mm}$ (1”) from the edge of any hole. If uncoated faying surfaces are blast-cleaned they are usually considered to fall under the Class B category for all North American standards.

The second type of faying surfaces is the coated faying surface which should be blast cleaned and then painted with a specified coating that is qualified to fall under either Class A or Class B. It is important to know which class of coating is applied. If the coating is a new type, then slip resistance testing must be done by the engineer in charge to determine its slip-critical coefficient.

The third type of faying surfaces is the galvanized faying surface which should be hot-dip galvanized in accordance with ASTM A123 requirement and roughened by wire brushing. Usually galvanized coatings are designed as Class A coatings or some codes classify them as Class C, as explained more in-depth in Section 2.3.5.

Table 2-5 summarizes the joint type that should be used for different load resistance applications and whether faying surface preparation is required. 
Table 2-5: Summary of Applications and Requirements for Bolted Joints (RCSC, 2014)

\begin{tabular}{|c|c|c|c|}
\hline Load Transfer & Application & Joint Type & $\begin{array}{c}\text { Faying } \\
\text { Surface } \\
\text { Prep. }\end{array}$ \\
\hline \multirow{3}{*}{ Shear Only } & $\begin{array}{c}\text { Resistance to shear load by } \\
\text { shear/bearing }\end{array}$ & Snug Tight & No \\
\hline & $\begin{array}{l}\text { Resistance to shear by } \\
\text { shear/bearing. Bolt pretension is } \\
\text { required, but for reasons other than } \\
\text { slip resistance. }\end{array}$ & Pretensioned & No \\
\hline & $\begin{array}{l}\text { Shear-load resistance by friction on } \\
\text { faying surfaces is required. }\end{array}$ & Slip-critical & Yes \\
\hline \multirow{3}{*}{$\begin{array}{l}\text { Combined shear } \\
\text { and tension }\end{array}$} & $\begin{array}{c}\text { Resistance to shear load by } \\
\text { shear/bearing. Tension load is static } \\
\text { only. }\end{array}$ & Snug Tight & No \\
\hline & $\begin{array}{l}\text { Resistance to shear by } \\
\text { shear/bearing. Bolt pretension is } \\
\text { required, but for reasons other than } \\
\text { slip resistance. }\end{array}$ & Pretensioned & No \\
\hline & $\begin{array}{l}\text { Shear-load resistance by friction on } \\
\text { faying surface is required. }\end{array}$ & Slip-critical & Yes \\
\hline \multirow[b]{2}{*}{ Tension Only } & Static loading only & Snug Tight & No \\
\hline & $\begin{array}{l}\text { All other conditions of tension-only } \\
\text { loading. }\end{array}$ & Pretensioned & No \\
\hline
\end{tabular}

\subsubsection{Bolt Pretension on Slip-Critical Connections}

In North America, the main bolts used in bridges are A325 and A490 bolts. Each of these has a different ultimate strength. According to several sources (among them: RCSC, 2014; CSA, 2014b) bolts in slip-critical connections should be tightened to $70 \%$ of their specified minimum tensile strength. The best method to properly ensure that the minimum bolt tension requirement is achieved in-field is to use the turn-of-nut method. For A325 or A490 bolts, the nuts are supposed to be tightened from the snug tight position, which is reached with the full effort of an ironworker using a spud wrench or a few clicks of an impact wrench. Figure 2-23, shows the minimum pretension force required depending on bolt type (A325 or A490) and bolt diameter used (CSA, 2014b). Figure 2-24, shows how much a nut should be turned in order to meet or exceed the required minimum tension. This depends heavily on the type of joint, type of bolt used, and the bolt length. Previous research shows that the turn-of-nut method usually exceeds the required 
minimum pretension method by $20 \%$ for A 325 bolts and by about $26 \%$ for A 490 bolts turned $180^{\circ}$ (1/2 turn) as can be seen in Figure 2-25 (Kulak et al., 2001).

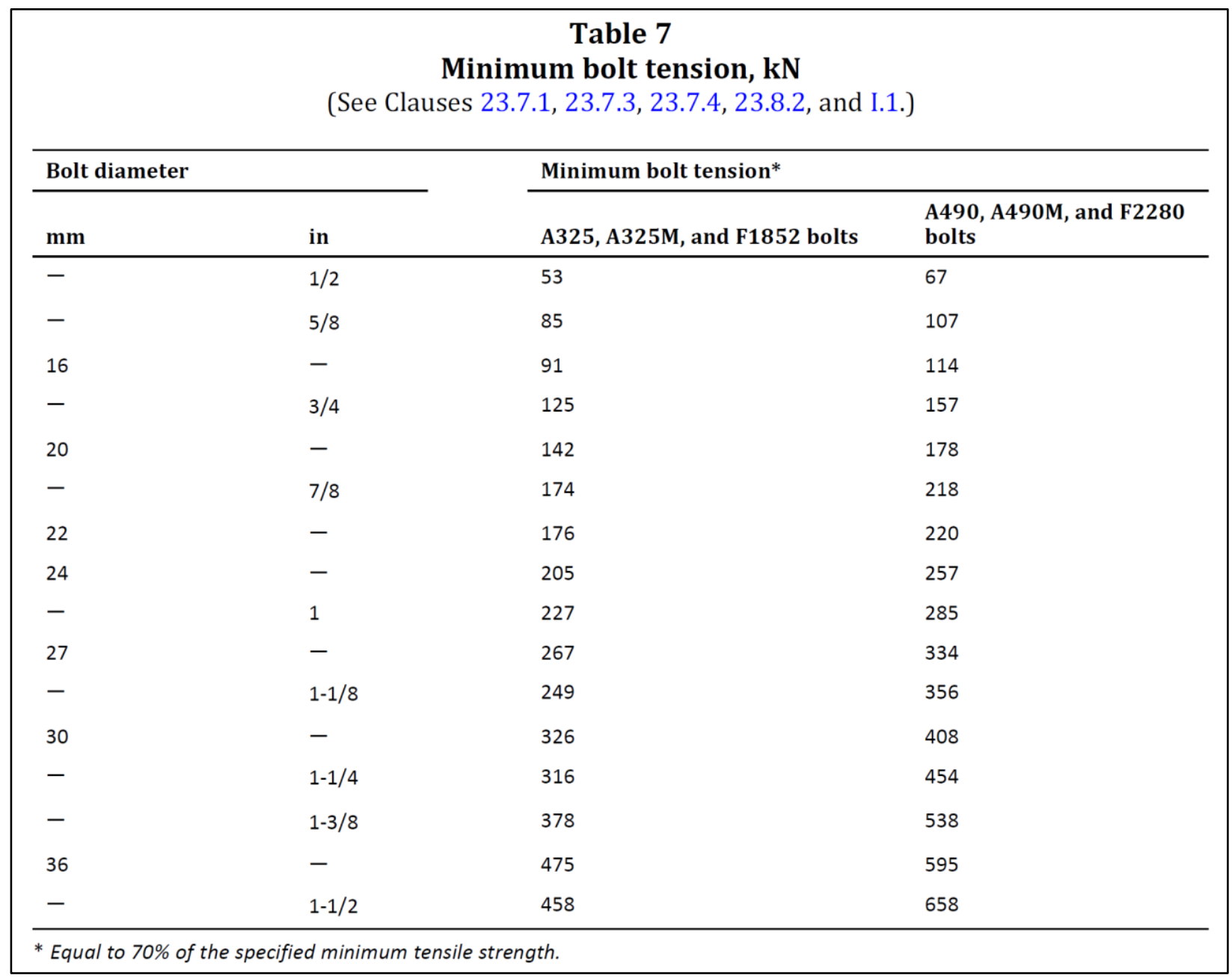

Figure 2-23: Minimum bolt pretension requirements depending on their diameter (CSA, 2014b) 


\begin{tabular}{|c|c|c|}
\hline \multicolumn{3}{|c|}{$\begin{array}{c}\text { Table } 8 \\
\text { Nut rotation from snug-tight condition* } \\
\text { (See Clauses } 23.7 .2 \text { and I.1.) }\end{array}$} \\
\hline Disposition of outer faces of bolted parts & Bolt length $\dagger$ & Turn \\
\hline \multirow{3}{*}{$\begin{array}{l}\text { Both faces normal to bolt axis or one face normal to axis and } \\
\text { other face sloped 1:20 max. (bevelled washers not used)‡ }\end{array}$} & Up to and including 4 diameters & $1 / 3$ \\
\hline & $\begin{array}{l}\text { Over } 4 \text { diameters and not exceeding } 8 \\
\text { diameters or } 200 \mathrm{~mm}\end{array}$ & $1 / 2$ \\
\hline & Exceeding 8 diameters or $200 \mathrm{~mm}$ & $2 / 3$ \\
\hline $\begin{array}{l}\text { Both faces sloped 1:20 max. from normal to bolt axis } \\
\text { (bevelled washers not used) } \ddagger\end{array}$ & All lengths of bolts & $3 / 4$ \\
\hline \multicolumn{3}{|c|}{$\begin{array}{l}\text { * Nut rotation is rotation relative to a bolt regardless of whether the nut or bolt is turned. The tolerance on rotation is } 30^{\circ} \text { ove } \\
\text { or under. This Table applies to coarse-thread heavy-hex structural bolts of all sizes and lengths used with heavy-hex semi- } \\
\text { finished nuts. } \\
+ \text { Bolt length is measured from the underside of the head to the extreme end of point. } \\
\text { ‡ Bevelled washers are necessary when } A 490, A 490 M \text {, or F2280 bolts are used. }\end{array}$} \\
\hline
\end{tabular}

Figure 2-24: Nut rotation to meet or exceed minimum pretension force (CSA, 2014b)

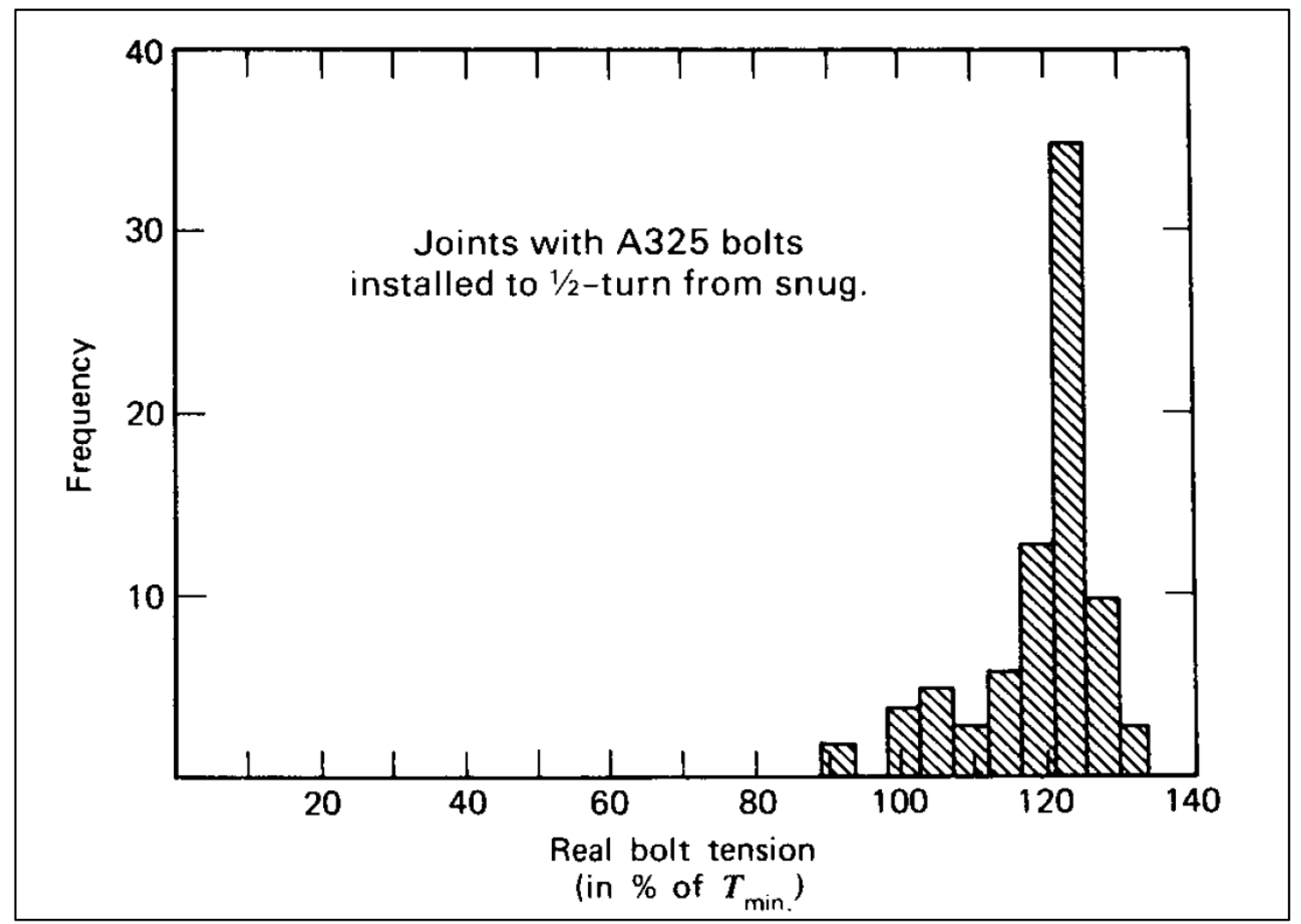

Figure 2-25: Real bolt tension exceeding minimum requirement when the turn-of-nut tightening method is used (Kulak et al., 2001) 


\subsubsection{Research Council on Structural Connections' Slip Coefficient Testing Method}

The Research Council on Structural Connections (RCSC) published in 2014 their new standard specification for using structural joints using high-strength bolts. In Appendix A, the standard described the testing method to determine the slip resistance coefficient for coatings used in bolted joints. This testing method was first developed by Yura and Frank (1981) and since been revised. Test specimens for the compression testing of slip-resistance are made of 3 plates, $101.6 \mathrm{~mm}$ by $101.6 \mathrm{~mm}$ (4" by 4") with a thickness of $15.875 \mathrm{~mm}(5 / 8$ ") and a hole diameter of $25.4 \mathrm{~mm}$ (1"), shown in Figure 2-26. In order to clamp the plates with an accurately measured force, a 7/8" threaded rod needs to pass through the specimen and a hydraulic compression ram is to exist. An ASTM A563 grade DH nut is used at both ends of the rod with two hardened washers on each side of the test specimen. The threaded rod is placed under pretension when pulled by the hydraulic piston. This simulates a pretension bolt on a slip-critical joint. The hydraulic piston should have the capability of applying a load of at least $218 \mathrm{kN}$ (49 kips) and maintain that load during the test with an accuracy of $2.2 \mathrm{kN}$ (0.5 kips) or $1 \%$. The clamping load accuracy should be measured either through the hydraulic pressure dial or by placing a load cell in series with the piston. The testing machine supplying the compressive load to the specimen should have a capacity of at least $534 \mathrm{kN}$ (120 kips). Displacement of the center plate relative to the two outside plates should be measured with an accuracy of $0.0254 \mathrm{~mm}(0.001$ ”). The compression load on the middle plate should be applied at a rate not exceeding $111.2 \mathrm{kN} / \mathrm{min}(25 \mathrm{kips} / \mathrm{min})$ or $0.076 \mathrm{~mm} / \mathrm{min}(0.003$ in./min) if the machine is in displacement control.

The test should be terminated when a slip of $1.27 \mathrm{~mm}(0.05 \mathrm{in}$.) or greater is reached. There are three cases when the slip load should be taken as seen in Figure 2-27. With curve (a), slip load should be the maximum load if the slip occurs prior to $0.5 \mathrm{~mm}(0.02 \mathrm{in}$.). If the slip rate stops suddenly as shown in curve (b), then this point should be taken as the slip load. If there is a gradual change in response to the load vs deformation curve as shown in curve (c), then the load corresponding to a slip of $0.5 \mathrm{~mm}$ (0.02 in.) should be taken as the slip load. Tension testing setup is also permitted provided that the load on the bolts is accurately maintained and measured throughout the duration of the test and that the displacement of the plates is accurately measured. 

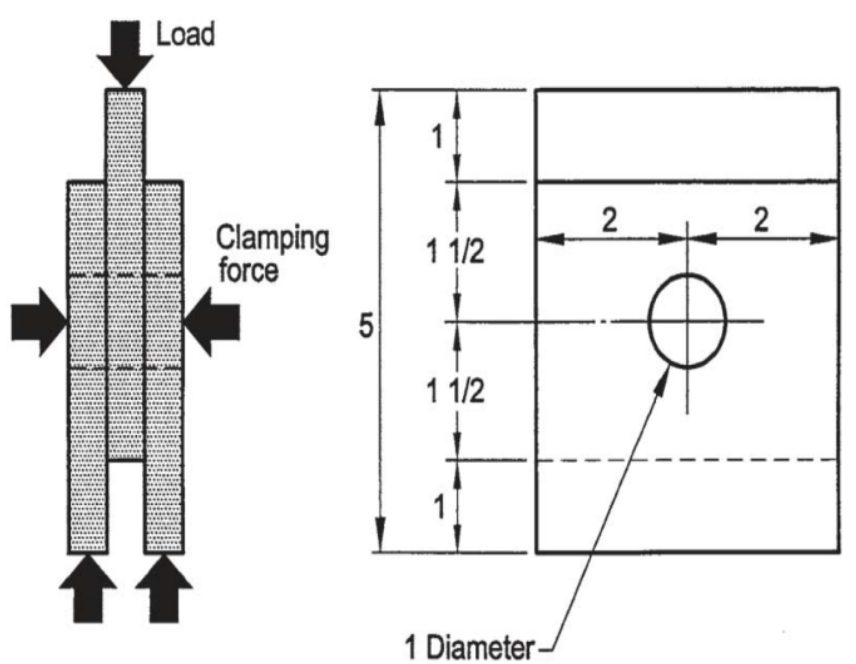

All plates are $5 / 8$-in. thick All dimensions are in inches

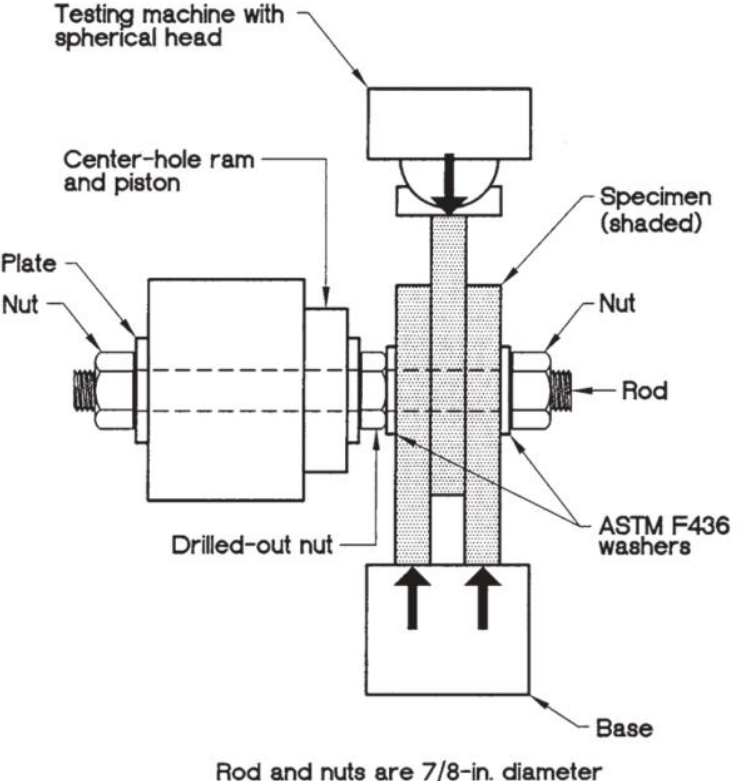

Rod and nuts are 7/8-in. diameter

Figure 2-26: Plate specimen dimensions and testing set up for slip resistance (RCSC, 2014)

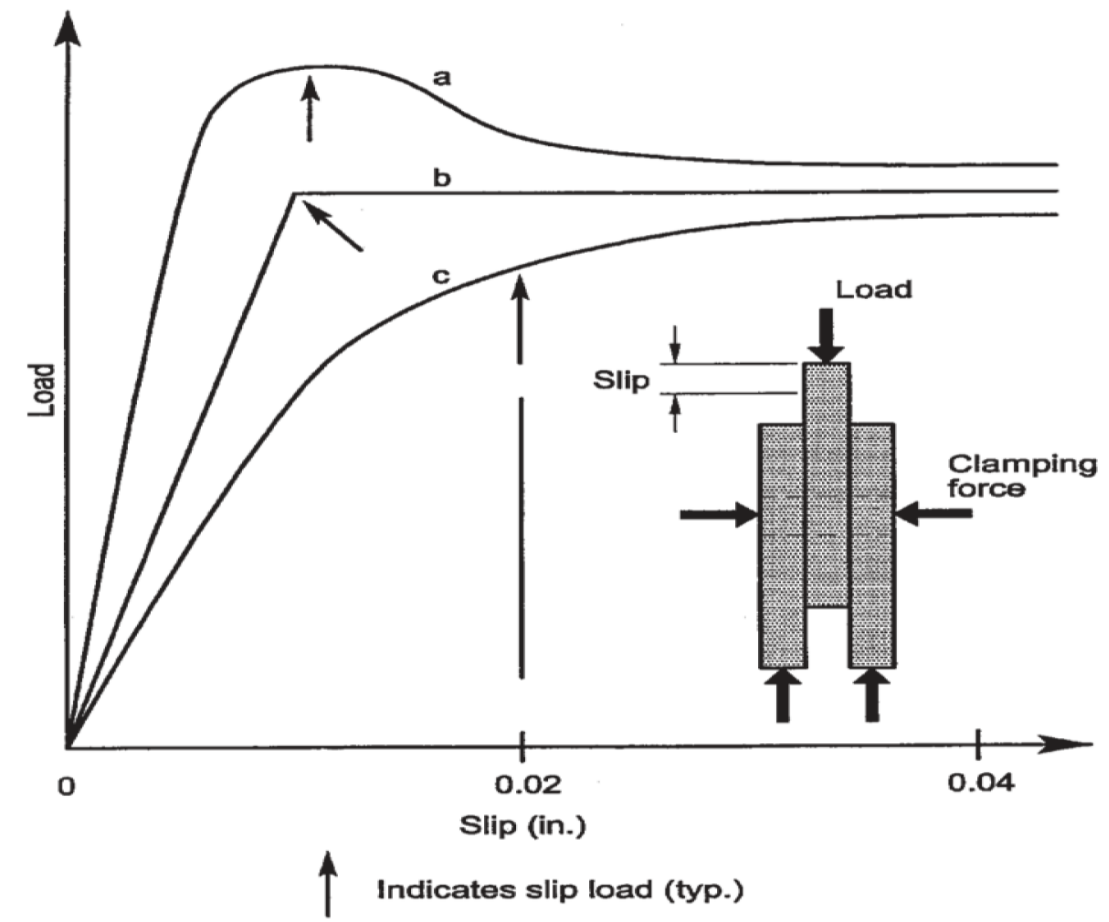

Figure 2-27: Slip Load Definitions (RCSC, 2014) 


\subsubsection{European Standard EN 1090-2 Annex G: Test to Determine Slip Resistance Factor}

EN1090 Part 2 Technical Requirements for Execution of Steel Structures (EN, 2019) gives a detailed description for finding the slip coefficient of structural steel that has undergone some type of surface treatment. Unlike the RCSC compressive slip test, the EN1090-2 slip test is a tensile test commonly used in Europe. The standard specimen should be the same dimension as Figure 2-28. There are two types of dimensions for the specimen depending on which bolt diameter is used, $22 \mathrm{~mm}$ or $16 \mathrm{~mm}$. The plate edges should be accurately cut and sufficiently flat so that they do not interfere with contact between the plate surfaces when the bolts are preloaded. Surfaces shall be free from all contaminants and burrs that would prevent solid surface contact. Bolts should be preloaded depending on their class. Class $8.822-\mathrm{mm}$ bolts need to be preloaded to $170 \mathrm{kN}$ and Class 10.9 22-mm bolts should be preloaded to $212 \mathrm{kN}$. If $16 \mathrm{~mm}$ bolts are used, they should be preloaded to $88 \mathrm{kN}$ and $110 \mathrm{kN}$ for Class 8.8 and Class 10.9, respectively. Similar to the North American codes, the minimum preloading force is taken at $70 \%$ of the bolt's nominal ultimate strength. These bolts should be tightened to within 5\% accuracy of the specified preload. Annex $\mathrm{G}$ of this standard specifies that the test should run for a duration of 10 to 15 minutes. However, it does not specify a loading rate. Also, there is no mention in terms of how or what accuracy should the load on the bolt be maintained at. The assumption is that when doing this test, bolts should be fitted with some sort of strain gauge or a washer type load cell should be used to accurately measure their pretension during the duration of the test. Slip shall be taken as the relative displacement between the inner plate and cover plates. The slip load is defined as the load that occurs at 0.15 $\mathrm{mm}$. 


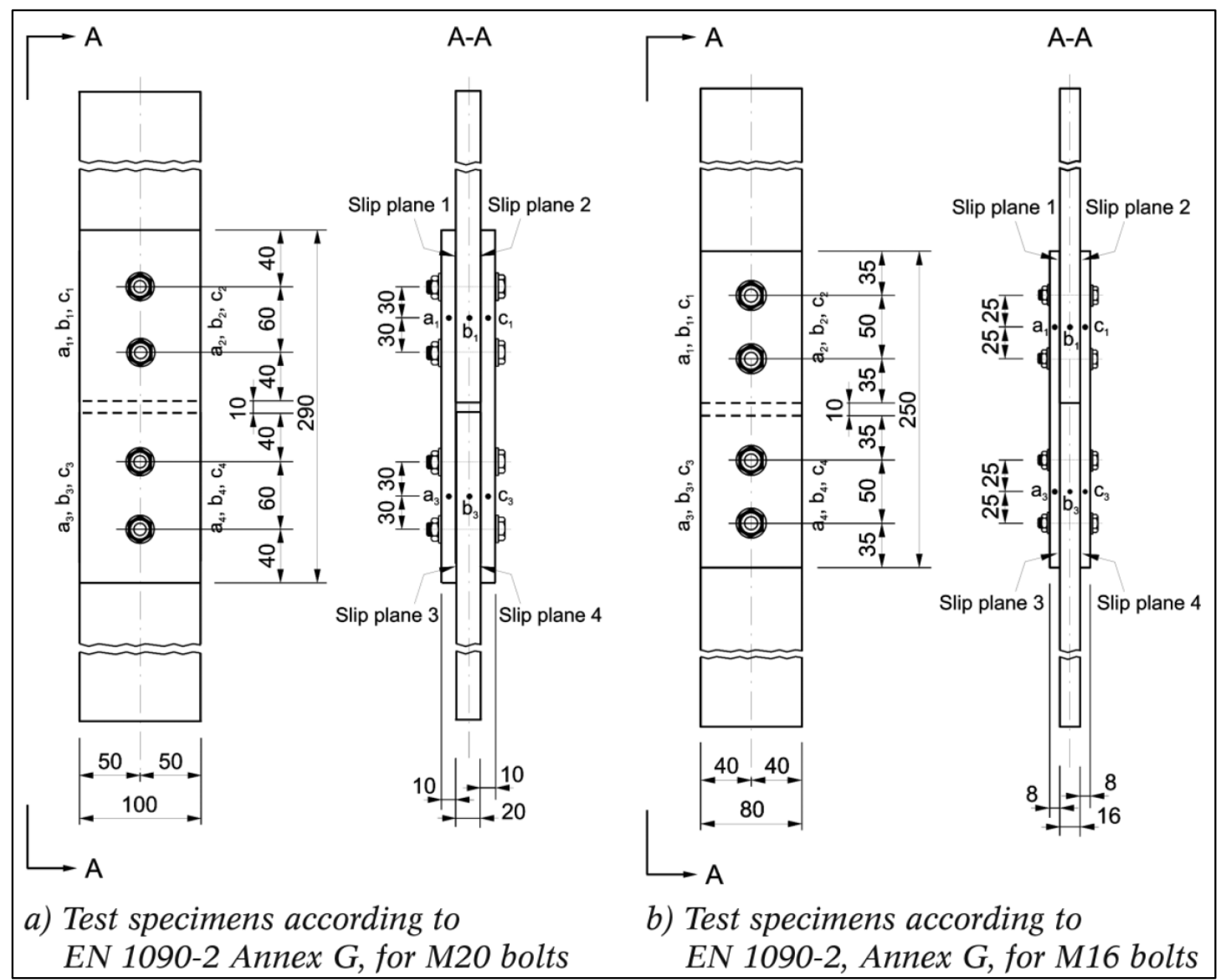

Figure 2-28: Standard Test Specimens for Slip Factor Test EN1090-2 (Stranghöner et al. 2017)

\subsubsection{Review of Codes}

\subsubsection{CSA S16-14 - Design of Steel Structures:}

Clause 13.12.2 on the Canadian steel design code for building (CSA, 2014b) specifies that bolts in slip-critical connections shall be able to resist slip. A slip-critical connection shall also satisfy the shear and bearing criteria at the ultimate limit state design. In order to calculate the slip resistance for shear connections the following equation shall be used:

$\mathrm{V}_{\mathrm{s}}=0.53 \mathrm{c}_{\mathrm{s}} \mathrm{k}_{\mathrm{s}} \mathrm{mnA}_{\mathrm{b}} \mathrm{F}_{\mathrm{u}}$ 
Where,

$\mathrm{c}_{\mathrm{s}}=$ the resistance factor for slip resistance of bolted joints

$\mathrm{k}_{\mathrm{s}}=$ the mean slip coefficient as determined by tests carried out in accordance with Annex A of RCSC Specification for Structural Joints Using High-Strength Bolts.

$\mathrm{m}=$ number of shear planes

$\mathrm{n}=$ number of bolts

$\mathrm{A}_{\mathrm{b}}=$ cross-sectional area of bolt

$\mathrm{F}_{\mathrm{u}}=$ specified minimum tensile strength of the bolt

Clause 23.2 of CSA S16-14 mentions that the defined surface conditions for slip-critical connections shall be as following:

a) Clean mill surface shall be free of oil, paint, lacquer, or any other coating for all areas within the bolt pattern and for a distance beyond the edge of the bolt hole that is the greater of $25 \mathrm{~mm}$ (1") or the bolt diameter.

b) For Classes $\mathrm{A}$ and $\mathrm{B}$ of the bolted parts, the blast-cleaning and the coating application shall be the same as those used in the tests to determine the mean slip coefficient.

c) For hot-dip galvanized surfaces, galvanizing shall be done in accordance with CAN/CSAG164 and the surface should be subsequently roughened by hand wire-brushing and not power wire-brushing.

d) For all other coatings, the surface preparation and coating application for the joint shall be the same as those used in the tests to determine the mean slip coefficient.

CSA S16-14 specifies that the slip coefficient $\left(\mathrm{k}_{\mathrm{s}}\right)$, shall be 0.30 for Class A and 0.52 for Class B surface condition for bolted parts. In this case, Class A surface condition is described as unpainted clean mill scale steel surfaces or surfaces with Class A coatings on blast-cleaned steel or hot-dip galvanized and roughened surfaces. While Class B surface condition is described as unpainted blast-cleaned steel surfaces or surfaces with Class B coatings on blast-cleaned steel. Similarly, the Canadian Highway Bridge Design Code (CSA, 2014a) mentions that slip is not permitted at the service load levels of a bridge connection. The equation listed in Clause 10.18.2.3.2 of this code is the same as equation 2.1 that is in the Canadian steel design code (CSA, 2014b). Figure 2-29 shows the table to obtain $\mathrm{k}_{\mathrm{s}}$ and $\mathrm{c}_{\mathrm{s}}$ as presented in these two CSA codes. 


\begin{tabular}{|c|c|c|c|c|c|}
\hline \multicolumn{6}{|c|}{$\begin{array}{c}\text { Table } 10.9 \\
\text { Values of } \boldsymbol{k}_{\boldsymbol{s}} \text { and } \boldsymbol{c}_{\mathbf{s}} \\
(\text { See Clauses } 10.18 .2 .3 .2 \text { and } \mathrm{A} 10.1 .6 .2 .)\end{array}$} \\
\hline \multicolumn{2}{|c|}{ Contact surface for bolted parts } & \multirow[b]{3}{*}{$k_{s}$} & \multirow{2}{*}{\multicolumn{2}{|c|}{$\begin{array}{l}\text { Resistance factor, } c_{s} \\
\text { Installation by turn-of-nut } \\
\text { method }\end{array}$}} & \multirow[b]{3}{*}{$\begin{array}{l}\text { ASTM F1852 } \\
\text { and F2280 }\end{array}$} \\
\hline & & & & & \\
\hline Class & Description & & $\begin{array}{l}\text { ASTM A325 } \\
\text { and A325M }\end{array}$ & $\begin{array}{l}\text { ASTM A490 } \\
\text { and A490M }\end{array}$ & \\
\hline A & $\begin{array}{l}\text { Unpainted clean mill scale steel } \\
\text { surfaces, or surfaces with Class A } \\
\text { coatings on blast-cleaned steel or } \\
\text { hot-dipped galvanized with hand } \\
\text { wire-brushed surfaces }\end{array}$ & 0.30 & 1.00 & 0.92 & 0.78 \\
\hline B & $\begin{array}{l}\text { Unpainted blast-cleaned steel surfaces } \\
\text { or surfaces with Class B coatings on } \\
\text { blast-cleaned steel }\end{array}$ & 0.52 & 1.04 & 0.96 & 0.81 \\
\hline
\end{tabular}

\section{Figure 2-29: Specified slip resistance coefficients in the Canadian Highway Bridge Design Code, CSA S6-14 (CSA, 2014a)}

\subsubsection{AASHTO LRFD Bridge Design Specifications}

Clause 6.13.2.8 of the 2.3.5.2 AASHTO LRFD Bridge Design Specifications (AASHTO, 2017) specifies that the nominal slip resistance of bolts in a slip-critical connection shall be taken as:

$\mathrm{R}_{\mathrm{n}}=\mathrm{K}_{\mathrm{h}} \mathrm{K}_{\mathrm{s}} \mathrm{N}_{\mathrm{s}} \mathrm{P}_{\mathrm{t}}$

Where:

$\mathrm{N}_{\mathrm{S}}=$ number of slip planes per bolt

$\mathrm{P}_{\mathrm{t}}=$ minimum required bolt tension specified in Table 6.13.2.8-1 in kip

$\mathrm{K}_{\mathrm{h}}=$ hole size factored specified in Table 6.13.2.8-2.

$\mathrm{K}_{\mathrm{s}}=$ surface condition factor specified in Table 6.13.2.8-3. 
Table 6.13.2.8-1-Minimum Required Bolt Tension, ASTM F3125 Bolts

\begin{tabular}{||c|c|c|}
\hline \multirow{2}{*}{$\begin{array}{c}\text { Bolt } \\
\text { Diameter, } \\
\text { in. }\end{array}$} & \multicolumn{2}{|c|}{ Required Tension- $P_{t}$ (kip) } \\
\cline { 2 - 3 } & Grade A325 or & $\begin{array}{c}\text { Grade A490 or } \\
\text { F1852 }\end{array}$ \\
\hline $5 / 8$ & 19 & 240 \\
\hline $3 / 4$ & 28 & 35 \\
\hline $7 / 8$ & 39 & 49 \\
\hline 1 & 51 & 64 \\
\hline $1 \frac{1}{8}$ & 64 & 80 \\
\hline $1 \frac{1}{4}$ & 81 & 102 \\
\hline $13 / 8$ & 97 & 121 \\
\hline $11 / 2$ & 118 & 148 \\
\hline
\end{tabular}

Table 6.13.2.8-2-Values of $K_{h}$

\begin{tabular}{||l|c||}
\hline For standard holes & 1.00 \\
\hline For oversize and short-slotted holes & 0.85 \\
\hline $\begin{array}{l}\text { For long-slotted holes with the slot } \\
\text { perpendicular to the direction of the force }\end{array}$ & 0.70 \\
\hline $\begin{array}{l}\text { For long-slotted holes with the slot parallel } \\
\text { to the direction of the force }\end{array}$ & 0.60 \\
\hline
\end{tabular}

Table 6.13.2.8-3-Values of $K_{s}$

\begin{tabular}{||l|c|}
\hline For Class A surface conditions & 0.30 \\
\hline For Class B surface conditions & 0.50 \\
\hline For Class C surface conditions & 0.30 \\
\hline For Class D surface conditions & 0.45 \\
\hline
\end{tabular}

Figure 2-30: AASHTO LRFD tables for minimum required bolt tension and coefficients for the calculation of slip resistance (AASHTO, 2017)

As mentioned earlier the minimum bolt pretension should be equal to $70 \%$ of the minimum tensile strength of the bolts. AASHTO LRFD Specifications have a more defined description for each Class of the surface condition of the bolted parts as follows.

- Class A surfaces include unpainted clean mill scale and blast-cleaned surfaces with predetermined Class A coatings.

- Class B surfaces include unpainted blast-cleaned surfaces to SSPC-SP6 or better, and blast cleaned surfaces with predetermined Class B coatings, or unsealed pure zinc 85/15 zinc/aluminum thermal-sprayed coatings with a thickness less than or equal to 16 mils.

- Class C surface include hot-dip galvanized surfaces.

- Class D surface includes blast cleaned surfaces with predetermined Class D coatings, such as organic zinc-rich coatings.

\subsubsection{Eurocode 3 - Design of Steel Structures}

Eurocode 3 Clause 3.9.1(1) specifies the following equation for the design of slip resistance of a preloaded Class 8.8 or Class 10.9 bolt (EN, 2009).

$F_{s, R d}=\frac{k_{s} n \mu}{\gamma_{M 3}} F_{p, C}$

Where, 
$\mathrm{k}_{\mathrm{s}}=$ factor for bolt hole size from section 3-1-8, Table 3.6. The factor is 1 for normal-size holes and less than 1 for larger holes due to the greater consequences of slip.

$\mathrm{n}=$ number of slip planes

$\mu=$ coefficient of friction depending on the type of faying surface.

$F_{p, C}=0.7 f_{u b} A_{s}$; minimum strength of the bolt pretension taken as $70 \%$ of its ultimate strength.

$\gamma_{\mathrm{M} 3}=1.25$ for the ultimate limit states as recommended in EN 1993-2, Table 6.1 for bridges due to fatigue loading. At serviceability, a value of 1.1 is recommended from the same table.

Eurocode 3 specifies four different surface classes for the bolted parts which are described as follows.

- Class A are surfaces that are blasted with shot or grit, with loose debris removed; spray metallized with aluminum; spray-metallized with zinc-based coating certified to provide slip coefficients not less than 0.5. All Class A surfaces have a slip coefficient, $\mu=0.50$.

- Class B surfaces are blasted with shot or grit and painted with an alkali-zinc silicate to produce a coating thickness of 50-80 $\mu \mathrm{m}$ (1.97 - 3.15 mils). All Class B surfaces have a slip coefficient, $\mu=0.40$.

- Class $\mathrm{C}$ surfaces are cleaned by wire brushing or flame cleaning and any loose rust or debris removed. All Class $\mathrm{C}$ surfaces have a coefficient of friction, $\mu=0.30$.

- Class D surfaces are not treated. All Class D surfaces have a slip coefficient, $\mu=0.20$.

\subsubsection{Review of Previous Slip Coefficient Studies}

The slip resistance coefficients specified in design codes are a result of extensive research conducted on the slip-resistance of various steel types and coatings. If the engineer in charge does not know under what category a certain type of steel or coating falls, then they need to perform their own testing to determine and evaluate the correct category. This literature review aims to figure out what testing methods and parameters have been used to determine the slip-coefficient of various other steels, coatings and faying surfaces already tested. Test parameters such as clamping methods, bolts used, loading rates, would provide aid in figuring out the best method(s) to test the slip resistance of A1010 stainless steel in the current study. 
Grondin et al. (2007) performed an extensive literature review on the study of slip-coefficients. Their aim was to come up with a reliability analysis of slip-critical connections for the design at the ultimate limit states. Table 2-6 shows a summary of the extensive literature review conducted by Grondin et al., on the slip coefficient of early and recent tests done on clean mill surfaces. The average slip coefficient found by adding up all the data was 0.306 . This is similar to Class A surfaces on both the Canadian and American standards. Table 2-7 shows a summary of the extensive literature review conducted by Grondin et al., on the slip coefficient of early and recent tests done on blasted clean surfaces of bolted parts. The average slip coefficient found by adding up all the data was 0.525 which is very similar to that of both the Canadian and American codes for Class B blasted clean surface conditions. Previous research that studied the slip coefficient of more than one carbon alloy structural steel concluded that changing the steel type did not cause much of a difference in values (Moss, 1979; Fisher and Kulak, 1968; Fouad, 1978; Kuperus, 1966).

Table 2-6: Summary of Slip Coefficients on Clean Mill Surfaces (Grondin et al., 2007)

\begin{tabular}{|c|c|c|c|c|}
\hline Source & Steel Grade & Sample Size & Mean & COV \\
\hline Allan and Fisher, 1968 & A36 & 12 & 0.274 & 0.089 \\
\hline Fisher et al., 1963 & A440 & 14 & 0.317 & 0.104 \\
\hline Foreman and Rumpf, 1961 & A7 & 8 & 0.420 & 0.125 \\
\hline \multirow{2}{*}{ Frank and Yura, 1981a } & A36 & 2 & 0.350 & 0.242 \\
\cline { 2 - 5 } & A572 & 6 & 0.217 & 0.069 \\
\cline { 2 - 5 } & A514 & 2 & 0.300 & 0.000 \\
\hline Hansen, 1980 & A514 & 2 & 0.324 & 0.105 \\
\hline Hojarczyk et al., 1959 & St37 & 3 & 0.269 & 0.328 \\
\hline Kennedy and Sanderson, 1968 & G40.8 Gr 8 & 23 & 0.252 & 0.069 \\
\hline \multirow{2}{*}{ Kuperus, 1966 } & Fe37 & 8 & 0.359 & 0.124 \\
\hline Laub and Philips, 1954 & Fe52 & 8 & 0.261 & 0.080 \\
\hline Nester, 1966 & A7 & 14 & 0.275 & 0.219 \\
\hline Prynne, 1965 & A36 & 15 & 0.272 & 0.202 \\
\hline Stankevicius et al., 2007 & Mild Steel & 4 & 0.483 & 0.064 \\
\hline Sterling and Fisher, 1966 & A588 & 190 & 0.387 & 0.164 \\
\hline Van Douwen et al., 1959 & A440 & 8 & 0.348 & 0.078 \\
\hline Vasarhelyi and Chiang, 1967 & St37 & 24 & 0.353 & 0.070 \\
\hline Yura et al., 1981 & A7 & 23 & 0.273 & 0.099 \\
\hline Total All Data & A588 & 31 & 0.265 & 0.064 \\
\hline & & 397 & 0.306 & $\mathbf{0 . 2 6 0}$ \\
\hline
\end{tabular}


Table 2-7: Summary of Slip Coefficients on Blasted Clean Surfaces (Grondin et al., 2007)

\begin{tabular}{|c|c|c|c|c|}
\hline Source & Steel Grade & Sample Size & Mean & COV \\
\hline $\begin{array}{l}\text { Douty and McGuire, } \\
1965\end{array}$ & A7 & 7 & 0.560 & 0.121 \\
\hline Dusel et al., 1977 & A36 & 7 & 0.532 & 0.153 \\
\hline Fisher and Kulak, 1968 & $\begin{array}{l}\text { A514, A36, } \\
\text { A440 }\end{array}$ & 9 & 0.343 & 0.153 \\
\hline Fouad, 1978 & $\begin{array}{c}\text { A572, A514, } \\
\text { A36 }\end{array}$ & 103 & 0.526 & 0.177 \\
\hline Frank and Yura, 1981a & A572 & 10 & 0.690 & 0.097 \\
\hline Frank and Yura, 1981b & A572 & 8 & 0.515 & 0.144 \\
\hline Kuperus, 1966 & Fe37 and Fe52 & 96 & 0.566 & 0.124 \\
\hline Lee and Fisher, 1968 & A36 & 21 & 0.489 & 0.307 \\
\hline Lee et al., 1969 & A36 & 3 & 0.493 & 0.024 \\
\hline Moss, 1979 & A514 \& A36 & 6 & 0.394 & 0.096 \\
\hline Van Douwen et al. 1959 & St37 & 64 & 0.486 & 0.175 \\
\hline Yura et al., 1981 & A588 & 20 & 0.518 & 0.207 \\
\hline Total All Data & & 354 & 0.525 & 0.193 \\
\hline
\end{tabular}

The Guide to Design Criteria for Bolted and Riveted Joints (Kulak et al., 2001) compiles slip resistance studies done throughout history on various steel (Figure 2-31). Kulak et al. make the distinction that grit blasting of quenched and tempered alloy steel has less of an effect on the slip coefficient than compared to low strength steel. This indicates that surface hardness is an important factor when it comes to the indication of surface roughness achieved through blast cleaning. The guide also makes mentions that blast cleaned surfaces are highly susceptible to corrosion during the period of construction. Research studies observed a reduction in slip resistance when blast or shot cleaned surfaces are rusted (Lee et al., 1969; Vasarhelyi and Chiang, 1967). 


\begin{tabular}{|c|c|c|c|c|}
\hline Type Steel & Treatment & Average & $\begin{array}{l}\text { Standard } \\
\text { Deviation }\end{array}$ & $\begin{array}{l}\text { Number } \\
\text { Of Tests }\end{array}$ \\
\hline A7, A36, A440 & Clean mill scale & 0.32 & 0.06 & 180 \\
\hline $\begin{array}{l}\text { A7, A36, A440, } \\
\text { Fe37, Fe52 }\end{array}$ & Clean mill scale & 0.33 & 0.07 & 327 \\
\hline A588 & Clean mill scale & 0.23 & 0.03 & 31 \\
\hline $\mathrm{Fe} 37$ & Grit Blasted & 0.49 & 0.07 & 167 \\
\hline $\mathrm{A} 36, \mathrm{Fe} 37, \mathrm{Fe} 52$ & Grit Blasted & 0.51 & 0.09 & 186 \\
\hline A514 & Grit Blasted & 0.33 & 0.04 & 17 \\
\hline $\mathrm{A} 36, \mathrm{Fe} 37$ & $\begin{array}{l}\text { Grit Blasted, exposed } \\
\text { (short period) }\end{array}$ & 0.53 & 0.06 & 51 \\
\hline $\mathrm{A} 36, \mathrm{Fe} 37, \mathrm{Fe} 52$ & $\begin{array}{l}\text { Grit Blasted, exposed } \\
\text { (short period) }\end{array}$ & 0.54 & 0.06 & 83 \\
\hline $\begin{array}{l}\text { A7, A36, A514, } \\
\text { A572 }\end{array}$ & Sand Blasted & 0.52 & 0.09 & 106 \\
\hline $\mathrm{A} 36, \mathrm{Fe} 37$ & Hot-dip galvanized & 0.18 & 0.04 & 27 \\
\hline A7, A36 & Semipolished & 0.28 & 0.04 & 12 \\
\hline \multirow[t]{6}{*}{ A36 } & Vinyl wash & 0.28 & 0.02 & 15 \\
\hline & Cold zinc painted & 0.30 & -- & 3 \\
\hline & Metallized & 0.48 & -- & 2 \\
\hline & $\begin{array}{l}\text { Galvanized and sand } \\
\text { blasted }\end{array}$ & 0.34 & -- & 1 \\
\hline & $\begin{array}{l}\text { Sand blasted and } \\
\text { treated with linseed } \\
\text { oil (exposed) }\end{array}$ & 0.26 & 0.01 & 3 \\
\hline & Red lead paint & 0.06 & -- & 6 \\
\hline
\end{tabular}

Figure 2-31: Summary of slip coefficients by steel type and surface treatment (Kulak et al., 2001)

More recently, an extensive report was published in 2019 by the Research Fund for Coal and Steel (RFCS) of the European Community titled "Execution and reliability of slip-resistant connections for steel structures using carbon steel and stainless steel (SIROCO, 2019). In this report, extensive research was completed on surface treatments and slip resistance of several types of stainless steels, namely: austenitic $\left(F_{y}=266 \mathrm{MPa}, F_{u}=585 \mathrm{MPa}\right)$, ferritic $\left(F_{y}=340 \mathrm{MPa}, F_{u}=517 \mathrm{MPa}\right)$, lean duplex $\left(\mathrm{F}_{\mathrm{y}}=552 \mathrm{MPa}, \mathrm{F}_{\mathrm{u}}=728 \mathrm{MPa}\right)$, and duplex $\left(\mathrm{F}_{\mathrm{y}}=538 \mathrm{MPa}, \mathrm{F}_{\mathrm{u}}=788 \mathrm{MPa}\right)$ grades (Stranghöner et al., 2017). Treatment of faying surfaces included mill scale, shot blasted, and grit blasted. The method of testing followed that in which is described in EN 1090-2, Annex G. A tensile test method including simple instrumentations such as strain gauges inserted into the bolts to keep accurate track of clamping force during the test. Results of static slip resistance tests show 
that the highest slip load for uncoated tests is achieved for ferritic stainless steel that is grit blasted, followed by grit blasted duplex, austenitic, and lean duplex grades. It was concluded that grit blasted stainless steels are able to achieve more than 0.5 slip resistance coefficient. On the other hand, shot blasting and as-rolled surface conditions for austenitic stainless steel resulted in much lower slip factors, 0.29 and 0.21 mean slip resistance coefficients respectively. Hence, Stranghöner et al. (2019) concluded that these types of surfaces are not very good at transferring load by friction. Grit blasting had a much higher surface roughness as compared to shot blasting, thereby providing better mechanical interlocking between the surfaces. This is thought to be the primary factor why much higher slip resistance coefficients were achieved with grit blasting. The study also concludes that higher bolt preload levels resulted in higher slip resistance factors for stainless steel connections. This is contrary to what is believed for regular carbon steels. Figure 2-32 summarizes the slip resistance coefficients for different stainless steel grades and surface treatments using Class 8.8 stainless steel bolts (Stranghöner et al., 2017).

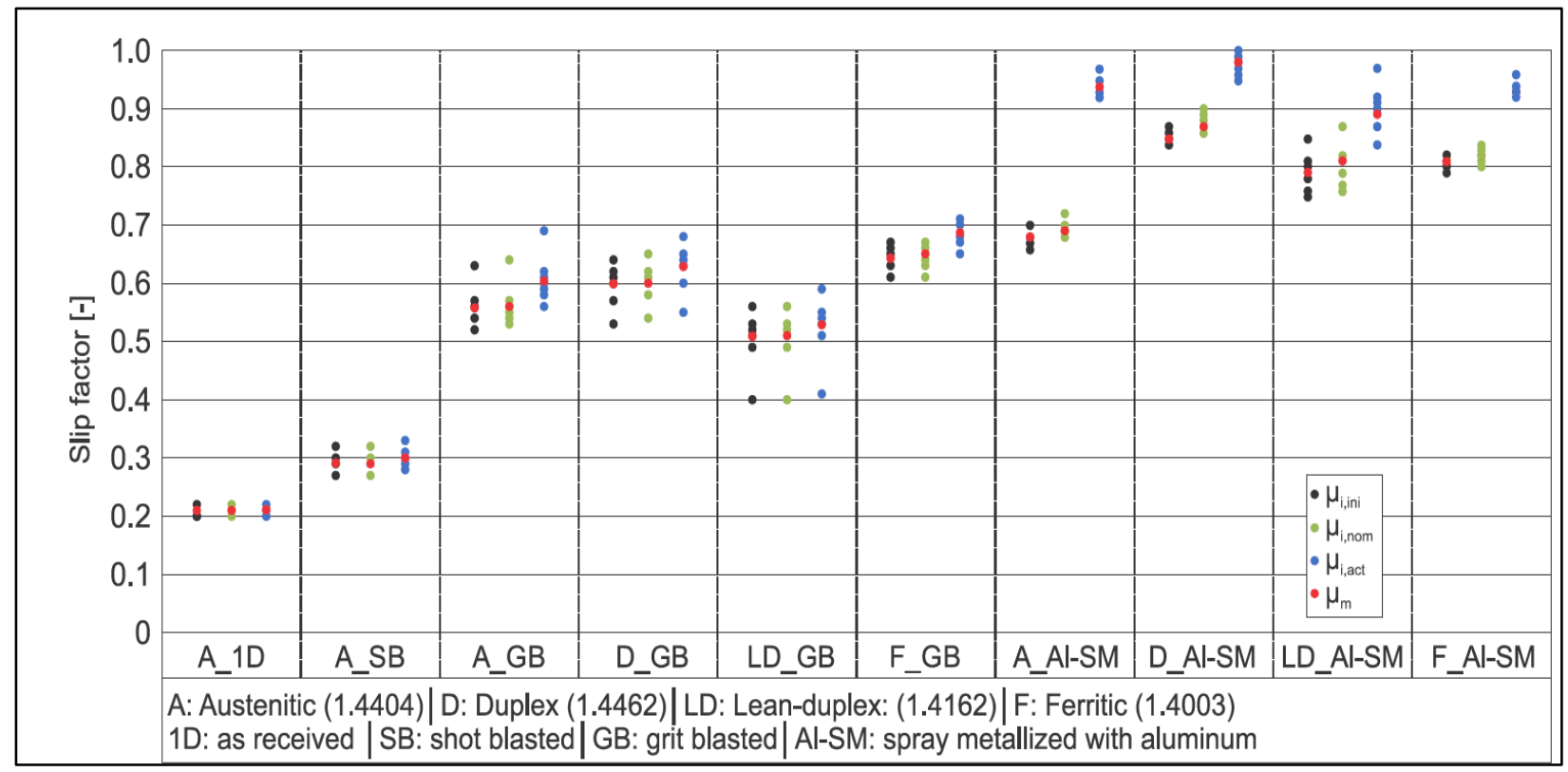

Figure 2-32: Slip resistance for different stainless steel grades and surface treatments using Class 8.8 stainless steel bolts (Stranghöner et al., 2017)

Hradil et al. (2017) performed a parametric study aimed at calibrating their finite element numerical model of stainless steel preloaded connections. Slip resistance was determined according to EN 1090-2, Annex G test for shot and grit-blasted surface finishes. A load cell was used to accurately measure and monitor bolt preload during the test. Similar to the study by 
Stranghöner et al. (2017), slip resistance tests were modeled on austenitic, ferritic, duplex and lean duplex stainless steel plates with austenitic class 8.8 and 10.9 stainless steel bolts. As a result, the calibrated finite element model gave very good results in comparison with actual experimental work. The results of the study showed that increasing the preloading rate can lead to larger bolt relaxation. Also, the study showed that it is possible to increase clamping force by re-tightening the bolt without overloading it. The conclusions from the parametric study examining the influence of geometric parameters on the slip resistance factors of the stainless steel bolt assembly showed that the slip resistance factors for stainless steel are similar to those for carbon steels. Also, the model gave similar results to that of the study done by Stranghöner et al. (2017) for the SIROCO project; the expected loss of preload is between 10 to $30 \%$; increase in clamping length decreases the loss of preload and improves slip resistance; and an increase in bolt or hole diameter can lead to an increase of preload loss.

As a result of all the research performed by Stranghöner et al. (2019), the SIROCO report published in Europe proposed to amend their own code EN 1090-2 with the following table (Figure 2-33) specifically for stainless steel plates. Accounting for safety factors, SIROCO recommends that a slip resistance coefficient of 0.4 be used for grit-blasted surfaces of austenitic and lean duplex stainless steels with a roughness of at least 45 and $40 \mu \mathrm{m}$, respectively. Whereas, a slip resistance coefficient of 0.5 is recommended for duplex and ferritic stainless steels that are grit blasted with a surface roughness of at least 50 and $45 \mu \mathrm{m}$, respectively. On the other hand, a recommended slip resistance coefficient of 0.2 for shot-blasted surfaces of austenitic stainless steels of a roughness greater than or equal to $35 \mu \mathrm{m}$ is proposed. From the gathered experimental data, no stainless steel slip resistance test conducted was close to a slip resistance coefficient of 0.3 and thus no proposed recommendations have been made for Class $\mathrm{C}$ friction surfaces of stainless steel. 


\begin{tabular}{|c|c|c|c|c|}
\hline \multicolumn{5}{|c|}{$\begin{array}{l}\text { New Table } 19 \text { for EN 1090-2: } \\
\text { Classifications that may be assumed for friction surfaces between stainless } \\
\text { steel plates }\end{array}$} \\
\hline \multirow{2}{*}{$\begin{array}{c}\text { Class of friction } \\
\text { surfaces }\end{array}$} & \multirow{2}{*}{$\begin{array}{c}\text { Stainless steel } \\
\text { grade }\end{array}$} & \multicolumn{2}{|c|}{ Surface condition } & \multirow{2}{*}{$\begin{array}{l}\text { Slip } \\
\text { factor } \mu\end{array}$} \\
\hline & & Surface finish & $\mathrm{Rz}[\mu \mathrm{m}]$ & \\
\hline$A++$ & $\begin{array}{l}\text { Duplex } 1.4462 / \\
\text { Lean Duplex } \\
1.4162\end{array}$ & \multirow{2}{*}{$\begin{array}{l}\text { Aluminium spray } \\
\text { metallized } \\
\text { (measured dry film } \\
\text { thickness }(D F T)=100 \\
\mu \mathrm{m} \pm 20 \mu \mathrm{m})\end{array}$} & \multirow{2}{*}{$\begin{array}{l}\geq 40 \\
\text { (before } \\
\text { coating } \\
\text { application) }\end{array}$} & 0.7 \\
\hline$A+$ & $\begin{array}{l}\text { Austenitic } \\
1.4404 / \text { Ferritic } \\
1.4003\end{array}$ & & & 0.6 \\
\hline \multirow[b]{2}{*}{ A } & Duplex 1.4462 & \multirow[b]{2}{*}{ Surfaces blasted with grit } & $\geq 50$ & \multirow[b]{2}{*}{0.5} \\
\hline & Ferritic 1.4003 & & $\geq 45$ & \\
\hline \multirow[b]{2}{*}{ B } & Austenitic 1.4404 & \multirow[b]{2}{*}{ Surfaces blasted with grit } & $\geq 45$ & \multirow[b]{2}{*}{0.4} \\
\hline & $\begin{array}{l}\text { Lean Duplex } \\
1.4162\end{array}$ & & $\geq 40$ & \\
\hline $\mathrm{C}$ & - & - & - & 0.3 \\
\hline $\mathrm{D}$ & Austenitic 1.4404 & $\begin{array}{l}\text { Surfaces blasted with } \\
\text { shot }\end{array}$ & $\geq 35$ & 0.2 \\
\hline $\mathrm{E}$ & Austenitic 1.4404 & Surfaces as rolled & $\geq 25$ & 0.15 \\
\hline
\end{tabular}

Figure 2-33: EN1090-2 Proposal for Stainless Steel Slip Coefficient based on Grade, Surface Roughness, and Surface Finish (Stranghöner et al., 2019)

\subsection{Stainless Steel Fastener Relaxation Literature Review}

Preload loss tests on stainless steel assemblies were recently conducted for the European SIROCO project published in 2019 (SIROCO, 2019) in which research conducted on determining slip resistance coefficients and preload losses were conducted by several authors (Afzali et al., 2017; and Stranghöner et al., 2017). Previously restrictions on the use of stainless steel fasteners were mainly caused as a result of the unknown plastic deformation behaviour that stainless steel has in comparison to carbon steel. This large deformation behaviour is thought to result in larger preload losses in bolting assemblies. Finally, there is a gap of knowledge regarding in-field installation 
techniques for stainless steel fasteners for slip-critical connections. It is known that preload losses are due to parameters such as plastic deformation of the clamped surfaces, creep deformation, and stress relaxation (Stranghöner et al., 2019).

Afzali et al. (2017) conducted a large study on the creep behavior of stainless steel plates, namely austenitic $\left(\mathrm{EN} 1.4404, \mathrm{~F}_{\mathrm{y}}=280 \mathrm{MPa}\right)$, ferritic $\left(\mathrm{EN} 1.4003, \mathrm{~F}_{\mathrm{y}}=304 \mathrm{MPa}\right)$, lean duplex $(\mathrm{EN} 1.4162$, $\left.\mathrm{F}_{\mathrm{y}}=509 \mathrm{MPa}\right)$ and duplex $\left(\mathrm{EN} 1.4462, \mathrm{~F}_{\mathrm{y}}=619 \mathrm{MPa}\right)$. The specimens were loaded in the rolling direction to $50,65,83$, and $100 \%$ of their proof strength to determine the creep rate at room temperature. The results showed that at $50 \%$ of the proof stress level, creep was observed for all the tested stainless steel grades and after 2.5 hours the inelastic strain became constant. Afzali et al. (2017) also determined the relaxation behavior of preloaded stainless steel bolted assemblies. The assemblies were made of austenitic, ferritic, duplex, and lean duplex stainless steel plates and bolted together with austenitic stainless steel bolts of $16 \mathrm{~mm}$ and $20 \mathrm{~mm}$ diameters. All stainless steel plate faying surfaces were mill scale without any surface treatment. All bolts were preloaded at $70 \%$ of their ultimate strength. The preload loss was measured by two different methods, strain gauged bolts and load cells. The results show that the loss of preload starts immediately after tightening of the bolts at a large rate and gradually continues at a smaller rate. The preload loss results are shown in Figure 2-34. As can be seen, the austenitic bolts and plates experienced the largest preload loss of about $10 \%$. Losses were also extrapolated to 50-year losses and it was determined that preloaded stainless steel connections and preloaded carbon steel connections experience similar losses. The authors claim that the loss of preload due to creep in the plates is negligible and that the main preload losses come from settling effects and stress relaxation in the bolts. Thus, preloaded stainless steel connections can be treated similarly to carbon steel connections.

Stranghöner et al. (2017) also measured the loss of preload loss on stainless steel connections made of the same stainless steel grades and stainless steel bolts used on the study conducted by Afzali et al. (2017). The only difference being that the stainless steel plates had shot and grit blasting applied to the faying surfaces. In this study, the short term preloaded losses were measured 30 minutes after the initial tightening procedure. However, the results were extrapolated to 50 years. It was shown that the losses due to preload on stainless steel connections were very similar to that of carbon steel connection. A distinction made in the study was that re-used bolts that were well 
lubricated had negligible creep/relaxation and the main preload loss caused by the plate material was much smaller. The estimated preload losses caused by the creep of the preloaded plate material varied between 2-3\% for the grit-blasted duplex, lean duplex, and ferritic grades. Whereas the creep preload losses for both shot and grit blasted austenitic plates were in the 6-7\% range. These higher preload losses on the austenitic plates were due to its low yield strength and hardness.

\begin{tabular}{|c|c|c|c|c|c|c|c|c|c|c|}
\hline & \multirow{3}{*}{$\begin{array}{c}\text { Specimen } \\
\text { ID }^{1)}\end{array}$} & \multirow{3}{*}{$\begin{array}{l}\text { Number } \\
\text { of tests }\end{array}$} & \multirow{3}{*}{$\begin{array}{c}\Sigma \mathrm{t}^{2)} \\
{[\mathrm{mm}]}\end{array}$} & \multirow{3}{*}{$\begin{array}{c}\Sigma \mathrm{t} / \mathrm{d} \\
{[-]}\end{array}$} & \multirow{3}{*}{$\begin{array}{c}\text { Bolt } \\
\text { material }\end{array}$} & \multicolumn{2}{|c|}{ Clamped plates } & \multirow{3}{*}{$\begin{array}{l}\text { Surface } \\
\text { condition }\end{array}$} & \multicolumn{2}{|c|}{ Loss of preload } \\
\hline & & & & & & \multirow{2}{*}{$\begin{array}{l}\text { Type of } \\
\text { material }\end{array}$} & \multirow{2}{*}{$\begin{array}{c}\text { Thickness } \\
{[\mathrm{mm}]}\end{array}$} & & $\begin{array}{l}\text { measured } \\
\text { after }\end{array}$ & \multirow{2}{*}{$\begin{array}{l}\text { after } 50 \text { years } \\
\text { (extrapolated) } \\
\min / \max [\%]\end{array}$} \\
\hline & & & & & & & & & $\begin{array}{c}\text { days }-\min / \\
\max [\%]\end{array}$ & \\
\hline \multirow{2}{*}{ 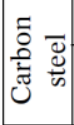 } & \multicolumn{10}{|c|}{ HV-bolts $-\mathrm{M} 20 \times 75$} \\
\hline & $\mathrm{CS}$ & 2 & 48 & 2.4 & $\begin{array}{c}\text { HV-bolt } \\
\text { Class }^{3)} 10.9\end{array}$ & Carbon steel & 20 & $\begin{array}{c}\text { Shot } \\
\text { blasted }\end{array}$ & $\begin{array}{c}68- \\
5.2 / 8.1\end{array}$ & $7.8 / 10.5$ \\
\hline \multirow{13}{*}{ 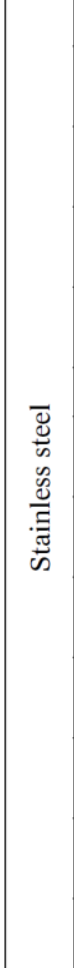 } & \multicolumn{10}{|c|}{ Bumax $88-\mathrm{M} 20 \times 100$} \\
\hline & SS01 & 12 & \multirow{4}{*}{75} & \multirow{4}{*}{3.75} & \multirow{4}{*}{ Bumax 88} & $\begin{array}{l}\text { Austenitic } \\
\text { EN } 1.4404\end{array}$ & \multirow{4}{*}{16} & \multirow{4}{*}{$1 \mathrm{D}$} & $\begin{array}{c}14- \\
3.7 / 6.0\end{array}$ & $6.0 / 8.7$ \\
\hline & SS02 & 12 & & & & $\begin{array}{c}\text { Ferritic } \\
\text { EN } 1.4003\end{array}$ & & & $\begin{array}{c}14- \\
3.4 / 4.7\end{array}$ & $5.3 / 7.5$ \\
\hline & SS03 & 8 & & & & $\begin{array}{c}\text { Duplex } \\
\text { EN } 1.4462\end{array}$ & & & $\begin{array}{c}55- \\
3.9 / 5.0\end{array}$ & $5.4 / 7.2$ \\
\hline & SS04 & 3 & & & & $\begin{array}{c}\text { Lean Duplex } \\
\text { EN } 1.4162\end{array}$ & & & $\begin{array}{c}14- \\
4.0 / 4.5\end{array}$ & $6.4 / 7.1$ \\
\hline & & & & & $\mathrm{Bu}$ & $\operatorname{lax} 88-\mathrm{M} 16 \times$ & & & & \\
\hline & SS21 & 12 & \multirow{7}{*}{59} & \multirow{7}{*}{3.70} & & $\begin{array}{l}\text { Austenitic } \\
\text { EN } 1.4404\end{array}$ & \multirow{7}{*}{8} & \multirow{7}{*}{$1 \mathrm{D}$} & $\begin{array}{c}14- \\
3.9 / 5.5\end{array}$ & $6.1 / 8.5$ \\
\hline & SS22 & 12 & & & Bumax 88 & $\begin{array}{c}\text { Ferritic } \\
\text { EN } 1.4003\end{array}$ & & & $\begin{array}{c}14- \\
3.5 / 5.0\end{array}$ & $5.6 / 7.7$ \\
\hline & SS23 & 12 & & & DUtmas ó & $\begin{array}{c}\text { Duplex } \\
\text { EN } 1.4462\end{array}$ & & & $\begin{array}{c}14- \\
3.9 / 5.8\end{array}$ & $6.1 / 8.7$ \\
\hline & SS24 & 3 & & & & $\begin{array}{c}\text { Lean Duplex } \\
\text { EN } 1.4162\end{array}$ & & & $\begin{array}{c}14- \\
4.9 / 5.5\end{array}$ & $7.3 / 8.5$ \\
\hline & SS26 & 2 & & & \multirow{3}{*}{ Bumax 109} & $\begin{array}{l}\text { Austenitic } \\
\text { EN 1.4404 }\end{array}$ & & & $\begin{array}{c}14- \\
5.7 / 6.6\end{array}$ & $9.2 / 10.3$ \\
\hline & SS27 & 2 & & & & $\begin{array}{c}\text { Ferritic } \\
\text { EN } 1.4003\end{array}$ & & & $\begin{array}{c}14- \\
4.2 / 4.9\end{array}$ & $6.2 / 7.4$ \\
\hline & SS28 & 12 & & & & $\begin{array}{c}\text { Duplex } \\
\text { EN } 1.4462\end{array}$ & & & $\begin{array}{c}55- \\
4.2 / 5.6\end{array}$ & $6.4 / 8.6$ \\
\hline
\end{tabular}

Figure 2-34: Test Matrix and Results of Fastener Assembly Preload Loss (Afzali et al., 2017)

Williams et al. (2017) conducted a study on behalf of the Virginia Department of Transportation to compare the mechanical properties of stainless steel fasteners for use with ASTM A1010 stainless steel plates in preparation for the construction of Route 340 bridge project in Waynesboro, 
Virginia. The project allowed for the use of $22 \mathrm{~mm}$ diameter (7/8") stainless steel fasteners with a minimum tensile strength of $690 \mathrm{MPa}(100 \mathrm{ksi})$. The required minimum bolt tension for this project was specified to be $134 \mathrm{kN}$ (30 kips) per bolt instead of the $174 \mathrm{kN}$ (39 kips) traditionally used for A325 bolts. ASTM A193 B8 stainless steel fasteners were tested under tension, their yielding strength ranged from 758-827 MPa (110-120 ksi) and their ultimate strength ranged between 930$965 \mathrm{MPa}$ (135-140 ksi). Incremental rotational testing was performed on B8, B8M, and B6 stainless steel fasteners, as well as, plain A325 and galvanized A325 carbon alloy fasteners. Williams et al. (2017) observed that the recorded torques were higher due to friction of the stainless steel nut grinding into the stainless steel washer. Hence, for this reason it was recommended to use hardened stainless steel washers instead. Measurement for the angle of rotation began after snug tight condition was achieved. The observation was that stainless steel fasteners had lower tension values than plain carbon steel fasteners at high angles of rotation. B8 and B6 fasteners developed the highest tension values up to $150^{\circ}$ of nut rotation. In comparison, the tension in A325 galvanized and plain fasteners greatly increased between $125^{\circ}$ and $250^{\circ}$. The study also noted that higher torque was required for the B6 and B8 stainless fasteners to reach an angle of rotation, in comparison to the A325 fasteners.

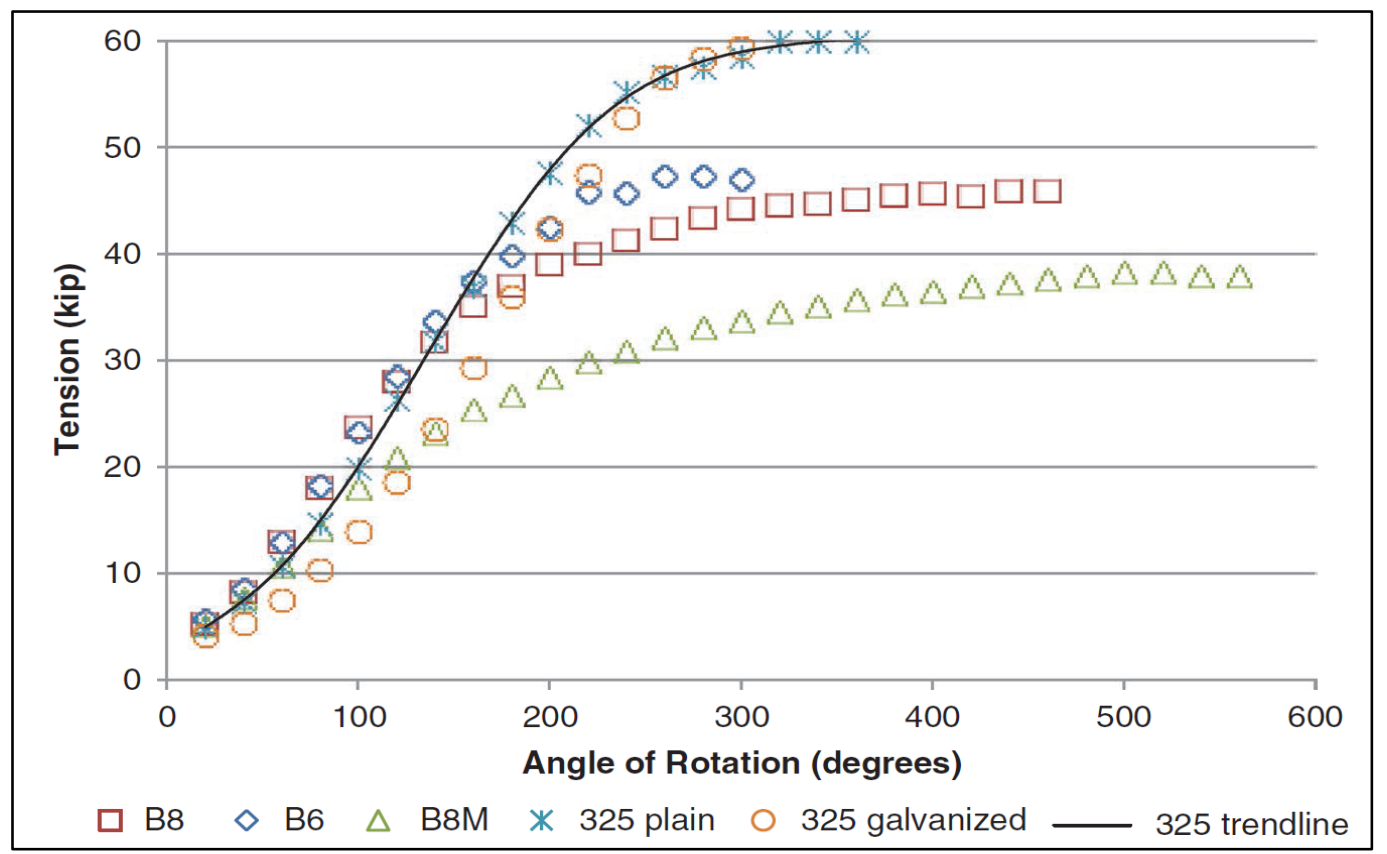

Figure 2-35: Tension development due to the angle of rotation for common stainless and carbon alloyed fasteners (Williams et al., 2017) 


\subsection{ASTM A1010 Tensile Testing Literature Review}

As previously mentioned, ASTM A1010/A1010M - Standard Specification for Higher-Strength Martensitic Stainless Steel Plate, Sheet, and Strip (ASTM, 2013b) describes the main two grades of this particular stainless steel. Grade 40 should have minimum yield strength of $275 \mathrm{MPa}$ (40 ksi) and a minimum tensile strength of 455 (66 ksi). Whereas, Grade 50 should have a minimum yield strength of $345 \mathrm{MPa}(50 \mathrm{ksi})$ and a minimum tensile strength of $485 \mathrm{MPa}$ (70 ksi). For both grades of A1010 stainless steel, the requirements for the minimum elongation in $50 \mathrm{~mm}(2$ ") is 18\% (ASTM, 2013b). ASTM A709 - Standards Specification for Structural Steel for Bridges (ASTM, 2019b) covers stainless steel for structural plates that are intended for use in bridges under Grade 50CR which stands for Grade 50 Corrosion Resistant. ASTM A709 50CR requires a minimum yield strength of $345 \mathrm{MPa}(50 \mathrm{ksi})$ and a minimum tensile strength of $485 \mathrm{MPa}$ (70 ksi). Both of these strengths are similar to ASTM A1010-13 (ASTM, 2013b) and should be measured in accordance with $0.2 \%$ offset or $0.5 \%$ extension under load as described in ASTM A370 (ASTM, 2019a). ASTM A709 50CR requires a minimum $50 \mathrm{~mm}$ (2”) elongation of $21 \%$ for plates and bars while the minimum $200 \mathrm{~mm}$ (8") elongation is $18 \%$ which is similar to that of ASTM A1010 (ASTM, 2013b). Both standards do not specify a minimum area reduction.

Daghash et al. (2019) conducted several tensile tests of ASTM A1010 stainless steel to determine its properties. The experimental study designed three-plate type specimens in accordance with ASTM E8 (ASTM, 2016) with a gauge length of $200 \mathrm{~mm}$ and a thickness of 12.5, 25, and $44 \mathrm{~mm}$, respectively. The rolling direction was oriented parallel to that of the tensile stress for all three of these specimen types. Daghash et al. also tested specimens with the rolling direction perpendicular to that of the tensile stress. These specimens were designed as a sheet-type specimen with a thickness of $12.5 \mathrm{~mm}$ and a gauge length of $50 \mathrm{~mm}$. All specimens were tested in accordance to ASTM E8 specification with a crosshead strain rate speed of $0.015 \mathrm{~mm} / \mathrm{mm}$ of the total length of the reduced section per minute in order to determine the yield point and then the speed was increased gradually to $13.5 \mathrm{~mm} / \mathrm{min}$ up until failure for the specimens with $200 \mathrm{~mm}$ gauge length. For the specimens with a gauge length of $50 \mathrm{~mm}$, the yield point was tested similarly with a strain rate of $0.015 \mathrm{~mm} / \mathrm{mm} / \mathrm{min}$, however, after the yield point and until failure the speed of the crosshead was increased gradually to $3.42 \mathrm{~mm} / \mathrm{min}$. The study used a video extensometer with a rate of $10 \mathrm{~Hz}$. The results obtained show average yield stresses of 315.8, 360.6, and 412.3 MPa for 
specimens tested parallel to the rolling direction with a thickness of $12.5,25,44 \mathrm{~mm}$, respectively; the average tensile strengths achieved for these specimens were 464.7, 515.1, and 568.8 $\mathrm{MPa}$, respectively. On the other hand, the $12.5 \mathrm{~mm}$ thick specimen tested perpendicularly to the rolling direction showed a higher average yield strength of $355.8 \mathrm{MPa}$ and a higher average tensile strength of 528.1 MPa. The study also observed that the fracture elongation decreases with an increase in plate thickness. The values obtained for specimens of 12.5, 25, and $44 \mathrm{~mm}$ thick were $25.6 \%, 24.7 \%$, and $24.2 \%$, respectively. Whereas, the average fracture elongation of the $12.5 \mathrm{~mm}$ specimen tested perpendicular to the rolling direction was higher at $32.8 \%$. Daghash et al. also observed a linear elastic behavior with a rounded yield point followed by considerable strainhardening as shown in Figure 2-36.

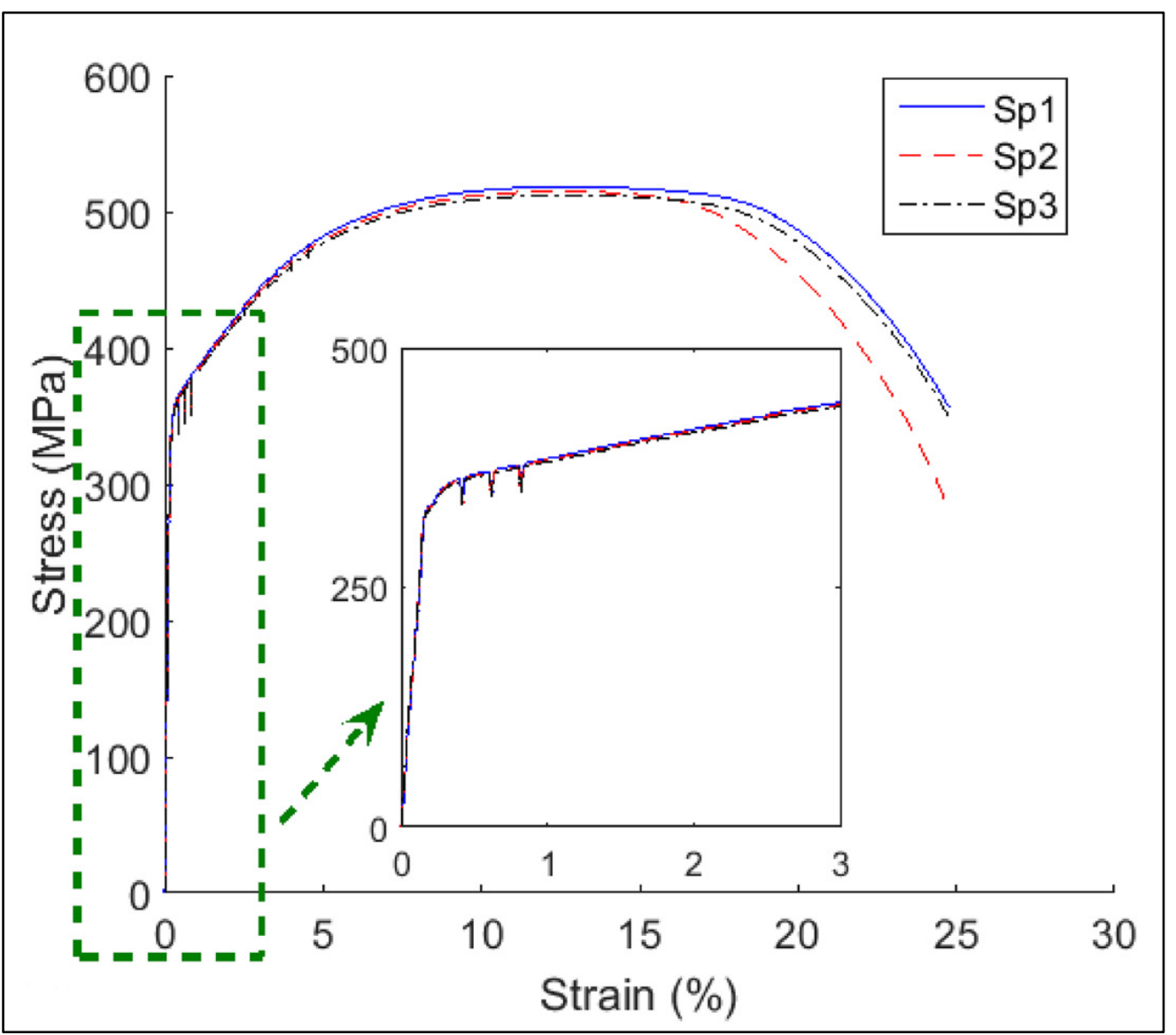

Figure 2-36: Stress-Strain Curve of 25 mm Thick ASTM A1010 (Daghash et al., 2019) 


\subsubsection{Fracture Modes of ASTM A1010 Literature Review}

Daghash et al. (2019) observed that the A1010 specimens tested under tensile loading experienced necking followed by several lines of delamination in the parallel to the applied load and a small fracture perpendicular to this load in between the delamination as depicted in Figure 2-37. Provines et al. (2019) experienced similar fracture failures during their tests. However, they claim that the delamination occurred just before the final fracture, within $1 \%$ strain, therefore they should not be a major concern for design. Figure 2-38 shows view of observed delamination of A1010 steel specimen along with necking and perpendicular fracture.

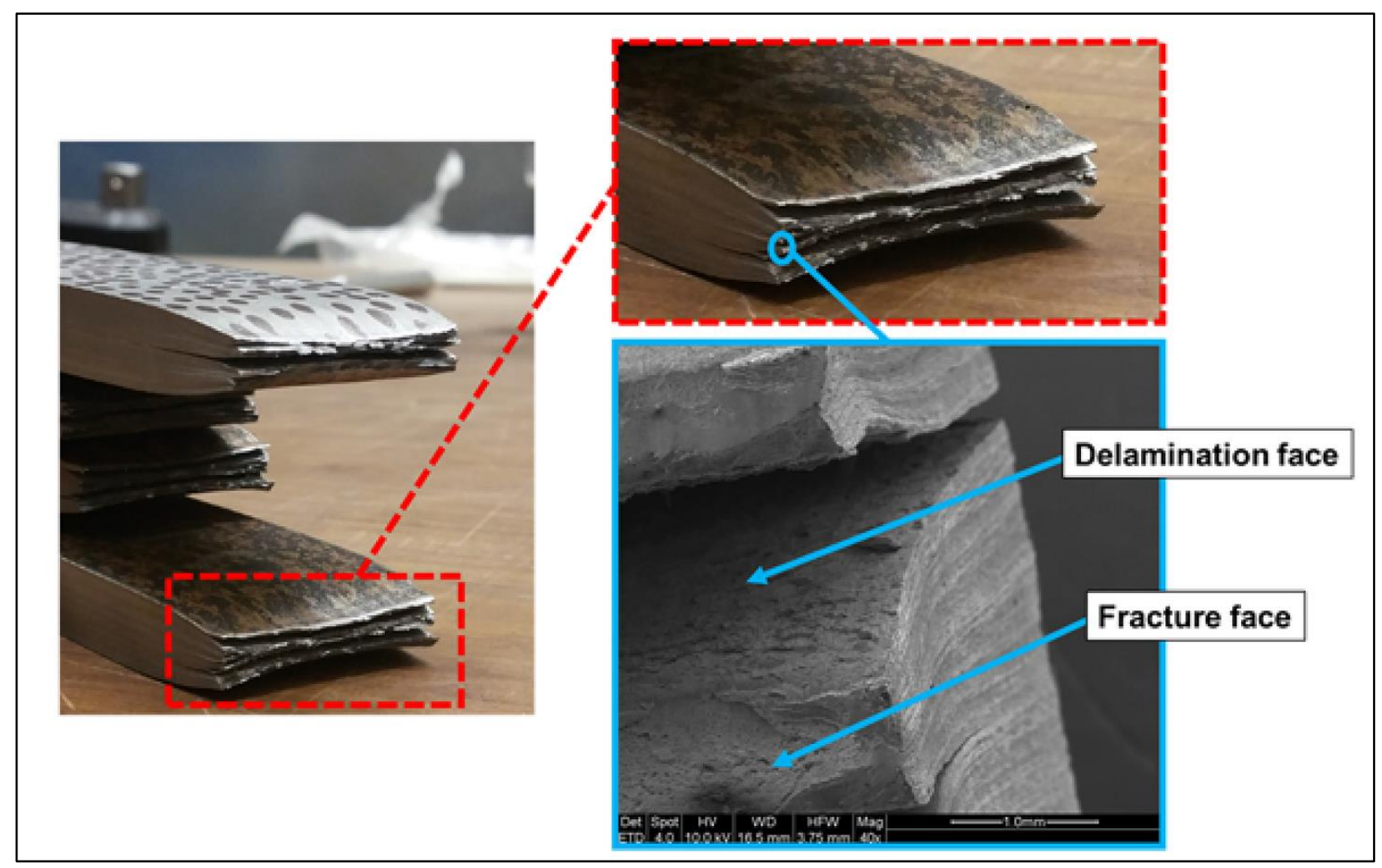

Figure 2-37: Delaminated Fracture of A1010 Tensile Specimen (Daghash et al. 2019) 


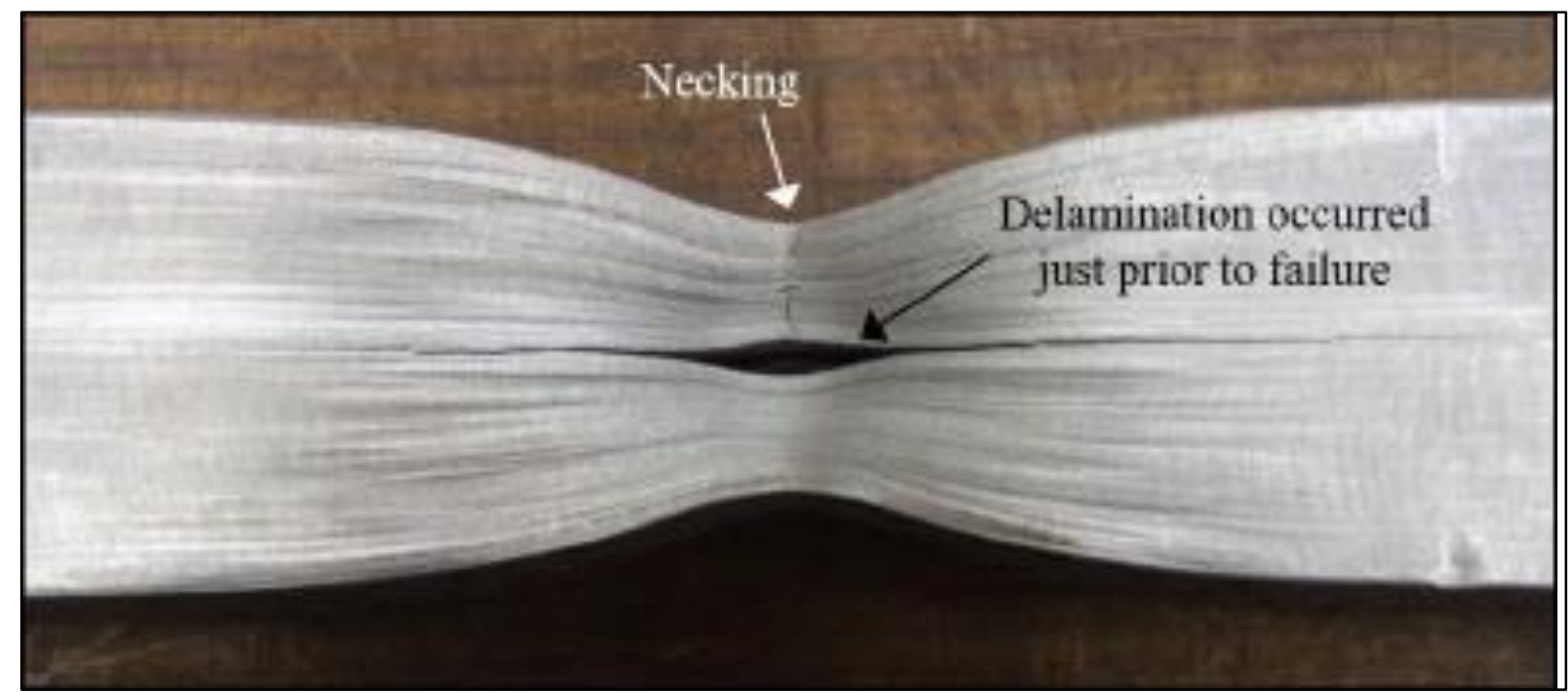

Figure 2-38: Delamination Showing Perpendicular Fracture. (Provines et al., 2019)

Seradj (2010) also reported on a similar fracture, as shown in Figure 2-39, for welded transverse tensile samples which showed the delamination just before fracture. The samples were inspected by ultrasonic testing and showed no indication of lamellar tearing.

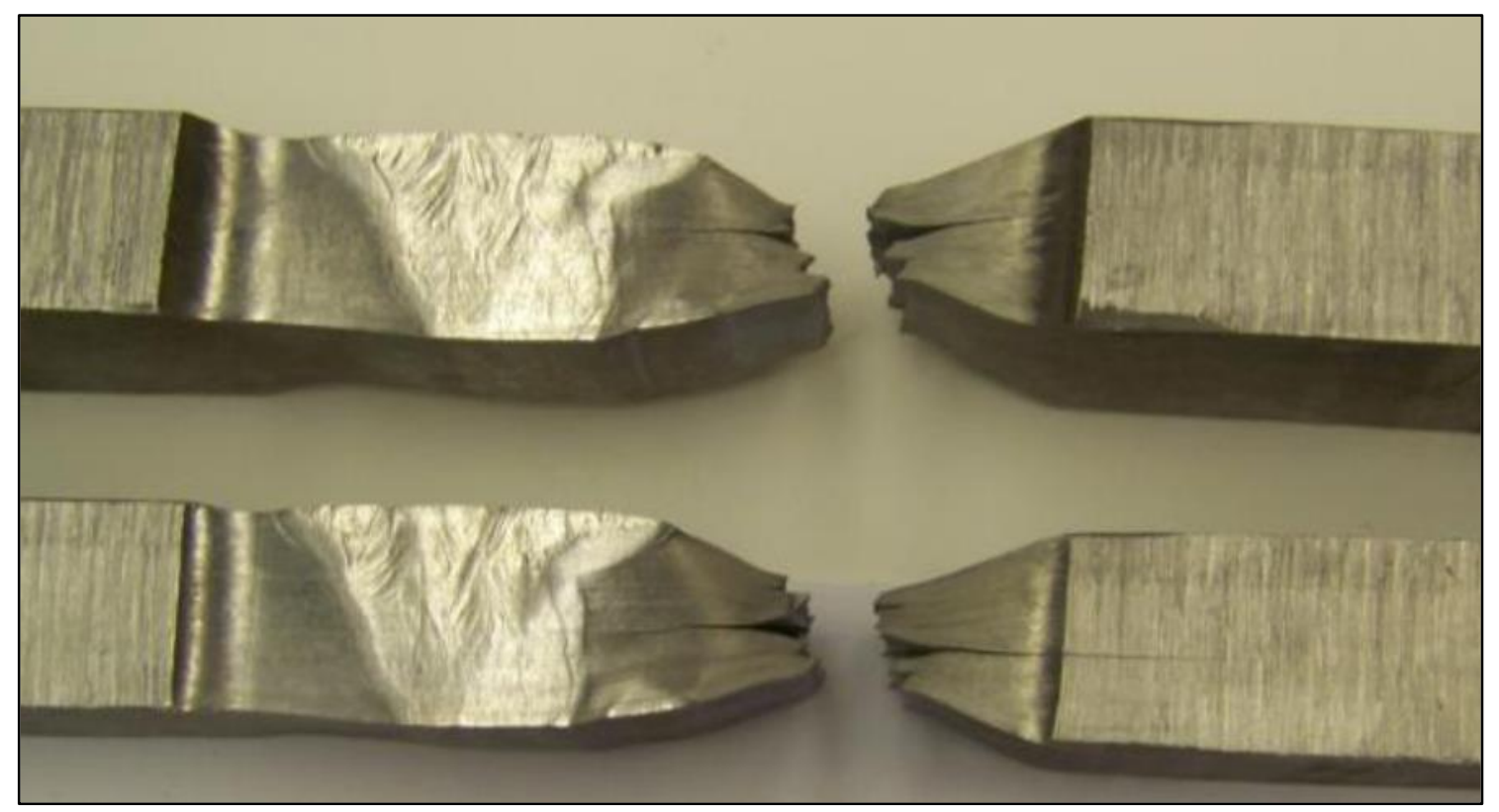

Figure 2-39: Welded A1010 Transverse Tensile Samples (Seradj, 2010)

Taban et al. (2009) experienced similar delamination along the direction of the applied load during testing of welded ferritic stainless steel containing $12 \%$ Chromium, which is similar to that of A1010. The delamination fracture that occurred on the base metal, shown in Figure 2-40, is 
attributed to de-cohesion along the ferrite-martensite grain boundary. Taban et al. claim that this sort of delamination is common in literature amongst low chromium stainless steels.

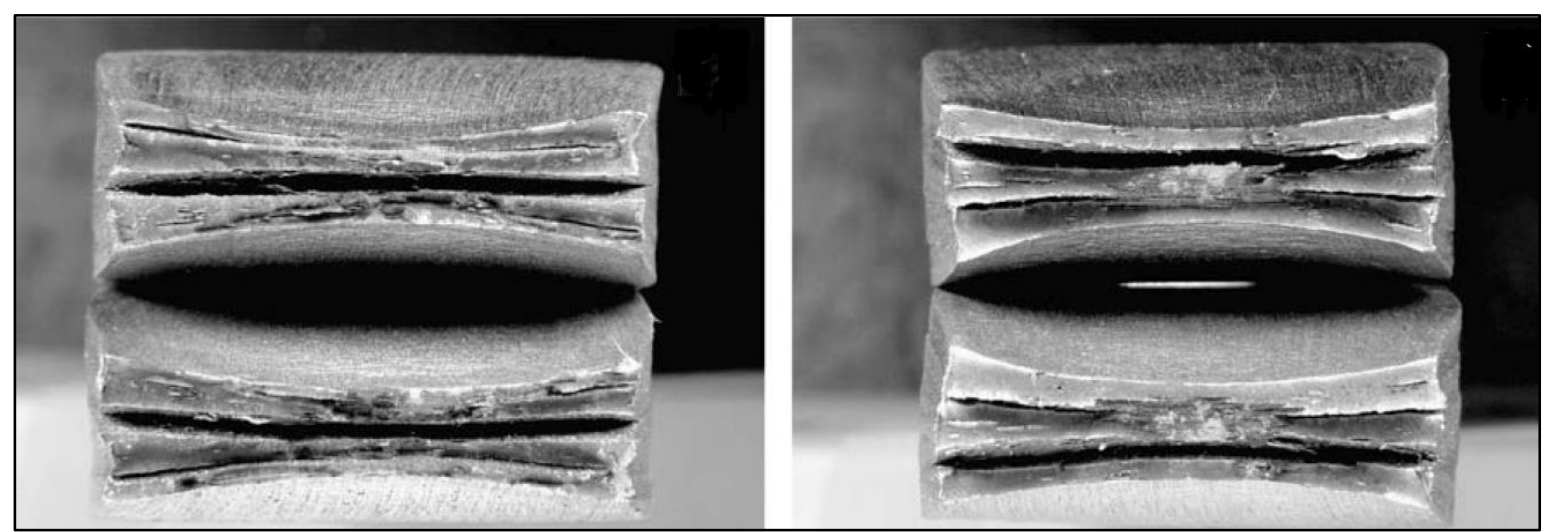

Figure 2-40: Tensile Fracture of $12 \%$ Cr Stainless Steel (Taban et al., 2009).

\subsection{Fatigue Literature Review}

\subsubsection{A Brief Introduction to Fatigue}

The generally accepted definition of fatigue is that it is the initiation and propagation of microscopic cracks by repeatedly applied loads. The continuous propagation of the crack becomes severe enough that it results in the reduced cross-section of a structural member to be incapable of sustaining the designed loading. The nature of the crack growth can be explained through fracture mechanics; the crack opens a certain distance when stress is applied, the stress that the opened area would have carried is diverted to the uncracked area which creates a high concentration of stress near the crack tip. This, in turn, causes the crack to propagate further (Fisher et al. 1998). Fatigue failures have been very problematic and are very common in all applications that experience high cyclic loading. An interesting fact about fatigue is that the magnitude of applied stress in which a failure can occur can be much lower than the yield strength of a metal, provided that the number of loading cycles is large enough. In civil engineering, bridges are some of the most common structures in which fatigue cracks are expected to occur due to traffic loads occurring periodically at various magnitudes (Fisher et al., 1998; Mertz, 2015).

The general consensus of fatigue for structures is that the grade of steel does not have any direct correlation to fatigue resistance, hence it has been ignored in many of the current design standards 
(Chen, 2005). Instead, the tensile residual stresses play a major factor in fatigue resistance (Fisher et al., 1998). What is more important is the steel microstructure for non-welded details which can influence fatigue resistance. An increase in fatigue resistance correlates very well in structure design details that minimize flaws and high-stress concentrations (Chen et al., 2005; Stephens et al., 2001). Details prone to fatigue cracks need to be avoided wherever possible, however, during fabrication and erection of steel structures, it is nearly impossible to fully avoid flaws such as cracks or discontinuities. One major discontinuity occurs on welded metals which are extensively used in all structures to piece together a large element. Welding details are most prone to having discontinuities due to flaws such as lack of weld penetration, porosity, undercuts, lack of fusion or penetration, slag inclusion, or cracks that usually come about as a result of improper welding procedures. Eliminating every little weld defect is said to be almost impossible from a practical and financial point of view (Kulak and Smith, 1993).

\subsubsection{Design Detail Classifications}

The design detail classification method is based on three major characteristics of fatigue design which are stress range, fatigue life, and type of design detail. Fatigue life curves (S-N curves) are arranged into different categories on a graph based on the structural detail type. Usually, the curves are represented with the stress range on the $y$-axis and design life on the $x$-axis of the graph. These graphs are usually on a logarithmic scale in order to have a linear representation of the curves (Mertz, 2015). The sloping straight lines that represent the detail category are based on historical experimental data. These lines represent the fatigue resistance of a particular detail at a $95 \%$ or $97.5 \%$ survival probability ( 2 standard deviations below the mean fatigue life). Since fatigue data points are heavily scattered, these confidence intervals are key in ensuring a safe design life prediction (Vilhauer, 2007; Tehrani, 2012). Both Canadian (CSA S16-14) and American (AASHTO LRFD) bridge codes establish 8 curves based on various detail design categories increasing in severity. These are the following: A, B, B', C, C', D, E, and E' for AASHTO LRFD and A, B, B1, C, C1, D, E, and E1 for CSA S16-14. The curves in the American code have a linear slope of 3 throughout the finite and infinite life portions of the graph. While the Canadian code

specifies the curves with a slope of 3 on the finite portion of the graph and a slope of 5 on the infinite portion of the graph. These curves have been derived from a large number of experimental 
tests that began in the 1960s and were funded by the National Cooperative Highway Research Program (NCHRP) in the United States (Fisher et al., 1998).

All detail category curves have the following equations:

$N=\frac{A}{\Delta \sigma_{R}{ }^{3}}$

Where $\mathrm{N}$ is the number of cycles, $\mathrm{A}$ is fatigue life constant and $\mathrm{S}_{\mathrm{R}}$ is the stress range.

The equation can also be represented in the log-log format:

$\log N=\log A-m \cdot \log \Delta \sigma_{R}$

Where $\mathrm{N}$ is the number of cycles, $\mathrm{A}$ is the fatigue life constant corresponding to each detail, $\mathrm{m}$ is the slope of the graph which is 3 and $\Delta \sigma_{\mathrm{R}}$ is the stress range.

Equation 2.5 is derived specifically from basic fracture mechanic analysis of fatigue by integrating the crack growth law equation with the limits of the initial and final crack length and substituting the change in stress intensity factor equation (Fisher et al., 1998).

Crack growth law in expressed by the following equation:

$\frac{d a}{d N}=A \Delta K^{m}$

Where $\mathrm{a}$ is the crack length, $\mathrm{N}$ is the number of cycles, $\mathrm{A}$ and $\mathrm{m}$ are constants determined from regression analysis of the experimental data. $\Delta \mathrm{K}$ is the change in stress intensity factor on a given change in stress range as follows.

$\Delta K=W Y \Delta \sigma \sqrt{\pi a}$

Where $\mathrm{W}$ is the correction factor for non-uniform local stress fields caused by residual stresses, stress concentrations, and stress gradients; $\mathrm{Y}$ is an expression that corrects the plate and crack geometry; $a$ is the crack length; and $\Delta \sigma_{\mathrm{R}}$ is the stress range.

Integrating equation 2.6 to express it in terms of crack growth propagation results in the following equation for the number of fatigue cycles: 
$N=\frac{1}{A} \int_{a_{i}}^{a_{f}} \frac{1}{\Delta K^{m}} d a$

Where $a_{\mathrm{f}}$ is the final length of the crack and $a_{i}$ is the initial crack length.

Substituting equation 2.7 in equation 2.8 and performing the integration results in equation 2.4. The reason for this is as follows. Due to crack sizes being very large compared to the initial crack size, any term with af can be neglected. The terms W and Y vary with crack length, however, for a known geometry and initial crack size, these terms within the integral also become constants. Therefore, all of these constant terms are given what is known as the fatigue life constant (A) in equation 2.4. The final result of the integration after applying all these rules would be exactly the same as equation 2.4; that is $\mathrm{N}=\mathrm{A} / \Delta \sigma^{\mathrm{m}}$.

Both the American and Canadian bridge codes have almost the same fatigue life constants and constant amplitude stress range. This can be observed on Table 2-8 and Table 2-9 on the next page. Another slight difference between the codes in terms of fatigue is that the American code has a slope of 3 for their fatigue curves throughout all stress ranges. On the other hand, the Canadian code has a slope of 5 for all curves below the constant amplitude threshold stress range.

Table 2-8: Constant Amplitude Threshold Stress Range \& Fatigue Life Constant Specified in the Canadian Highway Bridge Design Code (CSA, 2014a)

\begin{tabular}{|c|c|c|c|}
\hline Detail Category & $\begin{array}{c}\text { Constant Amplitude } \\
\text { Threshold Stress } \\
\text { Range, Frt, MPa }\end{array}$ & $\begin{array}{c}\text { Fatigue Life } \\
\text { Constant, } \boldsymbol{\gamma}\end{array}$ & $\begin{array}{c}\text { Fatigue Life } \\
\text { Constant, } \boldsymbol{\gamma}\end{array}$ \\
\hline A & 165 & $8190 \times 10^{9}$ & $223 \times 10^{15}$ \\
\hline B & 110 & $3930 \times 10^{9}$ & $47.6 \times 10^{15}$ \\
\hline B1 & 83 & $2000 \times 10^{9}$ & $13.8 \times 10^{15}$ \\
\hline C & 69 & $1440 \times 10^{9}$ & $6.86 \times 10^{15}$ \\
\hline C1 & 83 & $1440 \times 10^{9}$ & $9.92 \times 10^{15}$ \\
\hline D & 48 & $721 \times 10^{9}$ & $1.66 \times 10^{15}$ \\
\hline E & 31 & $361 \times 10^{9}$ & $0.347 \times 10^{15}$ \\
\hline E1 & 18 & $128 \times 10^{9}$ & $0.0415 \times 10^{15}$ \\
\hline
\end{tabular}


Table 2-9: Constant Amplitude Threshold and Detail Category Constant Specified in the AASHTO LRFD Bridge Design Specifications (AASHTO, 2017)

\begin{tabular}{|c|c|c|}
\hline Detail Category & $\begin{array}{c}\text { Constant Amplitude } \\
\text { Fatigue Threshold, } \mathbf{M P a}\end{array}$ & $\begin{array}{c}\text { Detail Category Constant, } \\
\mathbf{A}, \mathbf{M P a}^{\mathbf{3}}\end{array}$ \\
\hline A & 165.0 & $82.0 \times 10^{11}$ \\
\hline B & 110.0 & $39.3 \times 10^{11}$ \\
\hline B' & 82.7 & $20.0 \times 10^{11}$ \\
\hline C & 69.0 & $14.4 \times 10^{11}$ \\
\hline C' & 82.7 & $14.4 \times 10^{11}$ \\
\hline D & 48.3 & $7.21 \times 10^{11}$ \\
\hline E & 31.0 & $3.61 \times 10^{11}$ \\
\hline E & 17.9 & $1.28 \times 10^{11}$ \\
\hline
\end{tabular}

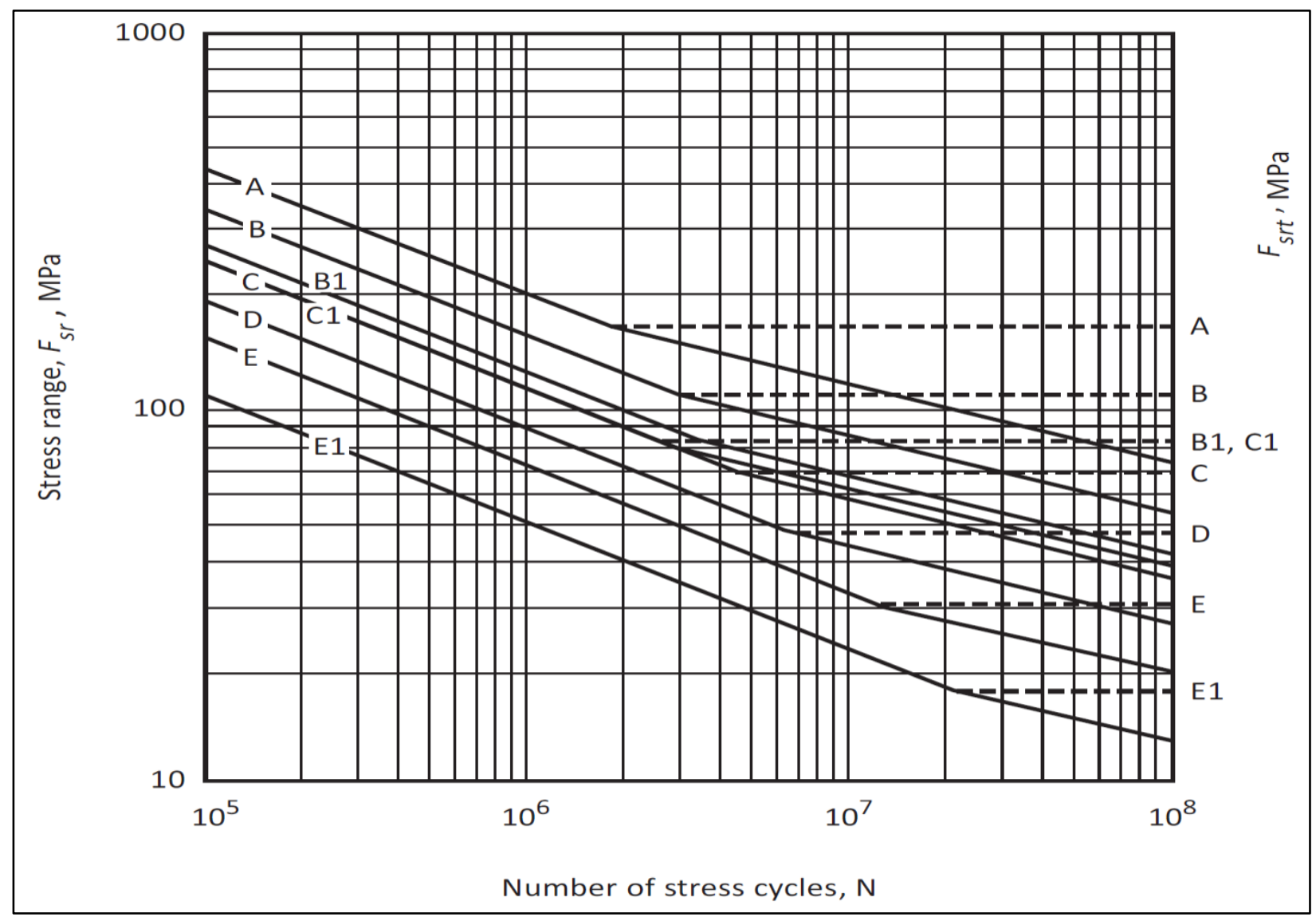

Figure 2-41: S-N Curves from the Canadian Highway Bridge Design Code (CSA, 2014a) 


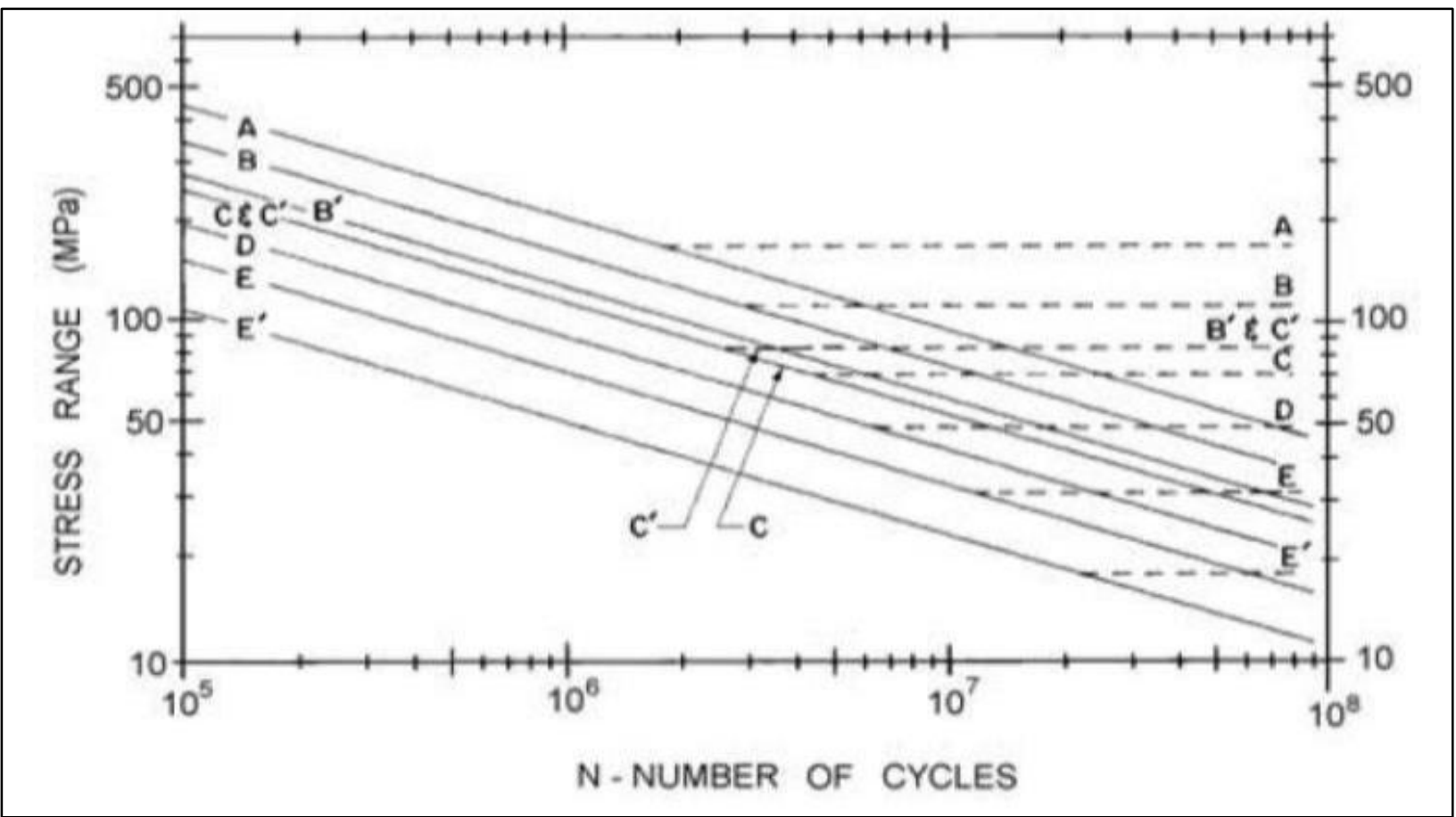

Figure 2-42: S-N Curves from AASHTO LRFD Bridge Design Specifications (AASHTO, 2017)

According to CSA S6-14, all structural components need to satisfy the requirements for the fatigue limit states (FLS) specified in Section 10.17. Direct live load effects must be included in fatigue limit state design. This includes the effect of local distortion within the members of the structure, otherwise known as distortion-induced fatigue. It is important to state that only stresses due to live load shall be used when determining the stress range of a certain component. The calculation of the stress range can be done by either elastic analysis and by using mechanics of material theory or could be done using more sophisticated analysis such as the finite element method, for detail cases that are not shown on Tables 10.7 and 10.8 of the Canadian Highway Bridge Design Code (CSA, 2014a).

Fatigue stress range resistance $\left(\mathrm{F}_{\mathrm{sr}}\right)$ of a member is calculated by using the following equation:

$F_{s r}=\left(\frac{\gamma}{N_{c}}\right)^{1 / 3}$

Where, 
$\gamma$ is a fatigue life constant that depends on the detail category. This is shown in Table 10.4 of CSA S16-14 or Table 2-8 of this report.

$\mathrm{N}_{\mathrm{c}}=365 \mathrm{yN}_{\mathrm{d}}\left(\mathrm{ADTT}_{\mathrm{f}}\right)$

$\mathrm{y}$ is the design life equal to 75 years unless otherwise specified by the Owner. $\mathrm{N}_{\mathrm{d}}$ is the number of design stress cycles experienced for each passage of the design truck specified in Table 10.5 of CSA S6-14 or as shown in Figure 2-43 of this report. ADTT $_{\mathrm{f}}$ is the average daily truck traffic for a single lane which is calculated by the following formula; $\mathrm{p}$ (ADTT); where $\mathrm{p}$ should be $1.0,0.85$, or 0.80 for the cases of one, two, or three or more lanes available to trucks, respectively. Whereas ADTT can be found in Table 10.6 of CSA S6-14 of Figure 2-43.

If the value of $\mathrm{F}_{\mathrm{sr}}$ calculated with equation 2.9, falls below the value of the constant amplitude threshold stress range $\left(\mathrm{F}_{\text {srt }}\right)$, then the following equation should be used to calculate the new fatigue resistance value, where $\gamma^{\prime}$ is the fatigue life constant for that portion of the curve:

$F_{s r}=\left(\frac{\gamma^{\prime}}{N_{c}}\right)^{1 / 5} \geq \frac{F_{s r t}}{2}$

The allowable stress range $\left(\mathrm{F}_{\text {sr }}\right)$ in equation 2.11 should not be less than $50 \%$ of the constant amplitude stress range $\left(\mathrm{F}_{\text {srt }}\right)$. The $\mathrm{F}_{\text {srt }}$ value is taken at $50 \%$ because the stress range is actually of variable amplitude (not constant amplitude) and can on occasions be twice as great as the calculated fatigue load, hence the $\mathrm{F}_{\text {srt }}$ value is limited at $50 \%$.

Table 10.5

Values of $\mathbf{N}_{\boldsymbol{d}}$

(See Clauses 10.3 .2 and 10.17 .2 .3 .1 .)

\begin{tabular}{lll}
\hline Longitudinal members & $\begin{array}{l}\text { Span length, } L, \\
\geq \mathbf{1 2} \mathbf{~ m}\end{array}$ & $\begin{array}{l}\text { Span length, } L, \\
<\mathbf{1 2} \mathbf{~ m}\end{array}$ \\
\hline $\begin{array}{l}\text { Simple-span girders } \\
\text { Continuous girders }\end{array}$ & 1.0 & 2.0 \\
$\quad$ Near interior support & 1.5 & 2.0 \\
$\quad$ (within 0.1 $L$ on either side) & 1.0 & 2.0 \\
$\quad$ All other locations & 5.0 & 5.0 \\
Cantilever girders & 1.0 & 1.0 \\
Trusses & Spacing $\geq \mathbf{6 ~ m}$ & Spacing $<\mathbf{6 ~ \mathbf { m }}$ \\
\hline Transverse members & 1 & 2 \\
\hline All cases & &
\end{tabular}

Table 10.6 Average daily truck traffic (See Clause 10.17.2.3.1.)

\begin{tabular}{lr}
\hline Class of highway & $A D T T$ \\
\hline A & 4000 \\
B & 1000 \\
C & 250 \\
D & 50 \\
\hline
\end{tabular}

Figure 2-43: Tables 10.5 and 10.6 Required for Fatigue Design from the Canadian Highway Bridge Design Code (CSA, 2014a) 


\subsubsection{Previous Relevant Fatigue Studies}

Provines et al. (2019) was the first author to perform fatigue testing on ASTM A1010 or otherwise known as ASTM A709 50CR bolted connections (Figure 2-44) as well as butt-welded coupons (Figure 2-46). Seven bolted specimens were tested at $207 \mathrm{MPa}$ (30 ksi) and two specimens were tested at $138 \mathrm{MPa}(20 \mathrm{ksi})$ stress range. The minimum stress was $20 \mathrm{MPa}$ (3 ksi) and loading was calculated using the gross cross-sectional area. The bolted fatigue specimens were designed as a double shear lap splice consisting of two $12.5 \mathrm{~mm}\left(0.5^{\prime \prime}\right)$ thick plates which were connected by two $12.5 \mathrm{~mm}$ (0.5") thick splice plates with eight $22.2 \mathrm{~mm}$ (7/8") A325 bolts which were tightened by the turn-of-nut method. The paper does not mention any details about the frequency at which the cycles were run. The results concluded that all specimens tested at $138 \mathrm{MPa}$ (20 ksi) surpassed 15 million cycles without failing. During testing, specimens failed either in fretting fatigue or net section fatigue failure. Figure 2-45 shows the 95\% regression confidence interval outperforms the AASHTO fatigue design Category B curve. Therefore, the study concludes that slip-critical bolted connections can be designed the same as regular structural steels in fatigue.

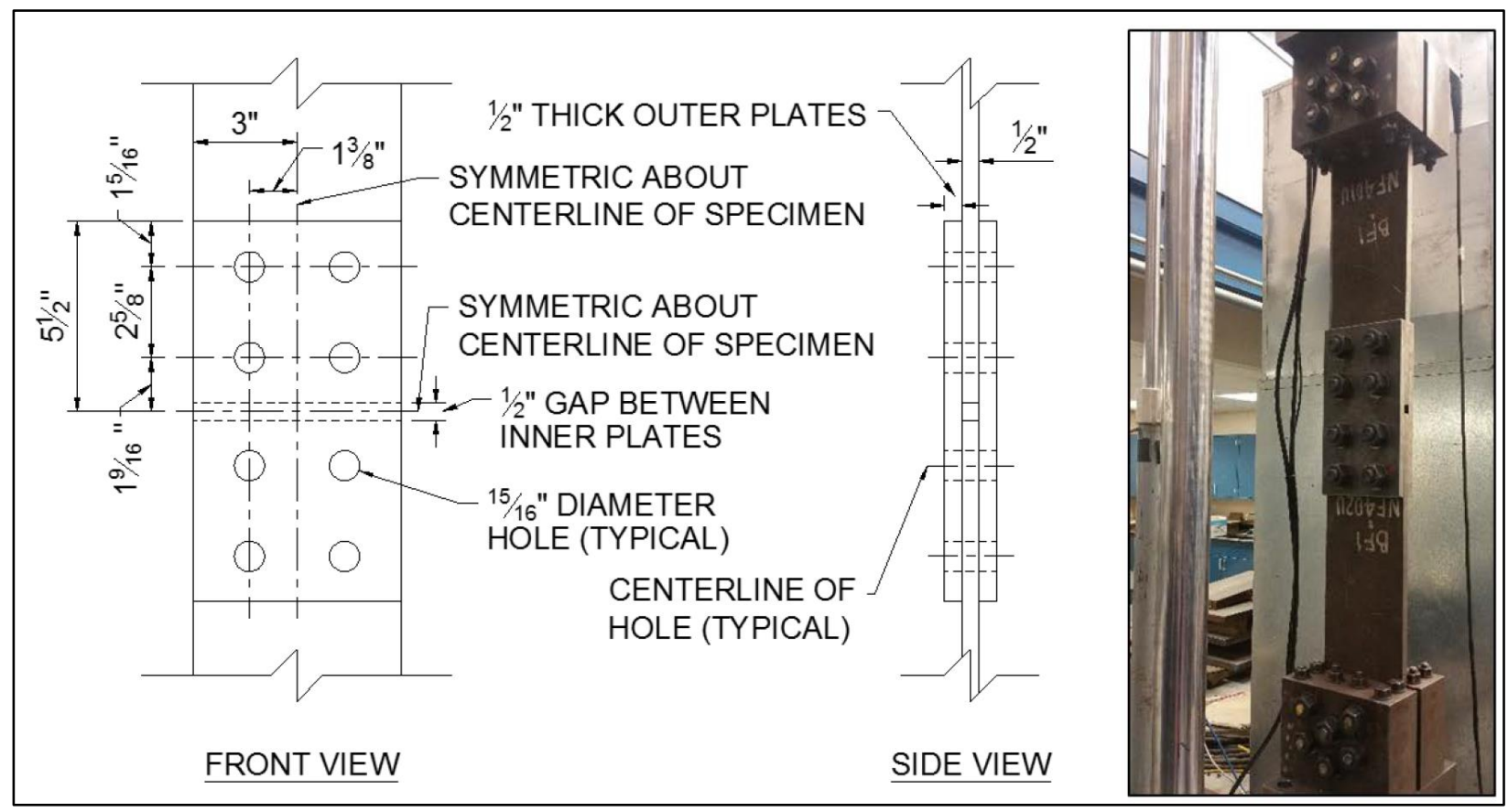

Figure 2-44: Fatigue Test Set-Up and Dimensions of Bolted Splice Connection (Provines et al. 2019) 


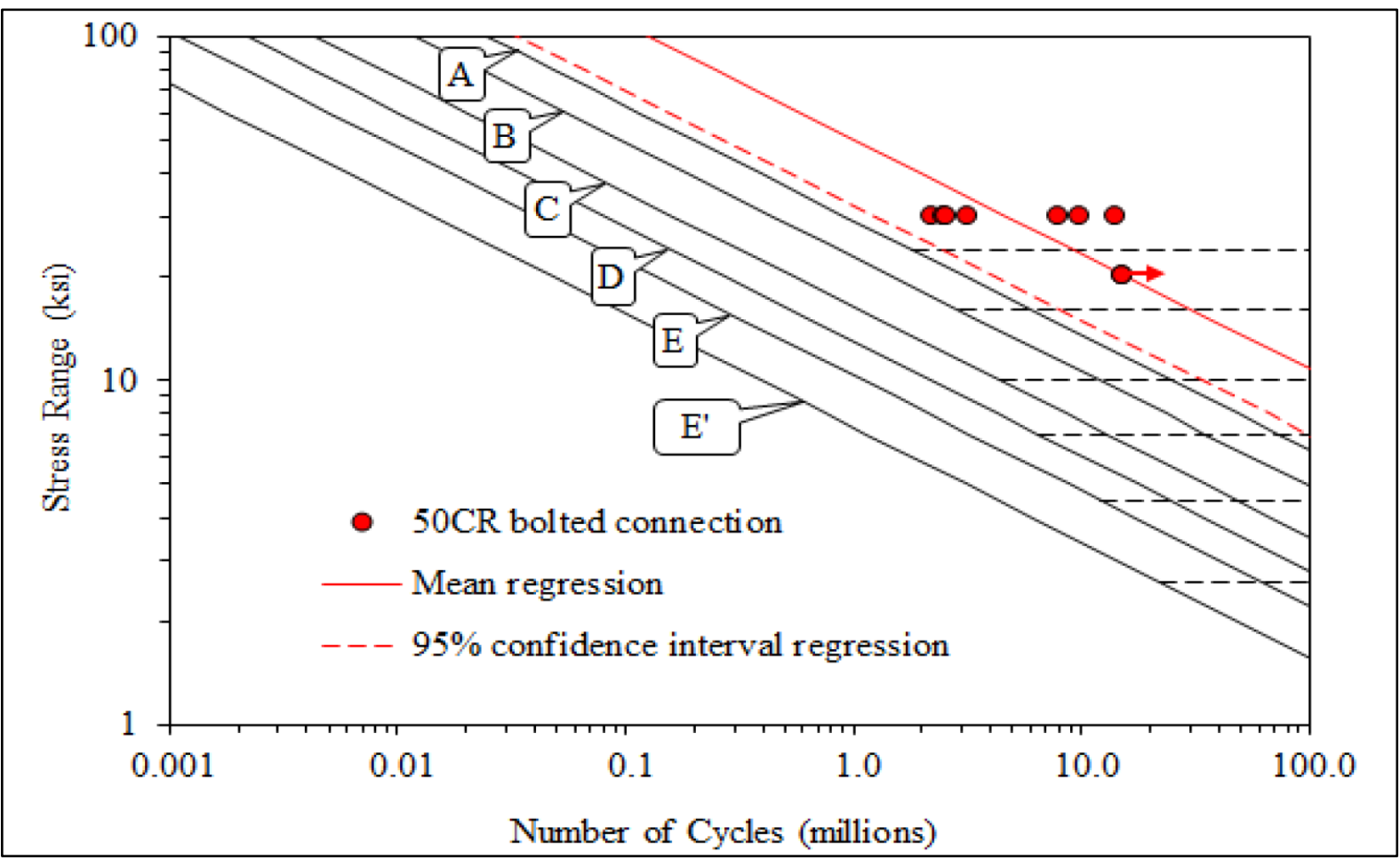

Figure 2-45: S-N Curve of A709 50CR Slip-Critical Bolted Connections (Provines et al. 2019)

Provines et al. (2019) also performed an experimental study on $12.5 \mathrm{~mm}$ (0.5”) thick welded ASTM A709 50CR stainless steel coupons designed in accordance with ASTM E466 (ASTM, 2015). The coupon, shown in Figure 2-46, was welded with complete joint penetration groove weld using the submerged arc welding (SAW) process using a one-pass weld on one side and a two-pass weld on the other side. The following welding parameters were used: welding current of 370 amps, voltage of 32 volts, $45 \mathrm{~kJ} / \mathrm{in}$. heat input, $16 \mathrm{in} / \mathrm{min}$ travel speed and a maximum interpass temperature of $300^{\circ} \mathrm{F}$. The stress ranges of the specimens varied from $138 \mathrm{MPa}(20 \mathrm{ksi}), 103 \mathrm{MPa}$ (15 ksi), and $76 \mathrm{MPa}(11 \mathrm{ksi})$. All coupons were tested with a minimum stress range of $7 \mathrm{MPa}$ (1 ksi). All fatigue tests were cycled with a frequency of 7-10 Hz. The experimental results from the study conducted by Provines et al. (2019) showed that the welded fatigue coupons fell under the Category D as depicted in Figure 2-47. This was due to the welds not meeting AWS D1.5 workmanship criteria for welds as it was not specified to conduct any NDT testing or ground smooth the welds. Therefore, the specimen came out with undercuts on their welds. 


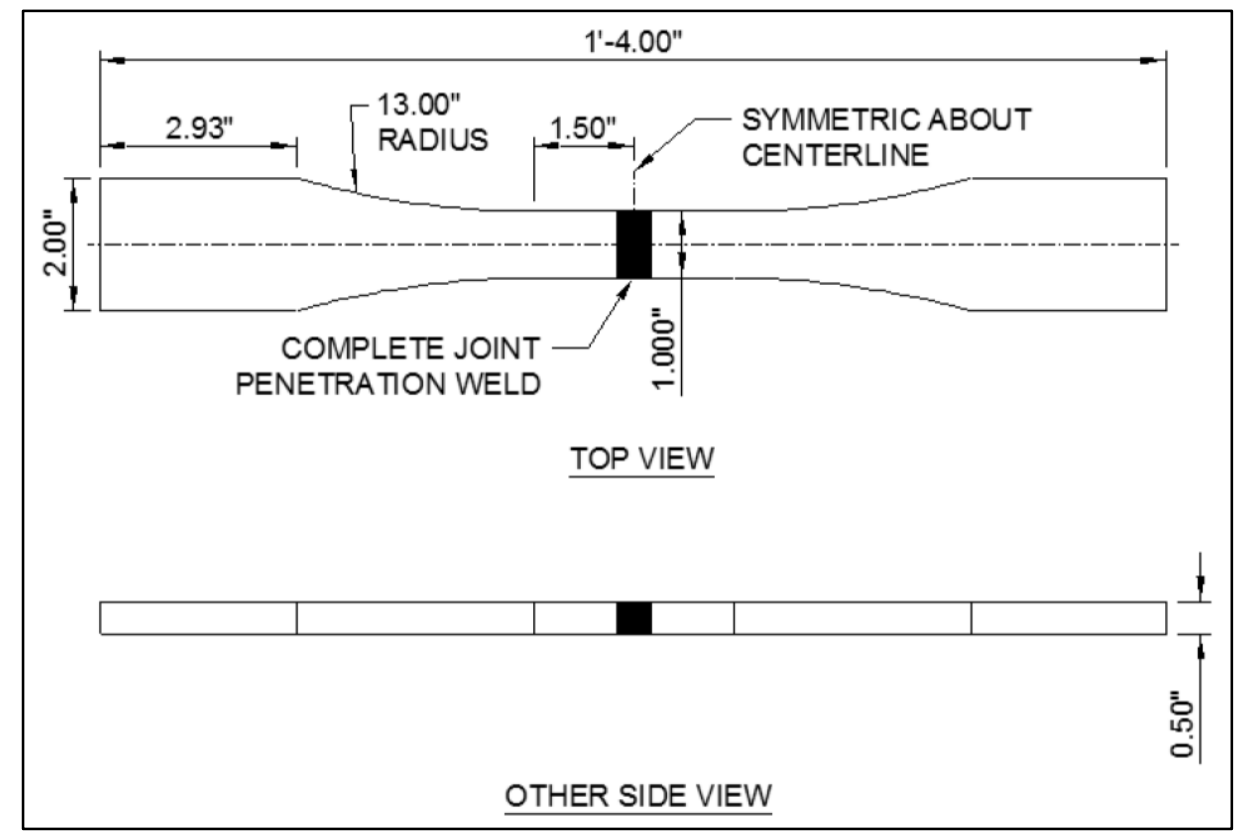

Figure 2-46: Fatigue Welded Specimen Dimensions (Provines et al. 2019)

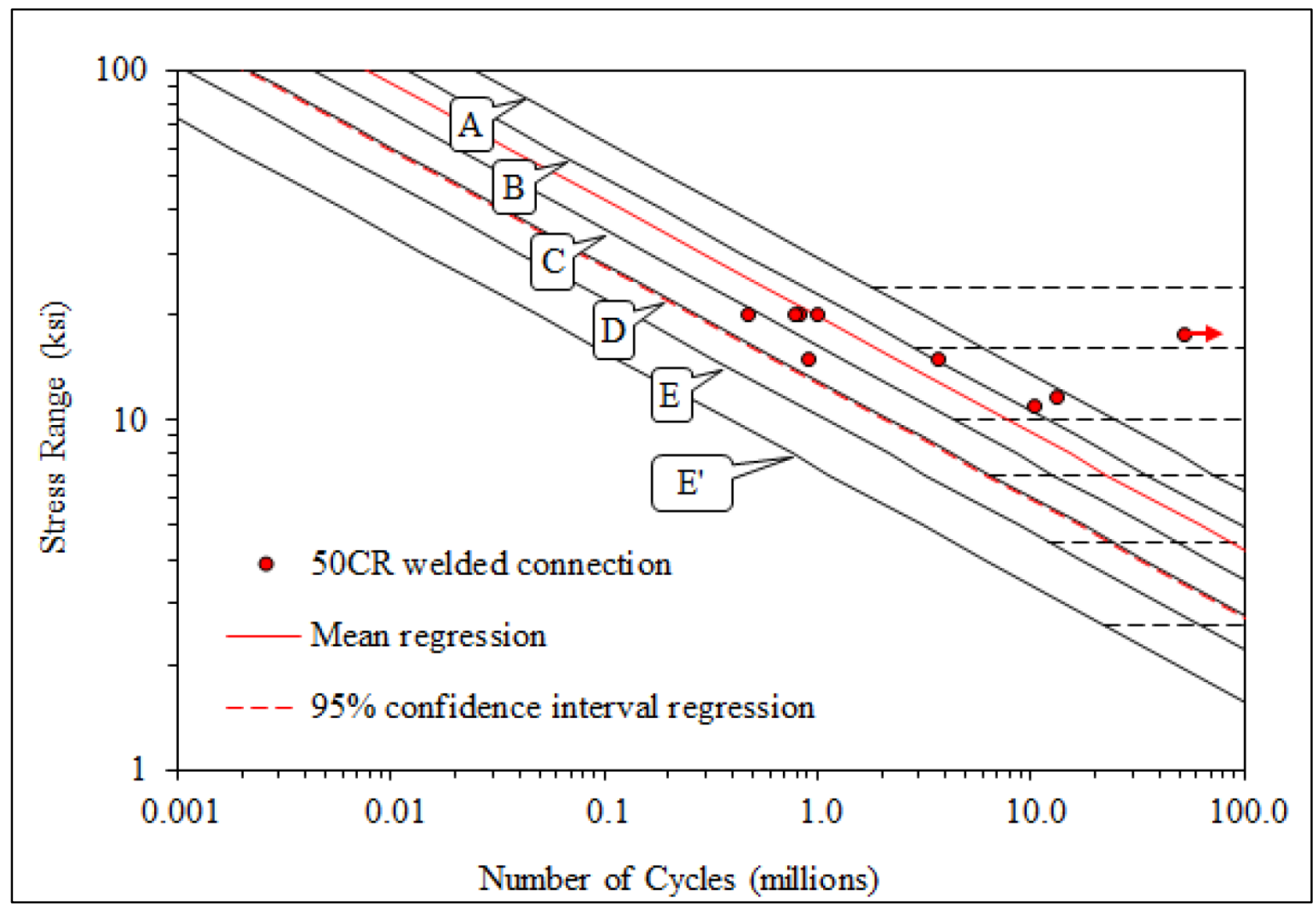

Figure 2-47: S-N Curves for Welded A709 50CR Stainless Steel Coupons (Provines et al. 2019) 
A recent report published by Iowa State University in partnership with the Iowa Department of Transportation investigated the structural behaviour of A1010 steel (Phares et al, 2020). A $52 \mathrm{ft} 9$ " long A1010 steel plate girder with a complete concrete deck was tested under four-point bending test to determine its flexural behaviour. The results of the test obtained from hand calculations matched up well with the actual laboratory testing. Flexural capacity of the A1010 composite girder were $15.4 \%$ higher than hand calculations (Phares et al. 2020). In addition to this Phares et al (2020) also carried out cyclic fatigue testing on plain A1010 coupon specimens in order to predict the stress to number of cycles to failure curve. The fatigue coupon specimens were waterjet cut in accordance to ASTM E466-15 standard. The specimen had a thickness of 0.5", a total length of 18", a reduced section length of 2", a grip length of 4", grip width of 3", a reduced section width of 1 " with a fillet radius of 8.5 " (Figure 2-48).

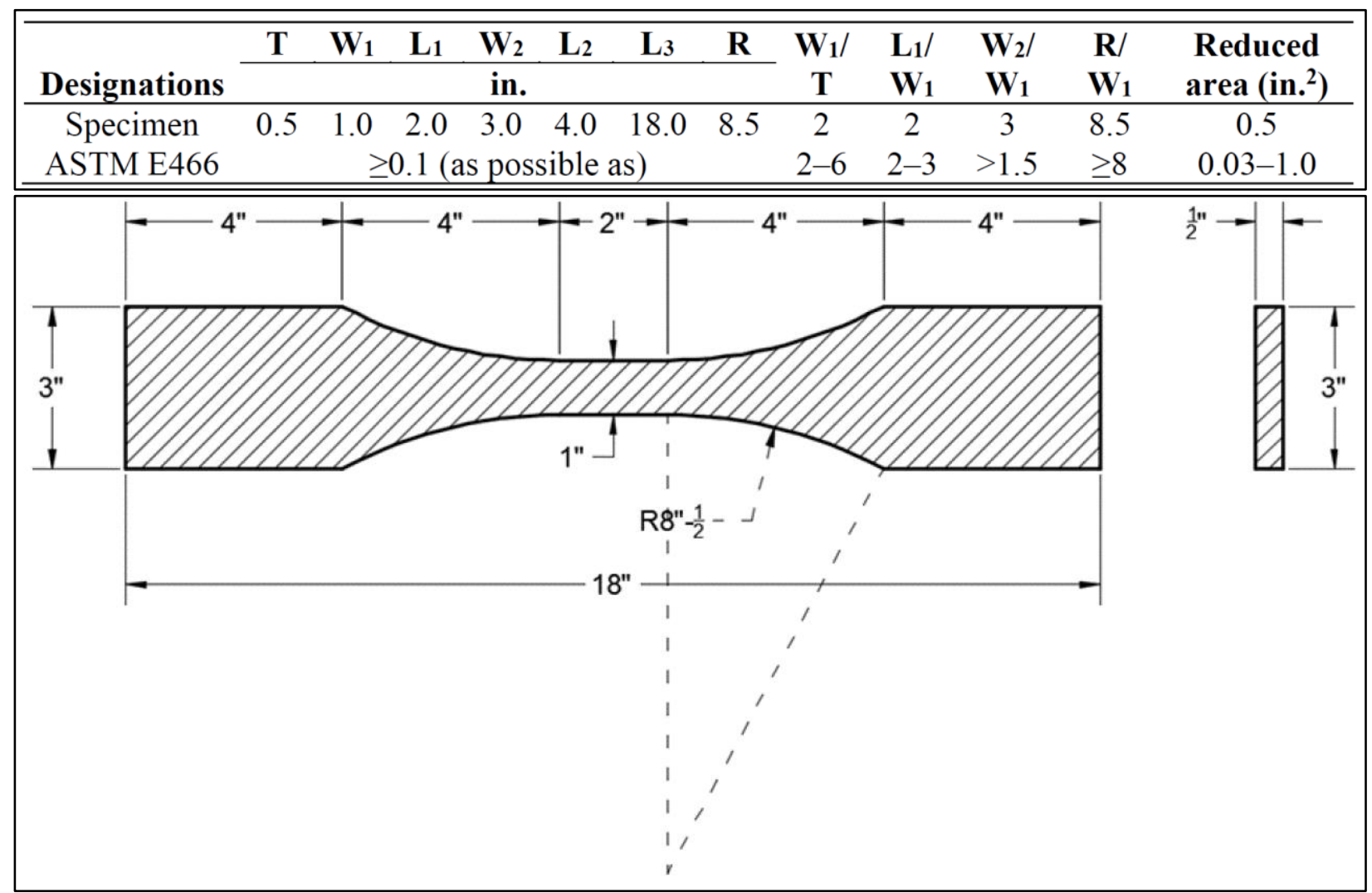

Figure 2-48: Fatigue Coupon Specimen Dimensions (Phares et al. 2020) 
All specimens were tested under stress-controlled set-up with a cyclic load that reversed from tension to compression. The stress ratio (ratio between min and max stress) used for all specimens was $\mathrm{R}=-1$ with a frequency of $8 \mathrm{~Hz}$ ( 8 cycles/second). If no failure occurred tests were terminated at 10 million cycles. The following stress-amplitudes were applied; $51 \mathrm{ksi}, 47.6 \mathrm{ksi}, 44.2 \mathrm{ksi}, 40.8$, $37.4 \mathrm{ksi}$, and $34 \mathrm{ksi}$. From the results shown on Figure 2-49, it was concluded that the fatigue limit for A1010 steel was found to be between $37.4 \mathrm{ksi}$ and $40.8 \mathrm{ksi}$. Phares et al (2020) compared the A1010 fatigue results to that of other steel types such as A7 and A709 weathering steel. It was found that A709 showed slightly higher fatigue resistance compared to A1010 steel. However, both A1010 and A709 showed higher fatigue resistance than A7 structural steel (Figure 2-50).

\begin{tabular}{|ccccccccc|}
\hline $\begin{array}{c}\text { Coupon } \\
\text { ID }\end{array}$ & $\begin{array}{c}\text { Frequency } \\
\text { (Hz) }\end{array}$ & $\begin{array}{c}\text { Stress } \\
\text { ratio }\end{array}$ & $\begin{array}{c}\text { Max } \\
\text { stress } \\
\text { (ksi) }\end{array}$ & $\begin{array}{c}\text { Min } \\
\text { stress } \\
\text { (ksi) }\end{array}$ & $\begin{array}{c}\text { Thickness } \\
\text { (in.) }\end{array}$ & $\begin{array}{c}\text { Width } \\
\text { (in.) }\end{array}$ & $\begin{array}{c}\text { Area } \\
\text { (in. }{ }^{2} \text { ) }\end{array}$ & $\begin{array}{c}\text { Load } \\
\text { cycles }\end{array}$ \\
\hline FC2-A & 8 & -1 & 47.6 & -47.6 & 0.520 & 0.990 & 0.515 & 231,991 \\
FC3-A & 8 & -1 & 40.8 & -40.8 & 0.520 & 1.001 & 0.521 & 748,801 \\
FC4-A & 8 & -1 & 34.0 & -34.0 & 0.519 & 0.999 & 0.518 & $10,000,000$ \\
FC6-A & 8 & -1 & 44.2 & -44.2 & 0.519 & 1.001 & 0.520 & 288,033 \\
FC7-A & 8 & -1 & 37.4 & -37.4 & 0.519 & 0.999 & 0.518 & $10,000,000$ \\
FC8-A & 3 & -1 & 51.0 & -51.0 & 0.523 & 1.000 & 0.523 & 124,689 \\
\hline
\end{tabular}

Figure 2-49: Table Showing Results of Fatigue Testing (Phares et al. 2020)

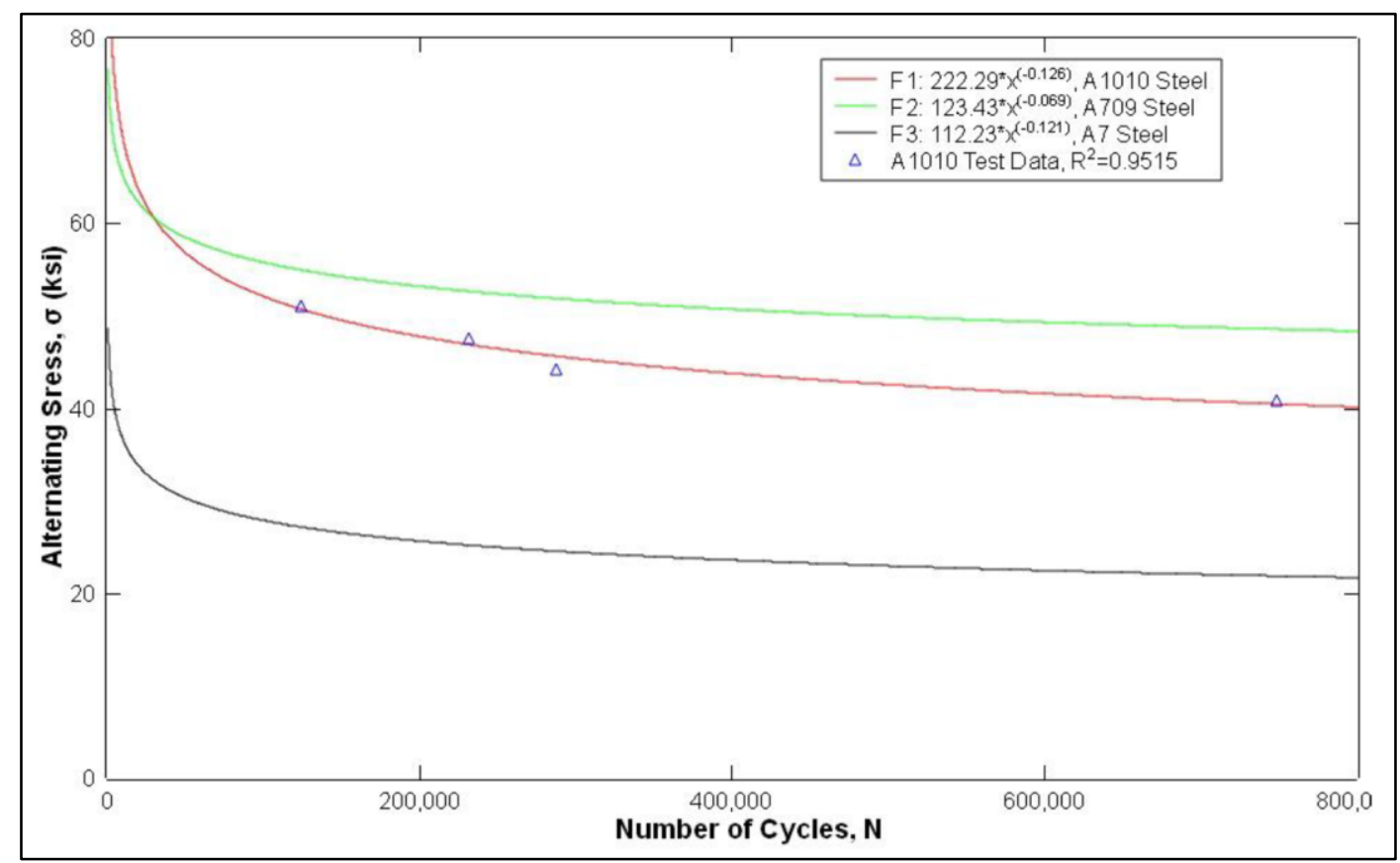

Figure 2-50: Fatigue Comparisons between A1010 and Other Steels (Phares et al. 2020) 
Ghahremani (2010) and Ghahremani and Wallbridge (2011) performed constant amplitude loading fatigue tests on CSA G40.21 350W structural steel in order to predict the effectiveness of postweld treatments. The fatigue specimens were designed as fillet welded specimens falling under CSA S6 Detail Category C and representing a transverse web stiffener. The specimen was 9.5 (3/8") thick with a reduced section width of $30 \mathrm{~mm}$, a total length of $400 \mathrm{~mm}$, and a radius of 200 $\mathrm{mm}$. The stiffener had a thickness of $9.5 \mathrm{~mm}$ and a height of $25 \mathrm{~mm}$. The FCAW welding process was used to weld the stiffener from both sides. Loading was performed at a frequency of $8 \mathrm{~Hz}$ and the stress ranges of $400 \mathrm{MPa}, 270 \mathrm{MPa}$, and $180 \mathrm{MPa}$. Stress ratios of -1, 0.1, and 0.4 with a maximum stress of $300 \mathrm{MPa}$ were used. Loadings were extracted from in-service histories using traffic data from the Ministry of Transportation of Ontario in 1995. The trucks on the sample were passed over influence lines on 2 locations of a simply supported bridge. As a result, all untreated fatigue specimens failed near the design Category $\mathrm{C}$ curve. It was determined that shot peening had a significant increase in fatigue life.

Tehrani (2012) also performed fatigue testing on CSA G40.21 350W welded cruciform specimens to determine the effects of ultrasonic impact treatment. Specimen dimensions were exactly the same as those in the study conducted by Ghahremani (2010). The specimen was of $400 \mathrm{~mm}$ total length, with a radius of $200 \mathrm{~mm}$, a reduced section length of $75 \mathrm{~mm}$ and a reduced section width of $30 \mathrm{~mm}$ with a thickness of $9.5 \mathrm{~mm}$ for both the specimen and the welded stiffener. Constant amplitude loadings were conducted at stress ranges of $200 \mathrm{MPa}, 225 \mathrm{MPa}$, and $250 \mathrm{MPa}$ at frequencies less than $23 \mathrm{~Hz}$. A stress ratio of 0.1 was used throughout all the experiments and the runout was set at 3 million cycles. All specimens failed at 248 383, 166 821, and 105487 cycles respectively.

Agerskov and Nielson (1999) and Agerskov (2000) tested over 520 sheet type welded plate specimens and 18 full-scale offshore tubular joints made out of conventional structural steel with yield strength ranging from 360 to $410 \mathrm{MPa}$, similar to other conventional structural steels used in North America. Two types of cruciform specimens were used. The large specimen had a length of $600 \mathrm{~mm}$, a constant width of $90 \mathrm{~mm}$ and a thickness of $16 \mathrm{~mm}$. The transverse stiffener was butt welded on both sides of the specimen with a welding angle of $45^{\circ}$. The stiffener had a length of $90 \mathrm{~mm}$ and a thickness of $10 \mathrm{~mm}$. On the other hand, the small plate specimen had a constant width of $40 \mathrm{~mm}$, a total length of $375 \mathrm{~mm}$, and a thickness of $8 \mathrm{~mm}$. The small transverse stiffener had 
a thickness of $5 \mathrm{~mm}$ and a length of $50 \mathrm{~mm}$. Loading histories were gathered from strain gage measurements placed on a steel deck on the Faro Bridge in Denmark. The stress ranges corresponding to the values obtained from the in-field strain measurements were approximately 90-200 MPa. Fatigue tests were performed on constant amplitude stress ranges between 80-150 MPa with a stress ratio of 0.25 . The research determined that in general fatigue life is shorter with variable amplitude loading compared to constant amplitude loading within the same equivalent stress range level. The author concluded that this was primarily due to crack growth acceleration due to the high tensile and compressive loads on the actual variable amplitude histories.

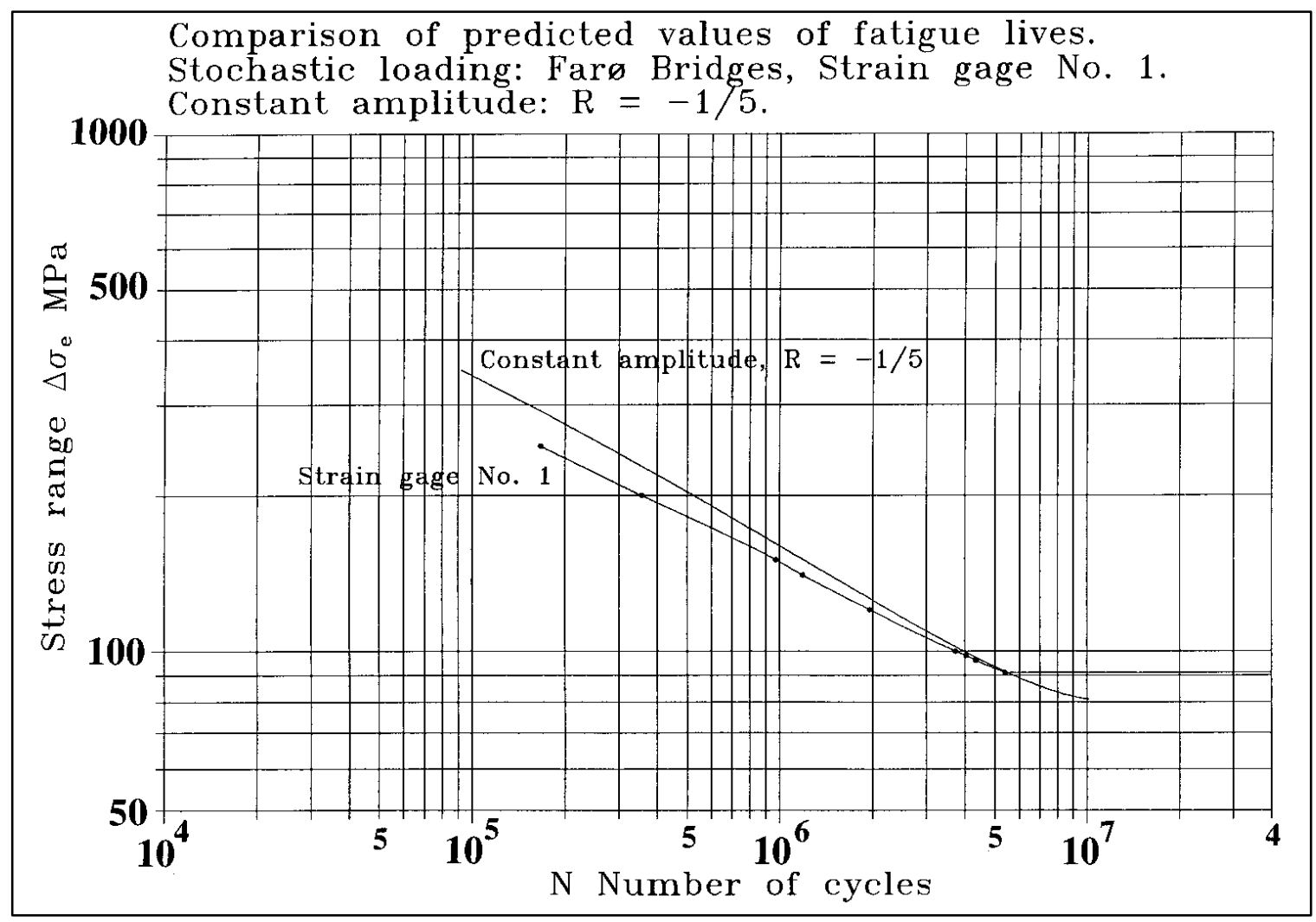

Figure 2-51: Comparison between Constant Amplitude Fatigue Loading and Actual Variable Amplitude Fatigue Loading (Agerskov, 1999)

Bennett et al. (2009) tested the fatigue resistance of high-performance steel ASTM A709 HPS485W (70W) welded butt-splice connections using narrow gap electroslag welding (NGI-ESW) and submerged arc welding (SAW). Two specimens thicknesses were considered in this study, namely: $17.8 \mathrm{~mm}$ and $22.9 \mathrm{~mm}$. They were tested at constant stress ranges of 153, 162, and 201 MPa with a frequency of $5 \mathrm{~Hz}$ and a minimum load of $2.22 \mathrm{kN}$. The results from the experimental study determined that all 10 welded butt-splice specimens surpassed run-out which was defined as 
a theoretical failure of 1 million cycles for Category A detail. Most of the specimens did not fail at 2 to 3 million cycles, hence they were tested under monotonic tensile testing. It was concluded that the ESW welding method was comparable in terms of achieving the same fatigue rating as the SAW technique. Figure 2-52 shows the S-N Curve with fatigue run-out of butt-welded HPS-485W specimens.

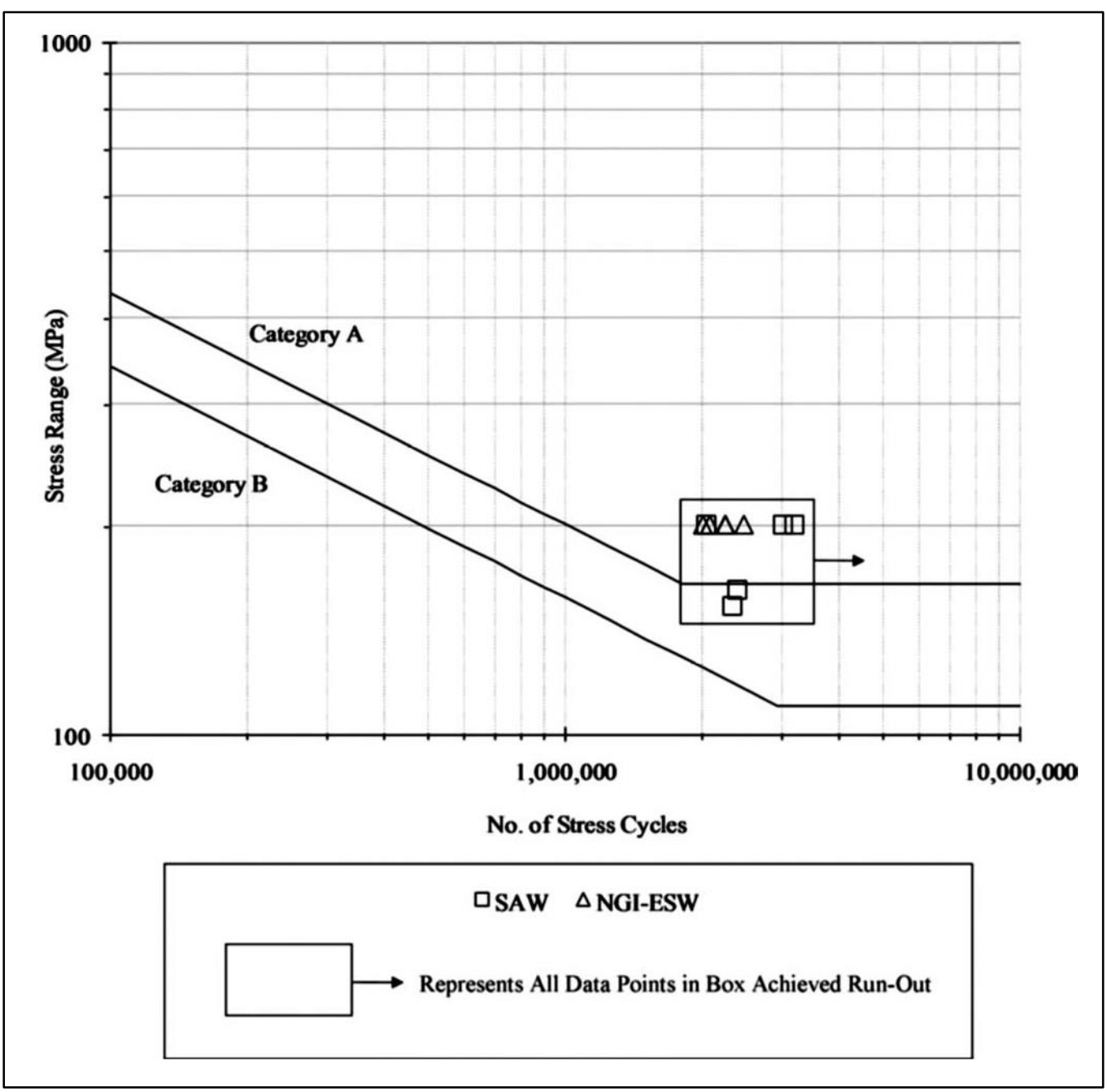

Figure 2-52: S-N Curve Showing Fatigue Run-Out of Butt Welded HPS-485W Specimens (Bennett et al. 2009)

Haftirman et al. (2012) investigated the fatigue of transverse butt joints and base material of mild steel with the conditions being as welded, overfill removed, and base material. Mild steel had a yield strength of $258.59 \mathrm{MPa}$ and an ultimate strength of $425.98 \mathrm{MPa}$. The ultimate tensile strength of the as welded specimen was $299.65 \mathrm{MPa}$, and the specimen with the overfill removed had a tensile strength of $307.40 \mathrm{MPa}$. All specimens had a thickness of $9 \mathrm{~mm}$, a total length of $200 \mathrm{~mm}$, 
a reduced section length of $80 \mathrm{~mm}$, a fillet radius of $20 \mathrm{~mm}$, and a grip length of $40 \mathrm{~mm}$. Eighteen specimens were tested under constant amplitude fatigue with a loading ratio of $R=0$ and a frequency of $30 \mathrm{~Hz}$. Regular base metal specimens were tested under various amplitude stresses, namely: 400, 350, 300, 250, 200, and $100 \mathrm{MPa}$. The as-welded specimens and overfill removed specimens were tested under 220,180,130, 90, 50, and $30 \mathrm{MPa}$ amplitude stresses. The regular specimens reached a stress amplitude endurance limit of $150 \mathrm{MPa}$ near the 10 million cycle mark, the welded specimens reached a stress amplitude endurance limit of $40 \mathrm{MPa}$ at 10 million cycles, and the specimens with the overfill removed reached a stress amplitude endurance limit of $35 \mathrm{MPa}$ at 10 million cycles. Figure 2-53 shows the S-N curve of regular mild steel, welded steel, and welded with overfill removed, as presented by Haftiman et al.

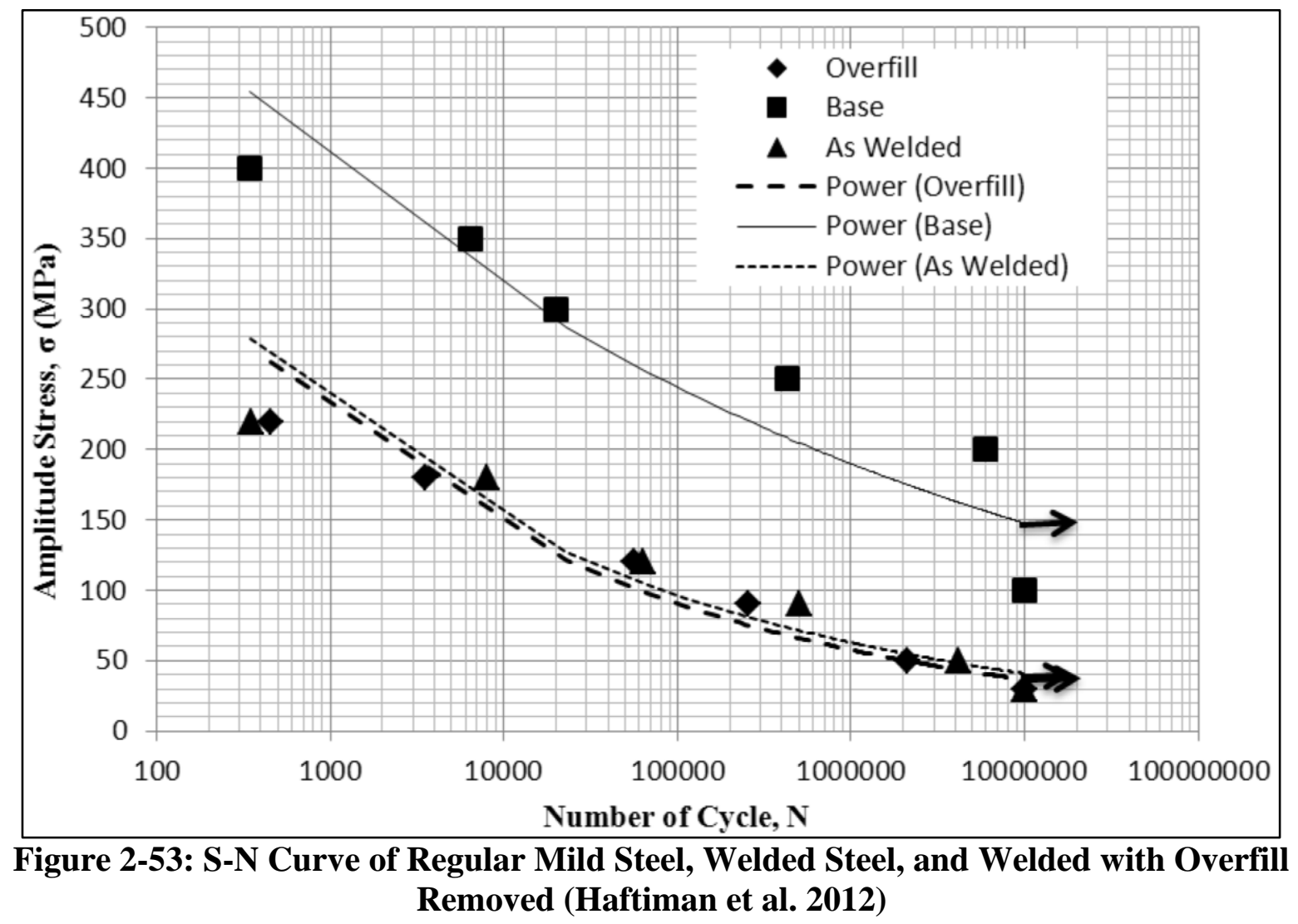


Zong et al., (2017) performed experimental fatigue testing on butt welded splices with plates of different thicknesses. Twenty-six tests were conducted at 7 stress range levels $(210,200$, 190, $180,170,160,150 \mathrm{MPa})$ under constant amplitude loading with a stress ratio (R) of 0.1 and a minimum stress range of $10 \mathrm{MPa}$. Specimens were manufactured from Q345qD grade steel $\left(\mathrm{f}_{\mathrm{y}}=\right.$ $350 \mathrm{MPa}, \mathrm{f}_{\mathrm{u}}>500 \mathrm{MPa}$ ) plates of 12 - and 8-mm thicknesses with a 1/4 transition slope. All specimens failed on the weld toe connected at the thinner plate side. Figure 2-54 shows the cycles at which the corresponding specimens failed.

\begin{tabular}{|llllll|}
\hline $\begin{array}{l}\text { Specimen } \\
\text { no. }\end{array}$ & $\begin{array}{l}\text { Maximum } \\
\text { stress/MPa }\end{array}$ & $\begin{array}{l}\text { Fatigue } \\
\text { life/cycle }\end{array}$ & $\begin{array}{l}\text { Specimen } \\
\text { no. }\end{array}$ & $\begin{array}{l}\text { Maximum } \\
\text { stress/MPa }\end{array}$ & $\begin{array}{l}\text { Fatigue } \\
\text { life/cycle }\end{array}$ \\
\hline BW1-1 & 220 & 596,973 & BW5-1 & 180 & $1,012,440$ \\
BW1-2 & 220 & 956,000 & BW5-2 & 180 & $1,110,680$ \\
BW1-3 & 220 & 719,628 & BW5-3 & 180 & 899,928 \\
BW2-1 & 210 & 506,200 & BW6-1 & 170 & $1,800,000$ \\
BW2-2 & 210 & 465,344 & BW6-2 & 170 & Run out \\
BW2-3 & 210 & 665,453 & BW6-3 & 170 & Run out \\
BW3-1 & 200 & 767,620 & BW7-1 & 160 & $1,900,000$ \\
BW3-2 & 200 & $1,013,410$ & BW7-2 & 160 & $1,112,570$ \\
BW3-3 & 200 & $1,233,680$ & BW7-3 & 160 & $1,346,080$ \\
BW3-4 & 200 & $1,021,430$ & BW0-1 & 160 & $1,154,800$ \\
BW4-1 & 190 & 967,040 & BW0-2 & 100 & Run out \\
BW4-2 & 190 & 604,561 & BW0-3 & 120 & Run out \\
BW4-3 & 190 & $1,294,040$ & BW0-4 & 140 & Run out \\
\hline
\end{tabular}

Figure 2-54: Table Showing Fatigue Life of Different Thickness Butt Welded Specimens (Zong et al. 2017) 


\section{Chapter 3 - Experimental Work}

\subsection{Slip Resistance Experimental Work}

A lot of the slip resistance studies on carbon alloy steels throughout history were conducted experimentally according to the main test method specified by Frank and Yura (1981) and later adopted by the Research Council on Structural Connections guide (RCSC, 2014) to perform slip resistance studies for different coating surfaces in which the slip resistance coefficient is not known. The main goal of this part of the experimental work was to determine the slip resistance coefficient of ASTM A1010 stainless steel and see if it conforms to that of what is specified for structural steel in the Canadian Highway Bridge Design Code, CSA S6-14 (CSA, 2014b). Identical specimens of traditional carbon alloy steel were fabricated and tested similar to those made of A1010 stainless steel as their baseline performance. Traditional steel commonly used in Canada under grade CSA G40.21 350W $\left(\mathrm{F}_{\mathrm{y}}=350 \mathrm{MPa}, \mathrm{F}_{\mathrm{u}}=450-620 \mathrm{MPa}\right)$ were tested in order to verify the results and ensure the experimental work is properly performed. At the same time, to alleviate concerns for in-field performance it was decided to test specimens where the clamping force was applied by using the turn-of-nut method, instead of using a hydraulic jack. The purpose of testing specimens with the turn-of-nut method is to see whether the compressive slip resistance loads were similar to those slip resistance loads achieved by the hydraulic jack with which the clamping force was maintained throughout the duration of the test. At the same time, it was decided to both maintain the clamping force with the hydraulic jack throughout the duration of the test and also without maintaining the clamping force to examine whether any kind of losses exists on the preload when applying the compression force on the middle base plate of the three-plate specimen.

The A1010 stainless steel plates donated for this research arrived with a blasted surface that had already formed a rust patina. Hence, it was decided that the plates would be re-blasted making them Class B surface condition. Table 3-1 shows the proposed research matrix for the slip resistance study. In order to establish a slip resistance coefficient, 15 ASTM A1010 steel specimens and 15 regular structural steel specimens made of CSA G40.21 350W steel grade were fabricated and tested under compression loading that creates shear force at the interface of connecting plates. Five of these specimens were bolted with the standard turn-of-nut method commonly used in the field and 10 of the remaining specimens were tightened together by a 
hydraulic load cell to accurately measure the clamping load applied by the bolt to the plates and as a result, come up with a precise slip resistance coefficient. In addition, 15 coupons specimens were fabricated from $350 \mathrm{~W}$ structural steel considering Class A surface condition (clean mill scale), 5 with turn-on-nut bolt clamping method and 10 with bolt clamping using a hydraulic jack.

Table 3-1: Research Matrix for Slip Resistance Test

\begin{tabular}{|c|c|c|c|c|c|}
\hline Specimen Type & $\begin{array}{c}\text { Surface } \\
\text { Condition } \\
\text { Class }\end{array}$ & $\begin{array}{c}\text { Surface } \\
\text { Condition }\end{array}$ & Clamping Method & $\begin{array}{c}\text { Clamping } \\
\text { Force }\end{array}$ & $\begin{array}{c}\text { Number } \\
\text { of } \\
\text { Specimens }\end{array}$ \\
\hline $\begin{array}{c}\text { A1010 Stainless } \\
\text { Steel }\end{array}$ & $\mathrm{B}$ & $\begin{array}{l}\text { White Metal } \\
\text { Blast Clean }\end{array}$ & Turn-of-Nut & $203 \mathrm{kN}$ & 5 \\
\hline $\begin{array}{c}\text { A1010 Stainless } \\
\text { Steel }\end{array}$ & $\mathrm{B}$ & $\begin{array}{l}\text { White Metal } \\
\text { Blast Clean }\end{array}$ & Hydraulic Jack & $230 \mathrm{kN}$ & 10 \\
\hline $\begin{array}{c}\text { 350W Structural } \\
\text { Steel }\end{array}$ & B & $\begin{array}{l}\text { White Metal } \\
\text { Blast Clean }\end{array}$ & Turn-of-Nut & $203 \mathrm{kN}$ & 5 \\
\hline $\begin{array}{c}\text { 350W Structural } \\
\text { Steel }\end{array}$ & $\mathrm{B}$ & $\begin{array}{l}\text { White Metal } \\
\text { Blast Clean }\end{array}$ & Hydraulic Jack & $230 \mathrm{kN}$ & 10 \\
\hline $\begin{array}{c}\text { 350W Structural } \\
\text { Steel }\end{array}$ & A & $\begin{array}{l}\text { Clean Mill } \\
\text { Scale }\end{array}$ & Turn-of-Nut & $203 \mathrm{kN}$ & 5 \\
\hline $\begin{array}{c}\text { 350W Structural } \\
\text { Steel }\end{array}$ & A & $\begin{array}{l}\text { Clean Mill } \\
\text { Scale }\end{array}$ & Hydraulic Jack & $230 \mathrm{kN}$ & 10 \\
\hline
\end{tabular}

\subsubsection{Preparation of Samples for Slip Resistance Testing}

To keep the study consistent with other studies, it was decided that specimens should be cut to the same dimensions as those specified in Appendix A of the RCSC 2014 guide. The test specimen was made of three identical plates as shown in Figure 3-1. Each plate was cut to dimensions of 101.6 by $101.6 \mathrm{~mm}$ (4" by 4") with a thickness of $15.875 \mathrm{~mm}\left(5 / 8^{\prime \prime}\right)$. The thickness of the specimen also matched with the thickness of the web portion for the inner girders of the Speed River Bridge in Cambridge, Ontario which was constructed with ASTM A1010 steel plates in 2017. A $25.4 \mathrm{~mm}$ (1") diameter hole was fabricated on the middle of the plate, $38.1 \mathrm{~mm}(1.5$ ") of the way down from the top as depicted in Figure 3-1. The plates were cut by using a water jet table as recommended by the manufacturer, see Figure 3-2. This ensured that the high heat that arises from traditional gas cutting does not have any adverse effects on the stainless steel composition. 


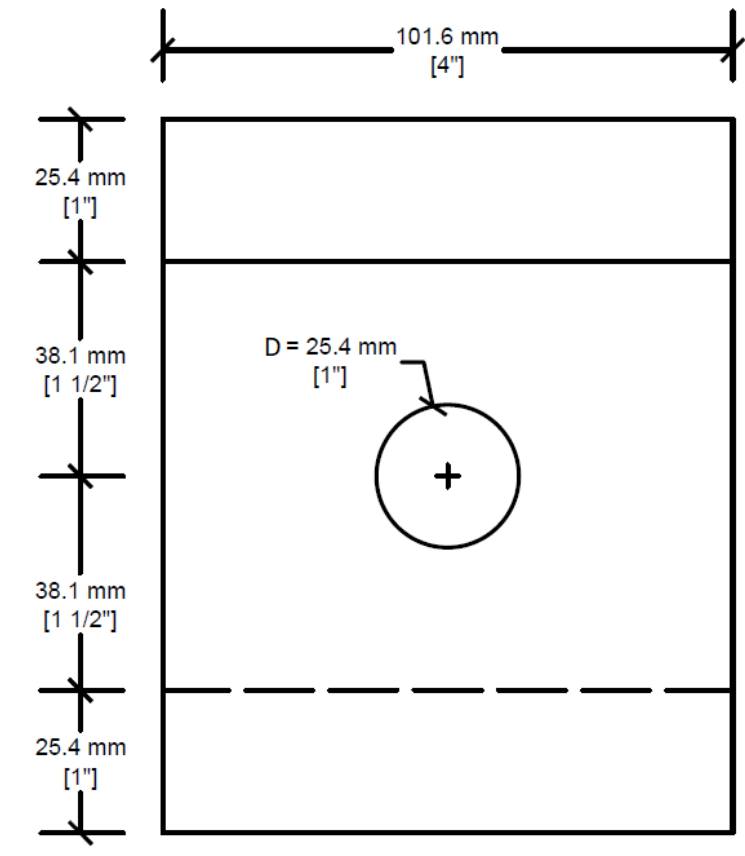

(a) Elevation

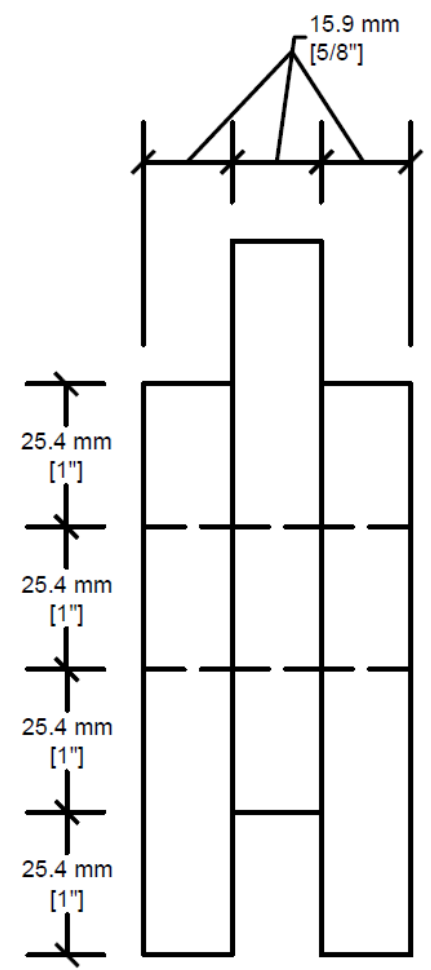

(b) Side view

Figure 3-1: Specimen Dimensions for Slip Resistance Test

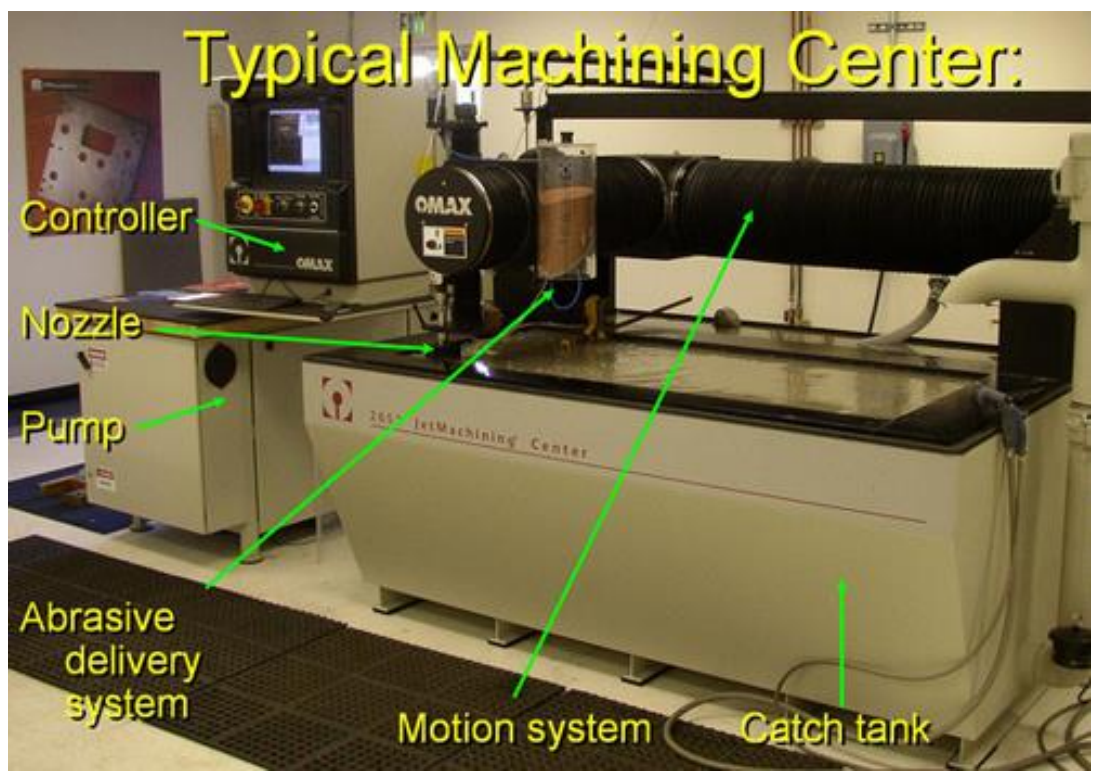

Figure 3-2: Waterjet table systems (Source: OMAX Corporation) 
The ASTM A1010 plates were received blasted with a rust patina formed on them from outside exposure. Therefore, it was decided to re-blast them with stainless steel grit to white metal blast (SSPC SP5) in order to remove all visible oil, grease, dust, dirt, rust, and mill scales from the faying surfaces of the plates. Table 3-2 lists available standards for surface roughness. Figure 3-3 shows a typical stainless steel plate before and after blasting it with stainless steel grit.

Table 3-2: Surface Roughness Standards

\begin{tabular}{|c|c|c|c|c|}
\hline SSPC Code & NACE & $\begin{array}{c}\text { Canadian } \\
\text { Government (CGSB) }\end{array}$ & Swedish Standard & British Standard \\
\hline SSPC SP5 & NACE \#1 & 31 GP 404 Type 1 & Sa.3 & BS4232 First Quality \\
\hline
\end{tabular}

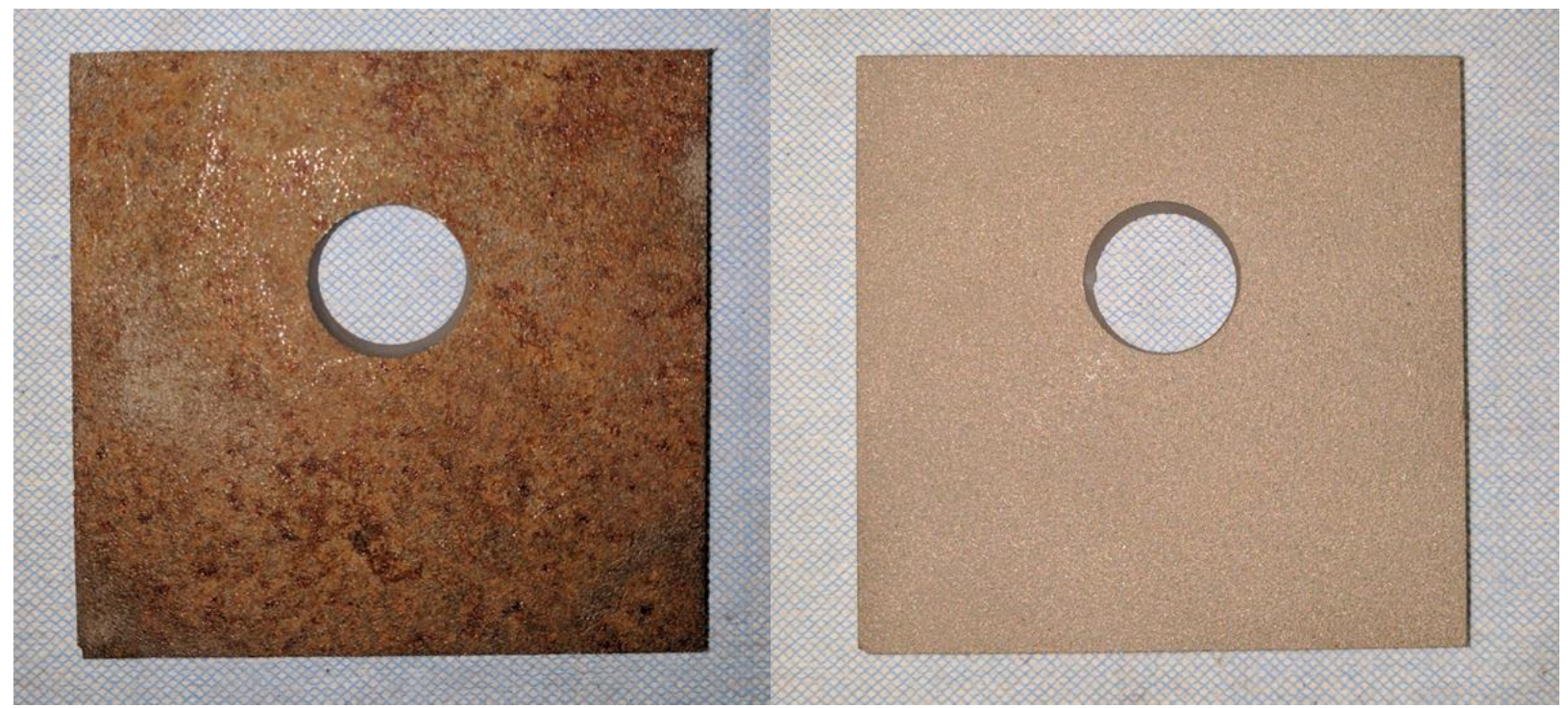

Figure 3-3: Specimen Before and After Blast Cleaning with Stainless Steel Grit

The surface roughness of the tested plates was measured at 5 different locations on the plate as depicted in Figure 3-4. Four of the test points were located around the middle hole and 1 location near the edge of the plate. The surface roughness of the plates was measured and verified by two different devices, named portable stylus instruments. The two devices used were Shimana SHGLST022 and Shimana SHGLST129. Both of these surface roughness testers meet ASTM D7127 standard test method for field measurement of the surface profile of blast cleaned steel (ASTM, 2013a). The Shimana SHGLST022 shown on Figure 3-5(a) and Figure 3-5(c) works by placing the sensor flat on the surface of the plates. The desired measurement parameters and cutoff lengths are selected on the device screen. The test starts by moving the testing probe along the 
surface generating an analog signal through the induction coils. The sensor converts and computes the analog signal into a reading of microns showing the actual selected parameter of surface roughness $\left(\mathrm{R}_{\mathrm{a}}, \mathrm{R}_{\mathrm{z}}, \mathrm{R}_{\mathrm{q}}\right.$, or $\left.\mathrm{R}_{\mathrm{t}}\right)$. The definition for each of those surface roughness parameters are as follows: $R_{a}$ is the arithmetical mean deviation of profile within the sampling length; $R_{z}$ is the average sum of five maximum profile peaks and average of five maximum profile valleys within the sampling length; $\mathrm{R}_{\mathrm{q}}$ is the root-mean-square of profile deviation within the sampling length; $R_{t}$ is the sum of maximum height of the profile peak and the maximum depth of the profile valley for the evaluation length.

The Shimana SHGLST129, shown in Figure 3-5(b), is a manual surface roughness tester, where the user places the tip on the desired point and only gets a single reading of the total peak-to-valley height of the surface profile $\left(\mathrm{R}_{\mathrm{t}}\right)$.

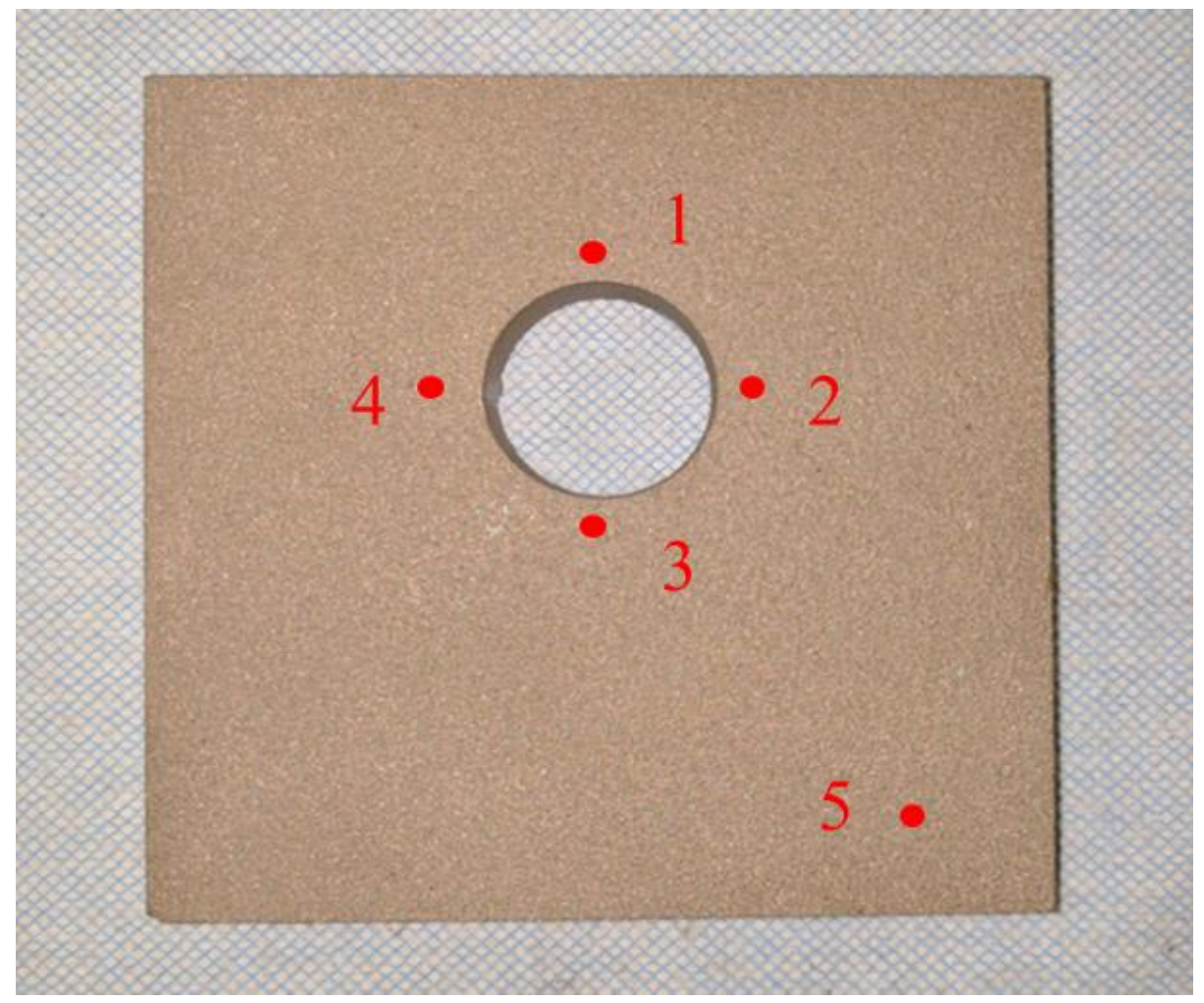

Figure 3-4: Surface Roughness Measurement Locations 


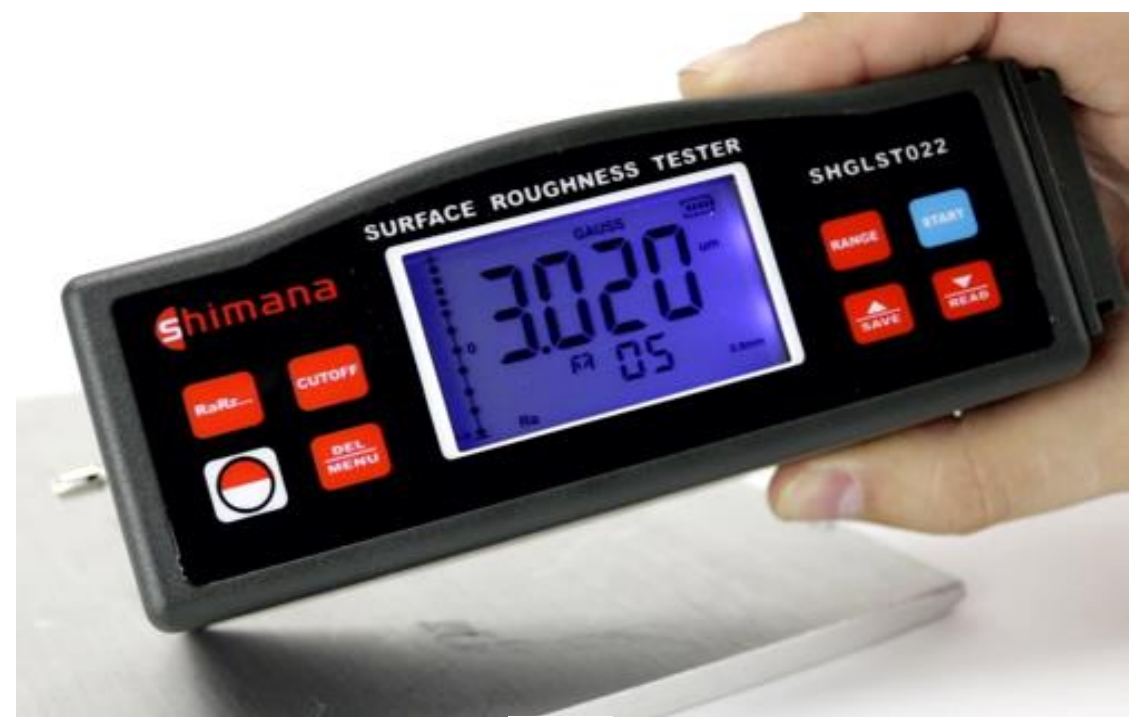

(a)

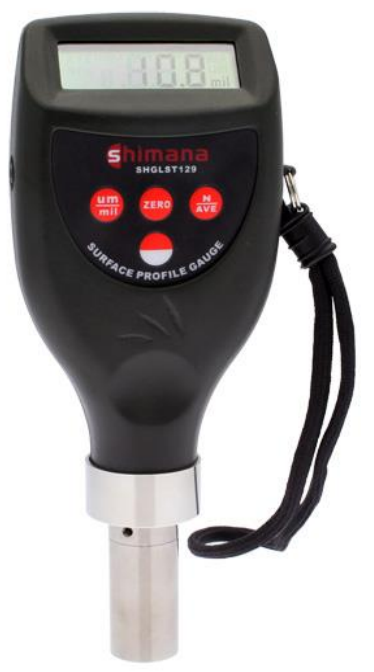

(b)

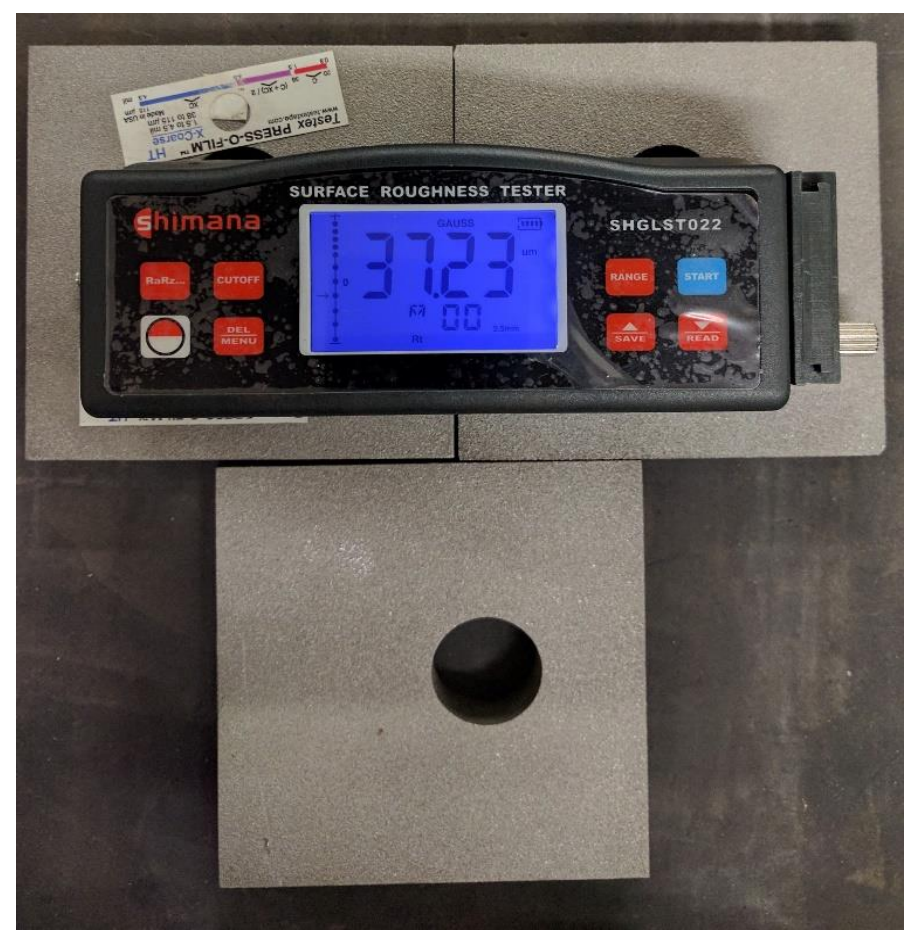

(c)

Figure 3-5: (a) Shimana SHGLST022; (b) Shimana SHGLST129;

(c) Surface Roughness Measurements of Blasted Plates On-Site using Shimana SHGLST022 


\subsubsection{Application of Clamping Force}

Figure 3-6 shows a schematic diagram of the slip resistance test setup. Clamping force during the test was applied through the use of a hydraulic bolt tensioning device (SPX SRT1 Hydraulic Tensioner) with a maximum load capacity of $280 \mathrm{kN}$ and a max piston stroke of $10 \mathrm{~mm}$ connected to a handheld hydraulic pump (Rehobot). A $125 \mathrm{~mm}$ (5") long plain A325 bolt was inserted through all 3 plates, the load cell, spacers and was threaded into the bolt tensioning device. As hydraulic fluid is pumped into the bolt tensioner it makes the piston move forward to apply a clamping force onto the plates as it pulled on the bolt simultaneously.

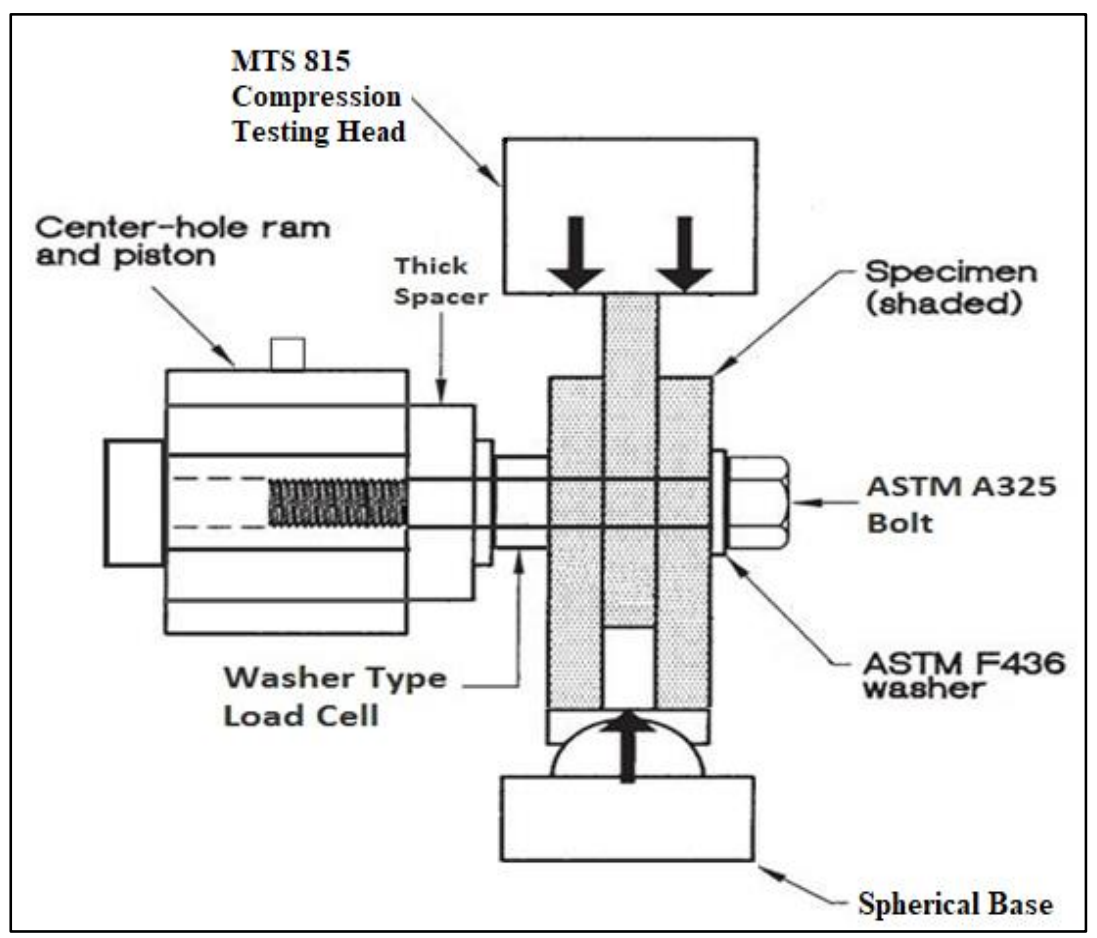

Figure 3-6: Clamping Load Test Set-Up with Hydraulic Jack

An HBM KMR strain gauge-based force washer load cell of $400 \mathrm{kN}$ capacity was used for monitoring the clamping load. The $400 \mathrm{kN}$ washer load cell made out of stainless steel was ideal for monitoring the load of $22 \mathrm{~mm}$ diameter bolts with an accuracy of $\pm 1 \%$. The washer type load cell was placed in series with the clamping piston, washers, spacers, and plates. This allowed the accurate measure of clamping force during the test. Figure 3-7 shows close-up view of the hydraulic jack and load cell in the test setup while Figure 3-8 shows views of the hydraulic piston 
and hydraulic pump. Dimension details of the washer-type load cell are shown in Figure 3-9 and Figure 3-10. Finally, a general view of the test setup in the MTS machine is shown in Figure 3-11.

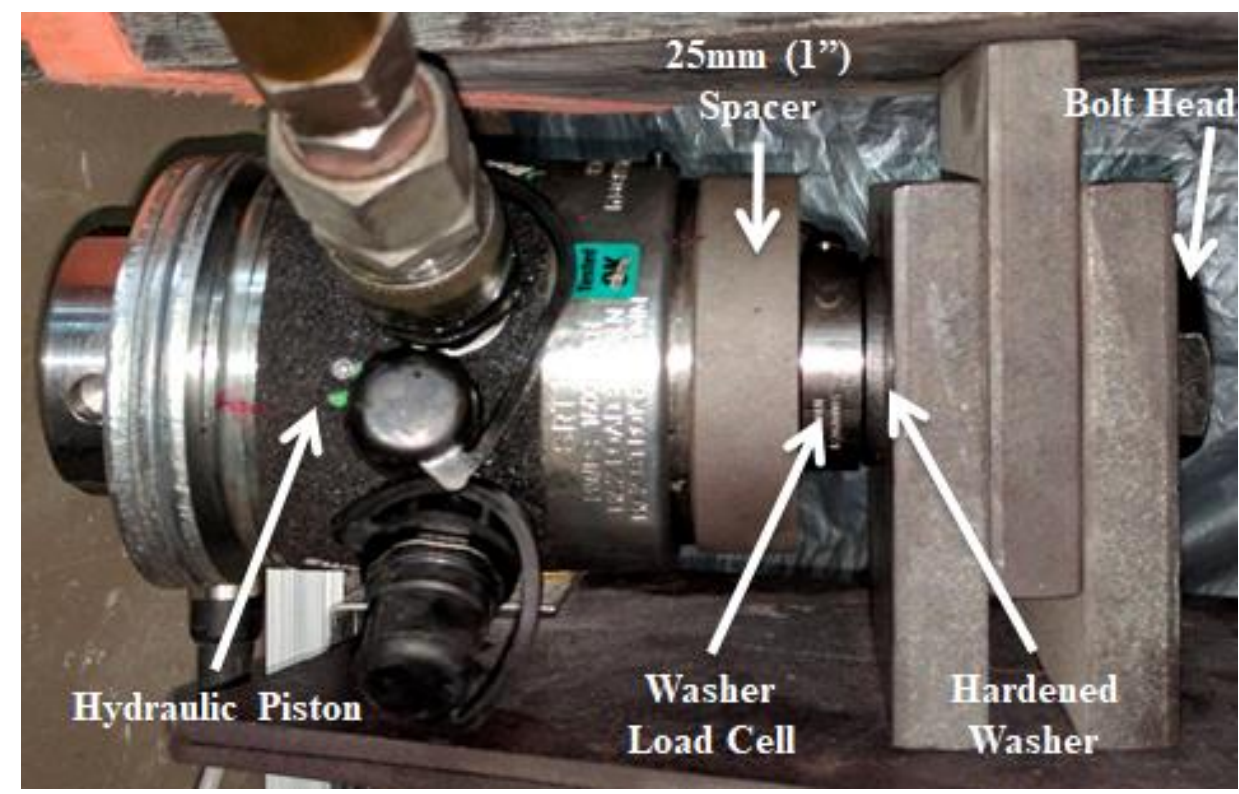

Figure 3-7: Close-Up View of Hydraulic Clamp Test Set-Up

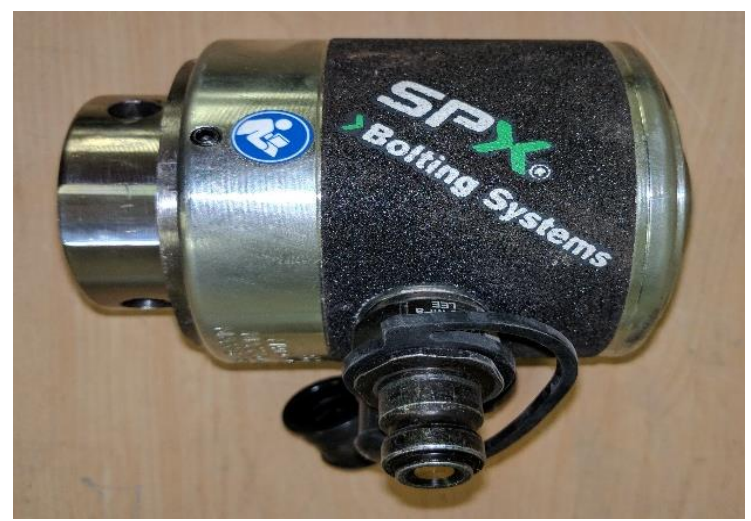

(a)

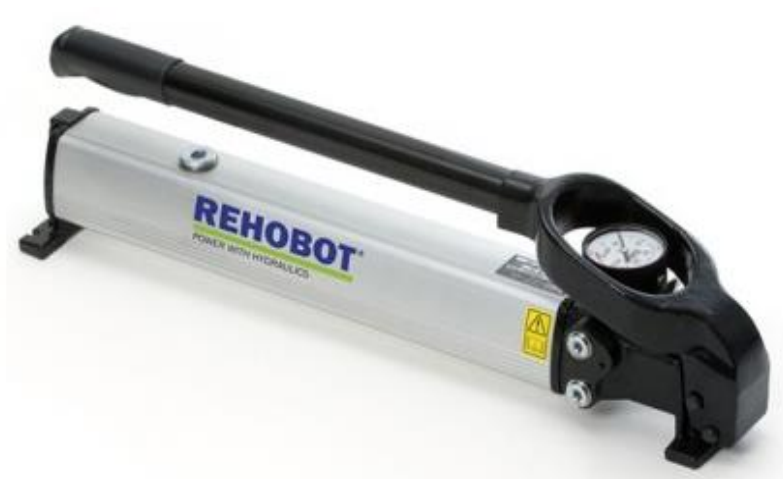

(b)

Figure 3-8: (a) Bolt Tensioning Hydraulic Piston; (b) Handheld Hydraulic Pump 


\section{Bending radius:}

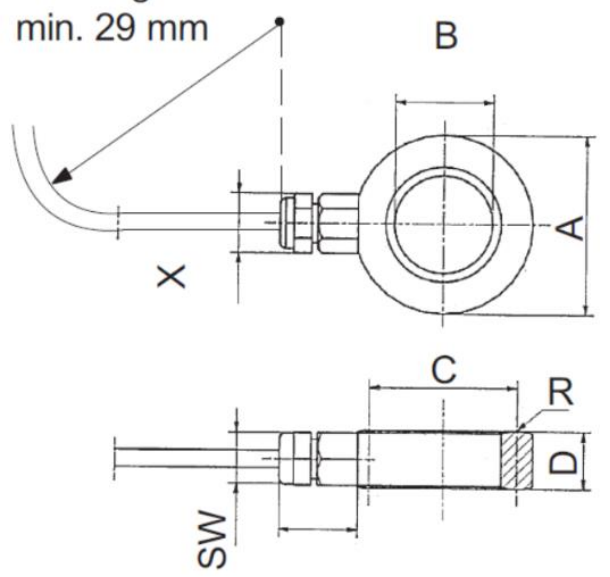

Hardened washer

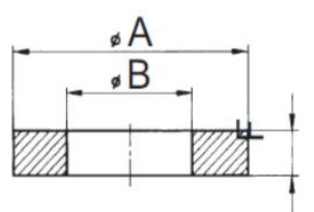

\begin{tabular}{|c|c|c|c|c|c|c|c|c|c|c|}
\hline $\begin{array}{c}\text { Nominal } \\
\text { (rated) } \\
\text { force in kN }\end{array}$ & $\varnothing \mathbf{A}_{-0.1}$ & $\varnothing \mathbf{B}^{+0.1}$ & $\varnothing \mathbf{C}$ & $\mathbf{D}$ & $\varnothing \mathbf{E}$ & $\mathbf{G}$ & $\mathbf{R}$ & $\begin{array}{c}\varnothing \mathbf{X} \\
\text { appr. }\end{array}$ & $\begin{array}{c}\mathbf{Y} \\
\text { appr. }\end{array}$ & $\begin{array}{c}\mathbf{Z} \\
\text { appr. }\end{array}$ \\
\hline $\mathbf{4 0 0}$ & 46 & 25 & 38 & 12.5 & - & - & 10 & 10.5 & 14.5 & - \\
\hline
\end{tabular}

Figure 3-9: HBM KBR 400 kN Load Cell and Hardened Washer Dimensioning

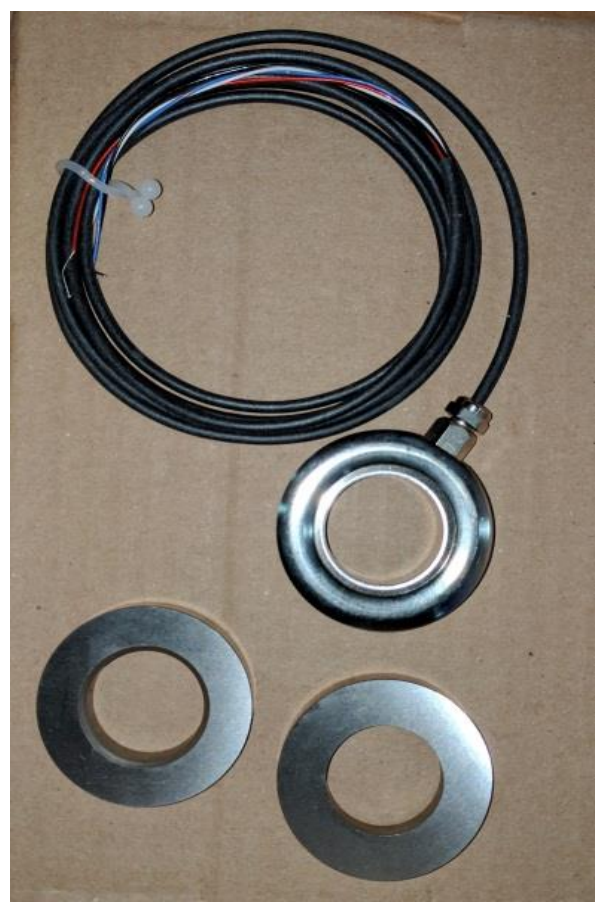

Figure 3-10: Photo of Washer Type Load Cell for Measuring Clamping Force 


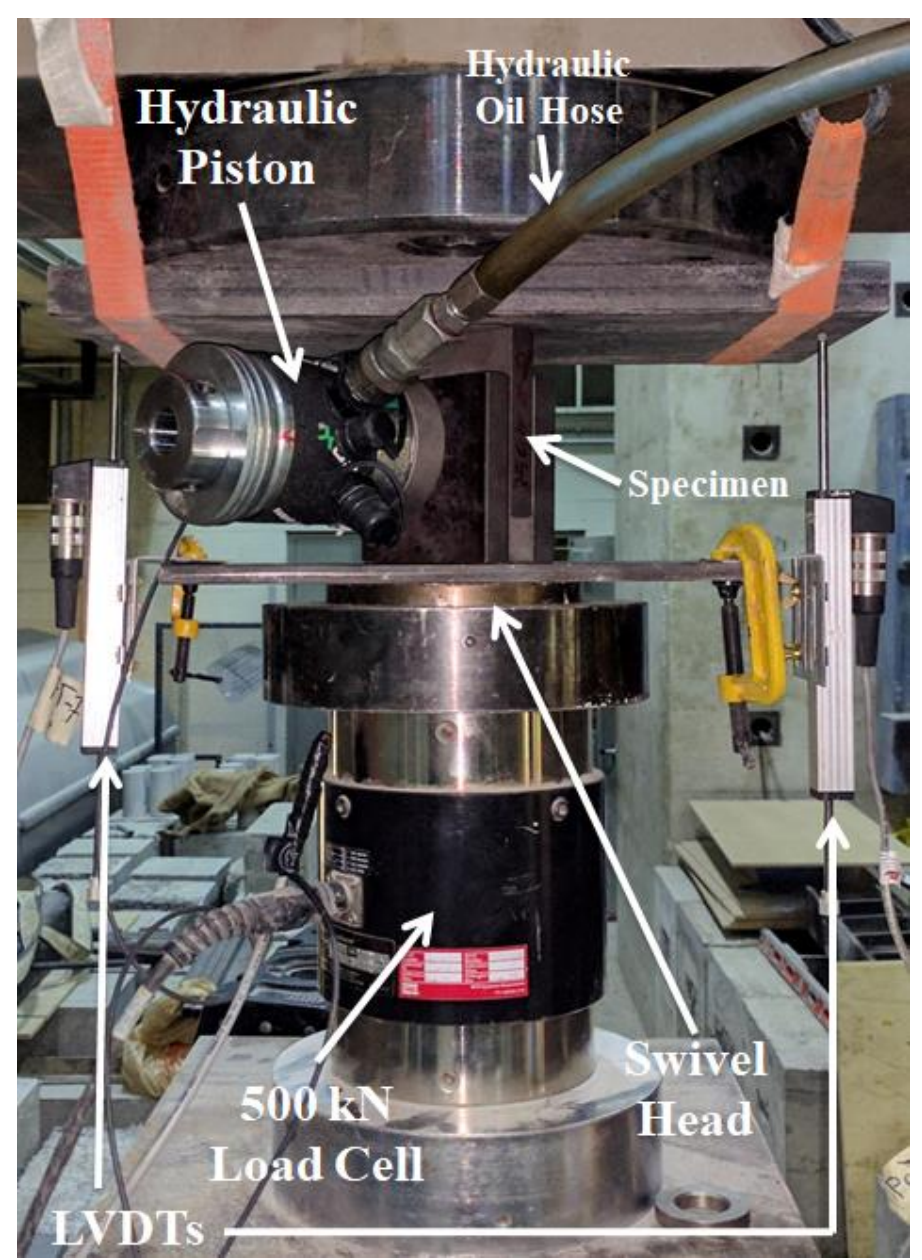

Figure 3-11: Slip Resistance Test Setup by Using Hydraulic Piston to Maintain the Clamping Load

\subsubsection{Bolt Tightening for Turn-of-Nut Method}

Bolt pretension was verified on a Skidmore-Wilhelm mechanical load cell commonly used to perform bolt pretension verification on-site. It was decided that high-strength heavy hex $22 \mathrm{~mm}$ (7/8") diameter ASTM A325 plain bolts would be used in this experiment because of their historical frequent use on structural steel bridges and the amount of data available showing the effect of geometric parameters on pretension load and turning radius. Figure 3-12(a) shows view of the Skidmore-Whilhelm load cell with inserted bolt and a nut in front of the circular disk that is divided into 36 angles, $10^{\circ}$ each. A large metal spacer with pre-defined angles ranging from $0^{\circ}$ to $360^{\circ}$ was placed on the front side of the Skidmore in order to verify how much the nut was turned from the snug-tightened position. Once the bolts and spacers were placed in the Skidmore, a spud 
wrench, shown in Figure 3-12(b), was used by the researcher to rotate the nut with its full strength. It must be noted that the force and rotation achieved through the power of the arm of the worker varies for each bolt. In the second step of tightening, a hydraulic torque wrench, shown in Figure $3-12$ (c), was used to turn the nut $1 / 3^{\text {rd }}$ of the way or $120^{\circ}$, as required by CSA S16-14 and CSA S6-14. The preload achieved by each bolt was recorded after $1 / 3^{\text {rd }}$ of the turn of the nut. After few tests, it was determined that the average preload achieved by a $22 \mathrm{~mm}$ (7/8") A325 bolt was around $203 \mathrm{kN}$ (Cameron, 2017). In order to place the three-plate specimens together and fully rotate the nut $1 / 3^{\text {rd }}$ of the turn after snug-tightening it, a special jig was formed of high-strength steel and welded onto a small I-girder which was bolted onto a table as shown in Figure 3-13. A schematic diagram of the final set of the three-plate specimen is shown in Figure 3-14. The tightening of the specimen was done only after ensuring that the middle plate was fully raised in order to allow space for the slip to occur (Figure 3-15). The maximum theoretical space for the slip to occur before the bolt shank goes into bearing with the plates is $3.175 \mathrm{~mm}\left(1 / 8^{\prime \prime}\right)$.

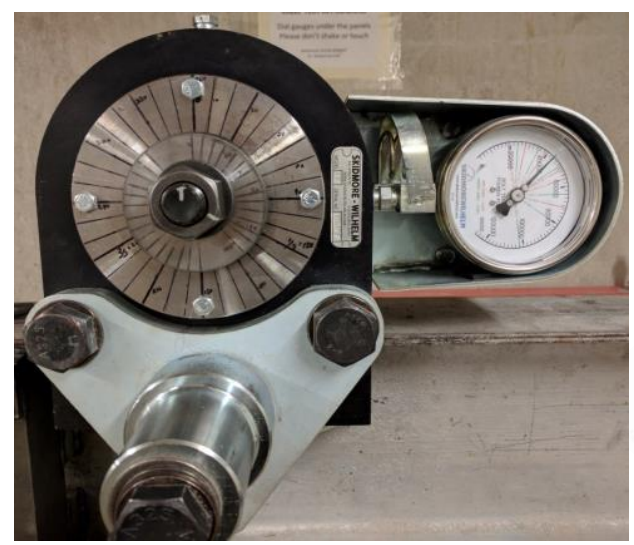

(a)

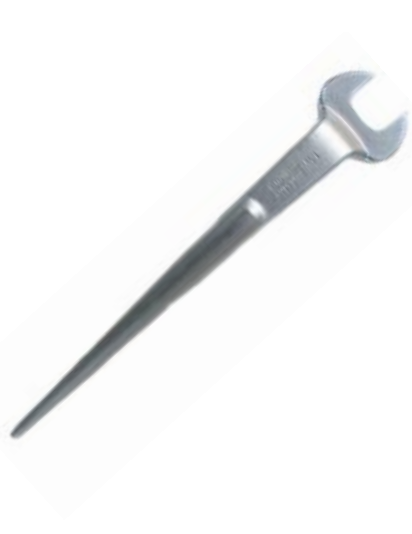

(b)

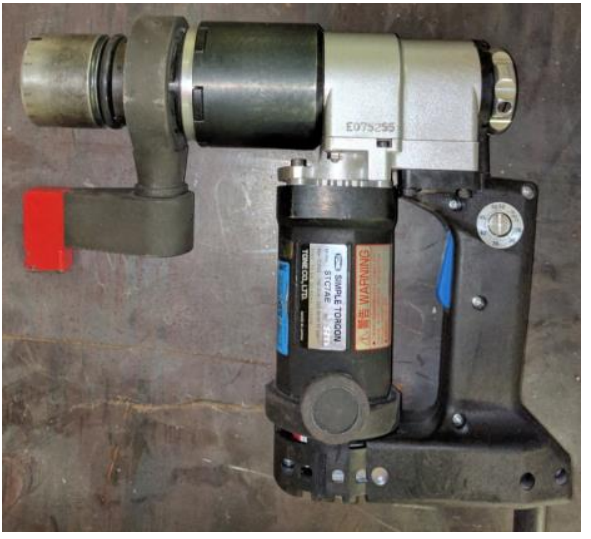

(c)

Figure 3-12: (a) Skidmore Whilhelm Load Cell with Bolt; (b) Spud Wrench Used for SnugTightening; (c) Electric Torque Wrench Used to Rotate the Nut $120^{\circ}$ 


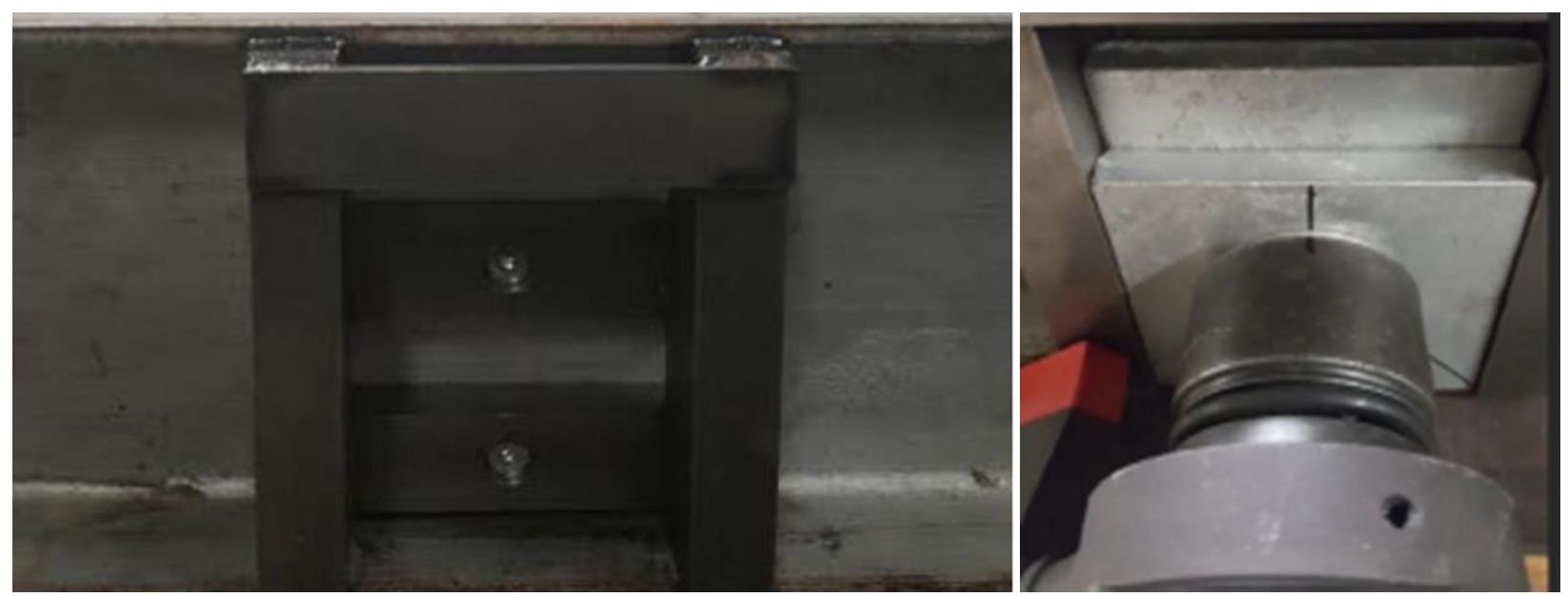

Figure 3-13: Specially manufactured jig and plate assembly for the turn-of-nut clamping method (Cameron, 2017)

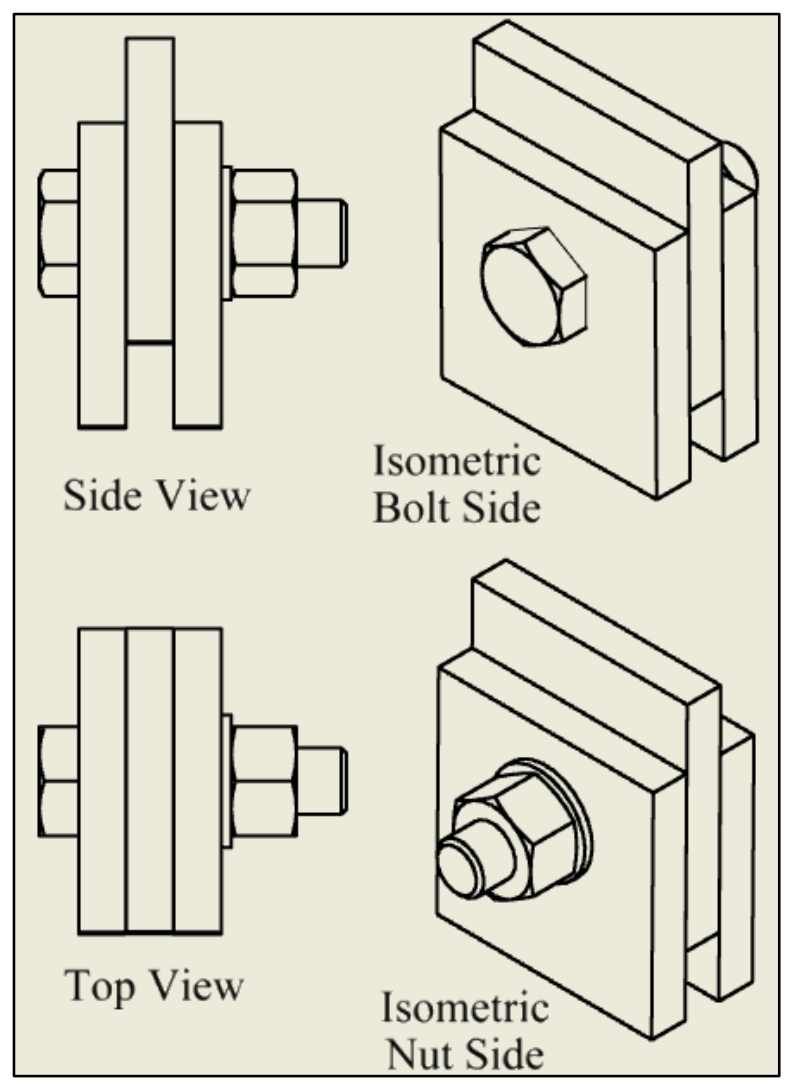

Figure 3-14: Specimen with Fastener Tightened by the Turn-of-Nut Method 

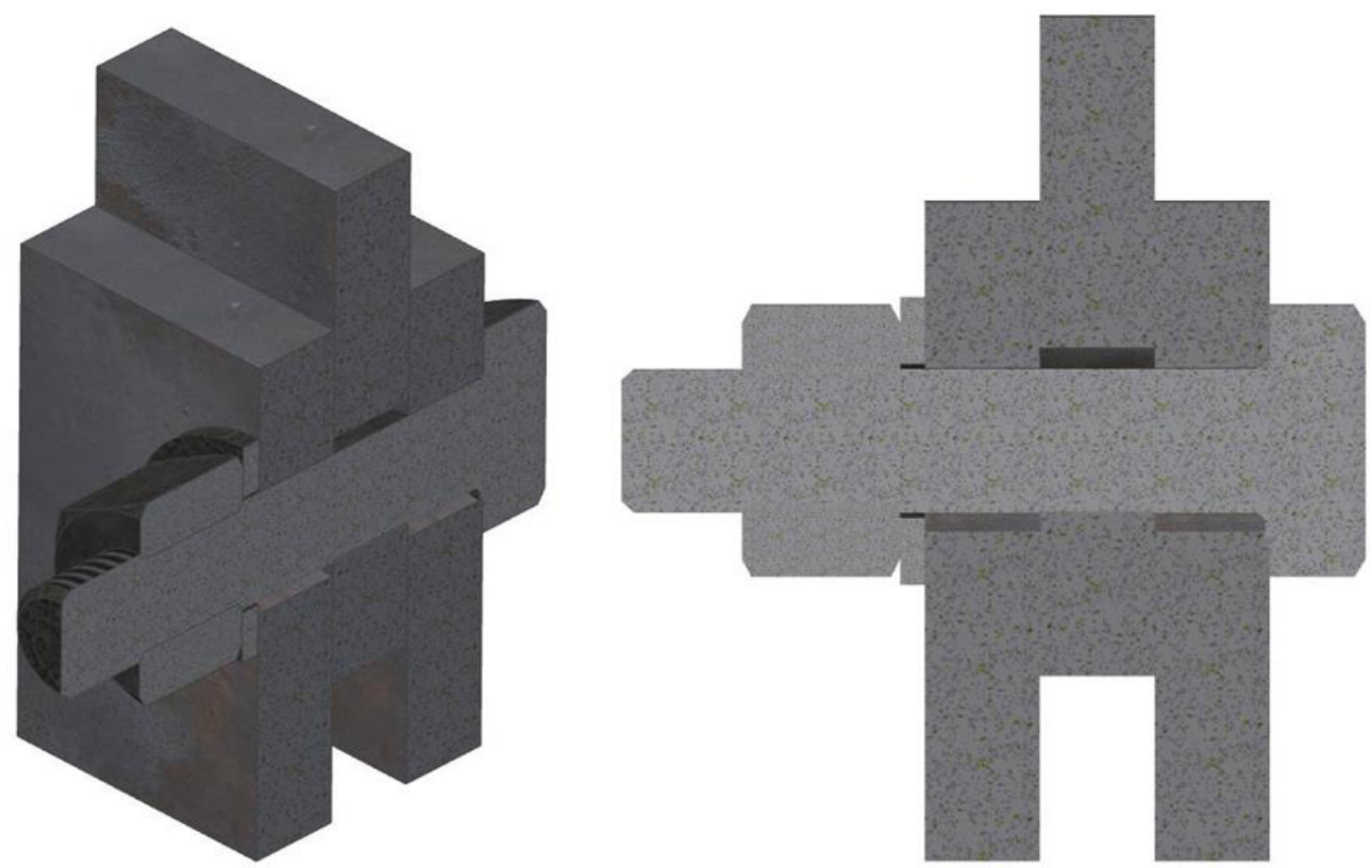

Figure 3-15: 3D Isometric and Side View Cut of Specimen Showing Plate Positioning

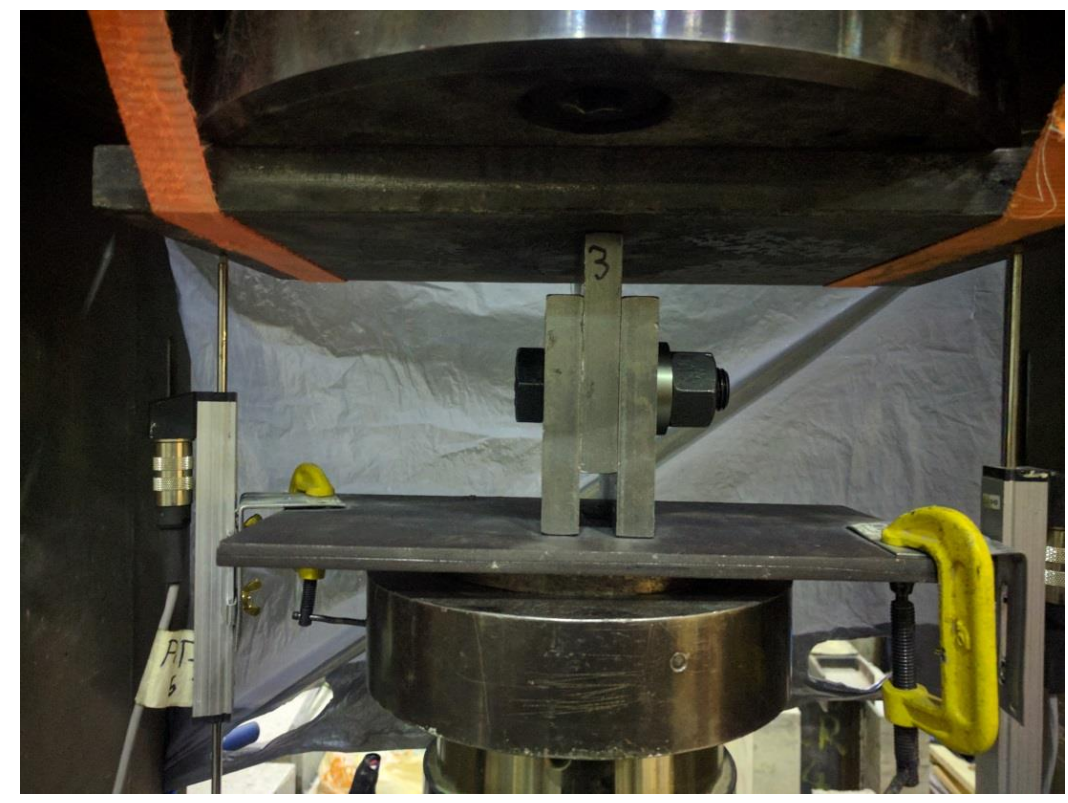

Figure 3-16: Test Specimen Set-Up for Turn-of-Nut Preload Application 


\subsubsection{Application of Compression Load}

A compressive force on the three-plate specimen was applied through an MTS 815 testing machine with a maximum compressive strength capacity of $4600 \mathrm{kN}$. The maximum stroke movement of the MTS piston is $100 \mathrm{~mm}$. The hydraulic piston is located in the bottom and moves in an upward direction when the load is applied. Due to the small size of the specimen, a large steel pedestal was used to raise the specimen together with a $500 \mathrm{kN}$ load cell (ensuring force accuracy) and a pivot plate until it made contact with the top surface of the MTS machine. A plate supporting two linear variable differential transformers (LVDTs) was set-up in order to have an accurate displacement measurement for the slip; Figure 3-17 shows a view of the test setup. The MTS machine was set up in displacement control mode with a loading rate of $0.07 \mathrm{~mm} / \mathrm{minute}$. As recommended by the RCSC Guide, an initial settling load of $4.45 \mathrm{kN}$ to help stabilize the specimen was applied before the actual test began. The test was terminated at $2 \mathrm{~mm}$ displacement which was more than enough for the slip to occur.

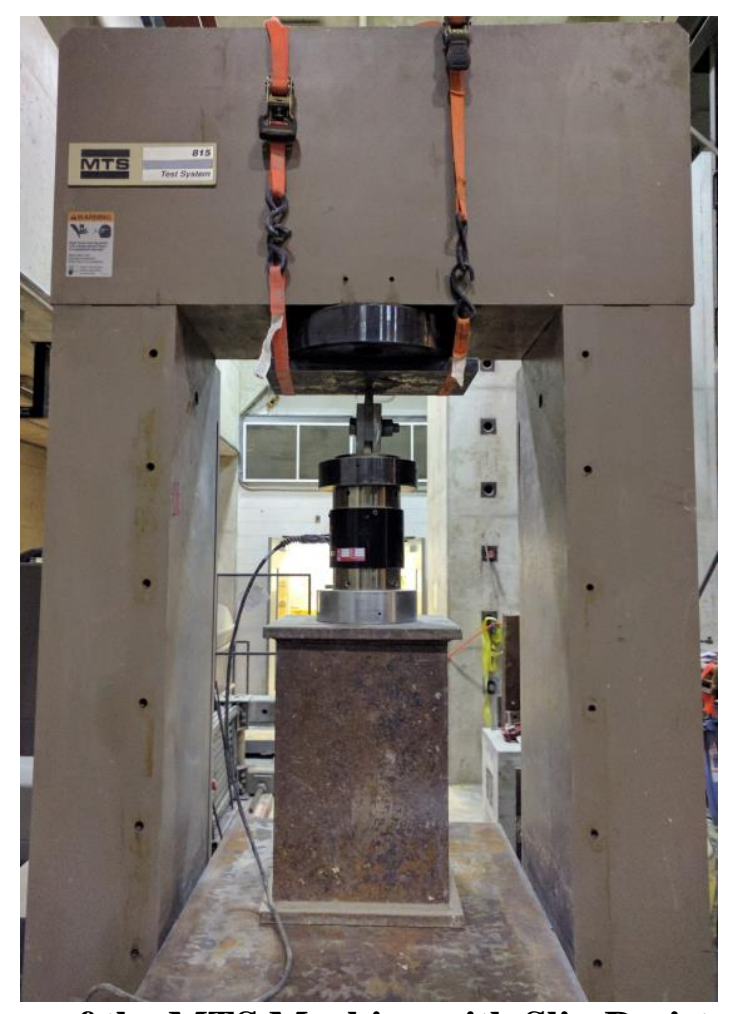

Figure 3-17: View of the MTS Machine with Slip Resistance Test Set-Up 


\subsection{Bolt Relaxation Experimental Work}

Bolt preload relaxation was tested directly on the Skidmore-Whilhelm device in series with a washer load cell as depicted in Figure 3-18. The loss of preload was mainly monitored by the washer load cell connected to a data acquisition system. Three main types of the $22 \mathrm{~mm}\left(7 / 8^{\prime \prime}\right)$ diameter bolts were tested, namely: A325 plain, A325 galvanized, and A193 B8 Class 2. The corresponding nuts and washers were used for each bolt. The plain A325 bolt was tested with a plain hard washer and nut. The A325 galvanized bolt was tested with a galvanized washer and galvanized nut. Whereas, the B8 stainless steel bolt was tested with a stainless steel washer and galvanized nut, as well as, a plain nut. Class 8 stainless steel nuts were not used because the minimum preload was not reached due to galling problems. An electric torque wrench was used to tighten all bolts at the required pretension force. Both A325 plain and galvanized bolts were tested for stress relaxation at $70 \%$ and $90 \%$ of the ultimate load. The corresponding loads for A325 plain and galvanized bolts were $174 \mathrm{kN}$ and $224 \mathrm{kN}$, respectively. Whereas, the A193 B8 Class 2 stainless steel bolt was only tested at $70 \%$ of its ultimate strength which corresponding to a load of $150 \mathrm{kN}$. Five identical specimens were considered for each bolt type and preload. Table 3-3 summarizes the test matrix considered for the bolt relaxation study.

Table 3-3: Bolt Relaxation Research Matrix

\begin{tabular}{|c|c|c|c|c|}
\hline Bolt Type & Nut Type & Washer Type & $\begin{array}{l}\text { Preload } \\
\left(\% \text { of } F_{u}\right)\end{array}$ & $\begin{array}{l}\text { Number of } \\
\text { Specimens }\end{array}$ \\
\hline \multirow{2}{*}{$\begin{array}{l}\text { ASTM A325 } \\
\text { Type } 1 \text { Plain }\end{array}$} & $\begin{array}{l}\text { ASTM A563 DH } \\
\text { Plain }\end{array}$ & ASTM F436-1 & $174 \mathrm{kN}(70 \%)$ & 5 \\
\hline & $\begin{array}{l}\text { ASTM A563 DH } \\
\text { Plain }\end{array}$ & ASTM F436-1 & $224 \mathrm{kN}(90 \%)$ & 5 \\
\hline \multirow{2}{*}{$\begin{array}{l}\text { ASTM A325 } \\
\text { Type } 1 \\
\text { Galvanized }\end{array}$} & $\begin{array}{c}\text { ASTM A563 DH } \\
\text { Galvanized }\end{array}$ & $\begin{array}{c}\text { ASTM F436-1 } \\
\text { Galvanized }\end{array}$ & $174 \mathrm{kN}(70 \%)$ & 5 \\
\hline & $\begin{array}{c}\text { ASTM A563 DH } \\
\text { Galvanized }\end{array}$ & $\begin{array}{l}\text { ASTM F436-1 } \\
\text { Galvanized }\end{array}$ & $224 \mathrm{kN}(90 \%)$ & 5 \\
\hline \multirow{2}{*}{$\begin{array}{c}\text { ASTM A193 B8 } \\
\text { Class } 2\end{array}$} & $\begin{array}{l}\text { ASTM A563 DH } \\
\text { Plain }\end{array}$ & $\begin{array}{l}\text { SS316L } \\
\text { Stainless }\end{array}$ & $150 \mathrm{kN}(70 \%)$ & 5 \\
\hline & $\begin{array}{c}\text { ASTM A563 DH } \\
\text { Galvanized }\end{array}$ & $\begin{array}{l}\text { SS316L } \\
\text { Stainless }\end{array}$ & $150 \mathrm{kN}(70 \%)$ & 5 \\
\hline
\end{tabular}




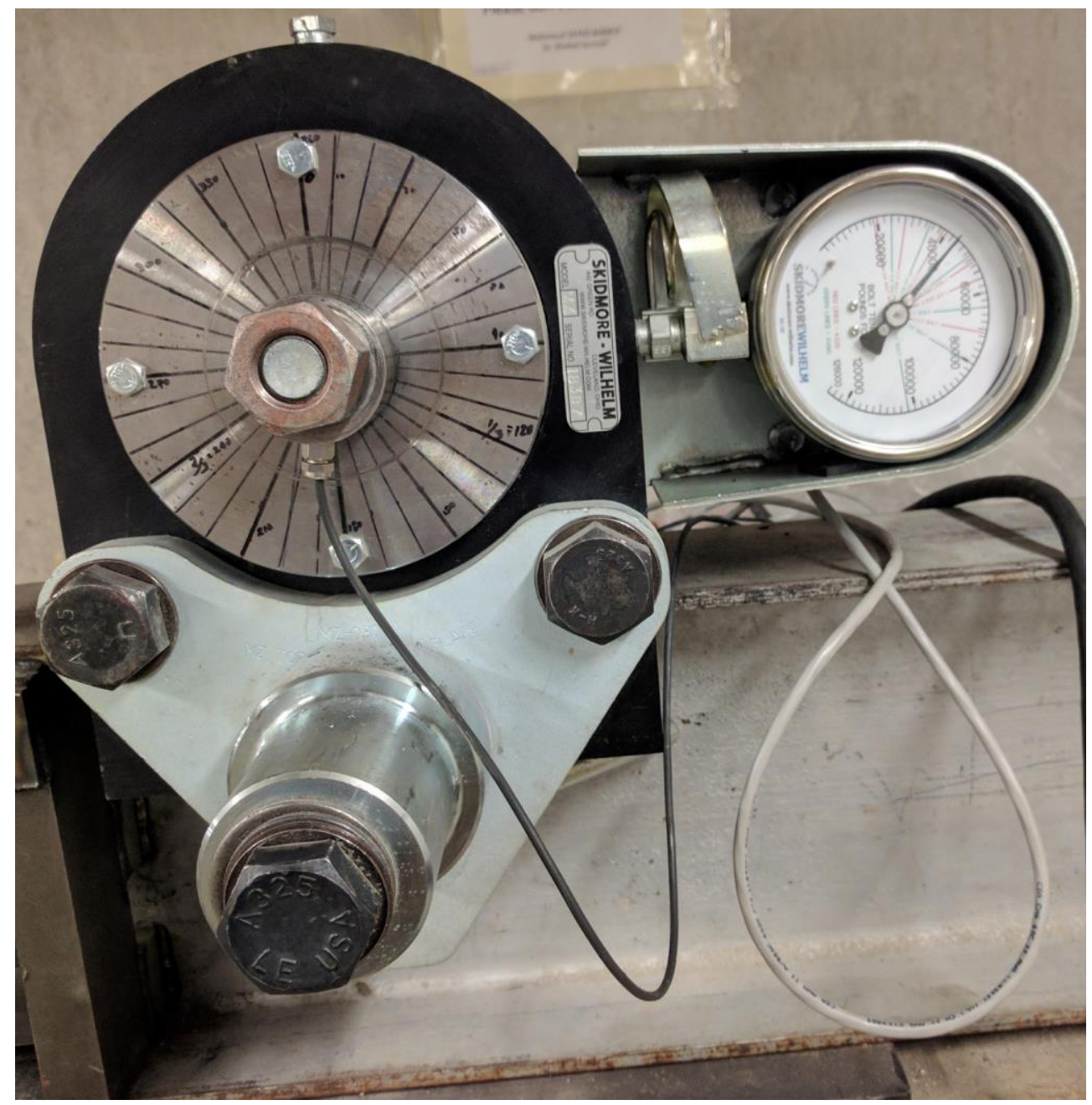

Figure 3-18: Bolt Relaxation Test Set-Up

\subsection{Dissimilar Metal Galvanic Corrosion Testing}

Accelerated galvanic corrosion testing was conducted in this study for different steel and bolt types using the three-plate specimens tested for slip-resistance. Both A1010 and 350W steel specimens were submerged in $5 \%$ sodium chloride, $0.1 \%$ calcium chloride and $0.075 \%$ sodium bicarbonate solution. A copper mesh connected to power supplies applied a large current through the bolt in order to have a visual representation of the effect of galvanic corrosion. The pairing of the tested specimens was as follows: (i) A325 bolt with 350W steel plates; (ii) A325 galvanized bolt with 350W steel plates; (iii) A193 B8 stainless steel bolt with 350W steel plates; (iv) A325 bolt with A1010 steel plates; (v) A325 galvanized bolt with A1010 steel plates; and (vi) A193 B8 stainless steel bolt with A1010 steel plates. These specimens were left in the solution for 7 days. A large 
current of 1 amp was applied initially to all the specimens. Figure 3-19 shows the accelerated test setup before the start of the corrosion while Figure 3-20 show the same setup after corrosion. It was noticed that as each specimen corroded at a different rate, the current would increase accordingly. At the end of the experiment, it was noticed that the bolts paired with the A1010 stainless steel plates exhibited smaller current, with the B8 bolt-A1010 steel pairing showing the lowest current of 1.5 amps when compared to all other specimens, which had currents varying from 1.6 to 2.1 amps. At the end of the 7 days, all the specimens were washed and scrubbed to get rid of all loose corrosion products.

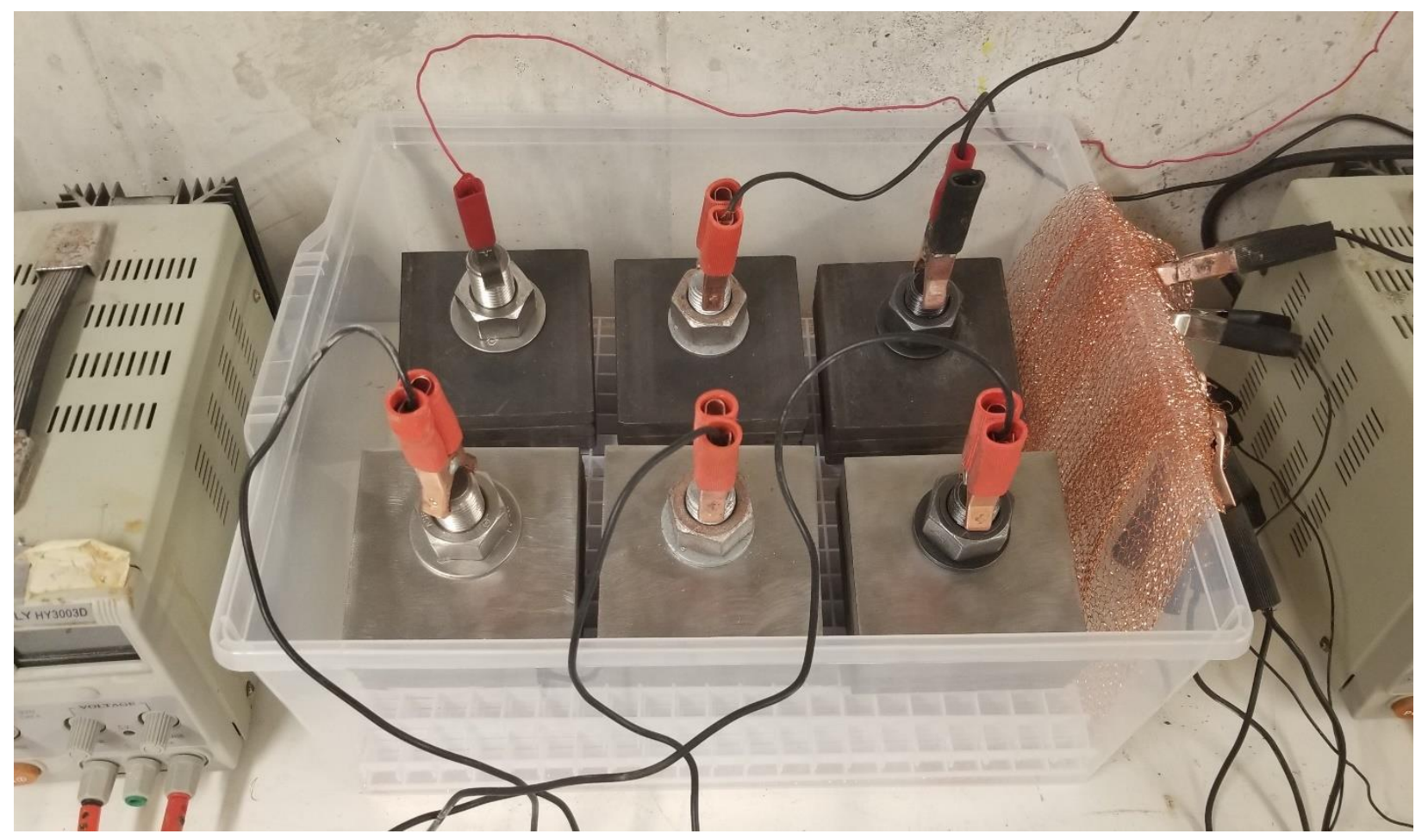

Figure 3-19: Accelerated Testing Set-Up Pre-Corrosion

Figure 3-21 shows views of the 6 specimens before the start the accelerated corrosion. Figure 3-22 and Figure 3-23 show the top and side views, respectively, of the tested specimens after acceleration galvanic corrosion. One may observe that B8 stainless steel bolt with the A1010 stainless steel plates outperformed all other bolt-metal combinations in terms of galvanic corrosion, as expected since both the bolt and the plates are from the same materials. The plain A325 bolt and A1010 stainless steel had the worst performance of all plates exhibiting significant wear of both the plates and the bolt material. Such pairing of dissimilar materials is not recommended to be used for bridges. Also, it can be noticed that the galvanic A325 bolt paired 
with the steel plates performed worse than the A325 galvanized bolt paired with A1010 stainless steel.
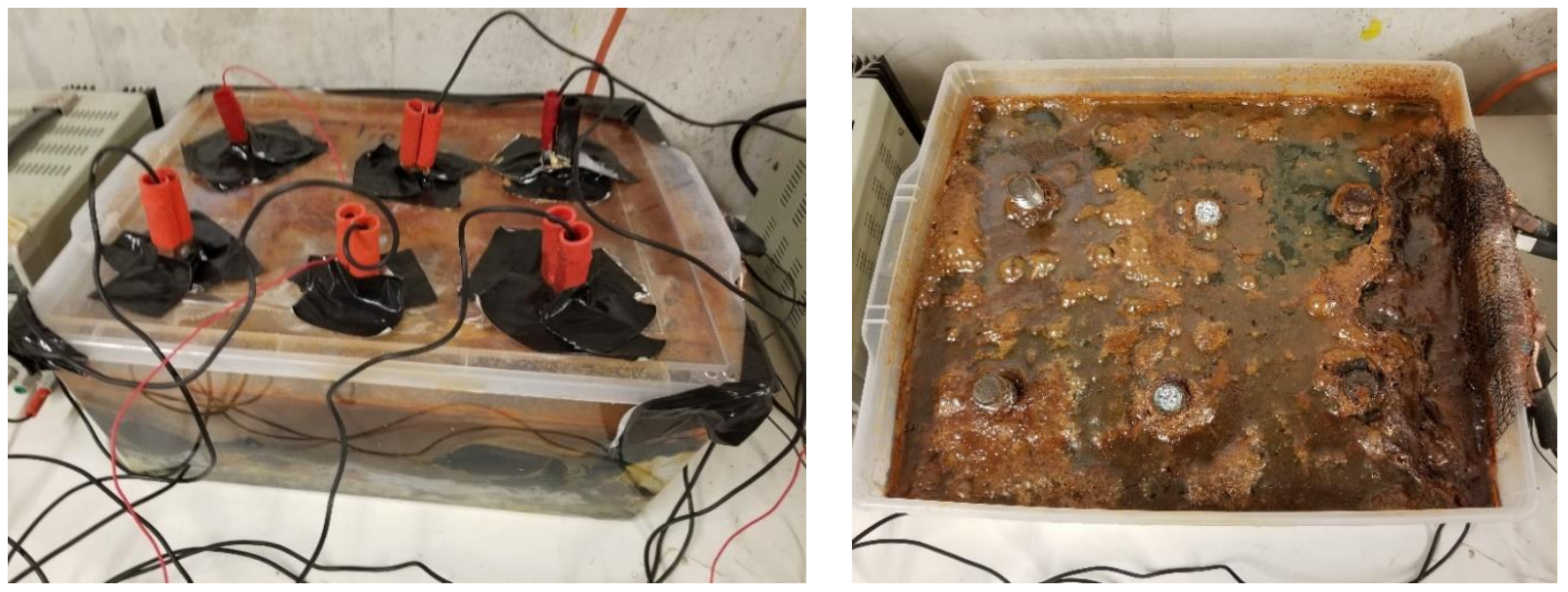

Figure 3-20: Accelerated Testing Setup Post-Corrosion

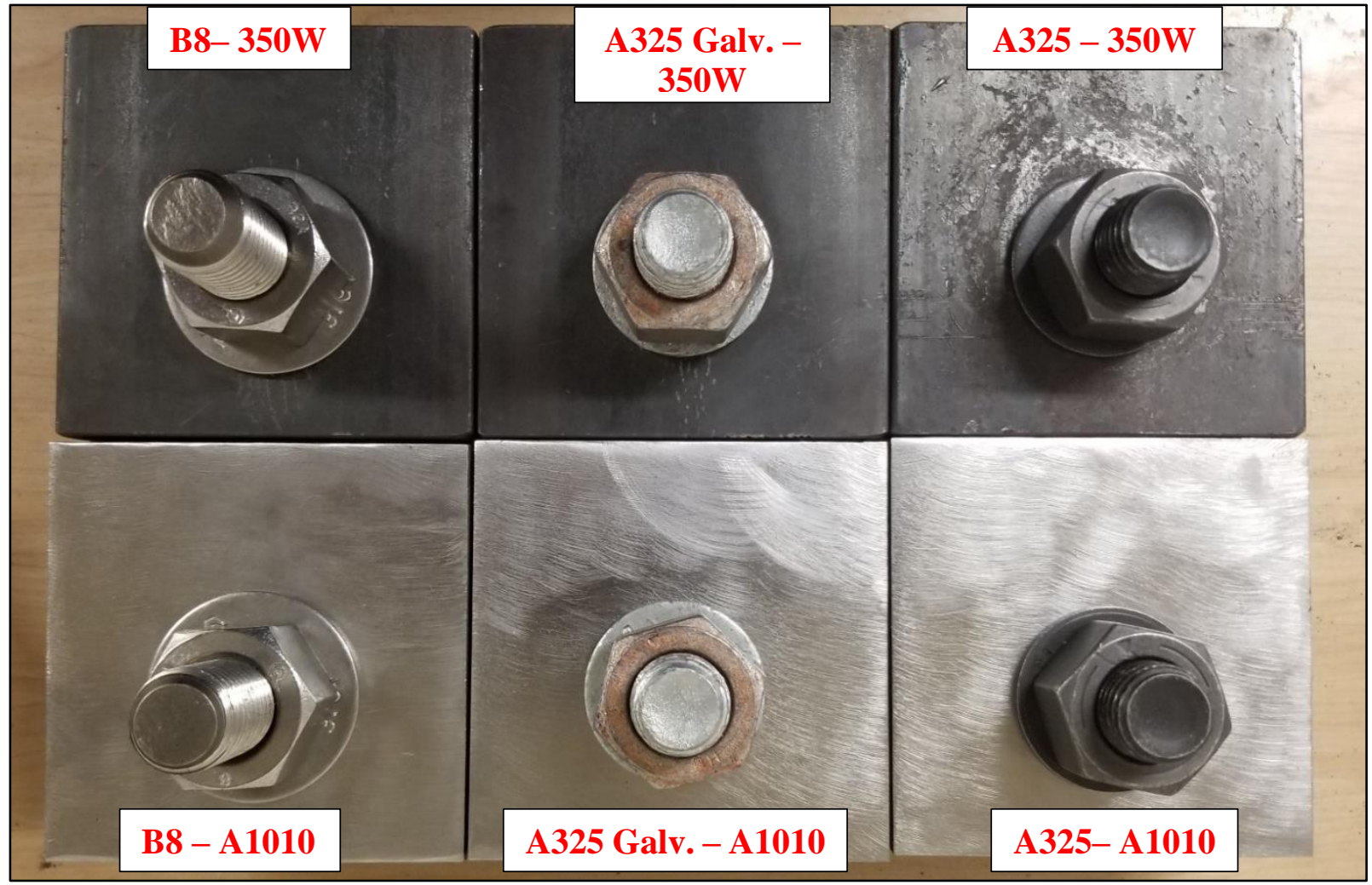

Figure 3-21: Specimens Pre-Corrosion Top View 


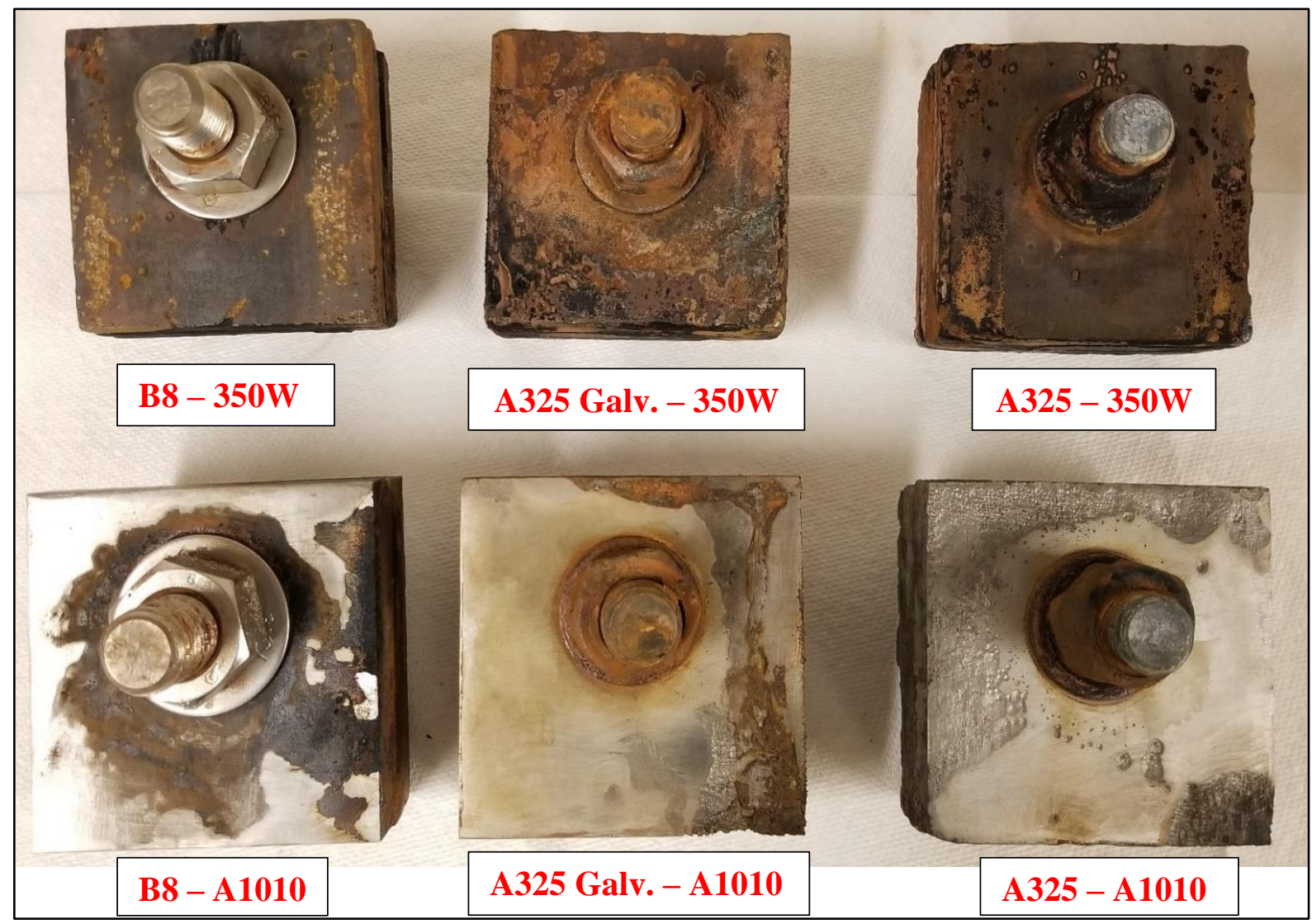

Figure 3-22: Specimens Post-Corrosion Top View

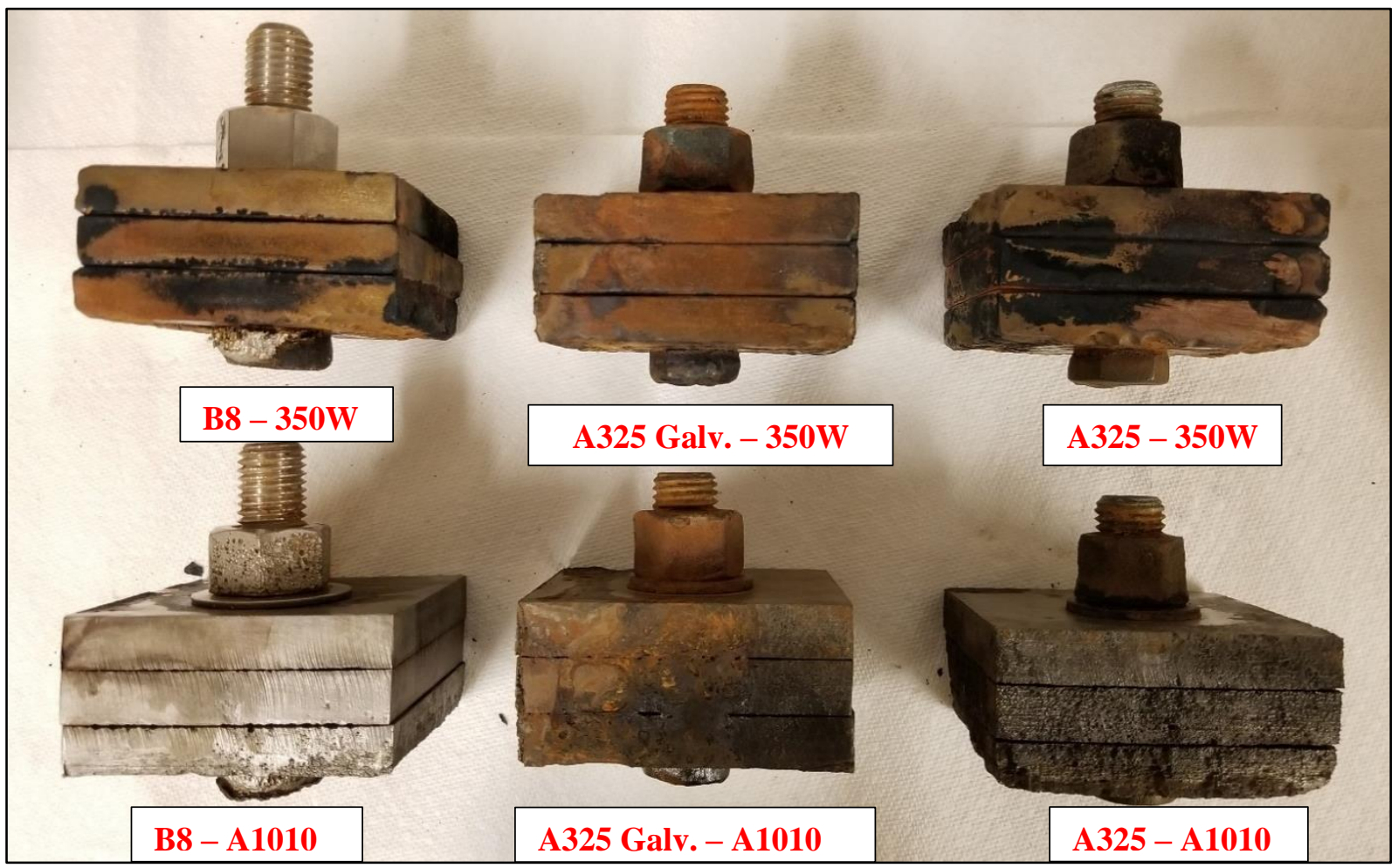

Figure 3-23: Specimens Post-Corrosion Side View 


\subsection{Fatigue and Tensile Testing Experimental Set-Up}

\subsubsection{Steel Coupon Dimensions and Fabrication}

Specimens to be tested for tensile strength and fatigue strength were fabricated from both A1010 stainless steel and conventional CSA G40.21 350W structural steel for comparison purposes. The research team decided to keep specimen thickness similar to the thickness of commonly used bottom girder flanges in stainless steel girders recently built in Ontario. More precisely, it was decided to use the same flange thickness as that used on the Highway 401 Speed River bridges located in Cambridge, Ontario. All I-girders for these bridges over the Speed River was constructed with ASTM A1010 stainless steel. The bridge itself had a span of 64 meters from the west abutment to the east abutment. There were two piers located 18 meters apart from each abutment. There were 3 built-up plate girders with lengths of $23.6 \mathrm{~m}, 17.4 \mathrm{~m}$, and $23.6 \mathrm{~m}$. The webs were connected by two fully bolted field splices. Whereas, the flanges were connected by full joint penetration double-v groove welds at $12 \mathrm{~m}$ from each abutment and also bolt-connected at the two other major splice locations. The bottom flange thickness was $25 \mathrm{~mm}(\sim 1$ ”) on the majority of the girders except for the portion of the girder sitting on top of the piers which had a bottom flange thickness of $30 \mathrm{~mm}$. Figure 3-24 shows typical A1010 girder elevation for the Speed River Bridge. While Figure 3-25 shows top and bottom flange connections at thickness change for Speed River Bridge that is made of full-penetration groove weld.

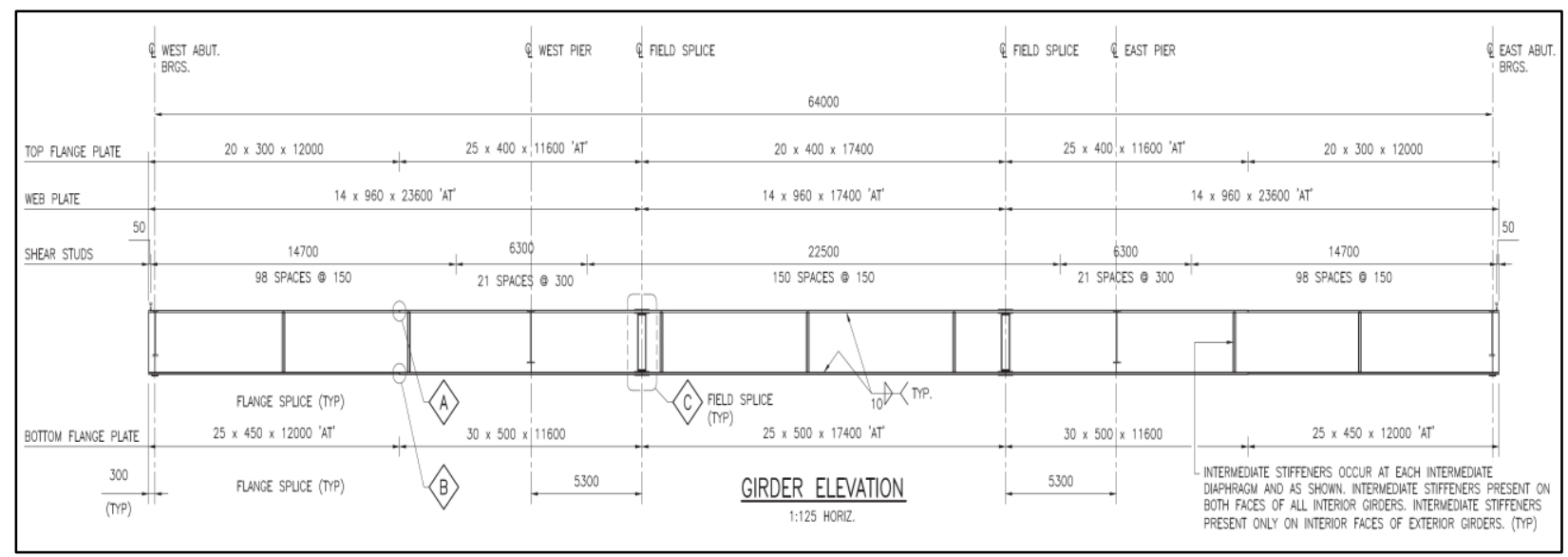

Figure 3-24: Typical A1010 Girder Elevation for the Speed River Bridge (Source: Parsons Corporation Drawing) 


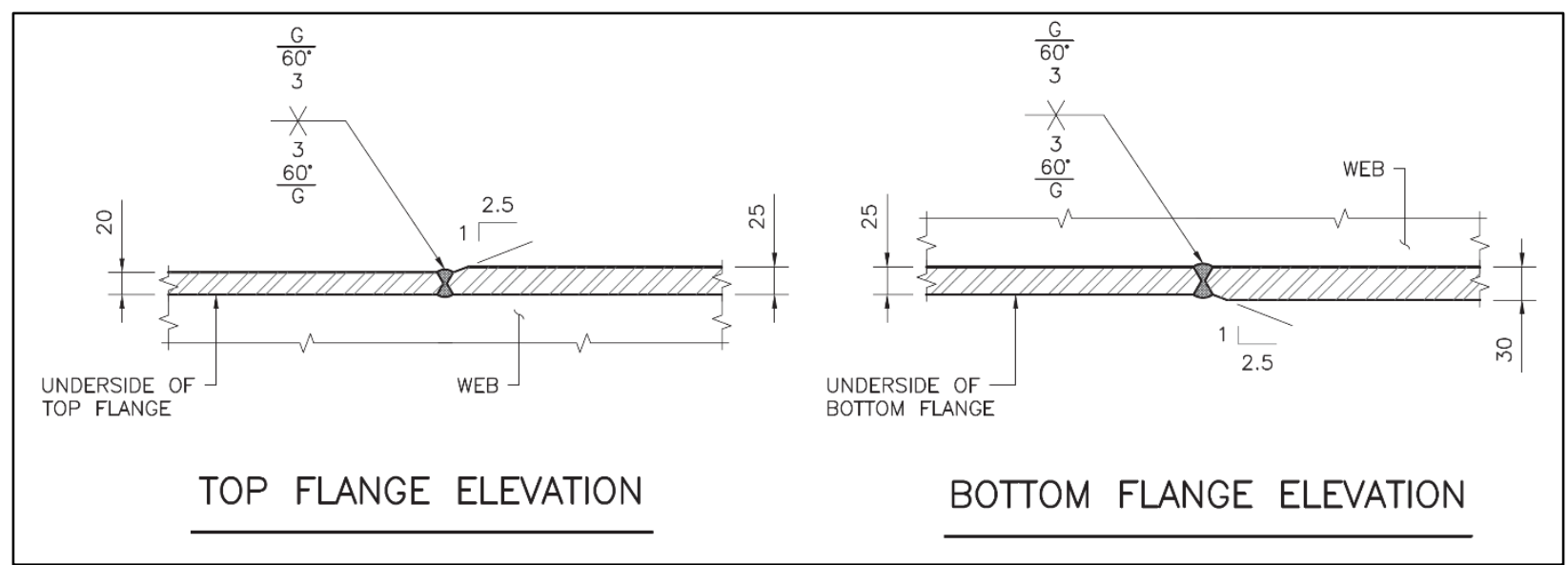

Figure 3-25: Top and Bottom Flange Connections at Thickness Change for Speed River Bridge (Source: Parsons Corporation Drawing)

It is also important to note that specimen dimensions were influenced by certain limitations such as the MTS 815 Universal Testing System located at Ryerson University only having a $100 \mathrm{~mm}$ (4") stroke, meaning that the maximum allowance for pushing and pulling a specimen is $100 \mathrm{~mm}$. Also, the maximum distance between the grips which had a tensile capacity of $450 \mathrm{kN}$ further imposed constraints on specimen length and thickness. The MTS 815 machine had a $4600 \mathrm{kN}$ capacity which is much more than enough to fail a very thick specimen. However, the grips only had a $450 \mathrm{kN}$ capacity and the stroke movement combined with the available length meant that the specimen design had to be large enough to simulate in-field behaviour of the bottom flange but small enough to fail within the constraints of the MTS 815 testing machine.

In general, ASTM E8 Standard Test Method for Tension Testing of Metallic Materials (ASTM, 2016) should be followed for guidance in determining specimen dimensions for tensile testing. The standard can be interpreted as saying that rectangular specimens with a thickness of $19 \mathrm{~mm}$ or greater, shall have a reduced section width of $40 \mathrm{~mm}$ and must have a total reduced section length of at least $225 \mathrm{~mm}$ and a notch radius of at least $25 \mathrm{~mm}$. However, it also states that narrower widths of the reduced section are also permitted. If this standard were to be followed with a specimen of a thickness of at least $25 \mathrm{~mm}$, then the specimen of this length would not fit into the MTS 815 testing system. Thus, the specimen dimensions had to be reduced. In addition, ASTM E606 Standard Test Method for Strain-Controlled Fatigue Testing (ASTM, 2012) also provides general guidance for rectangular specimen dimensions for fatigue testing as can be seen in Figure 
3-26. Still, following these recommendations in designing specimen's dimensions would exceed the length limitations of the MTS 815 testing system.

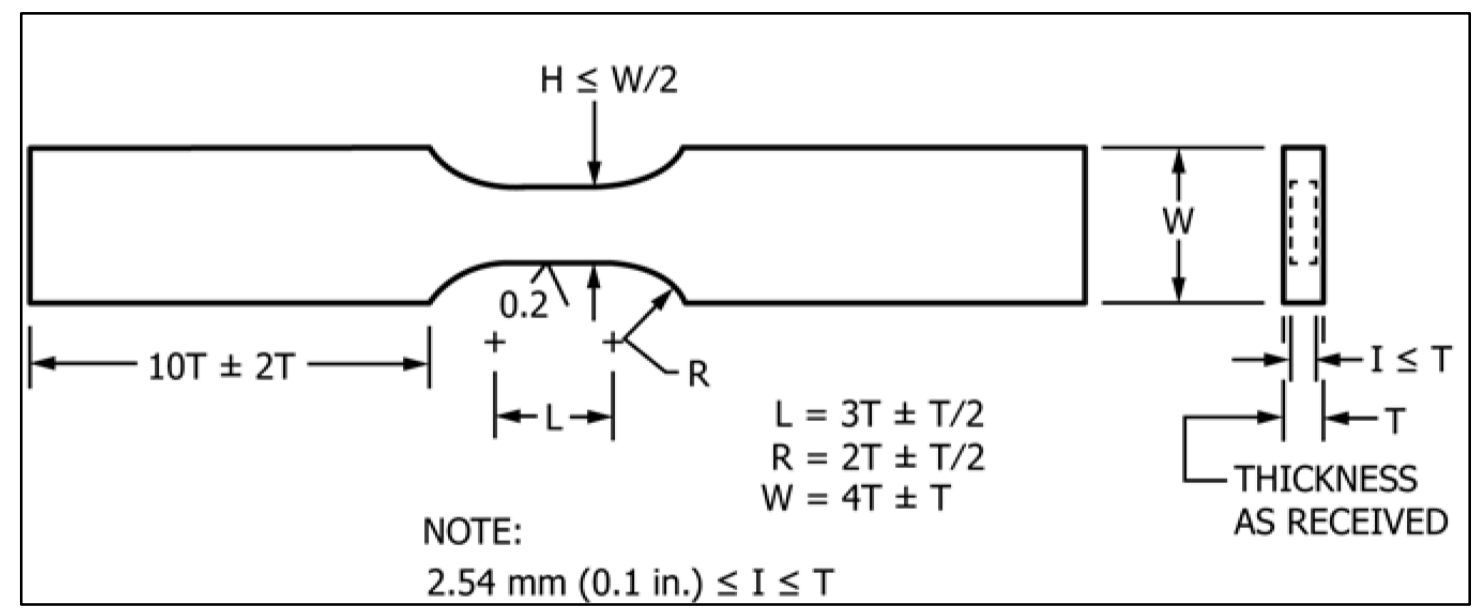

Figure 3-26: Rectangular Specimen Dimension Recommendations for Fatigue Testing (ASTM, 2012)

The fabricated coupon specimen in this research had a thickness of $25 \mathrm{~mm}$ (1"), a grip width of 50 $\mathrm{mm}(2 ")$ and a grip length of $75 \mathrm{~mm}$ (3") which closely matches up with ASTM E8 standard. The reduced section had a notch radius of $12.5 \mathrm{~mm}(0.5 ")$ and a reduced section length of $100 \mathrm{~mm}(4 ")$. The width of the reduced section was $25 \mathrm{~mm}$ (1"). This was intentionally set to accommodate the maximum capacity of the grips holding onto the specimen when testing to ultimate failure. The overall total length of the specimen was $275 \mathrm{~mm}$ ( 11"). The specimen drawings and dimensions are shown in Figure 3-29 for the bare coupons and Figure 3-30 for the coupons with unequal double bevel groove weld. The welded specimen had similar dimensions to the regular specimen.

After careful consideration and consultation with the same metal fabricator that was used for the Speed River bridge, it was decided to use their specific welding procedure to reduce distortion on A1010 specimens. Due to the confidentiality agreement, specific welding details in terms of parameters used for the tested coupons are not published in this report. However, Provines et al. (2019) published specific welding parameters for complete joint penetration groove weld completed by submerged arc welding (SAW). The welding parameters were set to $370 \mathrm{amps}, 32$ volts, $16 \mathrm{in} . / \mathrm{min}$ travel speed, $45 \mathrm{~kJ} / \mathrm{in}$. heat input and a maximum interpass temperature of $149^{\circ} \mathrm{C}$ $\left(300^{\circ} \mathrm{F}\right)$. Similar to the plates, all coupon specimens were cut by using a waterjet abrasive cutting technique. Waterjet cutting can be quick and easy in terms of cutting relatively complicated shapes 
with minimal effects on the microstructural composition of the steel. In the current research, the speed at which the waterjet cutting was performed was relatively quick because of the thickness of the plates and the high cost of cutting. This can leave an undesirable edge quality which may have negative effect on the fatigue results of the steel specimens. As seen in Figure 3-27, the difference in cutting speed between quality Q1 and Q5 can be as much as 6 times faster. Figure 3-28 shows lag of water jet stream creating poor quality edge finish when trying to achieve faster cutting speeds.

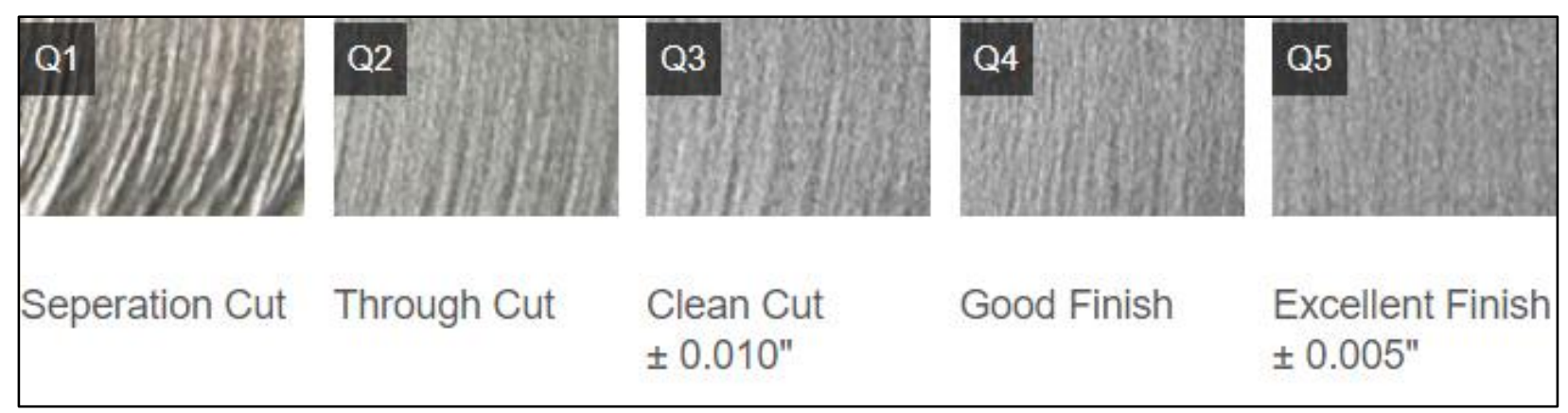

Figure 3-27: Difference in Waterjet Cutting Edge Quality (Source: WARDJet, wardjet.com)

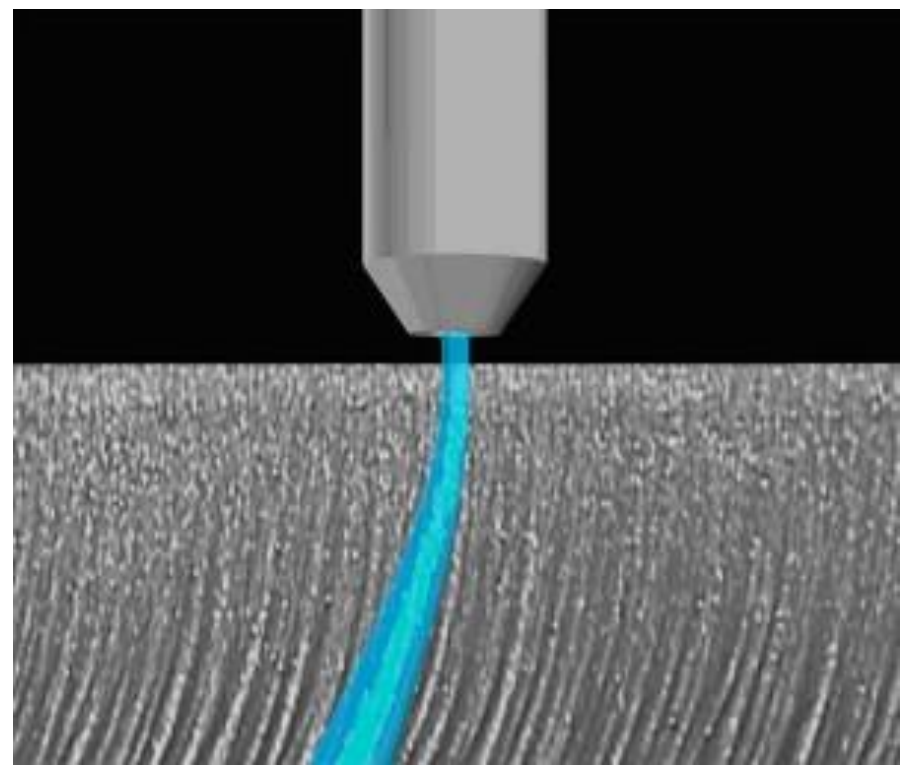

Figure 3-28: Lag of Jet Stream Creating Poor Quality Edge Finish (Source: Dr. J. Olsen, drolsenslab.com) 


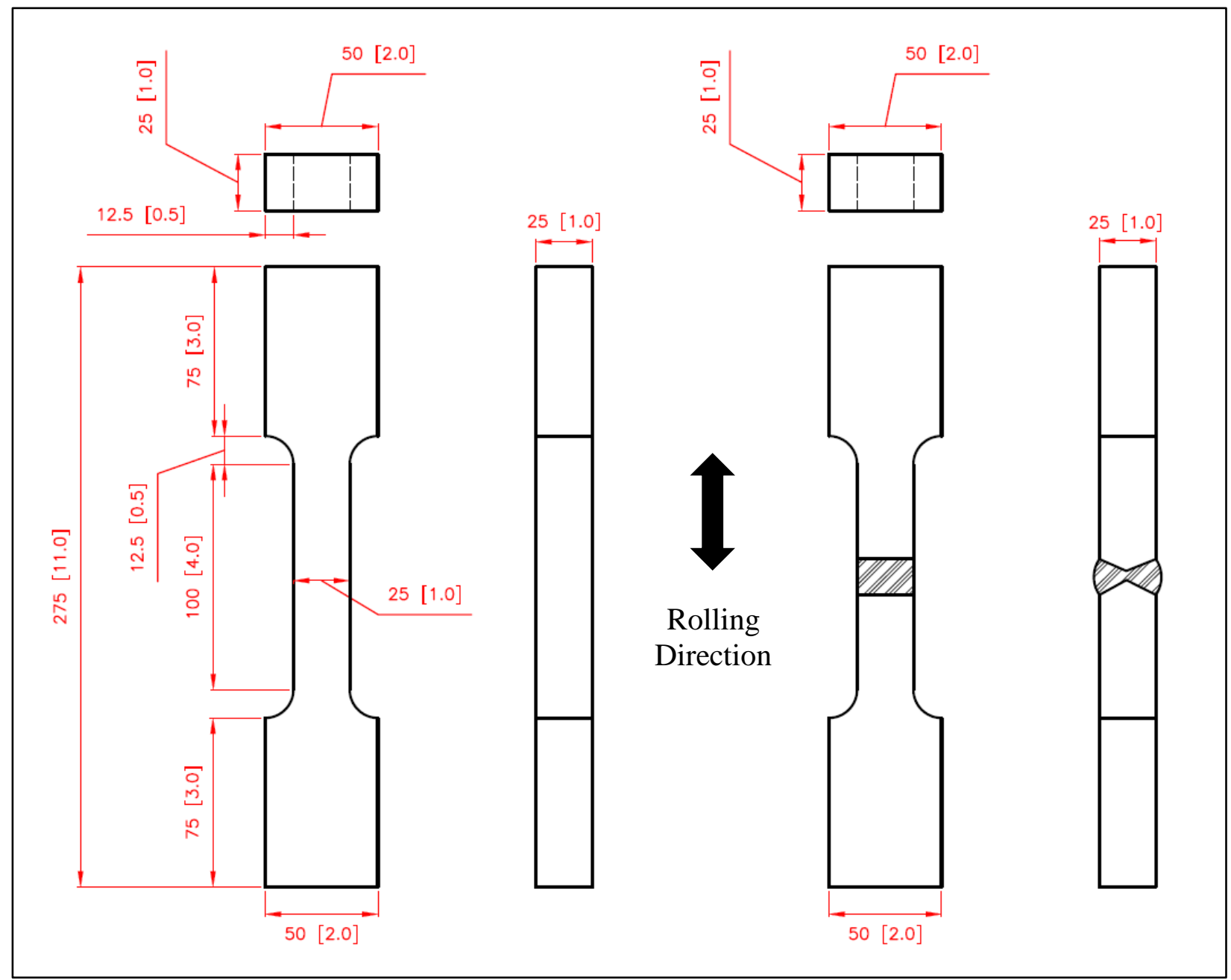

(a) Bare Steel

(b) Groove Welded Steel

Figure 3-29: Long Coupon Specimen Dimensioning for Bare Steel and Groove Welded Steel 


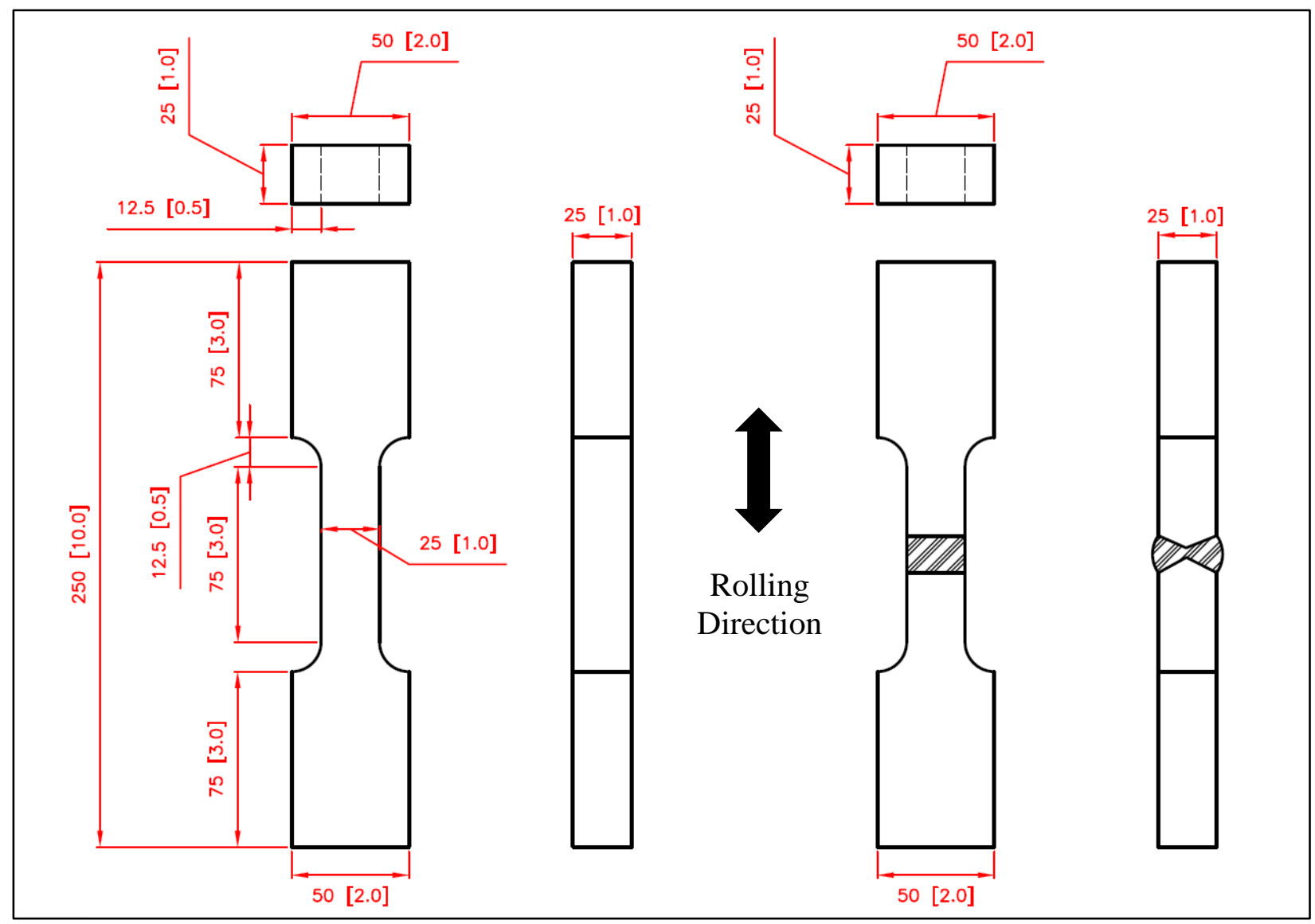

(a) Bare Steel

(b) Groove Welded Steel

Figure 3-30: Short Coupon Specimen Dimensioning for Bare Steel and Groove Welded Steel

\subsubsection{Fabrication of Welded Specimens}

In order to weld steel plates in the fabrication shop, the two $25 \mathrm{~mm}$ (1") thick and 1.5-meter long plates were beveled in order to get a $60^{\circ}$ weld angle. They were then placed together and tack welded onto a bottom flat bar for support as depicted in Figure 3-31(b). The fixed plates were then preheated up to the recommended specified temperature by the manufacturer as depicted in Figure 3-32(a). After preheating, the top side was welded using the submerged arc welding process with a welding system placed on a traveling gantry as shown in Figure 3-32(b). After a slight hardening period, the plates were turned, the supporting bar was removed, and the same welding procedure was applied to the bottom side to fully close the groove as shown in Figure 3-33. Then, the dogbone coupons were cut by abrasive waterjet cutting which is a cold cutting process. A similar procedure was followed for6 welding and fabrication of conventional CSA G40.21 350W 
structural steel coupons. Figure 3-34 and Figure 3-35 show typical top and side views of the welded A1010 coupons, respectively. On the other hand, Figure 3-36 shows a close-up view of the weld region of A1010 steel after it was chemically etched to show the heat-affected zone and any weld defects.

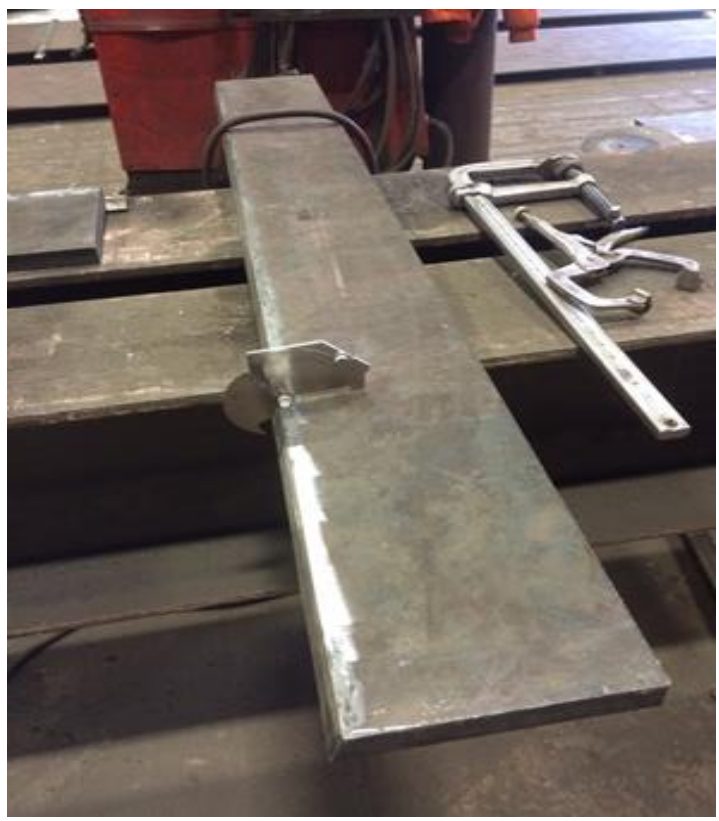

(a)

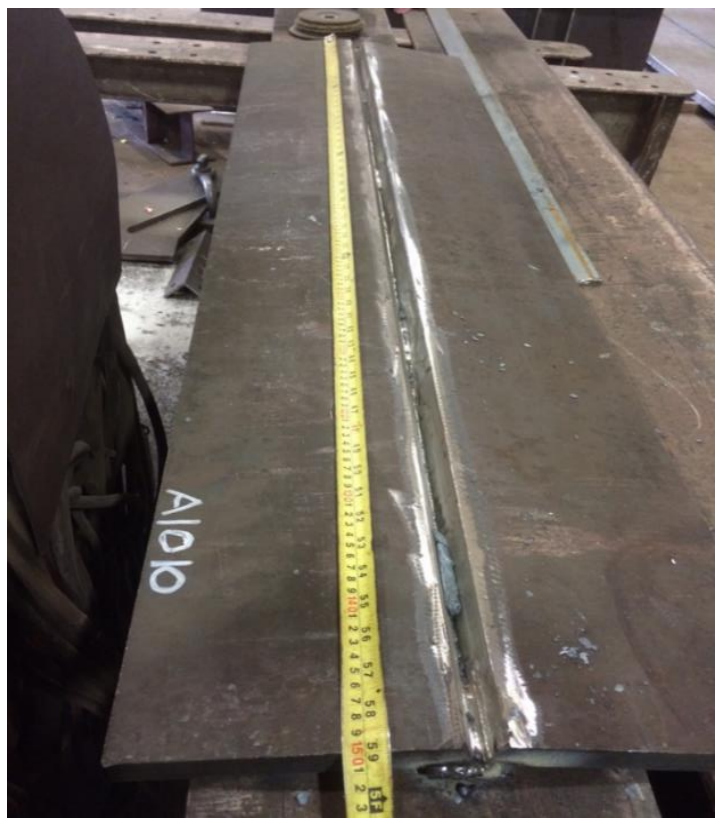

(b)

Figure 3-31: (a) A1010 Plate with Beveled Edge; (b) A1010 Plates Tack Welded to Bottom Strip

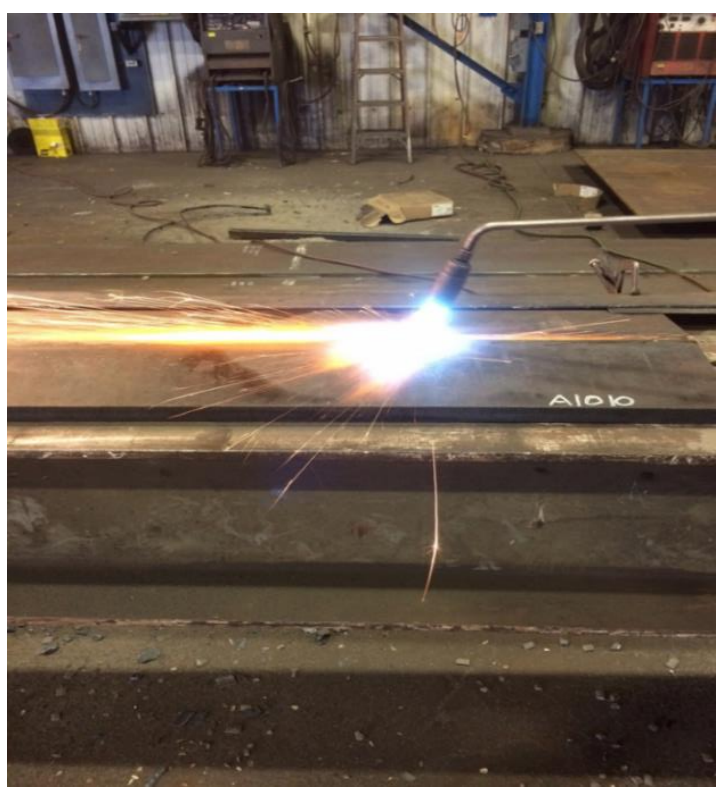

(a)

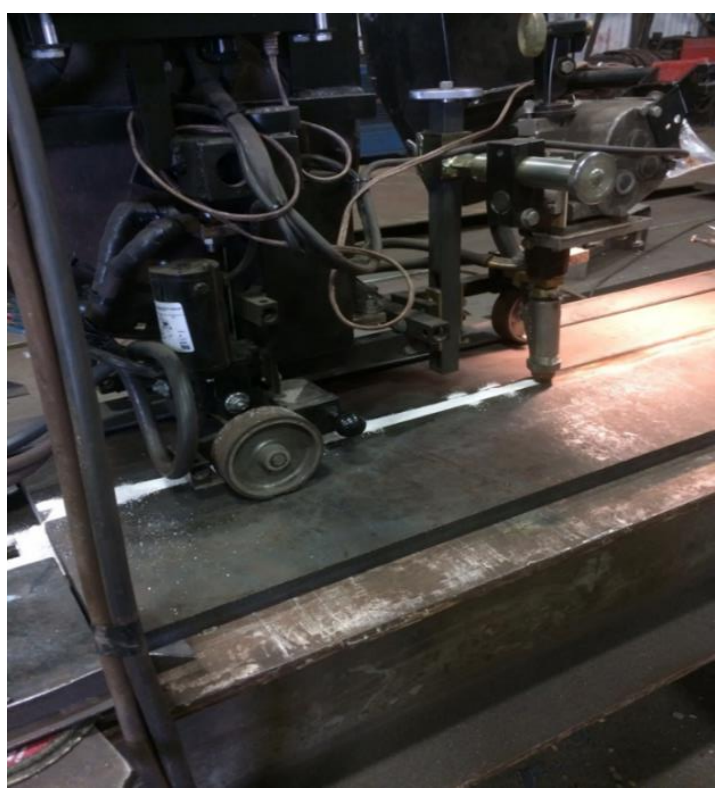

(b)

Figure 3-32: (a) Preheating of Groove; (b) SAW Welding of Groove 


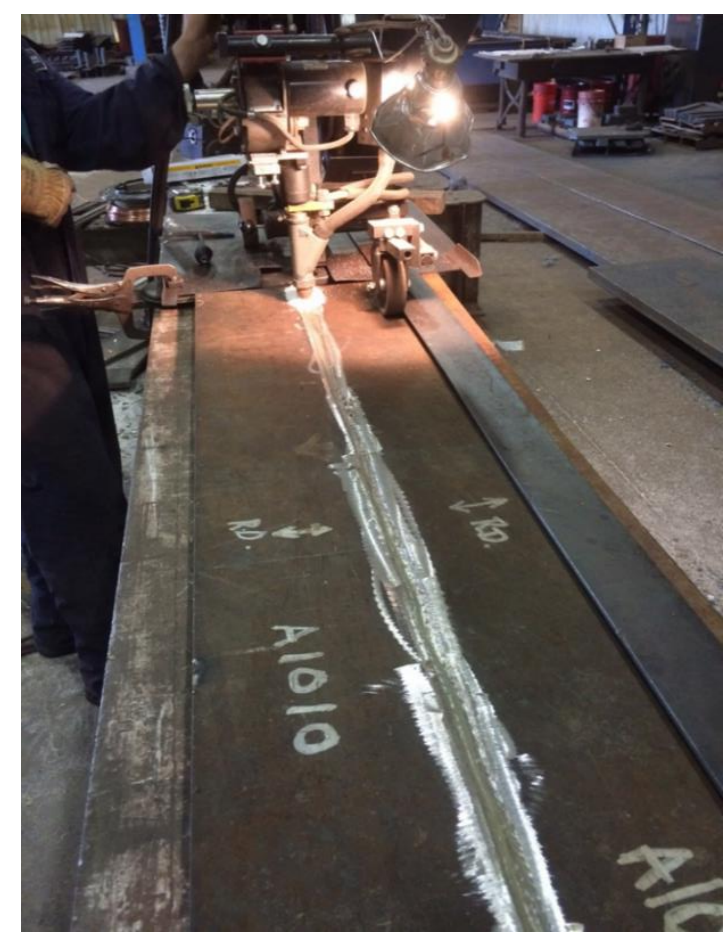

(a)

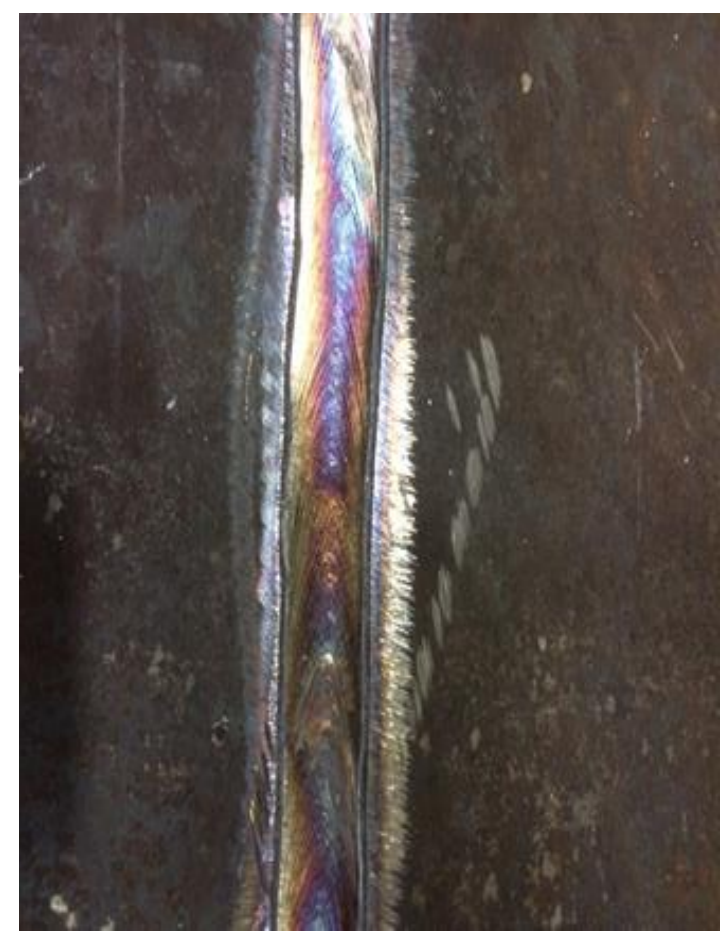

(b)

Figure 3-33: (a) SAW Welding of Other Side of Groove; (b) Close Up of Finished Welded Groove

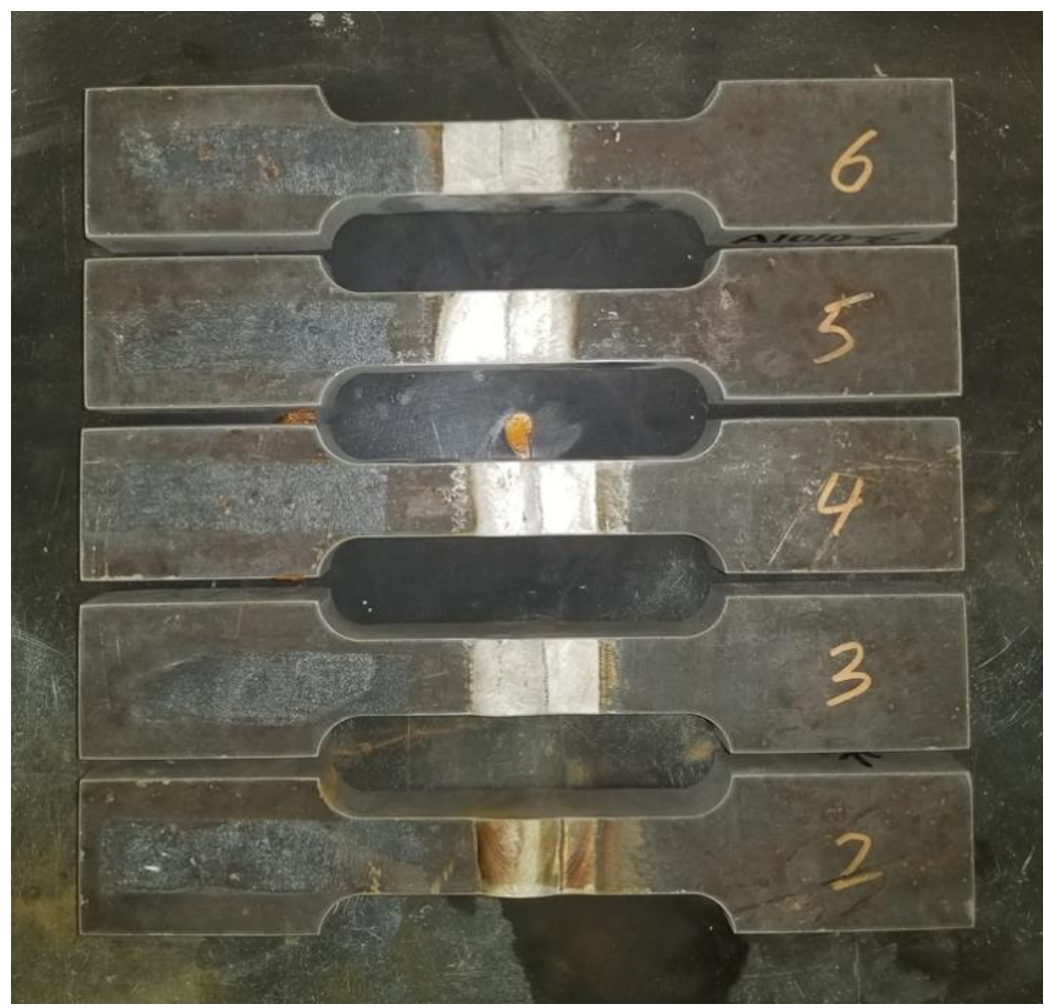

Figure 3-34: Plan View of Welded A1010 Coupons 


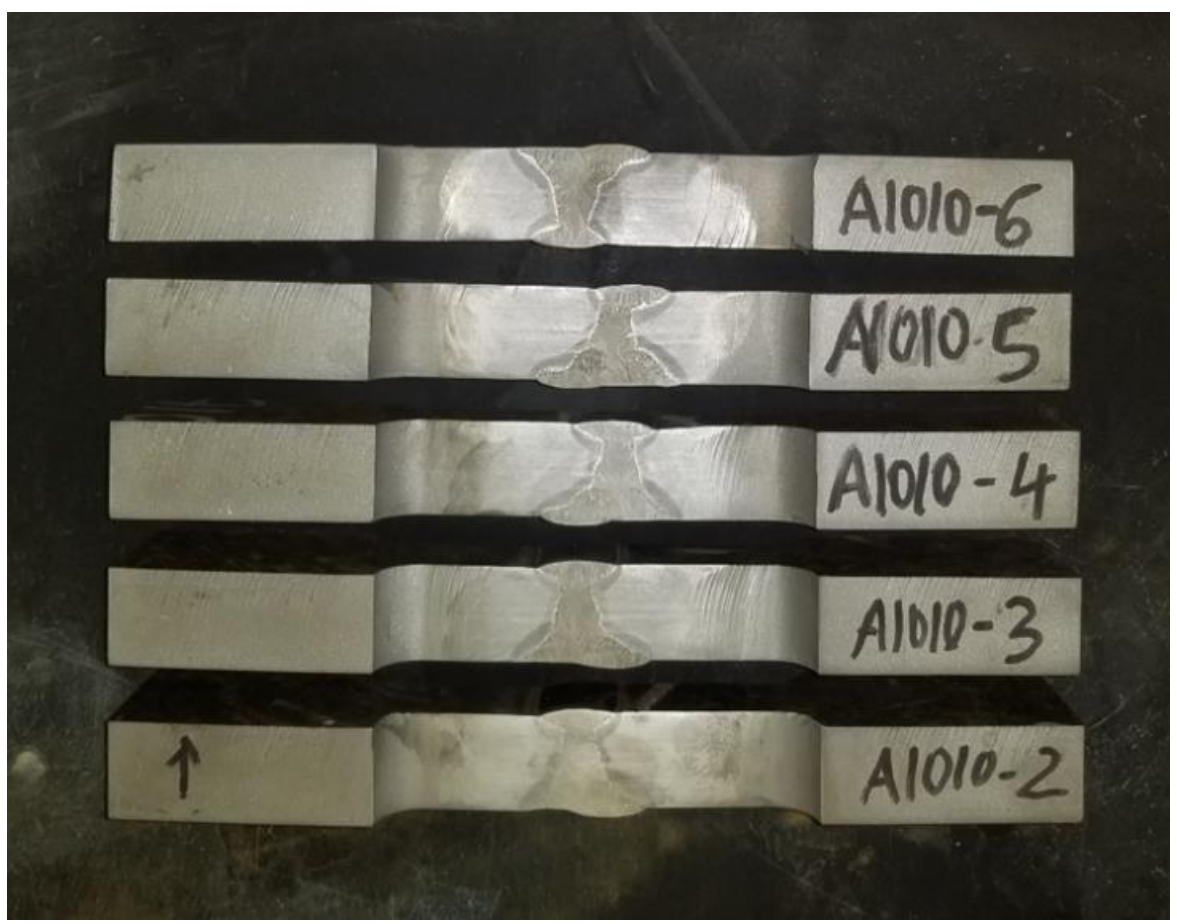

Figure 3-35: Side View of Welded A1010 Coupons

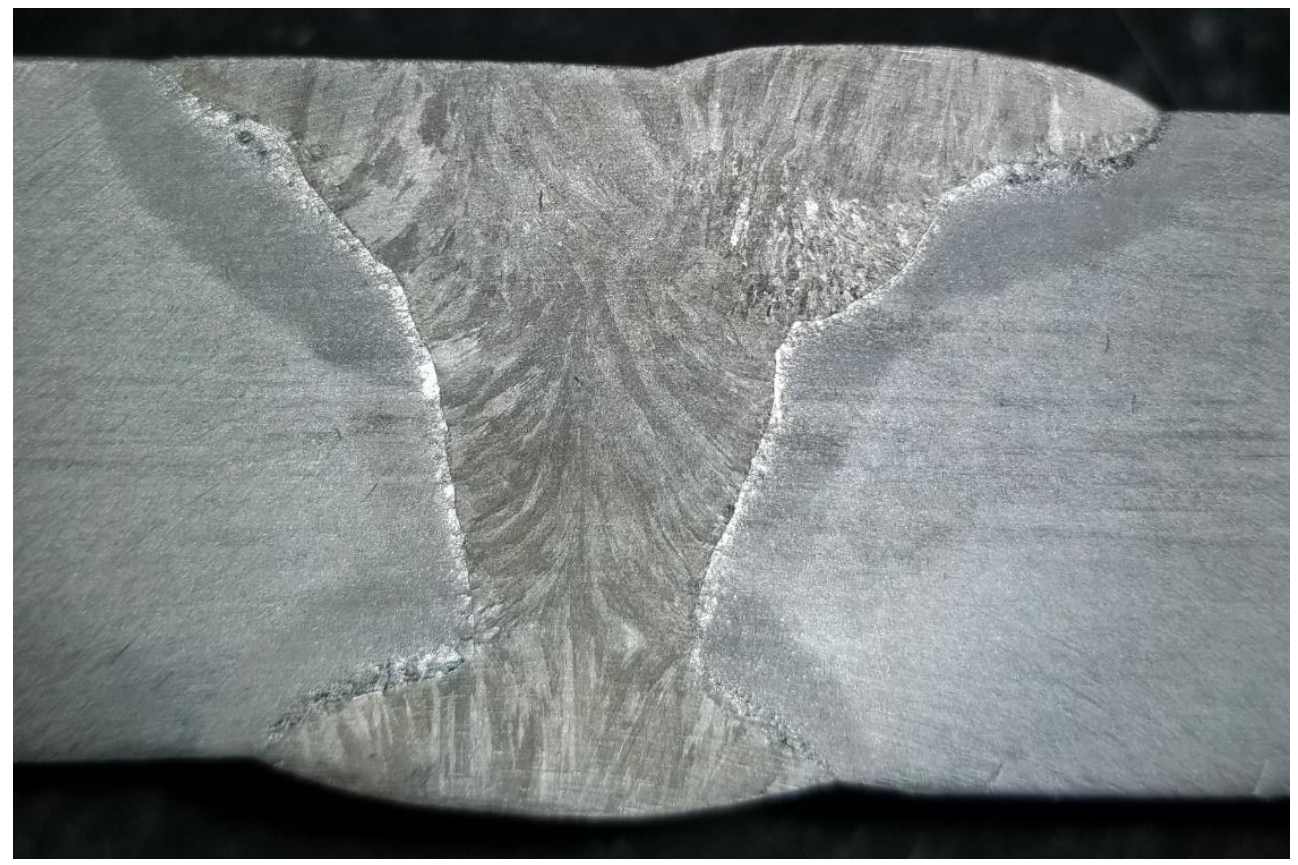

Figure 3-36: Close-Up View of Welded A1010 Specimen After Chemical Etching 
Table 3-4 shows a summary of the research matrix proposed for both montonic static testing and fatigue testing. Due to the limited types of plates available and their dimensions. The research team decided to test 2 coupon specimens for each type of steel, ASTM A1010 and CSA 350W, respectively for both bare and full penetration groove welded specimens. As mentioned, previously the difference between the long and short coupon specimens is a $25 \mathrm{~mm}$ shorter reduced section length. As for the fatigue testing it was decided to test 5 coupons from each steel at five different stress ranges, explained in section 3.4.4. Due to complications arising while testing the fatigue results for the groove welded specimens is not presented on this thesis and will be presented in a future paper.

Table 3-4: Summary of Coupon Specimens Tested for Fatigue and Tensile Testing

\begin{tabular}{|c|c|c|c|c|}
\hline Specimen Type & $\begin{array}{c}\text { Long } \\
\text { Specimens }\end{array}$ & $\begin{array}{c}\text { Short } \\
\text { Specimens }\end{array}$ & $\begin{array}{c}\text { Number of } \\
\text { Specimens } \\
\text { Tested for } \\
\text { Tensile Fatigue }\end{array}$ & $\begin{array}{c}\text { Number of } \\
\text { Specimens } \\
\text { Tested for Static } \\
\text { Tensile Strength }\end{array}$ \\
\hline $\begin{array}{c}\text { ASTM A1010 Stainless Steel } \\
\text { Groove-Welded ASTM A1010 } \\
\text { Stainless Steel }\end{array}$ & 6 & 6 & 5 & 2 \\
\hline $\begin{array}{c}\text { CSA G40.21 350W } \\
\text { Structural Steel }\end{array}$ & 6 & 6 & - & 2 \\
\hline $\begin{array}{c}\text { Groove-Welded CSA G40.21 } \\
\text { 350W Structural Steel }\end{array}$ & 6 & 6 & - & 2 \\
\hline
\end{tabular}

Note: - Welded specimens not yet tested for fatigue at the time of writing this report.

\subsubsection{Static Tensile Testing Setup}

The fabricated specimens were cut out specifically to fit perfectly onto the clearance allowance between the tensile grips which were manufactured by Curtis Sure-Grip Inc. The grips were rated for a capacity of approximately $445 \mathrm{kN}(100,000 \mathrm{lbf})$. After the grips were installed onto the MTS 815 universal testing system, a clearance matching precisely with the specimen length was left over for a perfect fit. It was also important for the grips to sit as close to each other as possible, in order to take full advantage of the $100 \mathrm{~mm}$ (4") maximum piston movement, just in case the material was more ductile than expected. The grips had a $50 \mathrm{~mm}(2$ ") wide coarse flat plate that would latch onto the specimen heads. When the test procedure started, it was important to hold 
tightly onto the grip handles so that the specimen does not slip before the grips fully latched onto the material itself, which usually occurred at a tensile force of about $8 \mathrm{kN}$. An Epsilon 3542-0200100-ST axial extensometer was used to measure the displacement. It had a gauge length of $50 \mathrm{~mm}$ (2") and a capacity of measuring strain up to $100 \%$. The axial extensometer was connected separately to the data acquisition system in addition to the MTS 815 load cell. It started at the same time as the testing program to keep everything constant. The extensometer was not in series with the MTS 815 testing machine due to the connection ports not being available. The extensometer was removed before ultimate failure in order to avoid damage, and the internal displacement from the MTS 815 system was used to measure strain. ASTM E8 - Standard Test Method for Tension Testing of Metallic Materials was used as a guide for the overall procedure. The MTS 815 testing system was placed in displacement control. The speed of testing was set to $0.018 \mathrm{~mm}$ per $\mathrm{mm}$ of the length of the reduced section per minute $(0.018 \mathrm{~mm} / \mathrm{mm} / \mathrm{min})$. Therefore, for our coupon reduced section length which is $100 \mathrm{~mm}$, the rate that the tensile load was applied at rate of 1.8 mm per minute. This number complies with section 7.6.4.3 of ASTM E8, which states that a rate equal to $0.015 \pm 0.003 \mathrm{~mm} / \mathrm{mm} / \mathrm{min}$ should be applied as a crosshead speed for determining yield properties. Overall, eight specimens were tested under tensile loading; 4 long specimens and 4 shorter specimens. The dimensions of all specimens were exactly the same as seen in Figure 3-29 except that the short specimens had a gauge length which was $25 \mathrm{~mm}$ shorter. The reason behind the design of the longer specimens was to allow for room for the extensometer to fit in-between the grips. Figure 3-37 shows view of the tensile test setup. 


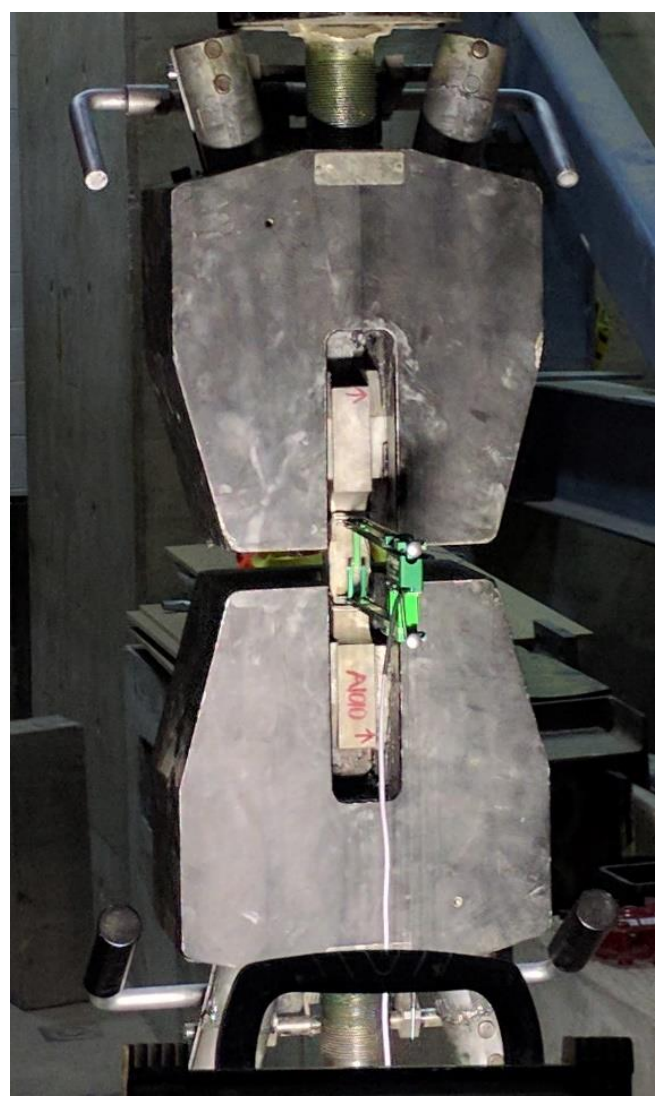

Figure 3-37: Tensile Test Set-Up

\subsubsection{Fatigue Testing Setup}

Fatigue experiments were setup in a similar fashion to that of tensile experiments (see Figure 3-37). The MTS 815 universal testing system with Curtis grips was used in combination with the extensometer attached initially but removed after a certain number of fatigue cycles of loading and unloading. This was determined by closely observing the specimen visually during the test for cracks and significant elongation indicating that the specimen was close to failing. At this point, the extensometer was removed to protect it from the abrupt failure. The specimen was always kept under tensile stress by applying an initial positive tensile load which would correspond to the minimum load and then applying a greater tensile load which corresponds to the maximum load. The test frequency was kept at $1 \mathrm{~Hz}$ (1 cycle per second) which was the maximum frequency that the MTS 815 system was able to run for the given stress range. Later on, a second servo-hydraulic pump was installed onto the MTS 815 system in order to increase the frequency to $2 \mathrm{~Hz}$ and have the experiments run faster. The next inputs into the MTS were the minimum load and the maximum 
load as well as the expected number of cycles to run until failure. It was important to have an input for maximum displacement so that the MTS 815 testing system automatically shuts off when failure on the specimen occurred, this was set at a displacement of $50 \mathrm{~mm}$, which was $50 \%$ of the $100 \mathrm{~mm}$ piston maximum stroke, more than enough to allow for failure of the specimen. Inputs for a maximum number of cycles were set for 150,000 cycles in order to allow the machine to rest in between intervals. Another reason for completing fatigue testing in intervals was because the bolts holding onto the top threaded plate connecting the grips to the MTS failed between 1 to 2 million cycles of testing. Therefore, it was decided to retighten or replace them every 500,000 cycles.

Due to A1010 stainless steel being a new material and never having been tested for fatigue before, it was important to introduce new experimental data corresponding to basic principles of fatigue design. Therefore, a constant force amplitude stress range was chosen for all fatigue specimens. Based on the literature review conducted and common stress ranges that occur as a result of actual loading in bridges, the following five stress ranges were used; $180 \mathrm{MPa}, 200 \mathrm{MPa} ; 225 \mathrm{MPa} ; 250$ $\mathrm{MPa} ; 270 \mathrm{MPa}$. The stress ratio (R), which is the ratio of minimum stress to maximum stress was kept at 0.1 . It was also important to keep the fatigue specimen always in tension in order to avoid any buckling that may arise as a result of compressive stresses. Therefore, the minimum stresses were chosen to be high enough for the grips to fully embed their teeth into the specimen so that no slip occurs. Hence it was chosen to keep the minimum stress above $20 \mathrm{MPa}$ for all specimens. All stresses were converted into actual loads based on the exact measurement of the cross-section of each specimen. These loads were then placed into the MTS computer system. Table 3-5 organizes all parameters used in this research. Figure 3-38 shows a one sinusoidal stress cycle for all tested fatigue stress ranges in this study. 
Table 3-5: Summary of Applied Fatigue Stresses

\begin{tabular}{|c|c|c|c|}
\hline $\begin{array}{c}\text { Applied Stress } \\
\text { Range (MPa) }\end{array}$ & $\begin{array}{c}\text { Minimum Stress, } \\
\Delta \sigma_{\min }(\mathbf{M P a})\end{array}$ & $\begin{array}{c}\text { Maximum Stress, } \\
\Delta \boldsymbol{\sigma}_{\max }(\mathbf{M P a})\end{array}$ & $\begin{array}{c}\text { Stress Ratio (R) } \\
\boldsymbol{R}=\frac{\Delta \boldsymbol{\sigma}_{\text {min }}}{\Delta \boldsymbol{\sigma}_{\max }}\end{array}$ \\
\hline 270 & 30.0 & 300.0 & 0.1 \\
\hline 250 & 27.5 & 277.5 & 0.1 \\
\hline 225 & 25.0 & 250.0 & 0.1 \\
\hline 200 & 22.5 & 222.5 & 0.1 \\
\hline 180 & 20.5 & 200.5 & 0.1 \\
\hline
\end{tabular}

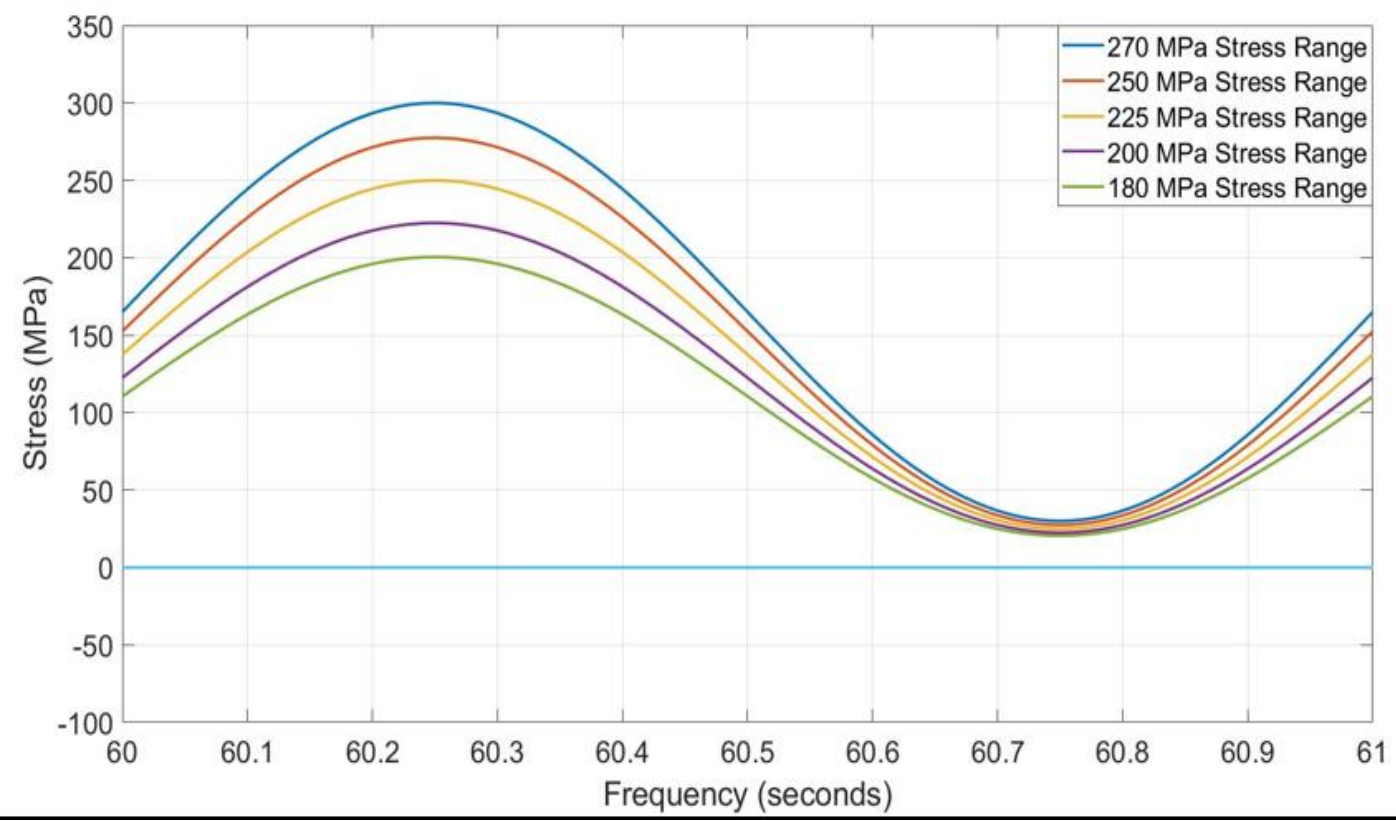

Figure 3-38: One Sinusoidal Stress Cycle for all Tested Fatigue Stress Ranges 


\section{Chapter 4 - Slip Resistance and Bolt Relaxation Results}

\subsection{Surface Roughness Test Results}

Measuring the surface roughness especially when evaluating slip resistance coefficient for structural bolted connections is a primary distinction in which the North American standards have yet to adopt. Hence, why the decision was made to take surface roughness measurements of the blasted-clean metals before they were tested. Regarding different methodologies to blast metals and the achieved surface topologies, literature review revealed that structural steel codes (CSA, 2014a; CSA 2014b; AASHTO, 2017) do not quantify surface profiles and categorize them in terms of their effects on the value of slip resistance. Kulak and Fisher (2001) mentioned that surface profiles of metals are a direct indication of metal hardness. It is common sense to assume that metals with low hardness will have a much deeper asperity when it is impacted by a certain medium (i.e. stainless still grit) in comparison to a harder surface metal. A deeper profile created during blasting will lead to a rougher surface and as a result, should lead to better interlocking between the grooves along the plate surfaces. However, this might not always result in a higher slip resistance coefficient because if the surface hardness is much weaker, one can assume that the profile peaks will yield before and thus 'slip' more than a harder material. Blasting metals with different materials of varied geometries and angles of impact should theoretically have an influence on the roughness and in turn slip resistance coefficient. These parameters were beyond the scope of this study, but further research is recommended so that they can also be quantified in order to make it easier in guiding fabricators so that the desired slip resistance coefficient is reached in practice.

Two parameters of surface roughness were measured for all 30 plates tested in this study to determine the slip resistance coefficient, namely $R_{z}$ and $R_{\max }$ (also known as $R_{t}$ ). $R_{z}$ parameter is defined as the average of 5 peaks to valley differences within 5 sampling lengths. While $R_{\max }$ is defined as simply the distance between the highest peak and lowest valley. These two surface profiles were selected because it was easier to compare results with other studies done primarily in Europe, where the usage of $R_{z}$ and $R_{\max }$ values are much more common and at the same time are listed on their codes. Another commonly used parameter is the $\mathrm{R}_{\mathrm{a}}$ which is also known as the arithmetic mean. It is defined as the distance between the average profile and mean center line 
divided by the evaluation length. In this study, it was decided against using $R_{a}$ as a measurement for average roughness because it is a statistical value and it is not sensitive to peaks/valleys, thus making it an untrue representative of surface characteristics. In other words, two very different looking surface profiles can have the same $\mathrm{R}_{\mathrm{a}}$ value. Figure 4-1 show a schematic diagram of surface roughness profile and associated parameters, while equations 4.1 and 4.2 provide the means for the calculation of these parameters.

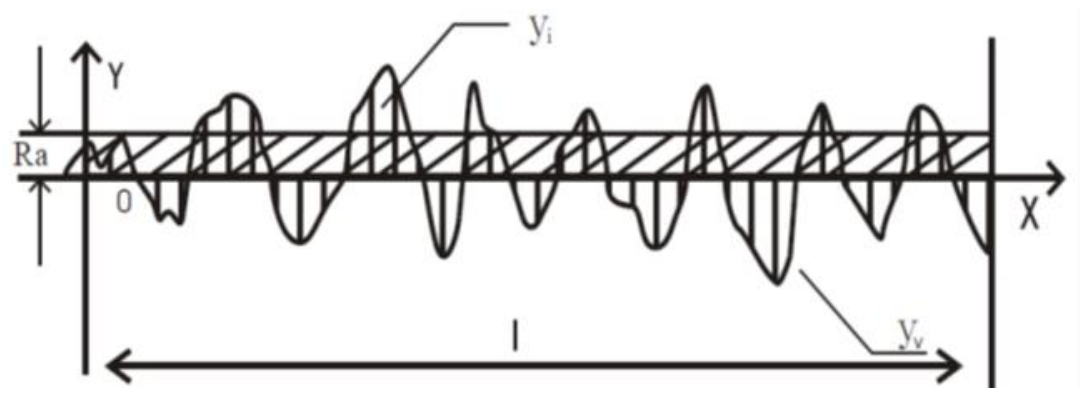

(a)

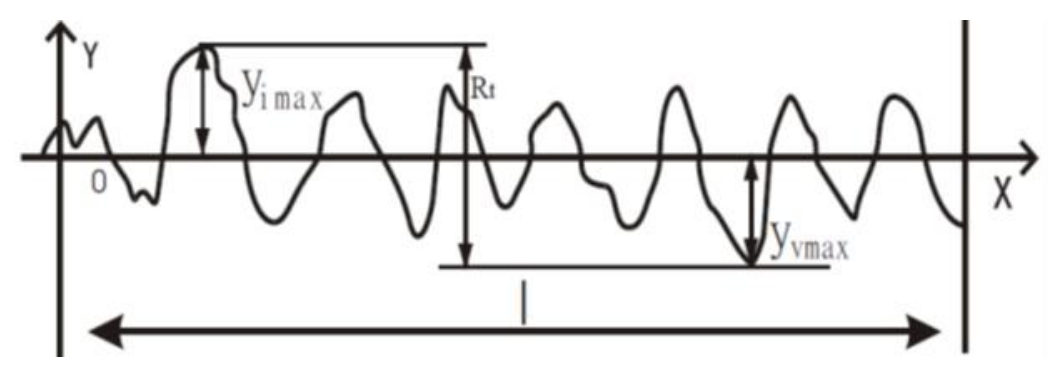

(b)

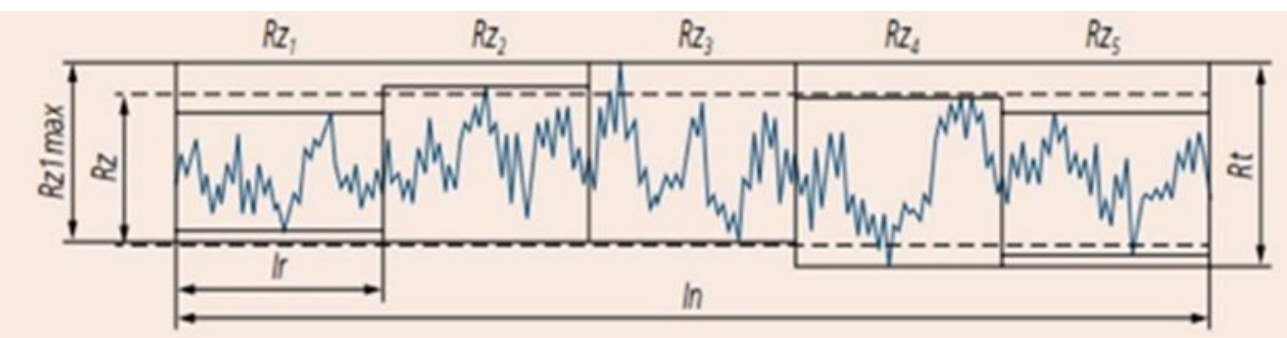

(c)

Figure 4-1: Surface Roughness Parameters: (a) $\mathbf{R}_{\mathbf{a}}$; (b) $\mathbf{R}_{\mathbf{t}}$; (c) $\mathbf{R}_{\mathbf{z}}$ (Source: Shimana)

$R_{a}=\frac{1}{n} \sum_{i=1}^{n}\left|y_{i}\right|$

$R_{Z}=\frac{\sum_{i=1}^{5} y_{i} \sum_{i=1}^{5} y_{v}}{5}$ 
Table 4-1: Recorded Average Surface Roughness

\section{Surface Profile}

Parameters

\section{ASTM A1010 Stainless Steel}

CSA G40.21 350W

Conventional Structural Steel

$59.53 \mu \mathrm{m}(2.34$ mils $)$

$61.99 \mu \mathrm{m}(2.44$ mils $)$

Note: $25.4 \mu \mathrm{m}=1 \mathrm{mil}$ (thousandth of an inch)

Surface roughness was measured at 5 different points, 4 of them located near the diameter of each hole and 1 located further down outside of the clamped area influenced by the washer diameter. Measurements were taken in 2 plates for each slip resistance specimen, more specifically on one side of the blasted clean middle plate and on the blasted side of the outer plate. Therefore, the surface roughness was measured in a total of 60 plates. Table 4-1 shows the average surface roughness of each parameter for ASTM A1010 stainless steel and that of the regular CSA G40.21 350W traditional structural steel. It can be observed that stainless steel grit used in surface blasting in this study resulted in a much deeper profile of the ASTM A1010 stainless steel plate compared to the traditional steel, approximately $23 \%$. This indicates that the stainless steel plates had a much lower surface hardness. These surface roughness values were verified by using two different surface profile gauges, namely: Shimana SHGLST022 and Shimana SHGLST129. Since the SHGLST129 gauge measured only the $\mathrm{R}_{\max }$ values, that is the maximum peak and valley distance, it was decided to use the $\mathrm{R}_{\max }$ value to verify the roughness measurements. The difference between the average $R_{\max }$ measured with two different gauges was $2 \mu \mathrm{m}$ (0.08 mils) for A1010 stainless steel $3.14 \mu \mathrm{m}$ (0.12 mils) for CSA G40.21 350W traditional steel. Therefore, it was concluded that the results were very close to one another and thus valid.

\subsection{Slip Resistance Coefficient Results}

All slip resistance tests were conducted under compression, similar to the test described by the Research Council of Structural Connections (RCSC, 2014). Initially, it was decided to conduct 5 tests by using the turn-of-nut bolt pretension method in order to compare the results to the tests conducted by Cameron (2017). Cameron (2017) conducted slip resistance tests on A1010 steel surfaces blasted clean with sandblasting. That study resulted in lower slip loads giving an average slip resistance coefficient in the range of 0.20 to 0.25 . It is important to note that the slip resistance coefficient was calculated by using the average preload of A325 plain bolts tested on the Skidmore- 
Whilhelm hydraulic load cell. However, in this study it was also decided to use a hydraulic piston in combination with a washer-type load cell to ascertain whether there is a large change in clamping force during the duration of the test and to precisely determine the slip resistance coefficient.

The slip coefficient $\left(\mathrm{k}_{\mathrm{s}}\right)$, as presented in equation 4.3, is determined by dividing the slip load over twice times the clamping force that was achieved at the beginning of the test. The slip load is divided by 2 which represents the number of faying planes in the three-plate specimen, which is similar in the case of a double shear joint.

$k_{s}=\frac{\text { Slip Load }}{2(\text { Clamping Load })}$

It is important to distinguish the definition of slip load when calculating the slip resistance coefficient for structural metals under compressive testing in the joint. The slip load is taken as the first major slip that occurs before a displacement of $0.5 \mathrm{~mm}$. If the major slip occurs after $0.5 \mathrm{~mm}$ then the slip load is taken at a displacement of $0.5 \mathrm{~mm}$. To determine the slip load at $0.5 \mathrm{~mm}$ displacement in the linear-elastic range, it was decided to draw a tangent line from the linear portion of the curve all the way down to the displacement axis and start counting $0.5 \mathrm{~mm}$ from there to get the corresponding slip load. Table 4-2 summarizes the average results obtained for the slip resistance test. It was observed that ASTM A1010 stainless steel plates resulted in a lower slip load compared to that of conventional steel $(350 \mathrm{~W})$. This was observed for both types of clamping methods.

Figure 4-2 depicts the average applied load - slip relationship for all the blasted clean tested specimens. One may observe that this relationship started with nonlinear relationship until the plate surface asperities in the setup 'lock' into place with a firmer grip, which occurred at a slip load of about $20 \mathrm{kN}$. Then, the relationship trended upward in a linear-elastic manner, followed by increase in the rate of displacement beyond the linear stage that led to decrease in the applied load after reaching its peak slip load value. The test was adjusted to terminate at maximum displacement of $2 \mathrm{~mm}$.

All the average graphs in Figure 4-2 are similar in shape and the average peak load occurred at a displacement of approximately $1 \mathrm{~mm}$. One may notice that the peak load for the conventional steel, 
$350 \mathrm{~W}$ is approximately $80 \mathrm{kN}$ higher (33\% higher) than that of A1010 stainless steel. The maximum slip resistance coefficient calculated at the peak load for the specimens clamped with a hydraulic jack was 0.49 for A1010 stainless steel and 0.68 for $350 \mathrm{~W}$ structural steel, respectively. Whereas, the maximum slip resistance coefficient calculated at the peak load for the specimens clamped by the turn-of-nut method was 0.54 and 0.74 for A1010 and 350W steel, respectively.

Figure 4-2 also shows that the pretension reached by using the turn-of-nut method and the hydraulic piston yielded almost similar load vs displacement curves. It is important to recall that the bolt being pulled by the hydraulic piston resulted in a clamping force of $230 \mathrm{kN}$. Thus, one can conclude that turning the nut $120^{\circ}$ from snug tight condition resulted in a similar slip load curve to that of the plates that were clamped by a hydraulic jack with a load of $230 \mathrm{kN}$. This is important to note because the average bolt clamping force from turning the nut $120^{\circ}$ from snug tight condition measured by Cameron (2017) in the Skidmore-Whilhelm load cell was $203 \mathrm{kN}$.

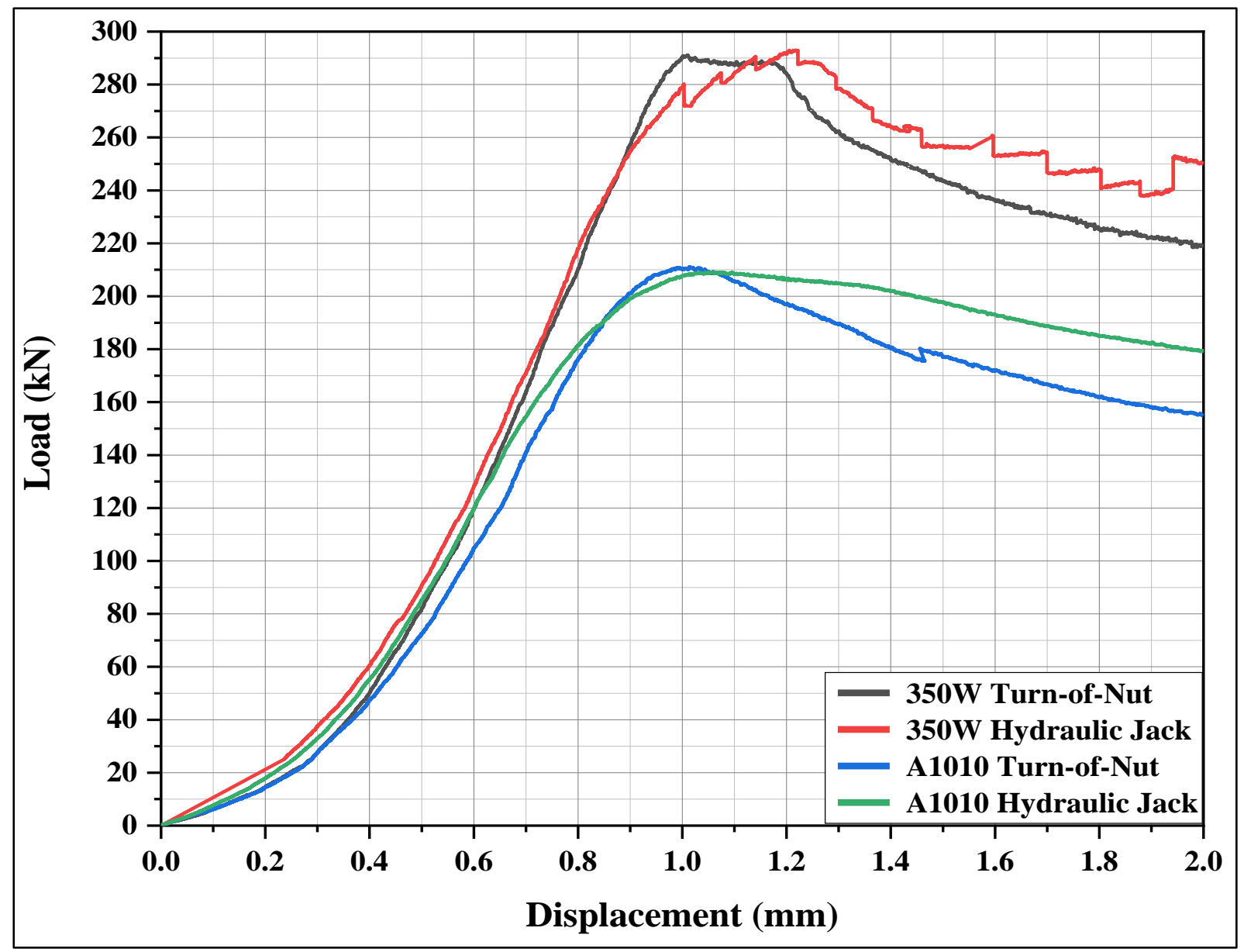

Figure 4-2: Average Load vs Slip Relationships from the Slip Resistance Test 
Table 4-2: Average Slip Coefficient for Class B Surface

\begin{tabular}{|c|c|c|c|c|c|c|}
\hline Steel Type & $\begin{array}{c}\text { Number of } \\
\text { Specimens } \\
\text { Tested }\end{array}$ & $\begin{array}{c}\text { Clamping } \\
\text { Method }\end{array}$ & $\begin{array}{c}\text { Average } \\
\text { Slip } \\
\text { Coefficient } \\
\text { at } \mathbf{0 . 5} \mathbf{~ m m}\end{array}$ & $\begin{array}{c}\text { Average } \\
\text { Maximum } \\
\text { Slip } \\
\text { Coefficient }\end{array}$ & $\begin{array}{c}\text { Average } \\
\text { Surface } \\
\text { Roughness } \\
\left(\mathbf{R}_{\text {max })}\right.\end{array}$ & $\begin{array}{c}\text { Average } \\
\text { Surface } \\
\text { Roughness } \\
(\boldsymbol{R z})\end{array}$ \\
\hline $\mathbf{A 1 0 1 0}$ & 10 & $\begin{array}{c}\text { Hydraulic } \\
\text { Piston }\end{array}$ & $0.43 \pm 0.07$ & $0.49 \pm 0.08$ & $\begin{array}{c}80.99 \mu \mathrm{m} \\
(3.19 \mathrm{mils})\end{array}$ & $\begin{array}{c}77.10 \mu \mathrm{m} \\
(3.03 \mathrm{mils})\end{array}$ \\
\hline $\mathbf{3 5 0 W}$ & 10 & $\begin{array}{c}\text { Hydraulic } \\
\text { Piston }\end{array}$ & $0.53 \pm 0.06$ & $0.68 \pm 0.12$ & $\begin{array}{c}61.99 \mu \mathrm{m} \\
(2.44 \mathrm{mils})\end{array}$ & $\begin{array}{c}59.36 \mu \mathrm{m} \\
(2.34 \mathrm{mils})\end{array}$ \\
\hline $\mathbf{A 1 0 1 0}$ & 5 & $\begin{array}{c}\text { Turn-of- } \\
\text { Nut }\end{array}$ & $0.43 \pm 0.10$ & $0.54 \pm 0.07$ & $\begin{array}{c}81.99 \mu \mathrm{m} \\
(3.23 \mathrm{mils})\end{array}$ & $\begin{array}{c}76.20 \mu \mathrm{m} \\
(3.00 \mathrm{mils})\end{array}$ \\
\hline $\mathbf{3 5 0 W}$ & 5 & $\begin{array}{c}\text { Turn-of- } \\
\text { Nut }\end{array}$ & $0.58 \pm 0.09$ & $0.76 \pm 0.13$ & $\begin{array}{c}62.00 \mu \mathrm{m} \\
(2.44 \mathrm{mils})\end{array}$ & $\begin{array}{c}58.87 \mu \mathrm{m} \\
(2.32 \mathrm{mils})\end{array}$ \\
\hline
\end{tabular}

Note: $25.4 \mu \mathrm{m}=1$ mil (thousandth of an inch)

Figure 4-3 shows a comparison between the slip resistance coefficient obtained in the current study and those available in the literature for different stainless steel types and different faying surface conditions (Stranghöner et al., 2017). The bar graph shows that the slip resistance coefficient obtained in this study for ASTM A1010 is much lower than those obtained by Stranghöner et al (2017) for grit blasting. It is important to distinguish the fact that the study by Stranghöner et al. used the testing method described in Annex G of EN 1092, which is a common test method performed on the tensile direction amongst European nations. In the current study for A1010 steel, the compressive test method described by the Research Council of Structural Connections is used. The main difference is that the slip resistance coefficient in EN 1092 is obtained at $0.15 \mathrm{~mm}$ if the major slip occurs after that point, whereas, the RCSC considers the slip load at $0.5 \mathrm{~mm}$. The slip load vs displacement graphs reported by Stranghöner et al. show that the major slip occurred before $0.15 \mathrm{~mm}$, at approximately $0.05 \mathrm{~mm}$. Also, it was observed in their graphs that there was no initial non-linear portion through which gripped parts were in the transition to be in firm contact. It was not clear whether these graphs were adjusted to start from zero with linear relationship directly to the slip load by omitting the nonlinear portion in the early stage of the application of the tensile loading. However, in the experimental tests for A1010 in the current study, there was an initial non-linear portion of the graph, as depicted in Figure 4-2, and the major slip load occurred way beyond $0.5 \mathrm{~mm}$ when starting from zero displacement (i.e. the peak load is at approximately $1 \mathrm{~mm}$ of total displacement). Taking into account these differences, one may calculate the slip resistance coefficient from data in Figure 4-2 using the peak load which is at a total displacement far beyond 
the $0.5 \mathrm{~mm}$ (approximately at $1 \mathrm{~mm}$ ). This will lead to a slip resistance coefficient between 0.49 and 0.54 based on the clamping method in contrast to being between 0.40 and 0.43 as shown in Table 4-2. These recalculated values are shown in Table 4-2 as the average maximum slip coefficients which are much more aligned with the values obtained by Stranghöner et al. in Figure 4-3.

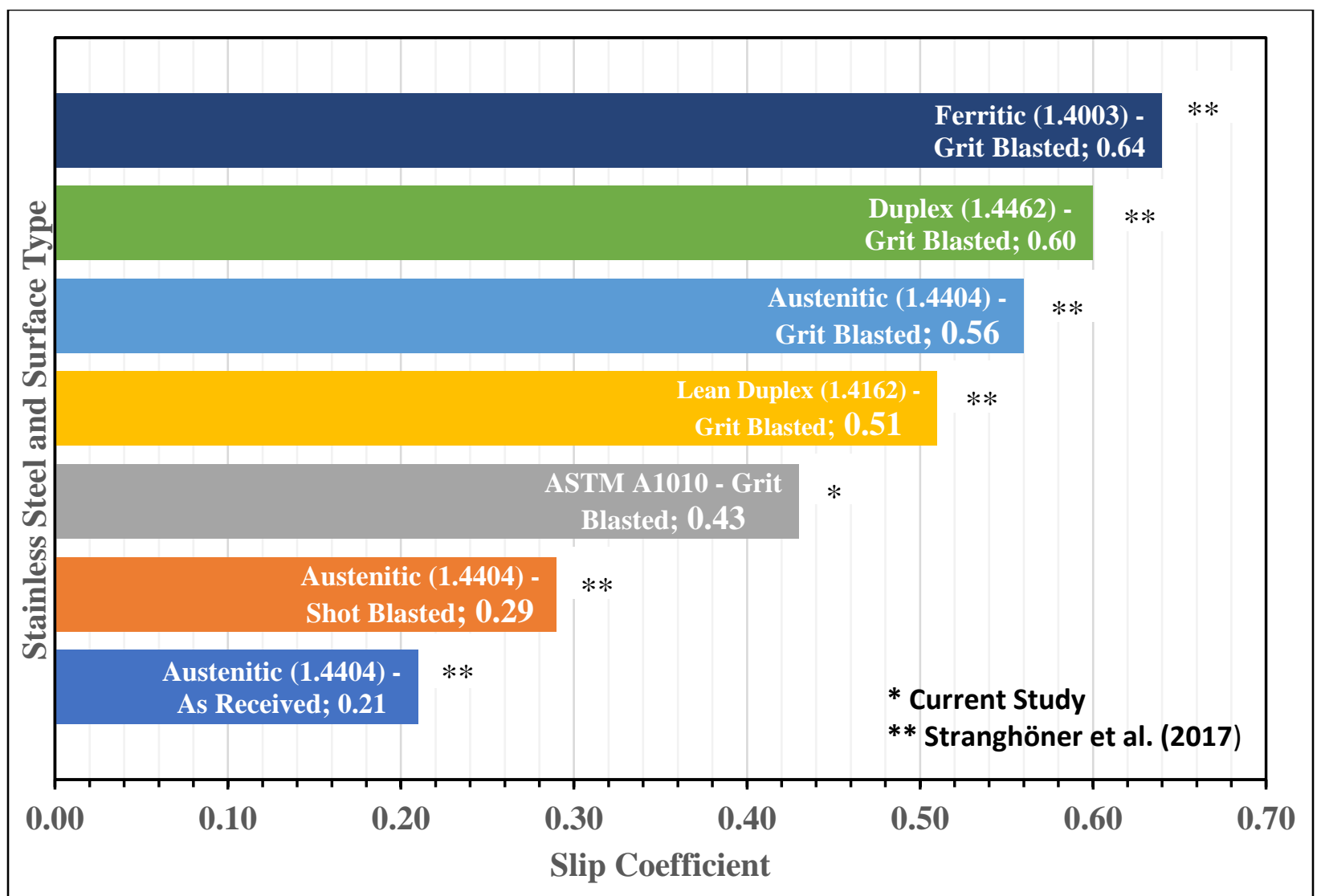

Figure 4-3: Slip Coefficients for Different Types of Stainless Steels and Surfaces

A blasted clean surface with stainless steel grit creates many uneven channels with sharp edges and contours on the faying surfaces. As the clamping force is applied through a bolt, the faying surfaces come together but the peaks and valleys from the opposite faces of the plates are unaligned with each other. The larger peaks and valleys fall into place and interlock as they reach plastic deformation from the clamping load, thus creating a much higher slip resistance. In the slip resistance test, the occurrence of the major slip is due to the yielding of these peaks where the sharp edges created by the grit experience the maximum stress concentration. As the load continues to drop, a similar phenomenon may occur where the smaller peaks and valleys fall into the proper 
place and create a larger slip resistance, however, this quickly drops because the majority of the peaks and valleys have already yielded, thus there would be no enough friction resistance to maintain the peak load that suddenly dropped.

Figure 4-4 and Figure 4-5 show photos of blasted surfaces of A1010 stainless steel post slip resistance testing. A filter was applied to the photos to better view the major points of contact and slip. As expected, the area around the washer and bolt was the area that has experienced the highest clamping force and as a result, the asperities have experienced plastic deformation and transformed permanently into flat surfaces linking the materials together. In Figure 4-6(a) and Figure 4-6(b), It can be observed that the shiny portions are the peaks and valleys that have been squished by the clamping force and/or sheared from the actual slip force. The shiny surfaces are oriented along the direction of the force. Also, one may observe that 'skid' mark like patterns on the plastic deformed peaks showing the direction of the applied stress. Usually, the plastically deformed asperities are the reason why rough surfaces experience a higher slip-coefficient. The two peaks are clamped together and experience plastic deformation which 'bind' the two surfaces together and produce a 'welded' surface which requires a larger force to cause a slip. Figure 4-6(c) shows the post-slip surface near the bolt and Figure 4-6(d) shows the same surface but near the outer edge of the plate. In the later, insignificant traces of plastic deformations along the peaks were observed. This supports that fact that the clamping force was mainly concentrated around the hole meaning that the outer surfaces near the edges did not have a large effect on slip resistance. 


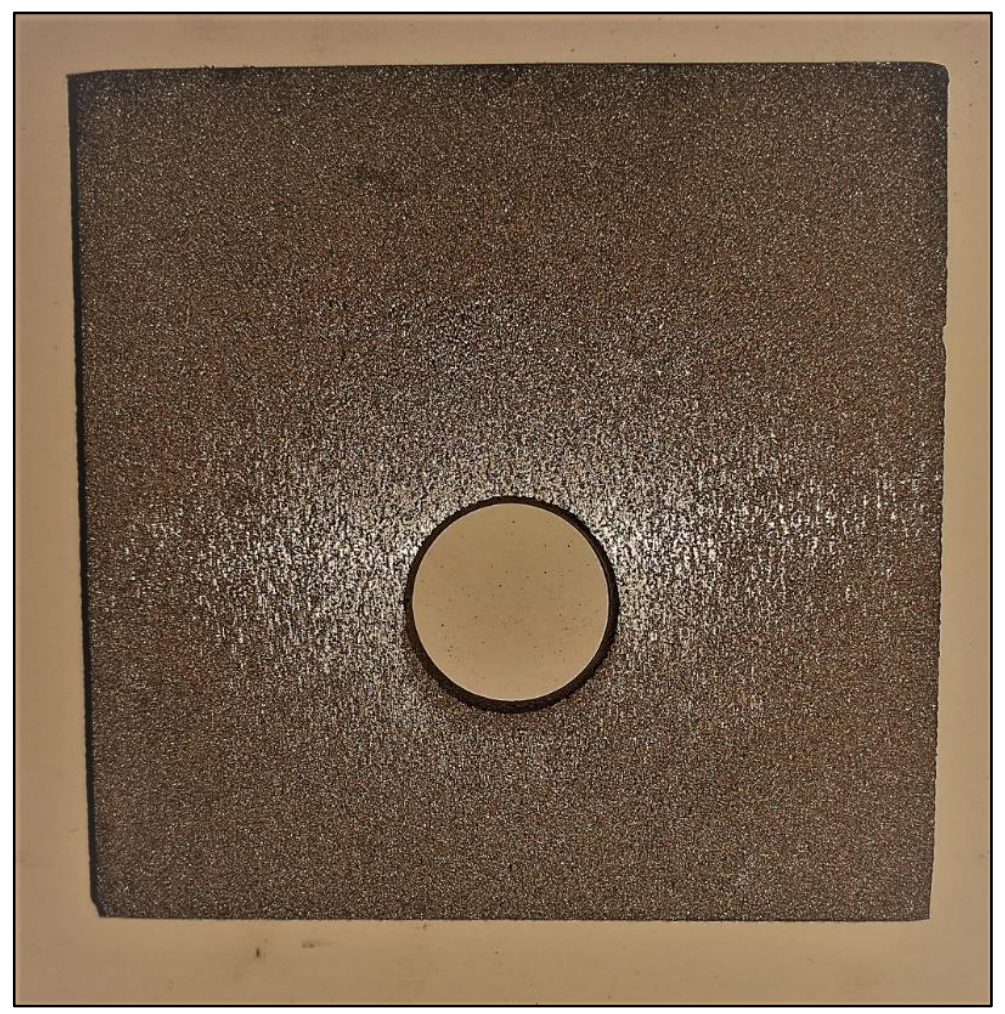

Figure 4-4: Filtered photo of A1010 plate showing slip area

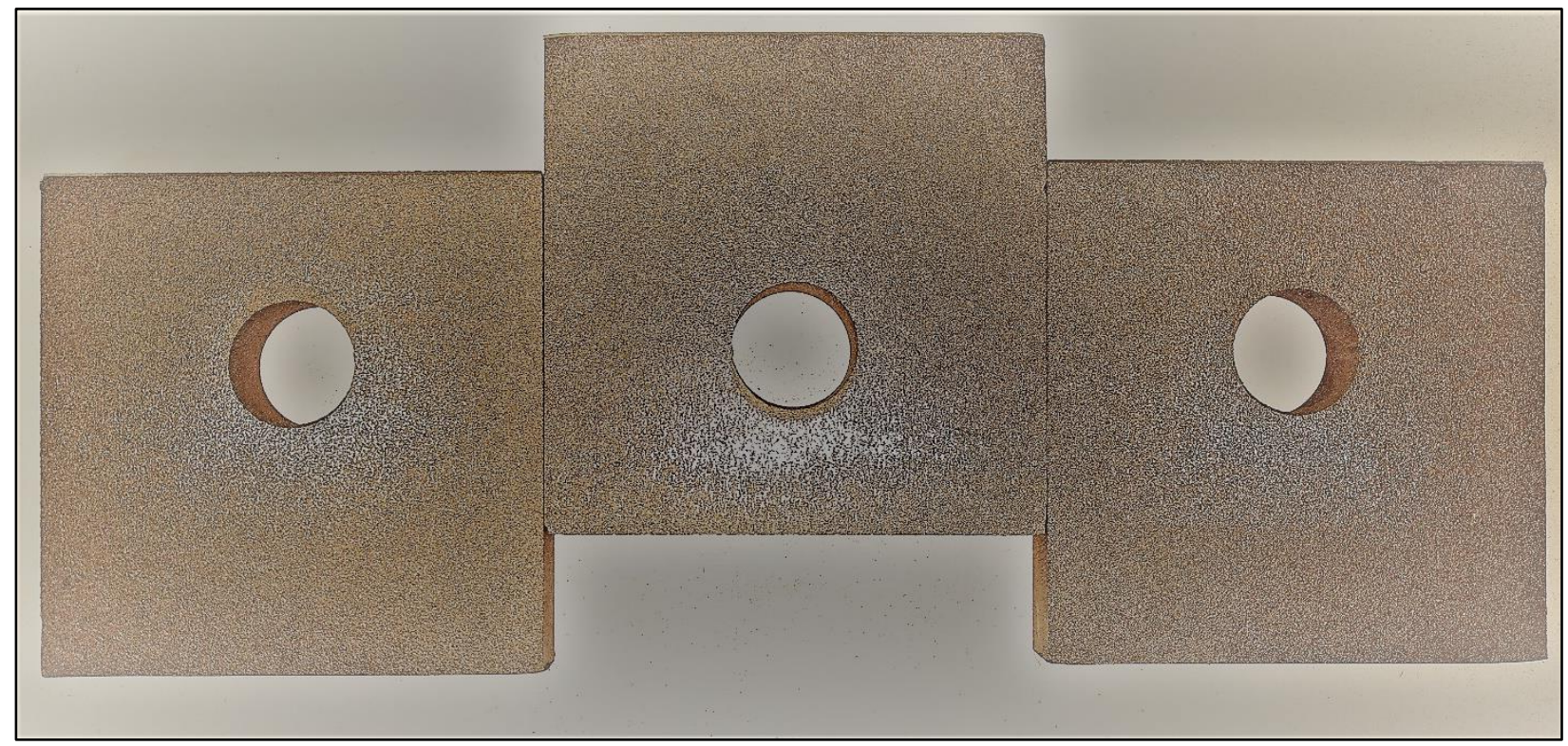

Figure 4-5: Filtered photo of A1010 plates after slip testing showing points of contact 


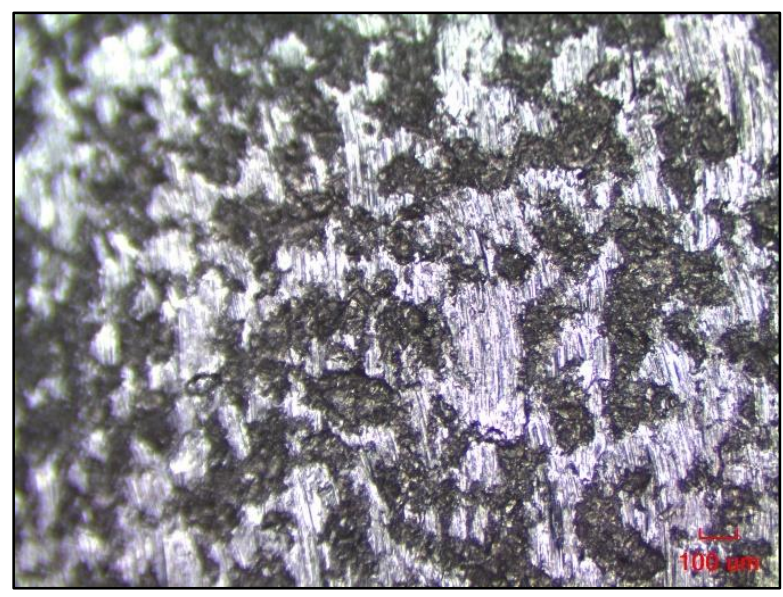

(a)

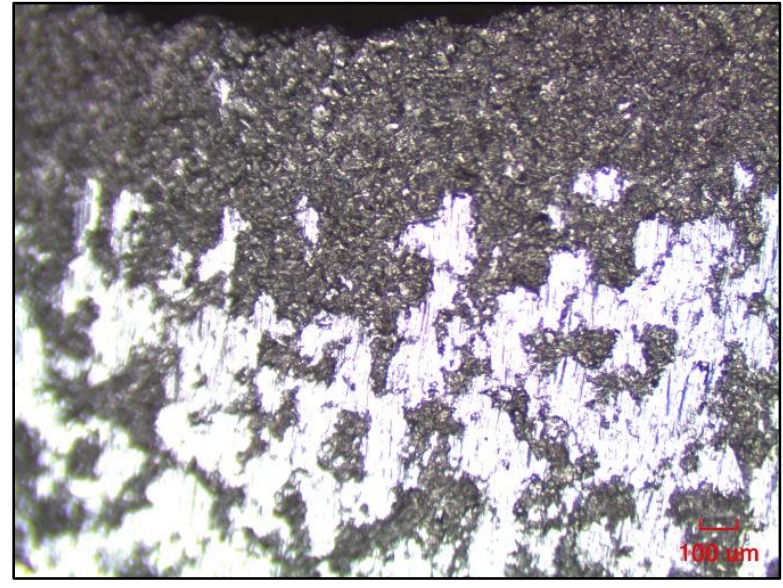

(c)

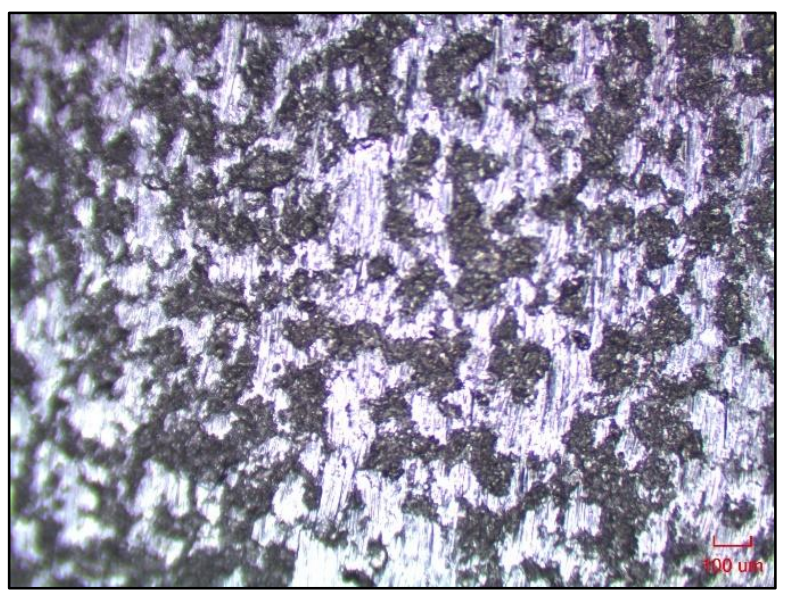

(b)

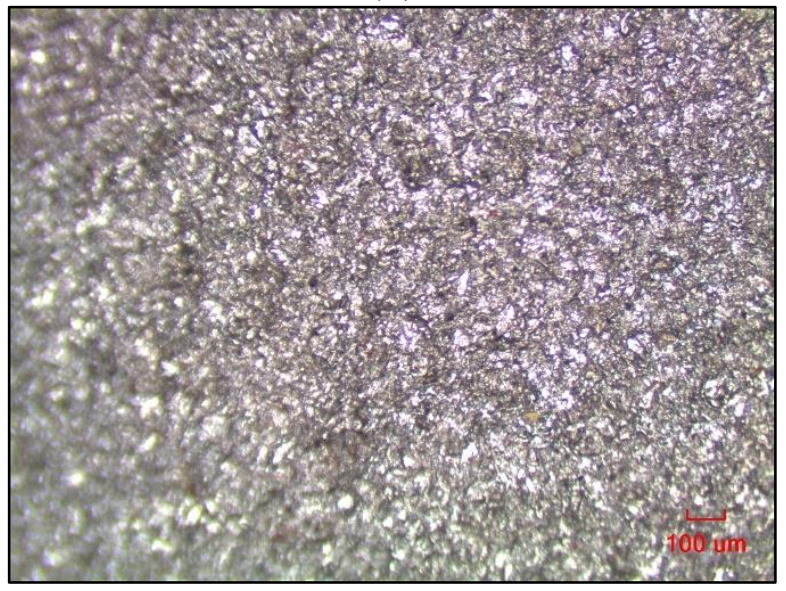

(d)

Figure 4-6: (a-b) Close-up photo of A1010 showing yielded rough surface contact points and slip marks in the direction of the applied shear load; (c) A1010 post-slip surface near the center hole; (d) A1010 post-slip surface near the edge of the plate

Figure 4-7(a) and Figure 4-7(b) show images of the outside non-contact surface of the rusted A1010 plate before applying grit blasting in the current research. It can be observed that the surface is still extremely rough, which meant that it is likely that the A1010 plates donated for the current research had most likely been blasted previously and left outside for the rust patina to form on them. Figure 4-7(a) shows plastic deformation around the hole which is caused by the bolt head pressure applied from the pretension force. 


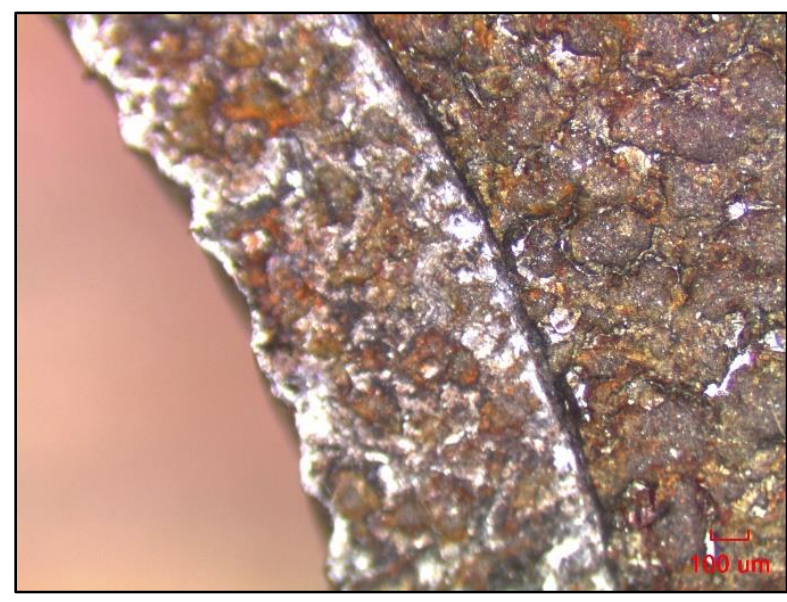

(a)

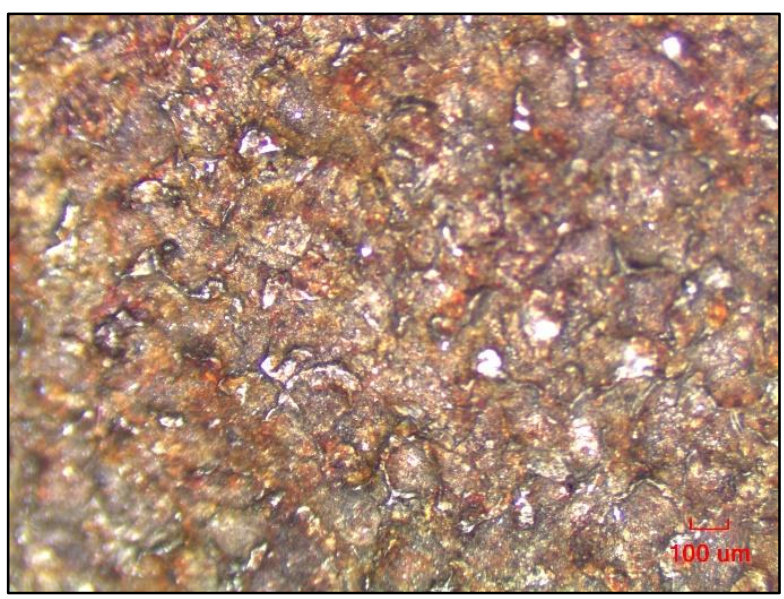

(b)

Figure 4-7: (a) A1010 close-up view of the rusted side near hole; (b) A1010 close-up view of the rusted side near edge, all before grit blasting in the current study

\subsubsection{A1010 Stainless Steel Slip Resistant Coefficient}

Table 4-3 summarizes all the slip resistance test results for A1010 stainless steel. Figure 4-8 shows the slip load vs displacement curves for all ten A1010 stainless steel specimens tested with a hydraulic piston applying the clamping load. The dashed line shows the average from all 10 curves. From the graph, it can be observed that there was an initial disturbance in the form of nonlinear load-displacement relationship occurring between 20 to $30 \mathrm{kN}$ where the plates on the specimens settle onto each other. This was followed by an increase of slip resistance that is fairly linear up until the first major slip occurs at the peak load. Then a fairly linear drop of peak load for almost all the specimens except for A1010_1, A1010_4, and A1010_6, where a buildup of slip load up until a second major slip with a second maximum peak occurred. As mentioned earlier, the slip load was obtained by drawing a tangent (dotted line) from the linear portion of the curves onto the $\mathrm{x}$-axis and then taking that displacement point as the starting displacement in order to determine the slip load at $0.5 \mathrm{~mm}$ away as depicted in Figure 4-8.

Figure 4-8 shows that the peak load occurred at a displacement between 0.7 and $1.1 \mathrm{~mm}$, with an average value of $1 \mathrm{~mm}$ for all tested specimens. It is important to note that A1010_1 specimen was the initial trial test for this experiment configuration. One may also notice that while there was a larger scatter of the peak load among the 10 tested specimens, the slope of the linear portion of the curves are almost identical. 
Table 4-3: ASTM A1010 Stainless Steel Results Detailed Summary

\begin{tabular}{|c|c|c|c|c|c|c|c|c|c|}
\hline \multirow{2}{*}{$\begin{array}{c}\text { Specimen } \\
\#\end{array}$} & \multirow{2}{*}{$\begin{array}{l}\text { Clamping } \\
\text { Method }\end{array}$} & \multirow{2}{*}{$\begin{array}{c}\text { Clamping } \\
\text { Load } \\
(\mathbf{k N})\end{array}$} & \multicolumn{2}{|c|}{$\begin{array}{c}\text { Surface } \\
\text { Roughness }\end{array}$} & \multirow{2}{*}{$\begin{array}{c}\text { Max } \\
\text { Slip } \\
\text { Load } \\
@ 0.5 \\
\text { mm } \\
(\mathbf{k N})\end{array}$} & \multirow{2}{*}{$\begin{array}{c}\text { Max } \\
\text { Slip } \\
\text { Load } \\
(\mathbf{k N})\end{array}$} & \multirow{2}{*}{$\begin{array}{c}\text { Displacement } \\
\text { @ Max Slip } \\
\text { Load } \\
\text { (mm) }\end{array}$} & \multirow{2}{*}{$\begin{array}{c}\text { Slip } \\
\text { Coefficient } \\
\text { @ } 0.5 \text { mm }\end{array}$} & \multirow{2}{*}{$\begin{array}{c}\text { Slip } \\
\text { Coefficient } \\
\text { @ Max Slip } \\
\text { Load }\end{array}$} \\
\hline & & & $\begin{array}{c}\mathbf{R z} \\
(\mu \mathrm{m})\end{array}$ & $\begin{array}{l}\operatorname{Rmax} \\
(\mu \mathrm{m})\end{array}$ & & & & & \\
\hline A1010_1 & Jack & 230 & 77.57 & 82.29 & 147.36 & 163.12 & 0.89 & 0.32 & 0.35 \\
\hline A1010_2 & Jack & 230 & 69.19 & 72.93 & 163.97 & 185.99 & 0.64 & 0.36 & 0.40 \\
\hline A1010_3 & Jack & 230 & 86.11 & 89.33 & 233.58 & 242.97 & 0.57 & 0.51 & 0.53 \\
\hline A1010_4 & Jack & 230 & 78.59 & 83.32 & 153.09 & 215.81 & 1.13 & 0.33 & 0.47 \\
\hline A1010_5 & Jack & 230 & 69.84 & 74.87 & 201.51 & 234.25 & 0.66 & 0.44 & 0.51 \\
\hline A1010_6 & Jack & 230 & 77.46 & 81.38 & 229.04 & 264.27 & 0.80 & 0.50 & 0.57 \\
\hline A1010_7 & Jack & 230 & 78.56 & 80.73 & 203.22 & 239.19 & 0.80 & 0.44 & 0.52 \\
\hline A1010_8 & Jack & 230 & 81.18 & 86.59 & 170.41 & 176.68 & 0.57 & 0.37 & 0.38 \\
\hline A1010_9 & Jack & 230 & 70.60 & 73.49 & 162.62 & 254.66 & 1.11 & 0.35 & 0.55 \\
\hline A1010_10 & Jack & 230 & 81.94 & 84.97 & 212.04 & 267.77 & 0.74 & 0.46 & 0.58 \\
\hline A1010_11 & $\begin{array}{c}\text { Turn-of- } \\
\text { Nut }\end{array}$ & 203 & 79.64 & 85.11 & 101.65 & 178.77 & 1.11 & $0.25^{*}$ & 0.44 \\
\hline A1010_12 & $\begin{array}{c}\text { Turn-of- } \\
\text { Nut }\end{array}$ & 203 & 67.58 & 75.13 & 190.15 & 235.97 & 0.68 & 0.47 & 0.58 \\
\hline A1010_13 & $\begin{array}{c}\text { Turn-of- } \\
\text { Nut }\end{array}$ & 203 & 90.82 & 94.89 & 193.37 & 200.62 & 0.56 & 0.48 & 0.49 \\
\hline A1010_14 & $\begin{array}{c}\text { Turn-of- } \\
\text { Nut }\end{array}$ & 203 & 70.76 & 77.18 & 199.21 & 214.57 & 0.59 & 0.49 & 0.53 \\
\hline A1010_15 & $\begin{array}{c}\text { Turn-of- } \\
\text { Nut }\end{array}$ & 203 & 72.17 & 77.63 & 198.05 & 256.24 & 0.72 & 0.49 & 0.63 \\
\hline
\end{tabular}

Note: Specimens A1010_1 \& A1010_11 were initial trial demonstrations.

* Number not included when taking the total average slip coefficient seen in Table 4-1 because the recorded displacement was taken from the MTS machine rather than the LVDT. 


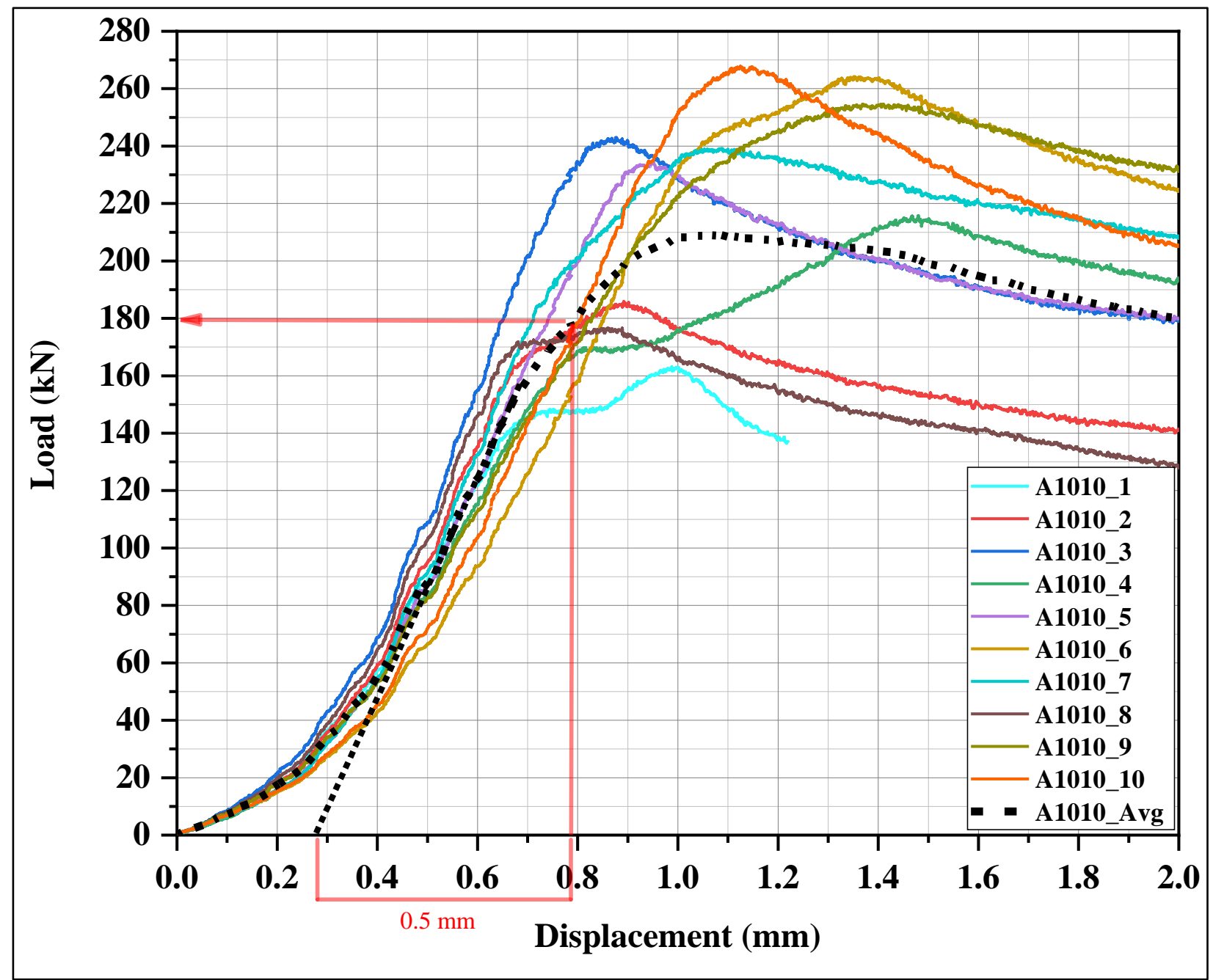

Figure 4-8: Recorded Load-Slip Relationships for A1010 Hydraulic Clamped Specimens

When conducting the slip resistance test with the presence of the jack, pump and the load cell, the plan was to record the reading of the load cell with the increase of displacement or applied load to determine whether there is a loss in clamping load throughout the loading history before slip. Figure 4-9 shows the clamping force measured by the load cell during the test for all specimens. It can be observed that the clamping load had insignificant change for the majority of the tested specimens, with acceptable change in few of them. Specifically, the clamping load of specimen A1010_9 dropped by about 10\%. Also, the clamping loads for specimens A1010_6 and A1010_7 increased by about $7 \%$. One may notice that such increase or drop in the clamping load occurred at a slip load load (depicted in Figure 4-8) close to the peak load and generally at the beginning of the nonlinear range beyond the significant linear range on which the slip resistance was maintained through plate friction resistance. 
One may attribute the change in the peak load among the 10 specimens as well as the slight change in the clamping load during the test to the possibility of uneven plate edges during fabrication. As the specimen top plate is pushed into shear, the uneven plate edges at the two bottom plates in the test specimen could, in theory be pushed apart during the test by an applied eccentric load. This action can cause an increase in compressive pressure on the washer load cell that is wedged between a pushing hydraulic piston from one side and a pushing plate from the other side. This increase in clamping load has insignificant effect on the overall results. Nonetheless, it was decided to use the initial clamping force for the calculation of the slip resistance coefficient for all specimens in order to have a proper comparison with previous literature. It should be noted that when the clamping load drops during the test, the calculated slip resistance coefficient ends up being more conservative.

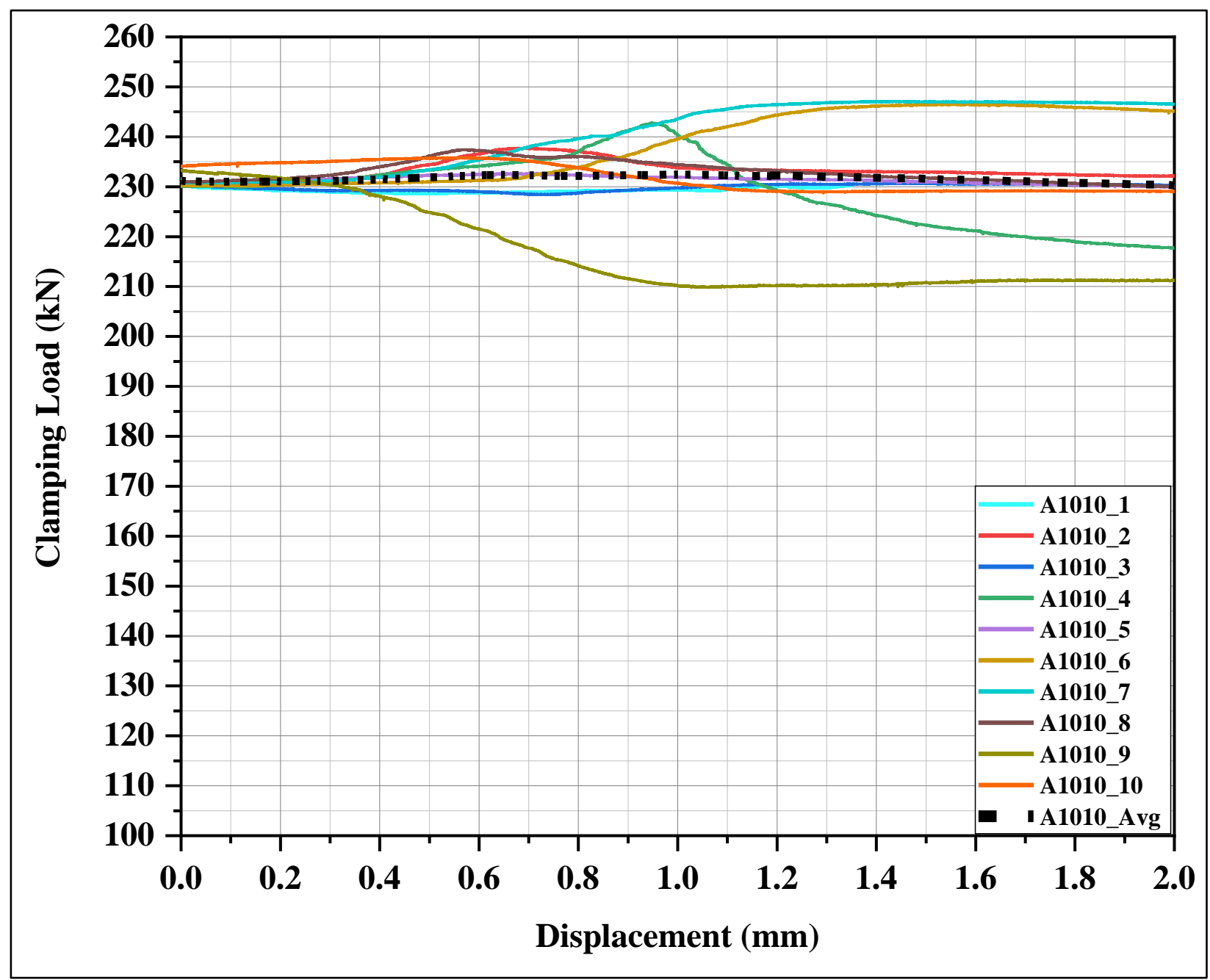

Figure 4-9: A1010 specimen clamping load throughout the test duration 
Figure 4-10 below shows all load vs displacement curves of the A1010 specimens tested by clamping them with a bolt tightened through the turn-of-nut method. One may notice that the shapes of the curves are all very similar except for A1010_11 specimen which was the first trial demonstration for this test method. The displacement measured for A1010_11 was done through the MTS testing machine, whereas, the displacement measured for all other curves was made by LVDTs placed between the ends of the specimens. As such, the result of A1010-11 specimen was not included in getting the average slip coefficient at $0.5 \mathrm{~mm}$ displacement reported in Table 4-3. Similar to Figure 4-2, initial portion of the load-displacement history with nonlinear relationship was observed in Figure 4-10 but up to about $40 \mathrm{kN}$ applied load.

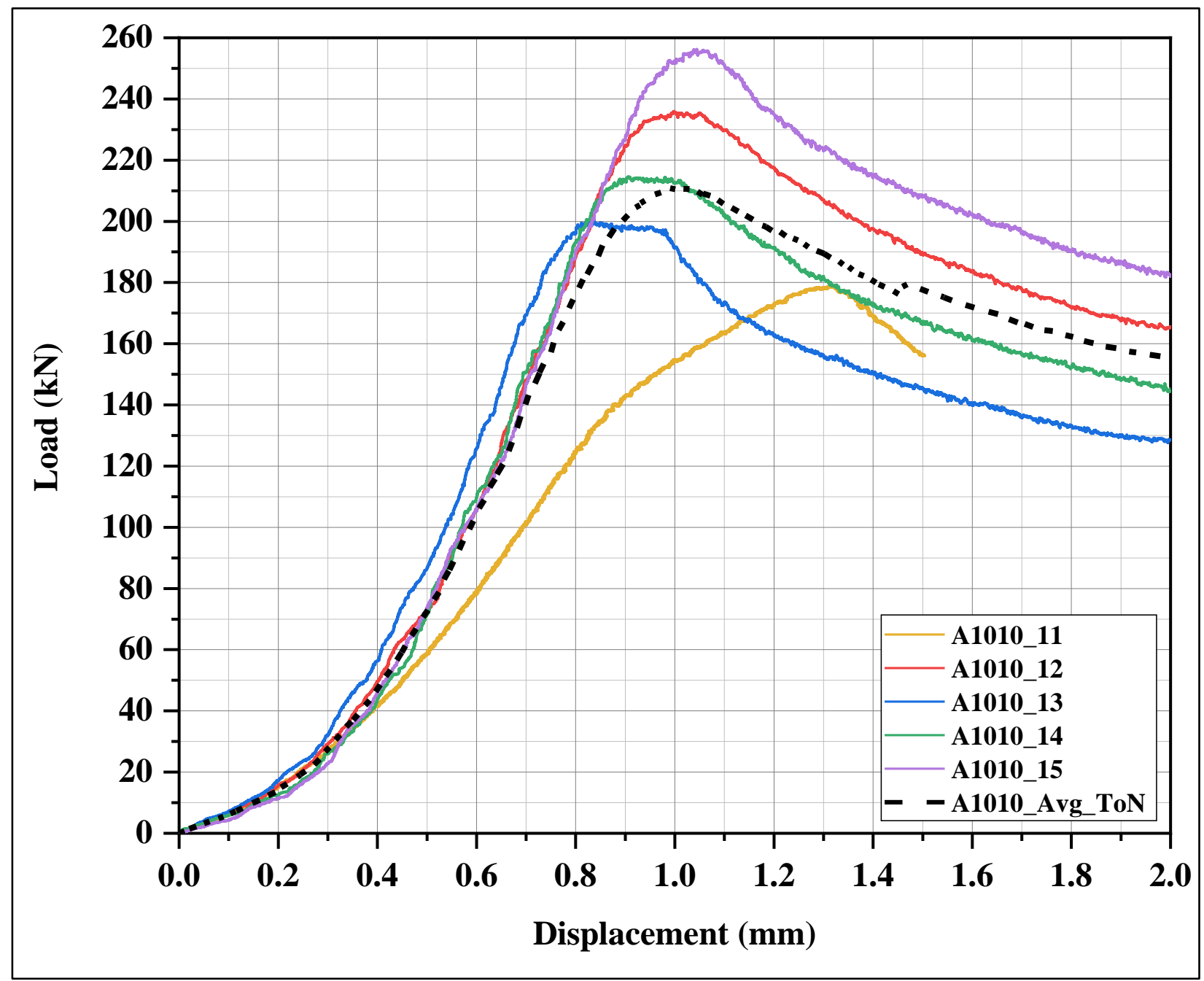

Figure 4-10: Load-Slip Relationship for A1010 Specimens Clamped by Using the Turn-ofNut Method 


\subsubsection{CSA G40.21 350W Slip Resistant Coefficient}

Table 4-4 shows a detailed summary of all the experimental results obtained for CSA G40.21 350W traditional carbon alloy structural steel commonly used for structural applications in Canada. In this study, the average value of slip resistance coefficients obtained by accurately measuring the clamping force was 0.53 . This number matches up very closely with the average value of historical research completed on different blasted clean carbon alloy steels, which was 0.525 on average as compiled by Grondin et al. (2007).

Table 4-4: Summary of Results of CSA G40.21 350W Steel with Class B Surface Condition

\begin{tabular}{|c|c|c|c|c|c|c|c|c|c|}
\hline \multirow{2}{*}{$\begin{array}{c}\text { Specimen } \\
\#\end{array}$} & \multirow{2}{*}{$\begin{array}{c}\text { Clamping } \\
\text { Method }\end{array}$} & \multirow{2}{*}{$\begin{array}{c}\text { Clamping } \\
\text { Load } \\
(\mathbf{k N})\end{array}$} & \multicolumn{2}{|c|}{$\begin{array}{c}\text { Surface } \\
\text { Roughness }\end{array}$} & \multirow{2}{*}{$\begin{array}{c}\text { Max } \\
\text { Slip } \\
\text { Load @ } \\
0.5 \text { mm } \\
(k N)\end{array}$} & \multirow{2}{*}{$\begin{array}{c}\text { Max } \\
\text { Slip } \\
\text { Load } \\
(\mathbf{k N})\end{array}$} & \multirow{2}{*}{$\begin{array}{c}\text { Displacement } \\
\text { @ Max Slip } \\
\text { Load } \\
(\mathrm{mm})\end{array}$} & \multirow{2}{*}{$\begin{array}{c}\text { Slip } \\
\text { Coefficient } \\
\text { @ } 0.5 \mathrm{~mm}\end{array}$} & \multirow{2}{*}{$\begin{array}{c}\text { Slip } \\
\text { Coefficient } \\
\text { @ Max } \\
\text { Slip Load }\end{array}$} \\
\hline & & & $\begin{array}{c}\mathbf{R z} \\
(\mu \mathrm{m})\end{array}$ & $\begin{array}{l}\text { Rmax } \\
(\mu \mathrm{m})\end{array}$ & & & & & \\
\hline 350W1 & Jack & 230 & 54.99 & 58.12 & - & 264.78 & 0.47 & - & 0.58 \\
\hline $350 W 2$ & Jack & 230 & 65.29 & 60.65 & 230.36 & 298.13 & 0.85 & 0.50 & 0.65 \\
\hline $350 W 3$ & Jack & 230 & 59.66 & 65.67 & 215.54 & 328.30 & 0.84 & 0.47 & 0.71 \\
\hline $350 W 4$ & Jack & 230 & 59.92 & 64.91 & 275.39 & 282.14 & 0.52 & 0.60 & 0.61 \\
\hline $350 W 5$ & Jack & 230 & 62.66 & 66.71 & 257.11 & 374.46 & 0.84 & 0.56 & 0.81 \\
\hline $350 W 6$ & Jack & 230 & 59.54 & 63.34 & 204.03 & 379.13 & 0.99 & 0.44 & 0.82 \\
\hline $350 W 7$ & Jack & 230 & 55.95 & 59.53 & - & 281.63 & 0.49 & - & 0.61 \\
\hline $350 W 8$ & Jack & 230 & 56.21 & 58.49 & 251.52 & 285.48 & 0.56 & 0.55 & 0.62 \\
\hline 350W9 & Jack & 230 & 55.92 & 57.75 & 201.56 & 237.29 & 0.75 & 0.44 & 0.52 \\
\hline $350 W 10$ & Jack & 230 & 63.48 & 65.89 & 246.63 & 399.71 & 0.87 & 0.54 & 0.87 \\
\hline $350 W 11$ & $\begin{array}{c}\text { Turn-of- } \\
\text { Nut }\end{array}$ & 203 & 60.27 & 62.39 & 202.57 & 320.22 & 1.11 & 0.50 & 0.79 \\
\hline $350 W 12$ & $\begin{array}{c}\text { Turn-of- } \\
\text { Nut }\end{array}$ & 203 & 61.24 & 63.54 & 272.82 & 372.93 & 0.72 & 0.67 & 0.92 \\
\hline $350 W 13$ & $\begin{array}{c}\text { Turn-of- } \\
\text { Nut }\end{array}$ & 203 & 60.73 & 61.21 & 273.69 & 339.65 & 0.65 & 0.67 & 0.84 \\
\hline $350 W 14$ & $\begin{array}{c}\text { Turn-of- } \\
\text { Nut }\end{array}$ & 203 & 61.35 & 65.72 & 207.44 & 264.82 & 0.71 & 0.51 & 0.65 \\
\hline $350 W 15$ & $\begin{array}{c}\text { Turn-of- } \\
\text { Nut }\end{array}$ & 203 & 55.75 & 57.14 & 221.23 & 251.85 & 0.60 & 0.54 & 0.62 \\
\hline
\end{tabular}

Note: - Maximum slip load occurred at or before $0.5 \mathrm{~mm}$ of slip, thus the slip coefficient is the same as that of the slip coefficient @ max slip load. 
Figure 4-11 shows the load-slip relationship for the 10 specimens made of CSA G40.21 350W conventional structural steel clamped by a hydraulic piston. The general shapes of the curves are very similar to the curves obtained for stainless steel. However, much higher peak load was observed for 350W steel. Specimen 350W1 was a trial test on which signal malfunctioning of the LVDT that measured the slip between the plates was observed, hence, a stepwise increase instead of a smooth line was observed for this specimen in Figure 4-11. The peak loads were scattered apart ranging from $265 \mathrm{kN}$ to almost $400 \mathrm{kN}$. This is a large scatter that is similar to that observed from the stainless steel specimens. However, the slip load obtained at $0.5 \mathrm{~mm}$ from the tangent to the linear portion of the curses shows much lower scatter, ranging from approximately $200 \mathrm{kN}$ to $275 \mathrm{kN}$. The maximum slip load occurred approximately between a displacement of $0.8 \mathrm{~mm}$ and $1.3 \mathrm{~mm}$. This is a larger scatter compared to the stainless steel curves.

As explained for the stainless steel curves, the shape of the $350 \mathrm{~W}$ curves can be divided into 3 phases. The initial phase was the settling portion, where the displacement rate increases beyond being linear until the loading system and the specimen stabilized. This phase was followed by an increased rate of applied load in a linear fashion until reaching very close to the peak load after which significant slip and drop of the applied load occurred. The third phase started with a drastic decrease in slip load, with occasional smaller phases of increased slip resistance for a lower load, as observed in few specimens as 350W9. Only in specimens 350W1 and 350W7 did the major slip load happen before $0.5 \mathrm{~mm}$ displacement. For all other specimens, the major slip load occurred after $0.5 \mathrm{~mm}$ displacement from the tangent line of the most linear portion. 


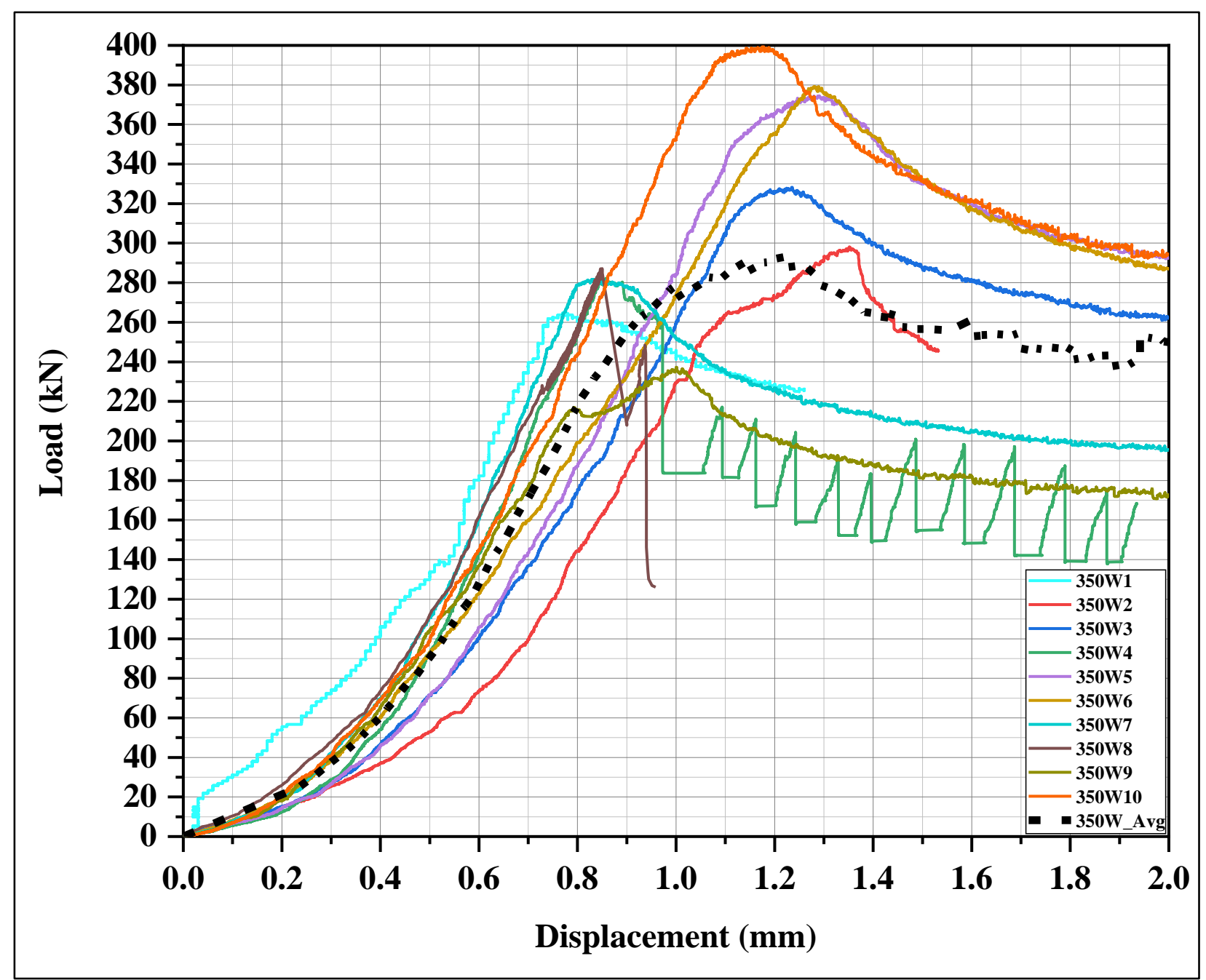

Figure 4-11: Load-Slip Relationship for 350W Hydraulic Clamped Specimens

Figure 4-12, shows us the behaviour of the clamping load measured by a washer type load cell for all the 10 specimens of $350 \mathrm{~W}$ steel. All specimens showed a small drop in clamping load which occurred around the same displacement in which the major slip occurs. This would make sense because naturally when the major slip occurs, there should also be a significant change in clamping load at that instance. Specimens 350W3 and 350W5 experienced a large increase in clamping force during the duration of the test (roughly $8.6 \%$ ). This can be explained by the unevenness of the plate edges resting on the swivel head platform. When the specimen is placed under compression and the edges are not completely even, the plates end up tilting slightly, thereby putting more compressive pressure on the washer type load cell, which is wedged between the plates and the hydraulic piston. For the purpose of taking the average measurements, the average clamping load throughout the duration of the test only dropped approximately $1.5 \%$ which means that the average 
slip load that leads to an average slip resistance coefficient of 0.53 for all $350 \mathrm{~W}$ curves is accurate. If there was a significant drop or increase in clamping load, then the slip resistance coefficient would need to be adjusted accordingly. It should be noted that the change in the clamping load during the tests as depicted in Figure 4-12 ranges from $-8 \%$ to $+9 \%$.

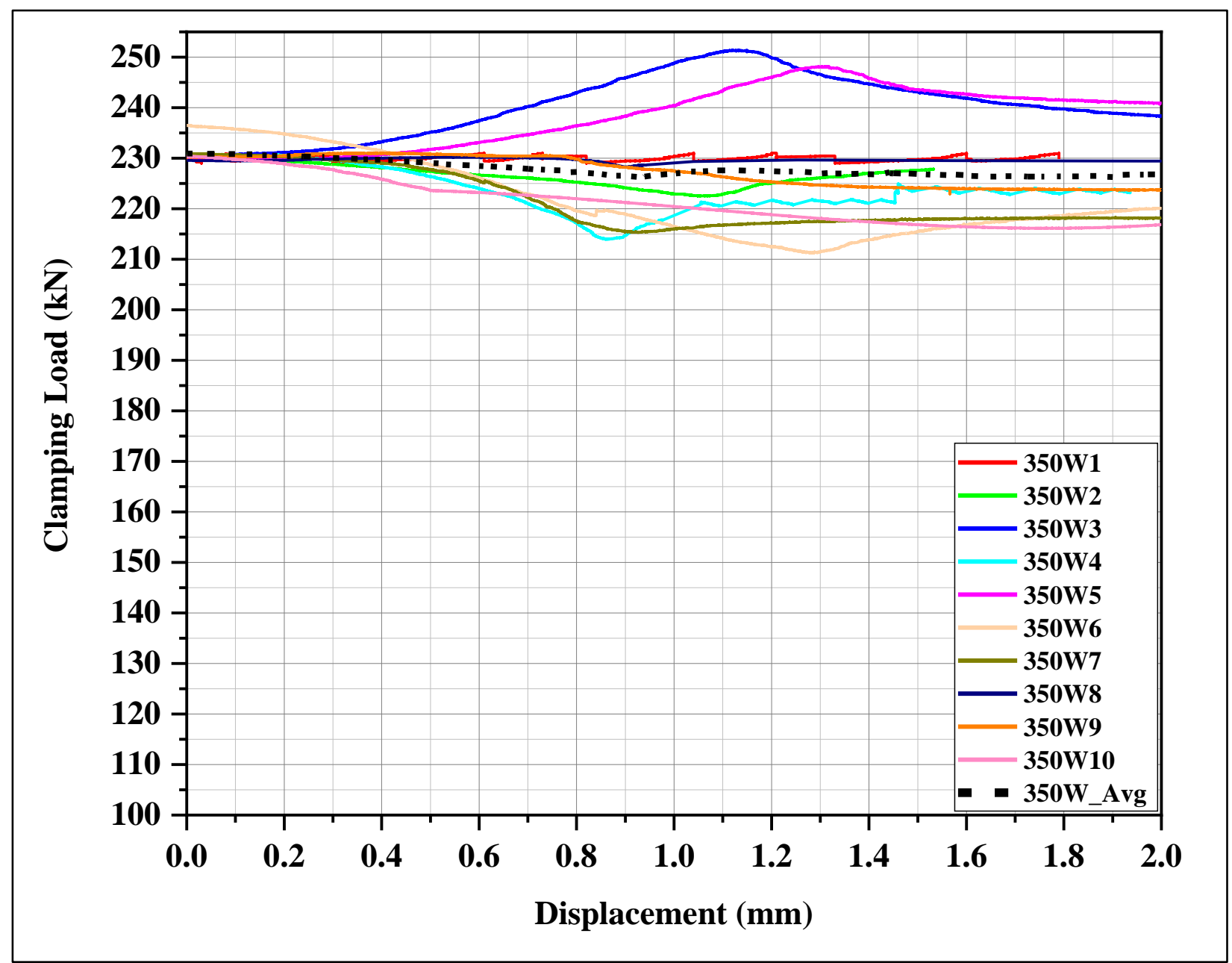

Figure 4-12: 350W Clamping Load Recorded Throughout the Test Duration

Figure 4-13 shows the load vs displacement curves for the five 350W specimens clamped with bolt tightened by the turn-of-nut method. All the curves are shown to have a similar shape to those of stainless steel but with much higher peak loads and corresponding slip. The maximum slip loads range from about $250 \mathrm{kN}$ to $370 \mathrm{kN}$, with a displacement range from 0.60 to $1.10 \mathrm{~mm}$ from the position of the tangent lines. 


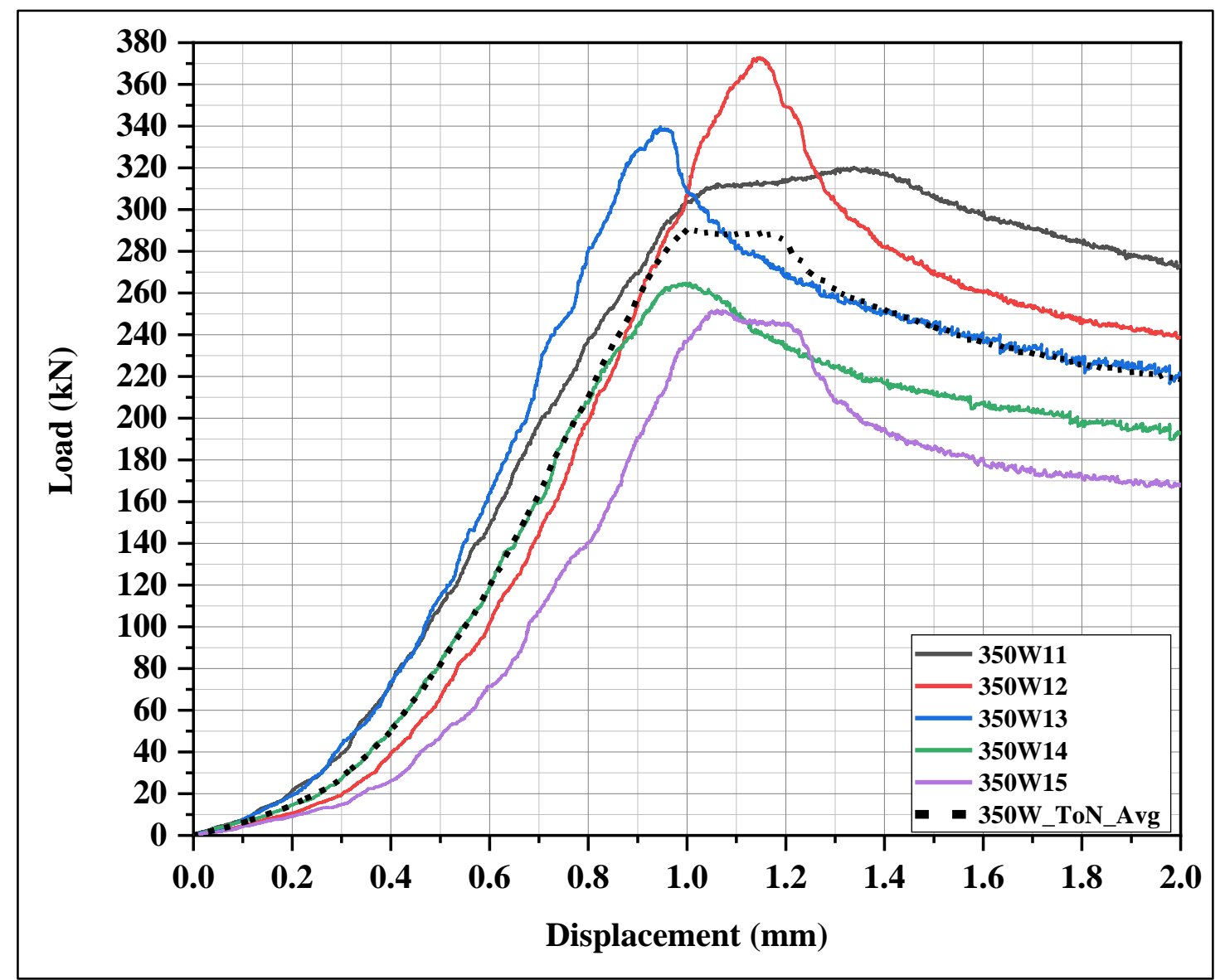

Figure 4-13: Load-Slip Relationship for 350W Specimens Clamped by Turn-of-Nut Method

Figure 4-14 show the plastic deformation near the hole and edge of the plate. Plastic deformation on the peaks of the roughened surface was observed similar to that of blasted A1010 stainless steel. Near the hole, it seems to have much more plastic deformation compared to the edge of the contact plate surfaces. If we compare Figure 4-14 with Figure 4-6, it is possible to observe that CSA G40.21 350W plates experienced more plastically deformed peaks which can be an explanation for the higher slip resistance observed when compared to A1010 stainless steel. 


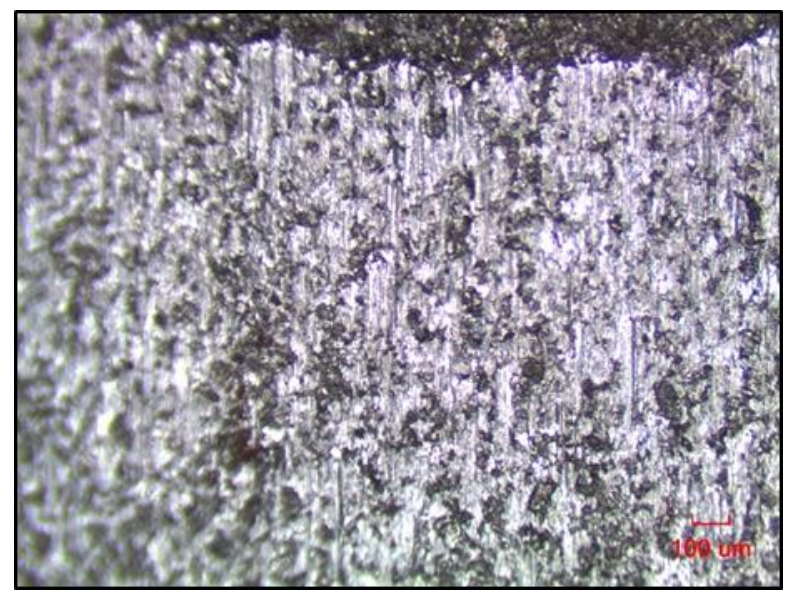

(a)

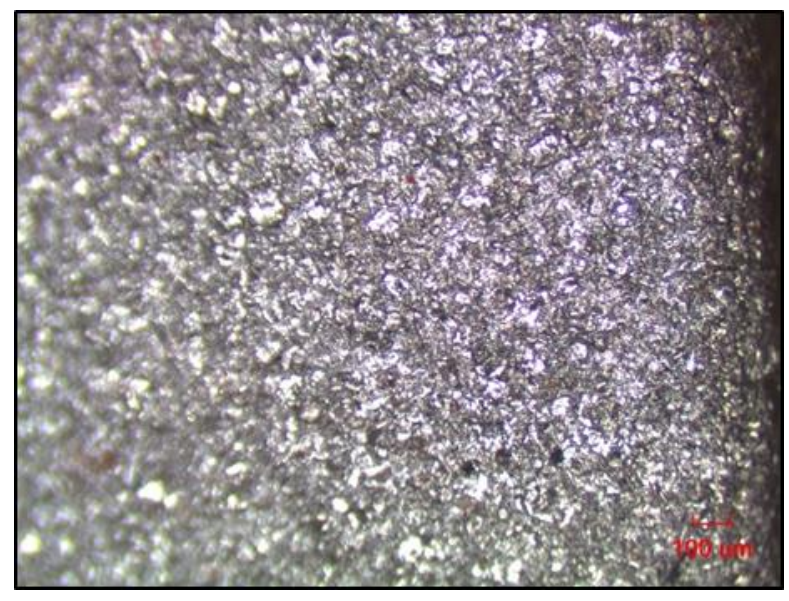

(b)

Figure 4-14: (a) 350W Steel with Class B Surface Condition Post-Slip Near Hole (b) 350W Steel with Class B Surface Condition Post-Slip Near the Edge of the Plate

Table 4-5 shows test results obtained from the slip resistance tests on CSA G40.21 350W structural steel with Class A surface, clean mill scale. Overall, it can be observed that the turn-of-nut method resulted in similar slip loads to those for the specimens which were clamped by a hydraulic jack at $230 \mathrm{kN}$. The average slip resistance coefficient at $0.5 \mathrm{~mm}$ for the specimens clamped with the hydraulic jack was 0.17 , with the average maximum slip resistance coefficient of 0.19 as calculated at peak loads. For the 5 specimens clamped by the turn-of-nut method, the average maximum slip resistance coefficient was 0.21. It should be noted that A1010 stainless steels with class A surface were not tested due to the unavailability of clean mill A1010 (16 mm (5/8") thick plates in this phase of research. However, Cameron (2017) tested the clean mill slip resistance of A1010 stainless steel by using the turn-of-nut clamping method and found the average slip resistance coefficient at $0.5 \mathrm{~mm}$ to be approximately 0.161 .

Figure 4-15 and Figure 4-17 show the load vs slip relationships for CSA G40.21 350W steel specimens with Class A surface conditions considering the bolts clamped using the hydraulic jack and using the turn-of-the-nut method, respectively. Also, comparing the slip load vs displacement curves of $350 \mathrm{~W}$ structural steel with clean mill surface (Class A) to those of $350 \mathrm{~W}$ with blasted clean surface (Class B), it is possible to observe that the clean mill 350W surface exhibited more of a constant linear increase in the slip load up until the point of major slip, which was sudden and sharp in the case of Class A surfaces. Often times there was an increase in the applied load after 
the occurrence of major slip for Class A surfaces as depicted in some of the curves in Figure 4-15 and Figure 4-17. This is contrary to the blasted Class B surfaces which exhibited a decrease in the applied load after the major slip. Figure 4-16 shows the average clamping load recorded throughout the test duration for $350 \mathrm{~W}$ steel specimens with Class A surface condition, clean mill scale. An insignificant change in the clamping load was observed. One may observe that there was a more linear clamping load sustained throughout the duration of the test in comparison to the 350W Class B specimens where a change in clamping loads was noticeable for applied loading beyond $0.8 \mathrm{~mm}$ slip, at which slip generally started notably.

Table 4-5: Slip Summary of Results of CSA G40.21 350W with Class A Surface

\begin{tabular}{|c|c|c|c|c|c|c|c|c|c|}
\hline \multirow{2}{*}{$\begin{array}{c}\text { Specimen } \\
\#\end{array}$} & \multirow{2}{*}{$\begin{array}{c}\text { Clamping } \\
\text { Method }\end{array}$} & \multirow{2}{*}{$\begin{array}{c}\text { Clamping } \\
\text { Load } \\
(\mathbf{k N})\end{array}$} & \multicolumn{2}{|c|}{$\begin{array}{c}\text { Surface } \\
\text { Roughness }\end{array}$} & \multirow{2}{*}{$\begin{array}{c}\text { Max } \\
\text { Slip } \\
\text { Load @ } \\
0.5 \text { mm } \\
(\mathbf{k N})\end{array}$} & \multirow{2}{*}{$\begin{array}{c}\text { Max } \\
\text { Slip } \\
\text { Load } \\
(\mathbf{k N})\end{array}$} & \multirow{2}{*}{$\begin{array}{c}\text { Displacement } \\
\text { @ Max Slip } \\
\text { Load } \\
(\mathbf{m m})\end{array}$} & \multirow{2}{*}{$\begin{array}{c}\text { Slip } \\
\text { Coefficient } \\
\text { @ } 0.5 \mathrm{~mm}\end{array}$} & \multirow{2}{*}{$\begin{array}{c}\text { Slip } \\
\text { Coefficient } \\
\text { @ Max } \\
\text { Slip Load }\end{array}$} \\
\hline & & & $\begin{array}{c}\mathbf{R z} \\
(\mu \mathrm{m})\end{array}$ & $\begin{array}{l}\operatorname{Rmax} \\
(\mu \mathrm{m})\end{array}$ & & & & & \\
\hline 350WA01 & Jack & 230 & 13.12 & 19.59 & - & 78.38 & 0.45 & - & 0.17 \\
\hline 350WA02 & Jack & 230 & 12.16 & 17.13 & - & 74.61 & 0.42 & - & 0.16 \\
\hline 350WA03 & Jack & 230 & 16.31 & 18.31 & - & 100.91 & 0.44 & - & 0.22 \\
\hline 350WA04 & Jack & 230 & 13.49 & 18.92 & 73.34 & 76.04 & 0.54 & 0.16 & 0.17 \\
\hline 350WA05 & Jack & 230 & 14.23 & 15.93 & 45.13 & 77.12 & 0.71 & 0.10 & 0.17 \\
\hline 350WA06 & Jack & 230 & 15.60 & 16.74 & 87.12 & 116.24 & 0.75 & 0.19 & 0.25 \\
\hline 350WA07 & Jack & 230 & 14.36 & 18.66 & - & 99.85 & 0.42 & - & 0.22 \\
\hline 350WA08 & Jack & 230 & 15.33 & 18.44 & - & 104.72 & 0.32 & - & 0.23 \\
\hline 350WA09 & Jack & 230 & 15.02 & 17.79 & 52.15 & 84.25 & 0.91 & 0.11 & 0.18 \\
\hline 350WA10 & Jack & 230 & 15.45 & 18.89 & 74.08 & 76.02 & 0.57 & 0.16 & 0.17 \\
\hline 350WA11 & $\begin{array}{c}\text { Turn-of- } \\
\text { Nut }\end{array}$ & 203 & 14.00 & 18.80 & - & 126.14 & 0.47 & - & 0.31 \\
\hline 350WA12 & $\begin{array}{c}\text { Turn-of- } \\
\text { Nut }\end{array}$ & 203 & 14.30 & 15.77 & - & 75.98 & 0.36 & - & 0.19 \\
\hline 350WA13 & $\begin{array}{c}\text { Turn-of- } \\
\text { Nut }\end{array}$ & 203 & 12.39 & 15.08 & - & 64.84 & 0.49 & - & 0.16 \\
\hline 350WA14 & $\begin{array}{c}\text { Turn-of- } \\
\text { Nut }\end{array}$ & 203 & 16.48 & 17.36 & - & 78.71 & 0.27 & - & 0.19 \\
\hline 350WA15 & $\begin{array}{c}\text { Turn-of- } \\
\text { Nut }\end{array}$ & 203 & 14.24 & 19.06 & - & 78.75 & 0.15 & - & 0.19 \\
\hline
\end{tabular}




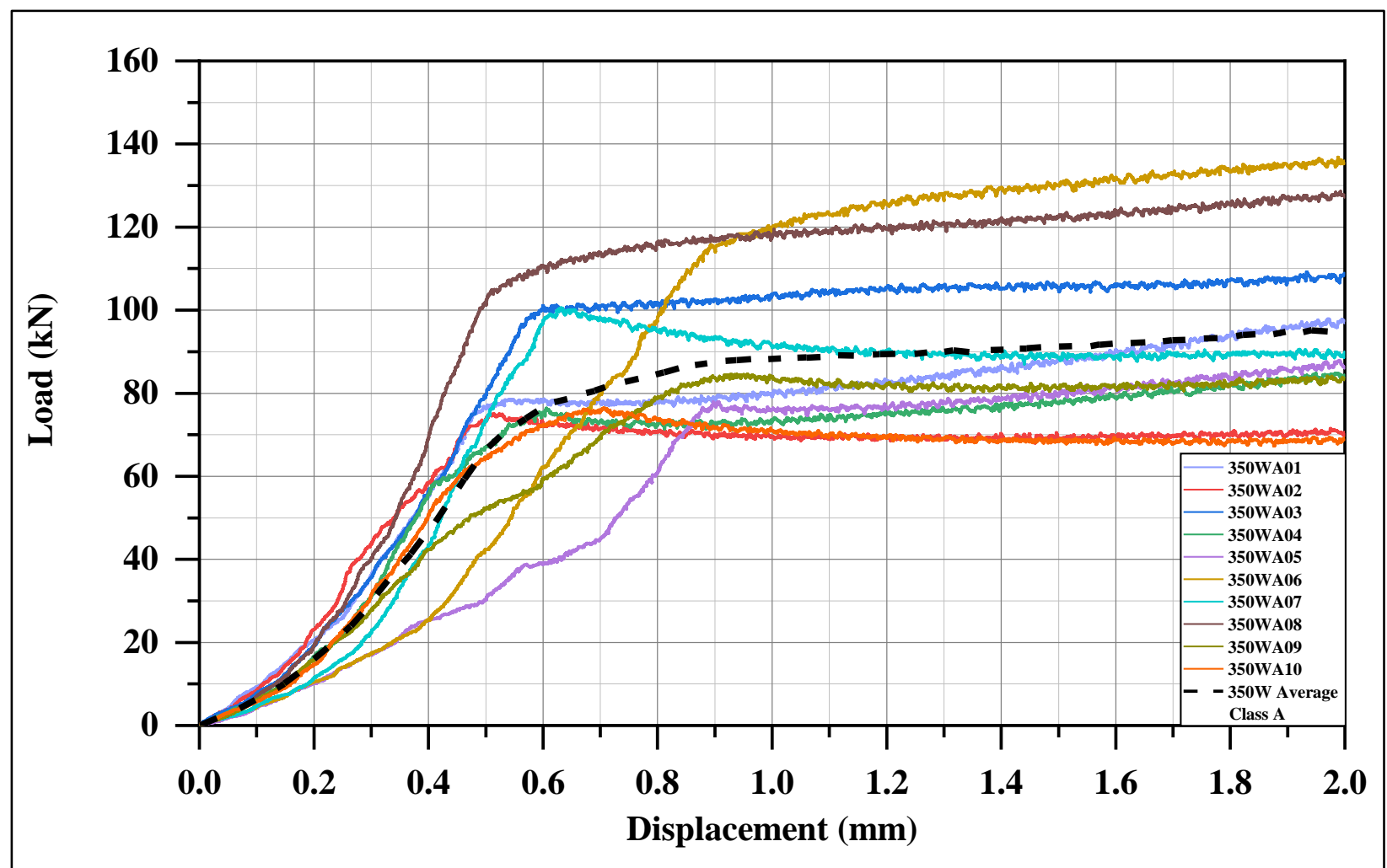

Figure 4-15: Load vs Slip Relationship for all CSA G40.21 350W Steel Specimens with Class A Surface Condition and Clamped by Hydraulic Jack

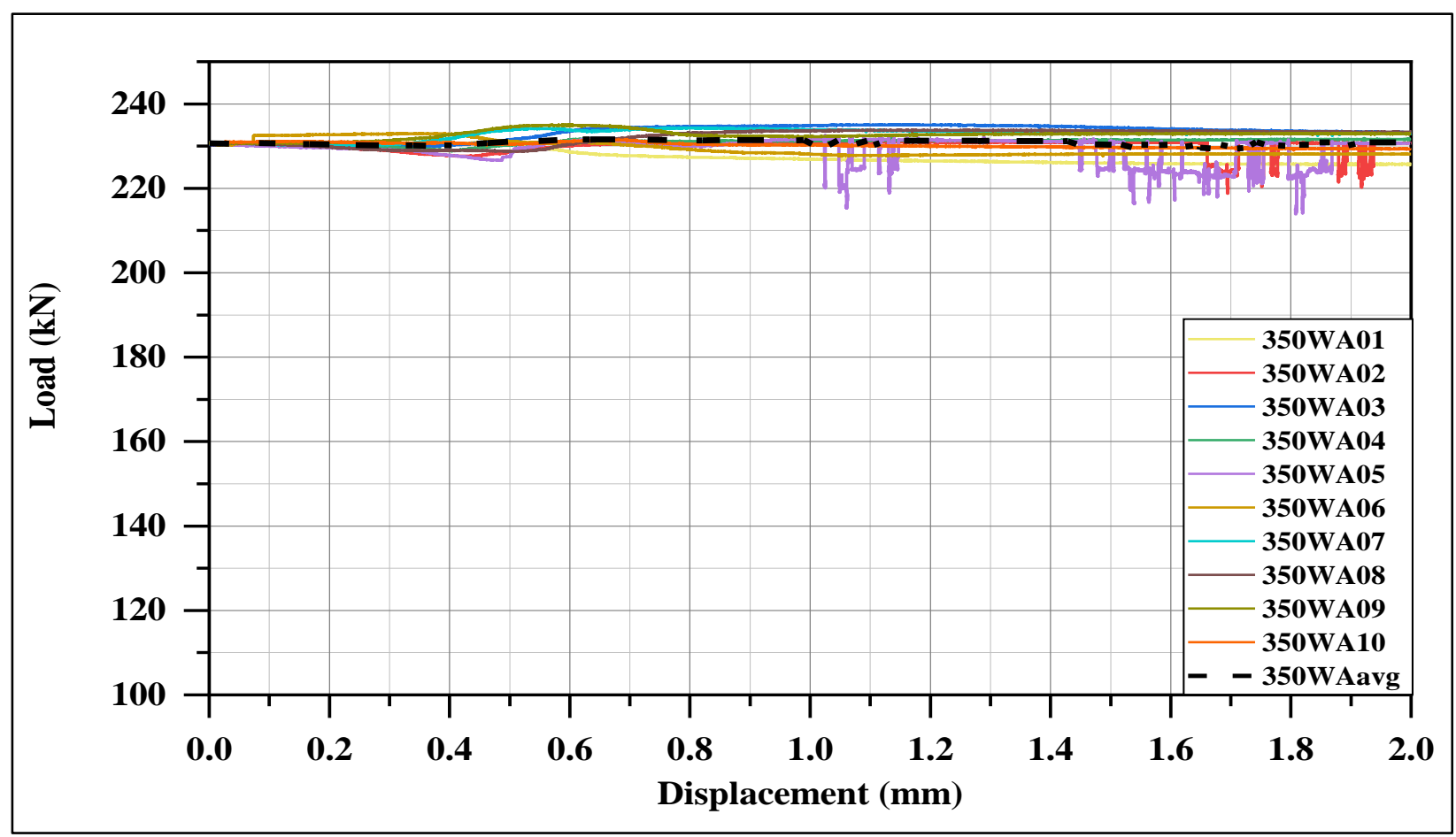

Figure 4-16: Average Clamping Load Recorded Throughout the Test Duration for CSA G40.21 350W Steel with Class A Surface Condition 


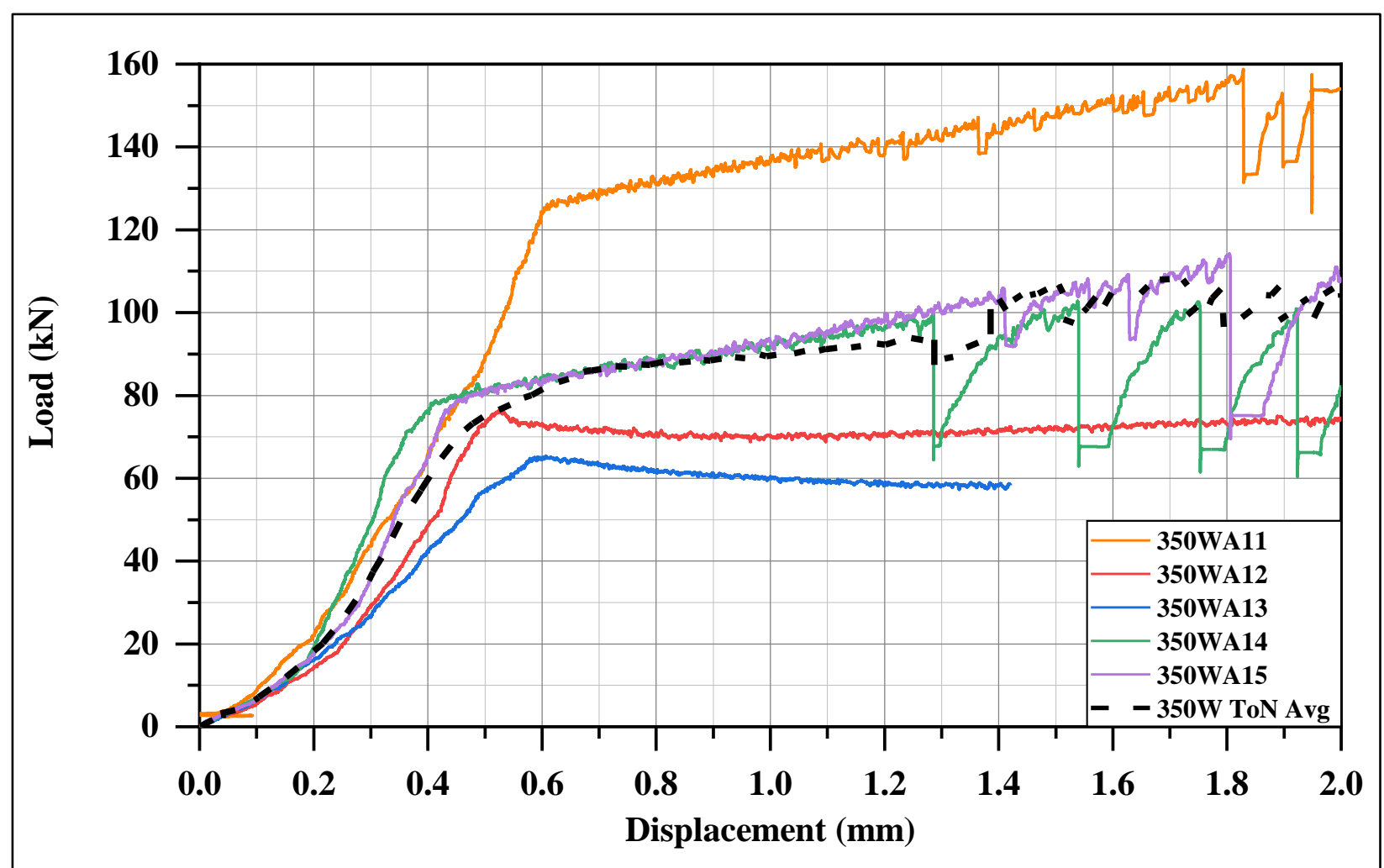

Figure 4-17: Load-Slip Relationship for all CSA G40.21 350W Steel Specimens with Class A Surface Condition and Clamped by the Turn-of-Nut Method

Figure 4-18 shows photos taken under a microscope for 350W structural steel with Class A clean mill surface. Only slight plastic deformation on the surface post slip was noticed around the hole given the skid marks appearing in Figure 4-18(a) and Figure 4-18(b) as it is the area most resistance to slip. However, Figure 4-18(b) show very much less plastic deformation post slip near the edge of the plates, as expected. 


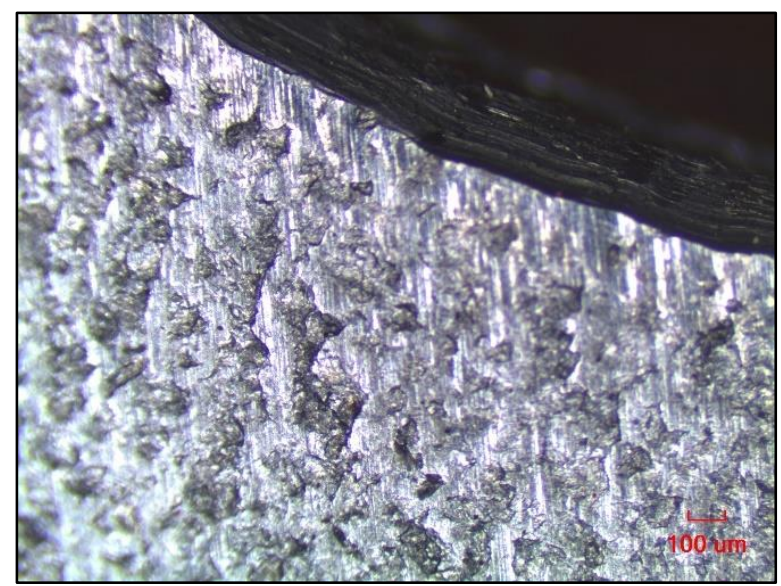

(a)

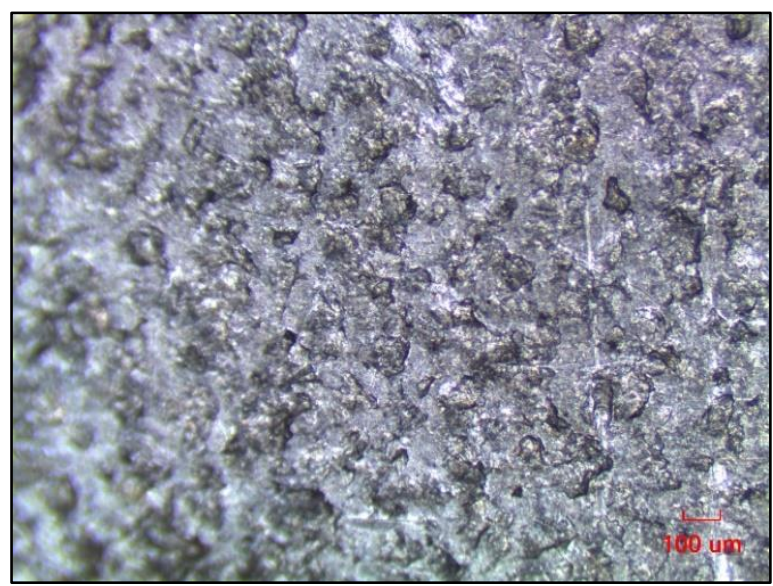

(b)

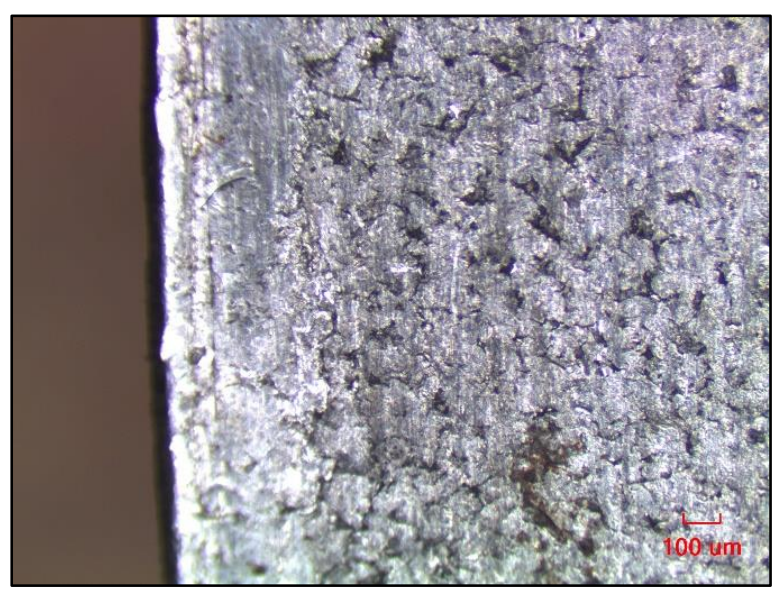

(c)

Figure 4-18: (a-b) 350W Steel with Class A Surface Condition Post-Slip Near Hole; (c) 350W Steel with Class A Surface Condition Post-Slip Near the Edge

\subsection{Slip Resistance Coefficient vs Roughness Analysis}

Figure 4-19 shows the slip resistance coefficients of all the grit-blasted A1010 stainless steel tests. Only 2 of the 15 slip resistance coefficients were able to meet the AASHTO-LRFD Class B limit and Eurocode 3 Class A limit of 0.50, which is the slip resistance coefficient limit for surfaces that are blasted clean. The Canadian Highway Bridge Design Code, CSA S6-14, states that the slip resistance coefficient for blasted surfaces should be at least 0.52 , therefore none of the specimens were able to achieve that. None of these codes distinguishes between different steel types but they do state that for painted or sprayed surfaces, it is up to the decision-maker to properly conduct laboratory tests in order to accurately measure the slip resistance coefficient. However, since the 
major slip always occurred after $0.5 \mathrm{~mm}$ for all the stainless steel specimens and in all of the literature reviewed in this research, the major slip occurred before $0.5 \mathrm{~mm}$, it is logical to take the slip resistance coefficients that occur at the major slip in the current study and compare them to the limits. This would lead to having 9 of the 15 specimens meeting the requirement of having a slip resistance coefficient of 0.50 as stated by both the Eurocode 3 and AASHTO-LRFD Specifications. Also, 8 of the 15 A1010 steel specimens met the slip resistance coefficient requirement of 0.52 stated on CSA S6-14. Further, it is important to note that both the Canadian and American codes do not distinguish a surface roughness or even a surface hardness. Hence, this research aims at comparing roughness values with the slip resistance coefficient. However, because all plates were blasted with the same stainless steel grit, no correlation between different types of blast mediums and their roughness achievements was conducted. This is something that should be done in future research.

Figure 4-20 shows the slip resistance coefficients of all grit blast-cleaned 350W structural steel tests against code values. It can be observed that 12 of the 15 conventional structural steel meet the slip coefficient requirement of 0.50 for Eurocode 3 and AASHTO-LRFD Specifications. Also, 9 of 15 specimens meet the CSA S6-14 slip resistance coefficient requirements of 0.52 . Since most of the major slips in this study occurred after $0.5 \mathrm{~mm}$, and again a lot of the major slips on the literature review occurred before or at $0.5 \mathrm{~mm}$, it is logical to consider the slip resistance coefficients occurring at the major slip in the current study. As such, one may claim that all 15 350W structural steel tests met the limits for all three codes taken into consideration in this study. 


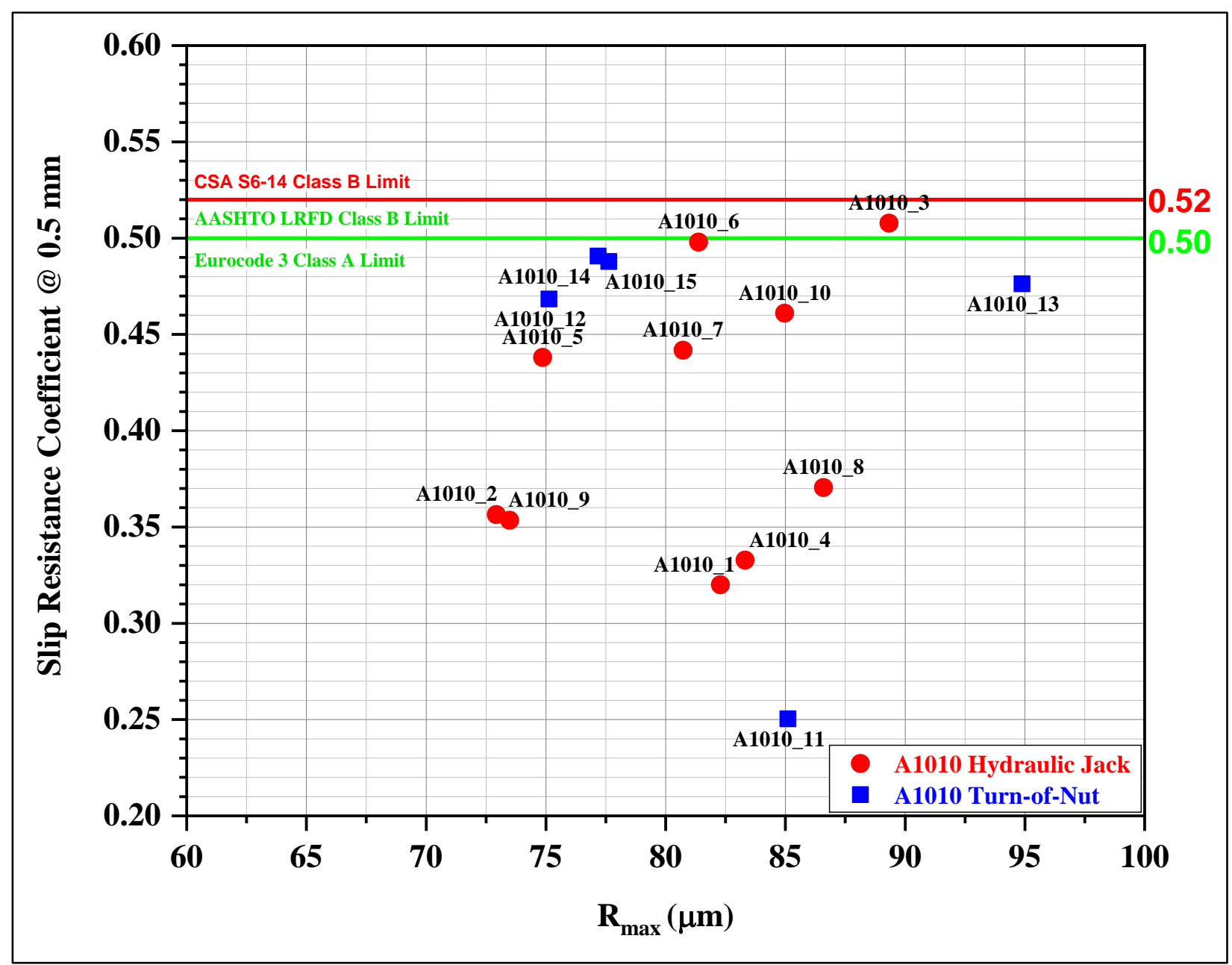

Figure 4-19: Slip Resistance Coefficient vs Surface Roughness for A1010 Stainless Steel 


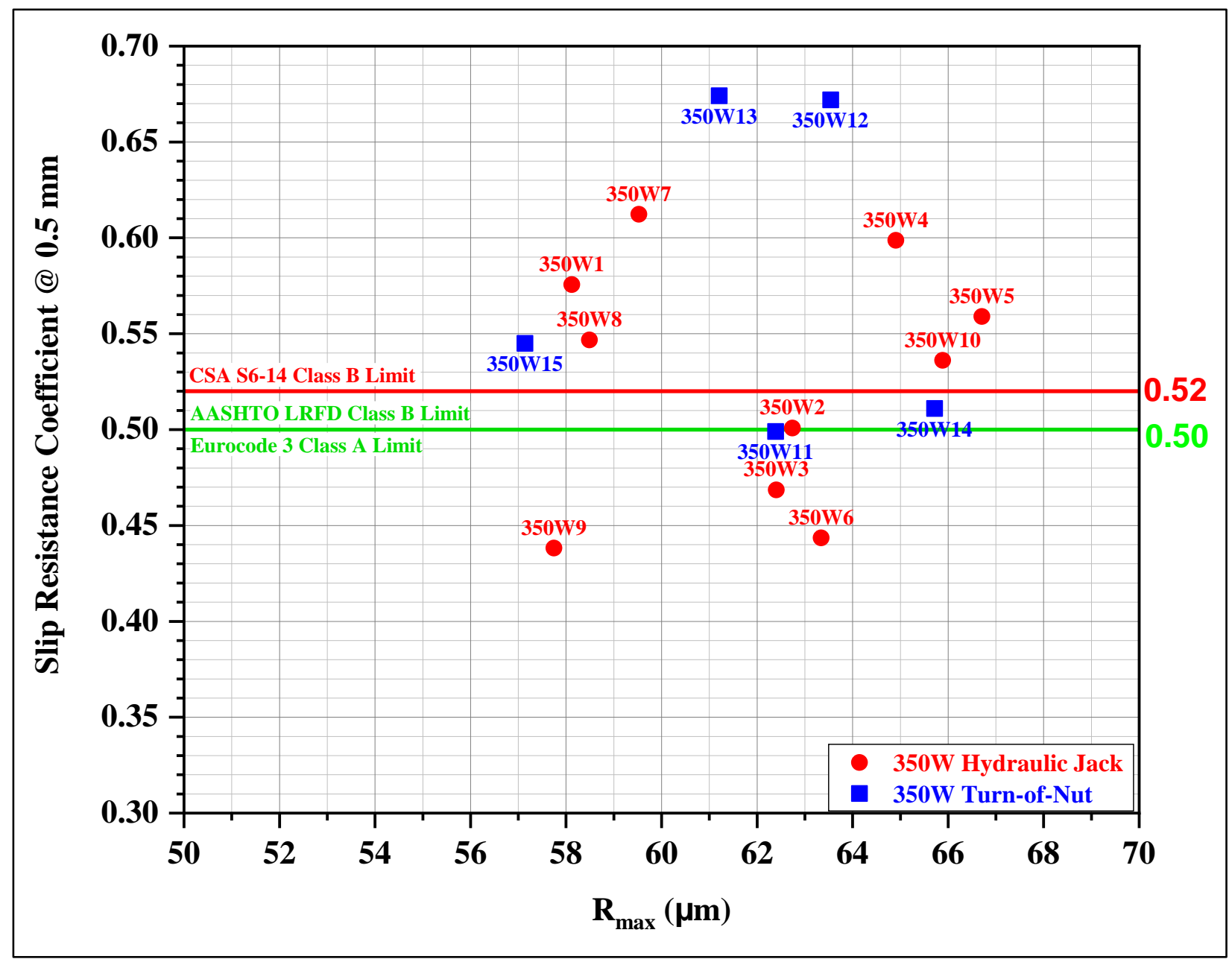

Figure 4-20: Slip Resistance Coefficient vs Surface Roughness for 350W Structural Steel

\subsection{Bolt Relaxation Results}

All the bolts used in this study had a diameter of $22.23 \mathrm{~mm}\left(7 / 8^{\prime \prime}\right)$. These bolts were placed on a Skidmore-Wilhelm hydraulic clamping force load cell in combination with a nut, washer, and washer-type load cell that accurately measured the initial clamping force and the loss of force over time. The numbers for the ultimate and yield strengths of these bolts listed in Table 4-6 were provided by the manufacturer. Since bolts in slip critical connections should be tightened to at least a $70 \%$ preload, they were tested for relaxation at that pretension load level. However, a lot of the literature states that the usual preload achieved in-field is actually much higher at $90 \%$ due to overtightening. Therefore, it was decided to test these bolts at $90 \%$ of the preload as well. Due to 
time constraints and also the fact that the majority of the preload loss occurs within the first 72 hours (Reuther et al, 2014), it was decided to test the bolts for relaxation up to 72 hours.

Table 4-6 shows the test matrix considered in this part of the study for preload of $70 \%$ and $90 \%$ of the bolt tensile strength for A325 bolts and galvanized A325 bolts. However, preload of $70 \%$ of the bolt tensile strength was considered for A193 B8 Class 2 stainless steel bolts with plain nuts as well as galvanized nuts. The reason for neglecting the test with preload of $90 \%$ of the tensile strength in this case is attributed to the fact that galling was experienced during tightening, only $50 \%$ of the preload was achieved before major galling of the threads started to occur. The galling was so strong that a smell of burning from the fusion of the threads was noticed during tightening the bolts. Even with using a common anti-seize lubricant, the bolts still experienced galling and did not reach even $70 \%$ of the preload when combined with a stainless steel nut. The aforementioned was also confirmed by the research conducted by Cameron (2017). According to stainless steel bolt manufacturers (Fastenal, an American supplier), galling occurs on fasteners that produce thin oxide surface films, such as stainless steel. Due to the pressure and heat build-up during the tightening process, the thin oxide film is destroyed. This leads to the exposed metal peaks and valleys on the two surfaces to come into contact with each other and cause an increase in friction. The increase in friction and heat, as well as the softness of stainless steel thread surfaces, starts to seize and eventually bind together to a point where the applied torque does not get converted to preload. This phenomenon is also known as "cold-welding". Through trial and error, it was found that using a regular carbon alloy galvanized nut or plain nut, the stainless steel bolt was easily able to reach $70 \%$ of its preload, but not $90 \%$. Therefore, it was decided to test the stress relaxation of the B8 Class 2 bolt at $70 \%$ of its preload with both types of nuts.

From the 72-hour relaxation tests, a clear pattern was observed on which a lower initial preload experiences a much lower stress relaxation for A325 bolts for both plain and galvanized fasteners. Also, galvanized bolts experienced higher relaxations for all tests conducted at both preload levels. This is more than likely due to the creep of the galvanized coating. Finally, the stainless steel bolt experienced the highest stress relaxation in comparison to the A325 carbon alloy bolts. Also, using the galvanized nut on the stainless steel bolt led to slightly higher relaxation levels but the difference was not as great as the difference between the relaxation levels of a plain A325 bolt with a galvanized A325 bolt. 
Table 4-6: Summary of Bolt Relaxation Results

\begin{tabular}{|c|c|c|c|c|c|c|c|c|}
\hline Bolt Type & $\begin{array}{c}\text { Bolt } \\
\text { Ultimate } \\
\text { Strength, } \\
\text { Fu }_{\mathbf{u}}\end{array}$ & $\begin{array}{c}\text { Bolt } \\
\text { Yield } \\
\text { Strength, } \\
\text { Fy }_{\mathbf{y}}\end{array}$ & $\begin{array}{c}\text { Preload } \\
\text { (\% of } \\
\left.F_{\mathrm{y}}\right)\end{array}$ & $\begin{array}{c}\text { Number } \\
\text { of } \\
\text { Specimens }\end{array}$ & Duration & $\begin{array}{c}\text { Average } \\
\text { Loss of } \\
\text { Preload } \\
\text { after } 72 \\
\text { hours } \\
(\%)\end{array}$ & $\begin{array}{c}50 \text { Year Loss } \\
\text { Extrapolation } \\
(\%)\end{array}$ & $\begin{array}{c}75 \text { Year Loss } \\
\text { Extrapolation } \\
(\%)\end{array}$ \\
\hline $\begin{array}{c}\text { A325 - } \\
\text { Plain w/ } \\
\text { Plain Nut } \\
\text { \& Washer }\end{array}$ & $\begin{array}{l}828 \mathrm{MPa} \\
(120 \mathrm{ksi})\end{array}$ & $\begin{array}{c}635 \mathrm{MPa} \\
(92 \mathrm{ksi})\end{array}$ & $70 \%$ & 5 & 72 hours & 1.87 & 2.81 & 2.85 \\
\hline $\begin{array}{c}\text { A325 - } \\
\text { Galvanized } \\
\text { w/ } \\
\text { Galvanized } \\
\text { Nut \& } \\
\text { Washer }\end{array}$ & $\begin{array}{l}828 \mathrm{MPa} \\
(120 \mathrm{ksi})\end{array}$ & $\begin{array}{c}635 \mathrm{MPa} \\
(92 \mathrm{ksi})\end{array}$ & $70 \%$ & 5 & 72 hours & 2.47 & 4.82 & 4.93 \\
\hline $\begin{array}{c}\text { A325 - } \\
\text { Plain w/ } \\
\text { Plain Nut } \\
\text { \& Washer }\end{array}$ & $\begin{array}{l}828 \mathrm{MPa} \\
(120 \mathrm{ksi})\end{array}$ & $\begin{array}{c}635 \mathrm{MPa} \\
(92 \mathrm{ksi})\end{array}$ & $90 \%$ & 5 & 72 hours & 2.99 & 5.27 & 5.38 \\
\hline $\begin{array}{c}\text { A325 - } \\
\text { Galvanized } \\
\text { w/ } \\
\text { Galvanized } \\
\text { Nut \& } \\
\text { Washer }\end{array}$ & $\begin{array}{l}828 \mathrm{MPa} \\
(120 \mathrm{ksi})\end{array}$ & $\begin{array}{c}635 \mathrm{MPa} \\
(92 \mathrm{ksi})\end{array}$ & $90 \%$ & 5 & 72 hours & 4.55 & 8.71 & 8.90 \\
\hline $\begin{array}{c}\text { A193 B8 } \\
\text { Class } 2 \text { w/ } \\
\text { Plain Nut } \\
\text { \& Stainless } \\
\text { Washer }\end{array}$ & $\begin{array}{l}794 \mathrm{MPa} \\
(115 \mathrm{ksi})\end{array}$ & $\begin{array}{c}552 \mathrm{MPa} \\
(80 \mathrm{ksi})\end{array}$ & $70 \%$ & 5 & 72 hours & 7.99 & 13.67 & 13.94 \\
\hline $\begin{array}{c}\text { A193 B8 } \\
\text { Class } 2 \text { w/ } \\
\text { Galvanized } \\
\text { Nut \& } \\
\text { Stainless } \\
\text { Washer }\end{array}$ & $\begin{array}{l}794 \mathrm{MPa} \\
(115 \mathrm{ksi})\end{array}$ & $\begin{array}{c}552 \mathrm{MPa} \\
(80 \mathrm{ksi})\end{array}$ & $70 \%$ & 5 & 72 hours & 8.23 & 14.30 & 14.58 \\
\hline
\end{tabular}

The preload relaxation shown in Table 4-6 are the average of 5 tested assemblies for each fastener type at its respective preload. The tables on 6.2.3Appendix D of this report show the specific relaxation result of each tested specimen.

\subsubsection{Bolt Relaxation at 70\% of Preload}

Figure 4-21 shows the reduction in the bolt pretension with time in case of plain A325 bolts and galvanized A325 bolts with $70 \%$ preload for plain nuts as well as galvanized nuts. It can be observed that most of the relaxation occurred within the first 20 minutes as shown in the enlarged 
potion of the graph. The majority of the preload loss occurred instantly when the hydraulic torque wrench was released. The preload loss after 72 hours for plain A325 bolts was 1.87\%, while the corresponding preload loss for galvanized A325 fastener was 2.47\%. From the graph, one may notice that the rate for the loss of preload for A325 plain fastener slowed down and was almost horizontal after 72 hours, therefore it is appropriate to extrapolate this to further years. However, the preload loss of the galvanized bolt was still falling gradually at the same rate at 72-hours. Therefore, the galvanized A325 fastener assembly should be tested for much longer than 72-hours until the rate of preload loss slows down.

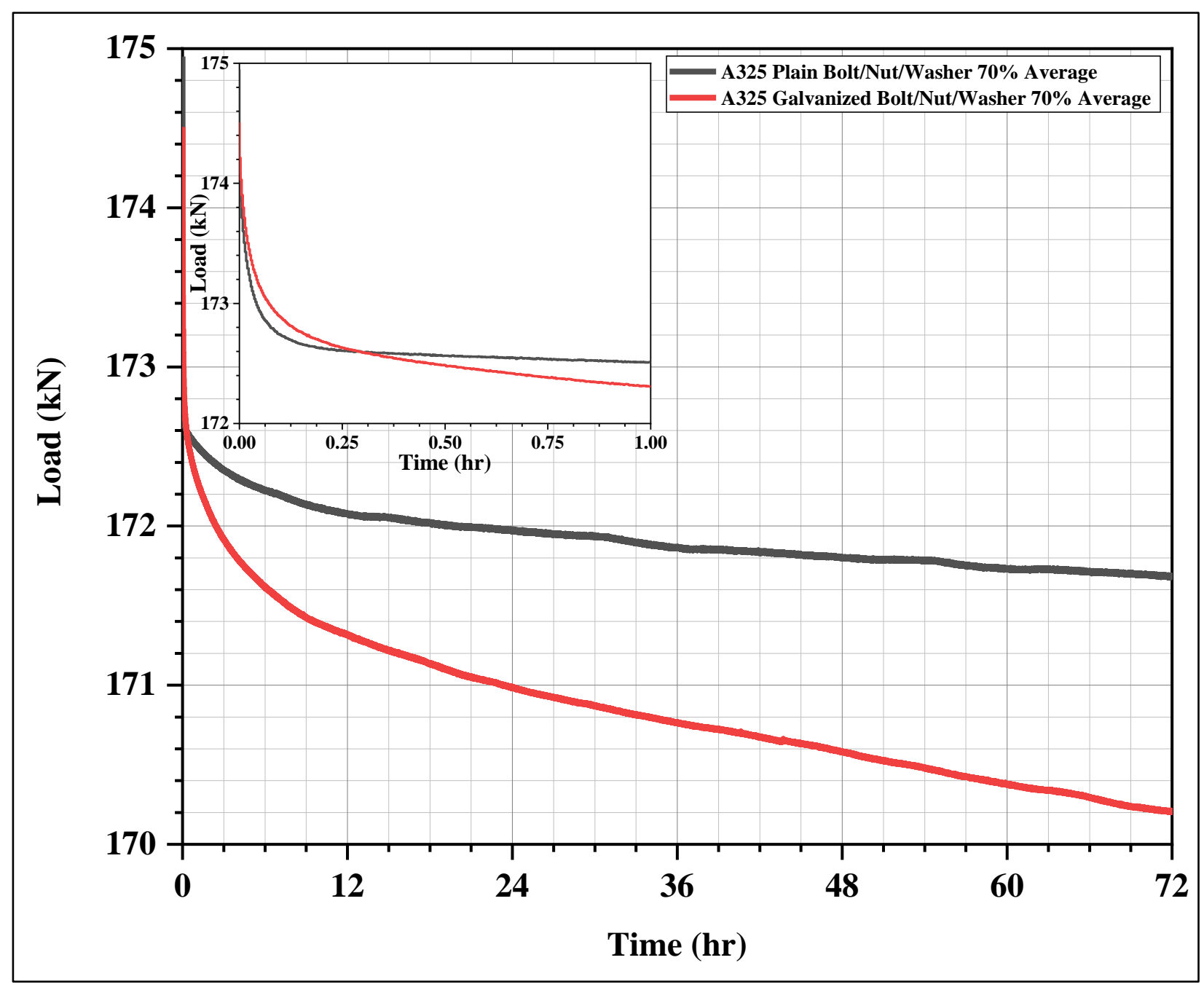

Figure 4-21: A325 Plain and Galvanized Bolt Relaxation from 70\% Preload

In Figure 4-22, the 72-hour percent loss of preload is graphed by turning the $\mathrm{x}$-axis into a logarithmic scale (base 10) so that the curve takes more of a linear shape. This makes it easier to extrapolate and create a linear line of best fit which is extended all the way up to $1,000,000$ hours. 
The preload loss is extrapolated to 50 years ( 438,000 hours) and 75 years ( 657,000 hours) because a lot of the older bridges were initially designed with a 50-year life-span in mind and it would be easy to compare these numbers with previous studies such as the one conducted by Afzali et al. (2017). Also, the 75-year point was chosen as a basis due to the fact that the Canadian Highway Bridge Design Code (CSA, 2014a) considers at least a 75-year life cycle of bridges. The extrapolated values for A325 plain and galvanized assemblies initially preloaded at $70 \%$ of their strength, as required by the code, showed to have losses of $2.85 \%$ and $4.93 \%$ at the 75 -year mark for plain A325 bolts and galvanized A325 bolts, respectively.

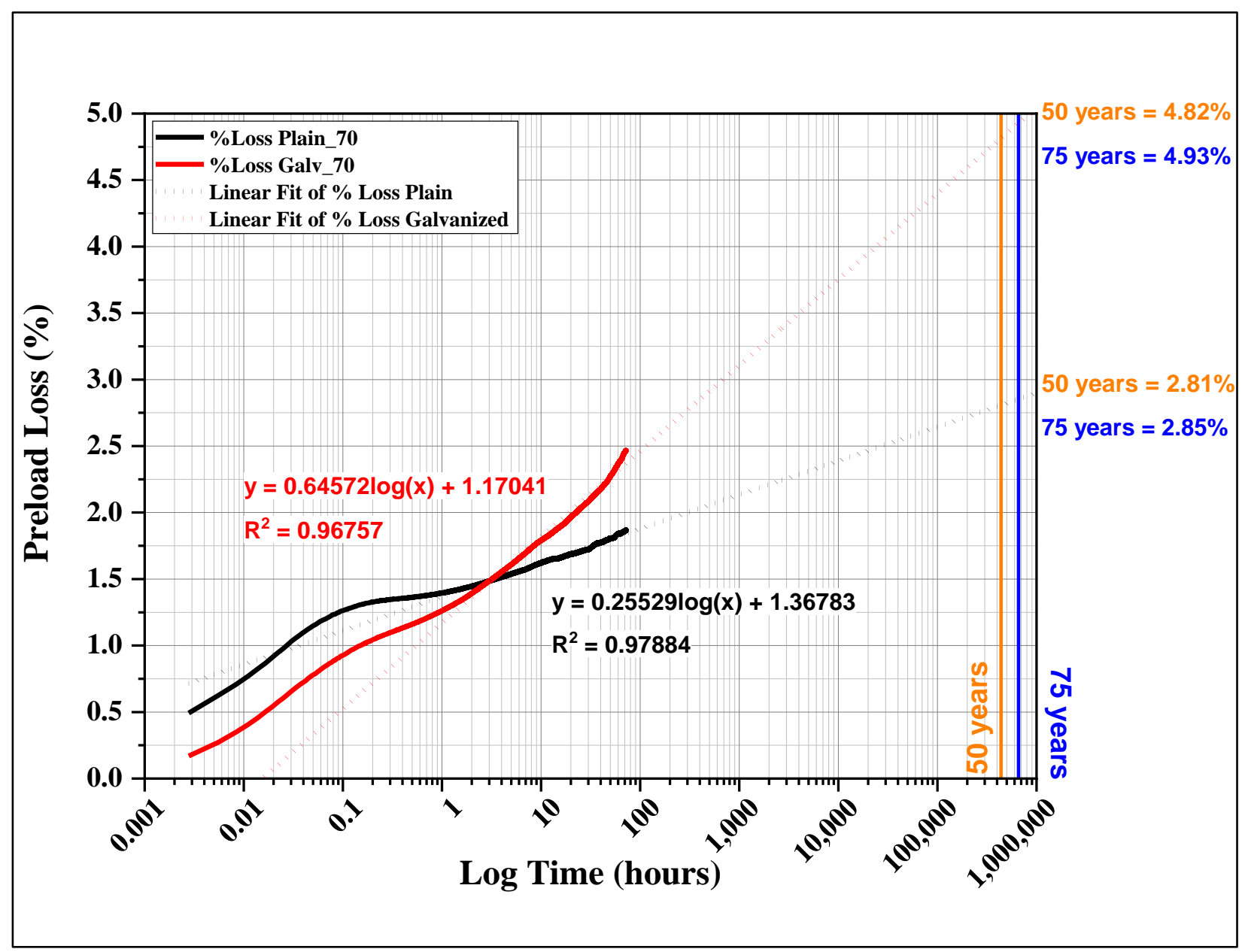

Figure 4-22: Extrapolation of 70\% Preload Loss for A325 Plain and Galvanized Bolts

\subsubsection{Bolt Relaxation at $90 \%$ of Preload}

Figure 4-23 below shows the preload loss for both plain and galvanized A325 bolts when initially tightened to $90 \%$ of their tensile strength. Similar to the $70 \%$ preload tightening level, one may 
observe that most preload loss occurred instantaneously when the hydraulic wrench was released due to the spring-like reaction of the threads. The majority of the loss occurred within the first hour and the rate of preload loss slows down gradually towards the end of the test. At $90 \%$ preload level, A325 plain bolts experienced a preload loss of 2.99\%, whereas the A325 galvanized bolts experienced a preload loss of $4.55 \%$ after 72 hours. It can be observed that at the 72 -hour mark, the galvanized bolt continued at a higher downward trending rate in comparison to the plain bolts. This means that the experiment should be continued for a longer period of time to see a flatter slope.

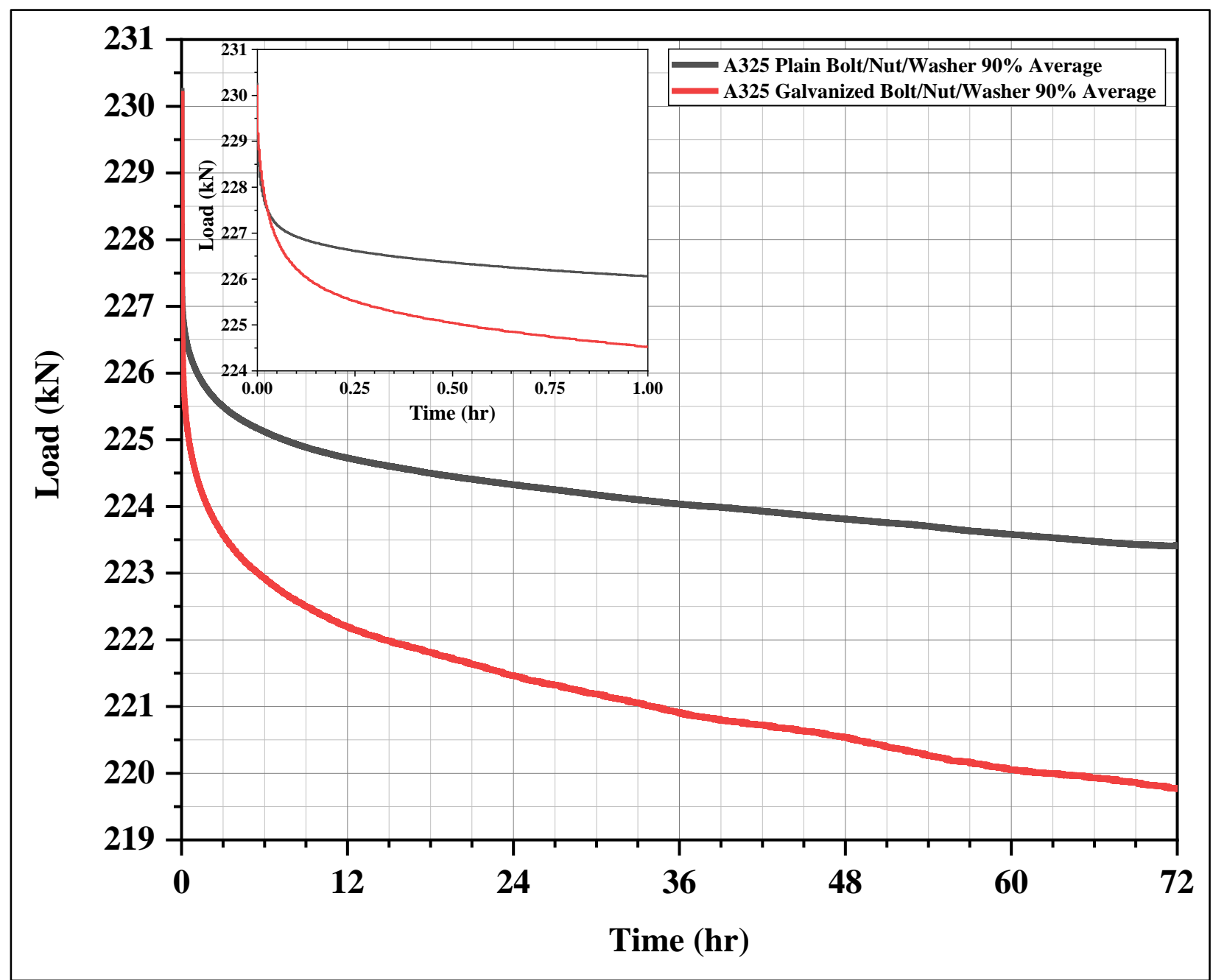

Figure 4-23: A325 Plain and Galvanized Bolt Relaxation from 90\% Preload

As shown in Figure 4-24, the log value of time is compared with value of relaxation for plain A325 and galvanized A325 bolts preloaded to $90 \%$ of the bolt tensile strength, leading to and almost linear scale for the ease of extrapolation of bolt pretension losses up to the 50 and 75 -year marks. 
One may observe that the values of pretension loss at the 75 -year mark obtained were $8.90 \%$ for the galvanized A325 bolt assembly compared to $5.38 \%$ for the plain A325 bolt assembly. Therefore, the galvanized bolting assembly shows almost $61 \%$ more relaxation than the same A325 plain bolt. These values are not significant given the fact that the bolts were pretention far beyond the code limit. One may also observe that bolt relaxation is higher if it is tightened at higher initial preloading value.

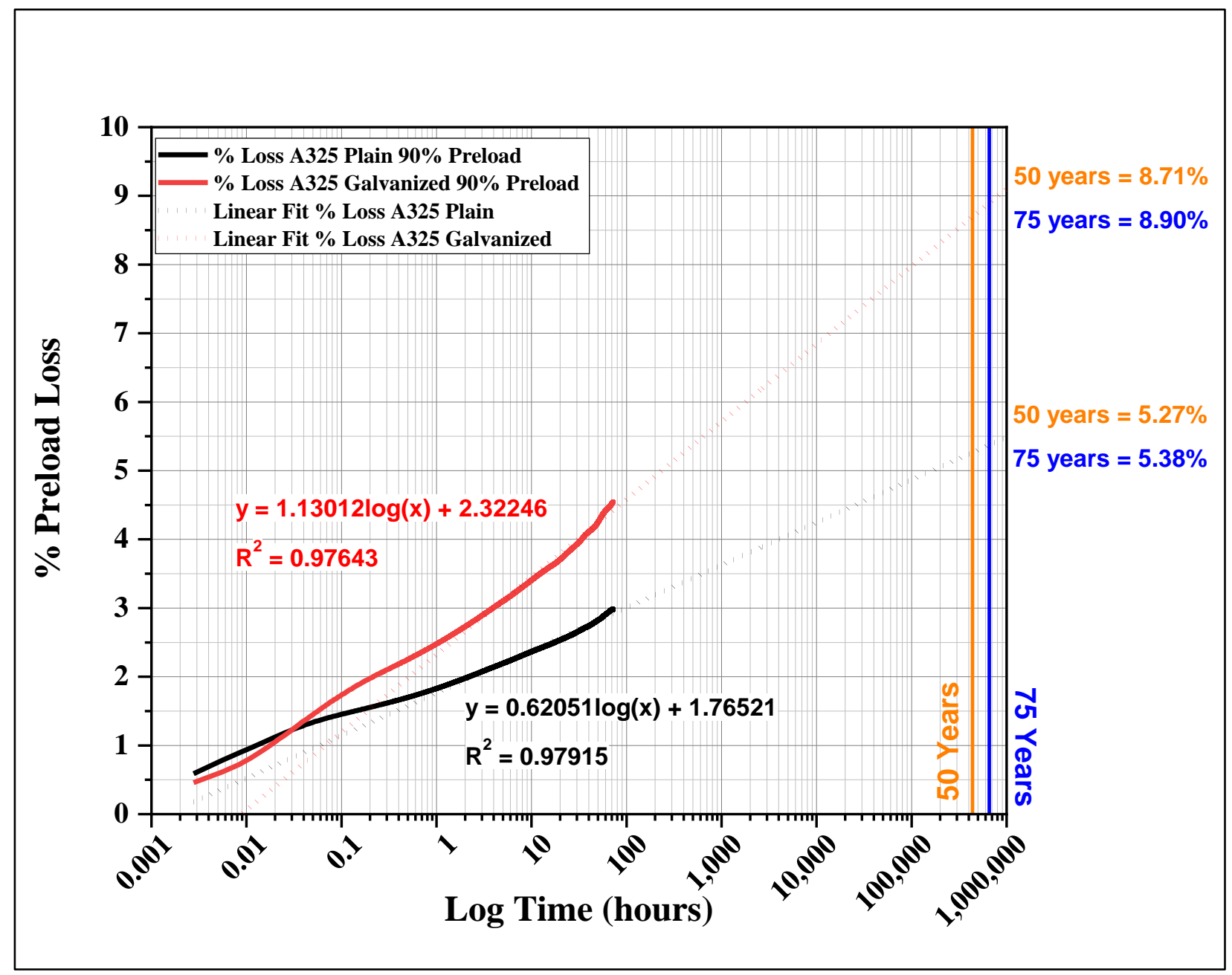

Figure 4-24: Extrapolation of $90 \%$ Preload Loss for A325 Plain and Galvanized Bolts

\subsubsection{ASTM A193 B8 Class 2 Stainless Steel Bolt Relaxation}

Figure 4-25 shows the relaxation of A193 B8 Class 2 stainless steel bolts with plain and galvanized A563 DH nuts that were pretentioned to $70 \%$ of their tensile strength. Results show that the use of plain and galvanized A563 DH nuts to tighten the stainless steel bolts resulted in stress 
relaxation after 72 hours in the order of $7.99 \%$ and $8.23 \%$, respectively, which are much greater than those observed for A325 bolt assembly. It can also ben seen that the majority of the relaxation was almost instantaneous and can be attributed to the reaction that the threads had when the hydraulic wrench was released. The majority of the loss occurred within the first hour, after that there was a slow gradual decrease in the rate of the preload loss up to the end of the 72-hour test. Nevertheless, the preload seemed to still be decreasing at the 72 hours and thus extrapolating from this point on will not yield super precise results.

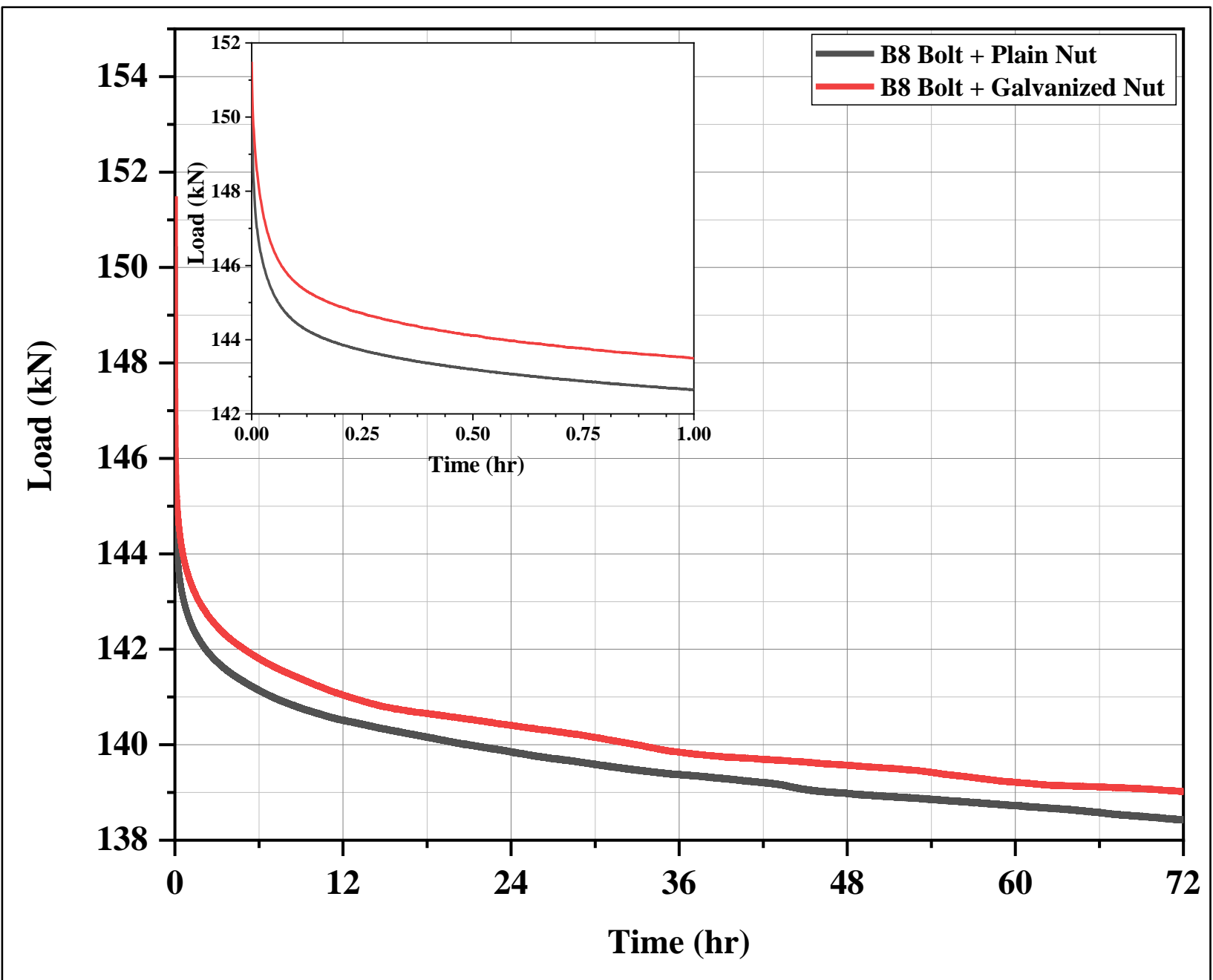

Figure 4-25: B8 Class 2 Stainless Steel Bolt with Plain and Galvanized Nut Relaxation from 70\% Preload

Figure 4-26 shows the change in bolt preload in percentage against time in a log scale. By extrapolating the experimental data up to the 75-year design mark, the bolt relaxations were calculated as $14.58 \%$ for B8 Class 2 stainless steel bolt with galvanized nut and $13.94 \%$ for B8 
Class 2 bolt with plain nut. It should be noted that Afzali et al. (2017) obtained stainless steel bolt relaxation values in the ranges of 8.5 to $10.5 \%$ at the 50 -year mark, but with smaller bolt diameter than that used in the current research. Although the relaxation values obtained in the current research are substantial compared to those for A325 bolts, this may be tolerated given the fact that previous research reported that workers, in general, tend to overtighten slip-critical bolts with values upwards of $20 \%$ of the minimum required pretension (Kulak et al., 2001).

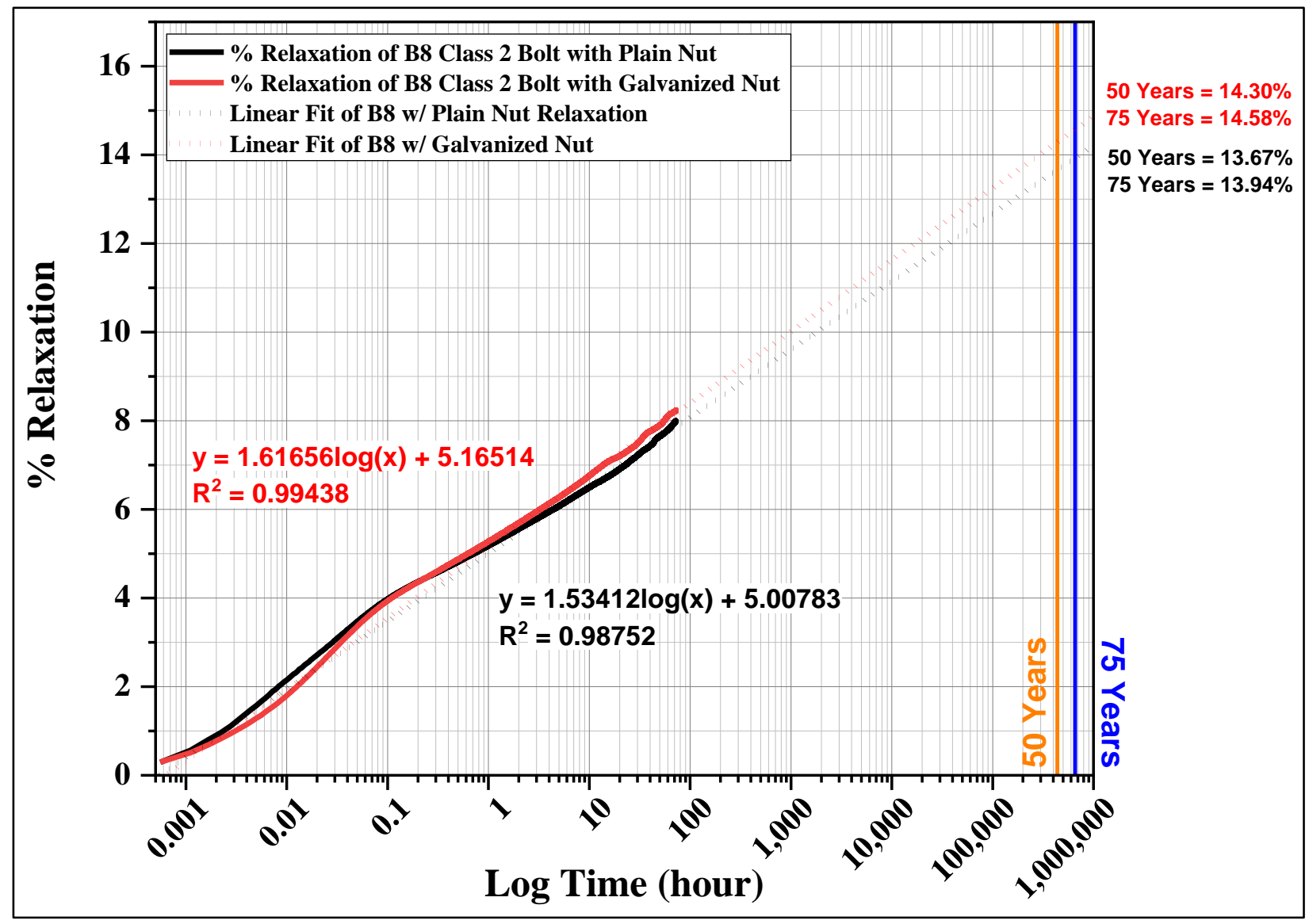

Figure 4-26: Extrapolation of \% Preload Loss for B8 Class 2 Bolts with Plain and Galvanized Nut 


\section{Chapter 5 - Tensile and Fatigue Test Results}

\subsection{Tensile Test Results}

Table 5-1 summarizes the results obtained from the tensile tests on A1010 and 350W coupon specimens under static loading to collapse. It can be observed that yield strength of A1010 stainless steel specimens exceed the minimum requirement of $345 \mathrm{MPa}(50 \mathrm{ksi})$ yield strength and minimum requirement of $480 \mathrm{MPa}(70 \mathrm{ksi})$ tensile strength specified in both ASTM A1010 and ASTM A709 50CR standards in case of bare steel and full-penetration groove welded coupons. The fracture elongation percent, which is supposed to be $21 \%$ for plate type A709 50CR steel for bridges, is also met accordingly for all specimens. One may observe that ASTM A1010 steel has very similar behavior to that of CSA G40.21 350W conventional structural steel commonly used in Canadian steel bridge design. It should be noted that all coupons specimens tested were $25 \mathrm{~mm}(1$ ") in thickness with the rolling direction parallel to the applied load. Daghash et al., (2019) obtained similar numbers for their $25 \mathrm{~mm}$ (1") thick specimen with a rolling direction parallel to the applied load; yield strength of $360.6 \mathrm{MPa}$; a tensile strength of $515.1 \mathrm{MPa}$; and a fracture elongation of $24.7 \%$ was obtained. Daghash et al. (2019) performed similar tests on A1010 steel and obtained a yield strength of $355.8 \mathrm{MPa}$, tensile strength of 528.1 MPa and fracture elongation of $32.8 \%$ for the specimens that were tested but with the applied load perpendicular to the rolling direction. It should be noted that the rolled specimens in the transverse direction of the applied load had a thickness of $12.5 \mathrm{~mm}$.

As stated earlier, the longer specimens for both $350 \mathrm{~W}$ and A1010 steel which had a gauge length $25 \mathrm{~mm}$ greater than the shorter specimens in the current research. For these longer specimens, on may observe slightly lower fracture elongations in comparison to the shorter specimens as reported in Table 5-1. Also, A1010 steel I shown to have slightly higher yield strength than $350 \mathrm{~W}$ steel but with a lower fracture strength. Results in Table 5-1 show that the welding of the coupon specimens did not have a major impact on the yield and tensile strength properties of the steel when compared to bare steel coupon specimens. On the other hand, welded coupons experienced slight increase in fracture strength and a significant decrease in elongation for both A1010 and 350W steel when compared to the results for bare steel coupons. It should be noted that all welded specimens were 
ground smooth and failed outside of the welded zone on the base metal. Whereas, the regular nonwelded specimens failed in the middle portion of the reduced section.

Table 5-1: Summary of Tensile Test Results for A1010 and 350W Steels

\begin{tabular}{|c|c|c|c|c|}
\hline $\begin{array}{c}\text { Specimen } \\
\text { Type }\end{array}$ & $\begin{array}{l}\text { Yield Strength, } \\
\text { (MPa) [ksi] }\end{array}$ & $\begin{array}{c}\text { Tensile } \\
\text { Strength, } \\
\text { (MPa) [ksi] }\end{array}$ & $\begin{array}{l}\text { Fracture } \\
\text { Strength, } \\
\text { (MPa) [ksi] }\end{array}$ & $\begin{array}{c}\text { Fracture } \\
\text { Elongation } \\
(\%)\end{array}$ \\
\hline $\begin{array}{c}\text { 350W Short } \\
\text { Specimen }\end{array}$ & $\begin{array}{l}358.6 \\
{[52.0]}\end{array}$ & $\begin{array}{l}587.1 \\
{[85.2]}\end{array}$ & $\begin{array}{l}402.1 \\
{[58.3]}\end{array}$ & 30.0 \\
\hline $\begin{array}{l}\text { 350W Long } \\
\text { Specimen }\end{array}$ & $\begin{array}{l}363.2 \\
{[52.7]}\end{array}$ & $\begin{array}{l}552.4 \\
{[80.1]}\end{array}$ & $\begin{array}{l}382.2 \\
{[55.4]}\end{array}$ & 29.3 \\
\hline $\begin{array}{l}\text { A1010 Short } \\
\text { Specimen }\end{array}$ & $\begin{array}{l}388.1 \\
{[56.3]}\end{array}$ & $\begin{array}{l}550.6 \\
{[79.9]}\end{array}$ & $\begin{array}{l}339.2 \\
{[49.2]}\end{array}$ & 28.8 \\
\hline $\begin{array}{l}\text { A1010 Long } \\
\text { Specimen }\end{array}$ & $\begin{array}{l}383.1 \\
{[55.6]}\end{array}$ & $\begin{array}{l}558.8 \\
{[81.1]}\end{array}$ & $\begin{array}{l}267.4 \\
{[38.8]}\end{array}$ & 26.6 \\
\hline $\begin{array}{l}\text { 350W Welded } \\
\text { Short Specimen }\end{array}$ & $\begin{array}{l}350.6 \\
{[50.9]}\end{array}$ & $\begin{array}{l}581.1 \\
{[84.3]}\end{array}$ & $\begin{array}{r}426.6 \\
{[61.9]}\end{array}$ & 23.3 \\
\hline $\begin{array}{l}\text { 350W Welded } \\
\text { Long Specimen }\end{array}$ & $\begin{array}{l}343.5 \\
{[49.8]}\end{array}$ & $\begin{array}{l}574.9 \\
{[83.4]}\end{array}$ & $\begin{array}{l}418.2 \\
{[60.7]}\end{array}$ & 21.8 \\
\hline $\begin{array}{l}\text { A1010 Welded } \\
\text { Short Specimen }\end{array}$ & $\begin{array}{l}410.8 \\
{[59.6]}\end{array}$ & $\begin{array}{l}562.7 \\
{[81.6]}\end{array}$ & $\begin{array}{l}354.6 \\
{[51.4]}\end{array}$ & 23.2 \\
\hline $\begin{array}{l}\text { A1010 Welded } \\
\text { Long Specimen }\end{array}$ & $\begin{array}{l}372.7 \\
{[54.1]}\end{array}$ & $\begin{array}{l}560.2 \\
{[81.3]}\end{array}$ & $\begin{array}{l}283.8 \\
{[41.2]}\end{array}$ & 22.7 \\
\hline
\end{tabular}

\subsubsection{Stress-Strain Relationships Obtained from Tensile Tests}

Figure 5-1 shows the stress-strain curves for all tested coupon specimens reported in Table 5-1. The dashed lines show results for $350 \mathrm{~W}$ bare steel coupons and the dotted lines show the results for the $350 \mathrm{~W}$ welded steel coupons. On the other hand, the full lines show the results for the A1010 bare and welded coupons. In general, all A1010 stainless steels experienced a rounder yield point followed by strain-hardening up until the ultimate tensile strength, followed by higher fracture strength at lower strains in comparison to $350 \mathrm{~W}$ steel. Figure 5-2 shows the stress-strain curves of 
only the A1010 bare and welded coupon specimens. Although the shape of the curves appears to be identical for bare and welded coupons up to the ultimate strength values, the A1010 bare steel coupon specimens experienced higher strains and elongations following the point of the ultimate strength, as expected. Figure 5-3 shows an enlarged portion of the first part of the stress and strain relationships for all A1010 stainless steel curves to detect the yield point. The yield point shown on Table 5-1 was calculated by using the $0.2 \%$ offset from the most linear portion of the graphs. All stress and strain curves show very similar behavior on the initial stress-strain relationship. Figure 5-4 shows the stress-strain of all conventional CSA G40.21 350W steels. The opposite phenomena occur for this steel in comparison to A1010. In general, lower ultimate strength and lower yield point were observed for the bare coupon specimens that those for welded coupon specimens.

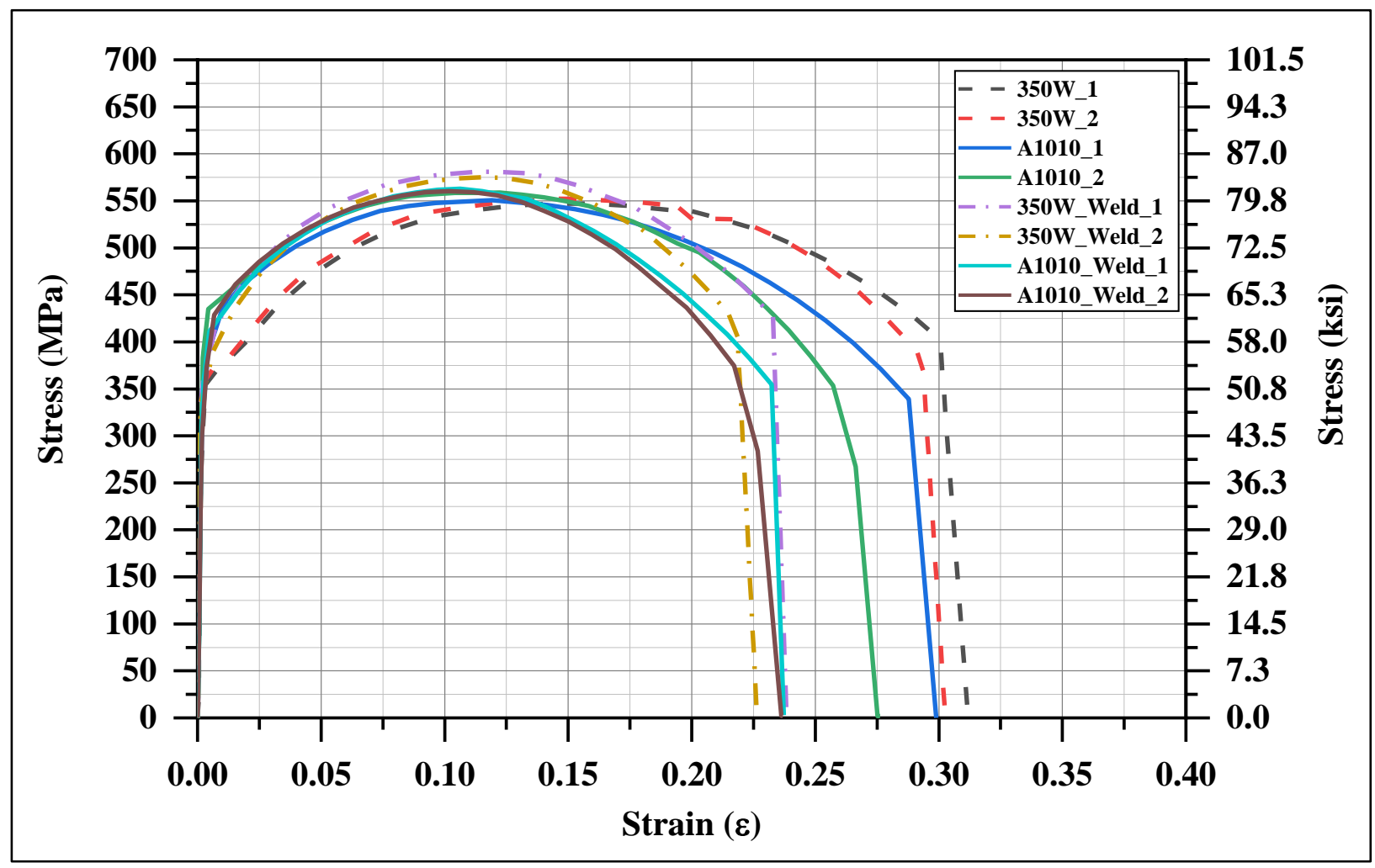

Figure 5-1: Stress-Strain Curves for All tested Coupon 


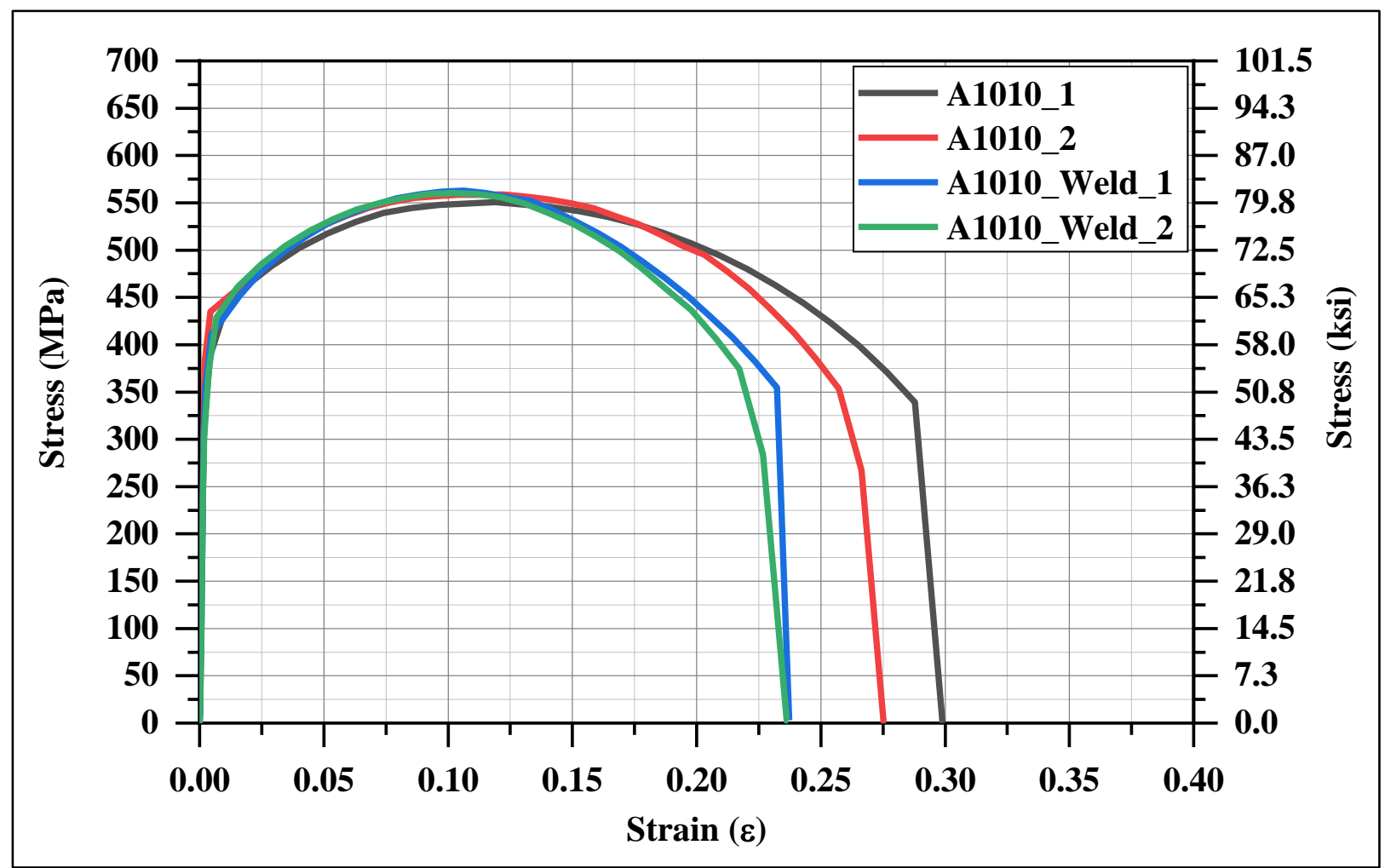

Figure 5-2: Stress-Strain Relationships for A1010 Regular and Welded Stainless Steel Coupons

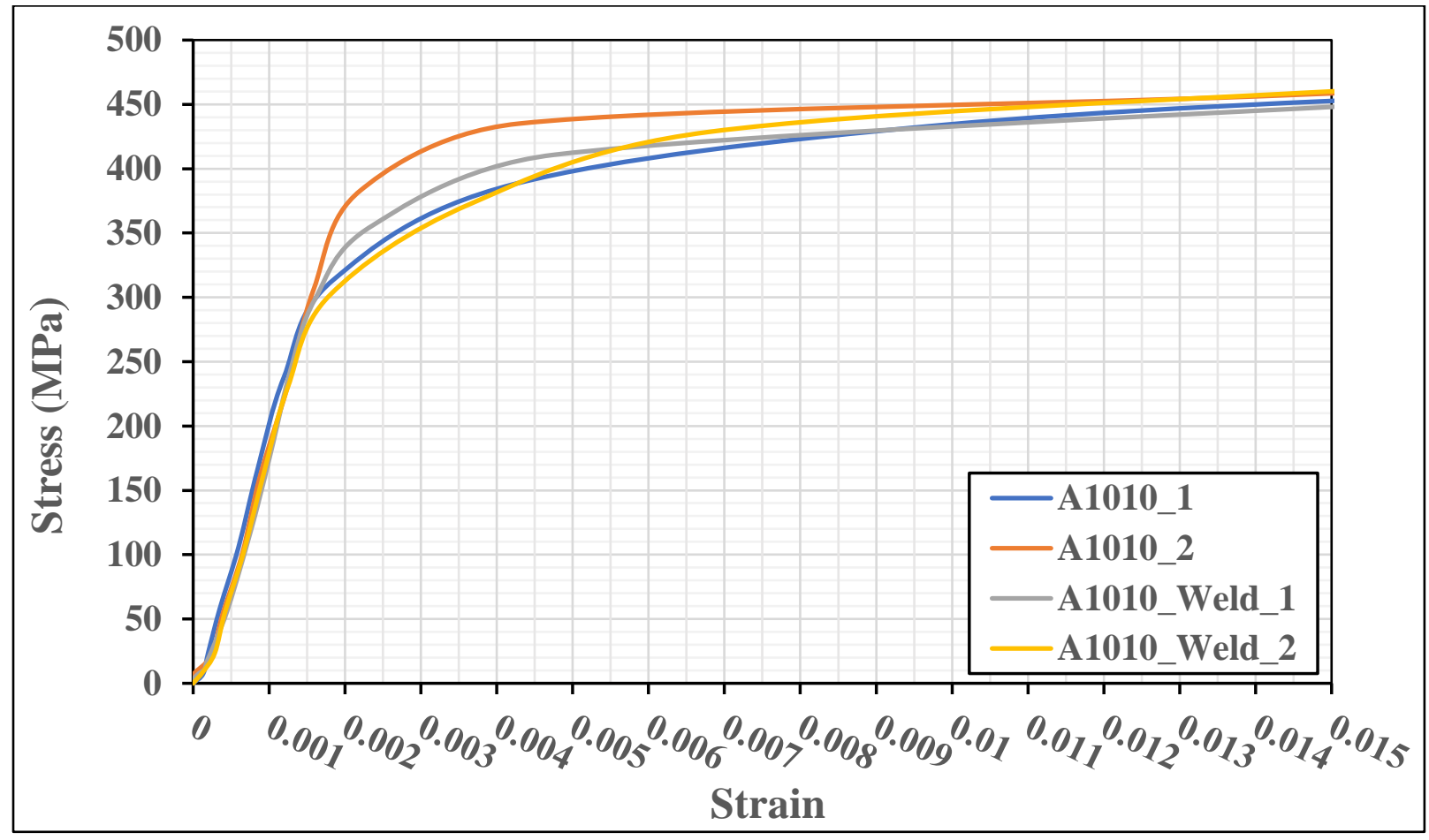

Figure 5-3: Close-up View of the First Porting of the Recorded Stress-Strain Relationship for A1010 Coupon Specimens 


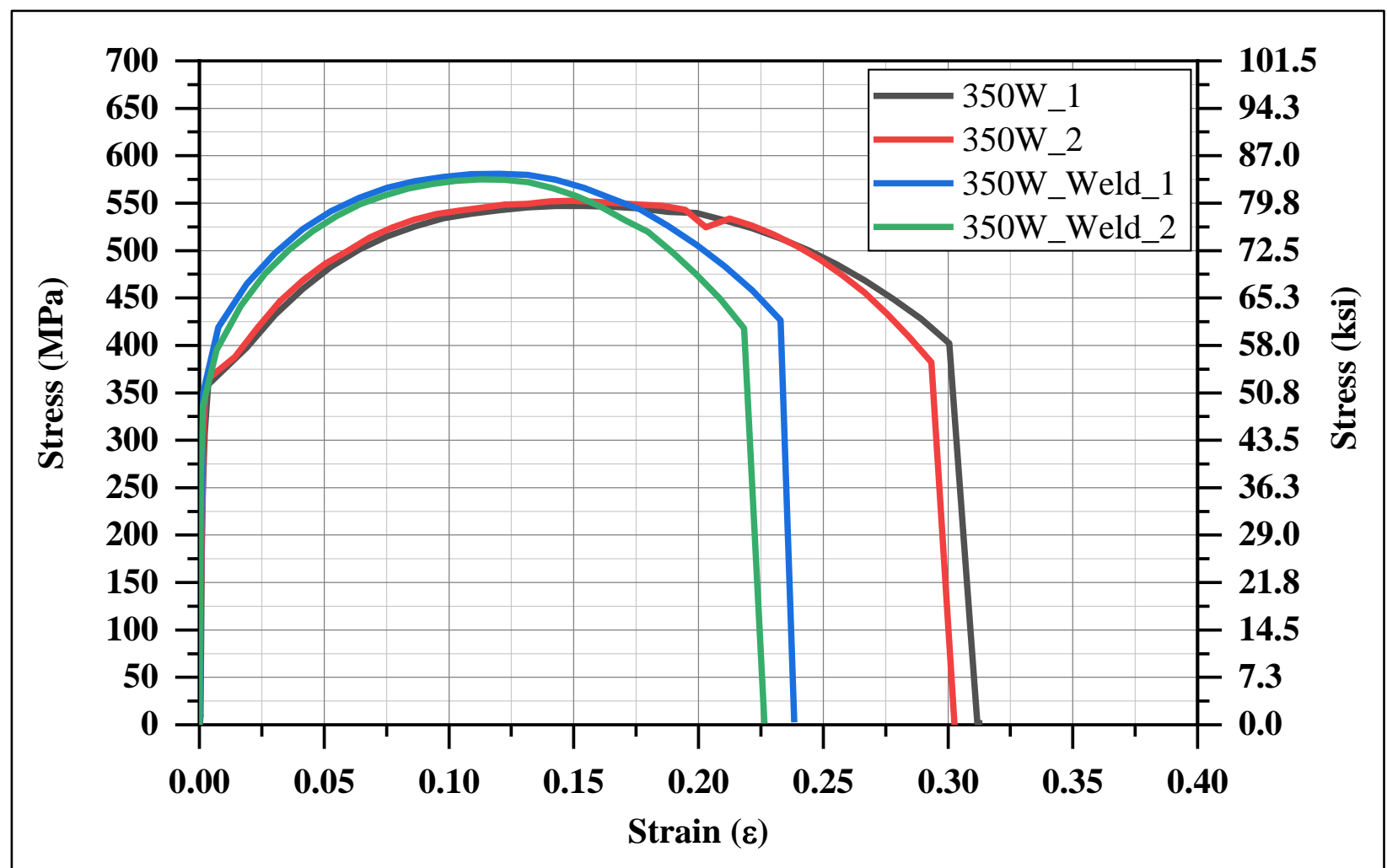

Figure 5-4: Stress-Strain Comparison between CSA G40.21 350W Regular \& Welded Steel

\subsubsection{Fracture Modes of Tensile Coupon Specimens}

ASTM A1010 stainless steel experienced necking and delamination splitting before the ultimate brittle fracture. This type of failure where delamination occurs just before ultimate failure is commonly found in the literature of A1010 and other lower chromium stainless steels (Daghash et al., 2019; Provines et al, 2019; Seradj, 2010; Taban et al, 2008). Figure 5-6 shows close-up view of the A1010 delaminated fracture. Such unique fracture type needs further examination from a microstructure perspective. However, the splitting of the material occurred way beyond the ultimate load and very close towards the fracture strength which occurs at strains that fall beyond ultimate design considerations. On the other hand, CSA G40.21 350W steel experienced only ductile necking before sudden rupturing at failure as depicted in Figure 5-7 and as compared to the A1010 fracture per photos in Figure 5-8. 


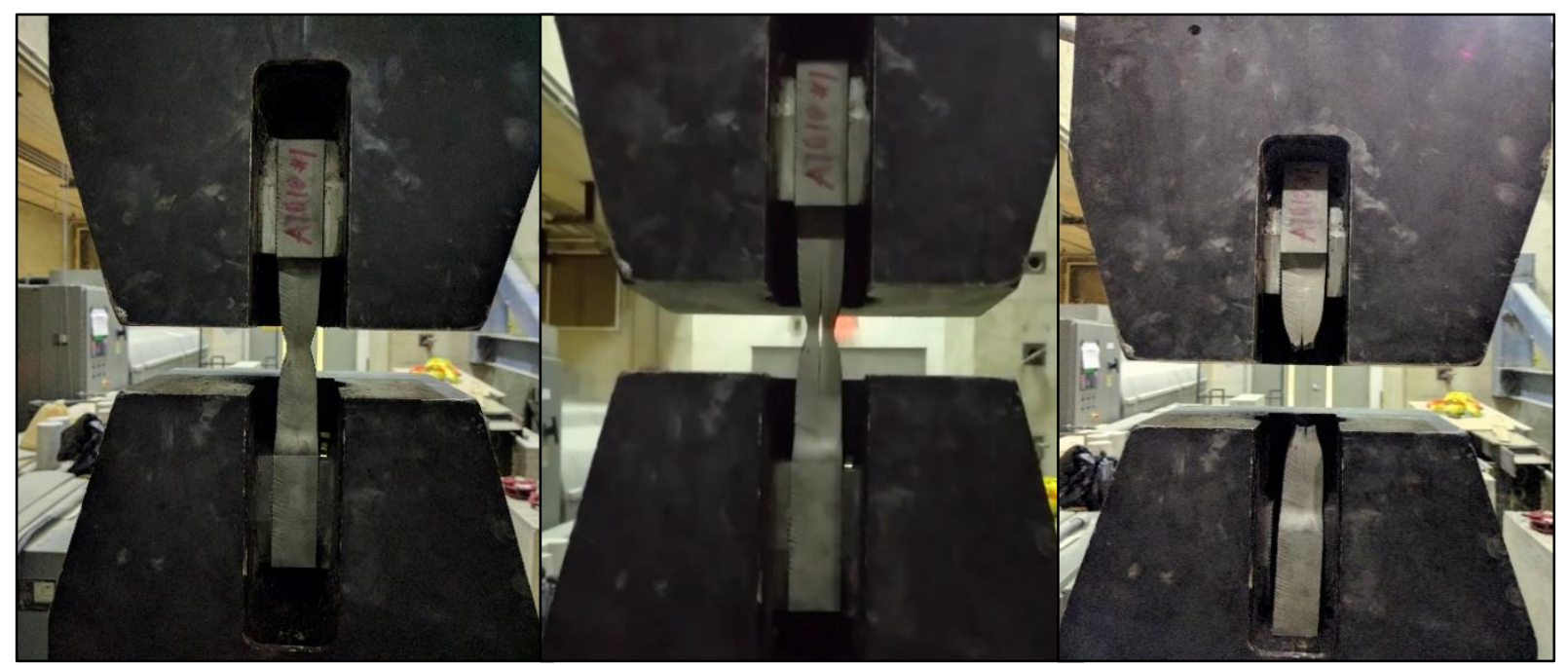

(a) Necking

(b) Delamination/Splitting

(c) Fracture

Figure 5-5: A1010 necking followed by delaminated splitting and ultimate rupture

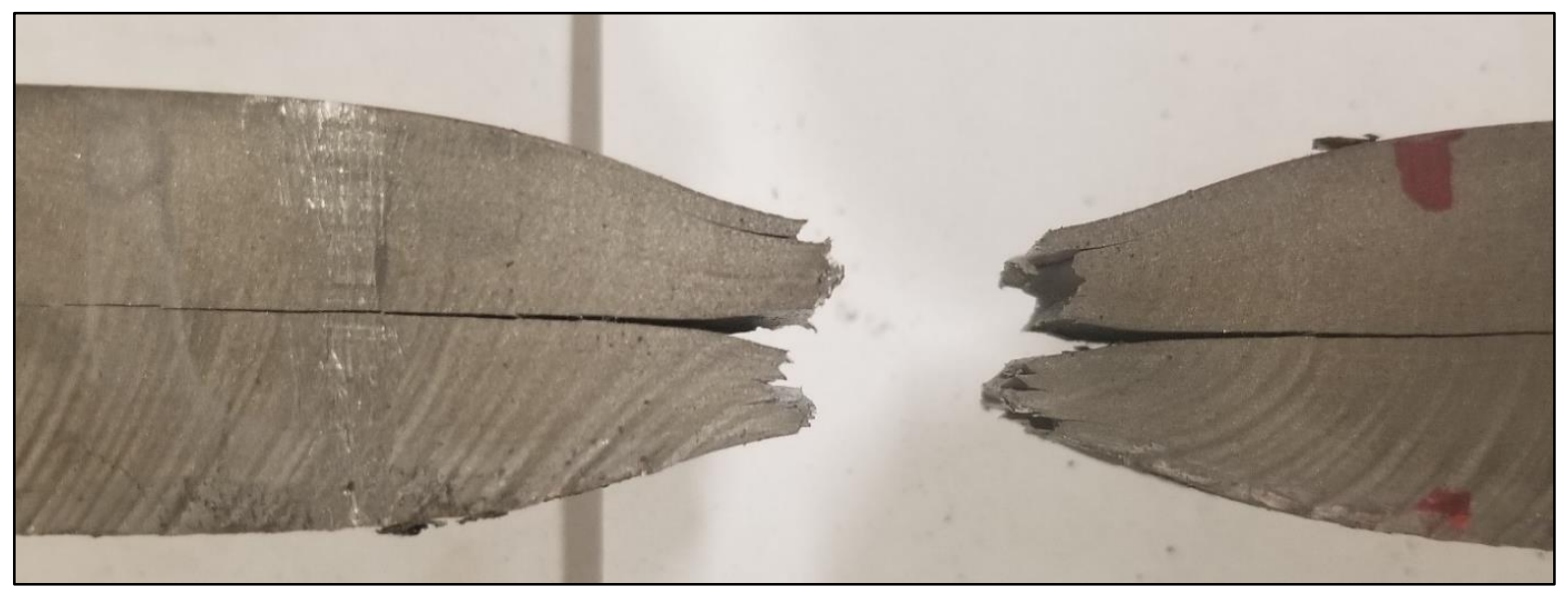

Figure 5-6: Close-Up View of A1010 Delaminated Fracture

Figure 5-7, shows a comparison between the top view of the regular A1010 stainless steel coupons and regular $350 \mathrm{~W}$ structural steel coupons. All coupons show ductile failure behaviour with a reduced cross-section near the middle of the coupon. What is interesting to note is that from the top-view, one can see no delamination present on the A1010 stainless steel coupons, even though the dimensions of the reduced section are very close. On the other hand, Figure 5-8 shows the side view of the coupons on which delamination appears in the A1010 coupon specimens. It should be noted that this side was the one cut by abrasive water jet cutting. $350 \mathrm{~W}$ steel coupon specimens fractured in the form of a cup and cone, as expected. 


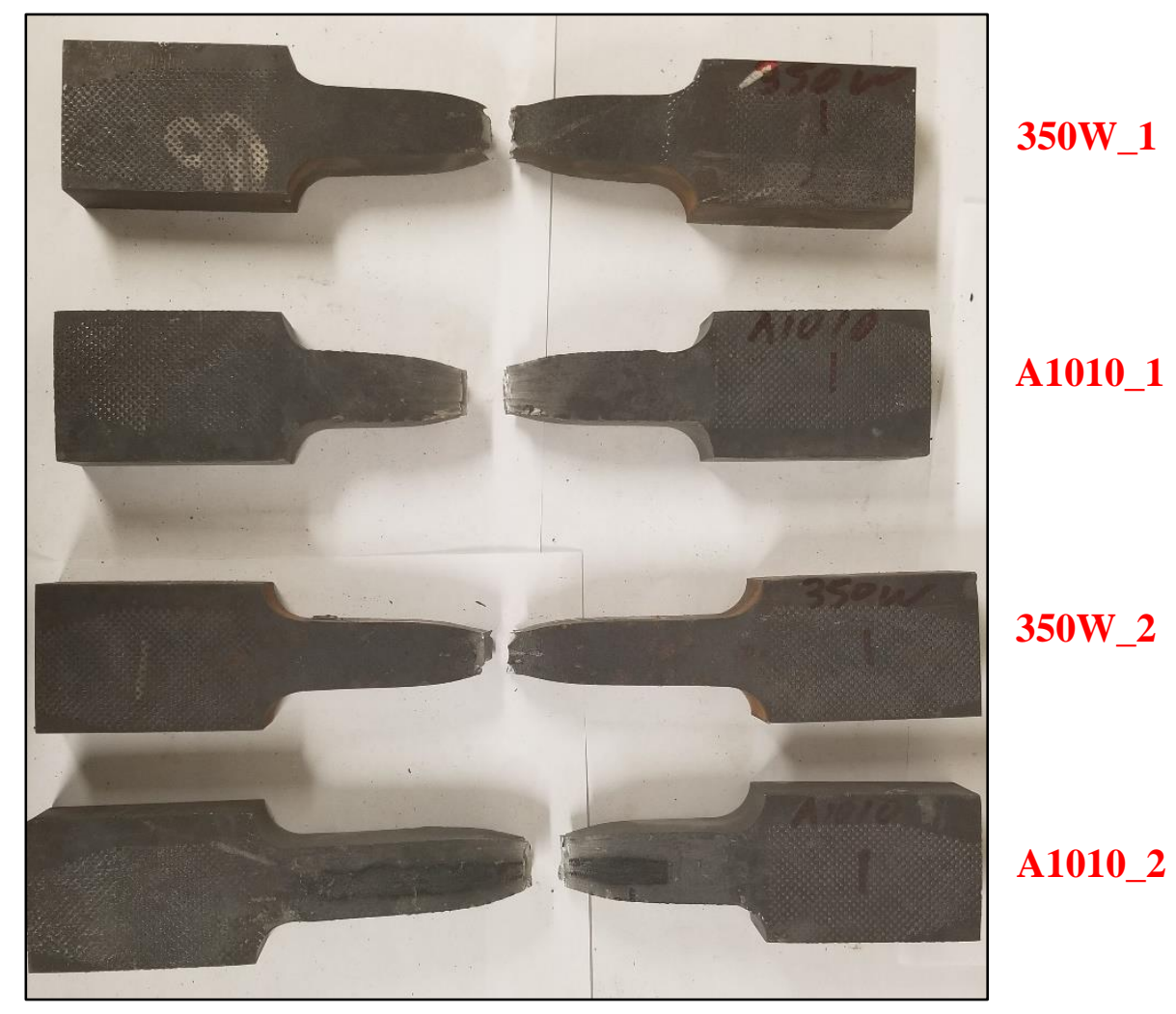

Figure 5-7: Top View of A1010 vs 350W Tensile Coupon Specimen Fracture

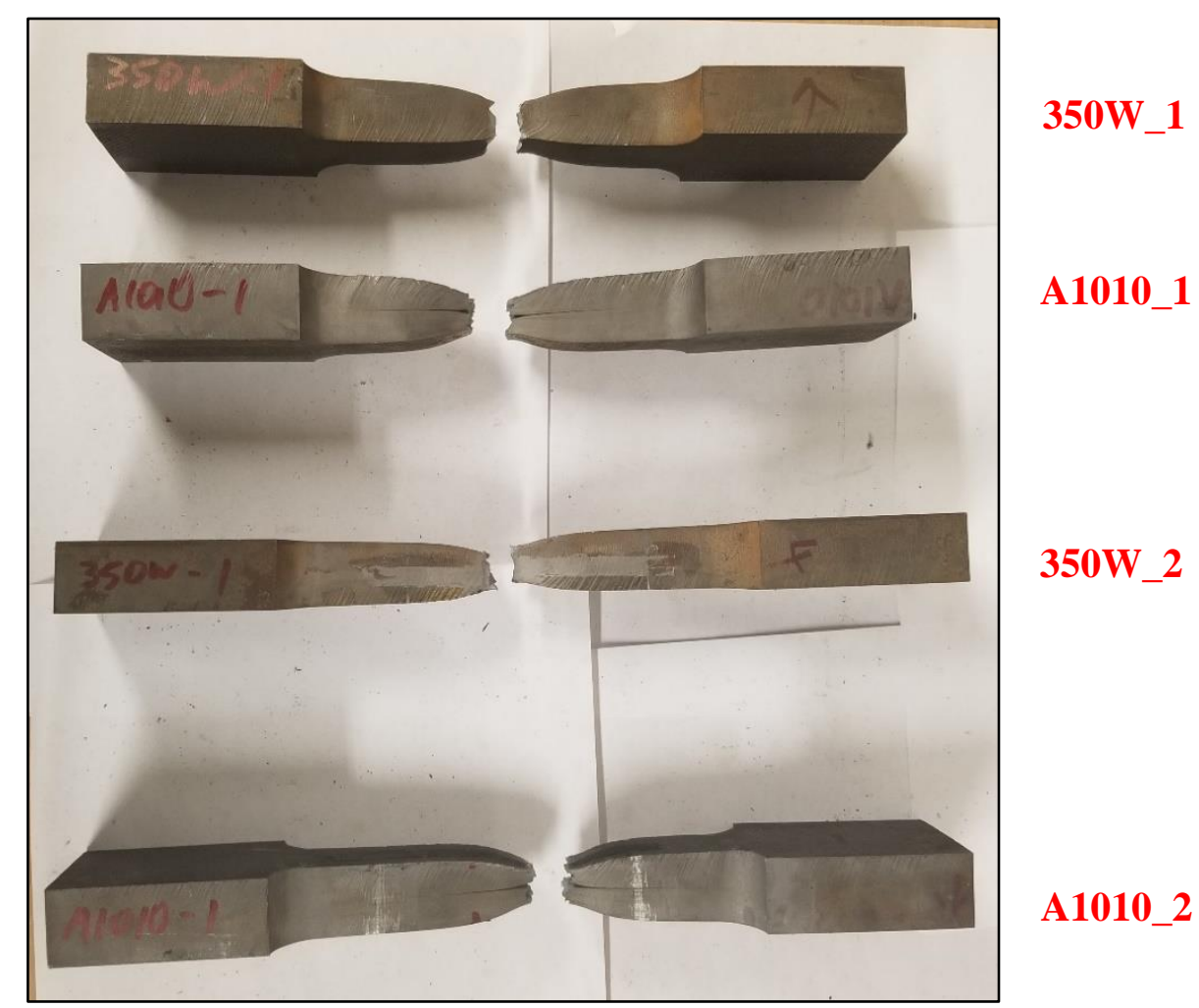

Figure 5-8: Side View of A1010 vs 350W Tensile Coupon Specimen Fracture 
Figure 5-9 and Figure 5-10 show the top and side views, respectively, for the welded A1010 and 350W steel coupons. It is noticed that all coupons failed outside of the welded area on the base metal. Also, the A1010 steel welded coupons show the same type of delamination fracture previously observed on the bare steel coupons. However, this delamination appears to be smaller since the failure occurred almost midway between the weld location and the round corner at the end of the gauge length. Figure 5-11 and Figure 5-12 show the fracture of 350W and A1010 steel, respectively. The fracture of the $350 \mathrm{~W}$ steel appears to be the same as that occurred commonly in conventional steels. Small cavities form on the interior of the cross-section followed by continuous crack propagation perpendicular to that of the applied load, and finally abrupt shear deformation around the outer perimeter of the neck. Figure 5-11 shows evidence of this phenomenon, a deeper and smoother inner crater followed by sharper edges around the perimeter which are evidence of abrupt brittle failure. Figure 5-12 shows cracks running deep parallel to the applied load but from a top view, the delamination lines are perpendicular to the sides that have been cut by waterjet cutting. It is important to note that the abrasive waterjet cutting left swirl marks (burrs) on the side because of the high speed at which it was running due to cost limitations. These burrs could act as stress raisers and be an explanation as to why the splitting of the specimen occurred on the side instead of the top. This can also be seen in Figure 5-15 which was taken under a microscope showing a close up of the split crack that propagated through the length of the reduced section and the wavy peaks and valleys which were caused as a result of the cutting technique. From Figure 5-13 and Figure 5-14, it is observed that the failure was much more violent and abrupt from the raised delaminated surfaces of the cracks that occur both outside and inside the perimeter of the neck in the A1010 steel. The conclusion from the way the material fractures is that further study of the microstructure needs to be done to find if the chemistry of the material can be adjusted to eliminate the delamination that occurs before final failure. 


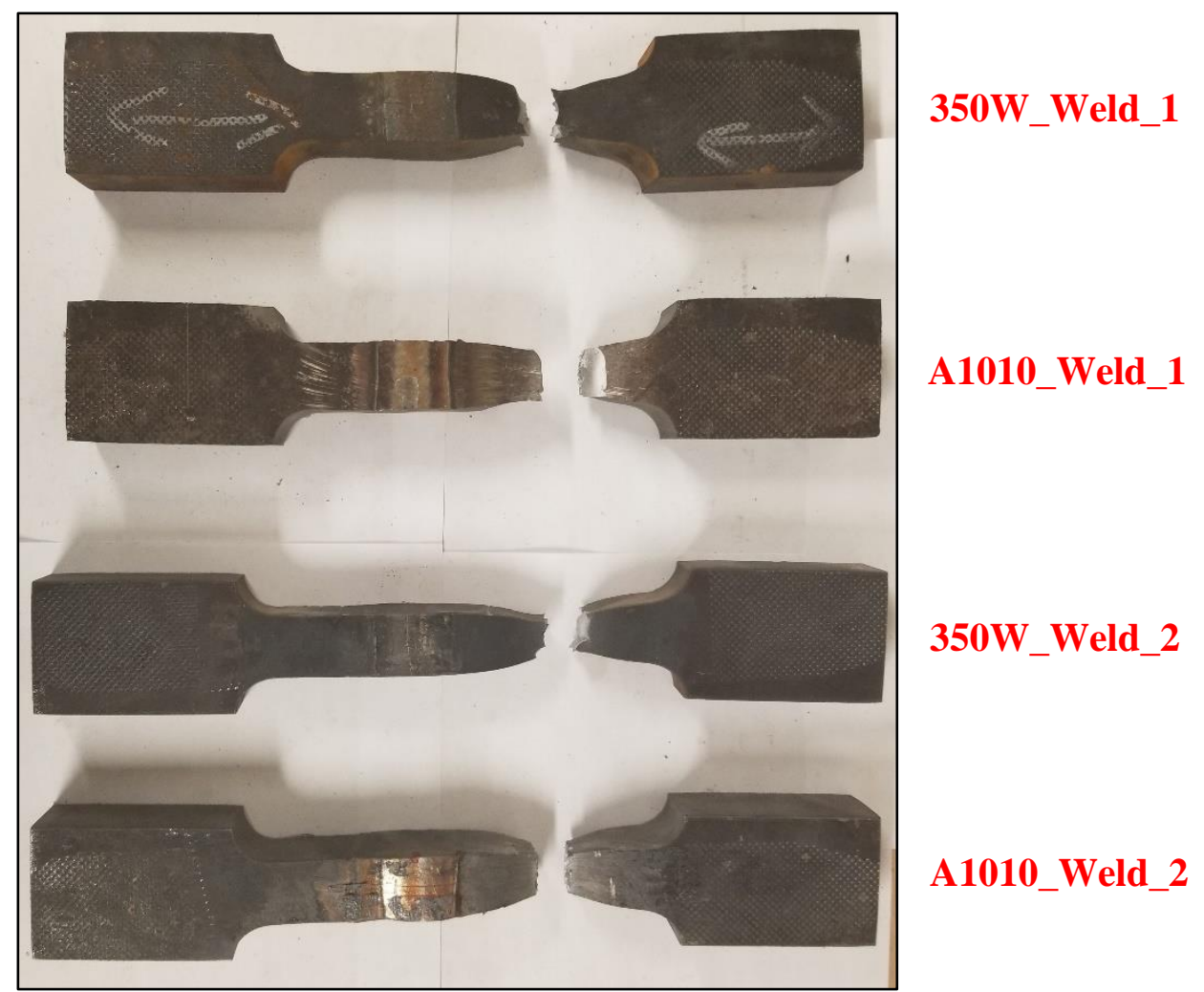

Figure 5-9: Top View of A1010 vs 350W Welded Coupon Specimens Fracture

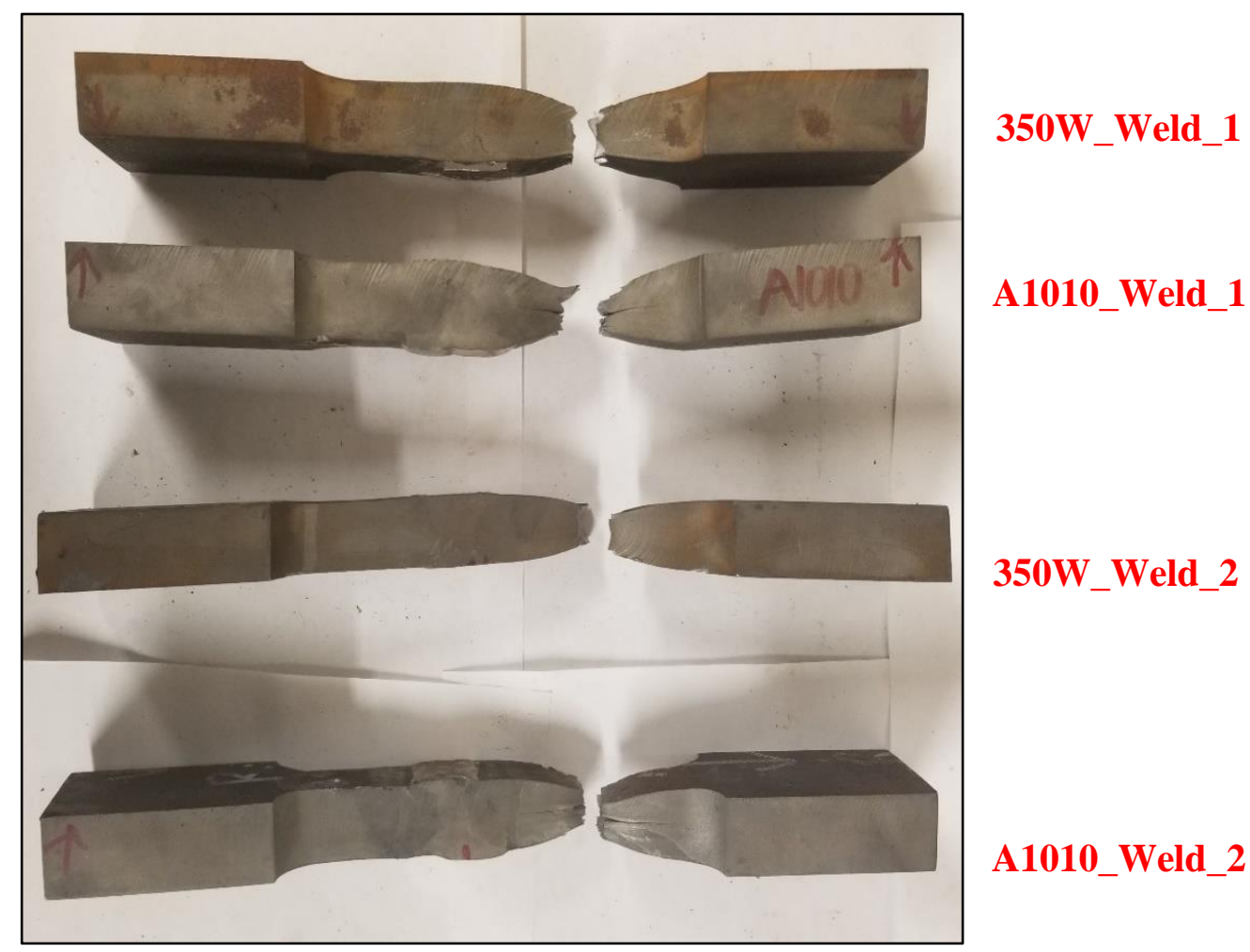

Figure 5-10: A1010 vs 350W Welded Coupon Specimens Fracture Side View 


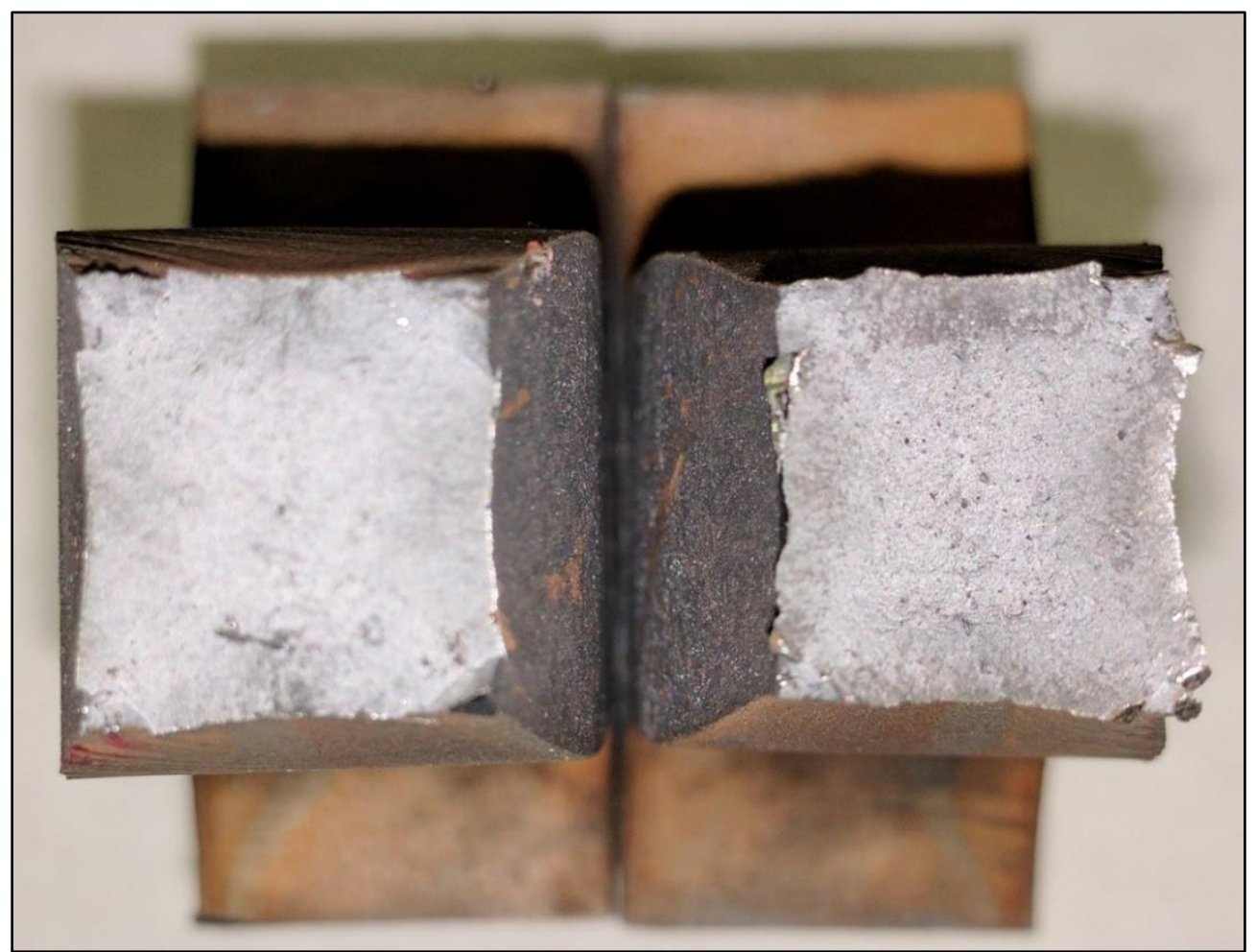

Figure 5-11: Fracture Close-Up of CSA G40.21 350W Structural Steel Coupon

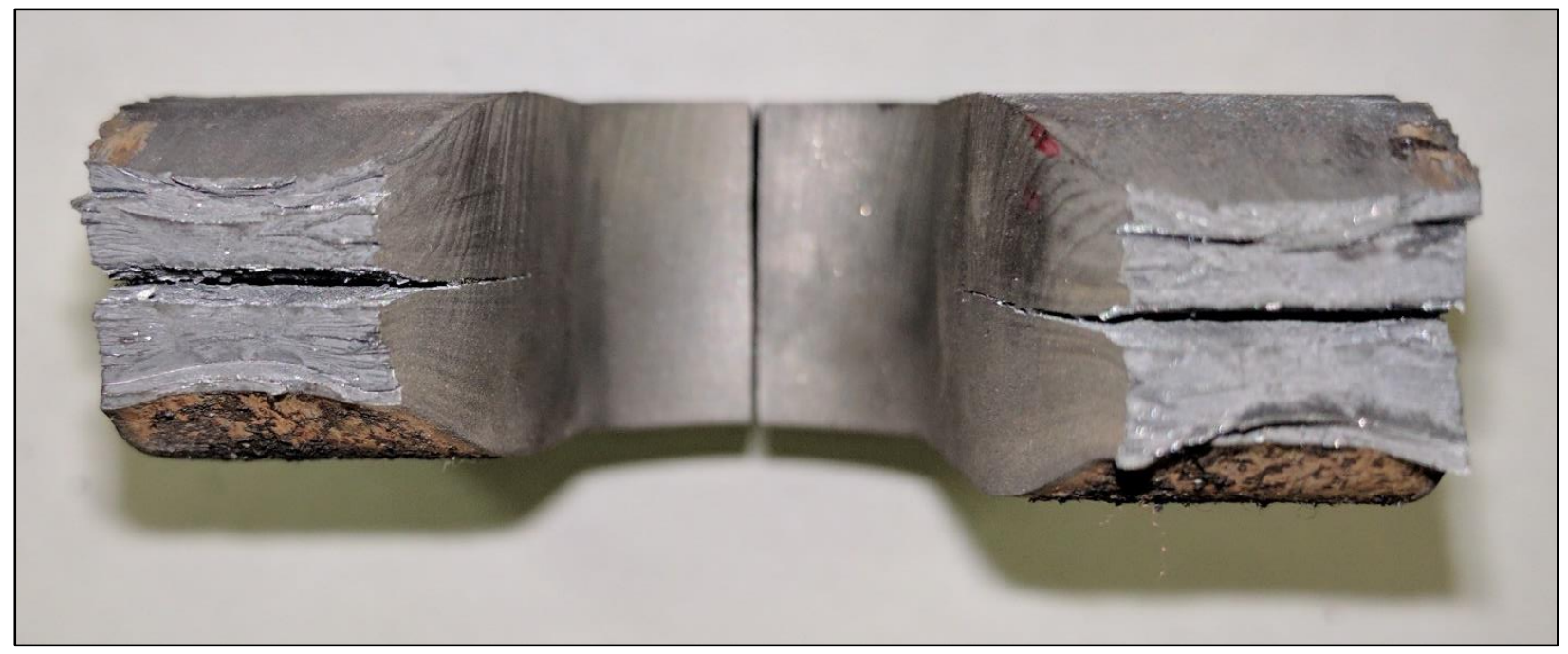

Figure 5-12: Fracture Close-Up of ASTM A1010 Stainless Steel Coupon 


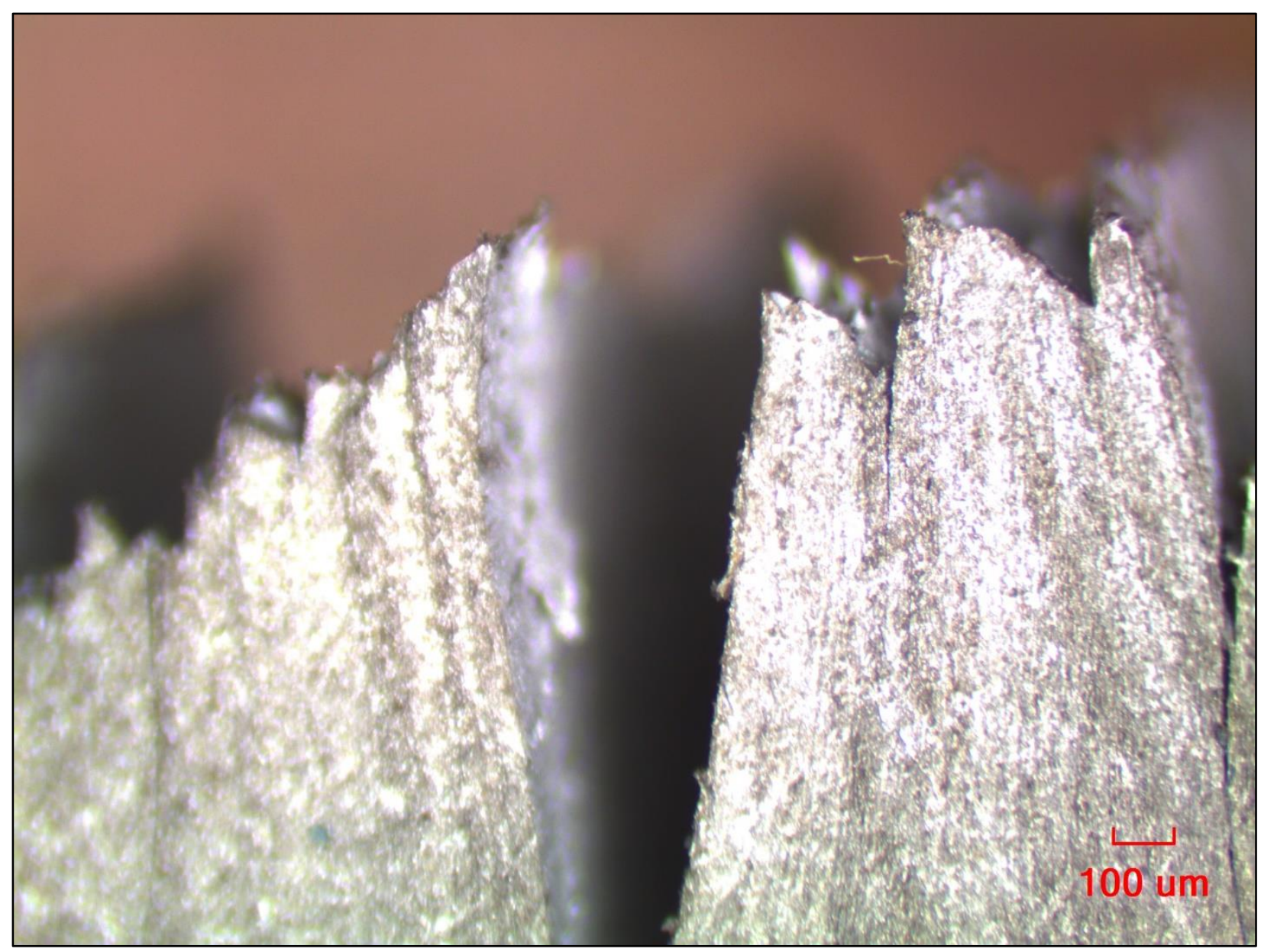

Figure 5-13: Close-Up Side View of Delaminated Fracture in A1010 Tensile Coupon

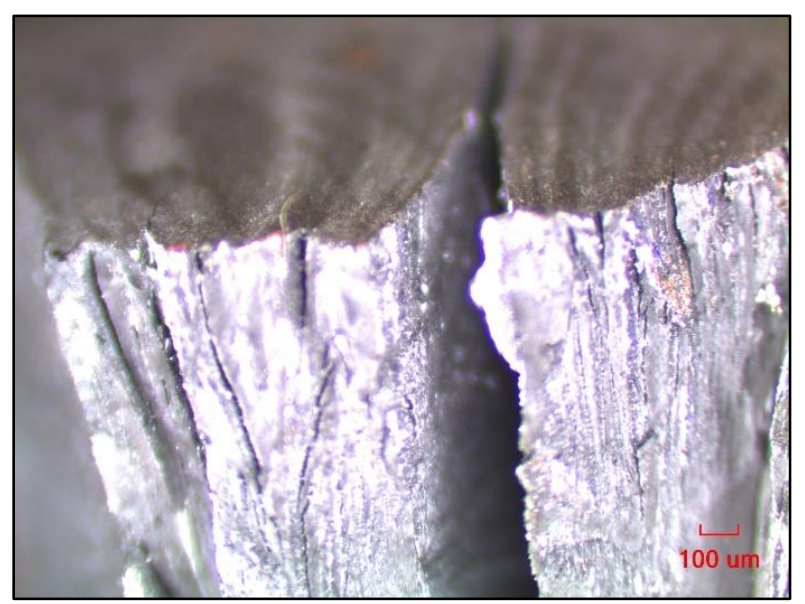

(a)

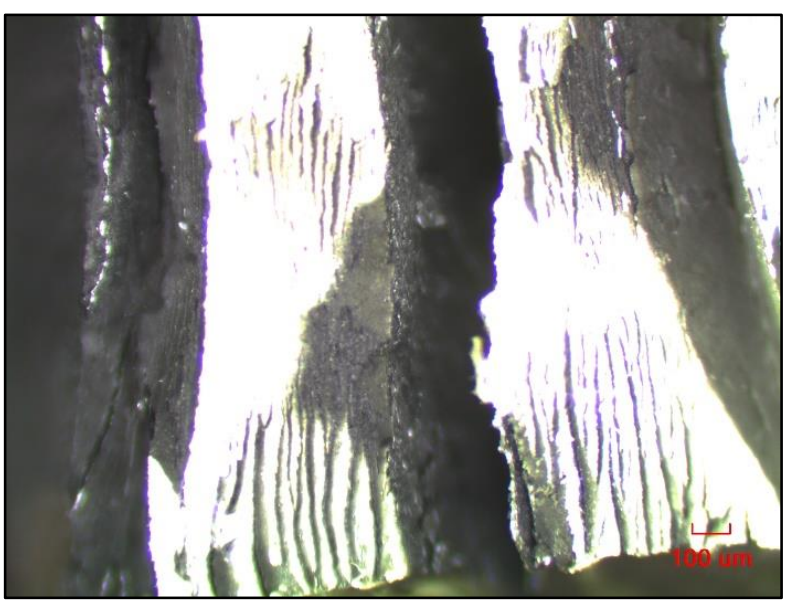

(b)

Figure 5-14: (a-b) Close-Up View of Fracture from the Top of A1010 Coupon 


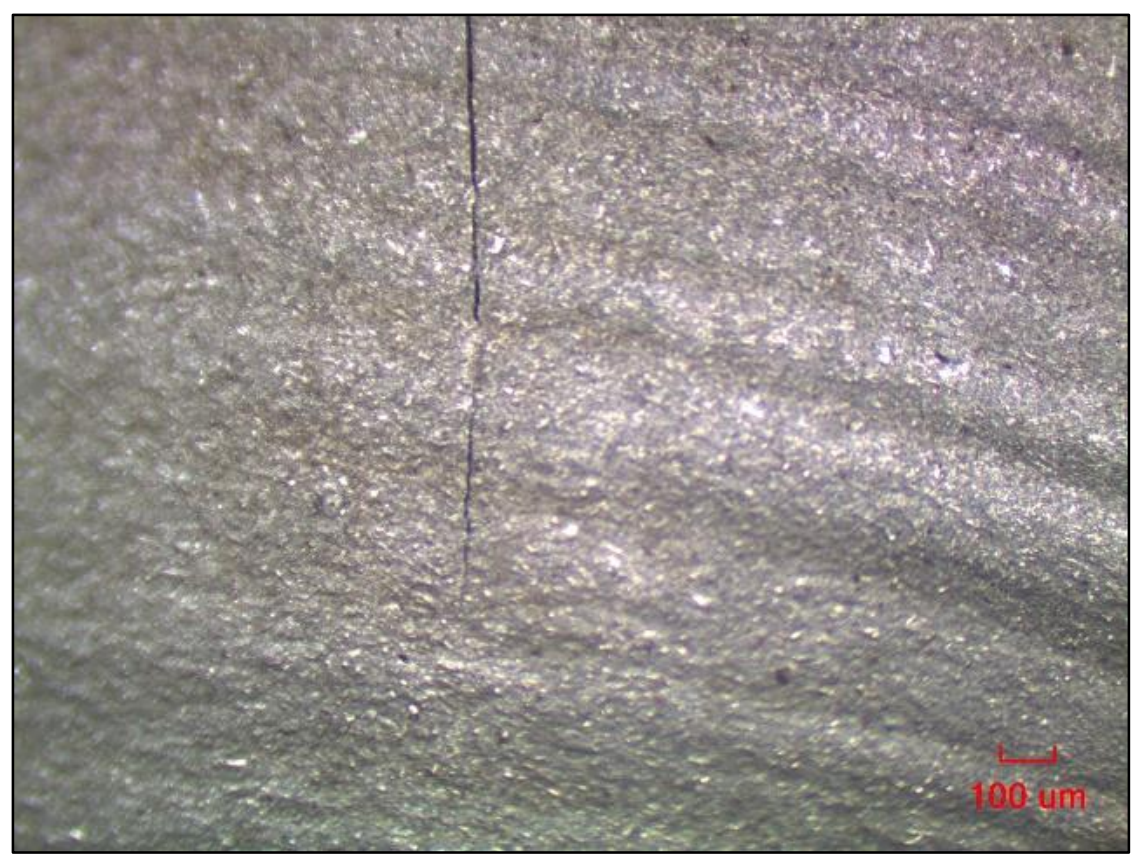

Figure 5-15: A1010 Delaminated Fracture Crack Tip and Discontinuities from Abrasive Cutting

\subsection{Fatigue Test Results for the Bare Steel Coupon Specimens}

All experimental test results were plotted on a $\log -\log \mathrm{S}-\mathrm{N}$ graph together with the curves from the corresponding fatigue detail categories from the Canadian Highway Bridge Design Code. While Table 5-2 summarizes the stress range and recorded fatigue life of the bare coupon specimens made of 350W and A1010 Steels in the of the number of fatigue cycles reached before fracture. As depicted in Figure 5-16, the bar steel coupon specimens are expected to be comparable with the highest stress curve A. It should be noted that the lowest fatigue life for Curve A corresponding to fatigue stress range of $180 \mathrm{MPa}$ is about 1.4 million cycles. Therefore, if the tested specimens fail above this range, one may claim that curve A can be used for the bare steel for that particular steel type. Hence, due to time constraints since the machine was running at 1 to 2 cycles per second, 1.4 million cycles were chosen as the runout for the given stress ranges when conducting fatigue tests. 
Table 5-2: Summary of Stress Range vs Fatigue Life of Regular 350W and A1010 Steel Coupon Specimens

\begin{tabular}{|c|c|c|}
\hline Stress Range (MPa) & $\begin{array}{c}\text { 350W Steel Long Regular } \\
\text { Specimen Cycles (N) }\end{array}$ & $\begin{array}{c}\text { A1010 Steel Long Regular } \\
\text { Specimen Cycles (N) }\end{array}$ \\
\hline $\mathbf{2 7 0}$ & 148,515 & 168,969 \\
\hline $\mathbf{2 5 0}$ & 103,187 & 369,043 \\
\hline $\mathbf{2 2 5}$ & 238,183 & 428,938 \\
\hline $\mathbf{2 0 0}$ & 304,689 & $1,485,456^{2}$ \\
\hline $\mathbf{1 8 0}$ & $1,399,092^{1}$ & -3 \\
\hline
\end{tabular}

${ }^{1}$ Specimen did not fail due to failure of MTS bolts.

${ }^{2}$ Testing stopped due to failure of MTS grips.

${ }^{3}$ Specimen not yet tested due to the failure of grips.

Looking at Figure 5-16, it can be observed that the plotted points for the higher stress ranges (270, 250, $225 \mathrm{MPa}$ ) fall much below Curve A for both steel types. In fact, for these stress ranges, one may claim that they meet the requirement for Curve $\mathrm{C}$ which is usually used for fillet welded details. This may be attributed to the abrasive water jet cutting which left behind wavy grooves on the sides of all the specimens because it was running at a higher speed due to cost constraints. An important factor to note is that at the lower chosen stress ranges 200 and $180 \mathrm{MPa}$, the specimens failed at life cycles that fall at or above Curve A, which represents the $95 \%$ probability of survival for bare steel plate. What is more important for the purpose of this research is that all specimens of A1010 failed at a higher cycle number when compared to $350 \mathrm{~W}$ for the same stress ranges.

Due to a large number of cycles running at high loads during the fatigue tests, the 1" bolts holding up the top threaded plate connecting the top grip to the MTS failed twice. Hence, the 350W specimen tested at a stress range of $180 \mathrm{MPa}$ did not fail as shown in Table 5-2. However, it did survive for almost 1.4 million cycles. Therefore, it was decided to discontinue with the test and move onto testing other specimens. It was also decided to change the bolts holding to the top plate of the MTS machine every 1 million cycles to avoid such bolt failure. Testing of the A1010 specimens commenced and after slightly less than 1 million cycles, the bolts holding the top plate of the MTS machine failed again in fatigue, therefore, it was decided to replace them every 500,000 cycles. Table 5-2 shows that no data exists for the A1010 coupon specimen tested at a stress range of $180 \mathrm{MPa}$. The reason for this is that the top grip completely sheared due to the large fatigue 
stresses and testing was stopped. Due to the grip failure, the A1010 steel coupon specimen tested at a stress range of $200 \mathrm{MPa}$ did not fracture, nevertheless, this data point was above Curve A.

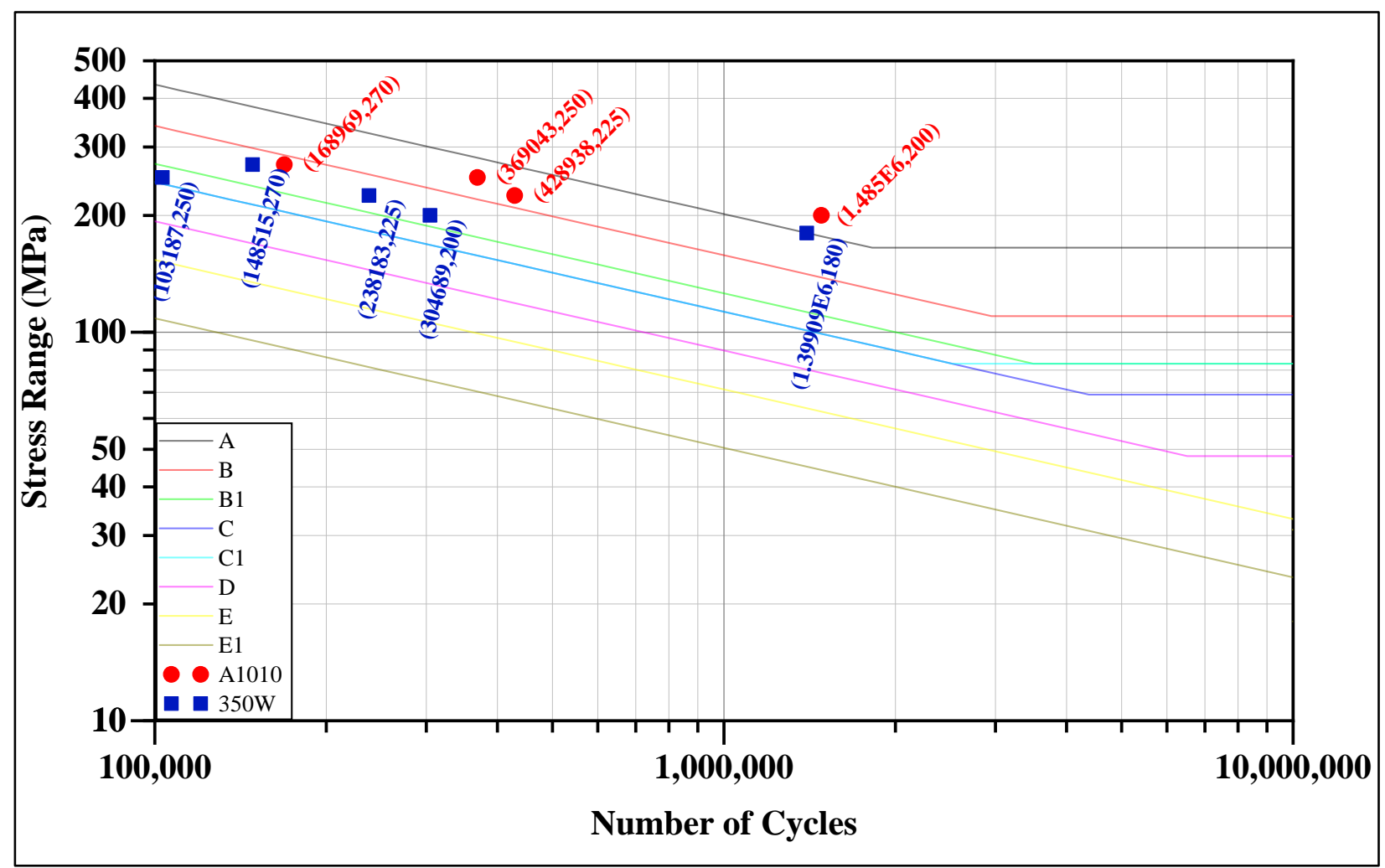

Figure 5-16: Fatigue test results plotted in the CSA S6-14 S-N Curve

Figure 5-17 shows the mean linear fit of all data points for both $350 \mathrm{~W}$ and A1010 steel. It can be observed that mean linear fit of A1010 falls below Curve A but above Curve B. On the other hand, the mean linear fit for $350 \mathrm{~W}$ is below Curve B but above Curve B1. Regression analysis performed by using graphical analysis within OriginLab ${ }^{\circledR}$ (OriginLab, 2016) to show that the $95 \%$ confidence interval falls at or below Curve C for A1010 and at or above Curve D for 350W steel. A 95\% prediction band means that there is $95 \%$ confidence that a new data point will fall within the band range.

Mean Linear Equation for A1010 Results: $\Delta F_{A 1010}=4.25369-\frac{1}{3} N$

Mean Linear Equation for 350W Results: $\Delta F_{350 \mathrm{~W}}=4.16018-\frac{1}{3} \mathrm{~N}$ 


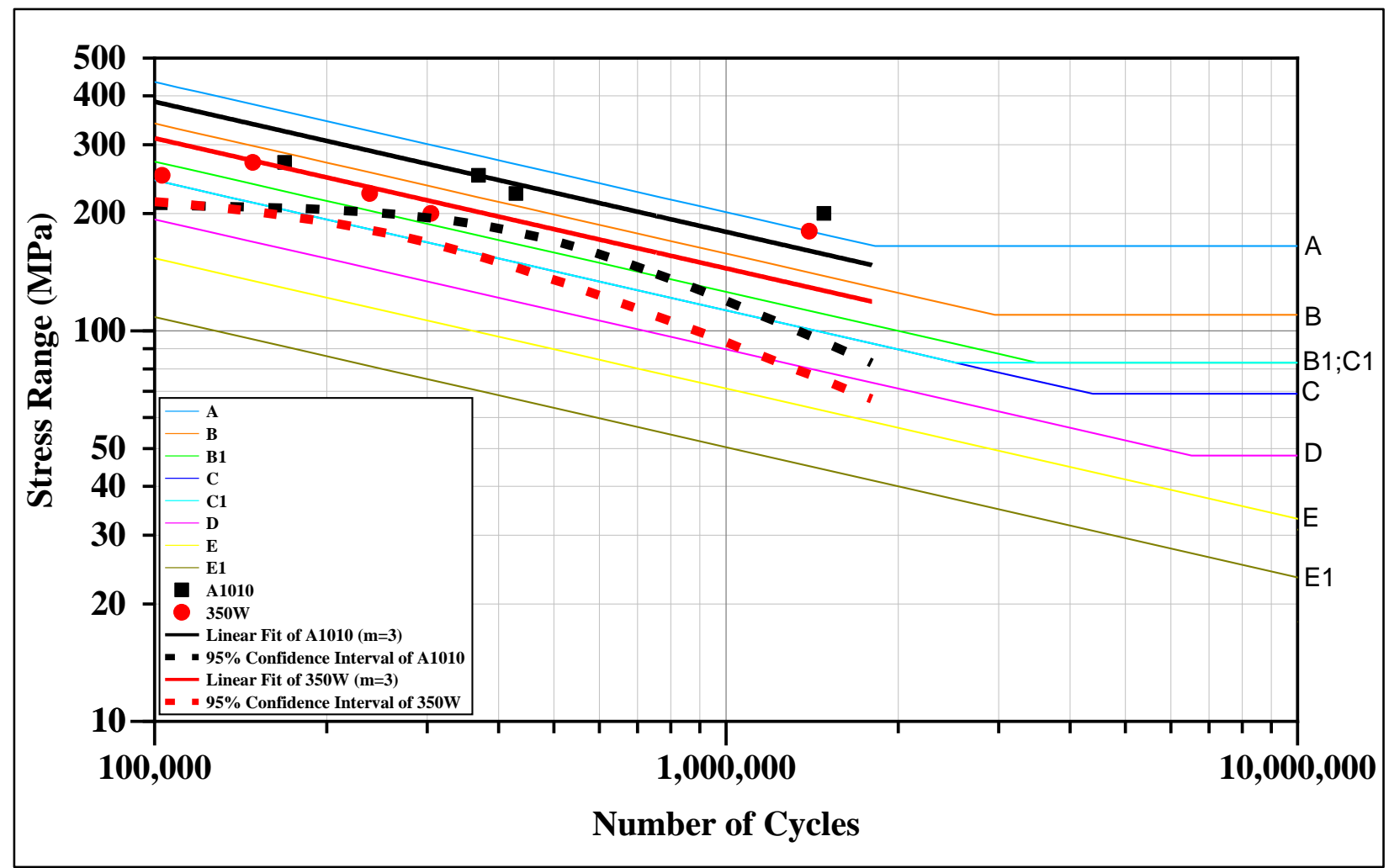

Figure 5-17: Regression Analysis of Fatigue Results of 350W and A1010 Regular Long Specimens

Figure 5-18 through Figure 5-23 show that all coupons fractured within the reduced section as expected. However, they fractured between the midpoint and closer to the beginning of the curved radius at the gripped part, which is a high-stress concentration area due to the change in section size. The fracture location near the bottom of the reduced section could also be due to the nonstandard length of the specimens created to fit in-between the MTS grips. Simply a longer radius will create a longer specimen but reduces stress concentration since the change in section size is more gradual. Another factor for the fracture location could be that the abrasive waterjet cutting left some discontinuities when creating the radius for the reduced section. Additionally, the MTS bottom grip is fixed and the top grip is allowed to sway slightly to allow for freedom of movement when inserting the specimen. Hence, the lower side of the specimen could experience higher stresses than the top side. The specimen was placed in the MTS to the best of the researcher's abilities ensuring that the grips were properly aligned with each other.

Figure 5-20 shows a closer look at the fatigue fractures of the 350W steel coupon specimens. Even though it is difficult to see the striations marks from the photos taken, interestingly, it seems the 
fatigue cracking started from the cut side of the specimen (bottom side on the photo). The fatigue cracks propagated slowly until the specimen failed in tension due to the reduced capacity. It can be observed that the fracture is less 'smooth' and more violent on the other side where the rupture occurred. Hence, on the top side of the photo, one case see different fracture elevations. Often times the specimens would get stuck on the grips due to the large force, therefore it had to be hammered in order to dislodge them from the grips. This is the reason Figure 5-20(b) shows chisel mark lines on it.

Figure 5-23 shows the fatigue fractures of A1010 steel coupon specimens tested at ranges 270, 250 , and $225 \mathrm{MPa}$. The fatigue crack started on the bottom cut side in the photo and propagates towards the middle. At a certain point about half-way through the cross-section, sudden failure was observed. The fracture of the sudden failure was very similar to that of the monotonic fracture, with delamination like streaks and splitting of the material. During the slow fatigue propagation, these streaks were not observed, instead, a 'smooth' crack propagation pattern was observed. The difference in fatigue stress range did not have an impact on fracture type for all specimens. 


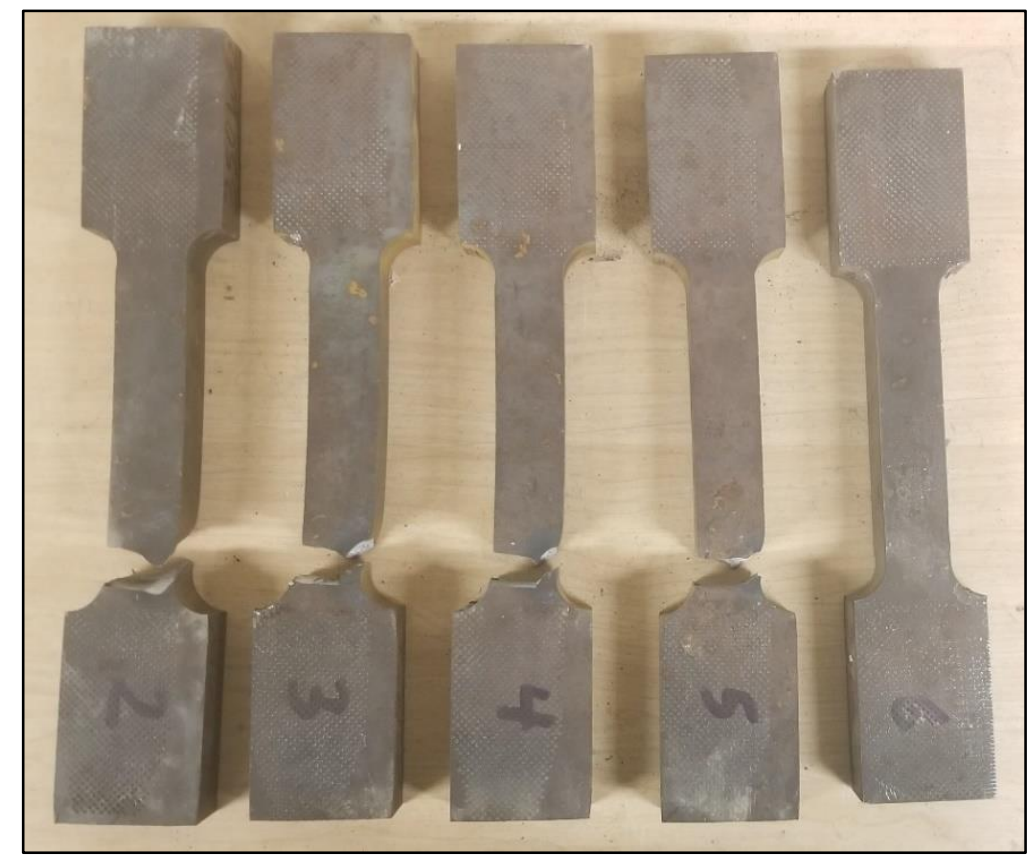

Figure 5-18: Top View of the Bare Coupons Made of 350W Post Fatigue

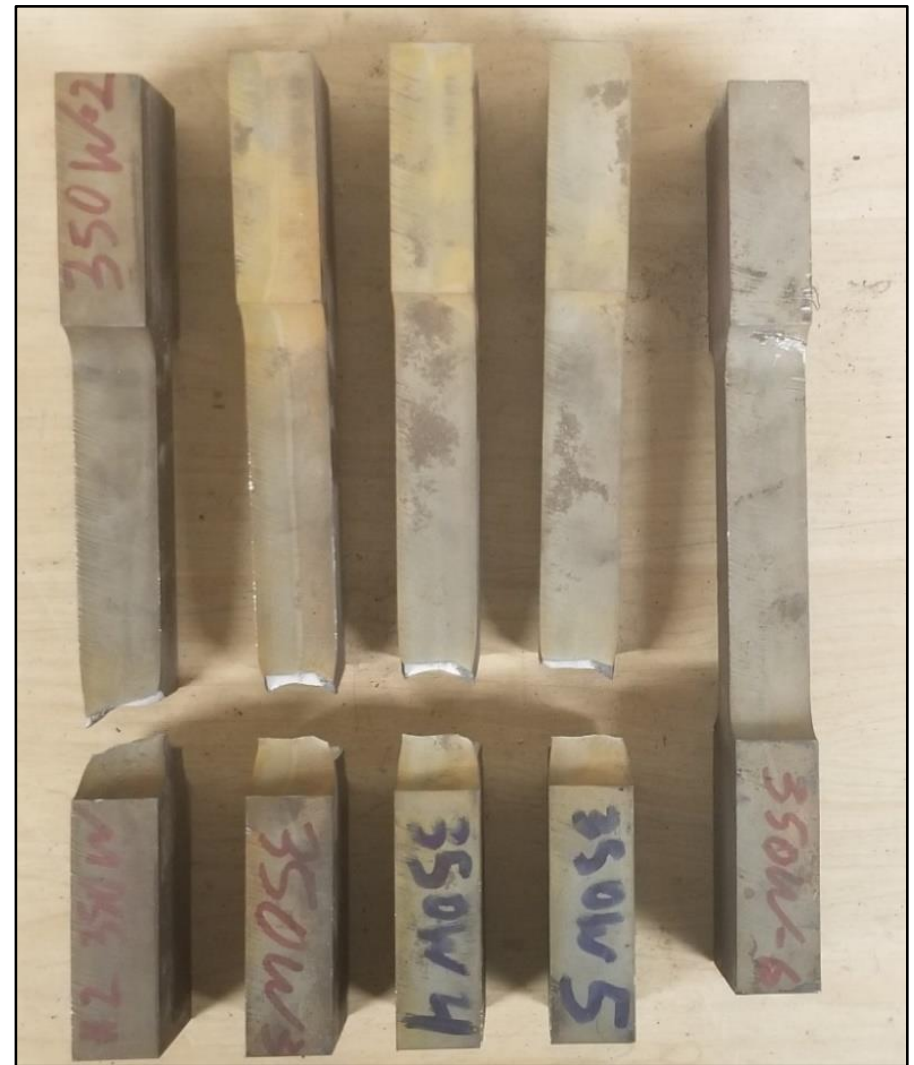

Figure 5-19: Side View of the Bare Coupons Made of 350W Post Fatigue 


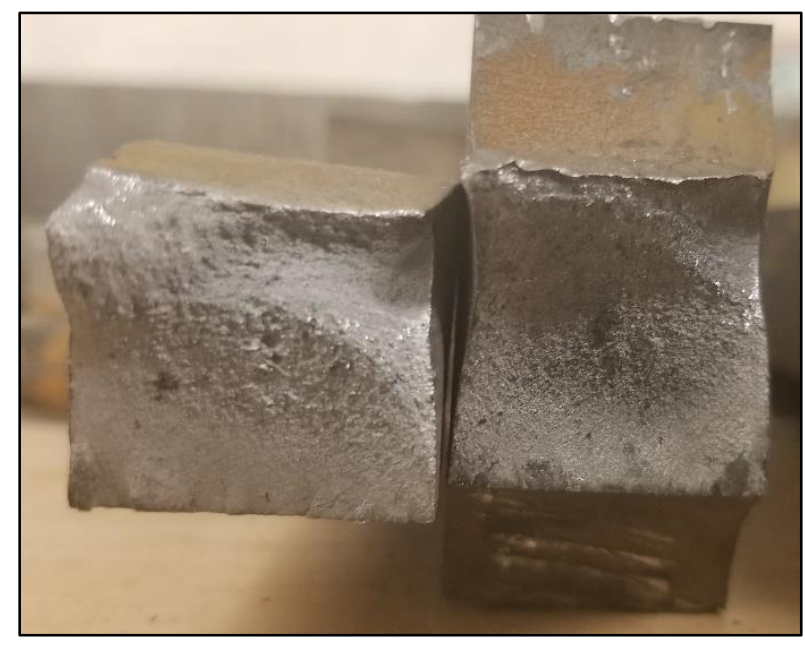

(a)

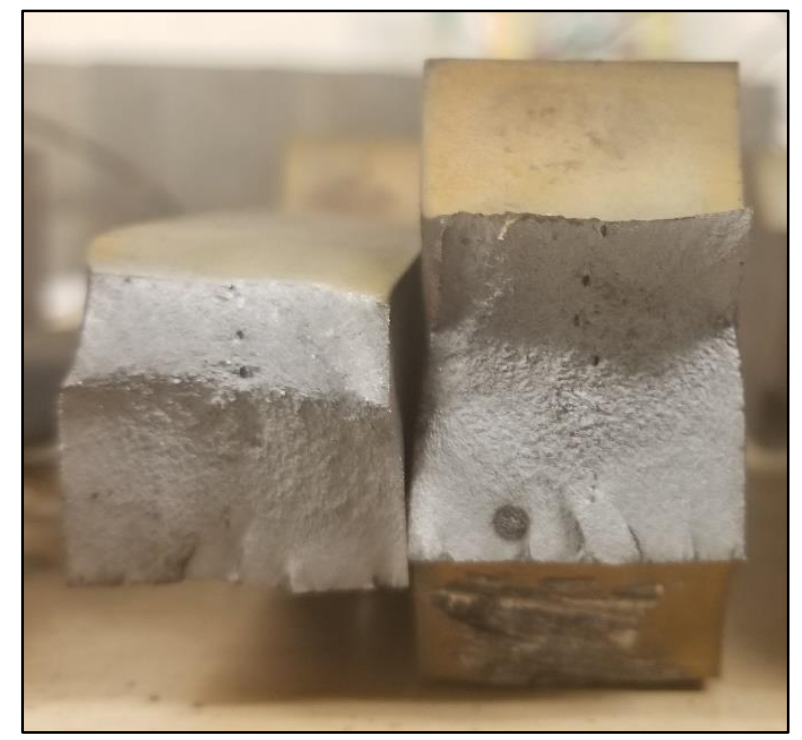

(c)

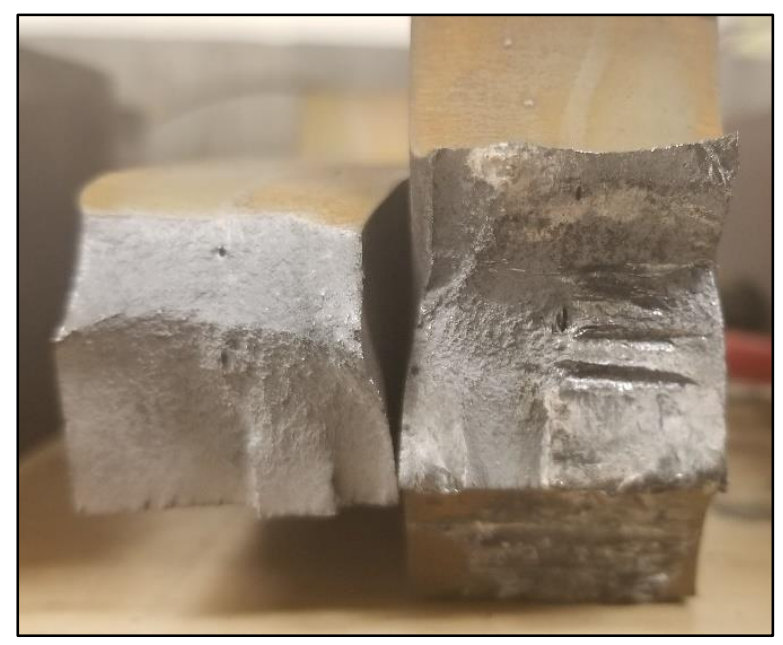

(b)

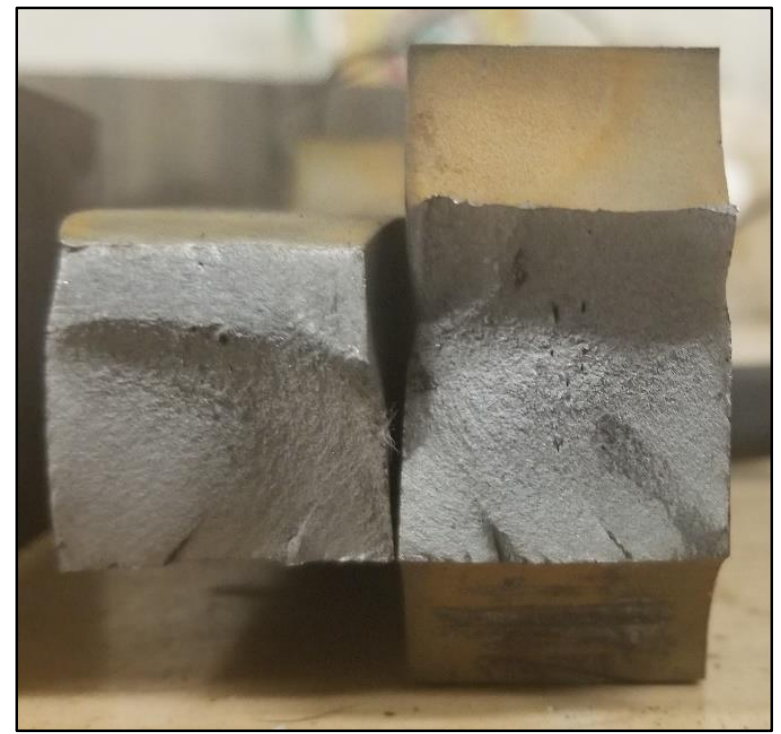

(d)

Figure 5-20: 350W Fatigue Fracture of: a) Specimen 2 tested at $\Delta \sigma=270$ MPa; b) Specimen 3 tested at $\Delta \sigma=250 \mathrm{MPa}$; c) Specimen 4 tested at $\Delta \sigma=225 \mathrm{MPa}$; d) Specimen 5 tested at $\Delta \sigma=200 \mathrm{MPa}$ 


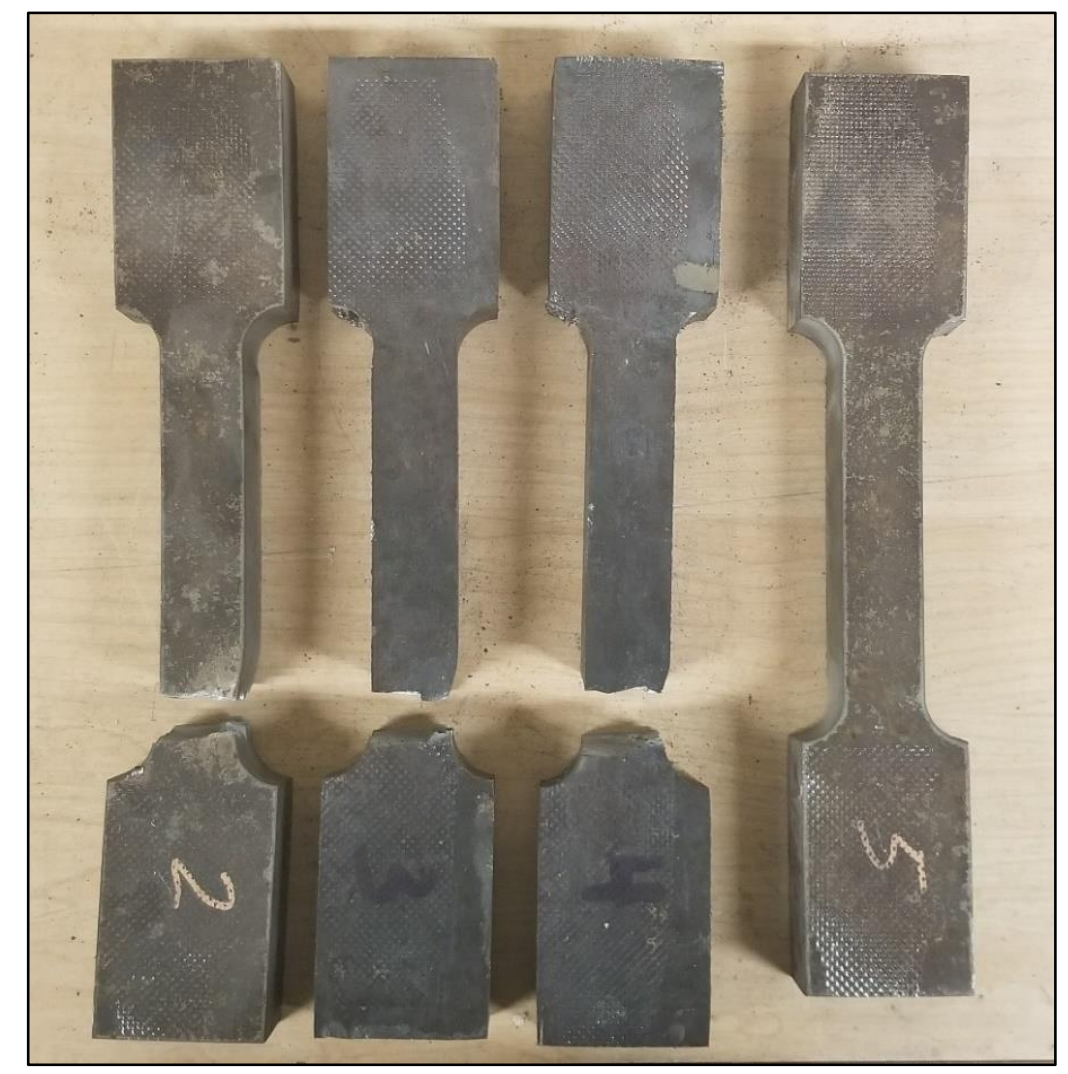

Figure 5-21: Top View of the Bare Coupons Made of A1010 Steel Post Fatigue

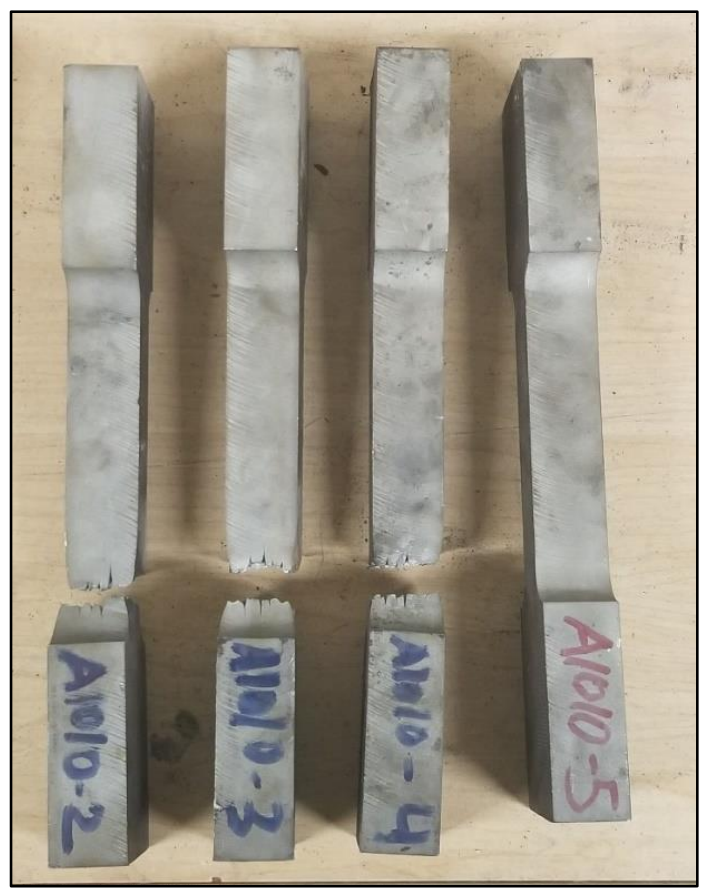

Figure 5-22: Side View of the Bare Coupons Made of A1010 Steel Post Fatigue 


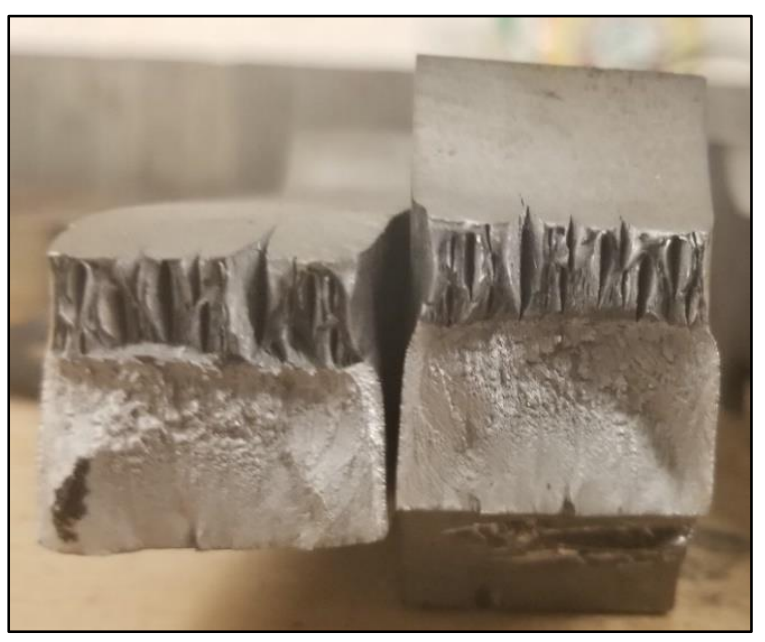

(a)

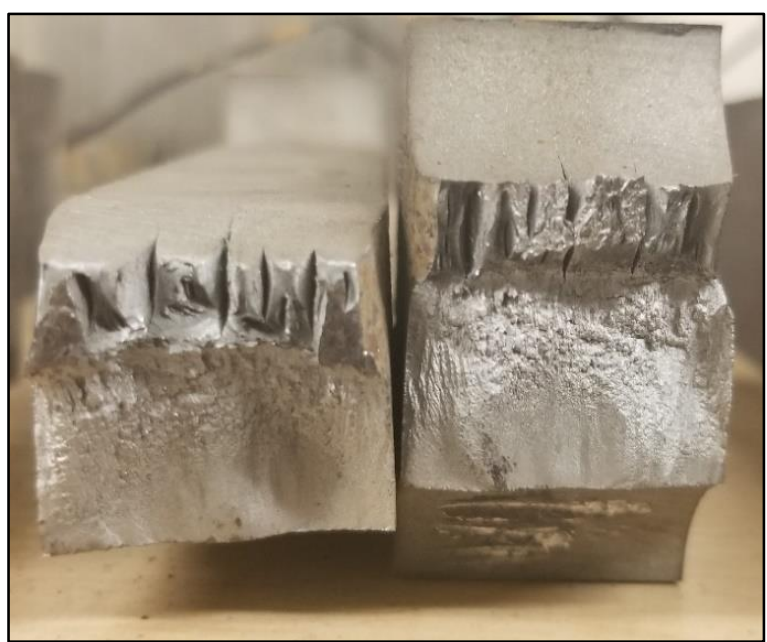

(b)

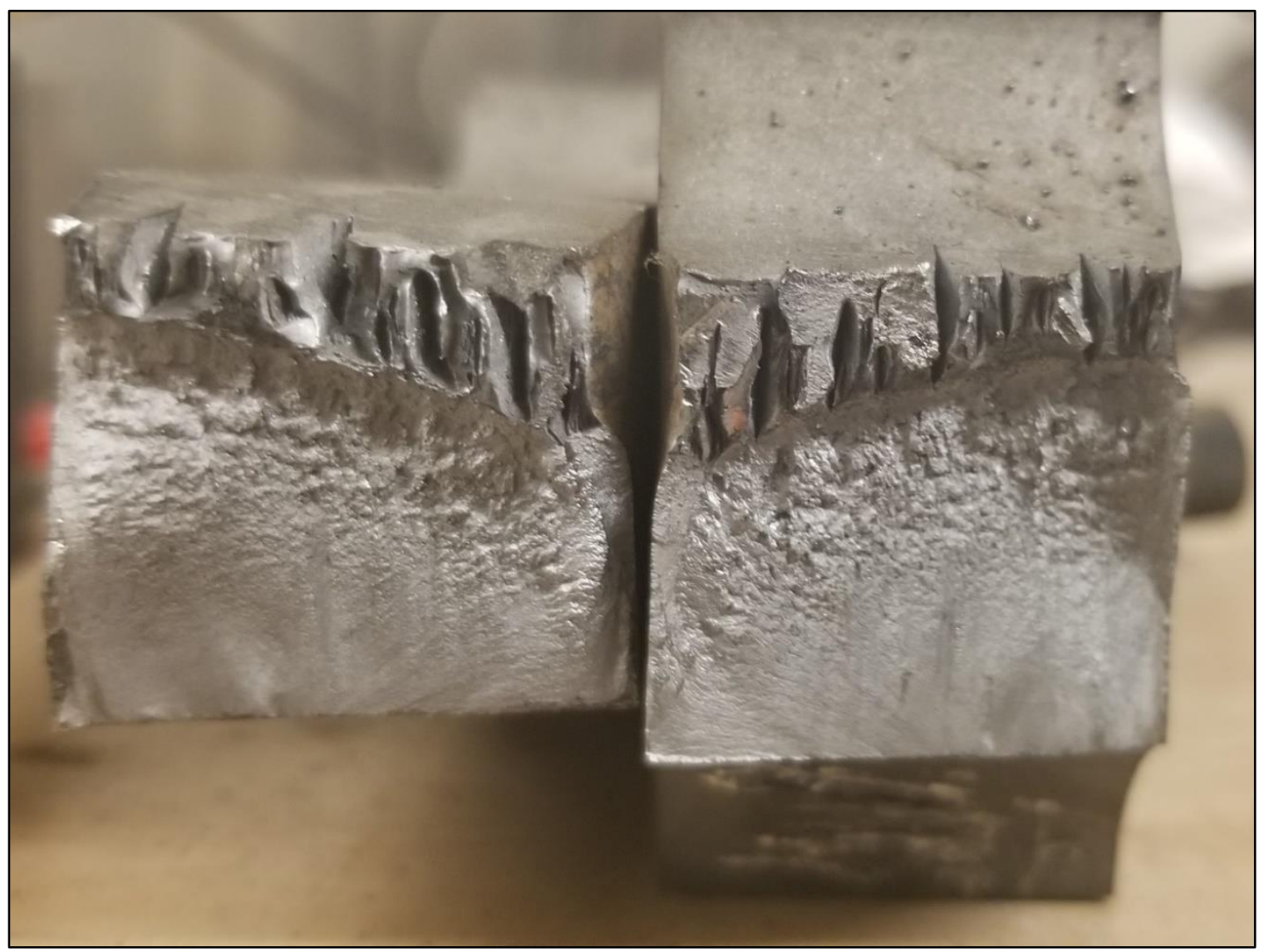

(c)

Figure 5-23: A1010 Fatigue Fracture of: (a) Coupon Specimen 2 tested at $\Delta \sigma=270 \mathrm{MPa}$; (b) Coupon Specimen 3 tested at $\Delta \sigma=250 \mathrm{MPa}$; (c) Coupon Specimen 4 tested at $\Delta \sigma=225$ MPa 


\section{Chapter 6 - Conclusions and Recommendations}

\subsection{Conclusions}

\subsubsection{Slip Resistance Coefficient and Bolt Relaxation}

The objective of this research was to obtain crucial data on the slip performance of ASTM A1010 stainless steel through experimental testing. It was important to determine whether ASTM A1010 stainless steel behaviour is similar to that of conventional structural steel commonly used in Canada, CSA G40.21 350W, and whether the slip resistance coefficient achieved matches up with that of what is specified in the latest edition of Canadian Highway Bridge Design Code (CSA S614). In order to accomplish this important task in the laboratory at Ryerson University, the research team conducted an extensive literature review on various historical methods used to conduct slip resistance testing of materials primarily used for structural applications. In total, 15 slip resistance tests were conduced for specimens made of ASTM A1010 stainless steel and other 15 slip resistance tests were conduced for specimens made of CSA G40.21 350W conventional. For 10 of these tests for each steel type, the clamping force was applied by a hydraulic piston and accurately measured with a washer-type load cell throughout the duration of the test, whereas, the other 5 tests were simply conducted with the clamping force applied through an A325 bolt tightened accordingly by the turn-of-nut method. The plates that were donated for this research and used for slip resistance testing came with an already formed rust patina with a high degree of surface roughness. Thus, it was decided to blast clean all faying surfaces with stainless steel grit and accurately measure the surface roughness for each faying surface. In addition to the slip resistance tests, a stress relaxation study was conducted on A325 plain, A325 galvanized and A193 B8 Class 2 stainless steel fastener assemblies to determine the immediate loss in the pretensioning force and to predict its value after 75-year service life of a bridge.

From the experimental testing the following conclusions were drawn:

The mean coefficient of slip resistance of ASTM A1010 stainless steel was 0.43 which was approximately $19 \%$ lower than that of CSA G40.21 350W conventional structural steel which achieved an average slip resistance of 0.53 . The slip resistance coefficient for 350W structural steel met all the limits outlined by the codes for blasted clean surfaces, 
whereas, the slip resistance coefficient of A1010 stainless steel did not meet the required limits for structural steel.

* The blast stainless steel grit media created a $23 \%$ deeper surface roughness profile on ASTM A1010 stainless steel in comparison with CSA G40.21 350W conventional steel. However, the surface hardness as tested was approximately $10 \%$ lower for A1010 stainless steel in comparison to CSA G40.21 350W conventional steel.

* The turn-of-nut clamping method as specified in CSA S6-14 and RCSC of 2014, yielded similar slip resistance coefficients to those obtained by tightening the nut to achieve a pretension force equal to $230 \mathrm{kN}$ which well exceeds the minimum $70 \%$ of total preload requirement that should be achieved by the turn-of-nut method.

* The clamping force during the duration of the test dropped upwards of $10 \%$ at times, however, it was determined that the drop of the clamping force during the test did not correlate with a drop in maximum slip resistance.

* A325 plain bolts experienced lower stress relaxations than A325 galvanized bolts at both preloading levels of $70 \%$ and $90 \%$ of the bolt tensile strength.

* A193 B8 Class 2 bolts with stainless steel nuts did not meet the minimum specified preload requirement of $70 \%$ due to major galling, even when lubricated properly. As such, it is not recommended to use it until further research is conducted. However, the B8 Class 2 bolts did meet the minimum preload requirement when a plain or galvanized ASTM A563 Type DH nut was used. Nevertheless, the B8 Class 2 bolt in combination with plain nut and galvanized nut experienced the most preload relaxation, $7.99 \%$ and $8.23 \%$ after 72 hours, respectively.

\subsubsection{Tensile Properties of ASTM A1010}

The objective of this part of research was to determine whether ASTM A1010 stainless steel has similar tensile properties to that of the commonly used CSA G40.21 350W structural steel and to gather preliminary information for the development of a fatigue study. From the tensile experimental tests conducted at Ryerson University, the following conclusions are drawn:

* Mechanical tensile properties from the tensile testing under static loading conducted on both bare and welded ASTM A1010 stainless steel coupons compared well and are similar to those of CSA G40.21 350W conventional structural steel. 
* All tensile tests of ASTM A1010 met and exceeded the minimum mechanical properties requirements that are outlined by the American Society for Testing \& Materials in the specific ASTM A1010 and ASTM A709 50CR Standards.

* ASTM A1010 bare coupons had an average yield strength of 385.6 MPa, average ultimate strength of 554.7 MPa, average fracture strength of 303.3 MPa; and an average elongation of $27.7 \%$ at failure. The length of the specimen did not have a significant impact on the yield and ultimate stress. However, the longer specimens did exhibit lower fracture strength and elongation.

* All ASTM A1010 steel bare coupon specimens exhibited necking and splitting just before fracture. Whereas, $350 \mathrm{~W}$ steel bare coupon specimens only exhibited necking before fracture in the form of a cup and cone.

* ASTM A1010 welded coupons had an average yield strength of $391.8 \mathrm{MPa}$, average ultimate strength of $561.5 \mathrm{MPa}$, average fracture strength of $319.2 \mathrm{MPa}$ and an average elongation of $23.0 \%$ at failure. The longer welded coupon specimen exhibited slightly lower tensile properties.

* All smooth full-penetration groove welded coupon specimens of ASTM A1010 and 350W failed on the base metal outside the welded zone. The A1010 welded coupon specimens also experienced necking, followed by splitting just before fracture.

\subsubsection{Fatigue Experiments of ASTM A1010}

The final research phase of this study aimed at finding the fatigue behaviour of ASTM A1010 stainless steel as compared to that of CSA G40.21 350W structural steel. Nine bare dog-bone specimens ( 5 of $350 \mathrm{~W}$ steel and 4 of A1010 steel) were tested at fatigue stress ranges of 270, 250, 225,200 , and $180 \mathrm{MPa}$. The data obtained from these tests were enough to draw some preliminary conclusions on the fatigue behaviour of A1010 stainless steel as follows.

All tested bare A1010 steel coupon specimens experienced longer fatigue life compared to conventional $350 \mathrm{~W}$ structural steel.

* A1010 specimens tested at the higher stress ranges (270, 250, and $225 \mathrm{MPa})$ experienced a significantly longer life than $350 \mathrm{~W}$ specimens tested at the same ranges. On the other hand, at the lower stress ranges of 200 and $180 \mathrm{MPa}$, the A1010 and 350W specimens tested resulted in similar fatigue life. 
Fabrication of the specimens, more specifically abrasive cutting method by waterjet, left several discontinuities at the plane of cutting on both A1010 and 350W steels. These flaws are suspected to have an impact on deciding on the fatigue detail category for the tested steel. Nevertheless, the linear fit curve of the mean for A1010 stainless steel fell in between detail category Curves A and B. On the other hand, the 350W steel linear fit of the mean fell close to the detail category Curve C. It is important to note that the data on the lower stress ranges 200 and $180 \mathrm{MPa}$ were above the detail category curve A.

* Fatigue fracture of ASTM A1010 was more violent than that of 350W steel. Fracture propagation started near the round corner at the end of the gauge length and propagated slowly towards the middle of the cross-section until it ruptured violently. Small delaminated cracks were only observed in the section which ruptured. However, no large splitting of the specimen like that observed in the monotonic tensile test was present in the fatigue failure of ASTM A1010 steel.

\subsection{Recommendations for Future Research}

\subsubsection{Slip Resistance Coefficient and Bolt Relaxation}

The following points are some of the most important recommendations for future research that arose from this study:

* Determine the slip resistance coefficient of clean mill as received ASTM A1010 stainless steel plates.

* Evaluate the effects of different blast media (i.e. shot blasting with different diameters, aluminum grit blasting, etc.) on A1010 stainless steel. Quantify the surface profile created by these different blast media, correlate it to the steel surface hardness and determine the effect that it has on the slip resistance coefficient. If different blast media creates different surface profiles, they should be properly specified on the CSA S6 and CSA S16 codes to avoid the ambiguity created by having only one value for all blasted surfaces.

* Properly evaluate the behaviour of A1010 stainless steel under various temperatures and extend the test beyond the 72 hours to provide more data to extrapolate it to 75 years of service. 
* Rather than conducting the bolt relaxation testing on Skidmore device, the test is recommended to be conducted on the 3-plate specimens used for slip resistance test, considering different surface roughness and plates made of A1010 steel as well as of 350W steel.

* Use different lubricants (namely Never Seez® NSSBT-16, Gleitmo WSP 5040, Gleitmo 1952V, Molykote 1000, Molykote D-321R Microgleit HV-paste LP440, Interflon HT1200) on A193 B8 Class 2 stainless steel bolts in combination with Grade 8 stainless steel nut to determine whether they reach the minimum preload requirements.

* Conduct a parametric study to be conducted using the finite element method to increase the scope of research at less cost.

\subsubsection{Tensile Experiments of ASTM A1010 Steel}

The following additional research opportunities can be pursued:

* Perform a microstructure analysis to determine the exact cause of the specimen splitting just before ultimate failure.

* Perform testing on A1010 specimens with a rolling direction perpendicular to that of the applied stress.

* Complete additional tensile tests for different specimen shapes, both rounded and flat of various thicknesses up to $75 \mathrm{~mm}$ (3"), in order to determine the effect that A1010 specimen geometry has on its tensile properties. Care should be taken to use more precise strain gauges or a laser-type extensometer in order to have a more precise measurement of the overall strain and the exact point that the initial splitting occurs before ultimate failure.

* Welded specimens should be designed with a shorter gauge length so that the failure occurs somewhere in the welding zone in order to determine the true tensile properties of the weld. Also, specimens with ground flush weld should be tested to determine if grinding the welding zone has an effect on failure in case of A1010 steel. 


\subsubsection{Fatigue of ASTM A1010 Steel}

The following are the recommendation for future research on fatigue performance of A1010 steel:

* Finish testing 10 of the short regular dog-bone specimens from both A1010 and 350W steels and determine whether length has an impact on fatigue resistance.

* Test all 20 full penetration groove welded A1010 and 350W specimens and determine whether weld fatigue falls under detail category B or C.

* Fabricate A1010 fillet welded cruciform specimens and test them under fatigue loading and determine whether these specimens fall under detail category $\mathrm{C}$ of the code.

* Fabricate thinner specimens to test them at higher frequencies and determine their results under high-cycle fatigue.

* Test specimens under variable amplitude loading and determine what effect it has on the fatigue of A1010 specimens.

* Complete welding treatment techniques such as ultrasonic or shot-peening on welded A1010 specimens and test them under fatigue to determine whether these techniques have an effect on extending fatigue life. 


\section{Appendix A - Slip Graphs of ASTM A1010 Stainless Steel with Class B Surface Treatment}

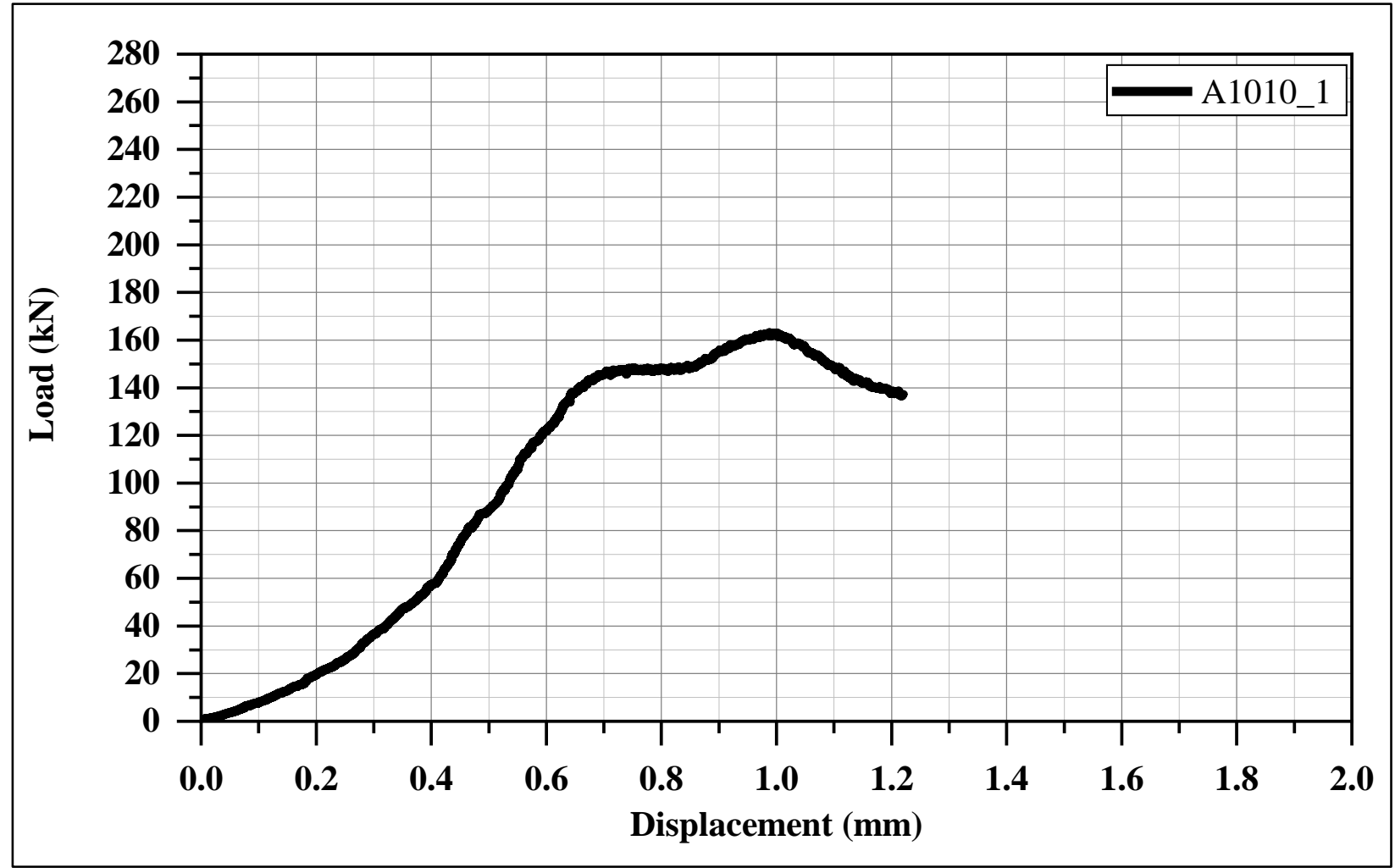

Figure A-1: Slip Load vs Displacement of Specimen A1010_1

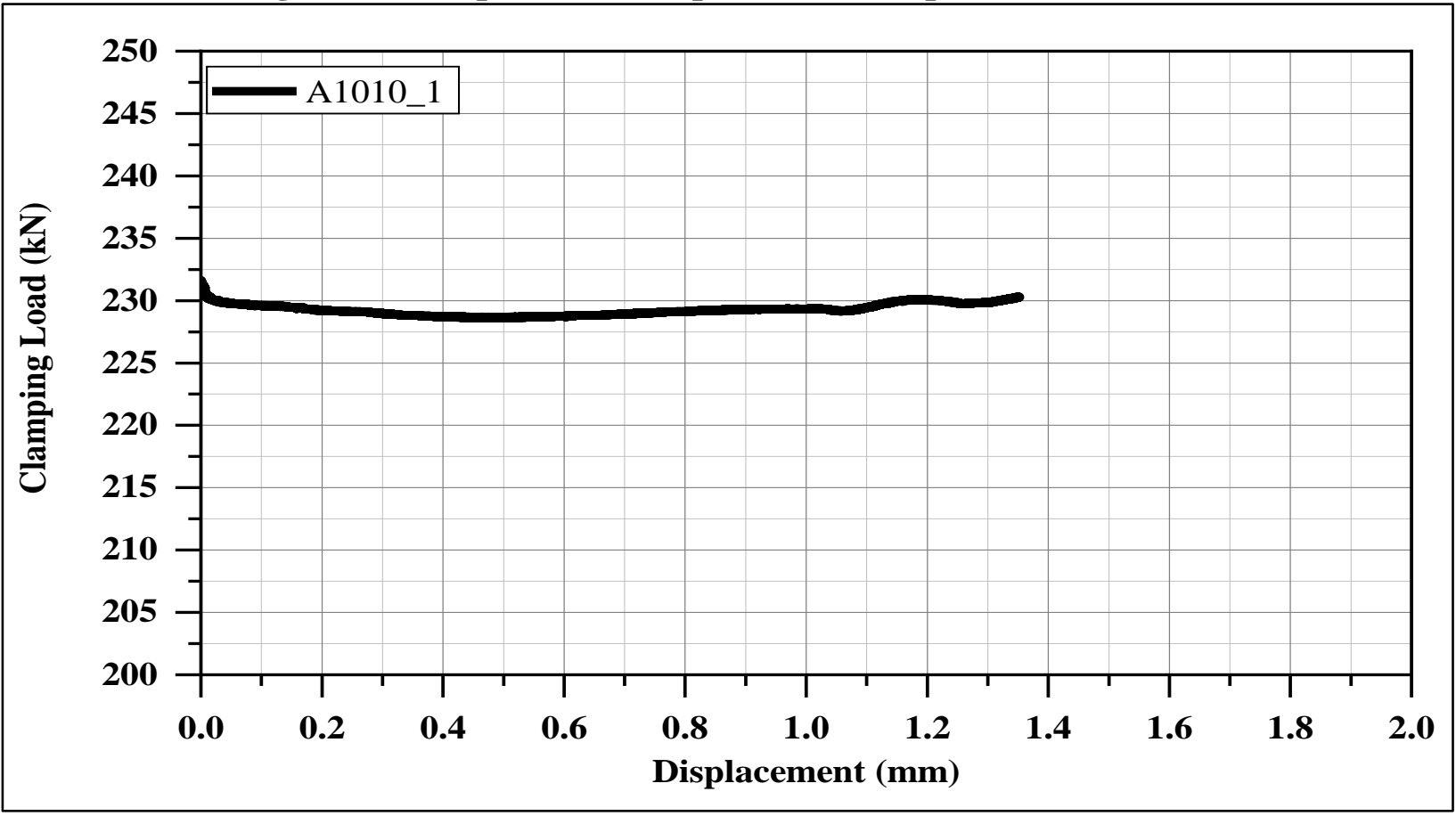

Figure A-2: Clamping Load of Specimen A1010_1 


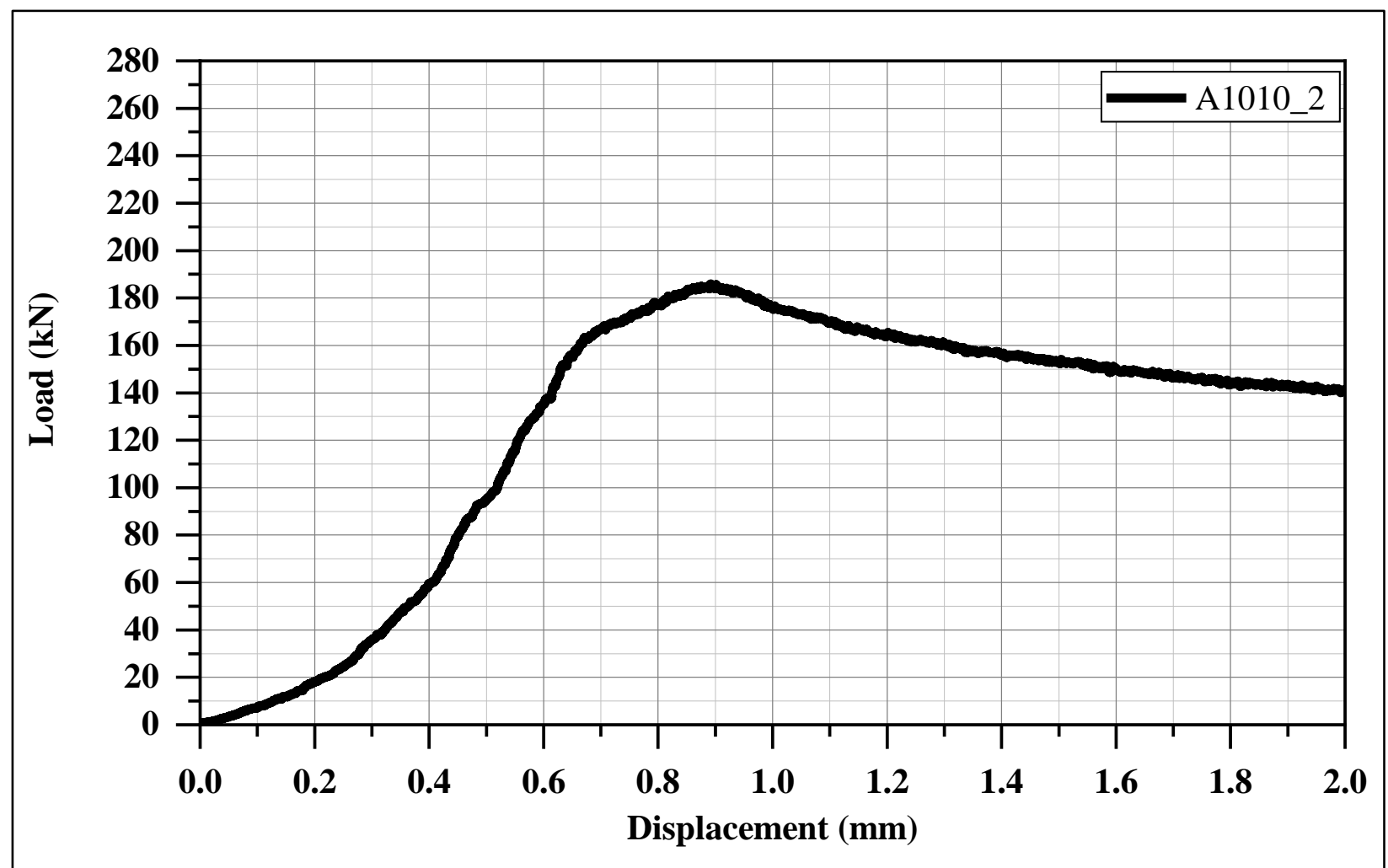

Figure A-3: Slip Load vs Displacement Graph of Specimen A1010_2

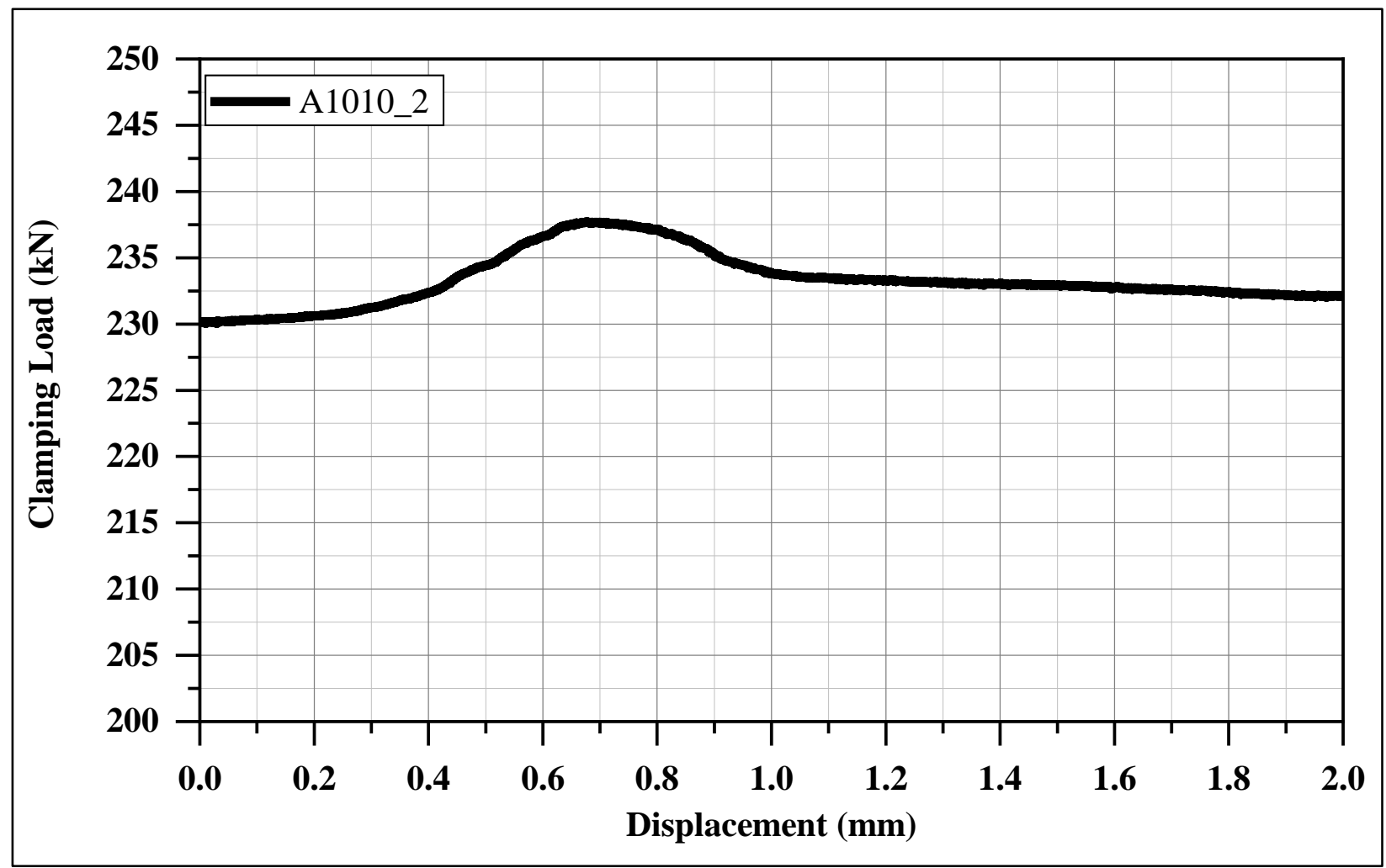

Figure A-4: Clamping Load of Specimen A1010_2 


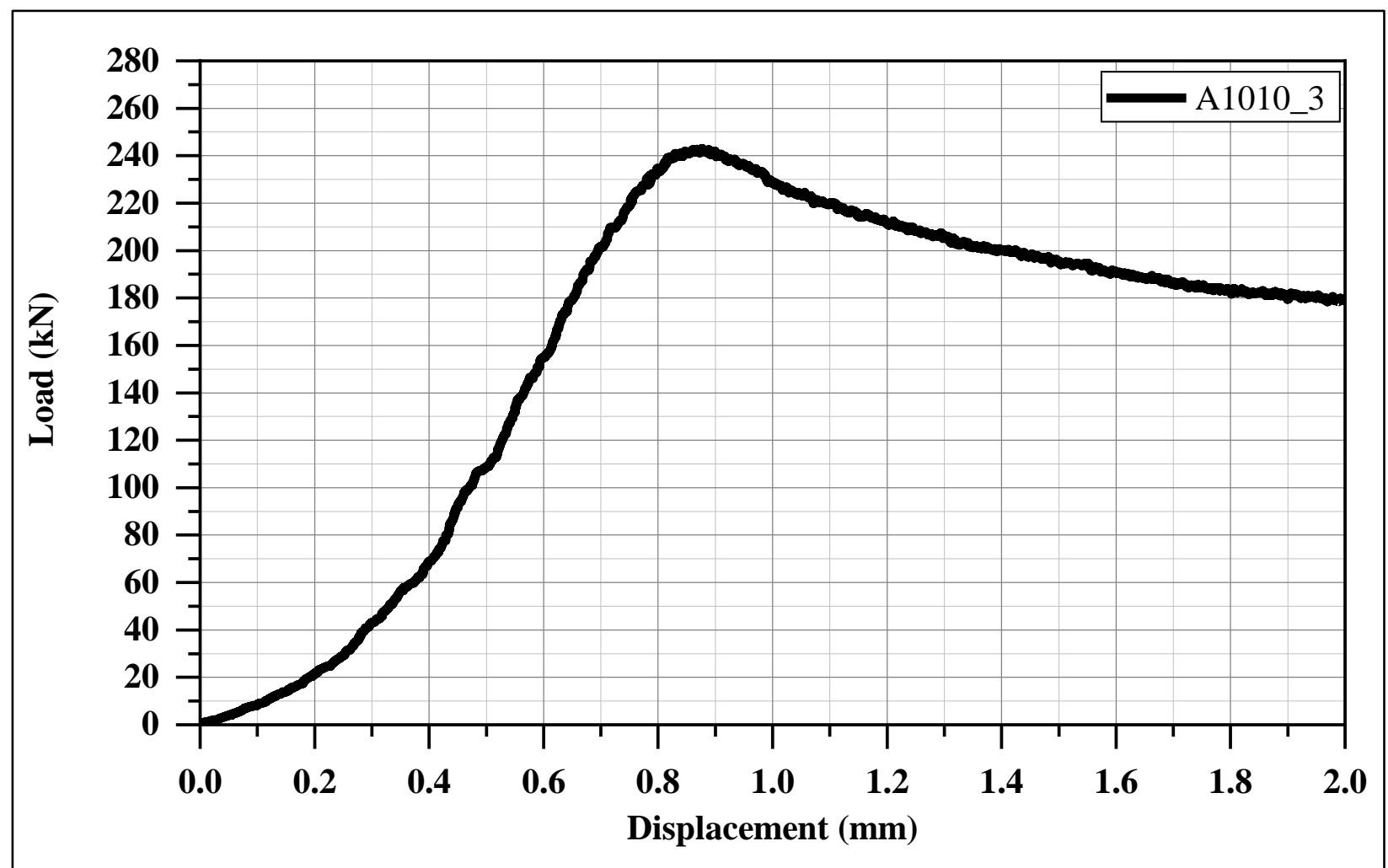

Figure A-5: Slip Load vs Displacement of Specimen A1010_3

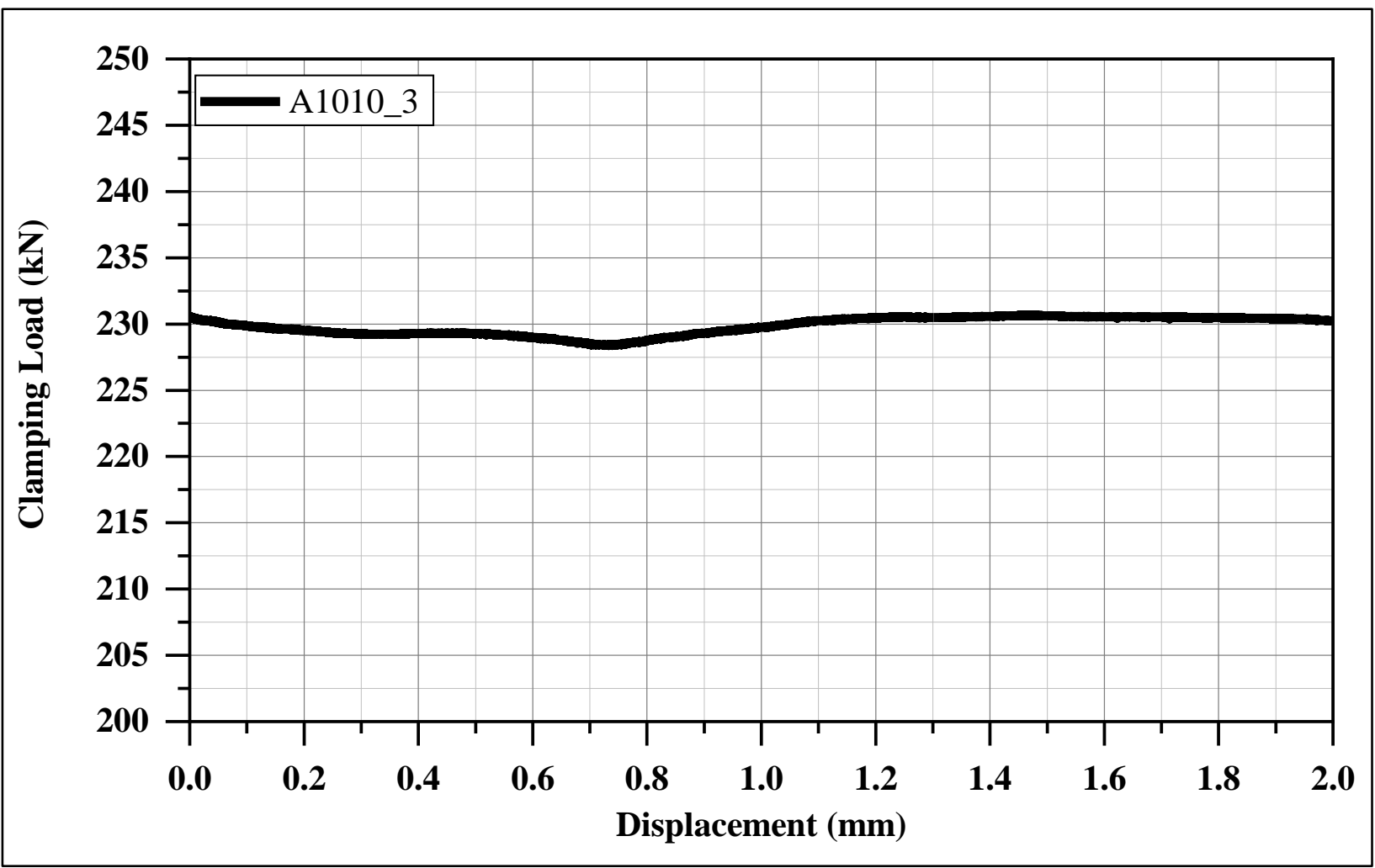

Figure A-6: Clamping Load of Specimen A1010_3 


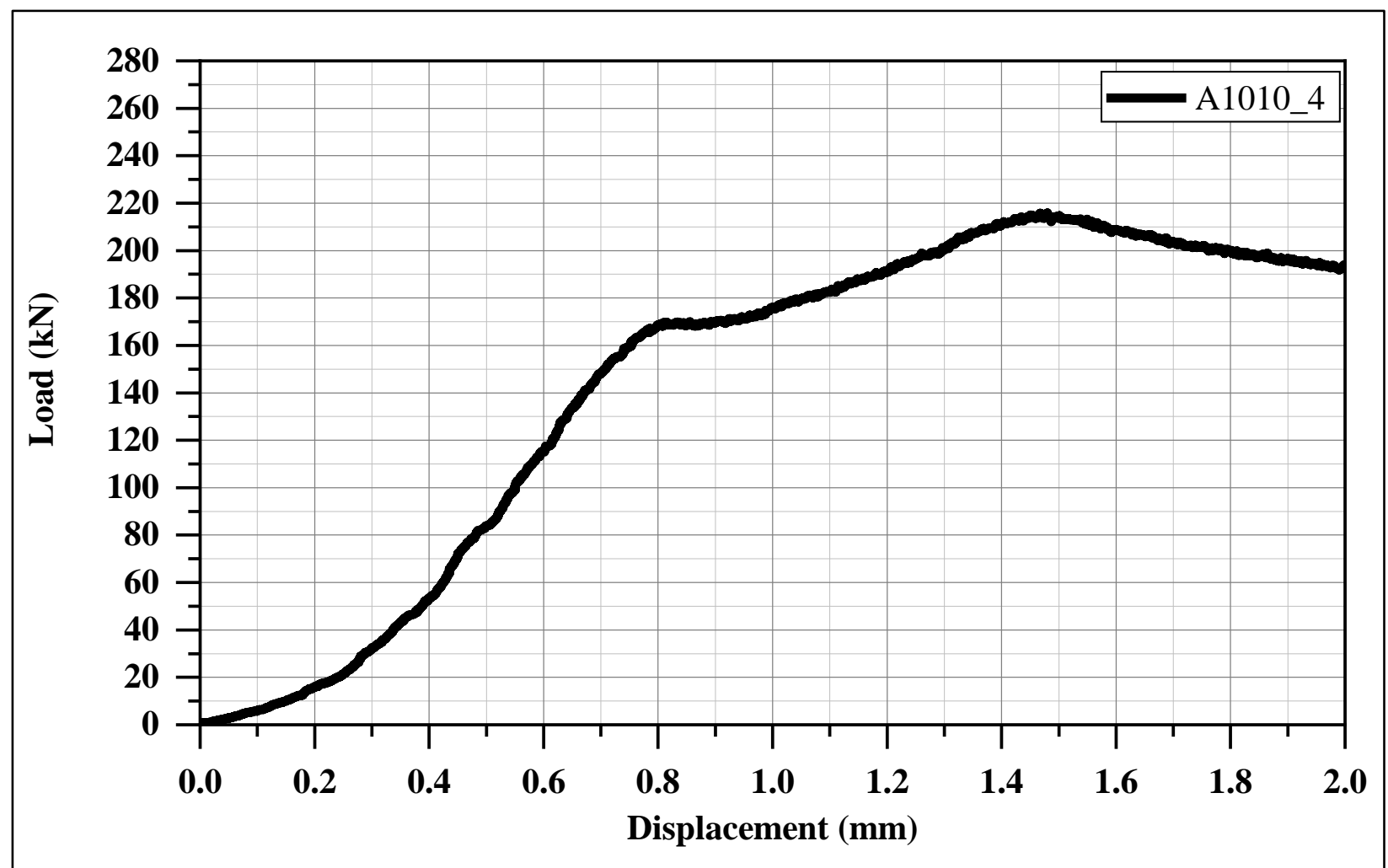

Figure A-7: Slip Load vs Displacement of Specimen A1010_4

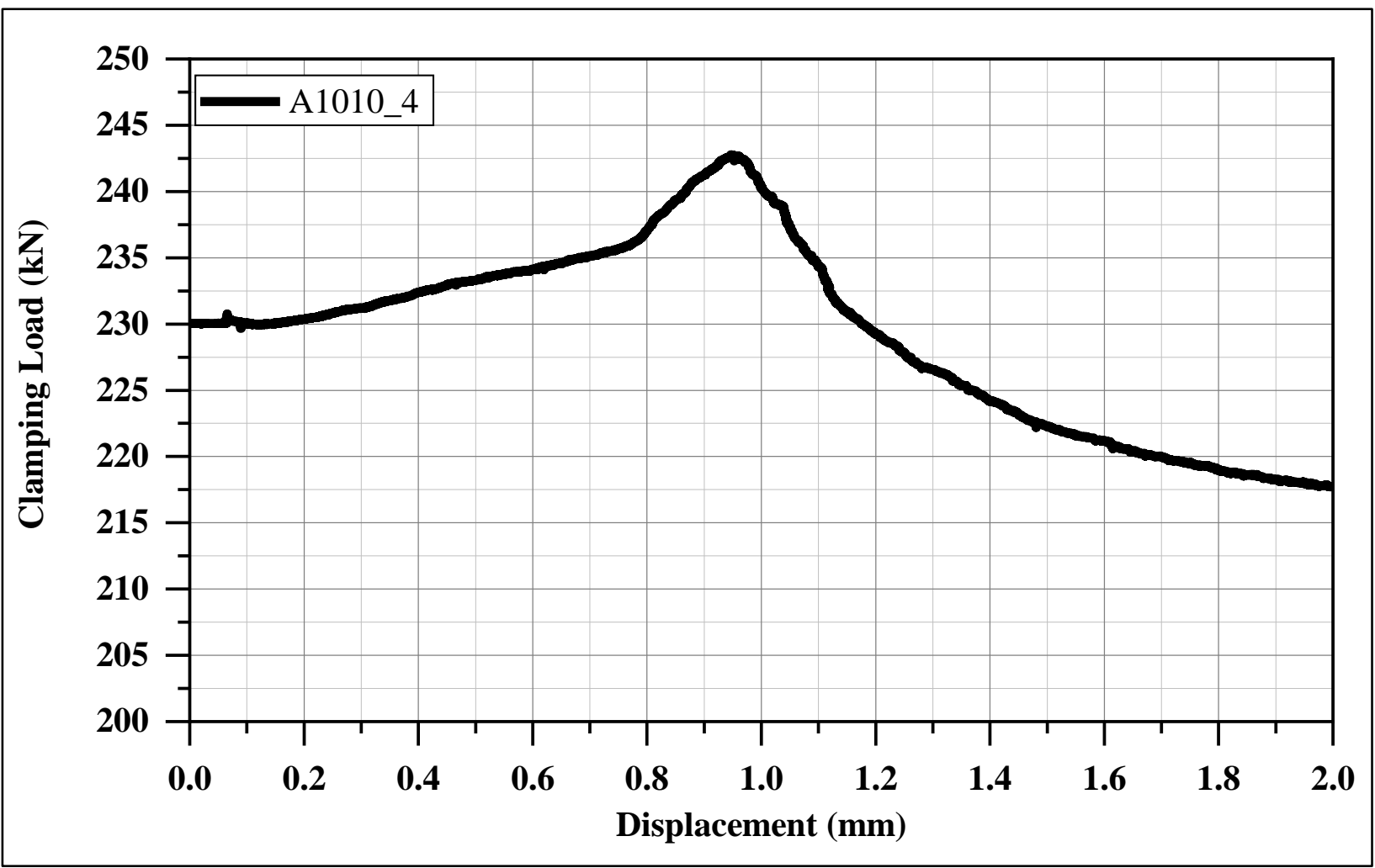

Figure A-8: Clamping Load of Specimen A1010_4 


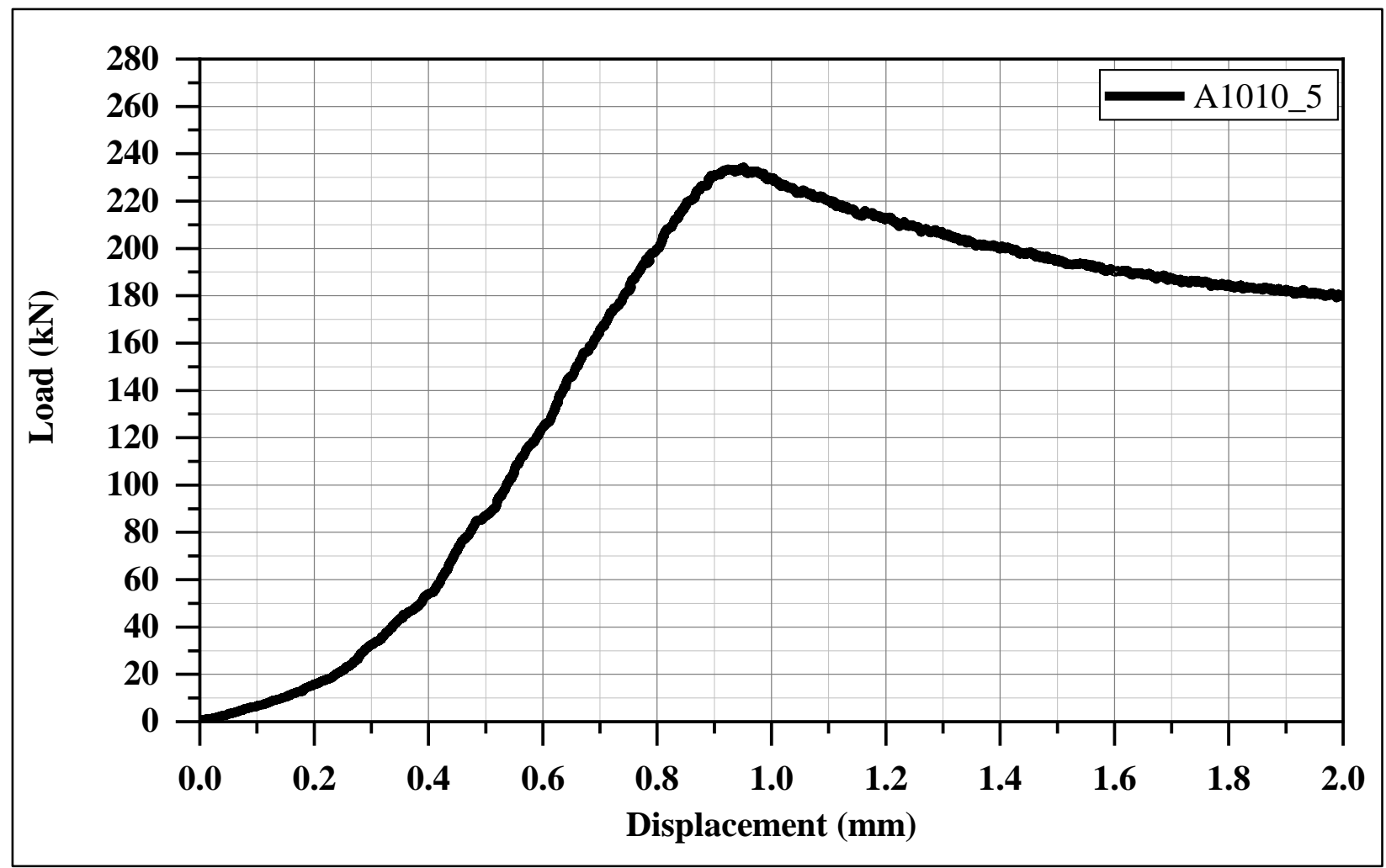

Figure A-9: Slip Load vs Displacement of Specimen A1010_5

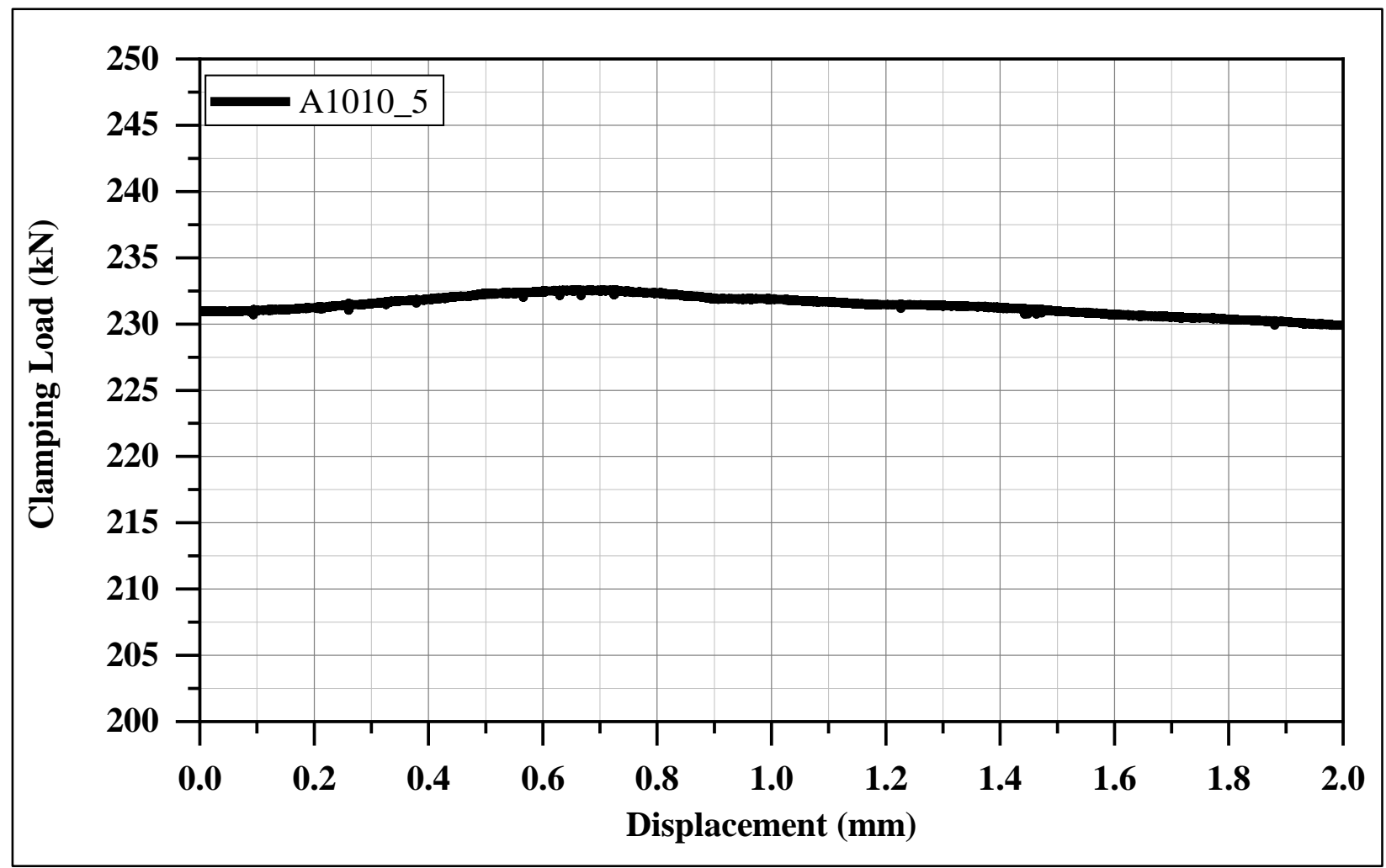

Figure A-10: Clamping Load of Specimen A1010_5 


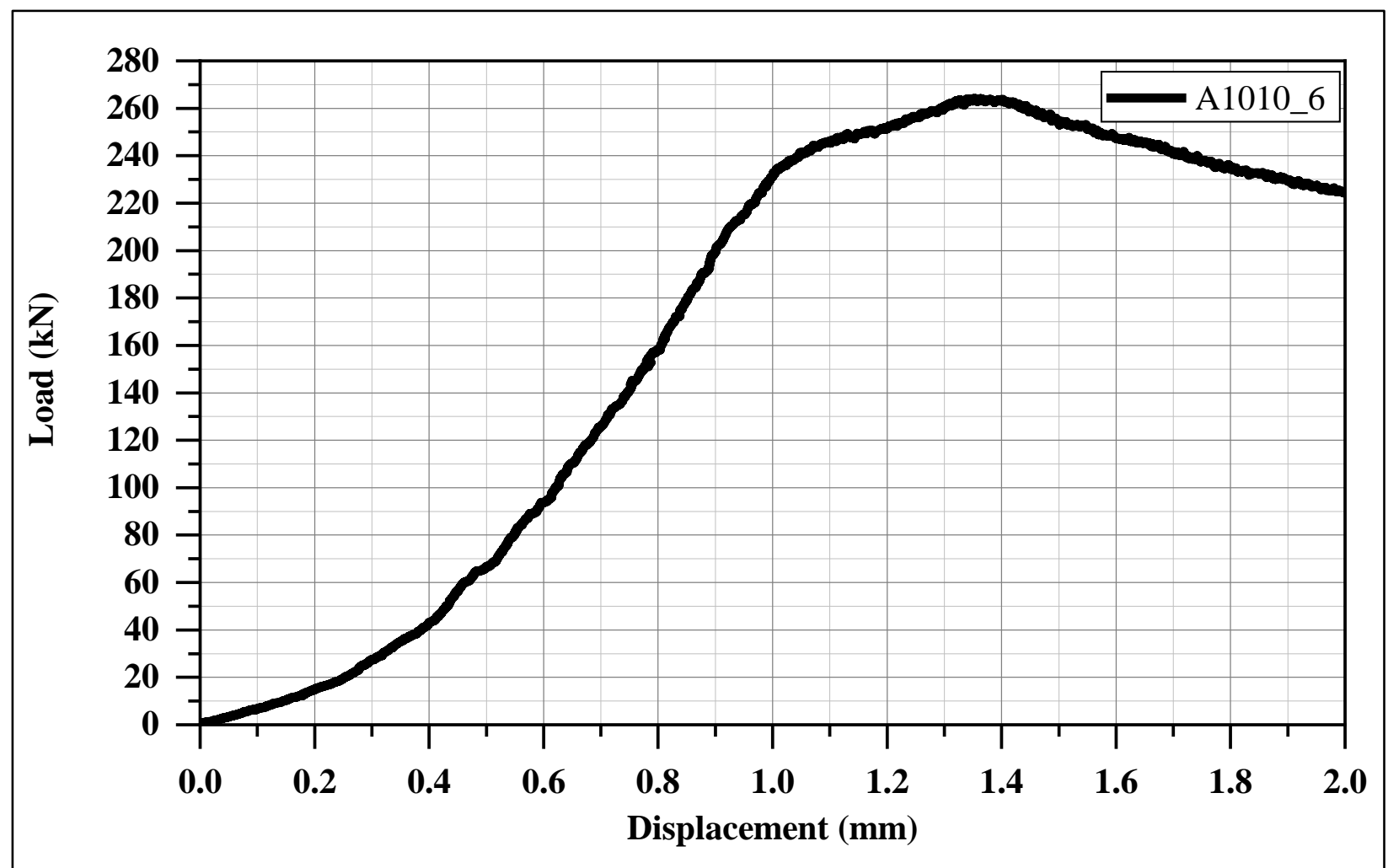

Figure A-11: Slip Load vs Displacement of Specimen A1010_6

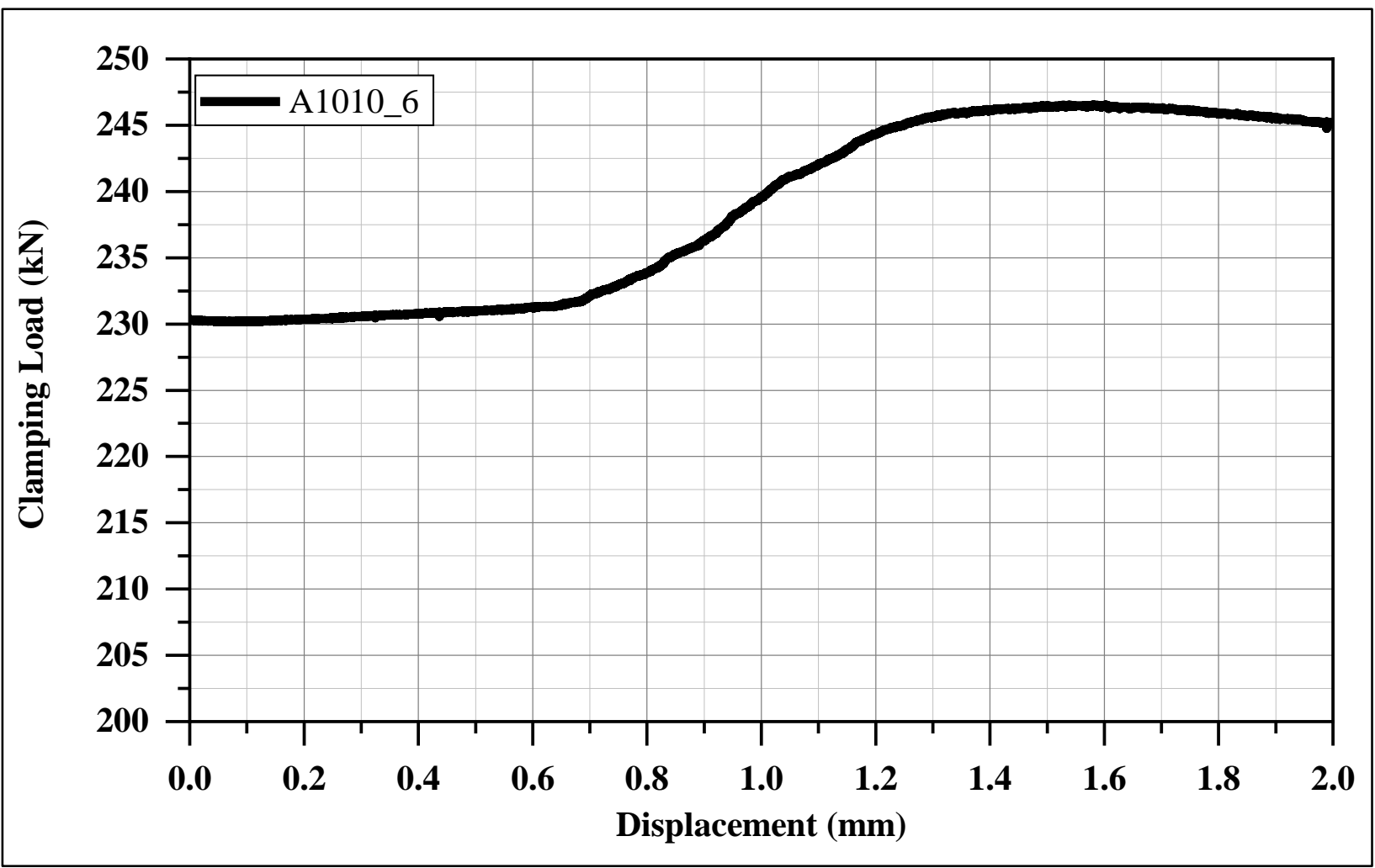

Figure A-12: Clamping Load of Specimen A1010_6 


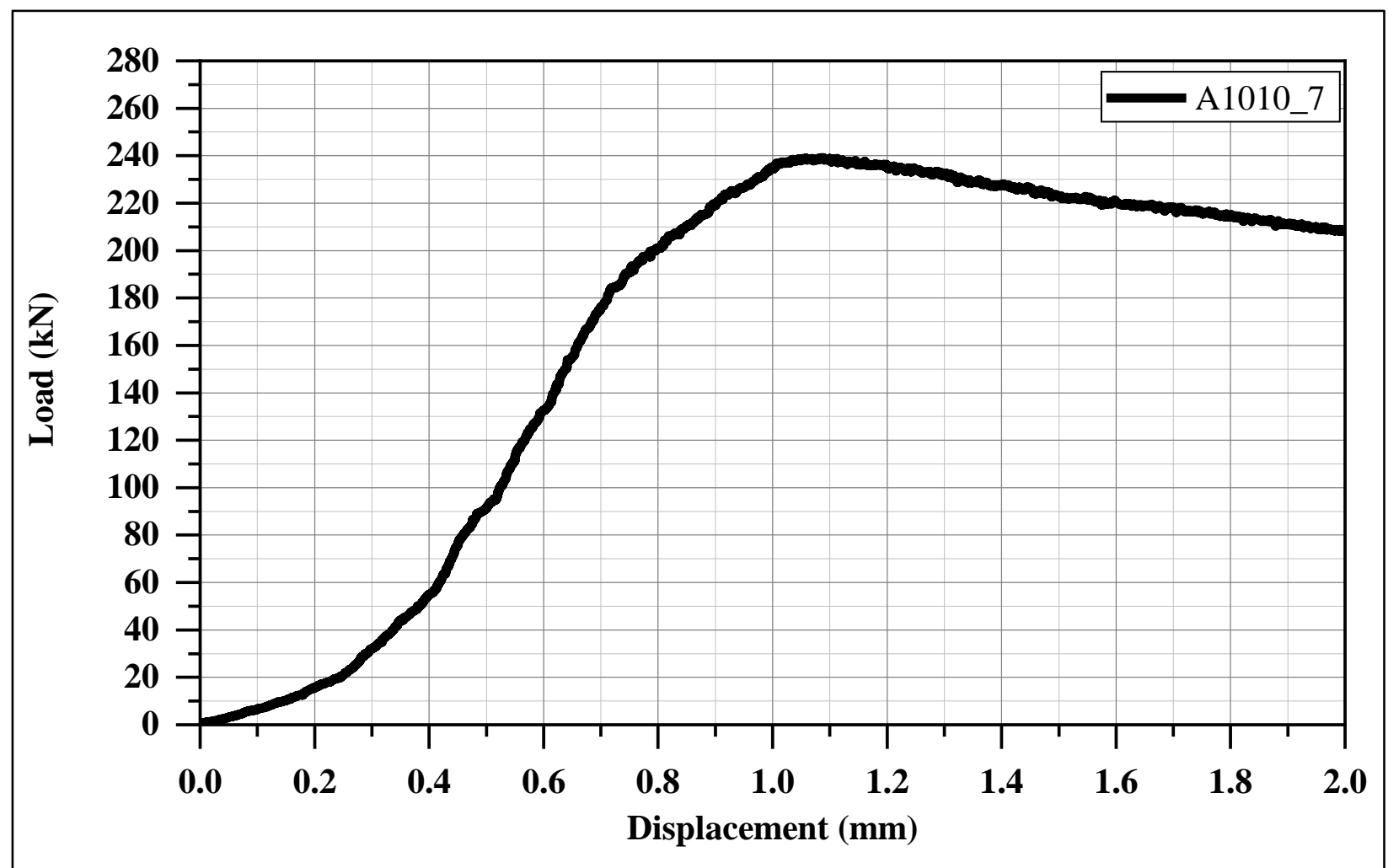

Figure A-13: Slip Load vs Displacement of Specimen A1010_7

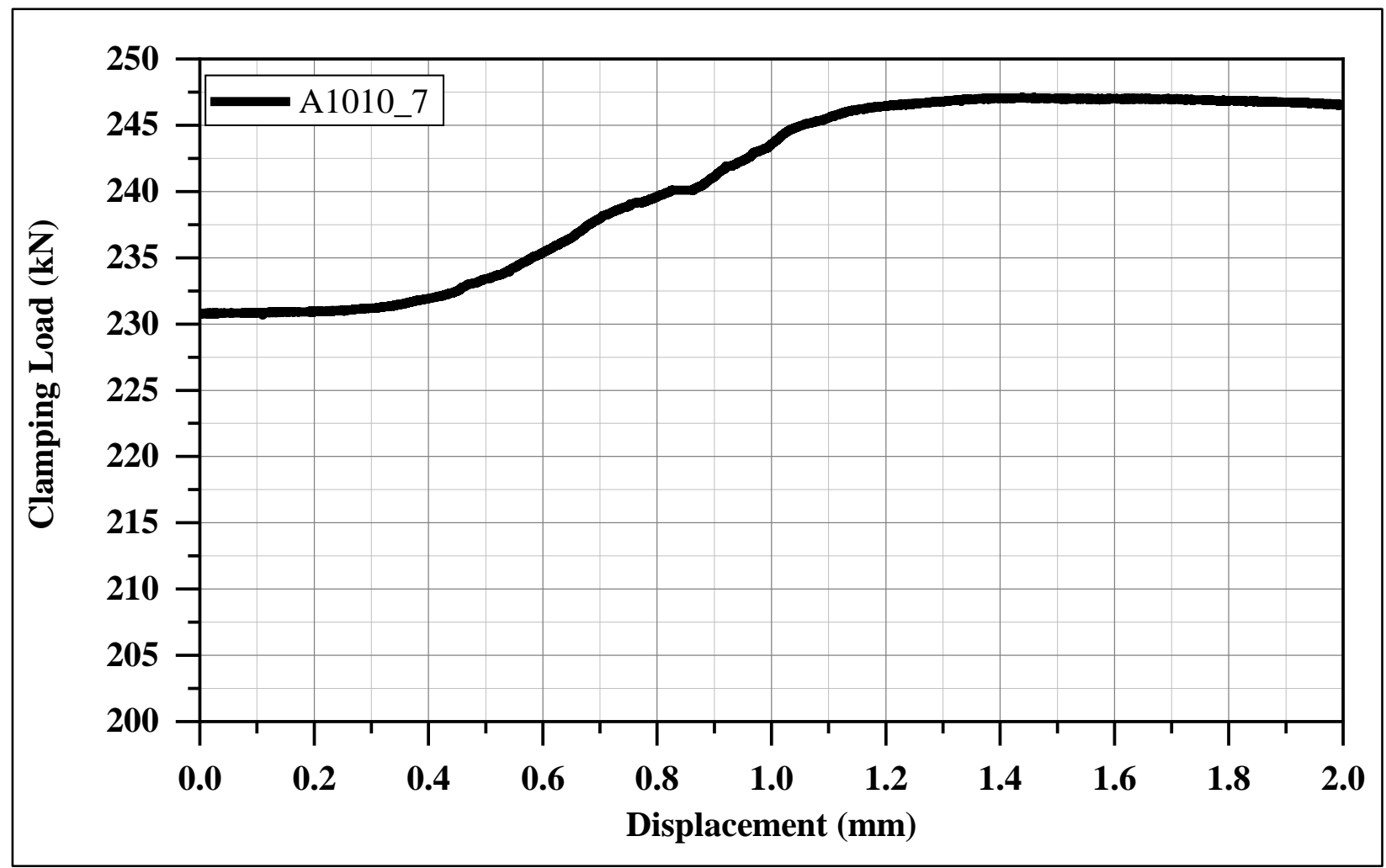

Figure A-14: Clamping Load of Specimen A1010_7 


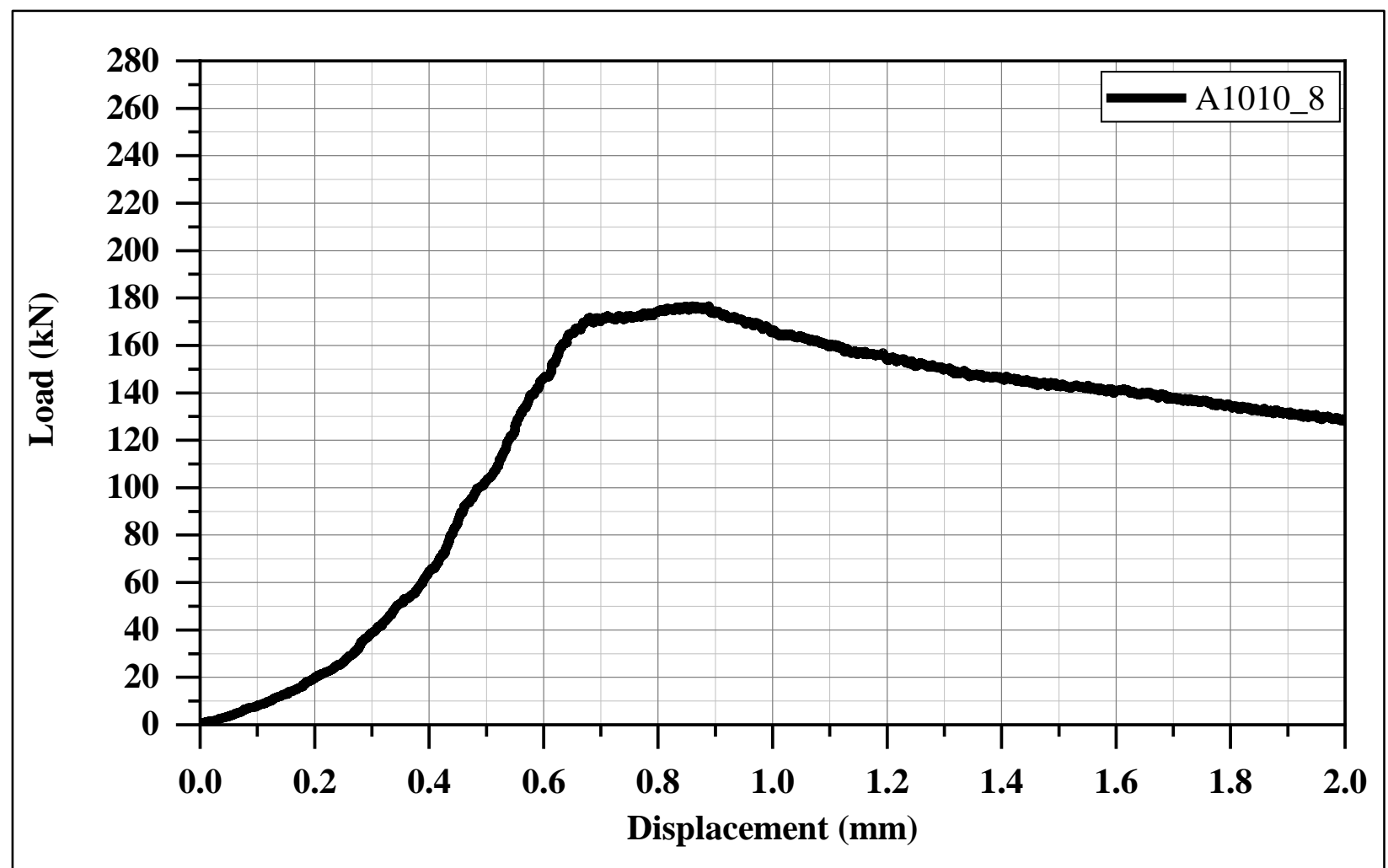

Figure A-15: Slip Load vs Displacement of Specimen A1010_8

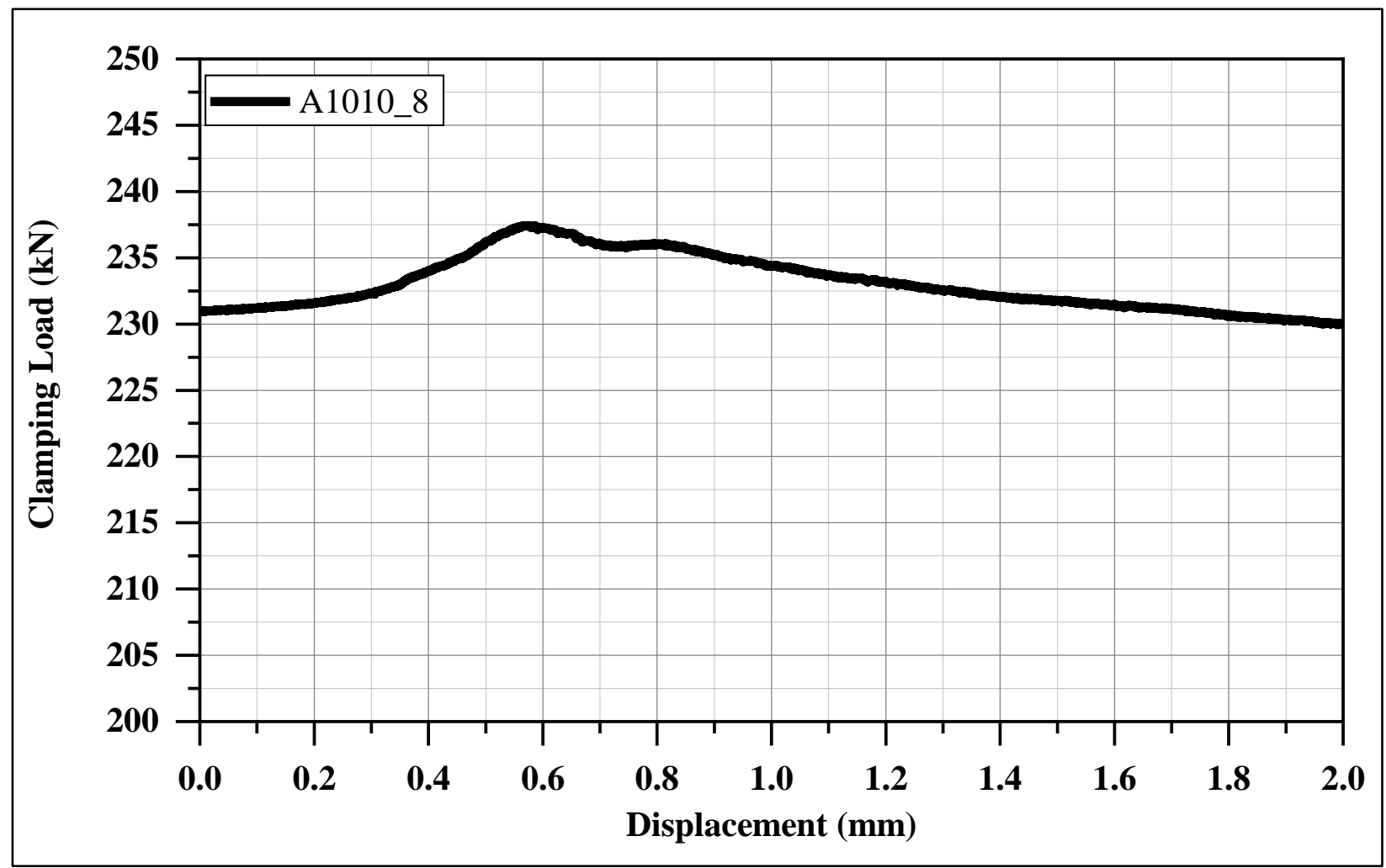

Figure A-16: Clamping Load of Specimen A1010_8 


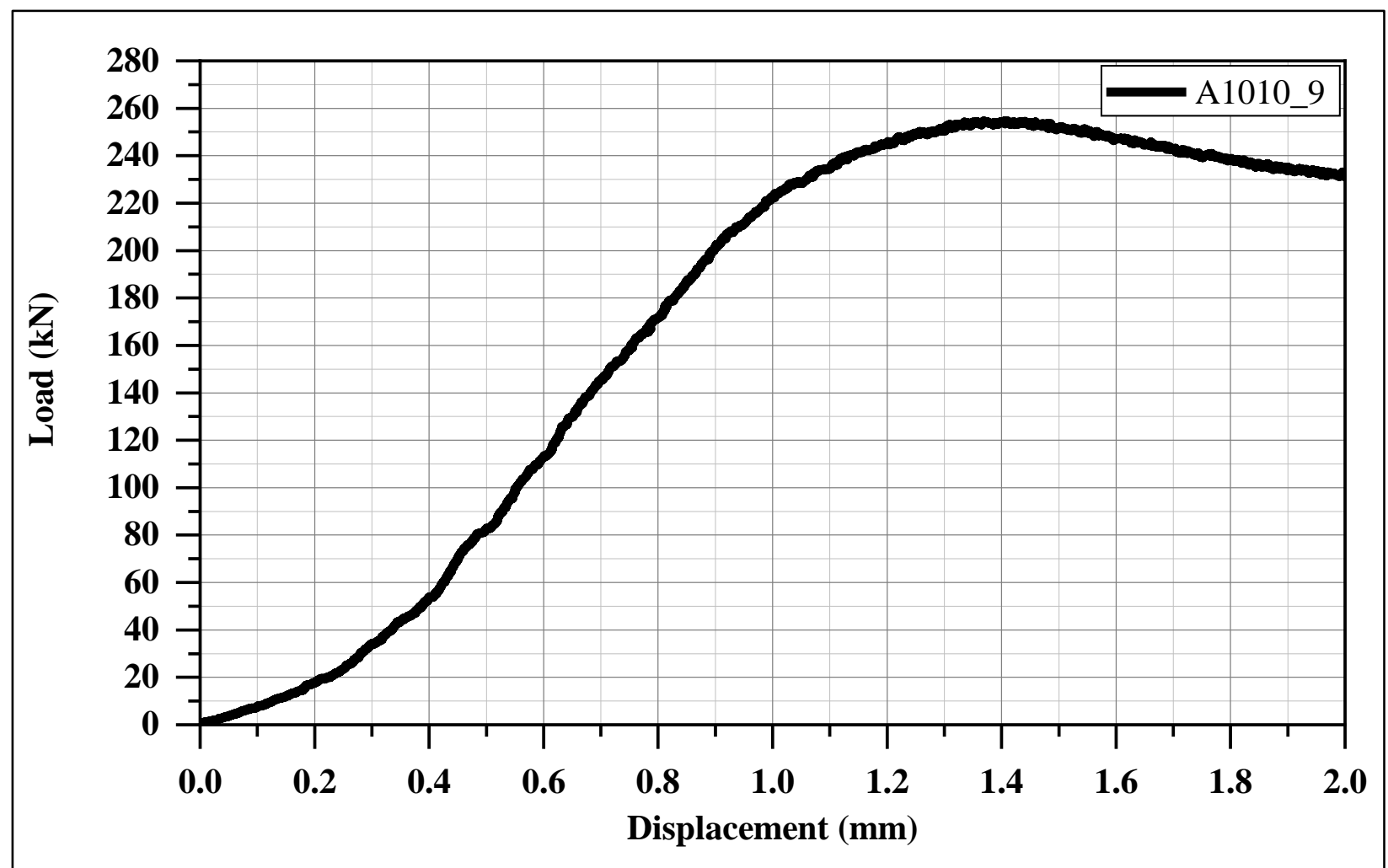

Figure A-17: Slip Load vs Displacement of Specimen A1010_9

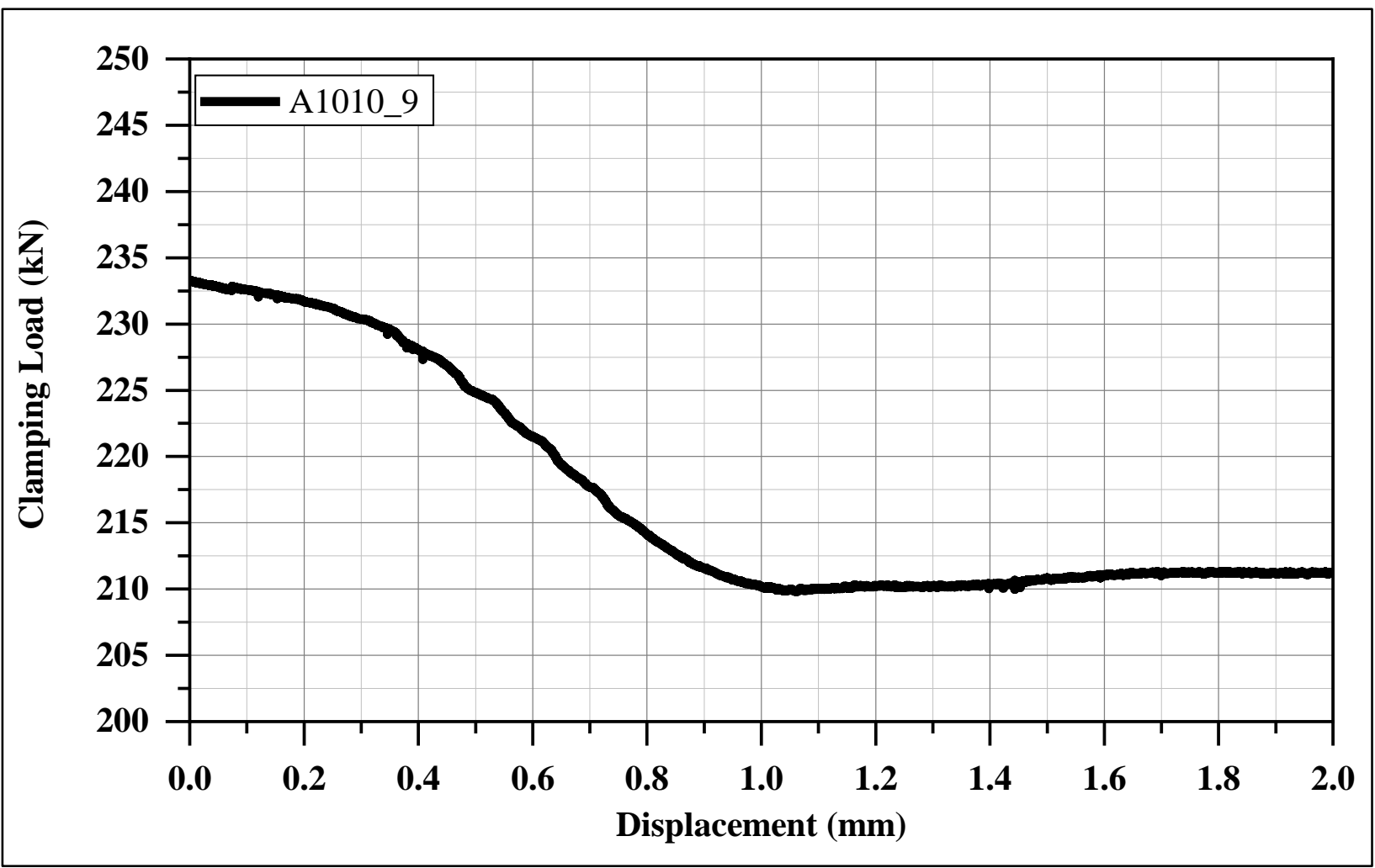

Figure A-18: Clamping Load of Specimen A1010_9 


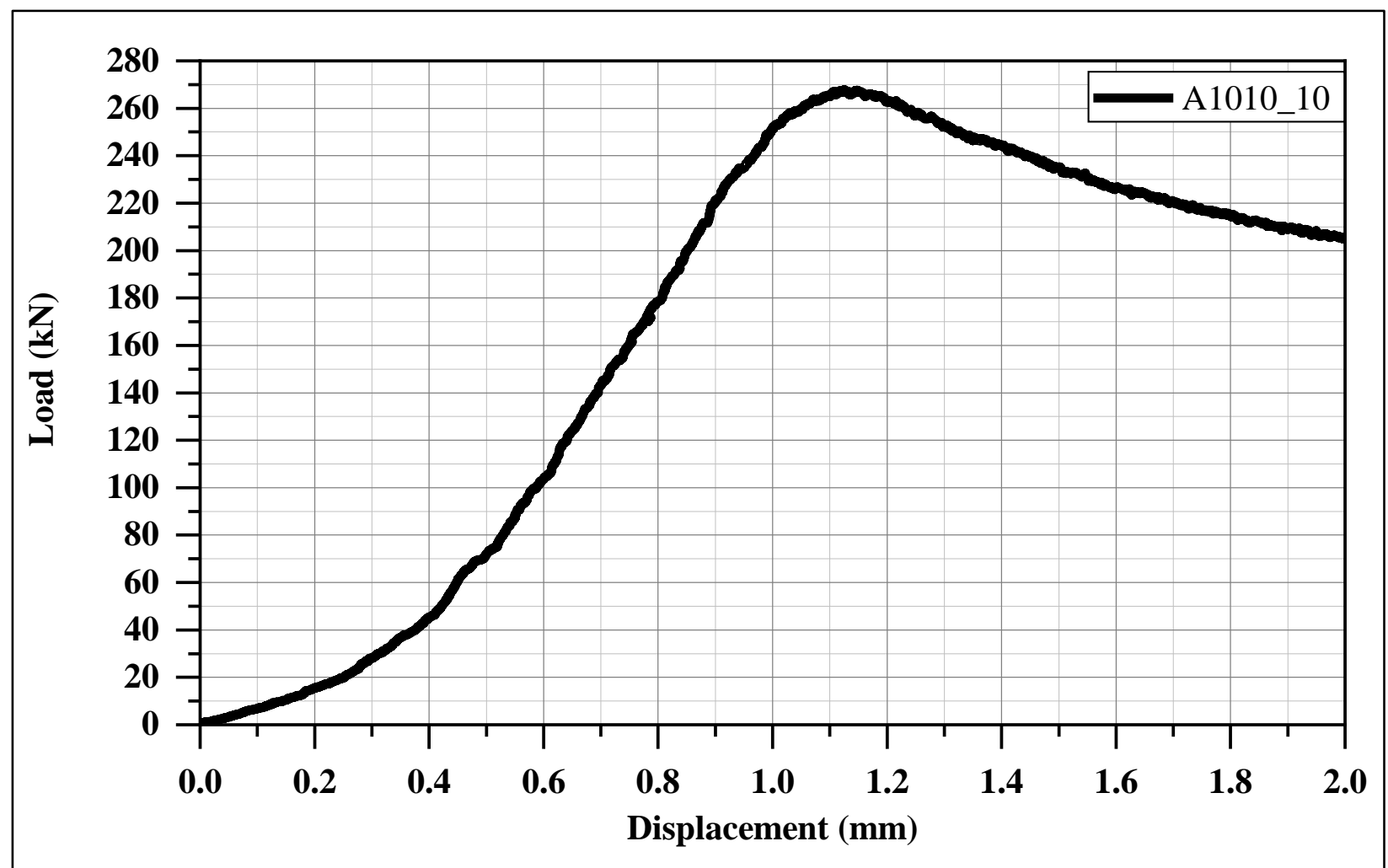

Figure A-19: Slip Load vs Displacement of Specimen A1010_10

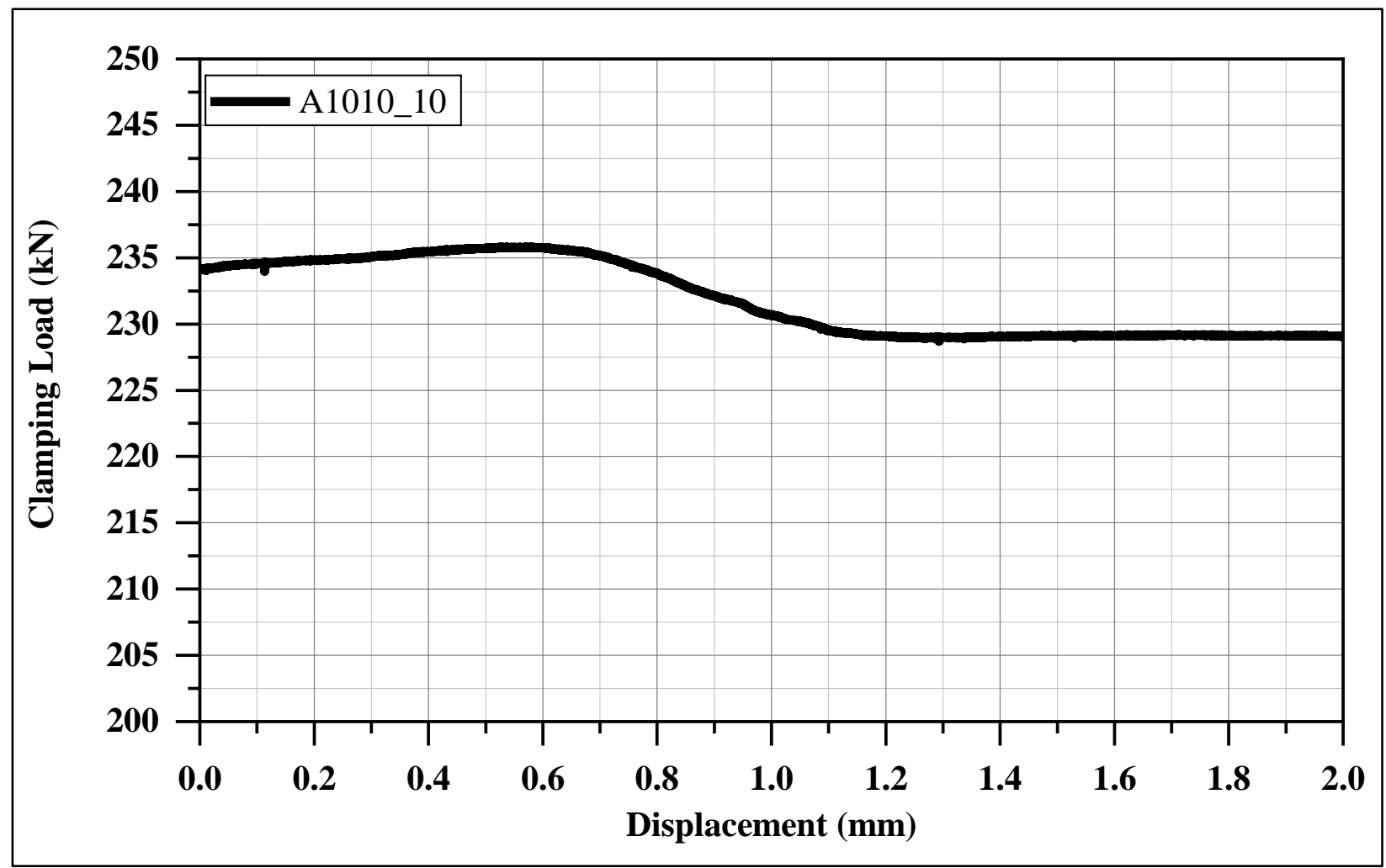

Figure A-20: Clamping Load of Specimen A1010_10 


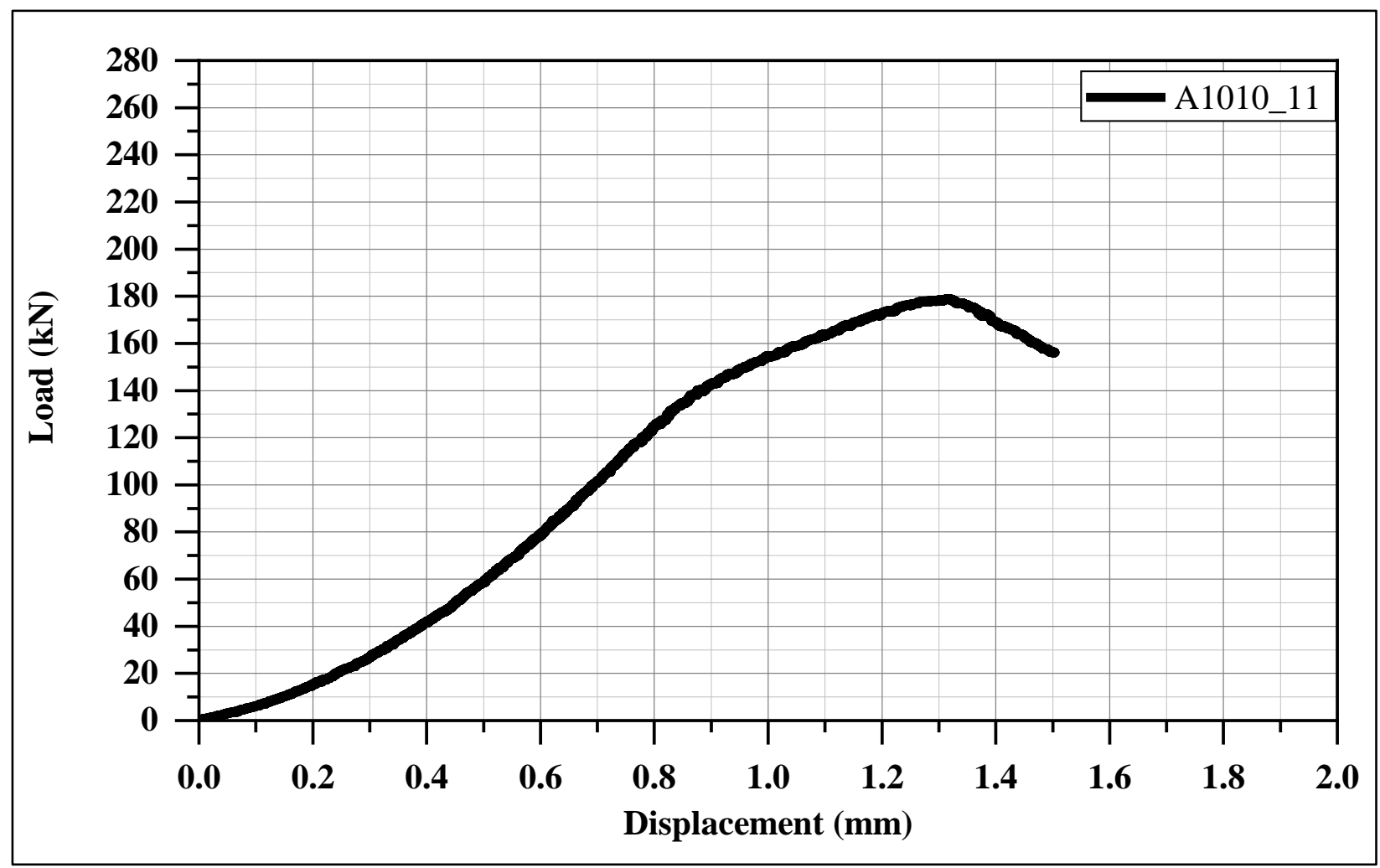

Figure A-21: Slip Load vs Displacement of Specimen A1010_11 Clamped with the Turn-ofNut Method.

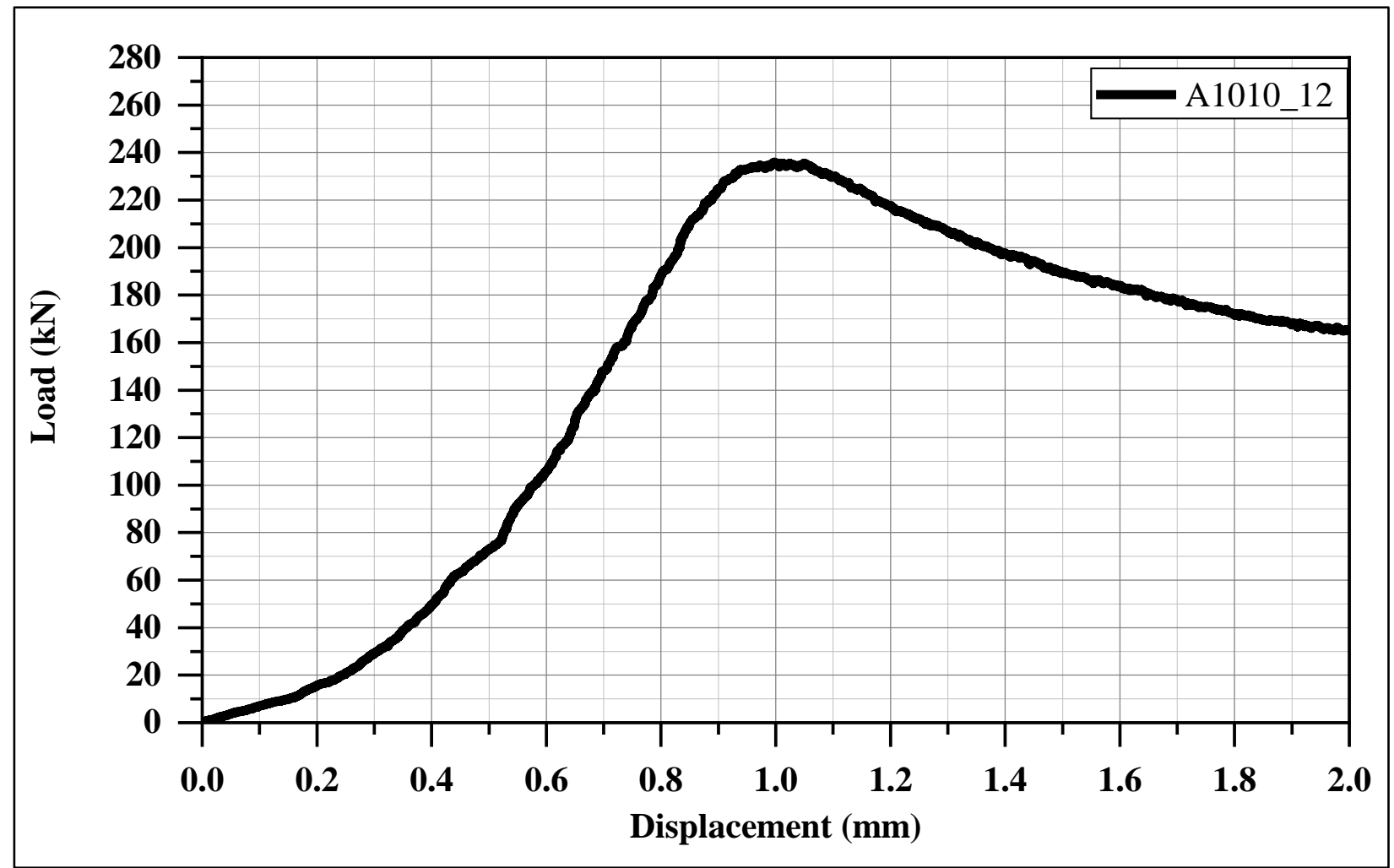

Figure A-22: Slip Load vs Displacement of Specimen A1010_12 Clamped with the Turn-ofNut Method 


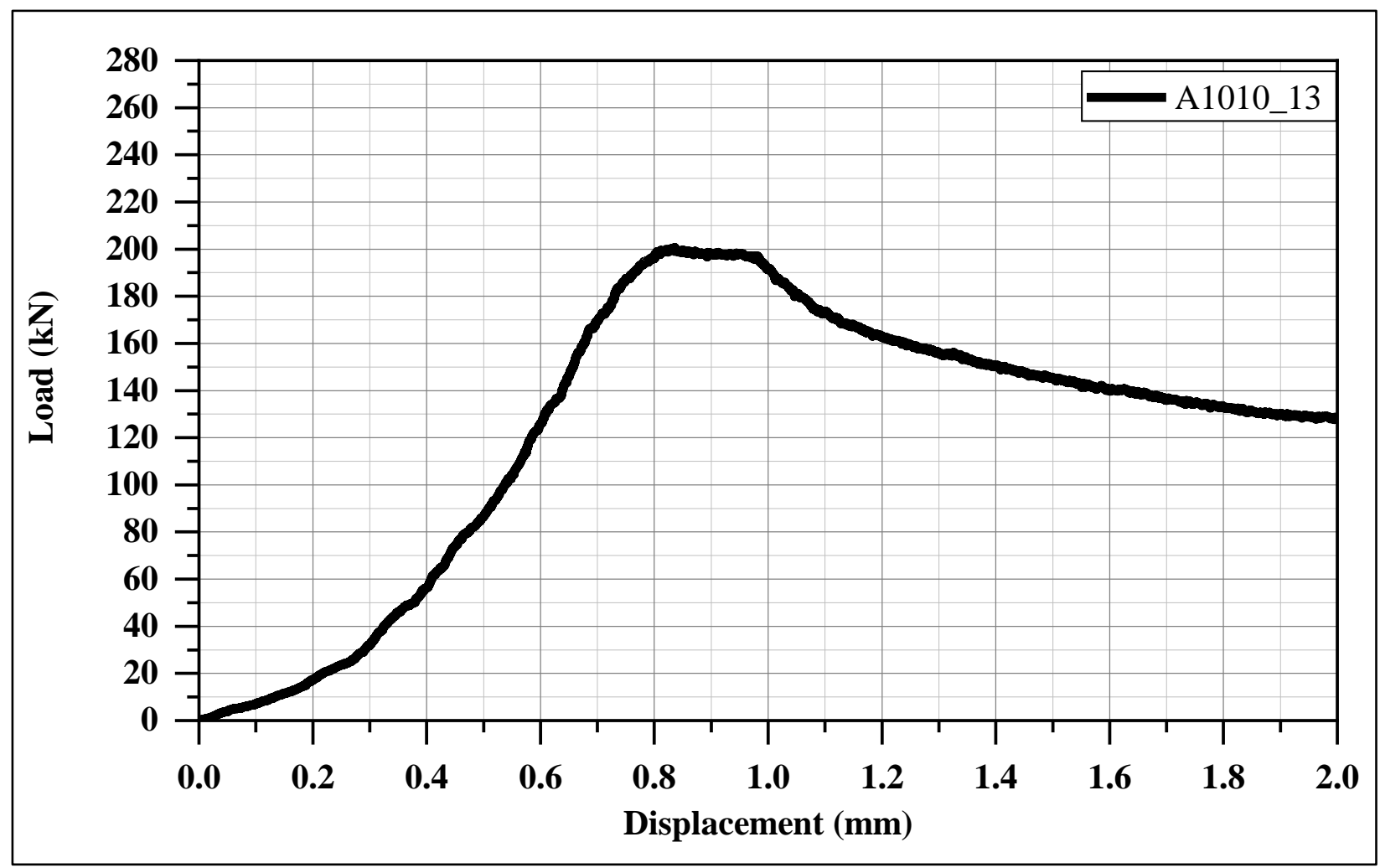

Figure A-23: Slip Load vs Displacement of Specimen A1010_13 Clamped with the Turn-ofNut Method

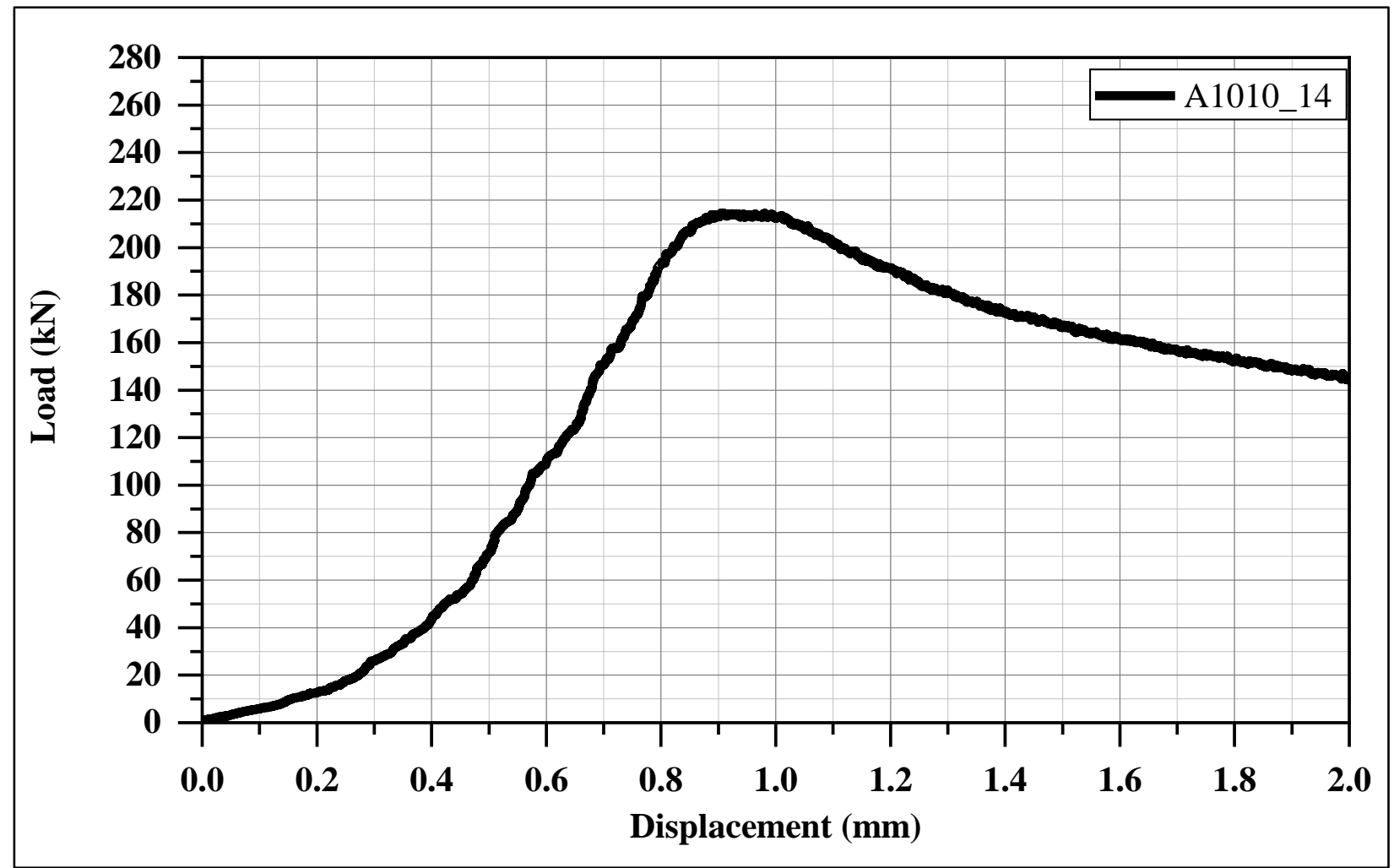

Figure A-24: Slip Load vs Displacement of Specimen A1010_14 Clmaped with the Turn-ofNut Method 


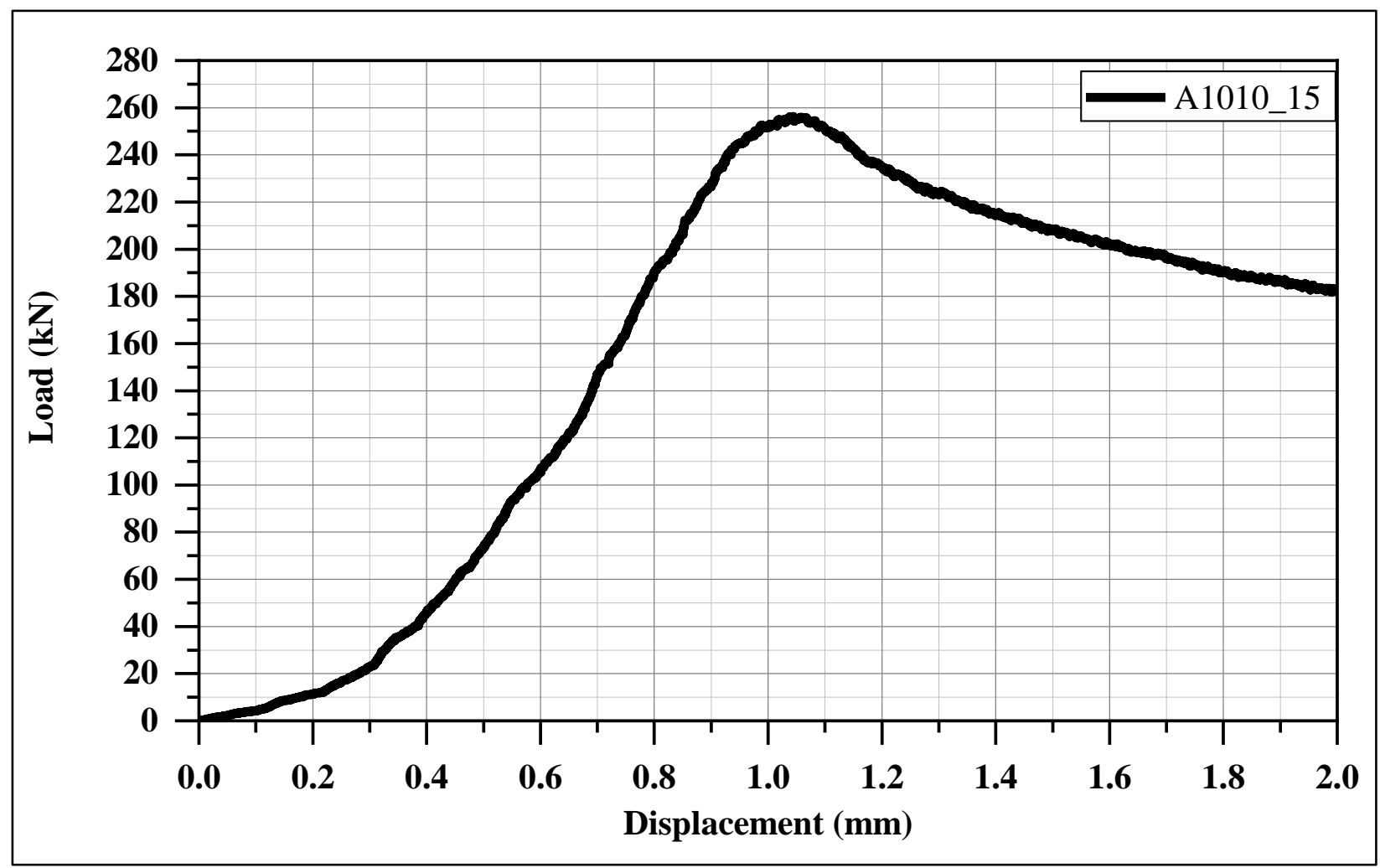

Figure A-25: Slip Load vs Displacement of Specimen A1010_15 Clamped with the Turn-ofNut Method 


\section{Appendix B - Slip Graphs of CSA G40.21 350W with Class B Surface Treatment}

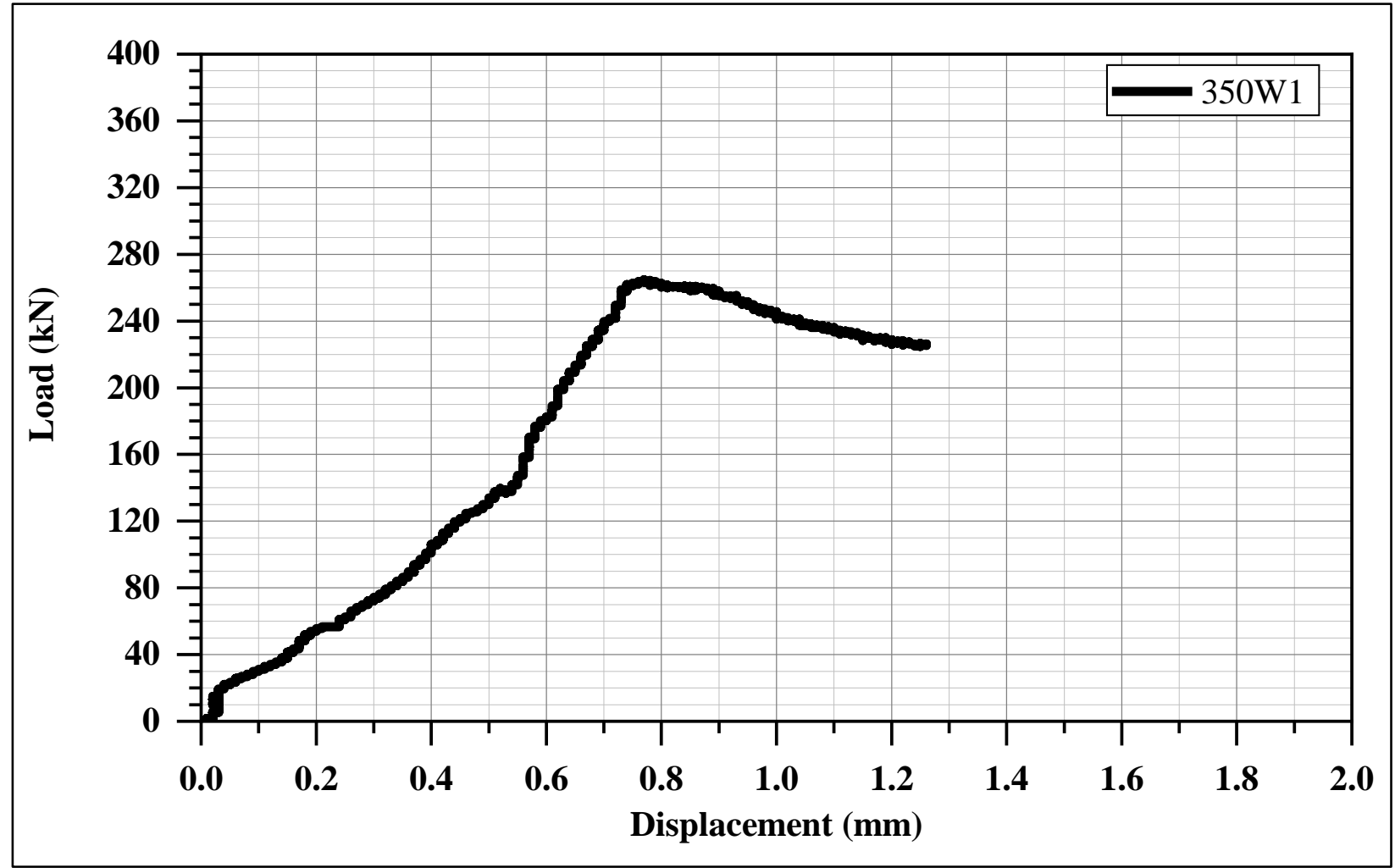

Figure B-1: Slip Load vs Displacement of Specimen 350W01

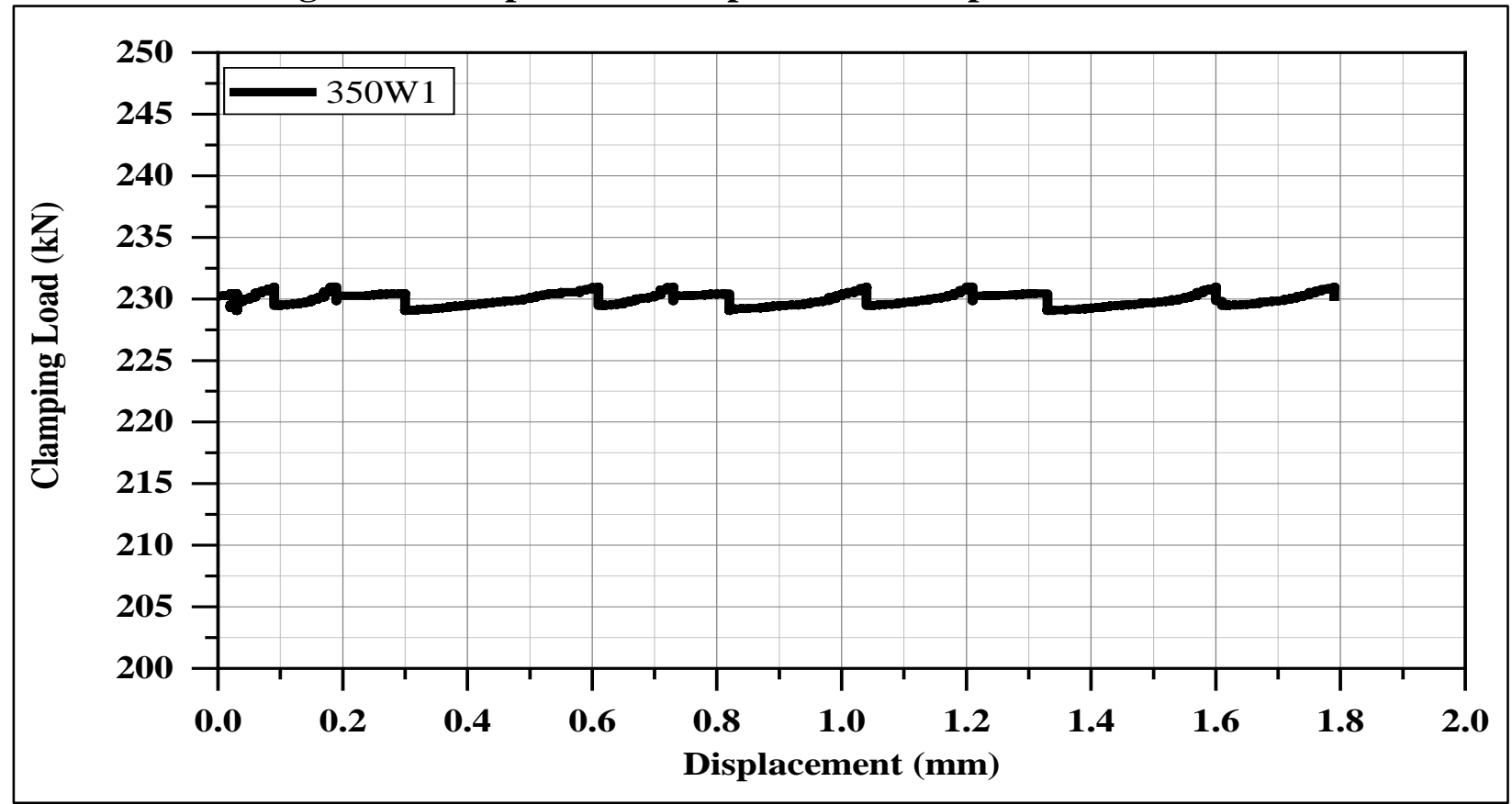

Figure B-2: Clamping Load of Specimen 350W01 


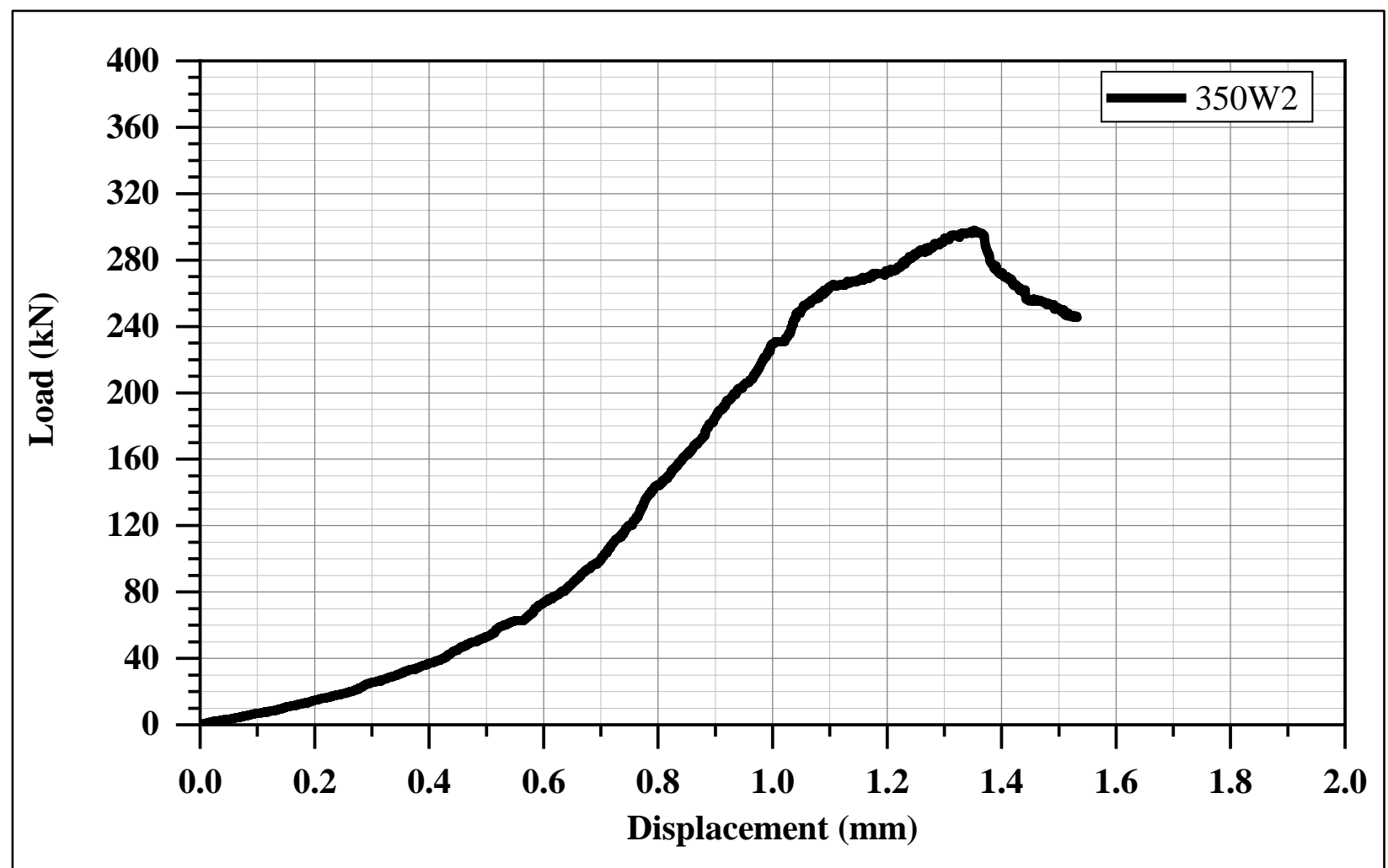

Figure B-3: Slip Load vs Displacement of Specimen 350W2

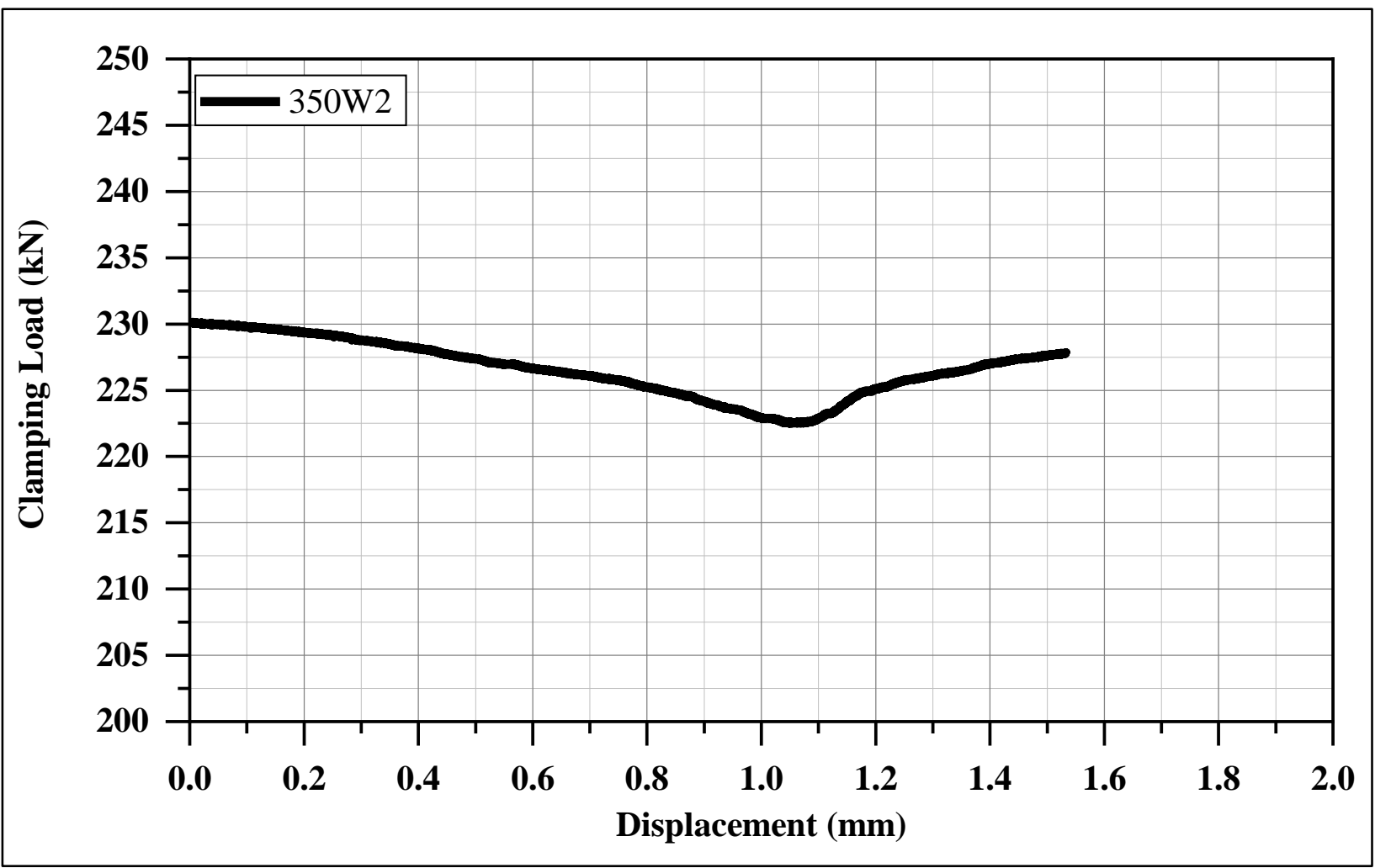

Figure B-4: Clamping Load of Specimen 350W2 


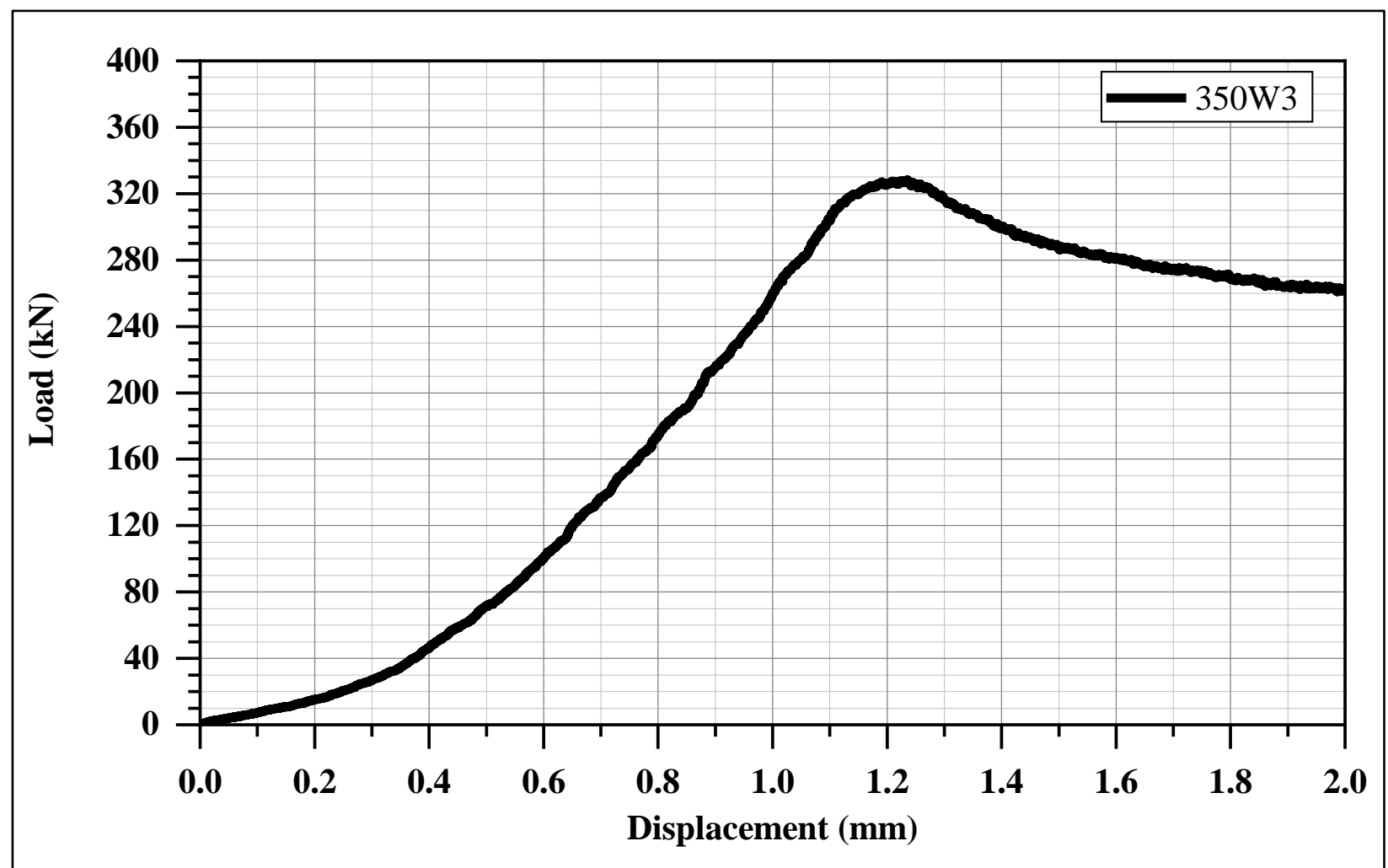

Figure B-5: Slip Load vs Displacement of Specimen 350W3

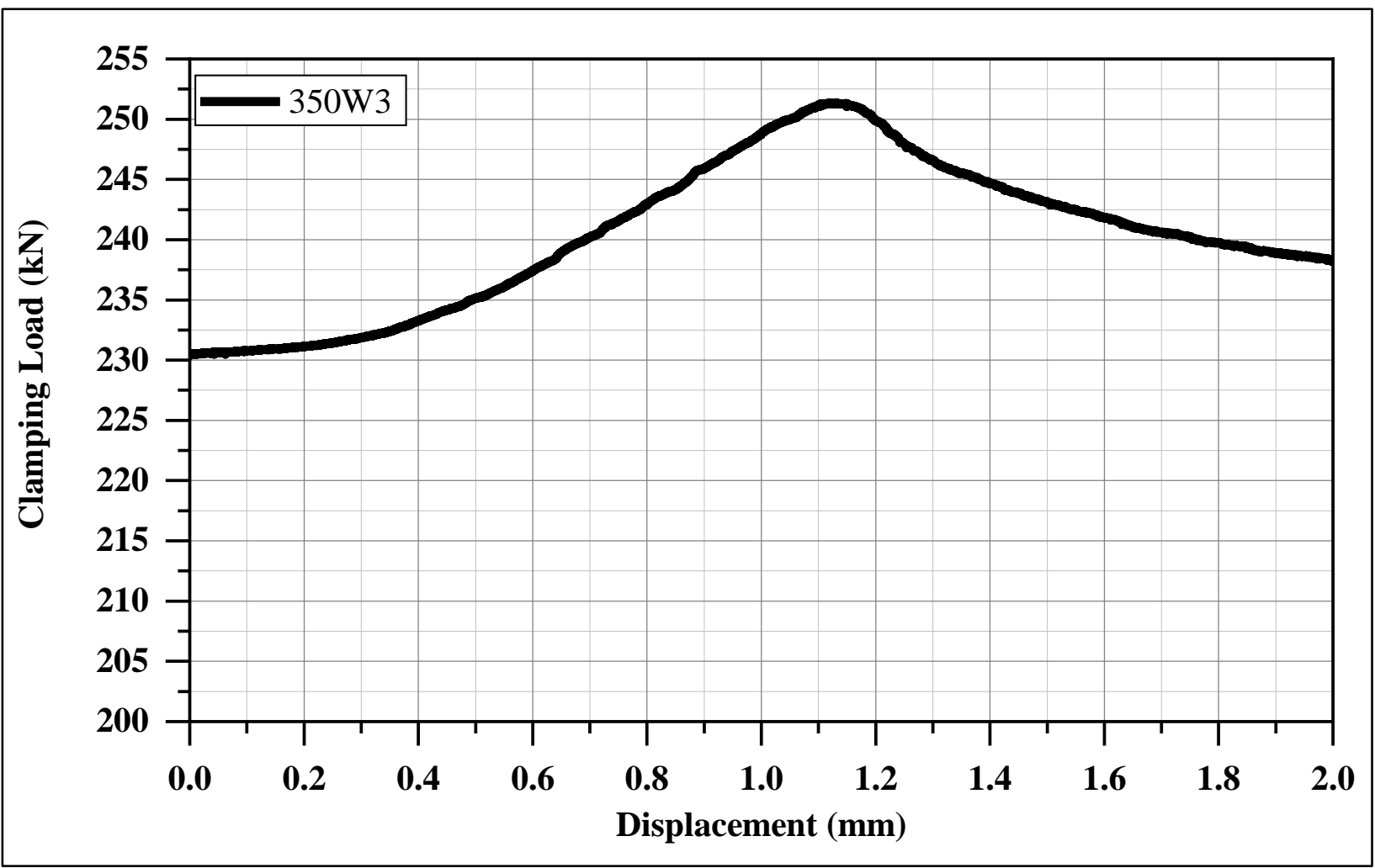

Figure B-6: Clamping Load of Specimen 350W3 


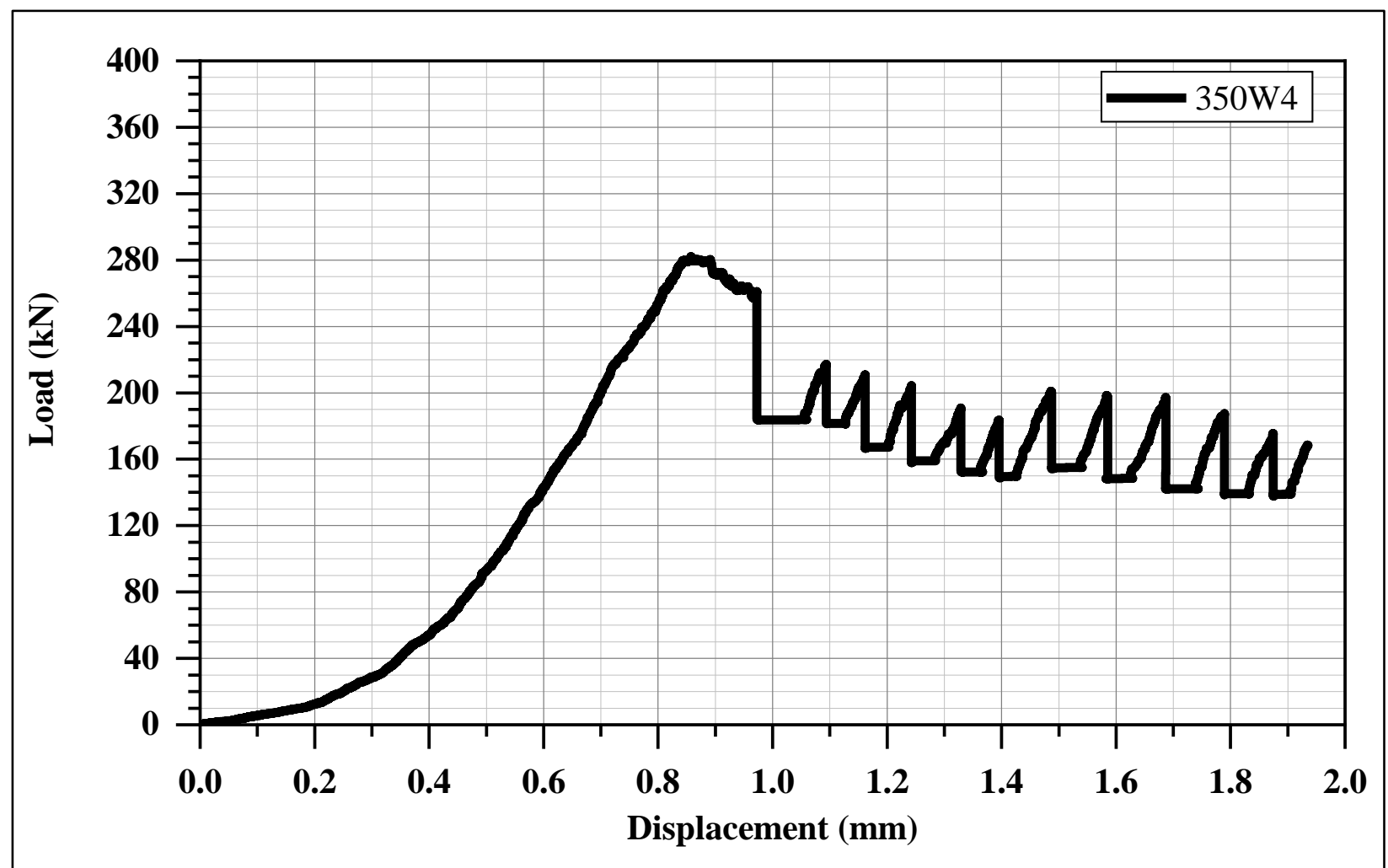

Figure B-7: Slip Load vs Displacement of Specimen 350W4

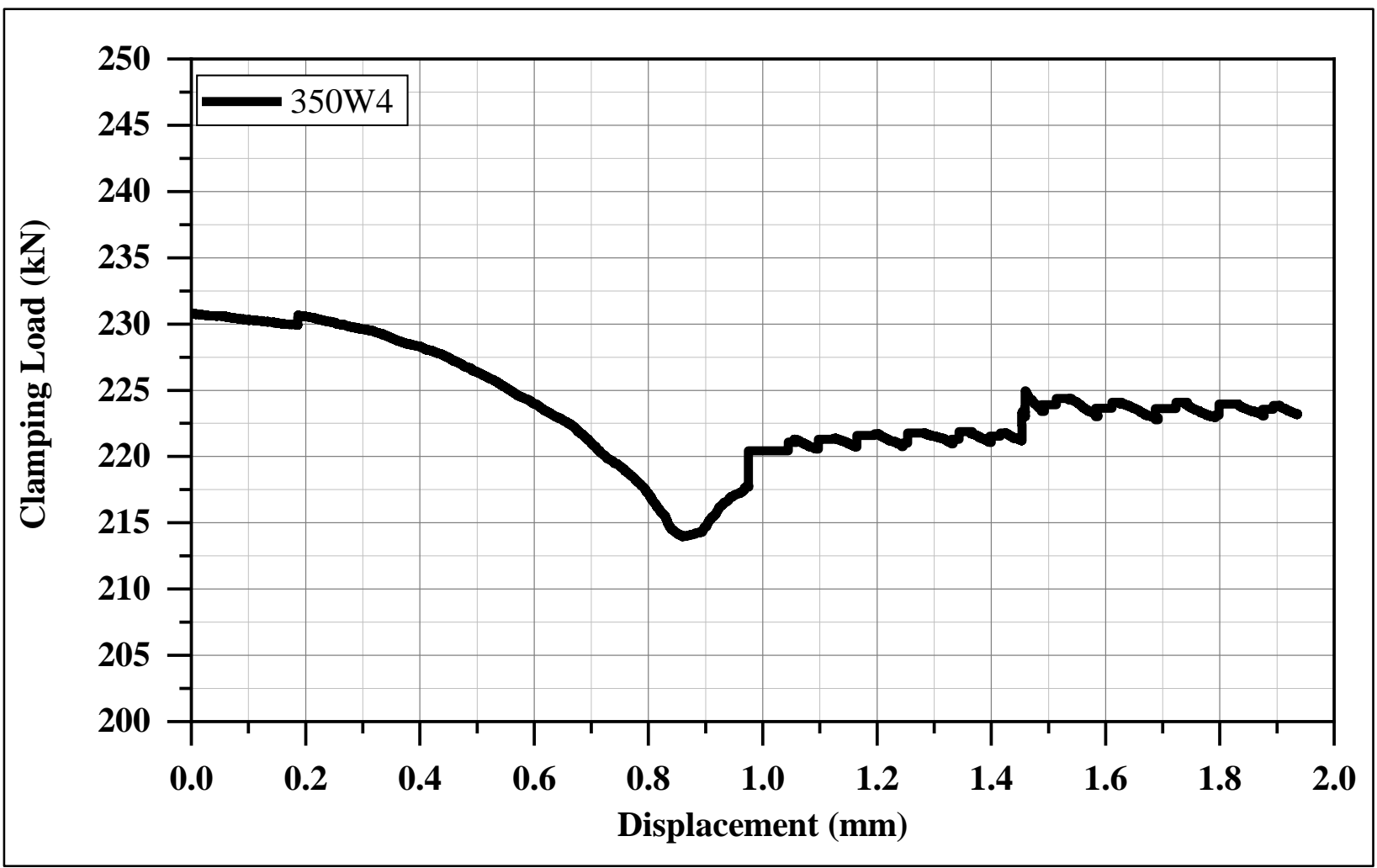

Figure B-8: Clamping Load of Specimen 350W4 


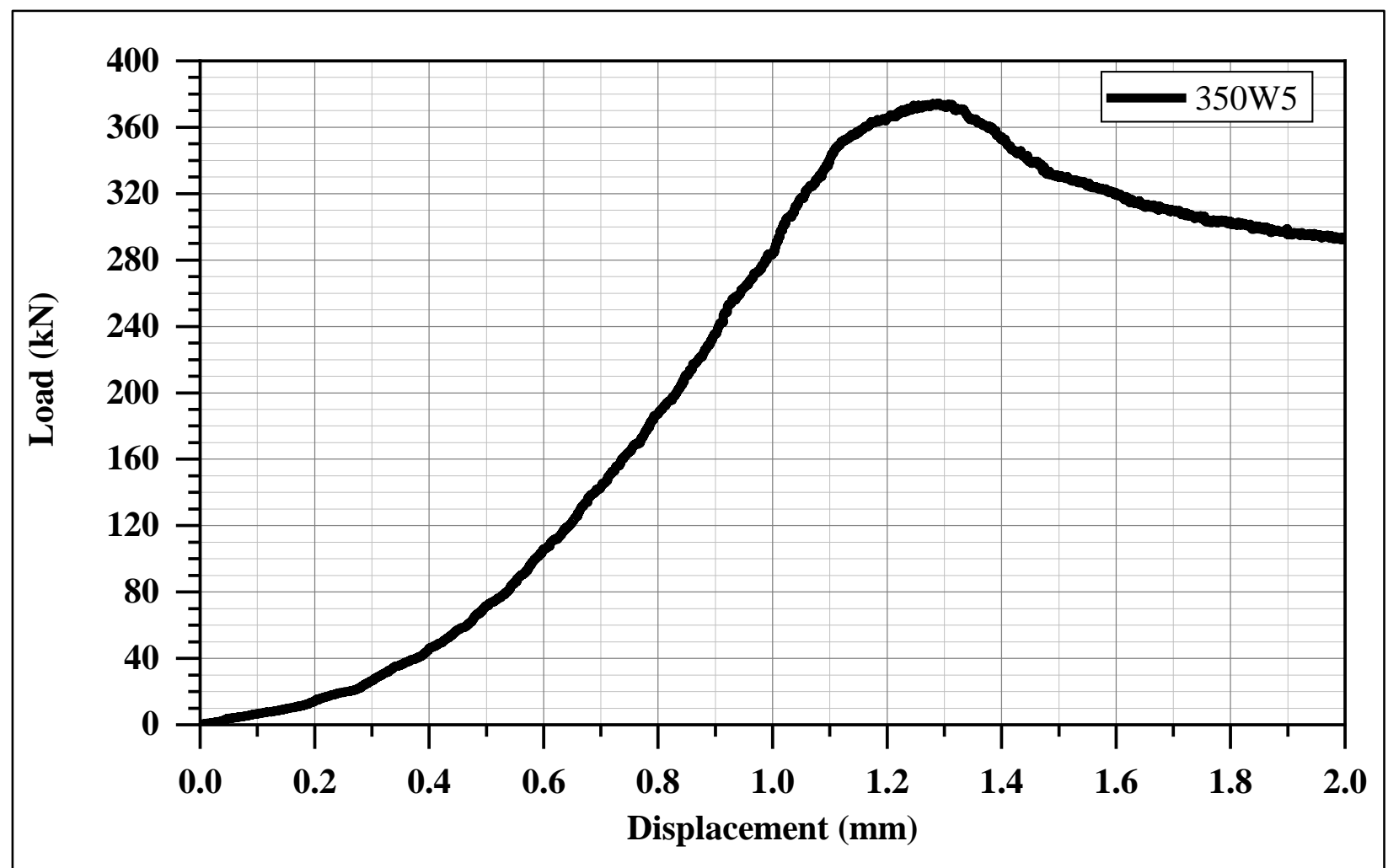

Figure B-9: Slip Load vs Displacement of Specimen 350W5

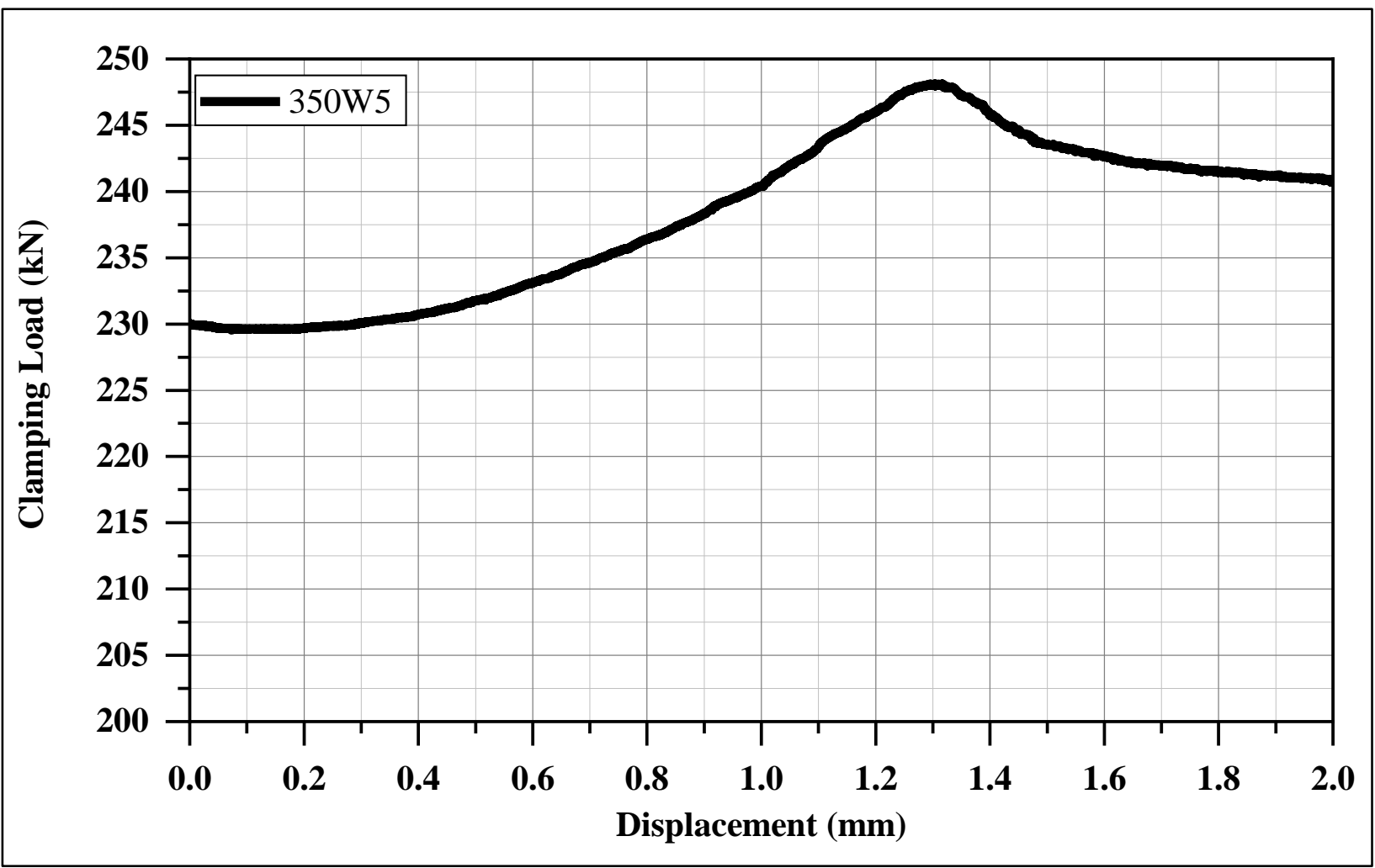

Figure B-10: Clamping Load of Specimen 350W5 


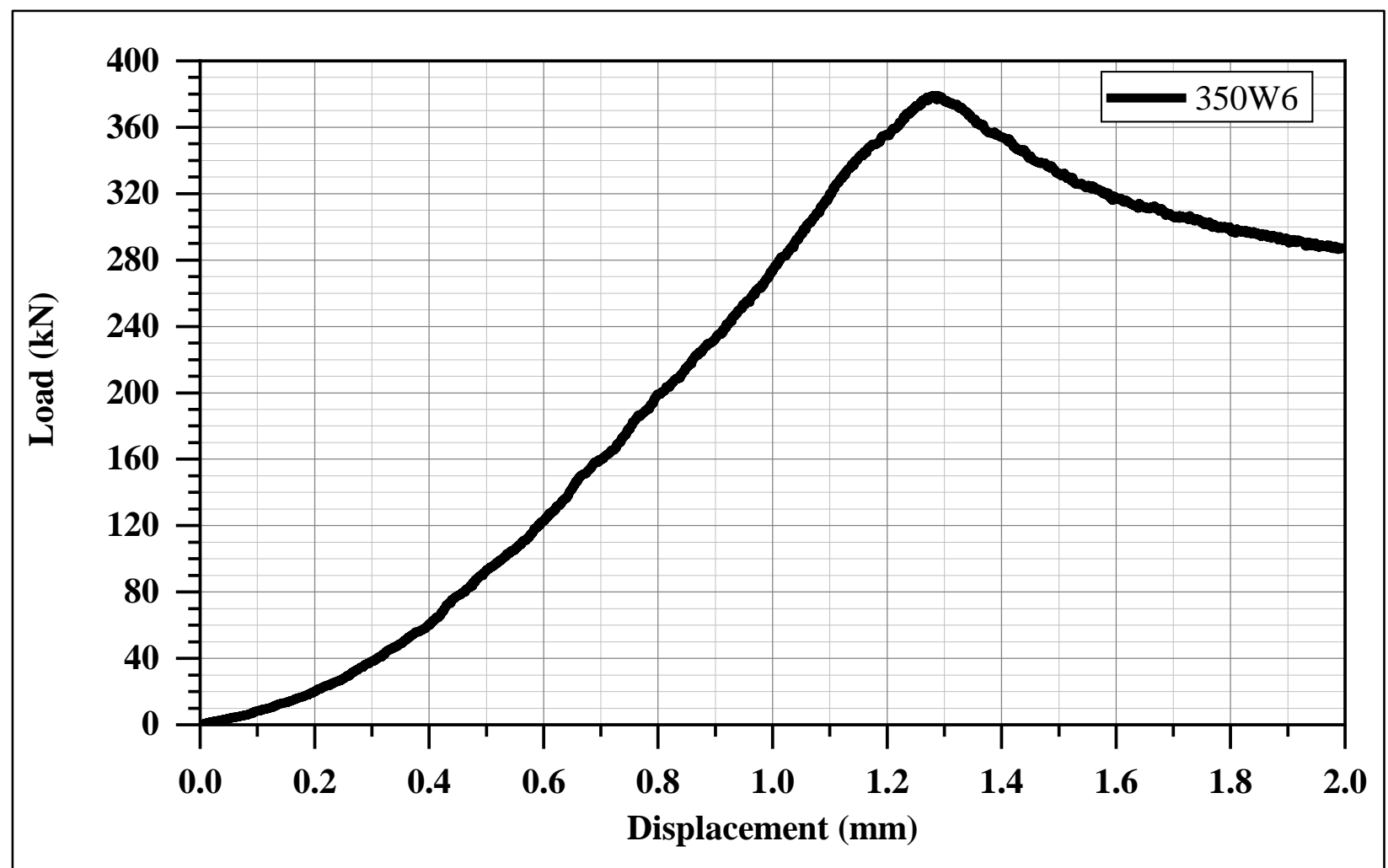

Figure B-11: Slip Load vs Displacement of Specimen 350W6

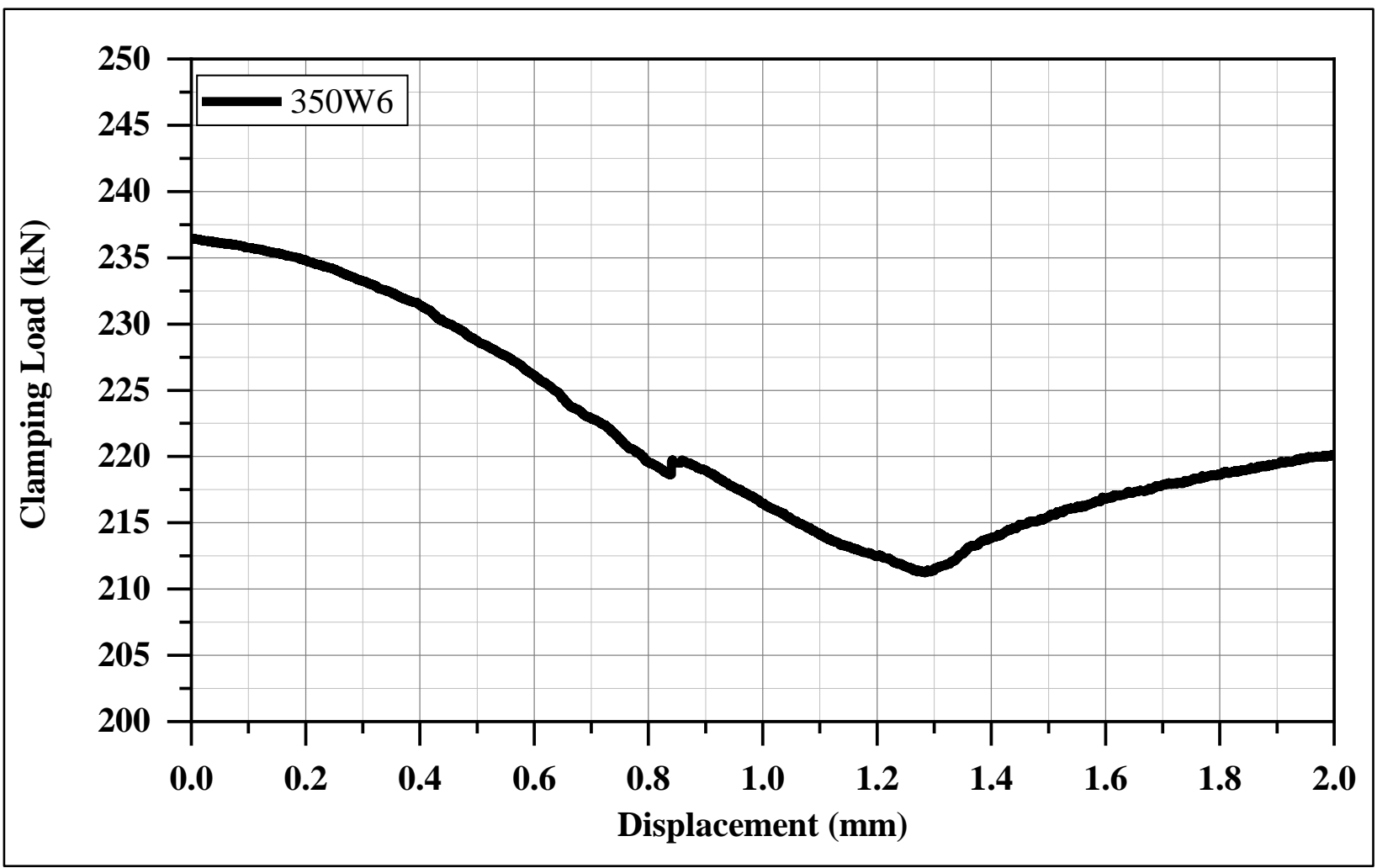

Figure B-12: Clamping Load of Specimen 350W6 


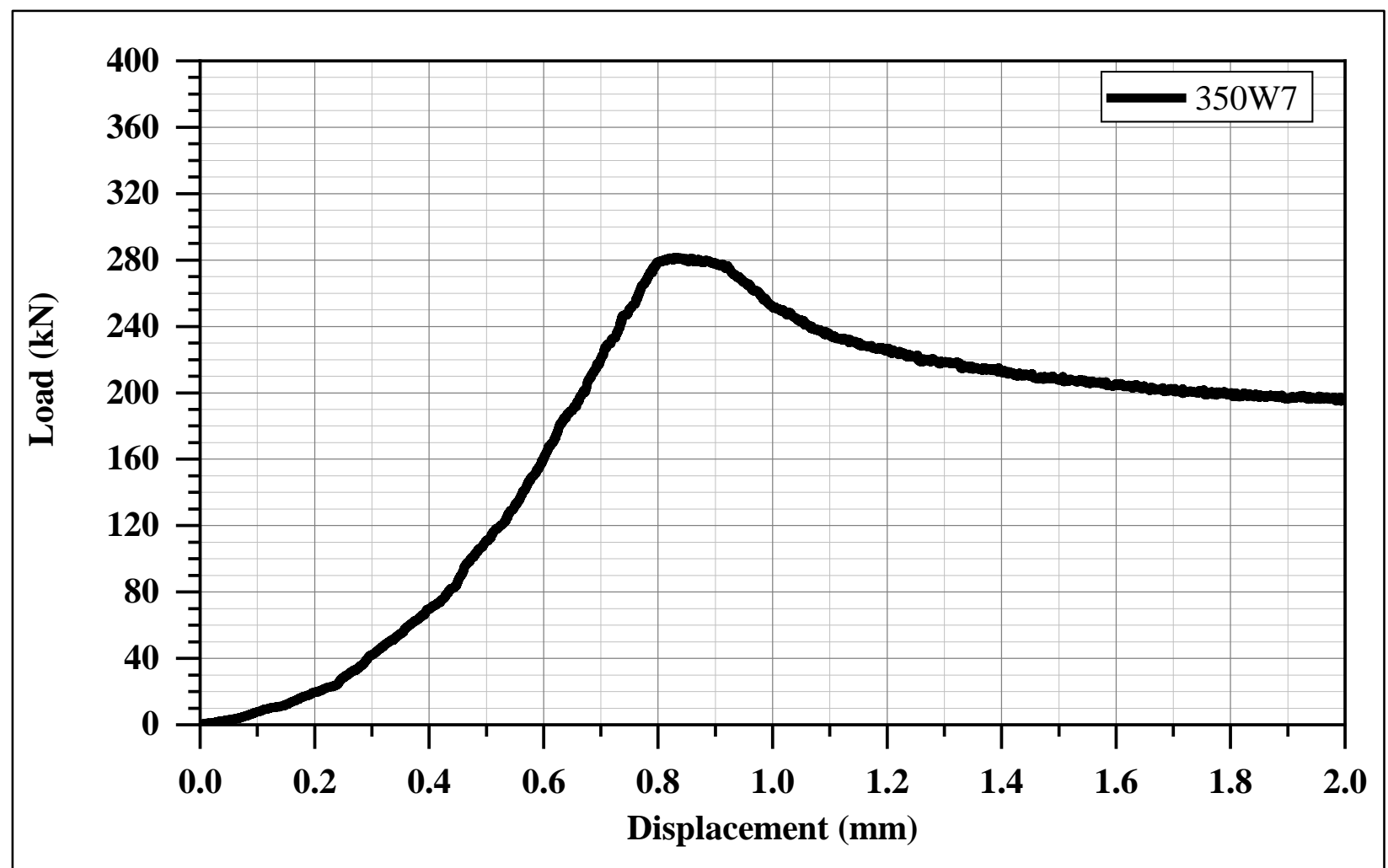

Figure B-13: Slip Load vs Displacement of Specimen 350W7

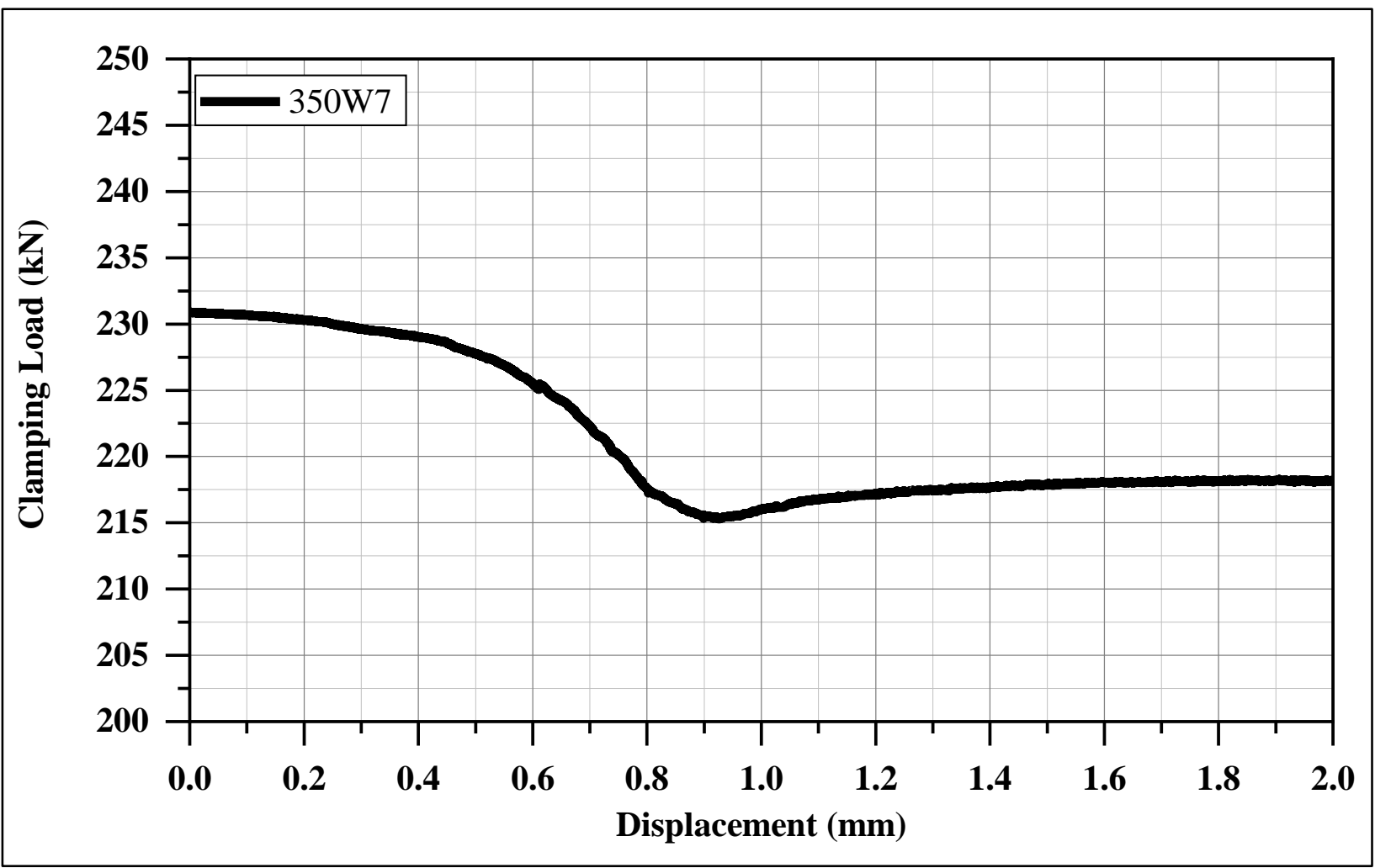

Figure B-14: Clamping Load of Specimen 350W7 


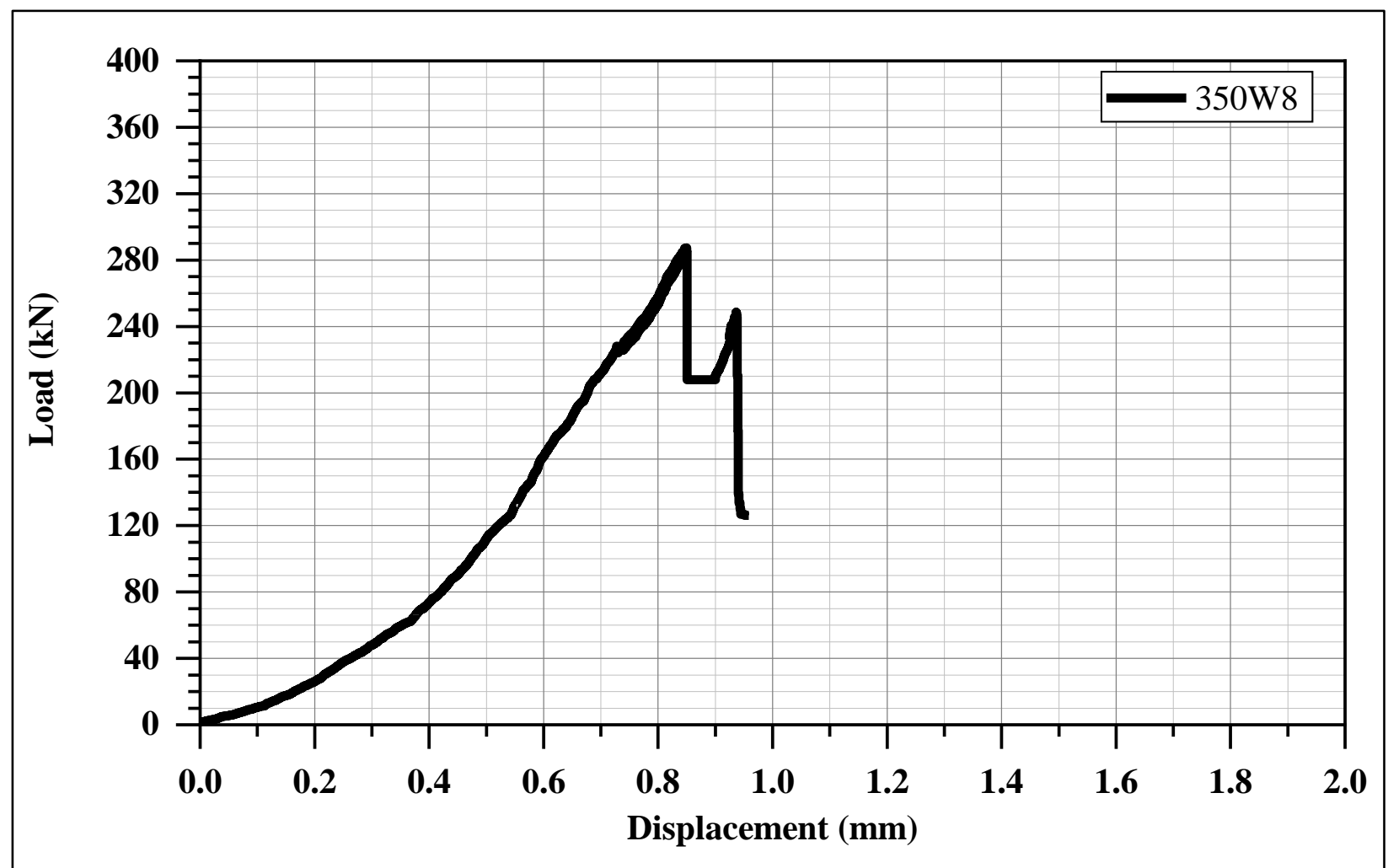

Figure B-15: Slip Load vs Displacement of Specimen 350W8

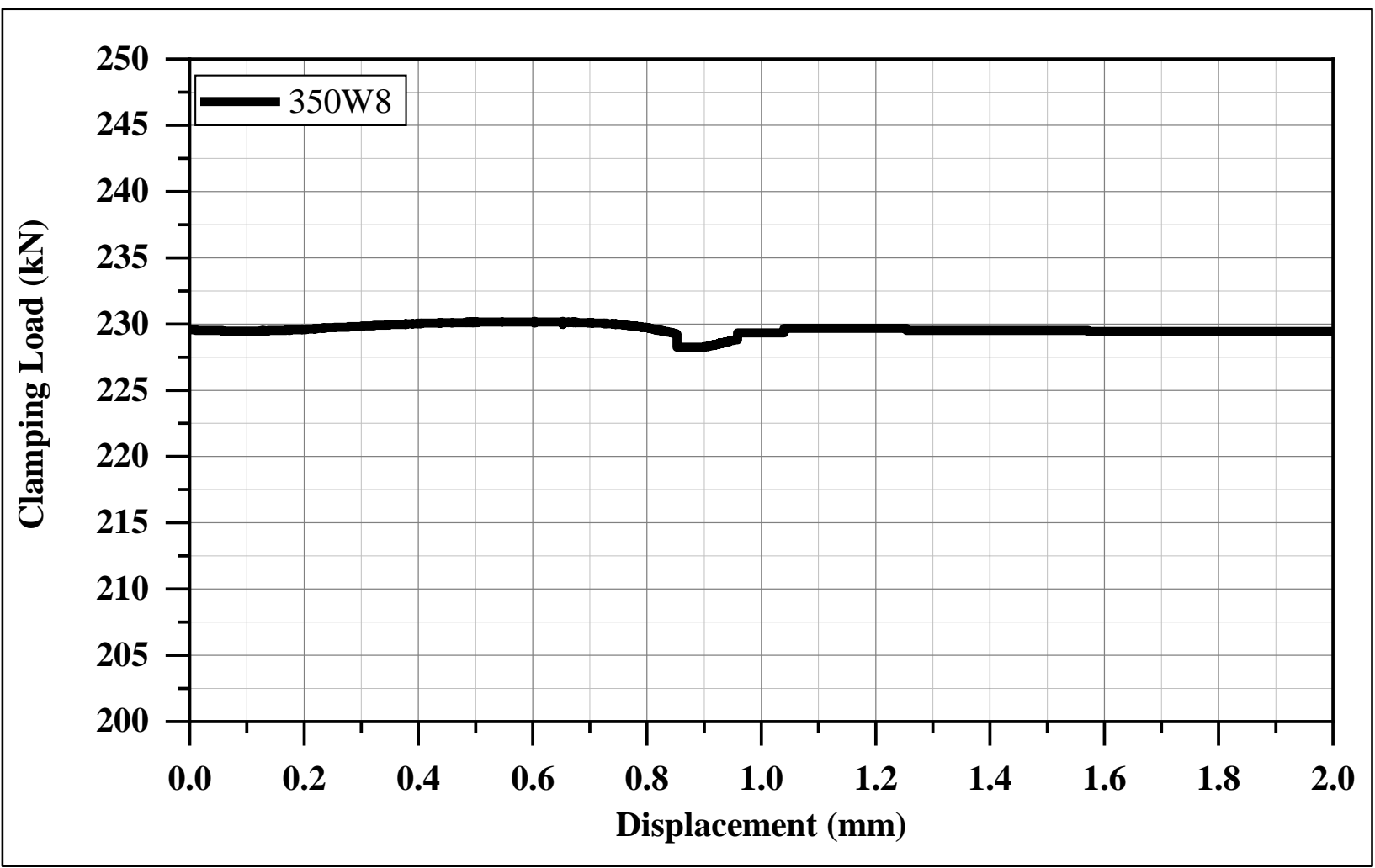

Figure B-16: Clamping Load of Specimen 350W8 


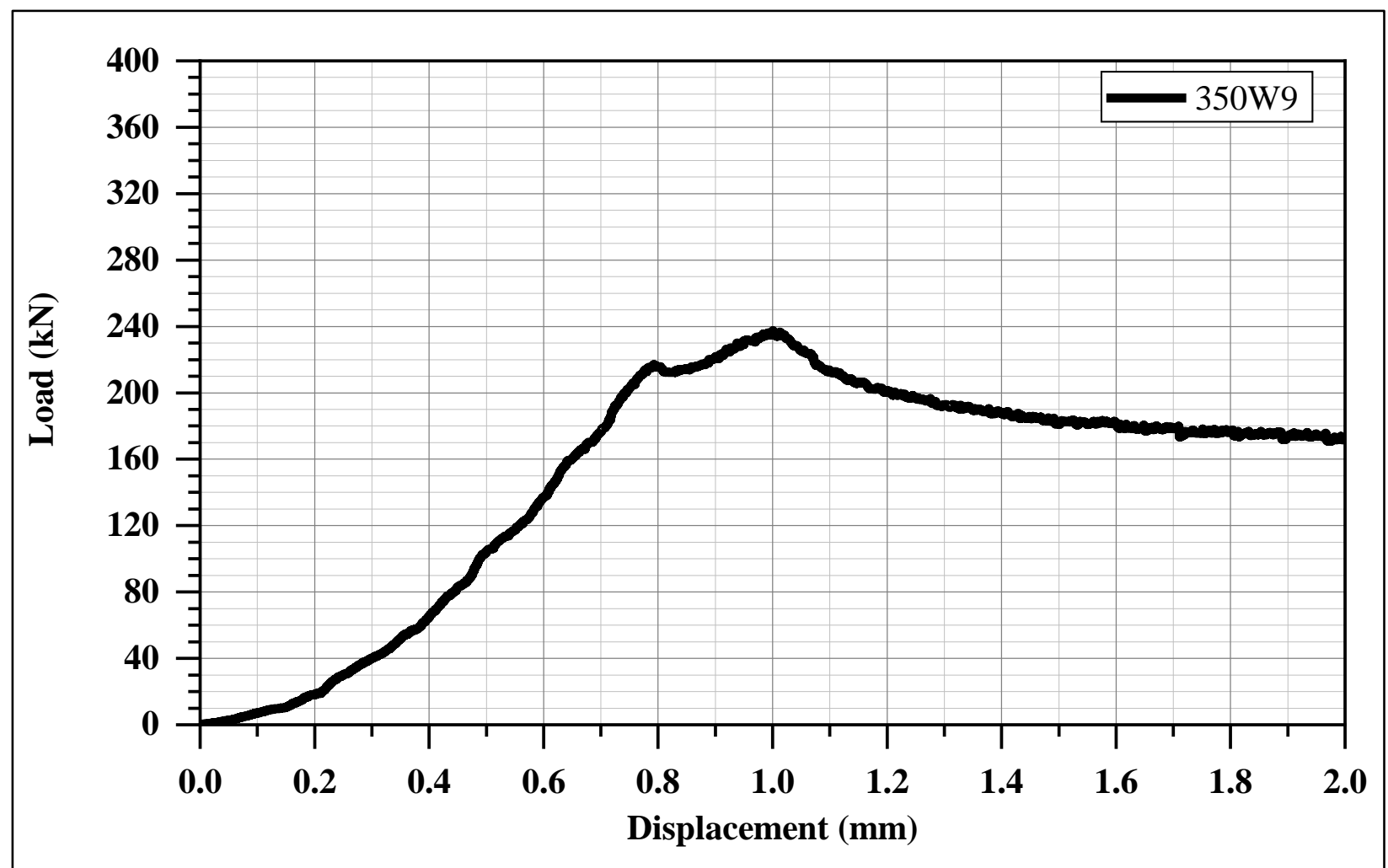

Figure B-17: Slip Load vs Displacement of Specimen 350W9

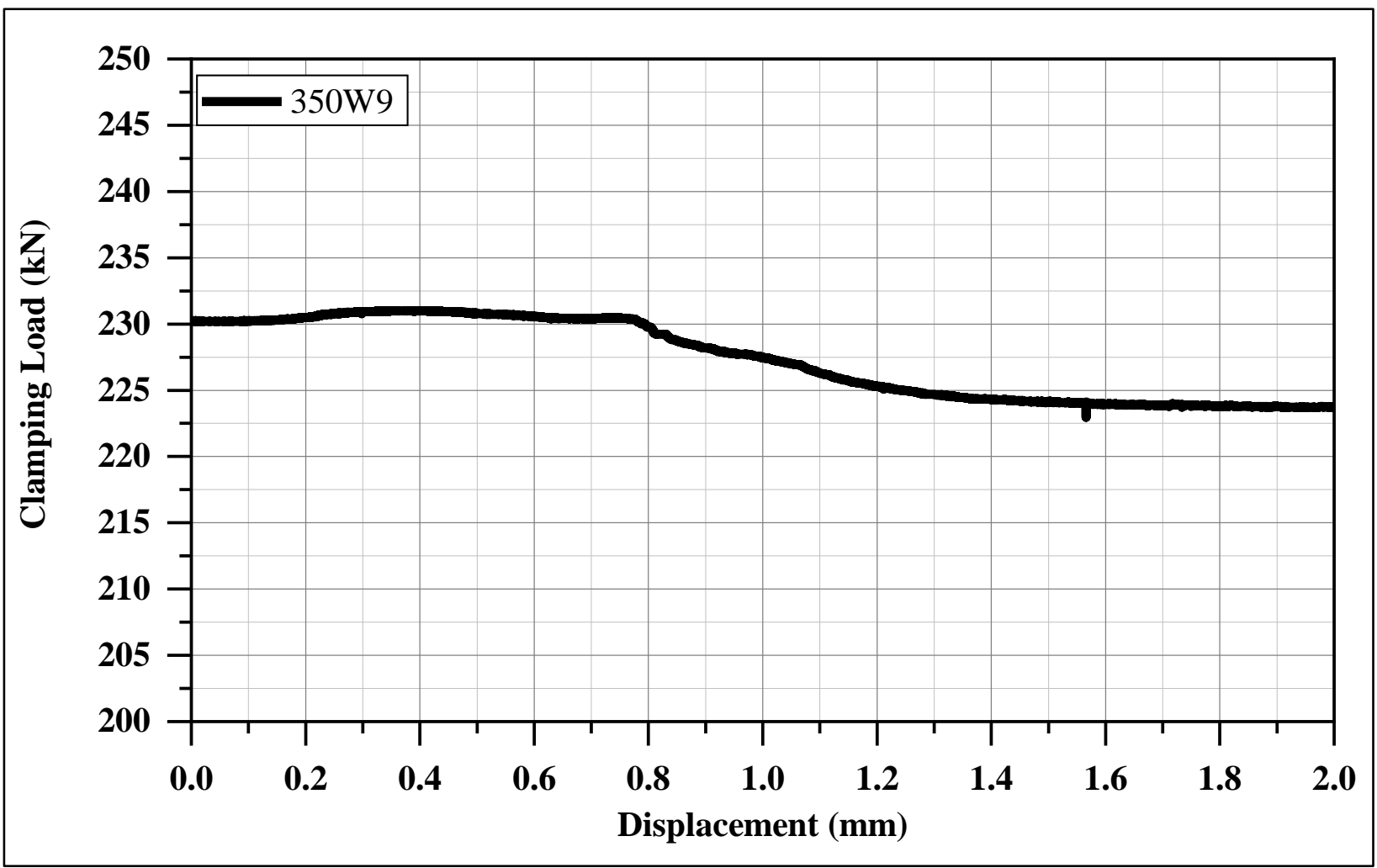

Figure B-18: Clamping Load of Specimen 350W9 


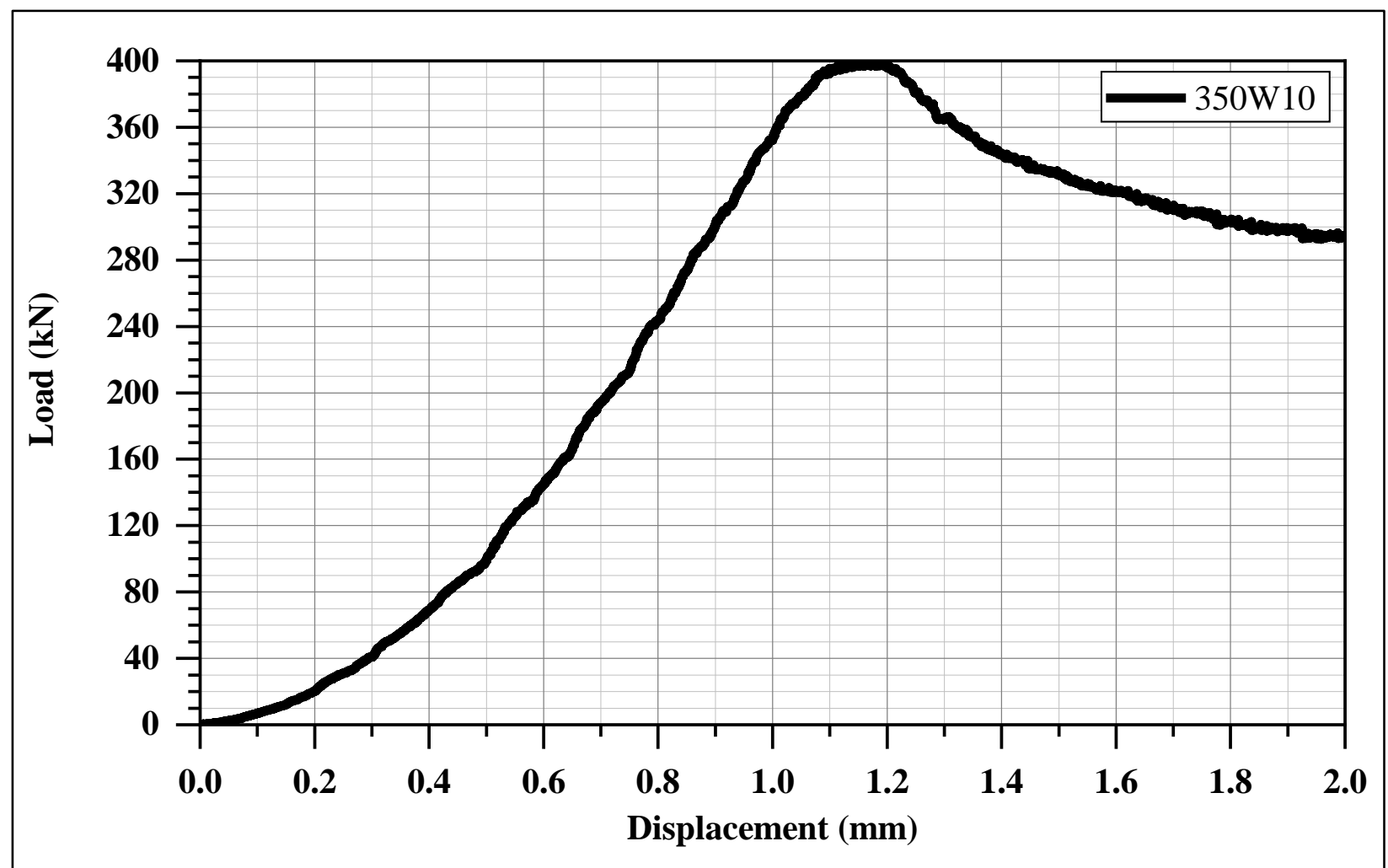

Figure B-19: Slip Load vs Displacement of Specimen 350W10

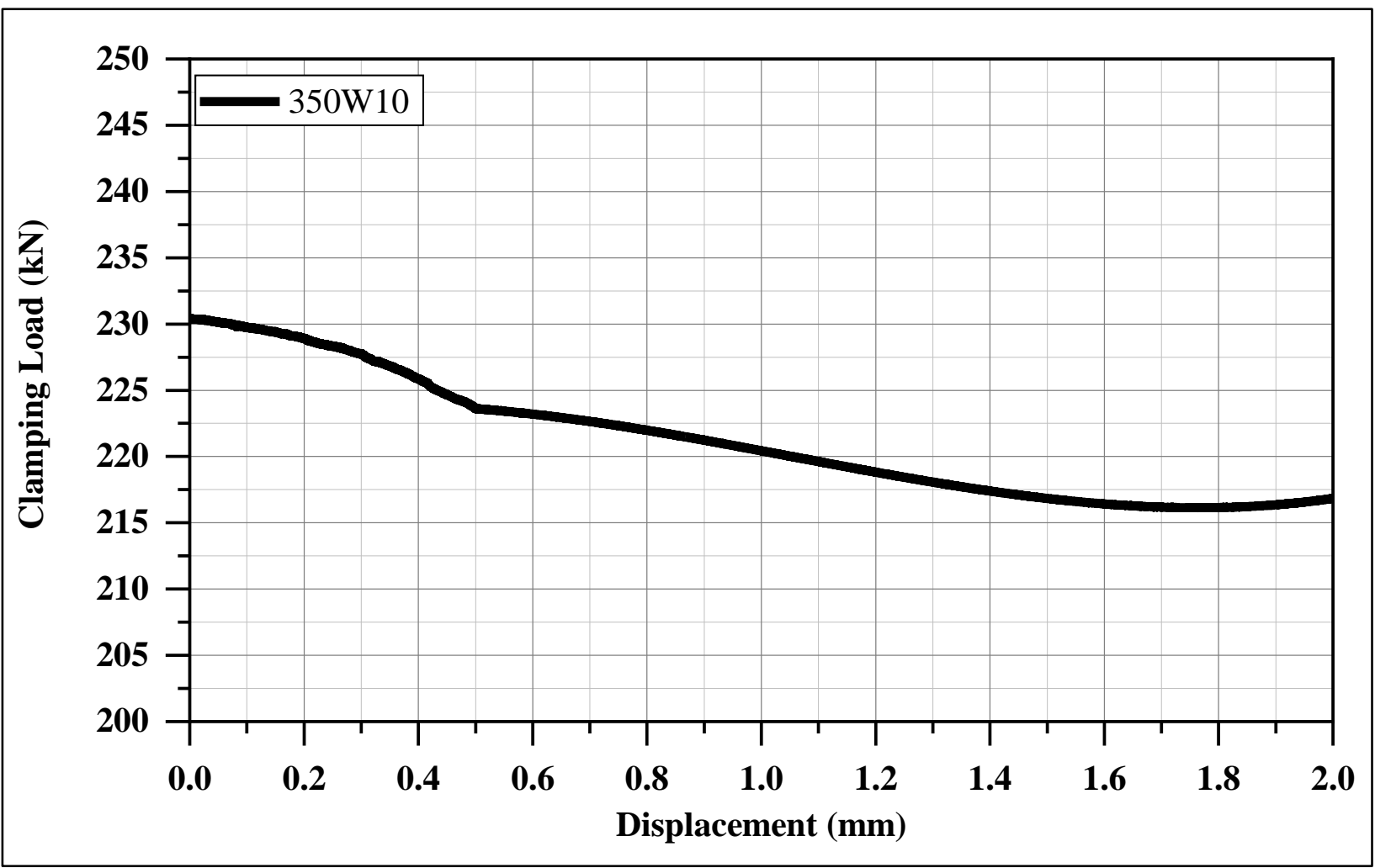

Figure B-20: Clamping Load of Specimen 350W10 


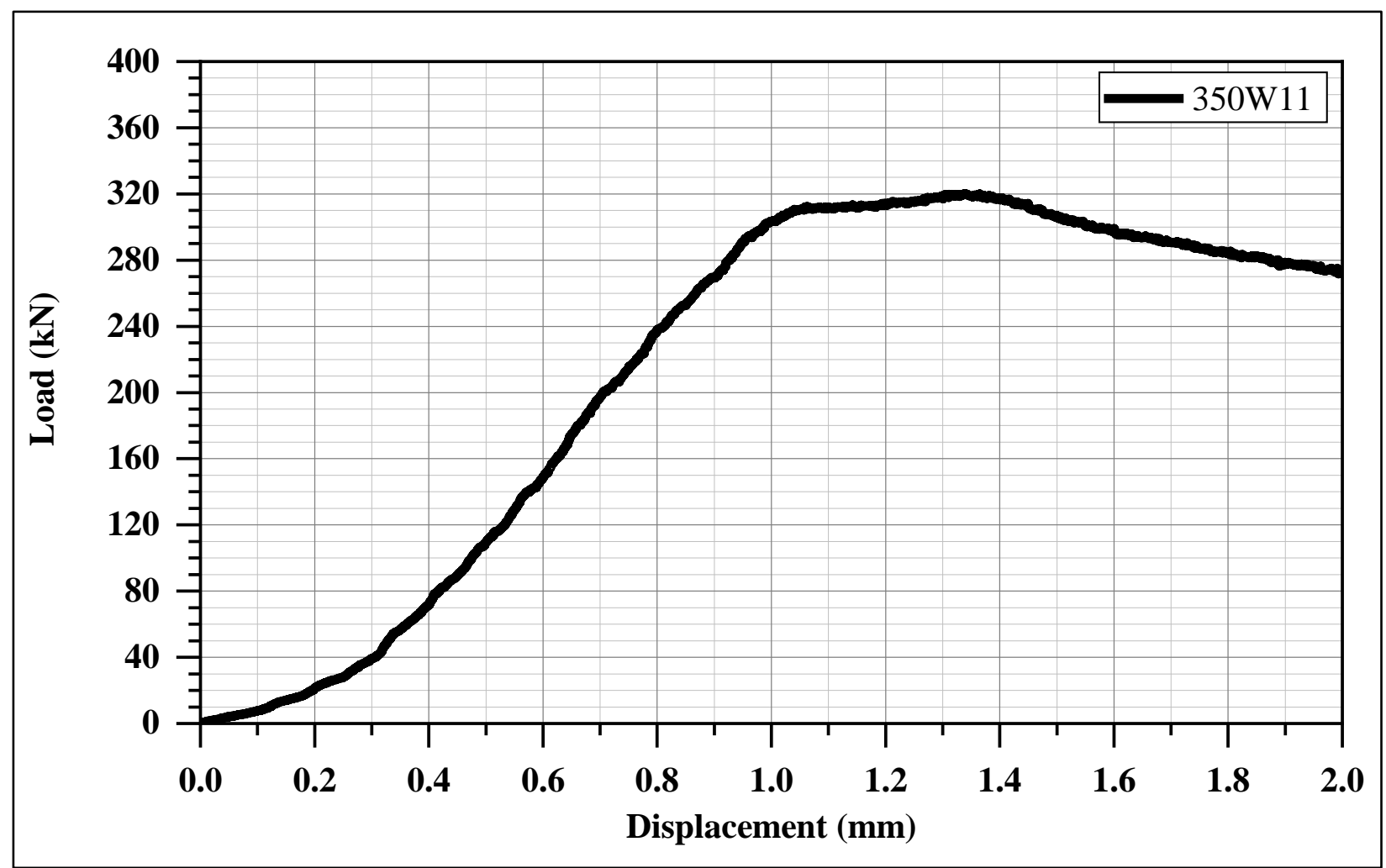

Figure B-21: Slip Load vs Displacement of Specimen 350W11 Clamped with the Turn-ofNut Method

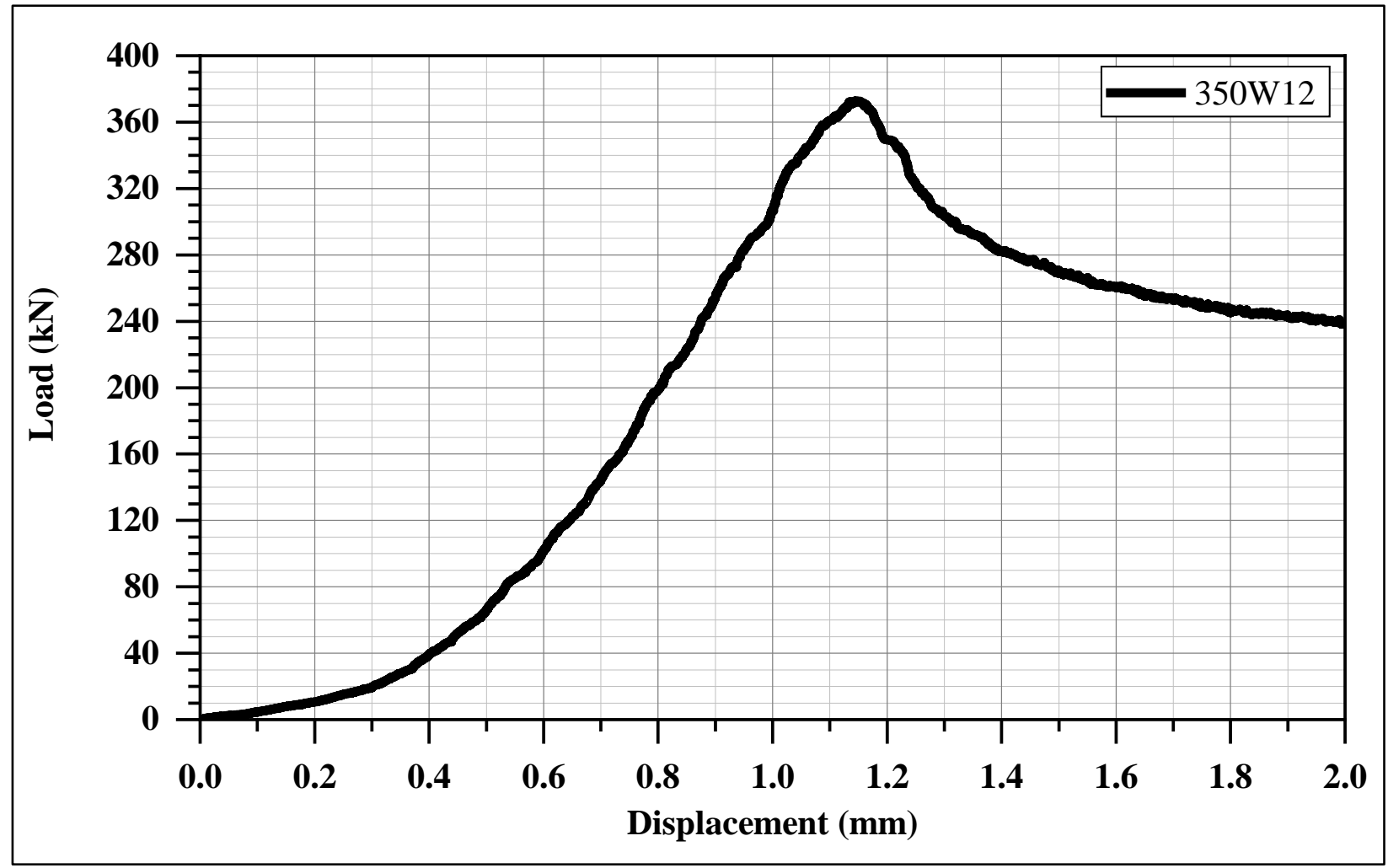

Figure B-22: Slip Load vs Displacement of Specimen 350W12 Clamped with the Turn-ofNut Method 


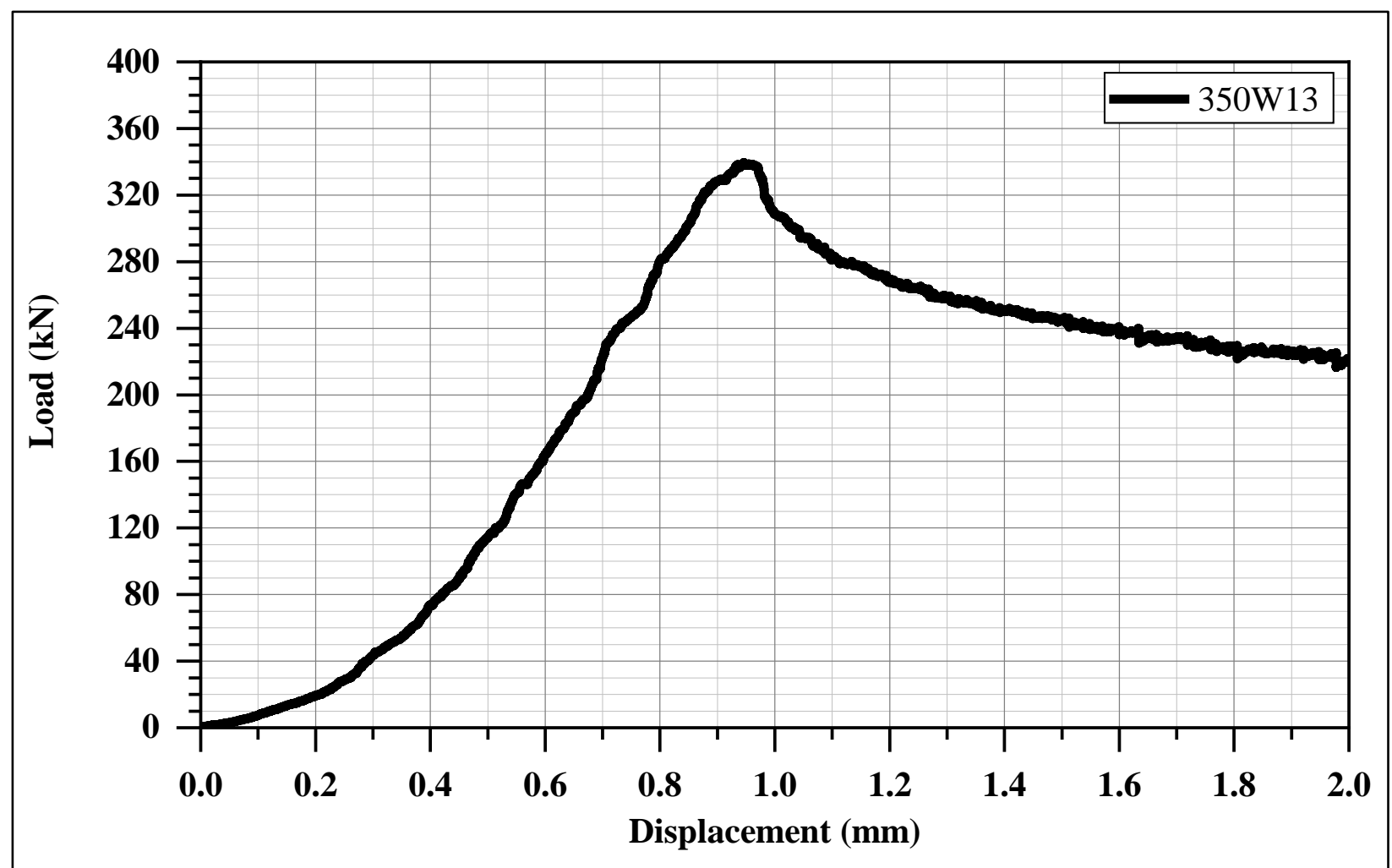

Figure B-23: Slip Load vs Displacement of Specimen 350W13 Clamped with the Turn-ofNut Method

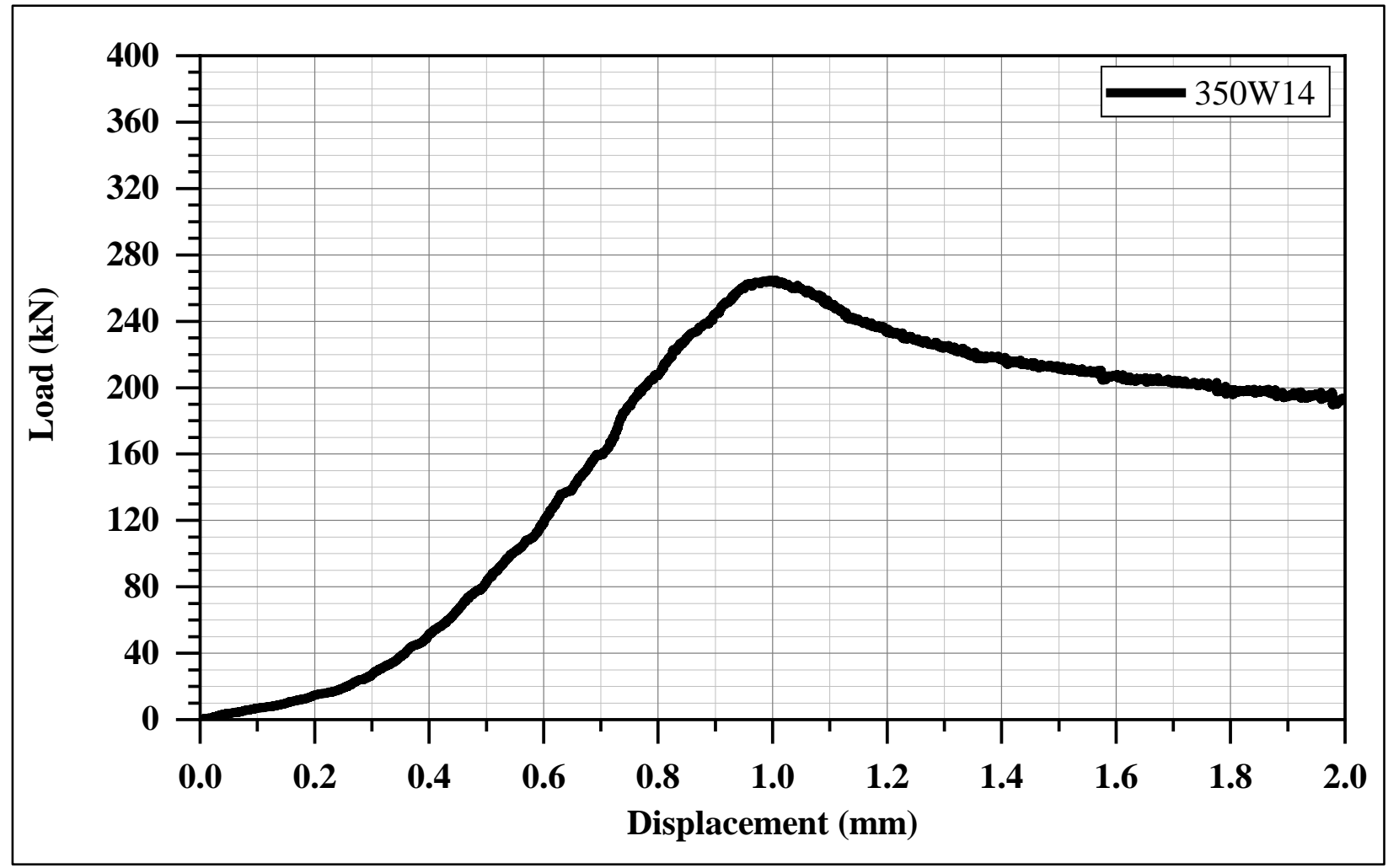

Figure B-24: Slip Load vs Displacement of Specimen 350W14 Clamped with the Turn-ofNut Method 


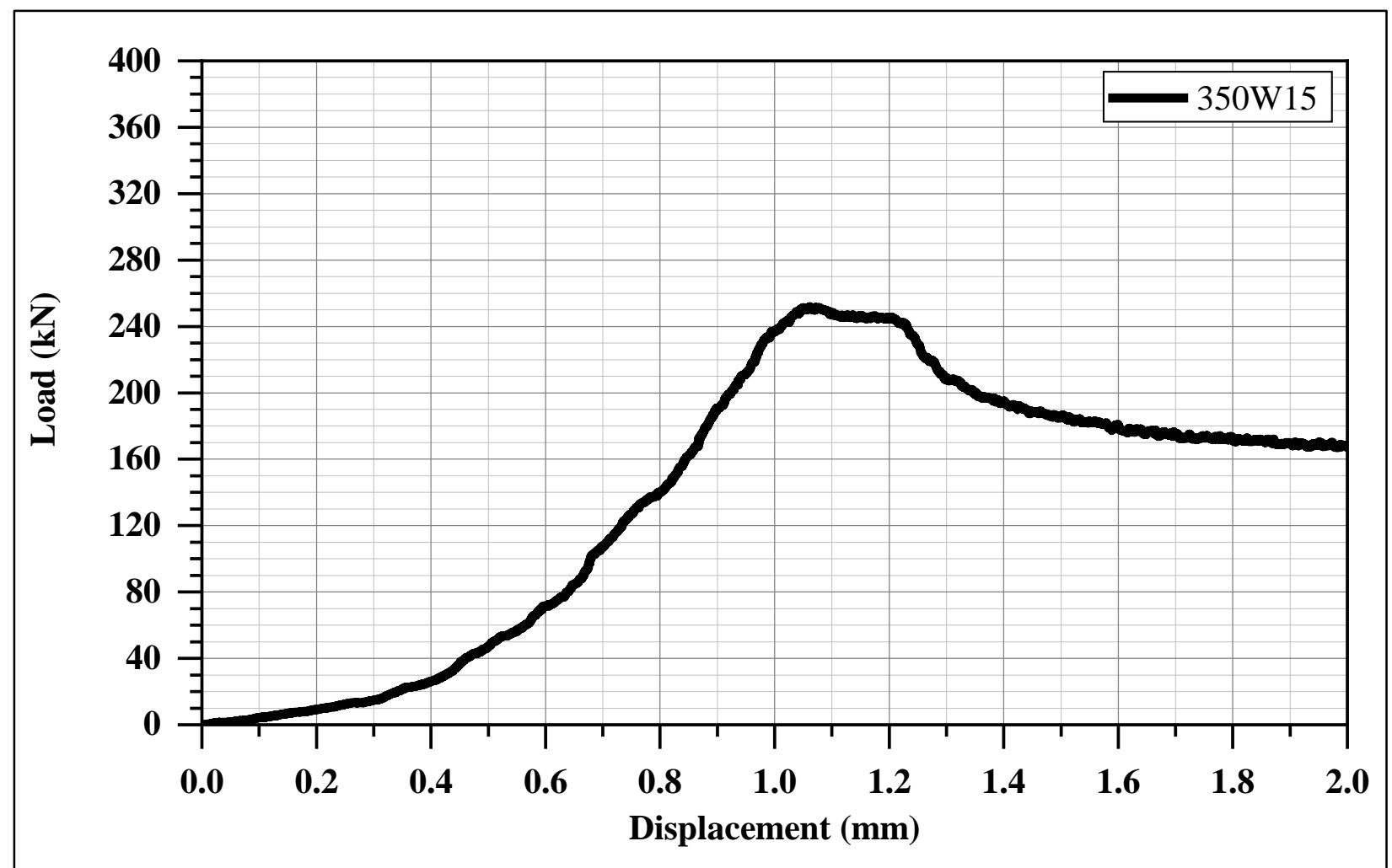

Figure B-25: Slip Load vs Displacement of Specimen 350W15 Clamped with the Turn-ofNut Method 


\section{Appendix C - Slip Graphs of CSA G40.21 350W Steel with Class A Surface Treatment}

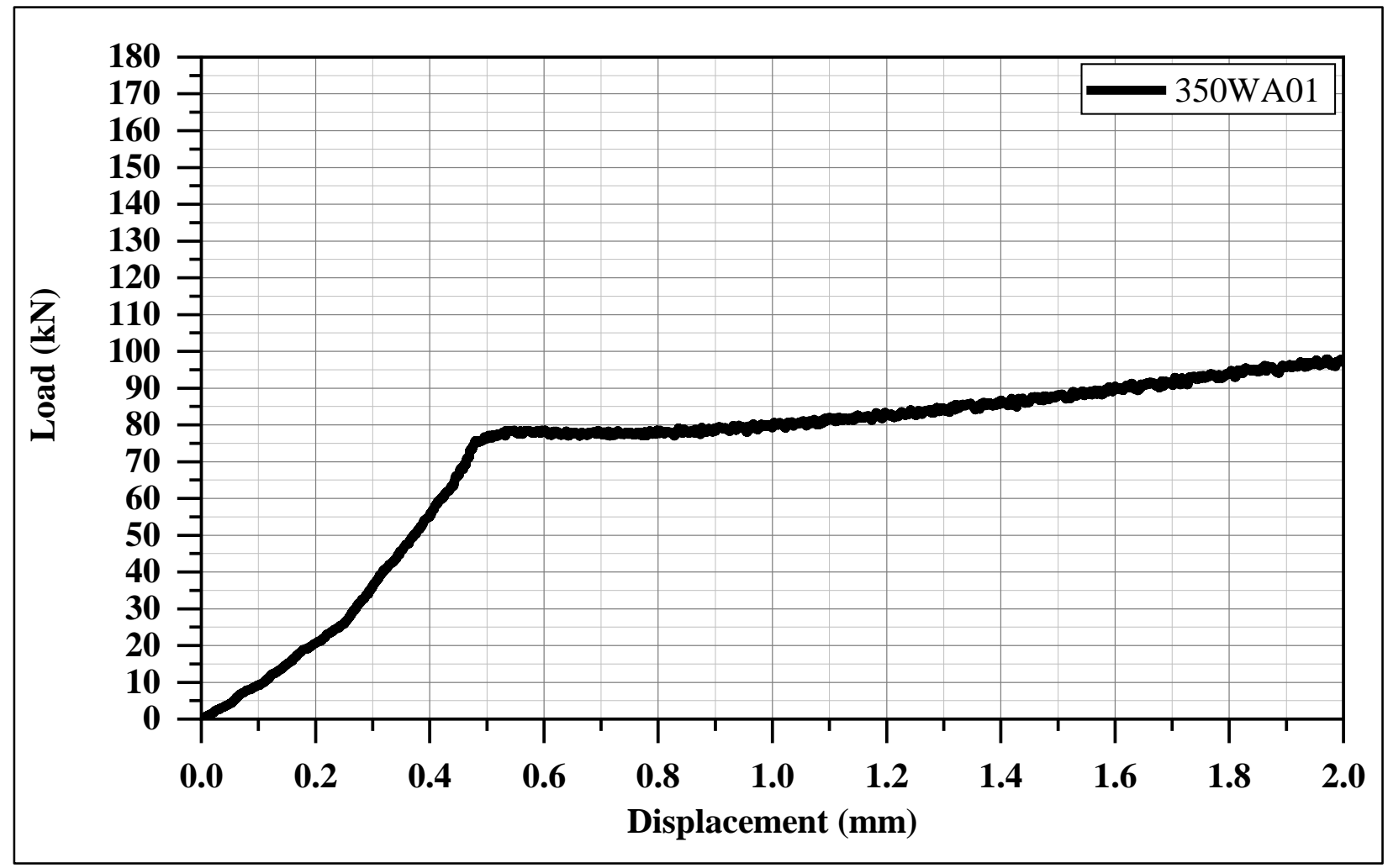

Figure C-1: Slip Load vs Displacement of Specimen 350WA01 with Class A Surface

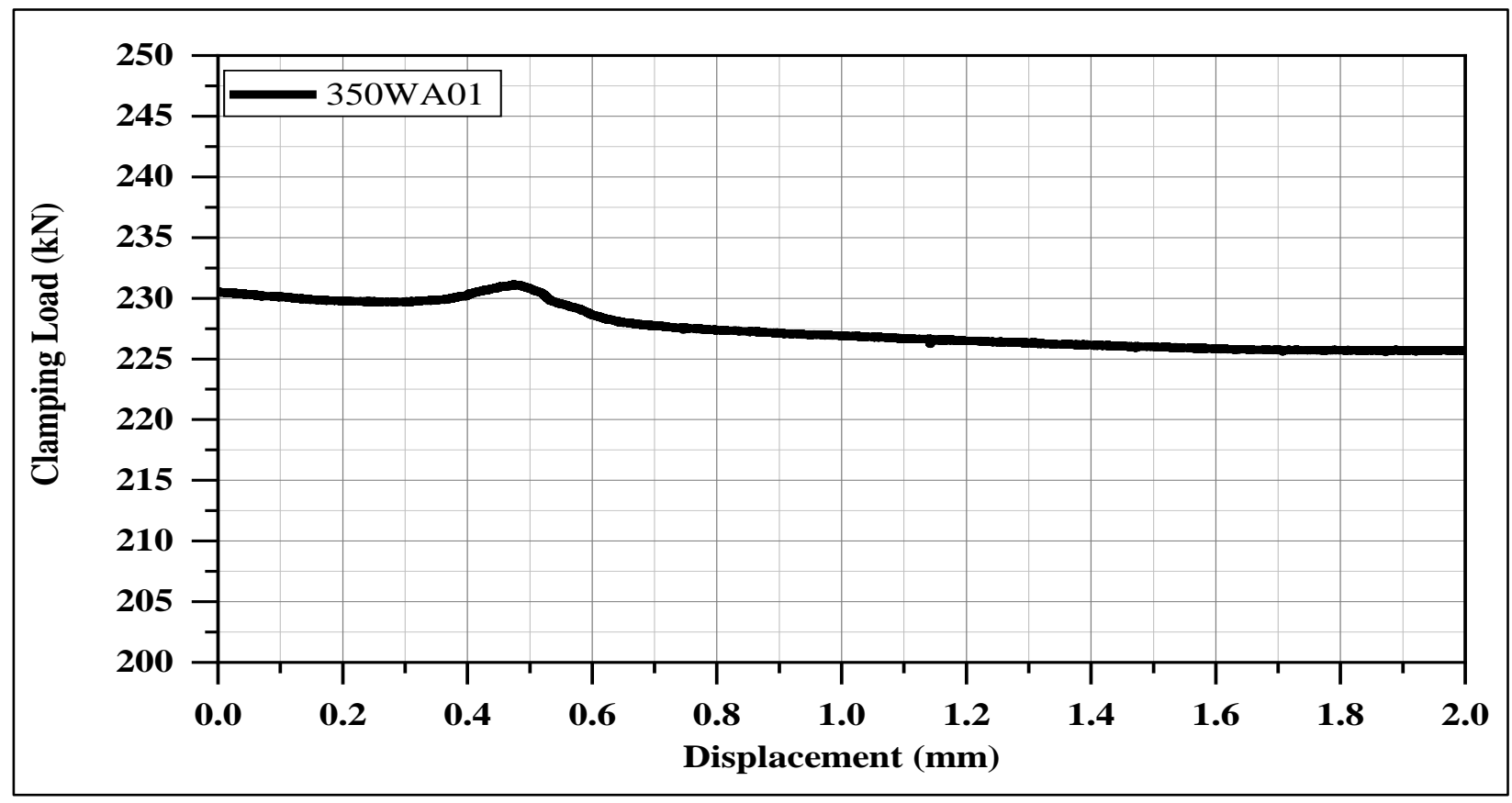

Figure C-2: Clamping Load of Specimen 350WA01 


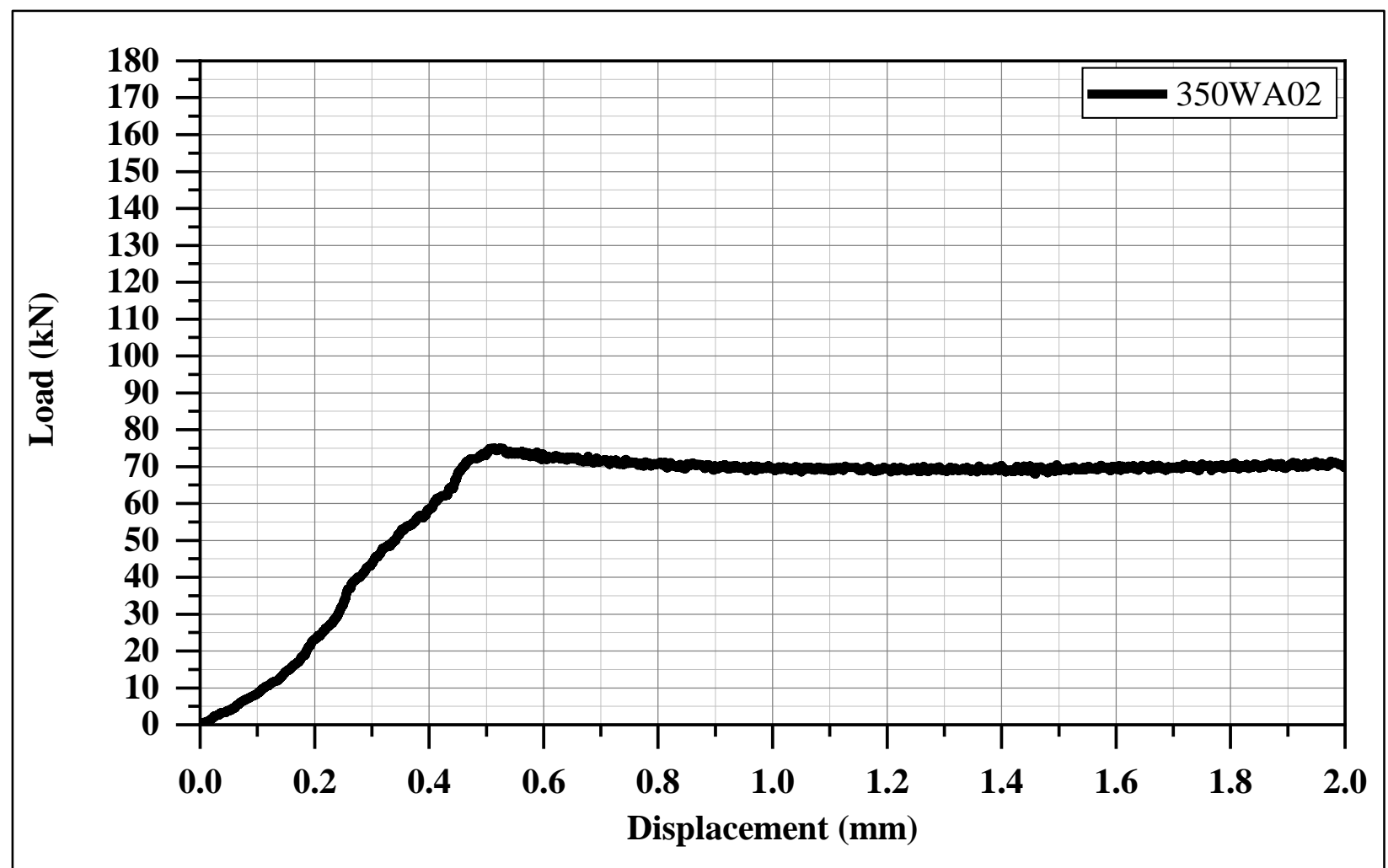

Figure C-3: Slip Load vs Displacement for Specimen 350WA02 with Class A Surface

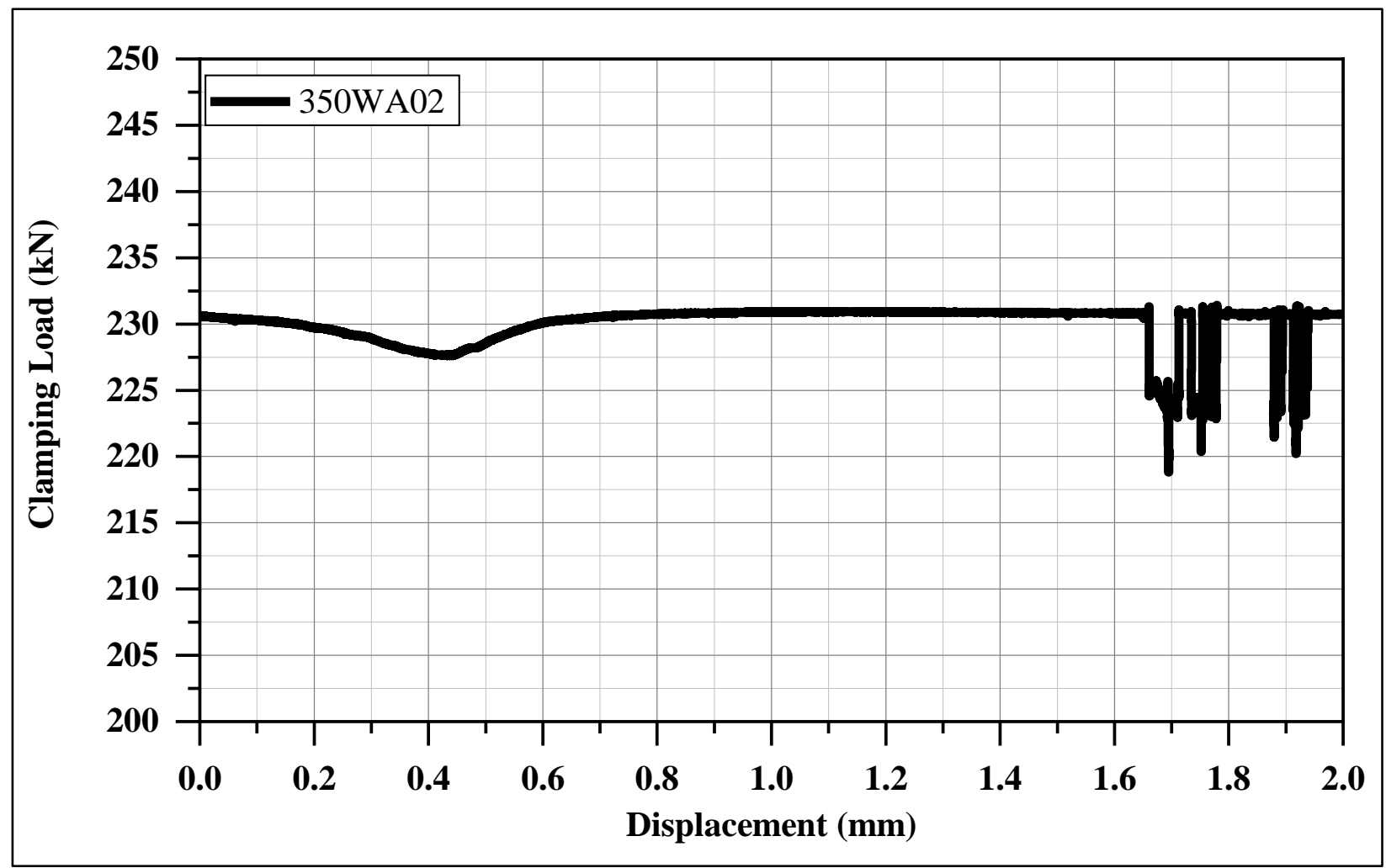

Figure C-4: Clamping Load for Specimen 350WA02 


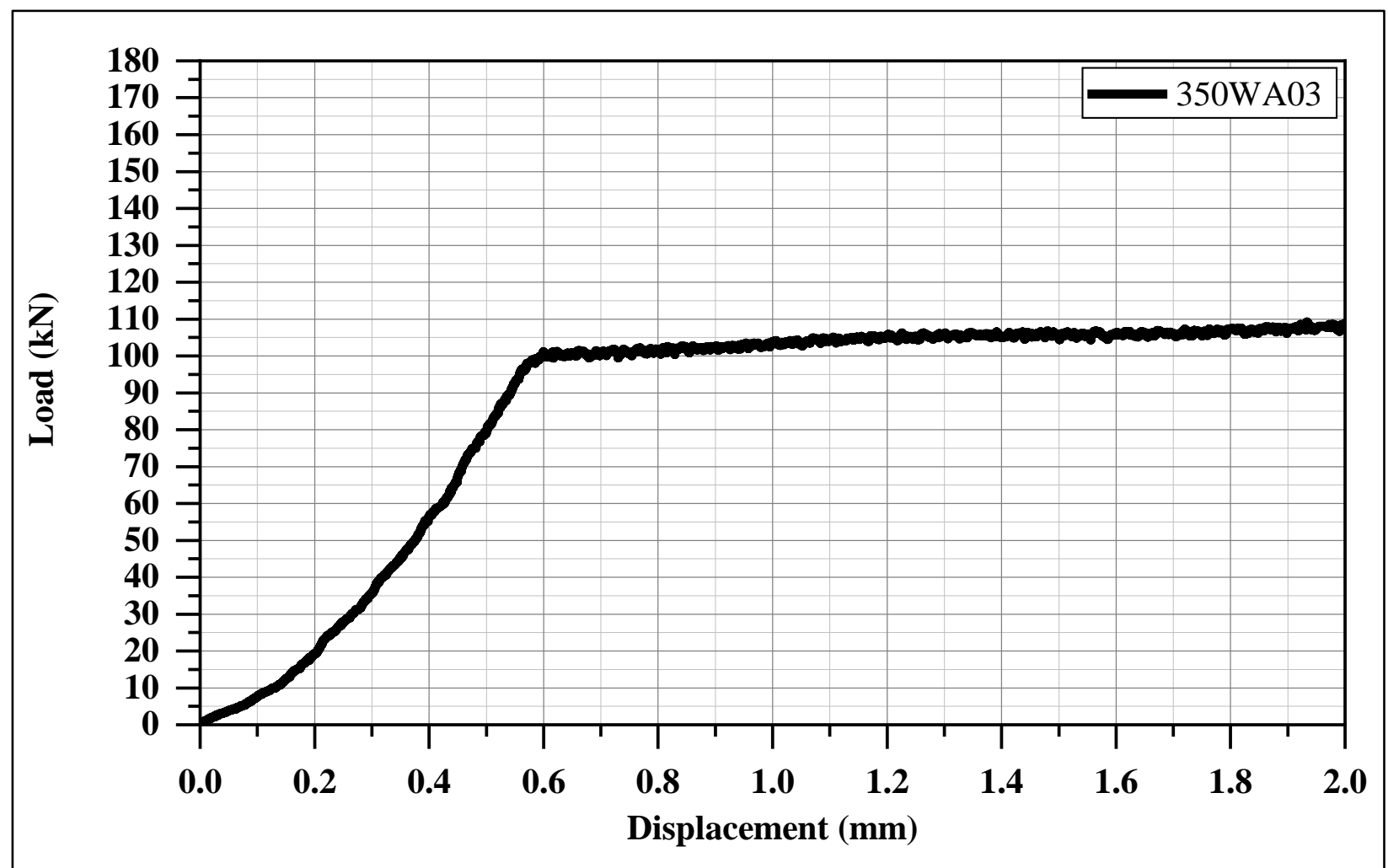

Figure C-5: Slip Load vs Displacement of Specimen 350WA03 with Class A Surface

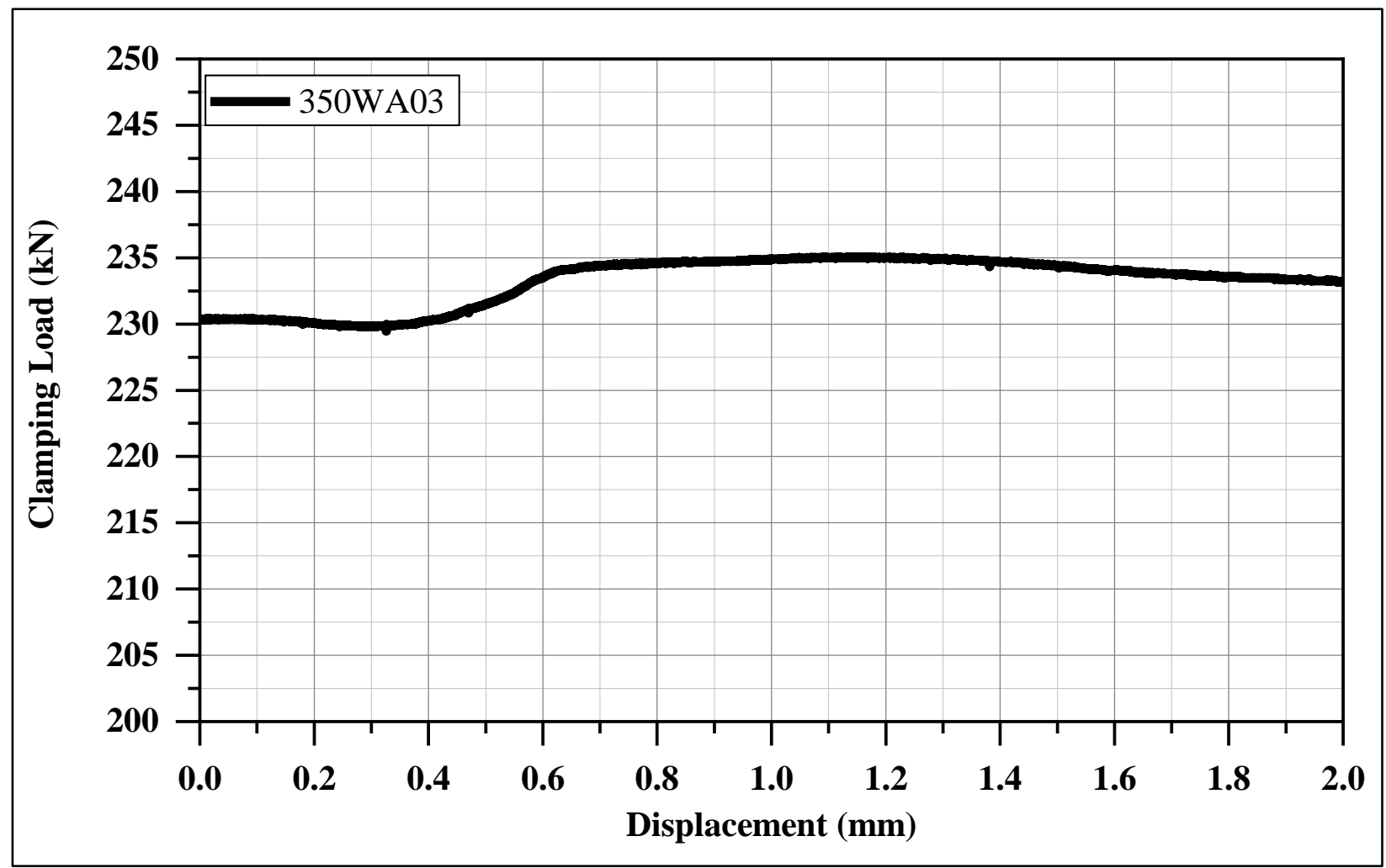

Figure C-6: Clamping Load of Specimen 350WA03 


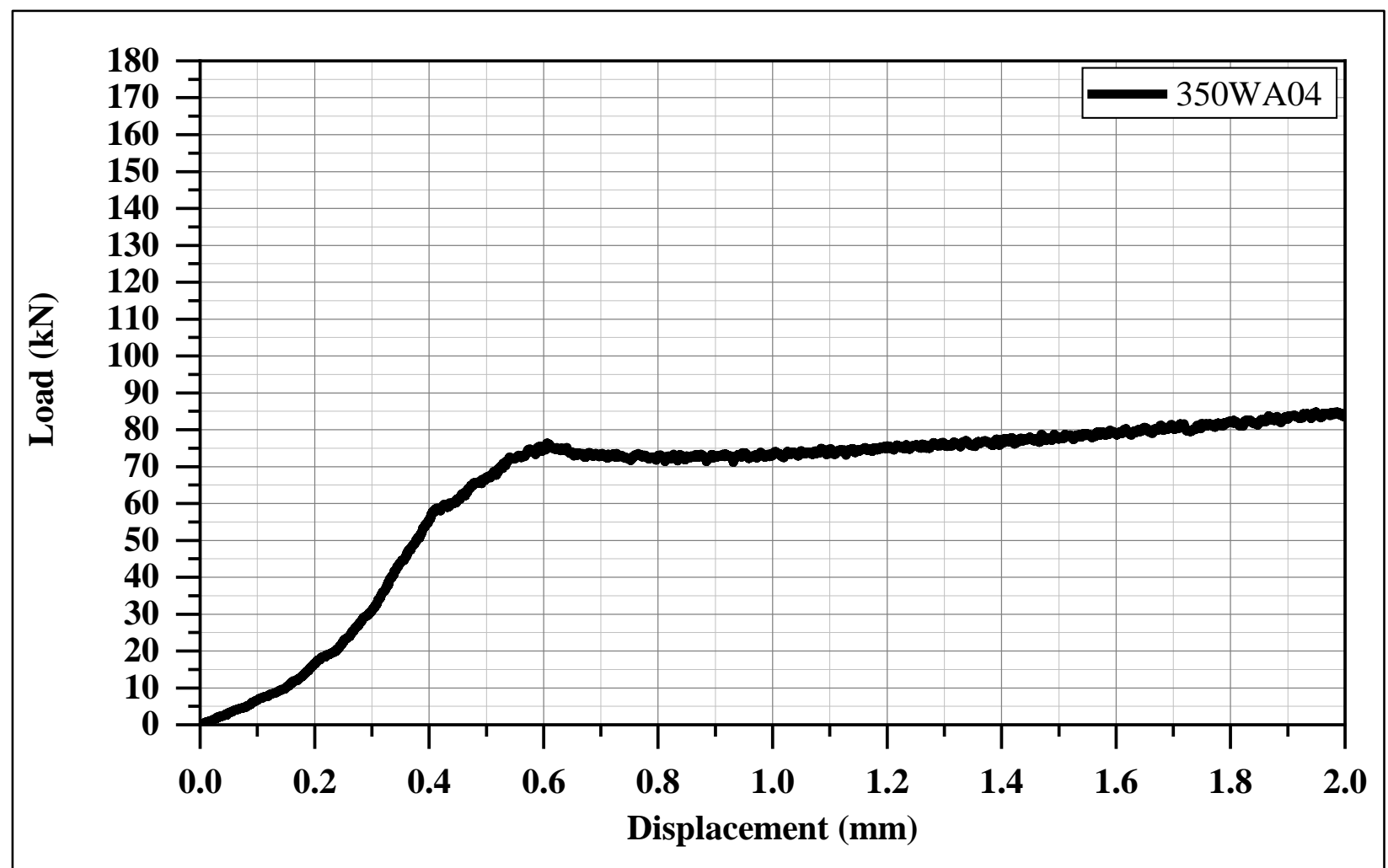

Figure C-7: Slip Load vs Displacement of Specimen 350WA04 with Class A Surface

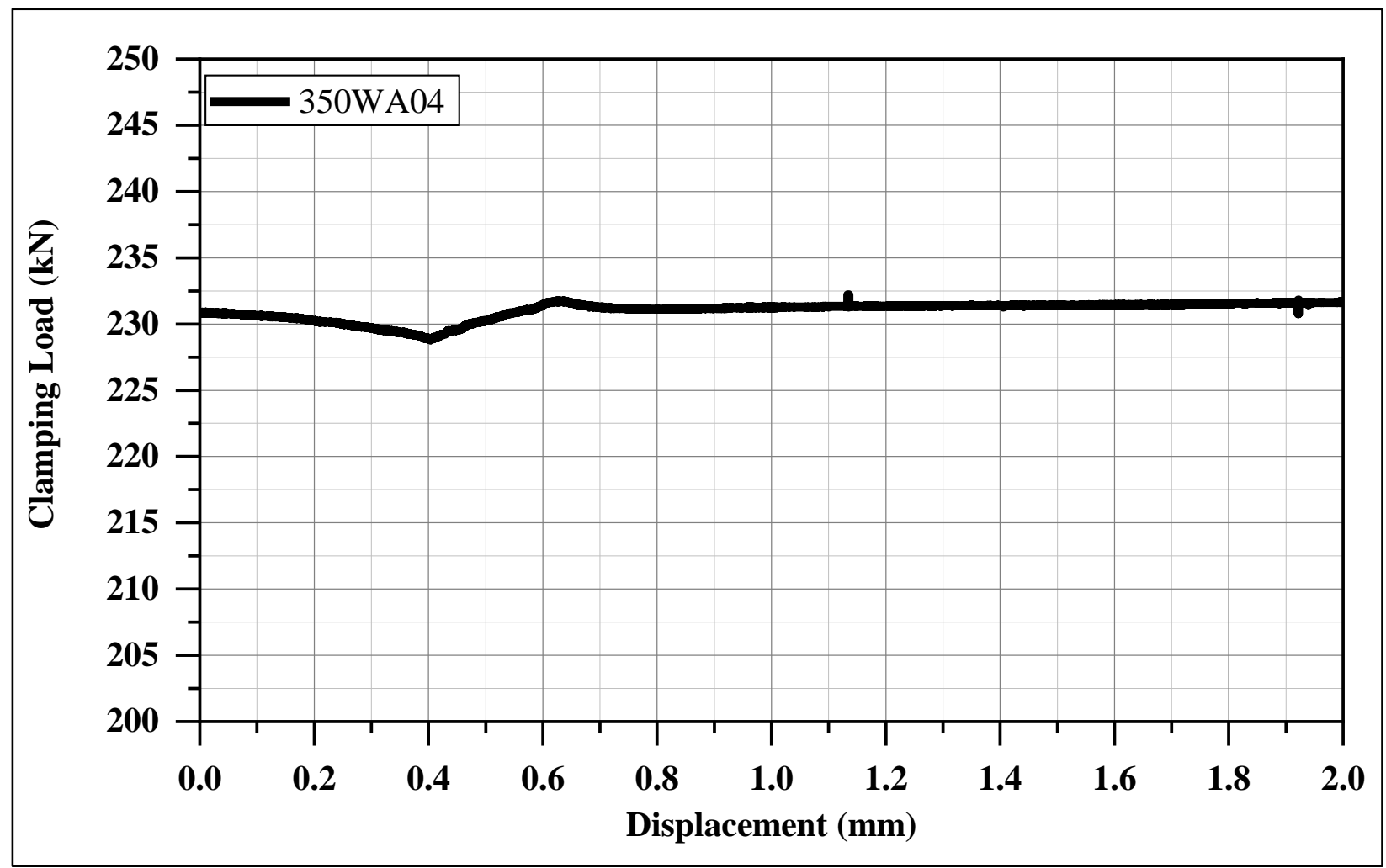

Figure C-8: Clamping Load of Specimen 350WA04 


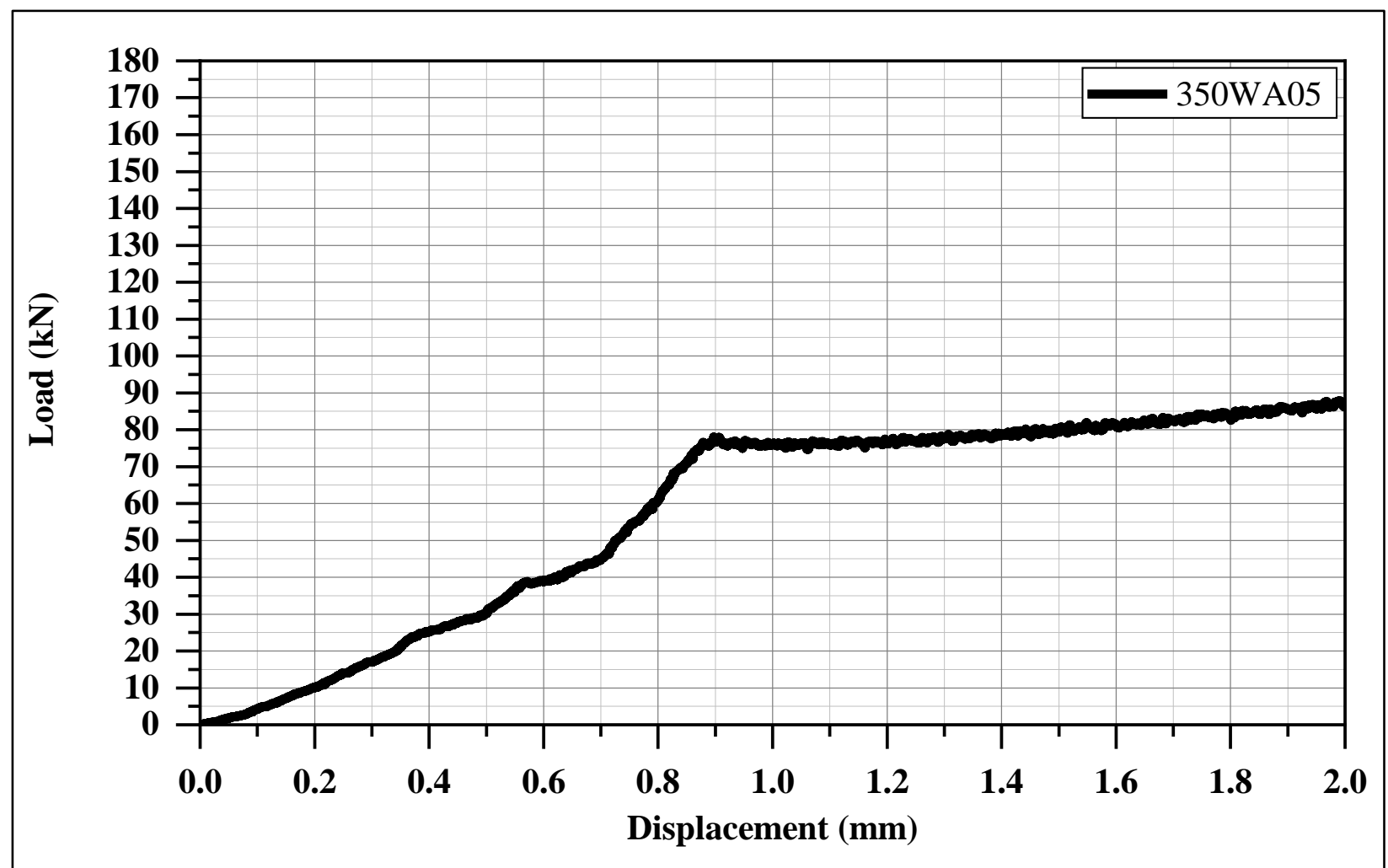

Figure C-9: Slip Load vs Displacement of Specimen 350WA05 with Class A Surface

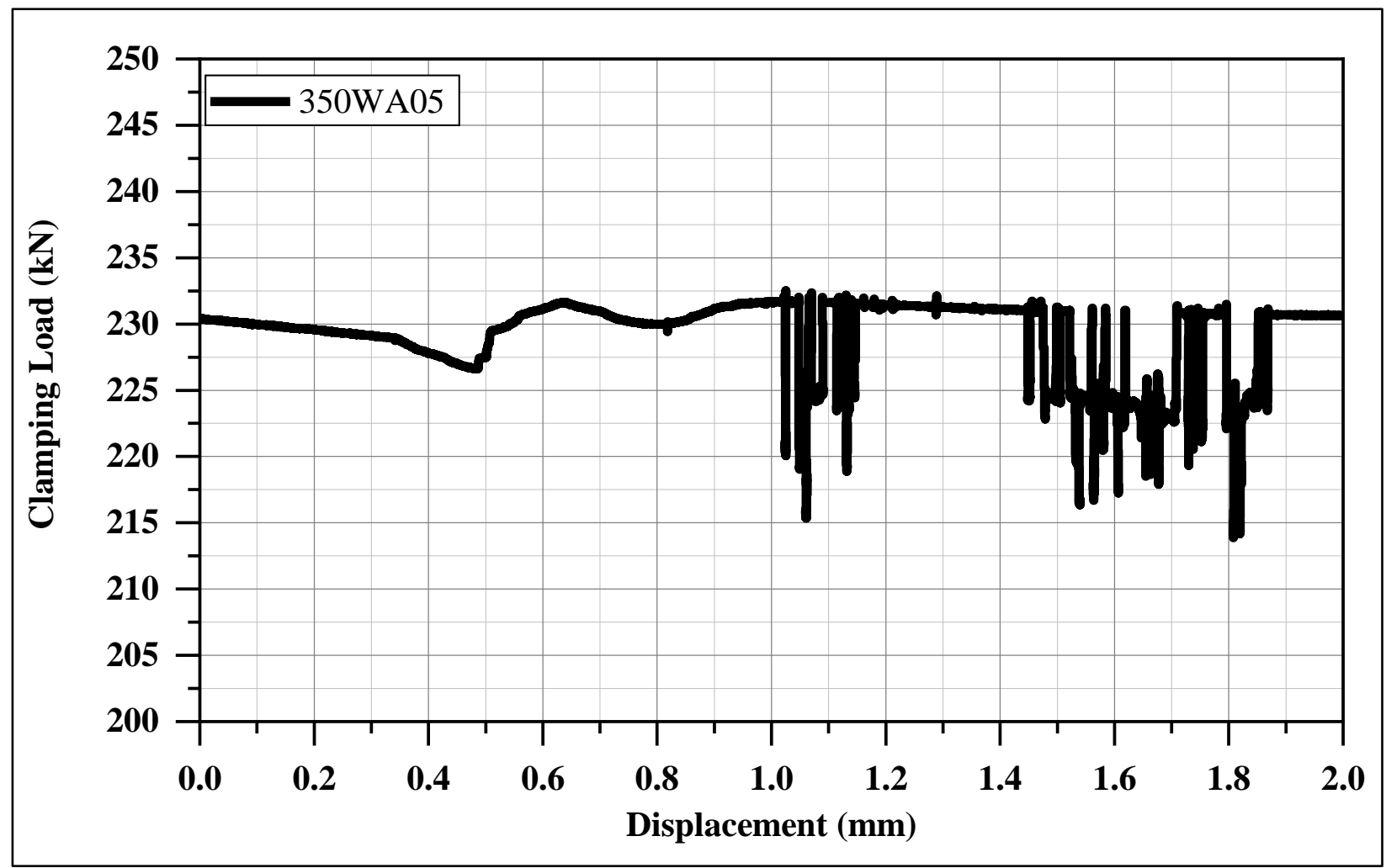

Figure C-10: Clamping Load of Specimen 350WA05 


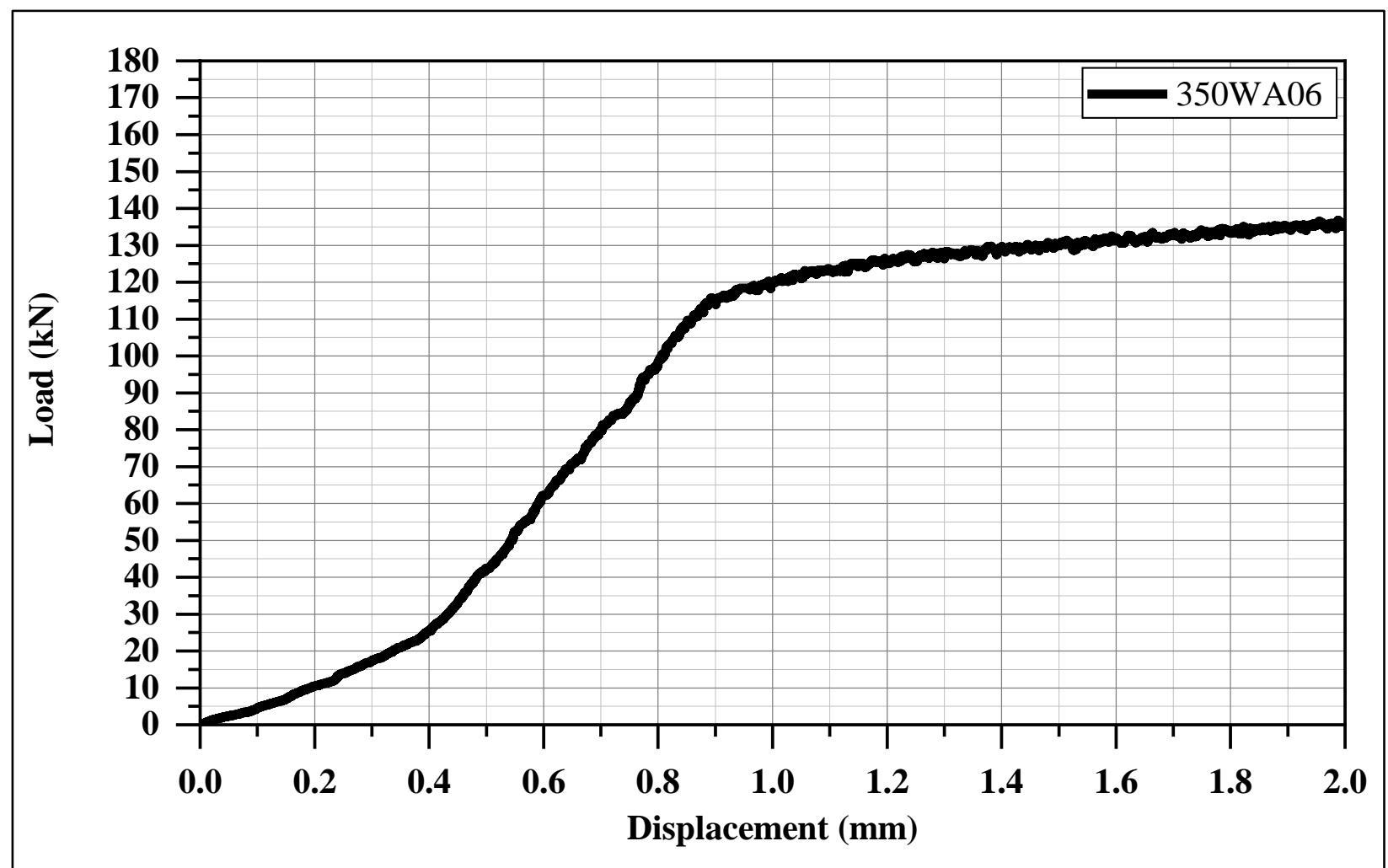

Figure C-11: Slip Load vs Displacement of Specimen 350 WA06 with Class A Surface

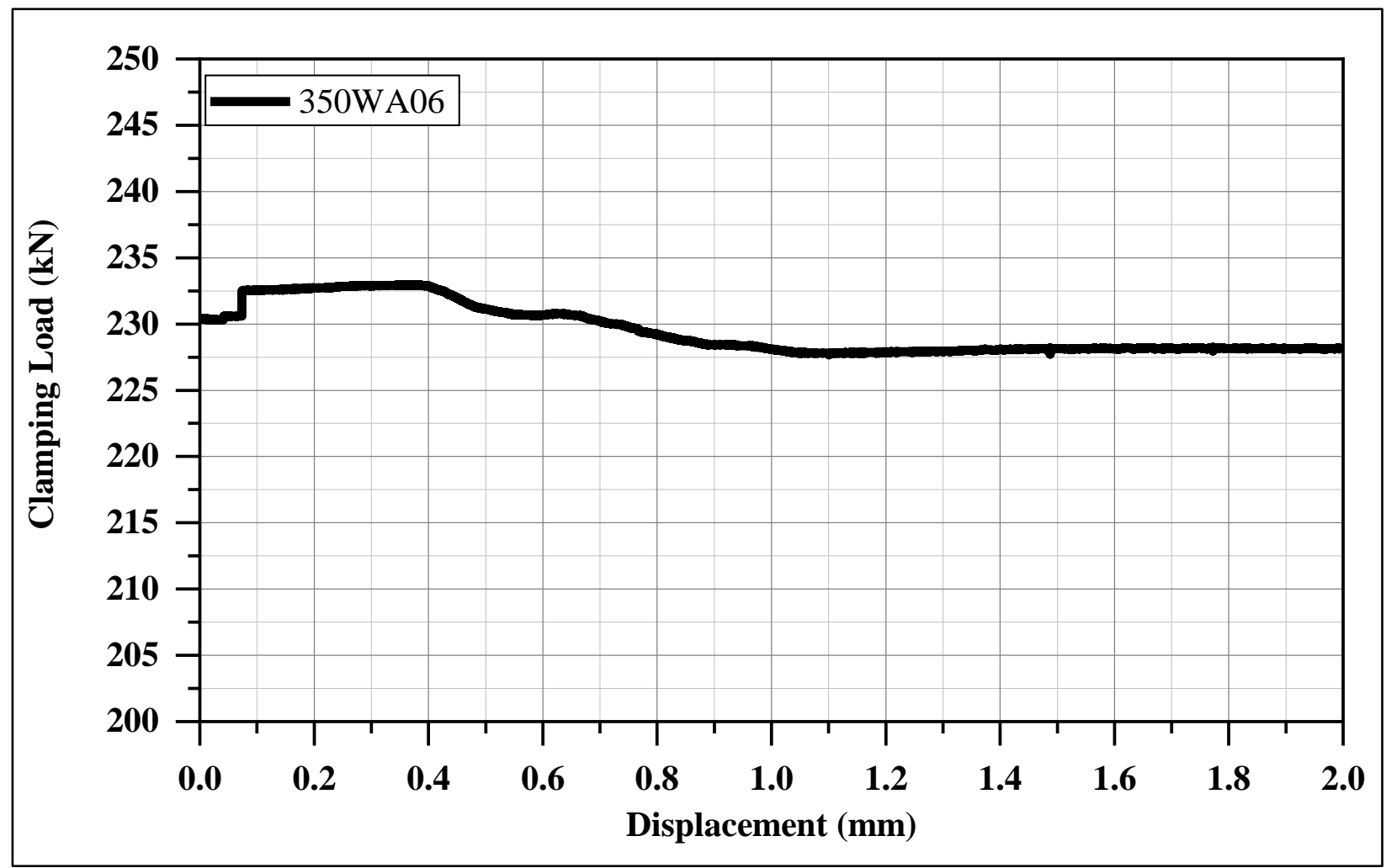

Figure C-12: Clamping Load of 350 WA06 


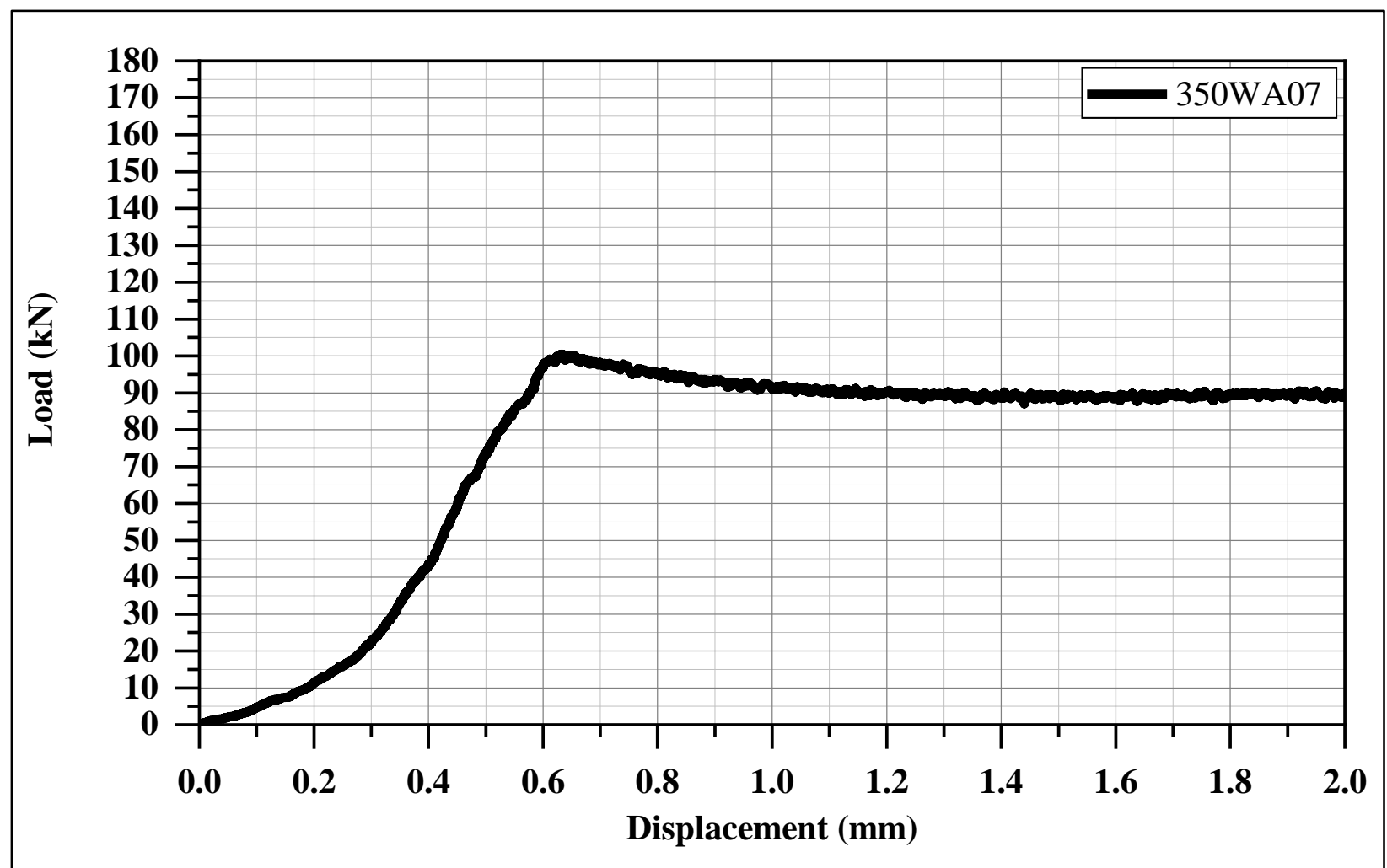

Figure C-13: Slip Load vs Displacement of Specimen 350WA07 with Class A Surface

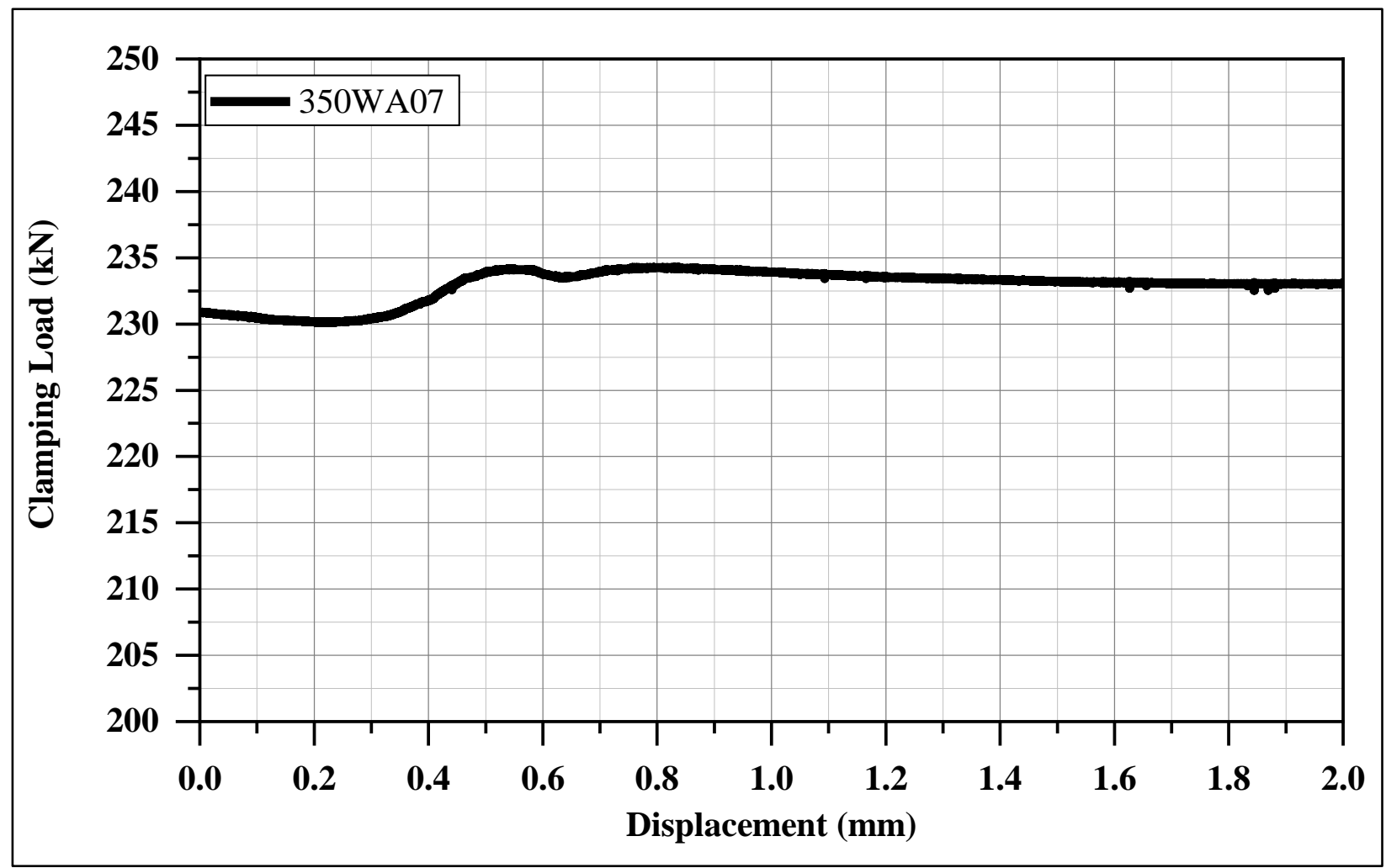

Figure C-14: Clamping Load of Specimen 350WA07 


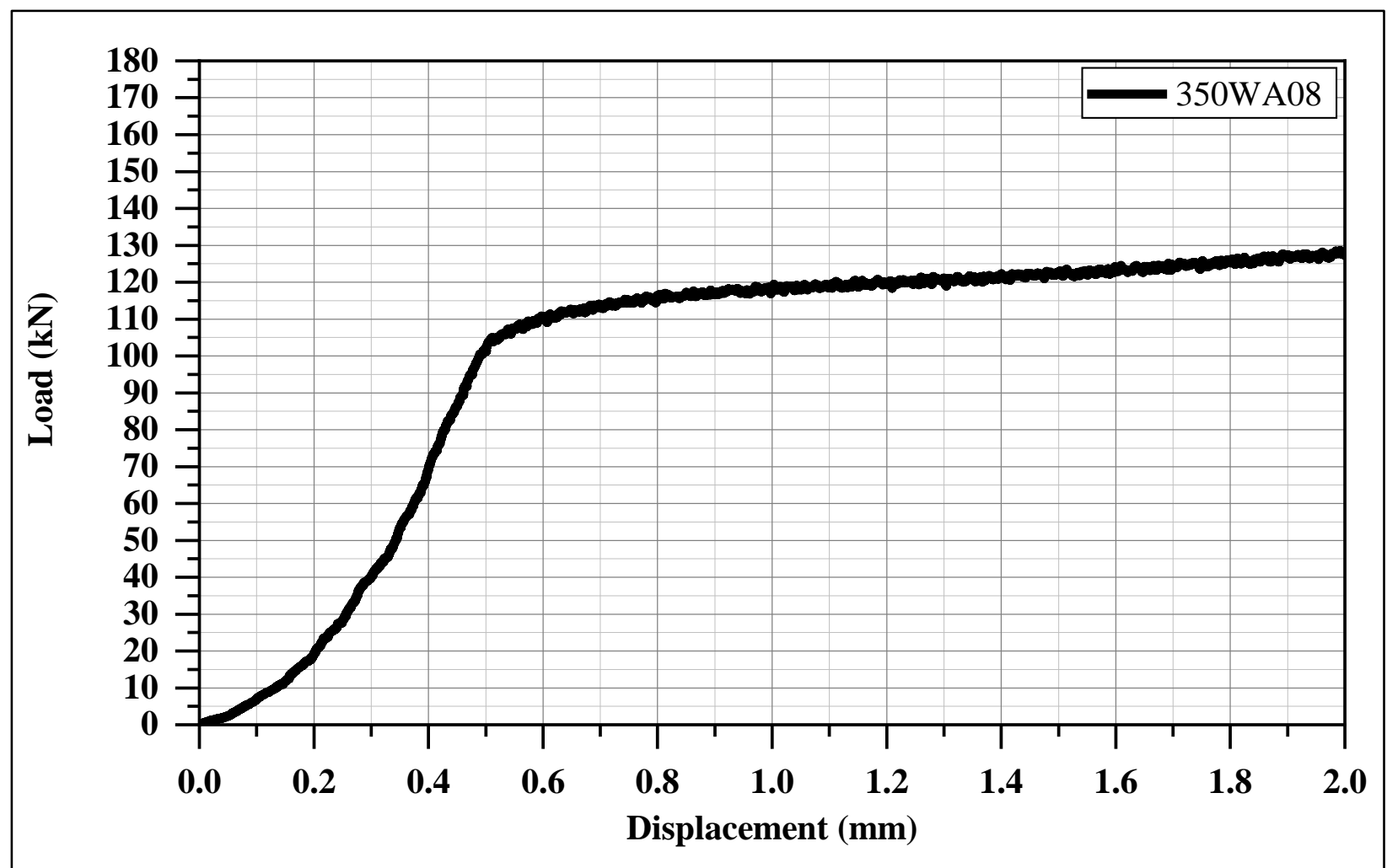

Figure C-15: Slip Load vs Displacement of Specimen 350WA08 with Class A Surface

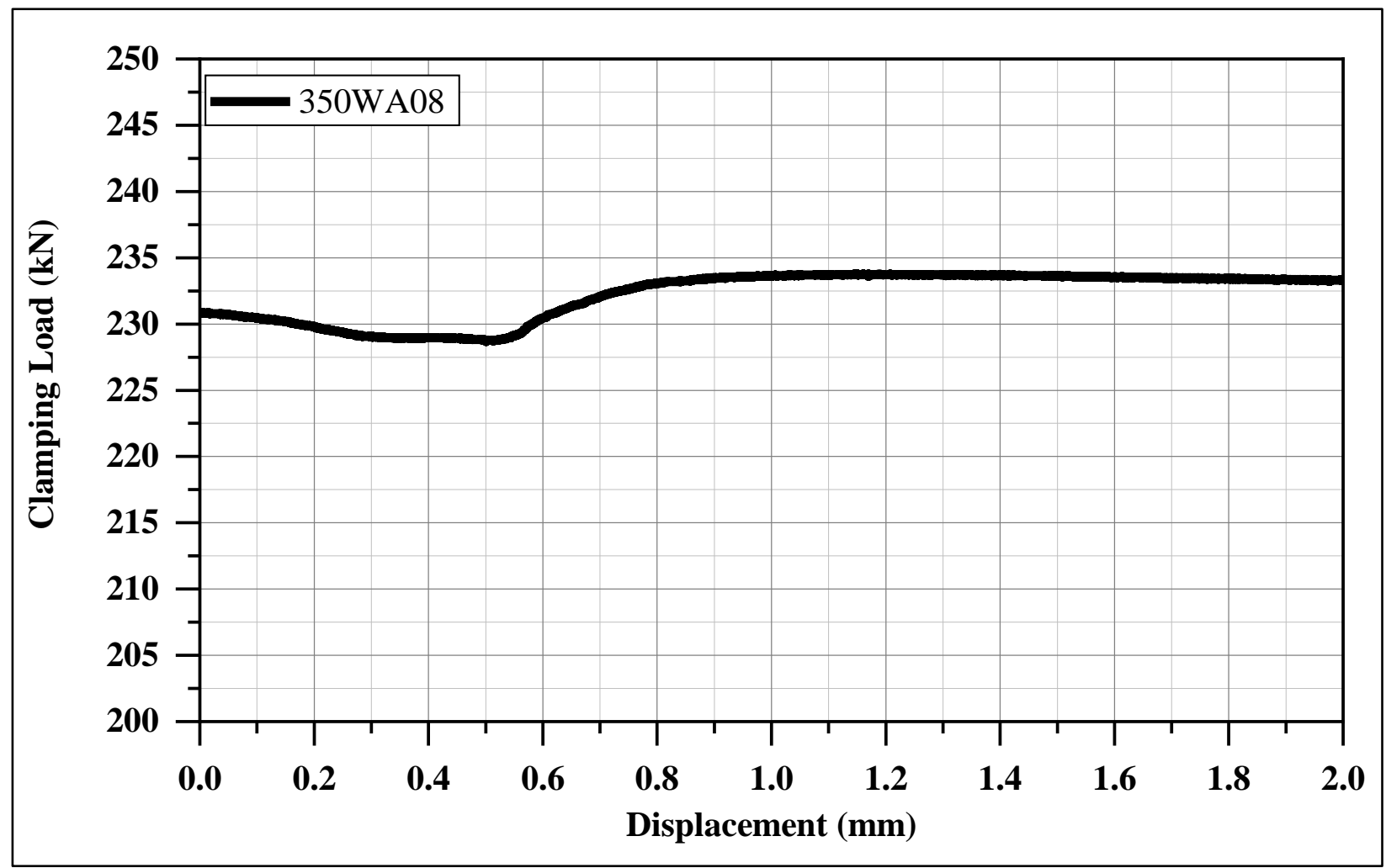

Figure C-16: Clamping Load of Specimen 350WA08 


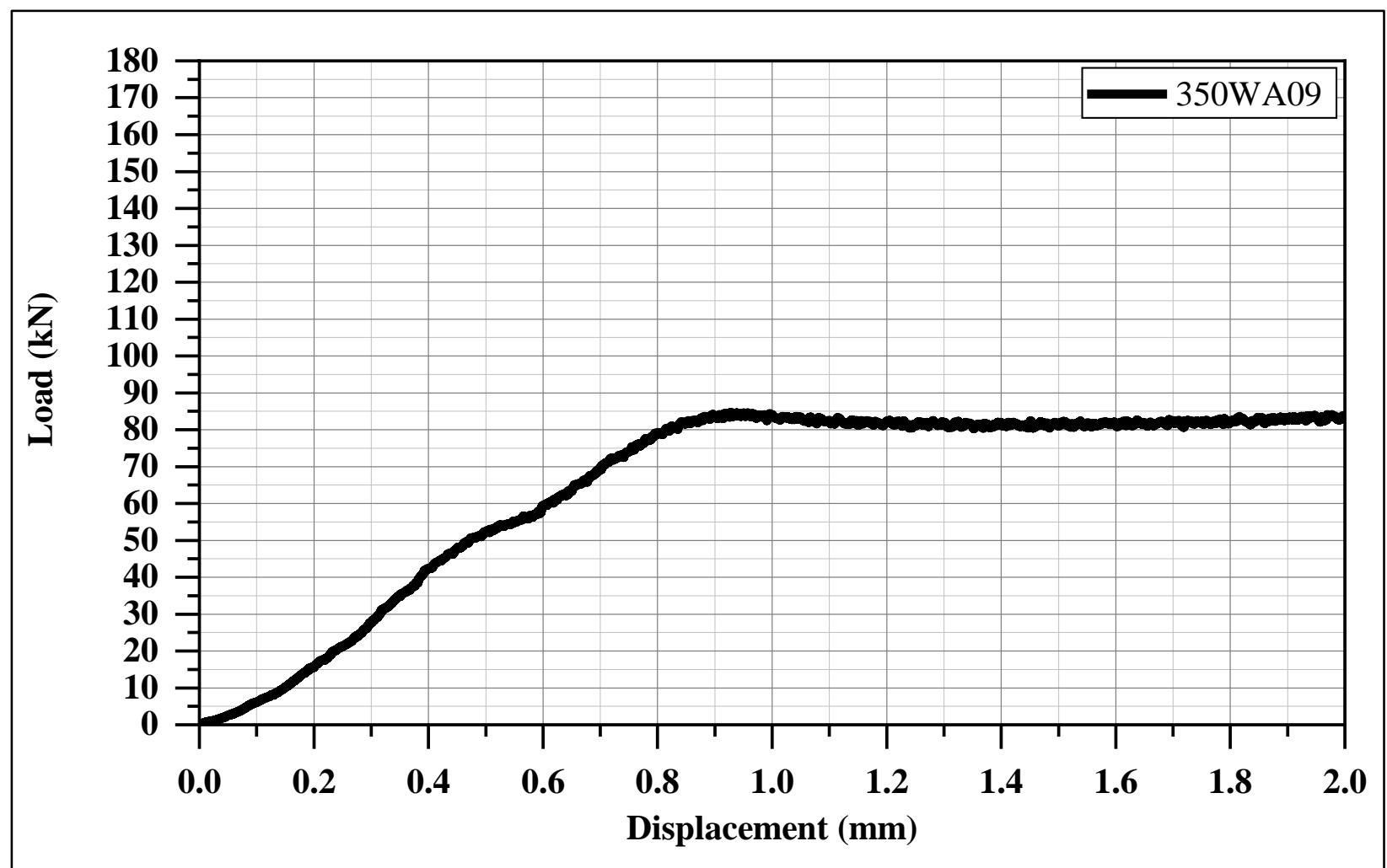

Figure C-17: Slip Load vs Displacement of Specimen 350WA09 with Class A Surface

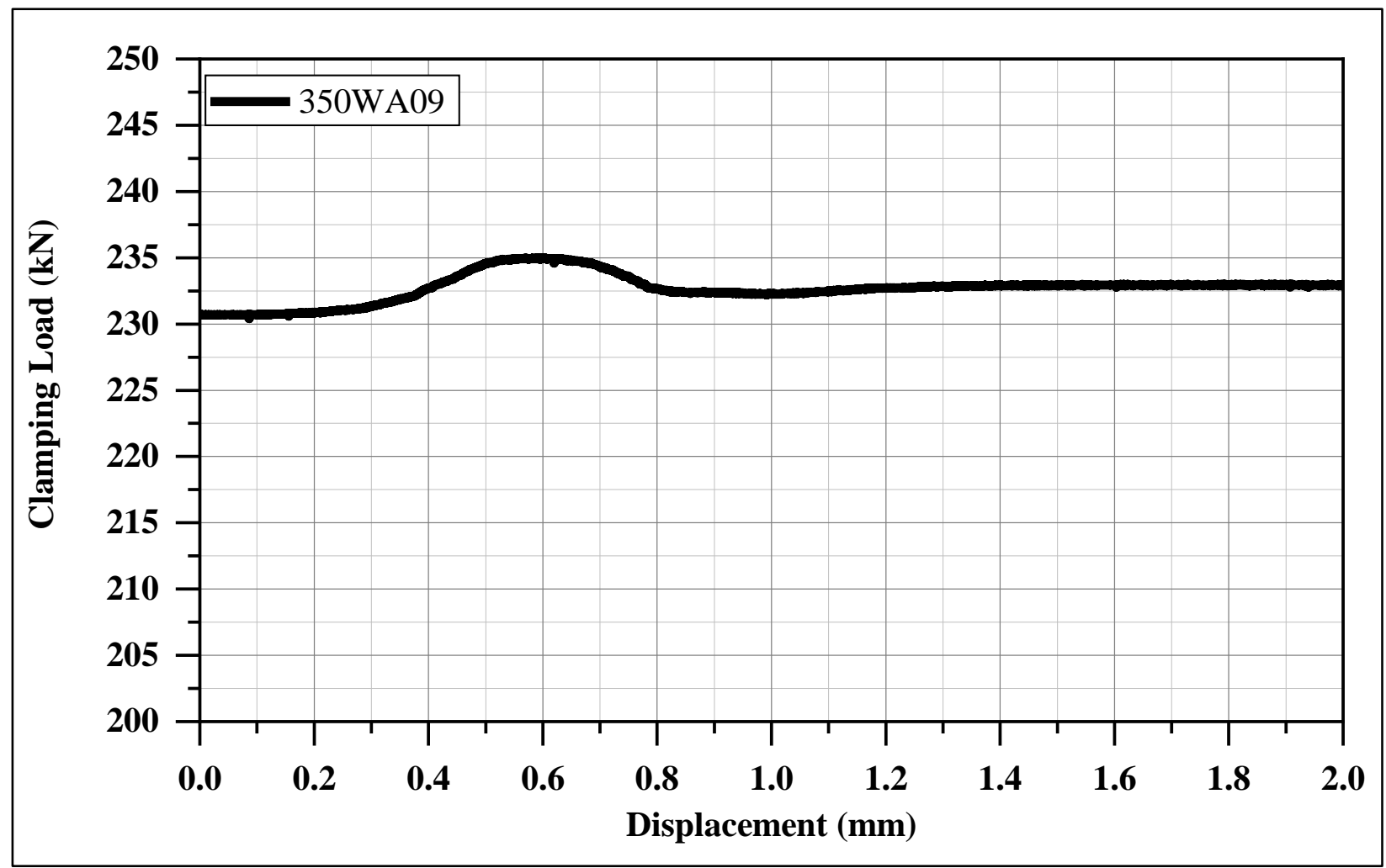

Figure C-18: Clamping Load of Specimen 350WA09 


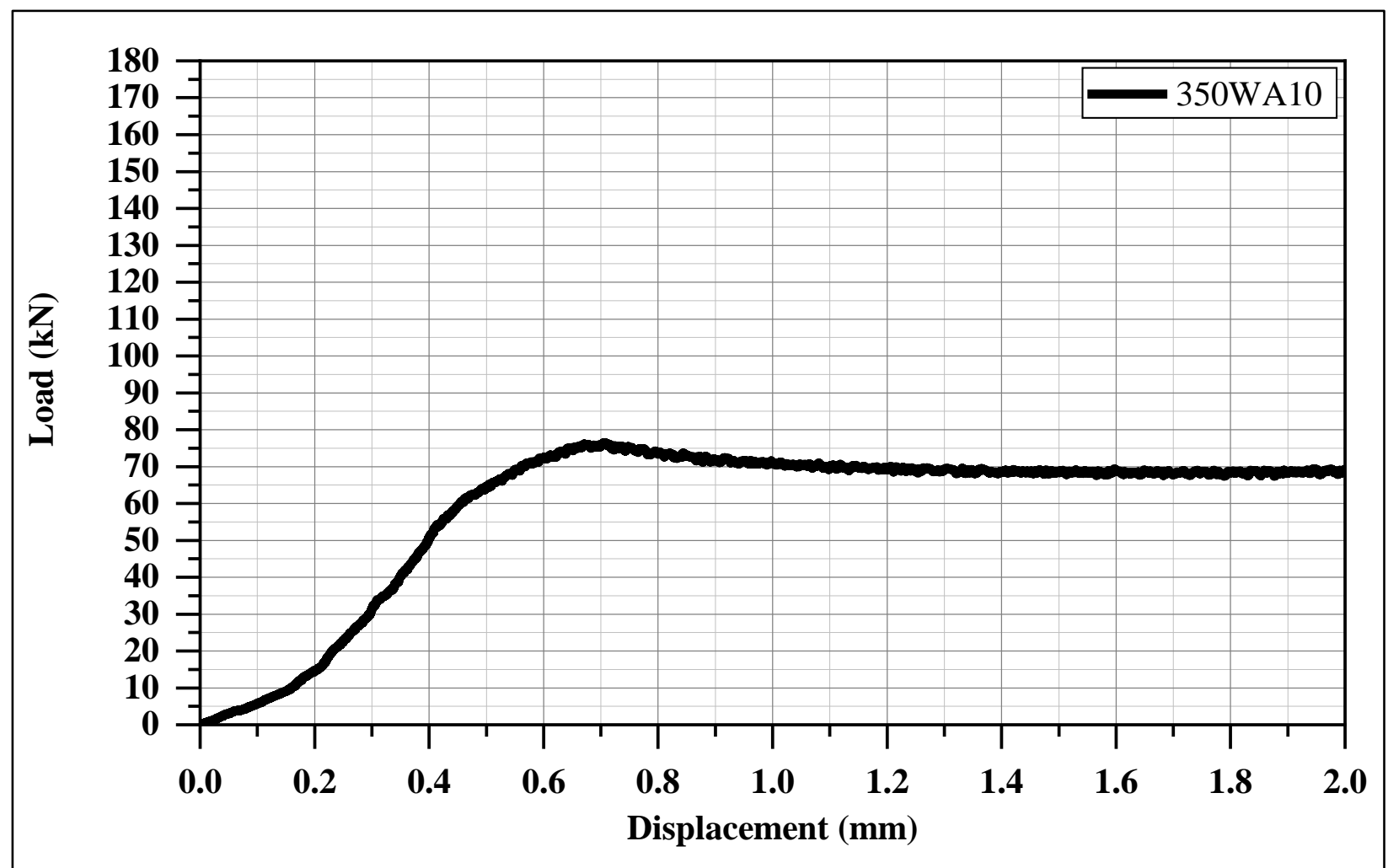

Figure C-19: Slip Load vs Displacement of Specimen 350WA10 with Class A Surface

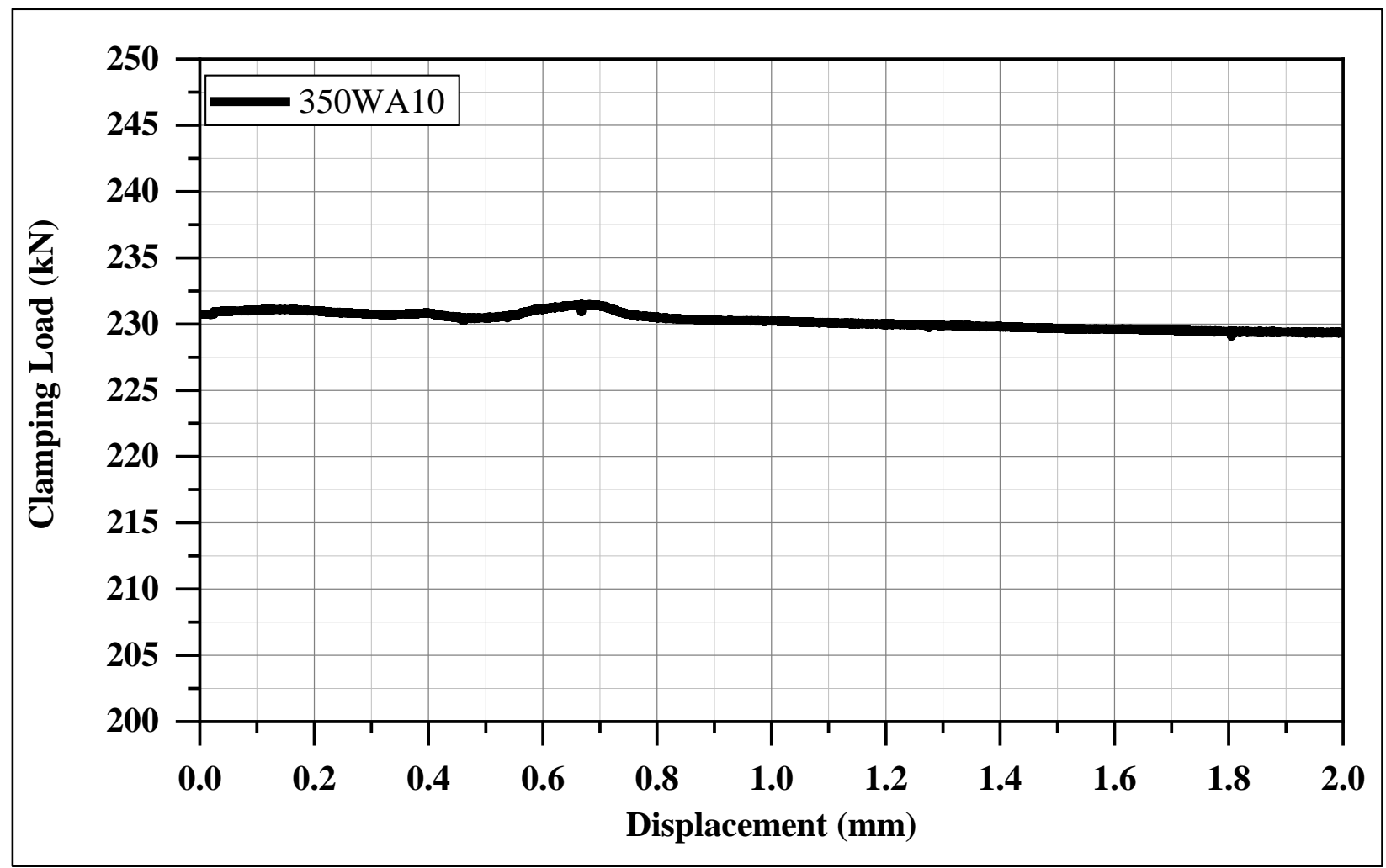

Figure C-20: Clamping Load of Specimen 350WA10 


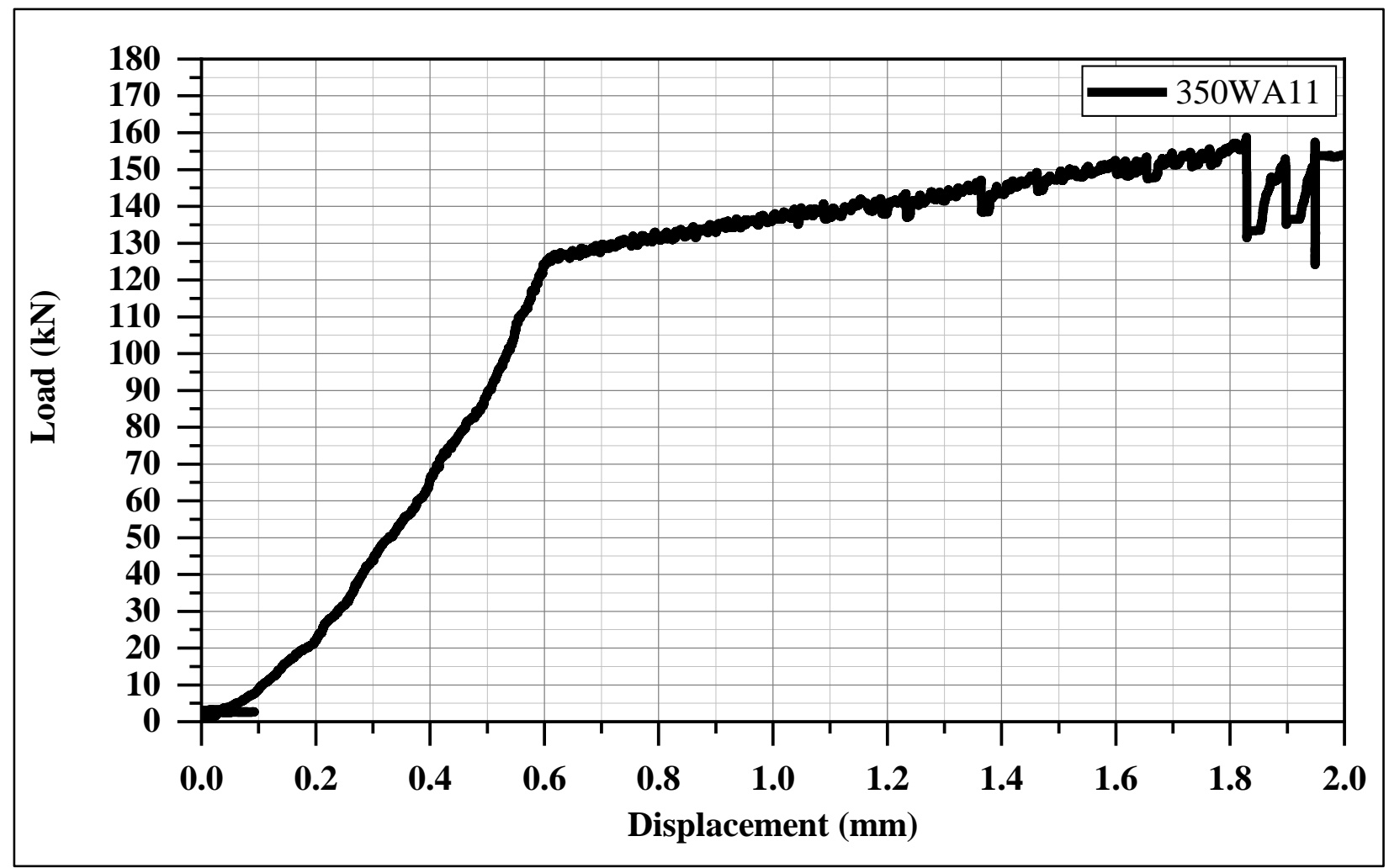

Figure C-21: Slip Load vs Displacement of Specimen 350WA11 with Class A Surface and Clamped by Using the Turn-of-Nut Method

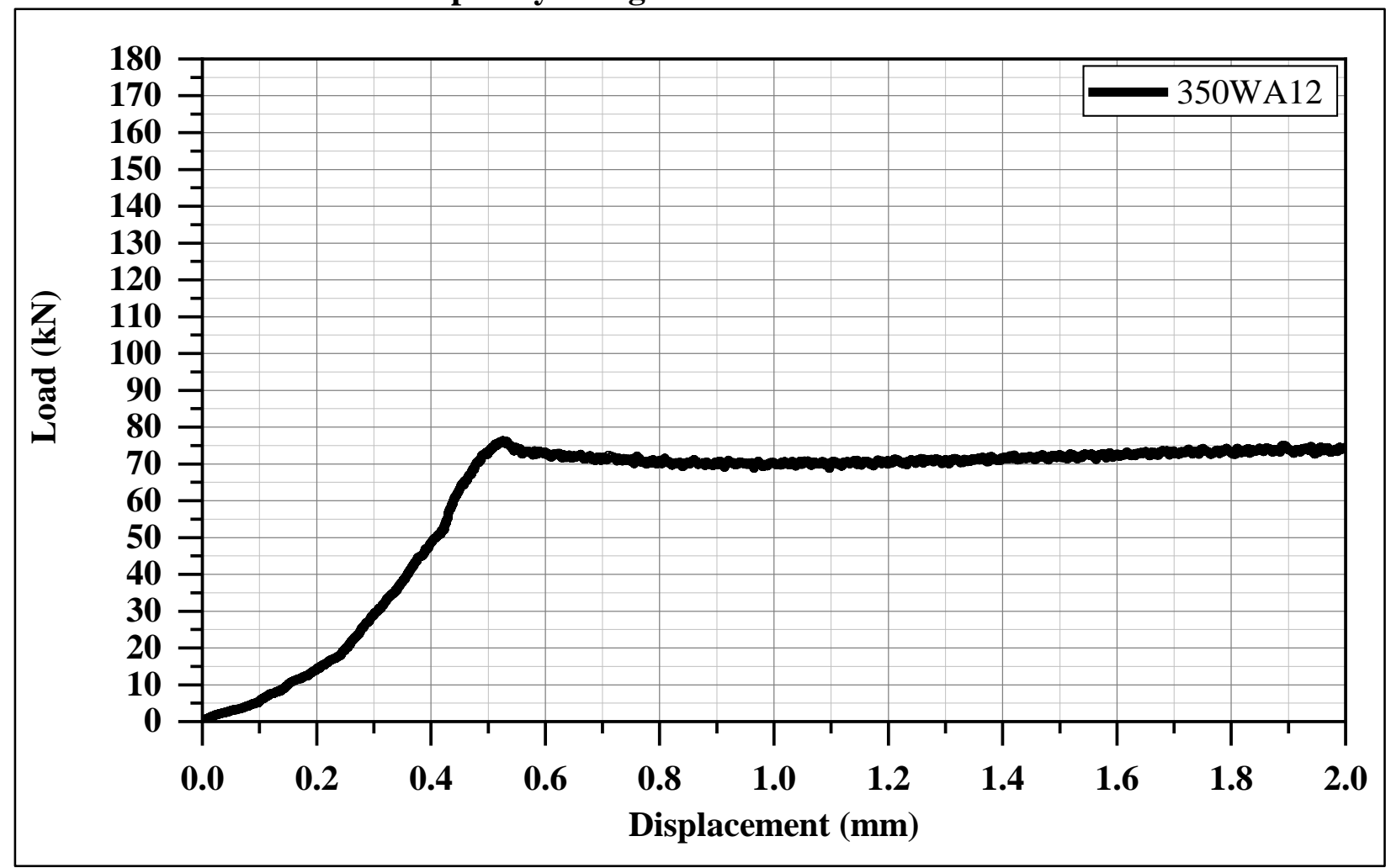

Figure C-22: Slip Load vs Displacement of Specimen 350WA12 with Class A Surface and Clamped by Using the Turn-of-Nut Method 


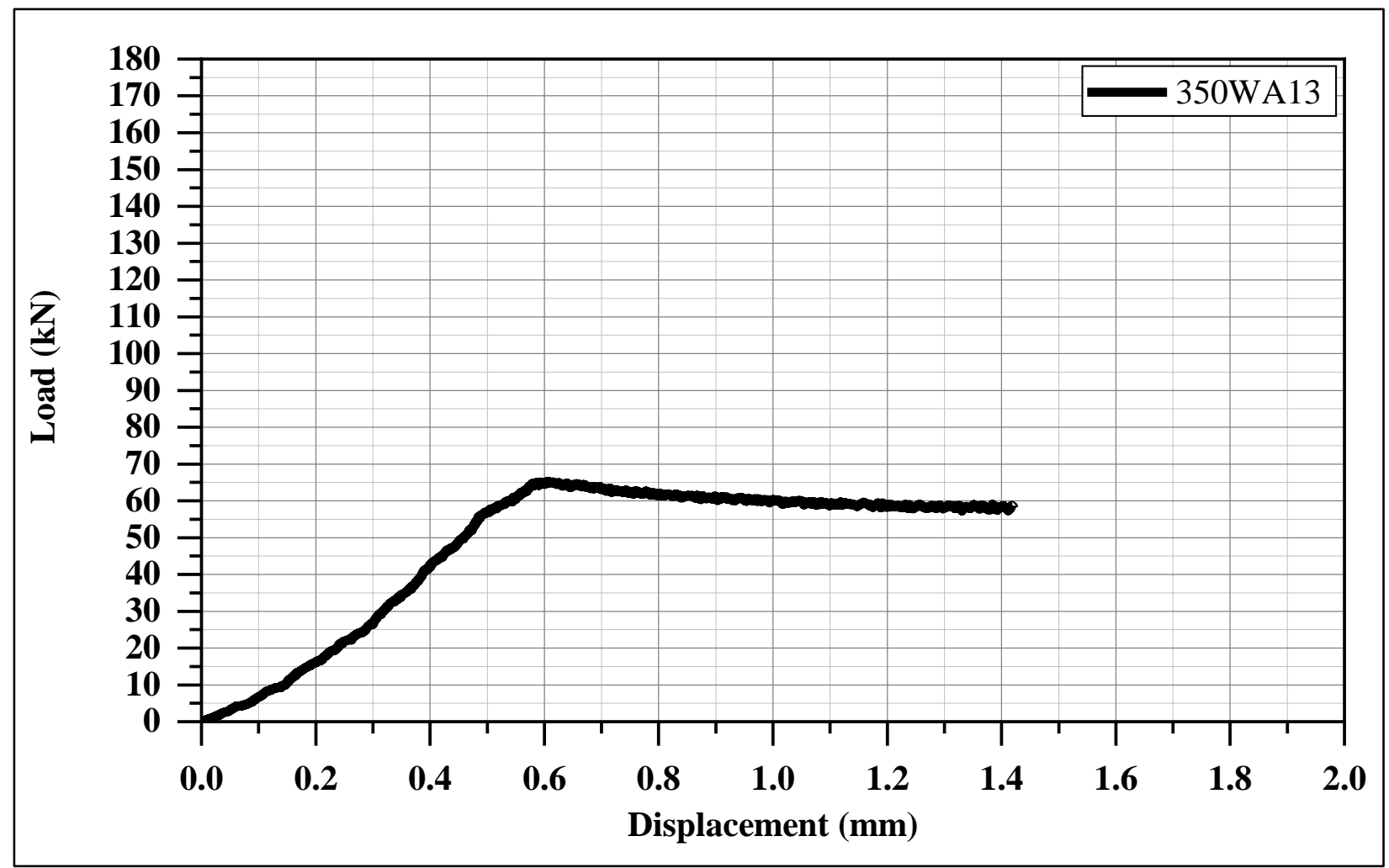

Figure C-23: Slip Load vs Displacement of Specimen 350WA13 with Class A Surface and Clamped by Using the Turn-of-Nut Method

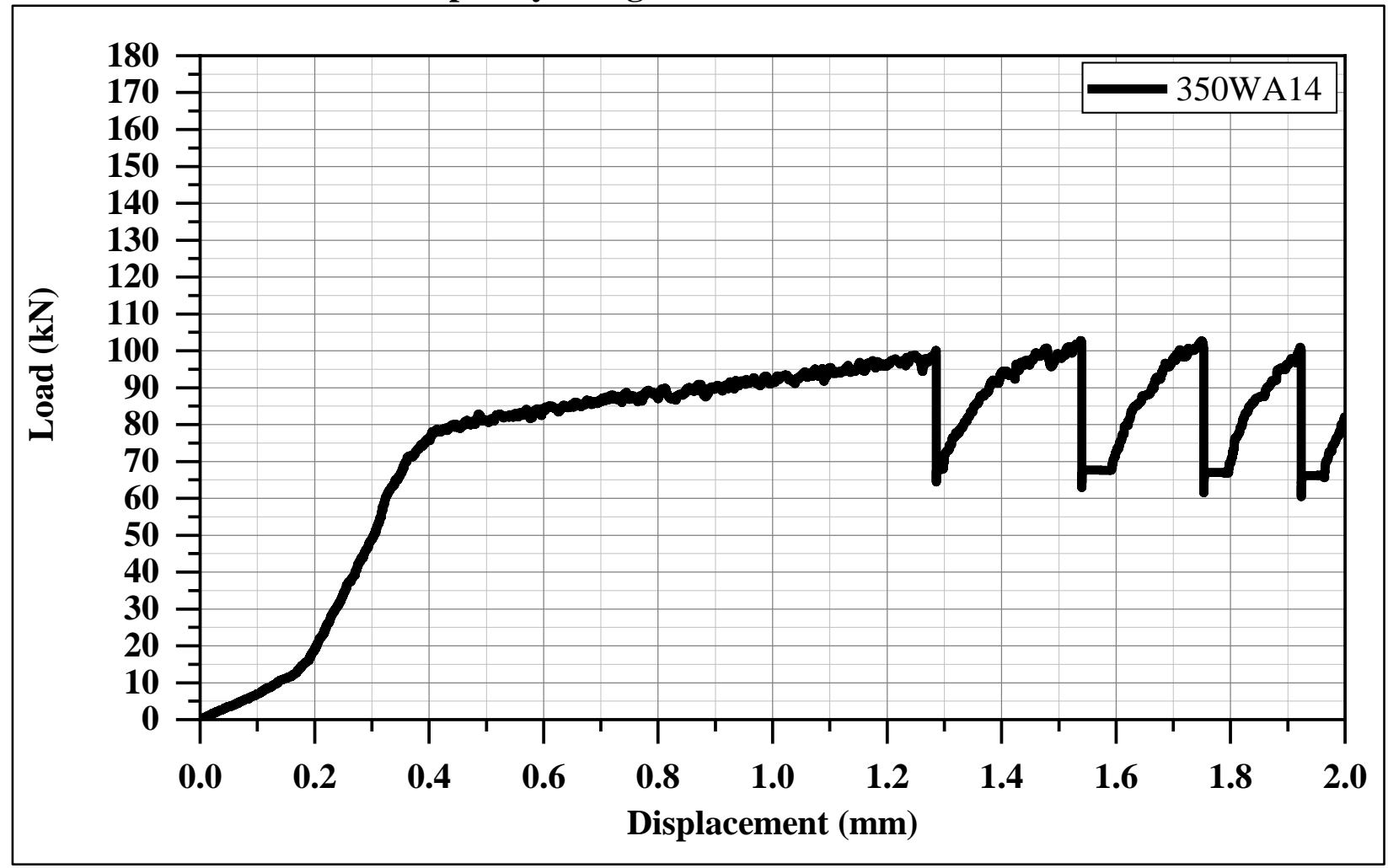

Figure C-24: Slip Load vs Displacement of Specimen 350WA14 with Class A Surface Clamped by Using the Turn-of-Nut Method 


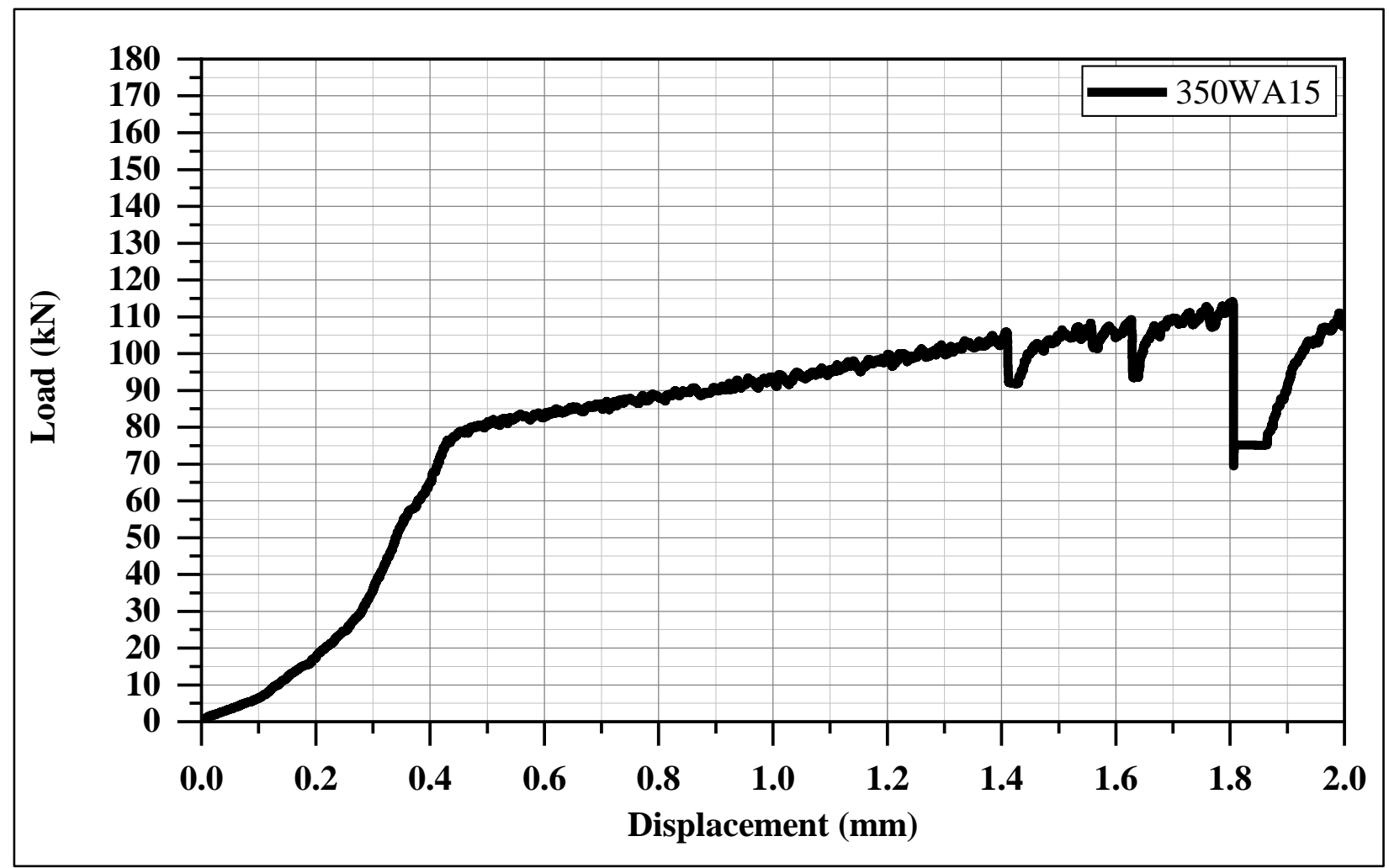

Figure C-25: Slip Load vs Displacement of Specimen 350WA15 with Class A Surface and Clamped by Using the Turn-of-Nut Method 


\section{Appendix D - Bolt Preload Relaxation Tables}

Table D-1: A325 Plain Bolt with Plain Nut \& Washer Pretensioned at $70 \%$ of $\mathrm{F}_{\mathrm{u}}$

\begin{tabular}{|c|c|c|c|c|c|}
\hline Bolt Number & Bolt Type & $\begin{array}{c}\text { Preload } \\
\text { (\% of Fu) }\end{array}$ & $\begin{array}{c}\text { Maximum } \\
\text { Load (kN) }\end{array}$ & $\begin{array}{c}\text { Minimum } \\
\text { Load (kN) }\end{array}$ & $\begin{array}{c}\text { \% } \\
\text { Relaxation } \\
\text { (72 hours) }\end{array}$ \\
\hline 1 & A325 - Plain & $70 \%$ & 174.333 & 171.304 & 1.74 \\
\hline 2 & A325 - Plain & $70 \%$ & 174.471 & 172.173 & 1.32 \\
\hline 3 & A325 - Plain & $70 \%$ & 175.956 & 172.314 & 2.07 \\
\hline 4 & A325 - Plain & $70 \%$ & 174.870 & 171.246 & 2.07 \\
\hline 5 & A325 - Plain & $70 \%$ & 175.121 & 171.290 & 2.19 \\
\hline Average & A325 - Plain & $\mathbf{7 0 \%}$ & $\mathbf{1 7 4 . 9 5 0}$ & $\mathbf{1 7 1 . 6 7 8}$ & $\mathbf{1 . 8 7}$ \\
\hline
\end{tabular}

Table D-2: A325 Plain Bolt with Plain Nut \& Washer Pretensioned at $90 \%$ of $\mathrm{F}_{\mathrm{u}}$

\begin{tabular}{|c|c|c|c|c|c|}
\hline Bolt Number & Bolt Type & $\begin{array}{c}\text { Preload } \\
(\% \text { of Fu) }\end{array}$ & $\begin{array}{c}\text { Maximum } \\
\text { Load (kN) }\end{array}$ & $\begin{array}{c}\text { Minimum } \\
\text { Load (kN) }\end{array}$ & $\begin{array}{c}\text { Relaxation } \\
\text { (72 hours) }\end{array}$ \\
\hline 1 & A325 - Plain & $90 \%$ & 230.189 & 224.456 & 2.49 \\
\hline 2 & A325 - Plain & $90 \%$ & 230.752 & 224.595 & 2.67 \\
\hline 3 & A325 - Plain & $90 \%$ & 230.174 & 223.116 & 3.07 \\
\hline 4 & A325 - Plain & $90 \%$ & 230.863 & 223.498 & 3.19 \\
\hline 5 & A325 - Plain & $90 \%$ & 229.592 & 221.307 & 3.61 \\
\hline Average & A325 - Plain & $\mathbf{9 0 \%}$ & $\mathbf{2 3 0 . 2 7 4}$ & $\mathbf{2 2 3 . 4 0 1}$ & $\mathbf{2 . 9 9}$ \\
\hline
\end{tabular}

Table D-3: A325 Galvanized Bolt with Galvanized Nut \& Washer Pretensioned at 70\% of

\begin{tabular}{|c|c|c|c|c|c|}
\hline \multirow{2}{*}{ Bolt Number } & Bolt Type & $\begin{array}{c}\text { Preload } \\
(\% \text { of Fu) }\end{array}$ & $\begin{array}{c}\text { Maximum } \\
\text { Load (kN) }\end{array}$ & $\begin{array}{c}\text { Minimum } \\
\text { Load (kN) }\end{array}$ & $\begin{array}{c}\text { \% } \\
\text { Relaxation } \\
\text { (72 hours) }\end{array}$ \\
\hline 1 & $\begin{array}{c}\text { A325 - } \\
\text { Galvanized }\end{array}$ & $70 \%$ & 174.149 & 168.886 & 3.02 \\
\hline 2 & $\begin{array}{c}\text { A325 - } \\
\text { Galvanized }\end{array}$ & $70 \%$ & 174.273 & 167.527 & 3.87 \\
\hline 3 & $\begin{array}{c}\text { A325 - } \\
\text { Galvanized } \\
\text { A325 - } \\
\text { Galvanized }\end{array}$ & $70 \%$ & 175.146 & 171.360 & 2.16 \\
\hline 5 & $\begin{array}{c}\text { A325 - } \\
\text { Galvanized }\end{array}$ & $70 \%$ & 174.496 & 172.474 & 1.16 \\
\hline A325 - & $70 \%$ & 174.477 & 170.739 & 2.14 \\
\hline Galvanized & $\mathbf{7 0 \%}$ & $\mathbf{1 7 4 . 5 0 8}$ & $\mathbf{1 7 0 . 2 0 2}$ & $\mathbf{2 . 4 7}$ \\
\hline
\end{tabular}


Table D-4: A325 Galvanized Bolt with Galvanized Nut and Washer Pretensioned to 90\% of

\begin{tabular}{|c|c|c|c|c|c|}
\hline \multirow{2}{*}{ Bolt Number } & Bolt Type & $\begin{array}{c}\text { Preload } \\
(\% \text { of Fu) }\end{array}$ & $\begin{array}{c}\text { Maximum } \\
\text { Load (kN) }\end{array}$ & $\begin{array}{c}\text { Minimum } \\
\text { Load (kN) }\end{array}$ & $\begin{array}{c}\text { \% } \\
\text { Relaxation } \\
(\mathbf{7 2} \text { hours) }\end{array}$ \\
\hline 1 & $\begin{array}{c}\text { A325 - } \\
\text { Galvanized }\end{array}$ & $90 \%$ & 230.200 & 218.500 & 5.08 \\
\hline 2 & $\begin{array}{c}\text { A325 - } \\
\text { Galvanized }\end{array}$ & $90 \%$ & 230.102 & 222.654 & 3.24 \\
\hline 3 & $\begin{array}{c}\text { A325- } \\
\text { Galvanized }\end{array}$ & $90 \%$ & 231.378 & 218.997 & 5.35 \\
\hline 4 & $\begin{array}{c}\text { A325- } \\
\text { Galvanized }\end{array}$ & $90 \%$ & 229.870 & 218.702 & 4.86 \\
\hline 5 & $\begin{array}{c}\text { A325- } \\
\text { Galvanized }\end{array}$ & $90 \%$ & 229.810 & 219.771 & 4.37 \\
\hline 6 & $\begin{array}{c}\text { A325- } \\
\text { Galvanized }\end{array}$ & $90 \%$ & 230.022 & 221.341 & 3.77 \\
\hline Average & $\begin{array}{c}\text { A325- } \\
\text { Galvanized }\end{array}$ & $\mathbf{9 0 \%}$ & $\mathbf{2 3 0 . 2 3}$ & $\mathbf{2 1 9 . 7 6 7}$ & $\mathbf{4 . 5 5}$ \\
\hline
\end{tabular}

Table D-5: A193 B8 Class 2 Stainless Steel Bolt with Galvanized Nut and Stainless Steel Washer Pretensioned at $70 \%$ of $\mathbf{F}_{\mathbf{u}}$

\begin{tabular}{|c|c|c|c|c|c|}
\hline Bolt Number & Bolt Type & $\begin{array}{l}\text { Preload } \\
(\% \text { of Fu) }\end{array}$ & $\begin{array}{l}\text { Maximum } \\
\text { Load }(k N)\end{array}$ & $\begin{array}{l}\text { Minimum } \\
\text { Load }(k N)\end{array}$ & $\begin{array}{c}\text { \% Relaxation } \\
\text { (72 hours) }\end{array}$ \\
\hline 1 & $\begin{array}{c}\text { A193 B8 } \\
\text { Class } 2 \mathrm{w} / \\
\text { Galvanized Nut }\end{array}$ & $70 \%$ & 151.389 & 142.843 & 5.65 \\
\hline 2 & $\begin{array}{c}\text { A193 B8 } \\
\text { Class } 2 \text { w/ } \\
\text { Galvanized Nut }\end{array}$ & $70 \%$ & 152.691 & 141.603 & 7.26 \\
\hline 3 & $\begin{array}{c}\text { A193 B8 } \\
\text { Class } 2 \mathrm{w} / \\
\text { Galvanized Nut }\end{array}$ & $70 \%$ & 151.690 & 136.104 & 10.28 \\
\hline 4 & $\begin{array}{c}\text { A193 B8 } \\
\text { Class } 2 \mathrm{w} / \\
\text { Galvanized Nut }\end{array}$ & $70 \%$ & 150.762 & 132.734 & 11.96 \\
\hline 5 & $\begin{array}{c}\text { A193 B8 } \\
\text { Class } 2 \mathrm{w} / \\
\text { Galvanized Nut }\end{array}$ & $70 \%$ & 151.078 & 141.748 & 6.18 \\
\hline Average & $\begin{array}{c}\text { A193 B8 } \\
\text { Class } 2 \text { w/ } \\
\text { Galvanized } \\
\text { Nut }\end{array}$ & $70 \%$ & 151.495 & 139.012 & 8.24 \\
\hline
\end{tabular}


Table D-6: A193 B8 Class 2 Stainless Steel Bolt with Plain Nut and Stainless Steel Washer Pretensioned at $70 \%$ of $\mathrm{F}_{\mathbf{u}}$

\begin{tabular}{|c|c|c|c|c|c|}
\hline Bolt Number & Bolt Type & $\begin{array}{l}\text { Preload } \\
\text { (\% of Fu) }\end{array}$ & $\begin{array}{l}\text { Maximum } \\
\text { Load }(k N)\end{array}$ & $\begin{array}{l}\text { Minimum } \\
\text { Load (kN) }\end{array}$ & $\begin{array}{c}\text { \% Relaxation } \\
\text { (72 hours) }\end{array}$ \\
\hline 1 & $\begin{array}{l}\text { A193 B8 } \\
\text { Class } 2 \text { w/ } \\
\text { Plain Nut }\end{array}$ & $70 \%$ & 150.356 & 144.782 & 3.71 \\
\hline 2 & $\begin{array}{c}\text { A193 B8 } \\
\text { Class } 2 \mathrm{w} / \\
\text { Plain Nut }\end{array}$ & $70 \%$ & 150.288 & 141.310 & 5.97 \\
\hline 3 & $\begin{array}{l}\text { A193 B8 } \\
\text { Class } 2 \text { w/ } \\
\text { Plain Nut }\end{array}$ & $70 \%$ & 150.024 & 138.377 & 7.76 \\
\hline 4 & $\begin{array}{l}\text { A193 B8 } \\
\text { Class } 2 \text { w/ } \\
\text { Plain Nut }\end{array}$ & $70 \%$ & 150.830 & 134.442 & 10.81 \\
\hline 5 & $\begin{array}{l}\text { A193 B8 } \\
\text { Class } 2 \text { w/ } \\
\text { Plain Nut }\end{array}$ & $70 \%$ & 150.730 & 133.242 & 11.60 \\
\hline Average & $\begin{array}{l}\text { A193 B8 } \\
\text { Class } 2 \text { w/ } \\
\text { Plain Nut }\end{array}$ & $70 \%$ & 150.446 & 138.431 & 7.99 \\
\hline
\end{tabular}




\section{Appendix E - Tensile Test Graphs}

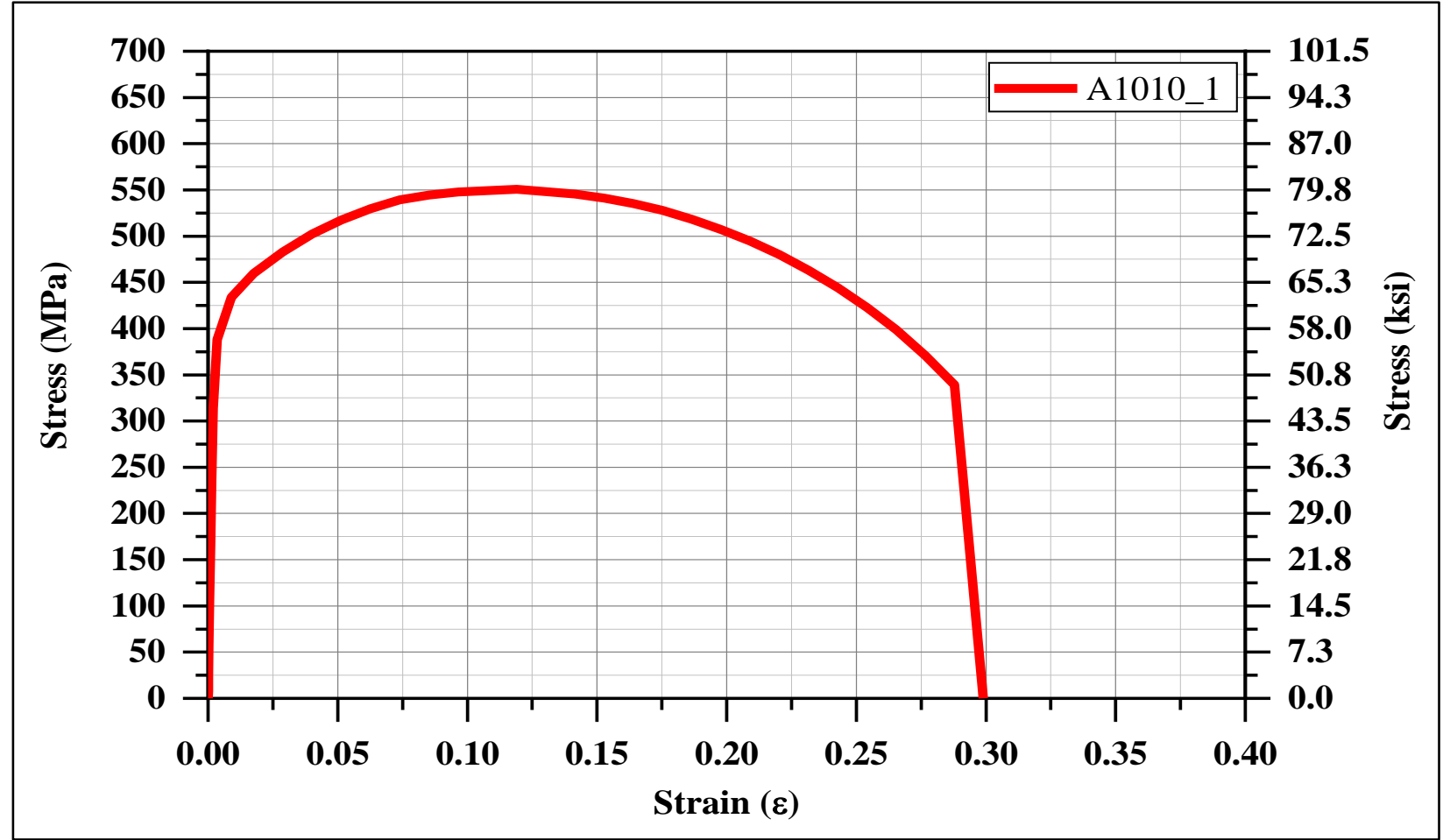

Figure E-1: Stress vs Strain Curve of A1010 Short Specimen

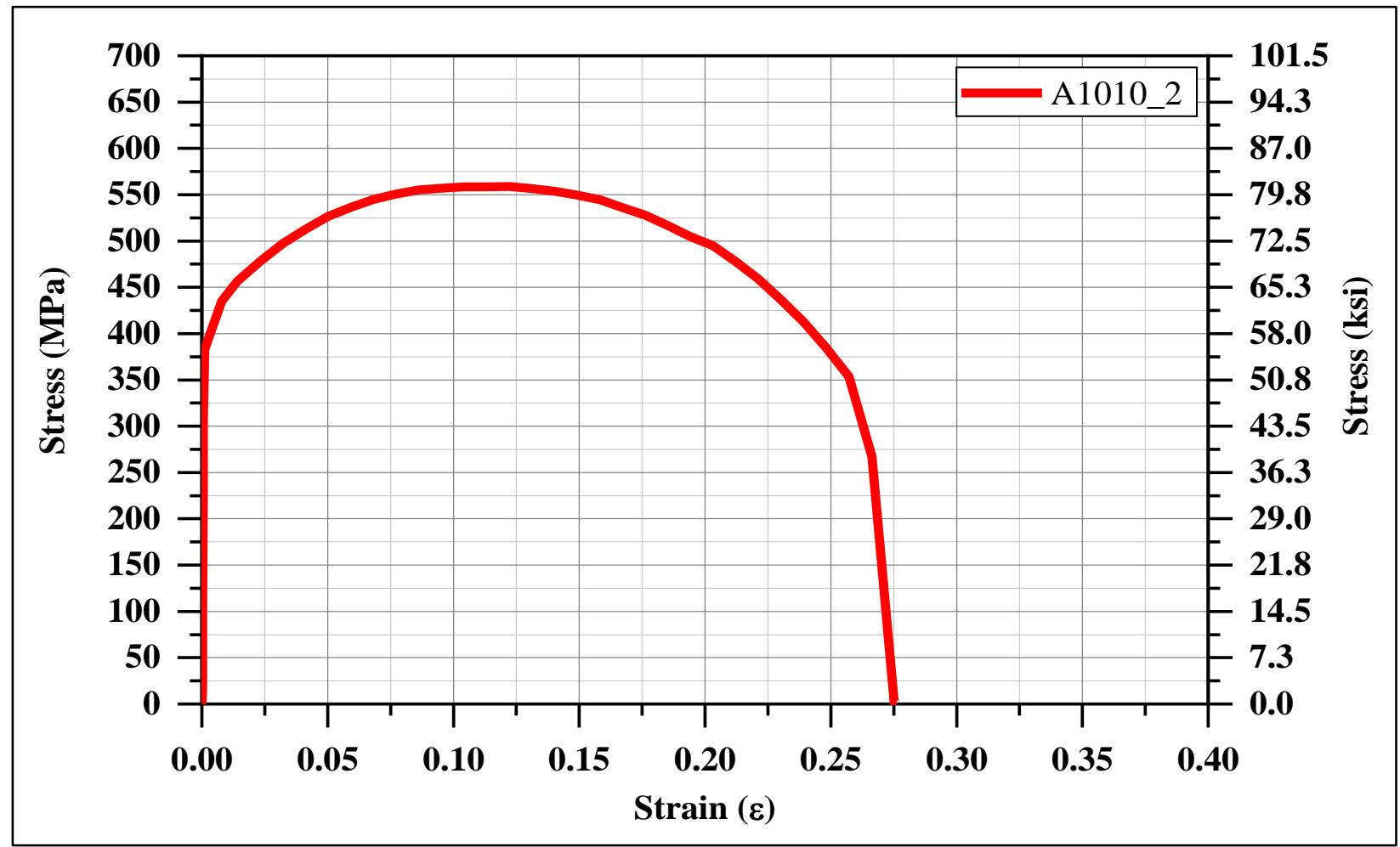

Figure E-2: Stress vs Strain Curve of A1010 Long Specimen 


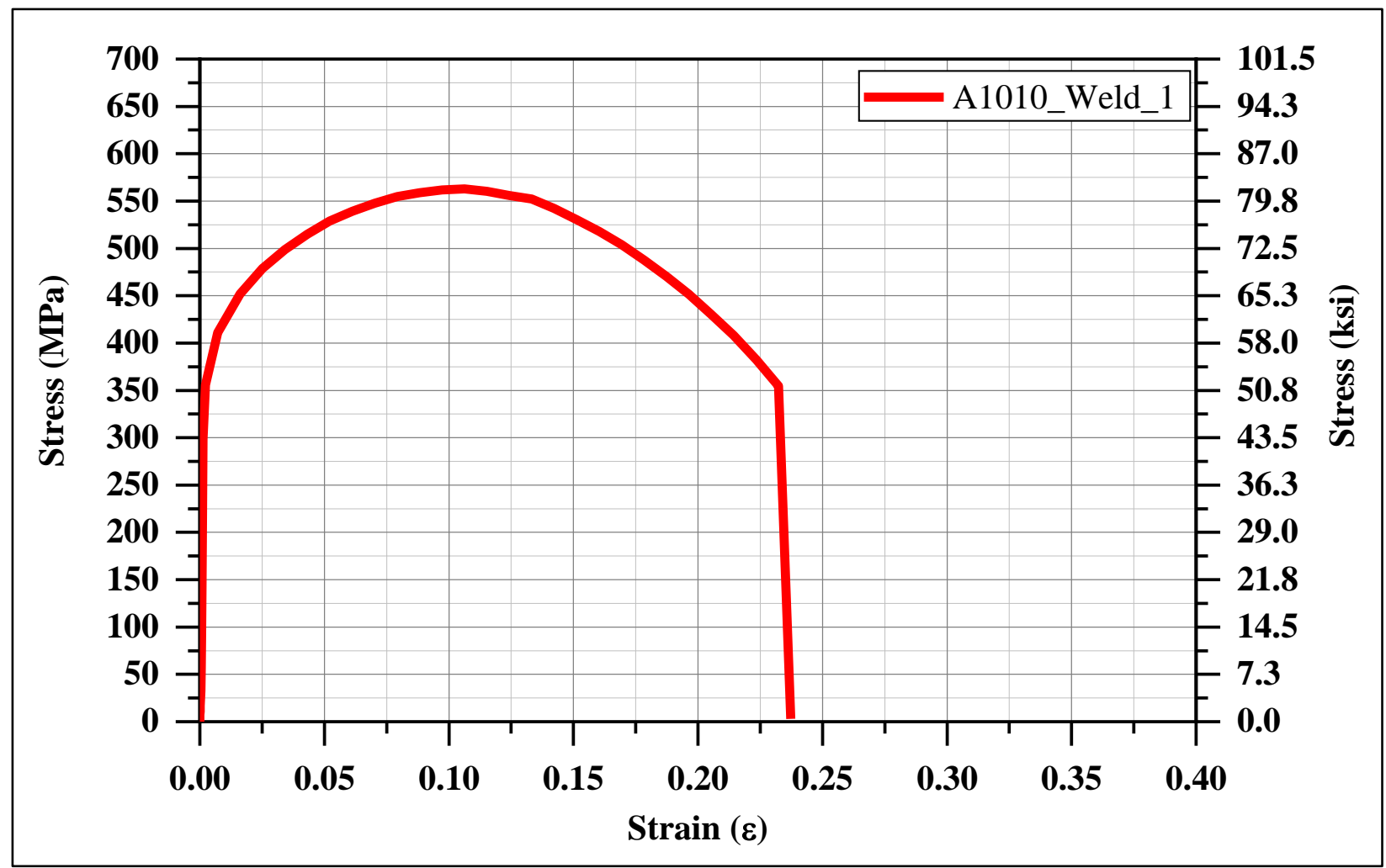

Figure E-3: Stress vs Strain Curve of A1010 Welded Short Specimen

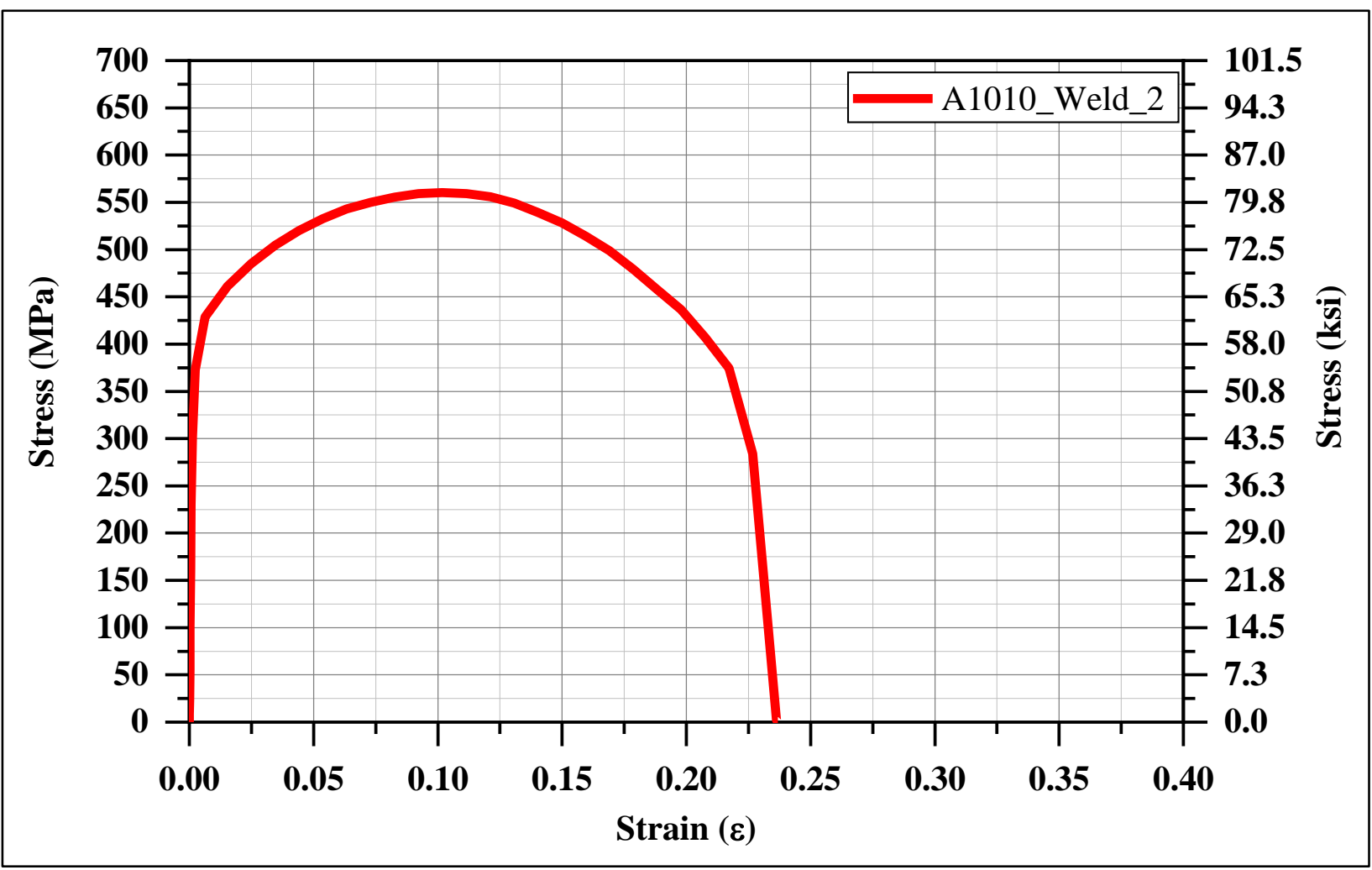

Figure E-4: Stress vs Strain Curve of A1010 Welded Long Specimen 


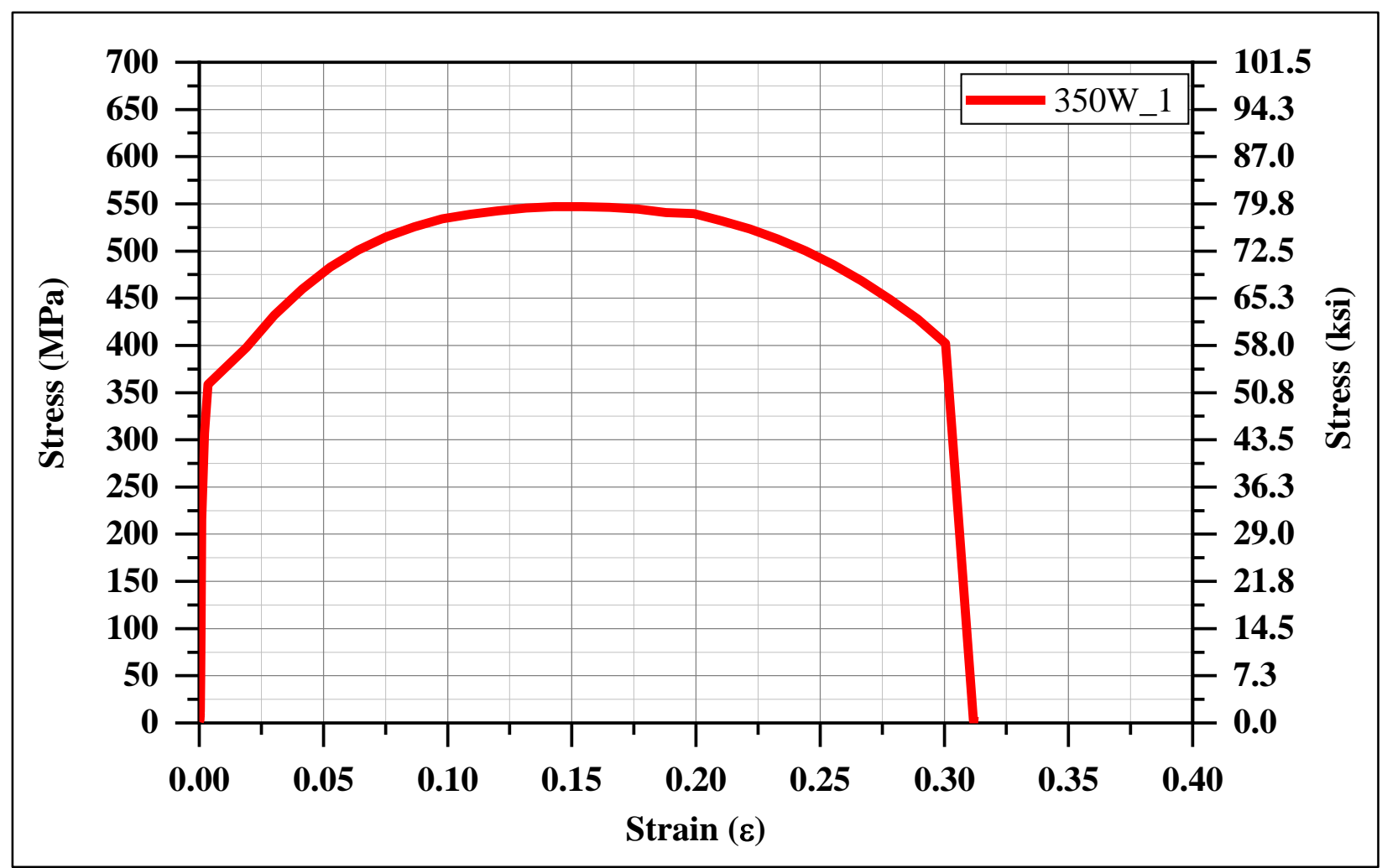

Figure E-5: Stress vs Strain Curve of 350W Short Specimen

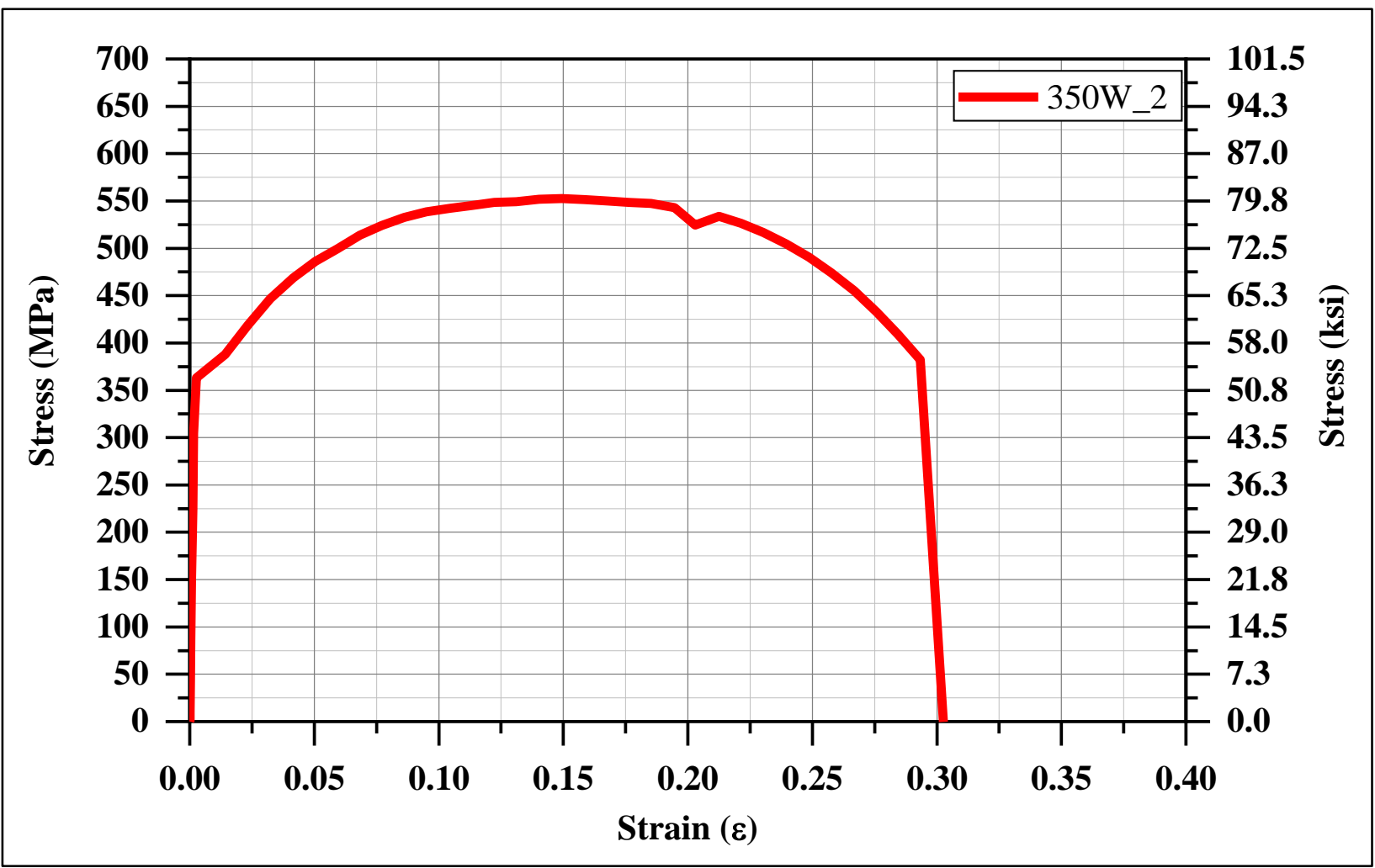

Figure E-6: Stress vs Strain Curve of 350W Long Specimen 


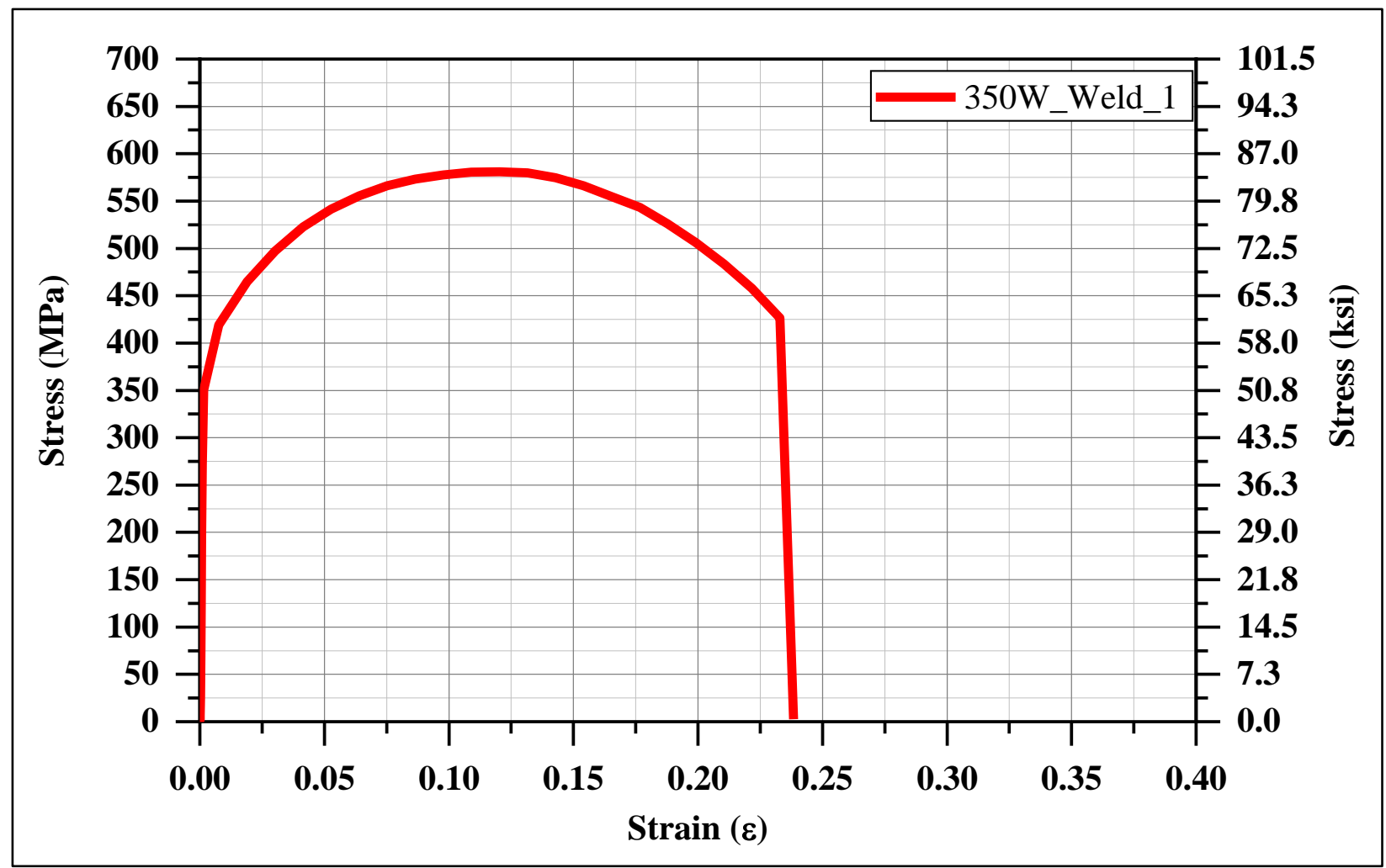

Figure E-7: Stress vs Strain Curve for 350W Welded Short Specimen

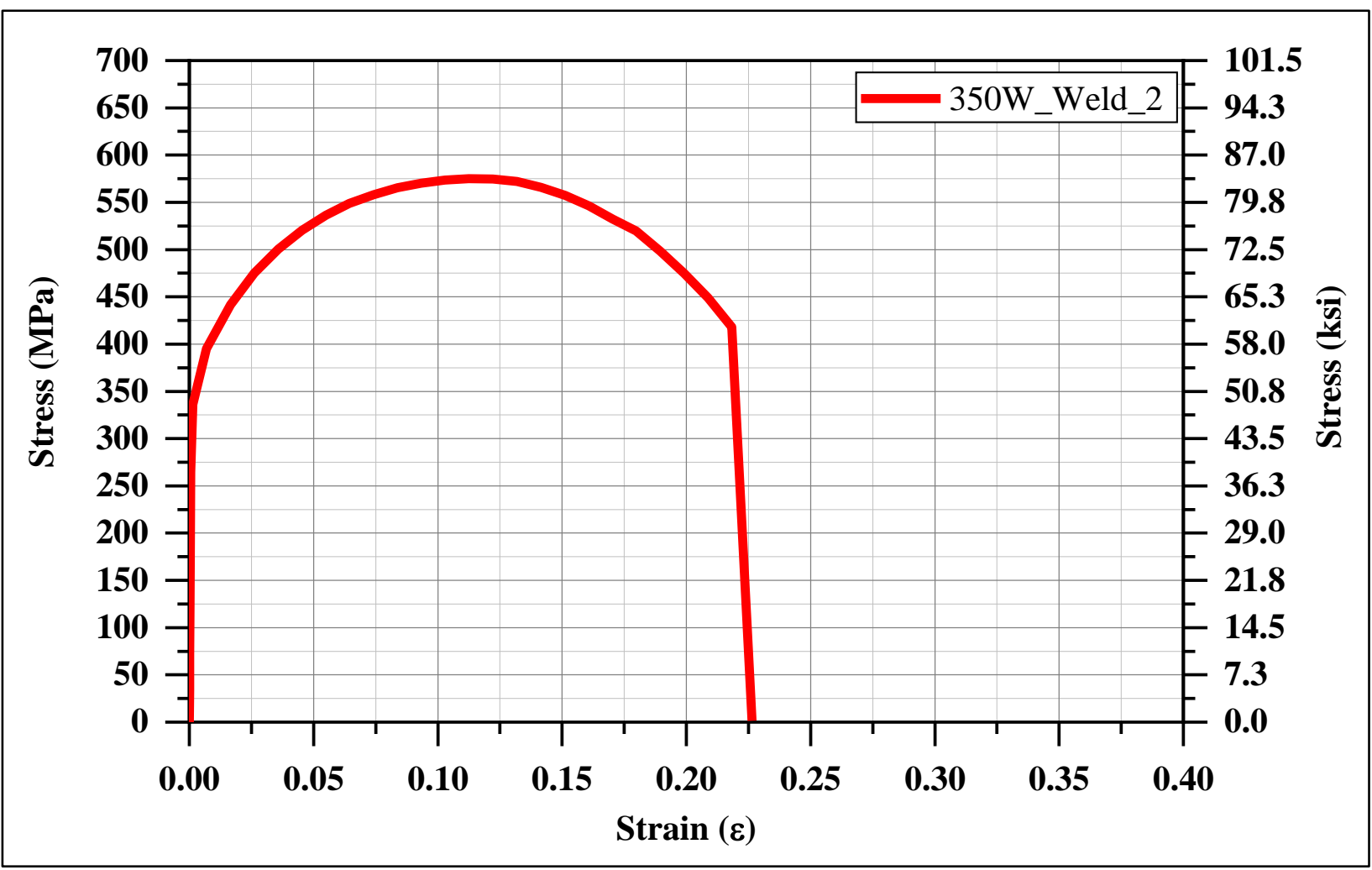

Figure E-8: Stress vs Strain Curve of 350W Welded Long Specimen 


\section{Appendix F - CSA G40.21 Steel Properties}

Some of the readers of this report might not be very familiar with Canadian manufactured steel. Thus, the purpose of this appendix is to define some of the technical properties of common Canadian steels used for bridges. In general, commonly used Canadian steels meet the requirements of ASTM A992/992M.

Grades of Canadian structural quality steel in accordance with CSA G40.21-13 include the following types:

Type W - Weldable steel: Steels of this type are suitable for general welded construction where notch toughness at low temperatures is not a design requirement. This type of steel can be used as compression members of bridges.

Type WT - Weldable notch-tough steel: Steels of this type are suitable for welded construction where notch toughness at low temperature is a design requirement. This type of steel can be used as primary tension members in bridges and similar elements.

Type A - Atmospheric corrosion-resistant weldable steel: Steels of this type are suitable in areas where corrosion resistance is required because they perform substantially better in most environments than carbon structural steels with or without copper addition. These steel types can be welded up to their maximum thickness specified in the standard.

Type AT - Atmospheric corrosion-resistant weldable notch-tough steel: Similar to Type A steel except it is used where notch toughness at low temperature is a design requirement.

Tables F-1 and F-2 on the next page will only show the chemical composition and mechanical properties of the various grade 350 type steels. If the reader needs more information for other grades and types of steels, they are encouraged to purchase a copy of the Canadian standard requirements for rolled or welded structural quality steel/Structural quality steel CSA G40.2013/G40.21-13, which explains in more detail the most common requirements of various grades and shapes. 
Table F-1: Chemical composition by heat analysis of Canadian grade 350 steel plates, bars, shapes, and sheets

\begin{tabular}{|c|c|c|c|c|c|c|c|c|c|}
\hline Grade & $\begin{array}{c}\text { C, } \\
\max \end{array}$ & Mn & $\mathbf{P}$ & $\begin{array}{c}\text { S, } \\
\text { max }\end{array}$ & $\mathbf{S i}$ & $\mathrm{Cr}$ & $\mathbf{N i}$ & $\mathrm{Cu}$ & $\begin{array}{c}\text { Grain } \\
\text { refining } \\
\text { elements, } \\
\text { max }\end{array}$ \\
\hline $350 W$ & 0.23 & $\begin{array}{c}0.50- \\
1.50\end{array}$ & $\begin{array}{l}0.04 \\
\max \end{array}$ & 0.05 & $\begin{array}{l}0.40 \\
\max \end{array}$ & - & - & - & 0.15 \\
\hline 350WT & 0.22 & $\begin{array}{c}0.80- \\
1.50\end{array}$ & $\begin{array}{l}0.03 \\
\max \end{array}$ & 0.04 & $\begin{array}{c}0.15- \\
0.40\end{array}$ & - & - & - & 0.15 \\
\hline $350 \mathrm{~A}$ & 0.20 & $\begin{array}{c}0.75- \\
1.35\end{array}$ & $\begin{array}{l}0.03 \\
\max \end{array}$ & 0.04 & $\begin{array}{c}0.15- \\
0.50\end{array}$ & $\begin{array}{l}0.70 \\
\max \end{array}$ & $\begin{array}{l}0.90 \\
\max \end{array}$ & $\begin{array}{c}0.20- \\
0.60\end{array}$ & 0.15 \\
\hline 350AT & 0.20 & $\begin{array}{c}0.75- \\
1.35\end{array}$ & $\begin{array}{l}0.03 \\
\max \end{array}$ & 0.04 & $\begin{array}{c}0.15- \\
0.50\end{array}$ & $\begin{array}{l}0.70 \\
\max \end{array}$ & $\begin{array}{l}0.90 \\
\max \end{array}$ & $\begin{array}{c}0.20- \\
0.60\end{array}$ & 0.15 \\
\hline
\end{tabular}

Table F-2: Mechanical properties of Canadian steel grade 350 plates, bars, sheets, and welded shapes

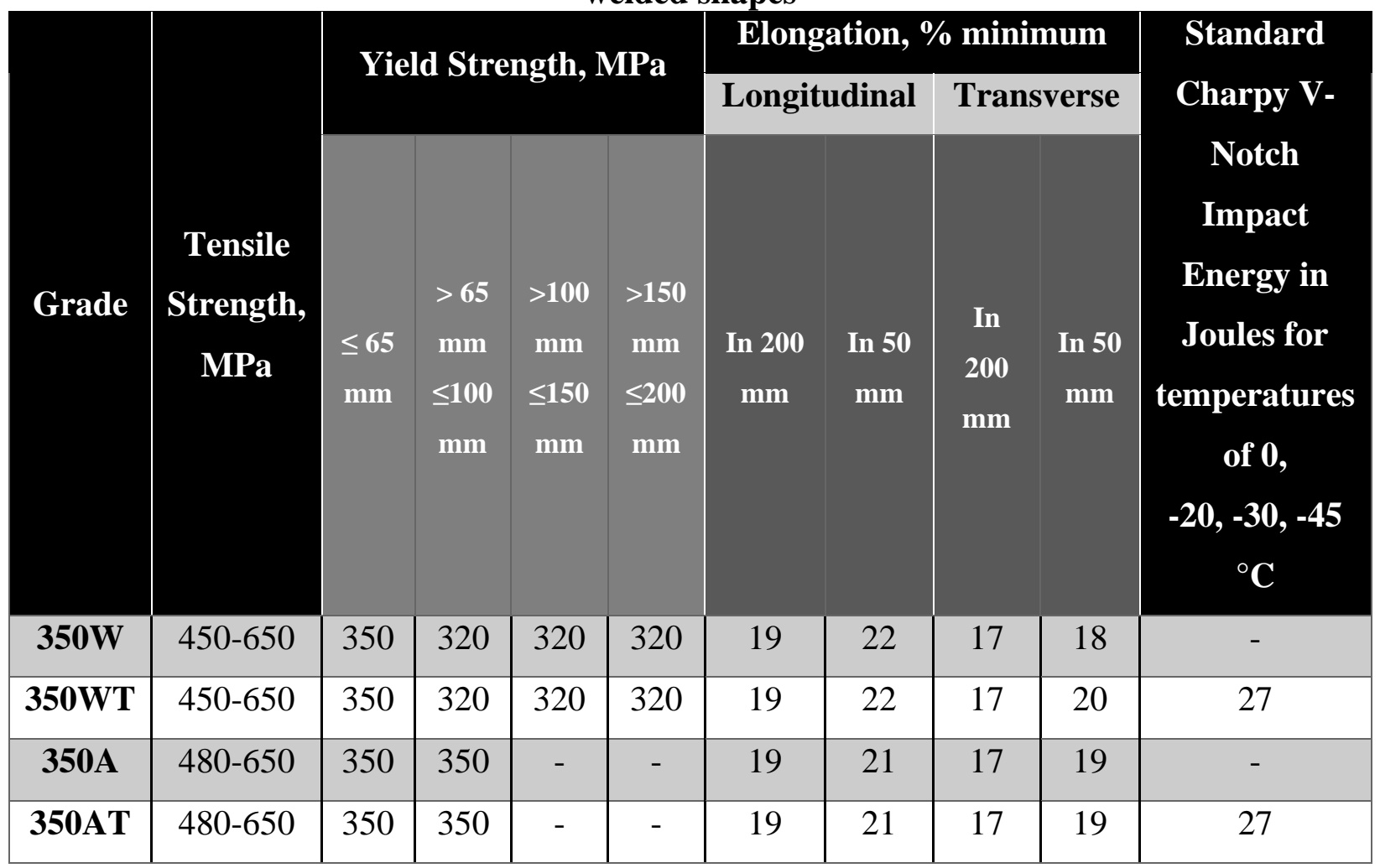




\section{BIBLIOGRAPHY}

AASHTO. (2017). LRFD Bridge Design Specifications 8th Edition. American Association of State Highway and Transportation Officials. Washington, D.C.

Afzali, N., Pilhagen, J., Manninen, T., Schedin, E., and Stranghöner, N. (2017). Preload Losses in Stainless Steel Bolting Assemblies. Steel Construction, 10(4), 310-318. doi:10.1002/stco.201710041.

Agerskov, H. (2000). Fatigue in Steel Structures Under Random Loading. Journal of Constructional Steel Research, 53(3), 283-305. doi:10.1016/S0143-974X(99)00042-5

Agerskov, H., and Nielsen, J. A. (1999). Fatigue in Steel Highway Bridges Under Random Loading. Journal of Structural Engineering, 125(2), 152-162. doi:10.1061/(ASCE)07339445(1999)125:2(152).

ArcelorMittal USA. (2015). Duracorr @: Life-Cycle Cost Effective 12\% Chromium Stainless Steel. Retrieved from: https://usa.arcelormittal.com/ /media/Files/A/Arcelormittal-USAV2/what-we-do/steel-products/plate-products/Duracorr-lifecycle.pdf

ArcelorMittal USA. (2016a). Duracorr ®/A1010: Bridge Applications and Fabrication Guidelines. Retrieved from: https://usa.arcelormittal.com/ /media/Files/A/Arcelormittal-USA-V2/what-wedo/steel-products/plate-products/Duracorr-Bridge.pdf

ArcelorMittal USA. (2016b). Duracorr ®: Welding Guidelines. Retrieved from: https://usa.arcelormittal.com/ /media/Files/A/Arcelormittal-USA-V2/what-we-do/steel-

products/plate-products/Duracorr-welding.pdf

ASM International. (1990). ASM Handbook: Volume 1. Properties and Selection: Irons Steels and High Performance Alloys. American Society for Metals. Materials Park, OH.

ASTM International. (2012). E606/E606M-12 Standard Test Method for Strain-Controlled Fatigue Testing. American Society for Testing and Materials.

ASTM International. (2013). A1010/A1010M-13, Standard Specification for Higher-Strength Martensitic Stainless Steel Plates, Sheet and Strip. American Society for Testing and Materials.

ASTM International. (2015). E466-15, Standard Practice for Conducting Force Controlled Constant Amplitude Axial Fatigue Tests of Metallic Materials. American Society for Testing and Materials.

ASTM International. (2016). E8/E8M-16a, Standard Test Methods for Tension Testing of Metallic Materials. American Society for Testing and Materials.

ASTM International. (2017a). A193/A193M-17, Standard Specification for Alloy-Steel and Stainless Steel Bolting for High Temperature or High Pressure Service and Other Special Purpose Applications. American Society for Testing and Materials. 
ASTM International. (2017b). D7127-17, Standard Test Method for the Measurement of Surface Roughness of Abrasive Blast Cleaned Metal Surface using a Portable Stylus Instrument. American Society for Testing and Materials.

ASTM International. (2018a). E468-18, Standard Practice for Presentation of Constant Amplitude Fatigue Test Results for Metallic Materials. American Society for Testing and Materials.

ASTM International. (2018b). F3125/F3125M-18, Standard Specification for High Strength Structural Bolts and Assemblies, Steel and Alloy Steel, Heat Treated, Inch Dimensions 120 ksi and $150 \mathrm{ksi}$ Minimum Tensile Strength, and Metric Dimensions $830 \mathrm{MPa}$ and $1040 \mathrm{MPa}$ Minimum Tensile Strength. American Society for Testing and Materials.

ASTM International. (2019a). A370-19e1, Standard Test Method and Definitions for Mechanical Testing of Steel Products. American Society for Testing and Materials.

ASTM International. (2019b). A709/A709M-19, Standard Specification for Structural Steel for Bridges. American Society for Testing and Materials.

ASTM International. (2019c). D4417-19, Standard Test Method for Field Measurement of Profile of Blast Cleaned Steel. American Society for Testing and Materials.

AWS D1.1/D1.1M: Structural Welding Code - Steel: 2015. American Welding Society.

AWS D1.5/D1.5M: Bridge Welding Code: 2015. American Welding Society.

Baddoo, N. (2013). Structural Stainless Steel. Design Guide 27. American Institute of Steel Construction. Chicago, IL.

Bennett, C. R., Swanson, J. A., and Linzell, D. G. (2009). Fatigue Resistance of HPS-485 W (70 W) Welded Butt-Splice Connections Using Narrow Gap Improved Electroslag Welding. Journal of Bridge Engineering, 14(6), 529-536. doi:10.1061/(ASCE)1084-0702(2009)14:6(529).

Cameron, O. (2017). Experimental Study on Slip Resistance Performance of ASTM A1010 Stainless Steel Bolted Connections. MASc Thesis. Ryerson University. Toronto, Canada.

Chen, H. (2005). Fatigue Resistance of High Performance Steel (HPS) Details. PhD Dissertation. University of Alberta. Edmonton, Alberta, Canada.

CISC. (2014). Handbook of Steel Construction, 11th edition. Canadian Institute of Steel Construction. Willowdale, Ontario.

Cook, D.C. (2010). Moore Drive Bridge: Coupon Exposure Tests. AISI Corrosion Advisory Group Meeting, Washington, D.C.

Corro, C.L. (1998). An Evaluation of the Behaviour of Slip-Critical Connections Subjected to Combined Shear and Tension. MASc Thesis. University of Windsor, Windsor, ON.

CSA (2014a). Canadian Highway Bridge Design Code, CSA-S6-14. Canadian Standards Association. Toronto, Ontario. 
CSA (2014b). Design of Steel Structures, CSA-S16-14. Canadian Standards Association. Toronto, Ontario.

CSA (2018). General Requirements for Rolled or Welded Structural Quality Steel / Structural Quality Steel, CSA G40.20-2013/G40.21-2013. Canadian Standards Association. Toronto, Ontario.

CSA (2018). Welded Steel Construction (Metal Arc Welding), CSA W59-18. Canadian Standards Association. Toronto, Ontario, Canada.

Daghash, S. M., Huang, Q., and Ozbulut, O. E. (2019). Tensile Behavior and Cost-Efficiency Evaluation of ASTM A1010 Steel for Bridge Construction. Journal of Bridge Engineering, 24(8), 4019078. doi:10.1061/(ASCE)BE.1943-5592.0001449.

Davis, J.R. (2000). Corrosion: Understanding the Basics. ASM International. Materials Park, OH.

EN 1090-2:2018 + A1:2018: Execution of Steel Structures and Aluminium Structures - Part 2: Technical Requirements for Steel Structures. European Committee for Standardization.

EN 1993-1-8:2005 + AC:2009: Design of Steel Structures - Part 1-8: Design of Joints. Eurocode 3. European Committee for Standardization.

Fisher, J.W. (1984). Fatigue and Fracture in Steel Bridges: Case Studies, Wiley Interscience.

Fisher, J.W. and Kulak, G.L. (1968). Tests of Bolted Butt Splices. Journal of the Structural Division, ASCE, Vol 94, ST11. pp.2609-2619.

Fisher, J.W., Kulak, G.L. and Smith, I.F.C. (1998). A Fatigue Primer for Structural Engineers, National Steel Bridge Alliance.

Fletcher, F.B. (2011). Improved Corrosion-Resistant Steel for Highway Bridge Construction. Report No. FHWA-HRT-11-062. Federal Highway Administration. McLean, VA, USA.

Fletcher, F.B., Wilson, A.D., Strasky, J., Kilpatrick, J.N., Mlcoch, T., Wrysinski, J.S. (2005). Stainless Steel for Accelerated Bridge Construction. FHWA Accelerated Bridge Construction Conference, San Diego, CA, USA.

Fouad, F.H. (1978). Slip Behaviour of Bolted Friction-Type Joints with Coated Faying Surfaces. MSc Thesis. University of Texas. Austin, Texas, USA.

Ghahremani, K. (2010). Predicting the Effectiveness of Post-Weld Treatments Applied Under Load. MASc Thesis. University of Waterloo, Waterloo, Ontario, Canada.

Ghahremani, K., and Walbridge, S. (2011). Fatigue Testing and Analysis of Peened Highway Bridge Welds Under In-Service Variable Amplitude Loading Conditions. International Journal of Fatigue, 33(3), 300-312. doi:10.1016/j.ijfatigue.2010.09.004.

Grondin, G. Y., Jin, M., and Georg, J. (2007). Slip Critical Bolted Connections: A Reliability Analysis for Design at the Ultimate Limit State. Structural Engineering Report 274. University of Alberta. Edmonton, Alberta, Canada. doi: https://doi.org/10.7939/R3QR4NQ55. 
Groshek, I. G. (2017). Corrosion Behavior of ASTM A1010 Stainless Steel for Applications in Bridge Components. PhD dissertation, Virginia Polytechnic Institute and State University. Blacksburg, Virginia, USA.

Groshek, I., Hebdon, M. (2018). Accelerated Corrosion Testing of ASTM A1010 Stainless Steel. Conference Proceedings World Steel Bridge Symposium. Baltimore, MD, USA.

Gurney, T.R. (1979). Fatigue of Welded Structures, 2nd Edition, Cambridge University Press.

Haftirman, R., Syayuthi, A.A.R., Afendi, M., Abdul Majid, M.S., Rong, T.C. (2012). Fatigue Behavior of Butt Welded Joints in Mild Steel. International Conference on Marine Technology. Kuala Terengganu, Malaysia.

Haodi, S. (2017). Experimental Investigation and Simulation of High Performance Surface Coating in Steel Bolted Slip-Critical Connections. MSc Thesis. University of Louisiana at Lafayette. Lafayette, Louisiana, USA.

Hebdon, M. (2018). Developments and Applications of a Corrosion Resistant Stainless Steel Bridge: A709 Grade 50CR (A1010). Proceedings of 63rd Annual Structural Engineering Conference. Lawrence, Kansas, USA.

Hradil, P., Chen, A., and Baddoo, N. (2017). Numerical Modelling of Stainless Steel Preloaded Bolted Connections. Steel Construction, 10(4), 344-353. doi:10.1002/stco.201710039.

Iowa DOT (2016). Iowa A1010 Experience. AASHTO T14 Meeting. August, 2016.

Kogler, R. (2015). Steel Bridge Design Handbook: Corrosion Protection of Steel Bridges. Report No. FHWA-HIF-16-002 - Volume 19. Federal Highway Administration. Washington, D.C., USA

Kulak, G. L., Fisher, J. W., and Struik, J. H. A. (2001). Guide to Design Criteria for Bolted and Riveted Joints, 2nd Edition. John Wiley and Son, New York, New York, USA.

Kulak, G.L., and Smith, I.F.C. (1993). Analysis and Design of Fabricated Steel Structures for Fatigue: A Primer for Civil Engineers. Structural Engineering Report No. 190. University of Alberta. Edmonton, Alberta, Canada.

Kuperus, A. (1966). The Ratio Between the Slip Factor of Fe52 and Fe37. C.E.A.C.M. X-6-27. Report 6-66-2, VB-13, Stevin Laboratory, Department of Civil Engineering. Delft University of Technology. Deflt, Netherlands.

Lee, J.H., O’Conner, C., and Fisher, J.W. (1969). Effect of Surface Coatings and Exposure on Slip. Journal of the Structural Division, ASCE, Vol. 95, ST11, pp.2371-2383.

Maiorana, E., and Pellegrino, C. (2013). Comparison Between Eurocodes and North American and Main International Codes for Design of Bolted Connections in Steel Bridges. Journal of Bridge Engineering, 18(12), 1298-1308. doi:10.1061/(ASCE)BE.1943-5592.0000512.

McLeod, C., Haalstra, M., and Lai, D. (2018). Implementation of ASTM A1010 Corrosion Resistant Steel for Bridges: Practical Design and Construction Considerations. Proceedings of the 10th International Conference on Short and Medium Span Bridges. Quebec City, Quebec, Canada. 
Mertz, D. (2015). Steel Bridge Design Handbook: Design for Fatigue. Report No. FHWA-HIF16-002- Volume 12. Federal Highway Administration. Washington, D.C, USA.

Moss, D.S. (1979). High Strength Friction Grip Bolted Joints - Effects After One Year of Weathering Under Load. Supplementary Report 409. Transport and Road Research Laboratory, Crowthorne, England.

Munse, W.H. and Grover, L.M. (1964). Fatigue of Welded Steel Structures, Welding Research Council, New York, New York, USA.

OriginLab. (2016). Origin User Guide. OriginLab Corporation. Northampton, MA, USA.

Phares. B., Shafei, B., Shi, W. (2020). Evaluation of the Performance of A1010 Bridge Steel. InTrans Project 16-562. Iowa Department of Transportation.

Provines, J.T., Sharp, S.R., Ozbulut, O., and Daghash, S. (2019). Maintenance-Free CorrosionResistant Steel Plate for Bridges. Report No.: FHWA/VTRC 19-R21. Virginia Transportation Research Council.

RCSC. (2014). Specification for Structural Joints Using ASTM A325 or A490 Bolts. Research Council on Structural Connections, American Institute of Steel Construction.

Reuther, D., Baker, I., Yetka, A., Cleary, D. B., and Riddell, W. (2014). Relaxation of ASTM A325 bolted assemblies. Journal of Structural Engineering, 140(9), 04014060.

Salib, S., Archibald, B., and Liu, K. (2018). Speed River Bridges: First Highway Bridges in Canada with Stainless Steel ASTM A1010 Girders. Proceedings of the 10th International Conference on Short and Medium Span Bridges. Quebec City, Quebec, Canada.

Seradj, H. (2010). Weldability of ASTM A1010 Steel. Proceedings of the 8th International Conference on Short and Medium Span Bridges, Niagara Falls, Canada.

Seradj, H. (2014). Oregon's Second ASTM A1010 Bridge. Proceedings of the World Steel Bridge Symposium Conference. Toronto, Ontario, Canada.

Seradj, H. (2015). Oregon's Experience with ASTM A1010. TRB Report No. 15-3926. Washington, D.C, USA.

Sharp, S. R., Provines, J., Moruza, A. K., Via, W. F., and Harrop, K.N. (2018). Design, Fabrication, Construction, and Cost Assessment of Virginia's First Corrosion Resistant ASTM A1010 Plate Girder Bridge. Transportation Research Record, 2672(26), 68-76. doi:10.1177/0361198118773888.

SIROCO. (2019). Execution and reliability of slip resistant connections for steel structures using CS and SS. European Commission. Research Fund for Coal and Steel. ISBN: 978-92-79-983115.

SSPC/NACE. (2018). Standard of the Society for Protective Coatings. National Association of Corrosion Engineers. SSPC SP-5/NACE\#1. White Metal Blasting. Pittsburgh, PA, USA. 
Stephens, R.I., Fatemi, A., Stephens, R.R., and Fuchs, H.O. (2001). Metal Fatigue in Engineering (2nd Edition). John Wiley \& Sons.

Sterner, F. (2015). Building the Ravenel Bridge. Retrieved from: ravenelbridge.net

Stranghöner, N., Afzali, N., de Vries, P., Schedin, E., and Pilhagen, J. (2019). Slip Factors for SlipResistant Connections Made of Stainless Steel. Journal of Constructional Steel Research, 152, 235-245.

Stranghöner, N., Afzali, N., de Vries, P., Schedin, E., Pilhagen, J., and Cardwell, S. (2017). SlipResistant Bolted Connections of Stainless Steel. Steel Construction, 10(4), 333-343.

Taban, E., Deleu, E., Dhooge, A., and Kaluc, E. (2009). Laser Welding of Modified 12\% CR Stainless Steel: Strength, Fatigue, Toughness, Microstructure and Corrosion Properties. Materials and Design, 30(4), 1193-1200. doi:10.1016/j.matdes.2008.06.030.

Tehrani, R. (2012). Acceptance Criteria for Ultrasonic Impact Treatment of Highway Bridges. MASc Thesis. University of Waterloo. Waterloo, Ontario, Canada.

Vasarhelyi, D.D. and Chiang, C. (1967). Coefficient of Friction in Joints of Various Steels. Journal of the Structural Division, ASCE, Vol 93, ST4, pp.227-243.

Vilhauer, B. (2007). Fatigue Behavior of Welded Connections Enhanced with UIT and Bolting. MSc Thesis. University of Kansas. Lawrence, Kansas, USA.

Williams, T. R., Xia, X., Darby, T. E., and Sharp, S. R. (2017). Evaluation of Stainless Steel Fasteners for Bolted Field Splice Connections of ASTM A1010 Corrosion-Resistant Steel Plate Girders. Transportation Research Record, 2630(1), 85-94. doi:10.3141/2630-11.

Zong, L., Shi, G., Wang, Y., \& Zhou, H. (2016). Fatigue Assessment on Butt Welded Splices in Plates of Different Thicknesses. Journal of Constructional Steel Research, 129, 93-100. doi:10.1016/j.jcsr.2016.11.010.

Zhang, J., Ebrahimi, N., and Lai, D. (2019). Galvanic Corrosion Risk of Using Galvanized A325 Bolts in Corrosion-Resistant Steel Bridges. Journal of Bridge Engineering, 24(6), 6019001. doi:10.1061/(ASCE)BE.1943-5592.0001395.

\section{Other Useful References Not Cited In-Text}

Afzali, N., Stranghöner, N., Pilhagen, J., Manninen, T., and Schedin, E. (2019). Viscoplastic Deformation Behaviour of Preloaded Stainless Steel Connections. Journal of Constructional Steel Research, 152, 225-234. doi:10.1016/j.jcsr.2018.07.004.

Annan, C.D., and Chiza, A. (2014). Slip Resistance of Metalized-Galvanized Faying Surface in Steel Bridge Construction. Journal of Constructional Steel Research, 95: 211-219.

Baddoo, N. R. (2008). Stainless steel in Construction: A Review of Research, Applications, Challenges and Opportunities. Journal of Constructional Steel Research, 64(11), 1199-1206. doi:10.1016/j.jcsr.2008.07.011. 
Bickford, J. H. (2007). Introduction to the Design and Behavior of Bolted Joints: Non-Gasketed Joints. CRC press.

Coughlin, R., and Walbridge, S. (2012). Fatigue Testing and Analysis of Aluminum Welds Under In-Service Highway Bridge Loading Conditions. Journal of Bridge Engineering, 17(3), 409-419. doi:10.1061/(ASCE)BE.1943-5592.0000223.

Frank, K.H., and Yura. J.A., (1981). An Experimental Study of Bolted Shear Connections, Report No. FHWA/RD-81/148, U.S. Department of Transportation, Washington, D.C., USA.

Hamdoon, M.M. (2012). Effect of Cyclic Loading on the Mechanical Behaviour of Structural Steels at Various Temperatures. PhD Dissertation. University of Windsor. Windsor, Ontario, Canada.

Kulak, G. (2002). High Strength Bolts A Primer for Structural Engineers, Design Guide 17. American Institute of Steel Construction.

Mermigas, K.K. (2018). Evolution of Bridge Practices in Ontario, Canada. Proceedings of the 2018 Transportation Association of Canada Conference. Saskatoon, SK, USA.

Nah, H., and Kim, K. (2011). Establishment of Slip Coefficient for Slip Resistant Connection. Journal of Civil Engineering and Architecture, 5(2): 112-120.

Provines, J., Ocel, J., Harrop, K., Darby, T.E., Sharp, S., and Moruza, A. (2018). Analysis and Construction of the United States' First Completely Stainless Steel Bolted Splice On A Steel Girder Highway Bridge. Proceedings of the World Steel Bridge Symposium Conference. Baltimore, MD, USA.

Ranjan, R., Ghahremani, K., Walbridge, S., and Ince, A. (2016). Testing and fracture mechanics analysis of strength effects on the fatigue behavior of HFMI-treated welds. Welding in the World, 60(5), 987-999. doi:10.1007/s40194-016-0354-4.

Seradj, H. (2012). Oregon's First ASTM A1010 Bridge and Risk Management. Proceedings of the World Steel Bridge Symposium Conference, Grapevine, Texas, USA.

Sharp, S.R., Provines, J.T., Moruza, A.K., Via Jr., W.F., and Harrop, K.N. (2019). Virginia's First Corrosion-Resistant ASTM A1010 Steel Plate Girder Bridge. Report No.: FHWA/VTRC 20-R10. Virginia Transportation Research Council.

Stankevicius, J., Josi, G., Grondin, G. Y., and Kulak, G. L. (2009). Measurement of Slip Coefficient for Grade ASTM A588 Steel. Structural Engineering Report SER 268. University of Alberta. Edmonton, Alberta, Canada.

Tamba, Y., Yukito, S., Kimura, S., Yamaguchi, T., and Sugiura, K. (2015). Slip Coefficient for High-Strength Bolted Frictional Joints with Roughened Steel Surface and Inorganic Zinc-Rich Painted Surface. JSCE Journal, Vol. 3, 19-32. Japan Society of Civil Engineers.

Tehrani Yekta, R., Ghahremani, K., and Walbridge, S. (2013). Effect of Quality Control Parameter Variations on the Fatigue Performance of Ultrasonic Impact Treated Welds. International Journal of Fatigue, 55, 245-256. doi:10.1016/j.ijfatigue.2013.06.023. 
Wang, Y., Wang, Y., Chen, K., and Li, G. (2019). Slip Factors of High Strength Steels with Shot Blasted Surface. Journal of Constructional Steel Research, 157, 10-18. doi:10.1016/j.jcsr.2019.01.023.

Weigand, J. M., and Berman, J. W. (2012). Behavior of Butt-Welds and Treatments Using LowCarbon Steel Under Cyclic Inelastic Strains. Journal of Constructional Steel Research, 75, 45-54. doi:10.1016/j.jcsr.2012.03.007.

Zhang, J., Ebrahimi, N., and Lai, D. (2018). Galvanic Corrosion Assessment of ASTM A1010

Bridge Steel and Bolts and Effect of Temperature and Acidity. Proceedings of the 10th International Conference on Short and Medium Span Bridges. Quebec City, Quebec, Canada. 